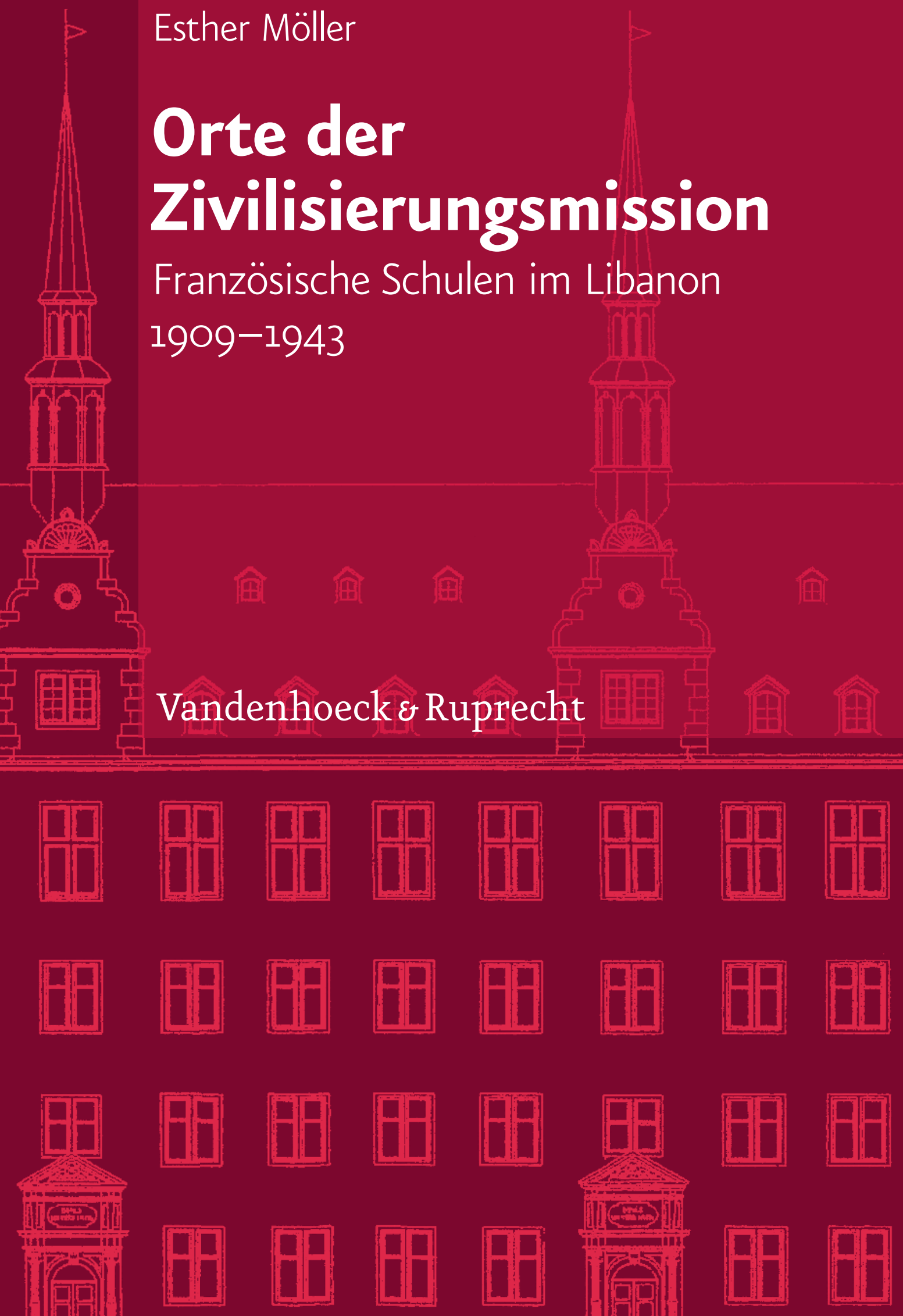




\section{V\&R}

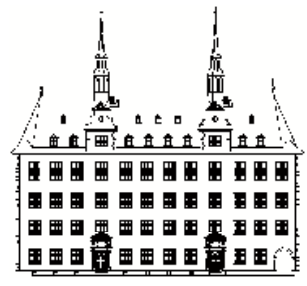




\section{Veröffentlichungen des \\ Instituts für Europäische Geschichte Mainz}

Abteilung für Universalgeschichte

Herausgegeben von Johannes Paulmann

Band 233

Vandenhoeck \& Ruprecht 


\title{
Orte der Zivilisierungsmission
}

Französische Schulen im Libanon 1909-1943

\author{
Von \\ Esther Möller
}

Vandenhoeck \& Ruprecht 
Mit 1 Karte, 5 Abbildungen und 8 Tabellen.

Bibliografische Information der Deutschen Nationalbibliothek

Die Deutsche Nationalbibliothek verzeichnet diese Publikation in der Deutschen Nationalbibliografie; detaillierte bibliografische Daten sind im Internet über http://dnb.d-nb.de abrufbar.

ISBN 978-3-525-10132-2 (Print)

ISBN 978-3-666-10132-8 (OA)

https://doi.org/10.13109/9783666101328

C 2013, Vandenhoeck \& Ruprecht GmbH \& Co. KG, Göttingen /

Vandenhoeck \& Ruprecht LLC, Bristol, CT, U.S.A.

www.v-r.de

Dieses Material steht unter der Creative-Commons-Lizenz Namensnennung - Nicht kommerziell - Keine Bearbeitungen 4.0 International. Um eine Kopie dieser Lizenz zu sehen, besuchen Sie http://creativecommons.org/licenses/by-nc-nd/4.0/.

Satz: Vanessa Brabsche 


\section{Inhalt}

Danksagung

Einleitung ........................................................................................... 13

Forschungsgegenstand ............................................................. 16

Forschungsstand ........................................................................ 29

Theoretische Herangehensweise .................................................. 36

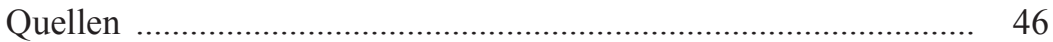

Aufbau der Arbeit …………………………………................. 48

Transkription ...................................................................... 49

I. Das Projekt der mission civilisatrice in Frankreich ........................ 51

1. Kulturelle Expansion als politisches und gesellschaftliches Produkt ................................................... 52

2. Zivilisierung durch Bildung:

Schulen im Fokus der auswärtigen Kulturpolitik .................... 65

3. Die Verortung auf der Akteursebene:

Lehrer als Träger der Zivilisierungsmission

II. Une ou Deux France? Die französische Schullandschaft im

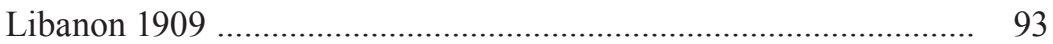

1. Rückbezug auf die französische Tradition im Libanon ........... 94

2. Unterstützung der Schulen auf Regierungsebene .................... 105

3. Mechanismen der Integration in die lokale Gesellschaft ......... 113

4. Zwischen Abgrenzung und Anpassung: Die Konfrontation der Mission laïque française mit den Beiruter Schulen ........... 123

III. Koloniale Bildung ohne Kolonie: Die französischen Schulen nach dem Ersten Weltkrieg ................................................................. 135

1. Verkörperung und Inszenierung der mission civilisatrice ....... 141

2. Bildungspolitik als französisch-libanesische Partnerschaft ..... 150

3. Lehren und Lernen für Frankreich: Die ambivalente Vereinheitlichung von Abschlüssen und Prüfungen ................ 160

4. Zur Mobilität von Bildung: Wissens- und Erfahrungstransfer aus den Kolonien 
IV. Sprachen zwischen Mission und Distinktion im Mandatsregime ... 177

1. Das Französische als Macht- und Identitätsmarker ................ 181

2. Arabischunterricht als Gratwanderung: Ignoranz oder nationales Bewusstsein?

V. Wer bildet den Libanon? Das Jahr 1925 als politische Zäsur .......... 215

1. Der Versuch einer Laizisierung der Zivilisierungsmission ..... 221

2. Forderungen nach arabischer Partizipation .............................. 234

3. Die Brisanz der Mädchenbildung ............................................ 246

4. Die Konstruktion der libanesischen Geschichte:
Debatten an und über Schulen ............................................... 260

VI. Zwischen Markt und Moderne: Globale und soziale Herausforderungen für französische Schulen und die libanesische Gesellschaft ab 1930

1. Koloniale Bildung zum Anfassen: Die Beteiligung der

Schulen an der Pariser Kolonialausstellung 1931

2. Bildung von Körper und Geist:

Die Rolle der Erziehung außerhalb des Klassenzimmers ........ 291

3. Die Ehemaligenarbeit der französischen Schulen .................... 303

4. Die Verlagerung der Zivilisierungsmission: Verstärkte

Kooperationen mit lokalen arabischsprachigen Schulen

VII. Angst, Anpassung, Aufbruch: Reaktionen auf das nahende Mandatsende

1. Zusammen gegen den Feind: Der Schulterschluss der französischen gegenüber anderen ausländischen Schulen 328

2. Die Schulen als Forum für nationalistische Bewegungen ....... 345

3. Der arabische Libanon in den Curricula .................................. 364

4. In die Unabhängigkeit entlassen: Berufs- und Karrierewege von Absolventen und Absolventinnen französischer Schulen .. 370

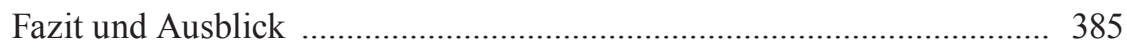

1. Ergebnisse .................................................................... 386

2. Historischer Ausblick ............................................................ 392 


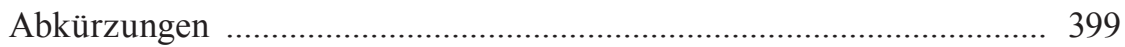

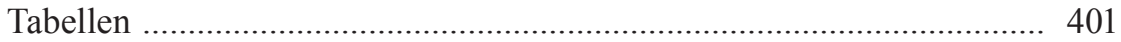

Archive und Interviewpartner ........................................................... 407

1. Frankreich ……................................................................... 407

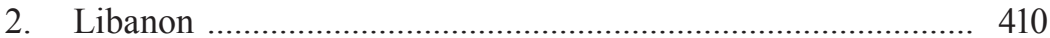

3. Interviewpartner ............................................................... 412

Bibliographie .................................................................................. 413

1. Geschichtsbücher der Schulen ................................................ 413

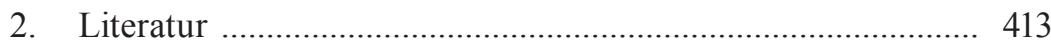

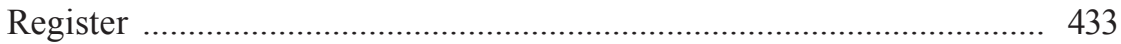





\section{Danksagung}

Dieses Buch ist das Ergebnis meiner 2011 an der Jacobs University Bremen eingereichten Dissertation. Beide wären nicht zur Vollendung gebracht worden ohne die großzügige Unterstützung vieler Personen und Institutionen.

An erster Stelle möchte ich von Herzen meinem Doktorvater Marc Frey für die Betreuung der Arbeit, die Unterstützung in allen Momenten ihrer Entstehung und für seinen inhaltlichen Weitblick danken. Meinem Zweitbetreuer Harald Fischer-Tiné bin ich für die Impulse zur kolonialen Bildung und für seine komparative Perspektive sehr dankbar. Ein großes Merci geht außerdem an Bernard Heyberger, den dritten Gutachter der Dissertation, für die konstrutkive Kritik, aber letztendliche Unterstützung des Promotionsthemas, für alle Orientierung in der französischen und libanesischen Geschichte und für die Vernetzung mit weiteren Historikern, die zu französischer Bildungspolitik im Nahen Osten arbeiten.

Für die finanzielle Unterstützung meines Promotionsvorhabens danke ich herzlich der Fritz-Thyssen-Stiftung, der Jacobs University Bremen, dem Orient-Institut Beirut, dem Deutschen Historischen Institut Paris und dem Leibniz-Institut für Europäische Geschichte in Mainz. Im Rahmen der Förderung durch diese Institutionen erfolgte in der Regel auch eine Präsentation und Diskussion meiner Forschungsergebnisse, wofür ich allen Beteiligten zu großem Dank verpflichtet bin. Dem Leibniz-Institut für Europäische Geschichte danke ich zudem herzlich für die Aufnahme der Arbeit in seine Schriftenreihe.

Die Arbeit in den französischen und libanesischen Archiven war oft nur durch das Vertrauen und Engagement einzelner Personen möglich, insbesondere wenn es sich um private oder institutionelle Archive handelte. Stellvertretend möchte ich an dieser Stelle Georgette Nakhlé, Charles Libois und Denis Paliès, Georges Krebs und Paul Henzmann danken, deren Unterstützung mir den Zugang zu vielen unbekannten Quellen ermöglicht hat. Für die Vermittlung wertvoller Kontakte für Interviews im Libanon und in Frankreich geht ein herzliches »Schukran« außerdem an Walid Arbid, Emma Bosanski, Fatmé Saghir, Familie Zimmermann, Malek Sharif und Mohammad Soubra. Allen meinen Interviewpartnern in Paris und Beirut danke ich von Herzen für ihr Vertrauen, ihre Zeit sowie die Dokumente und persönlichen Erinnerungen, die sie mir zur Verfügung gestellt haben.

Glücklicherweise konnte ich die Ergebnisse und Fragen meiner Arbeit mit vielen KollegInnen im In- und Ausland diskutieren, die ich nicht alle namentlich nennen kann. Repräsentativ sei an dieser Stelle Julia Hauser, Karène 
Sanchez, Jacques Thobie, Chantal Verdeil, Jérôme Bocquet, Kaïs Ezzerelli, Alain Messaoudi, Leyla Dakhli, Nadya Sbaiti, Dominique Trimbur, Christian Sassmannshausen, Malek Sharif, Theodor Hanf, Carla Eddé, Kamal Salibi, Souad Slim, Bashar Abbas, Malgorzata Maksymiak, Johannes Wischmeyer, Bernhard Gissibl, Manfred Sing und Sabine Dorpmüller für ihre kritische Auseinandersetzung mit meiner Arbeit und für alle wichtigen Hinweise sowie Bereitstellung von Quellen- und Sekundärmaterial gedankt. Für die Unterstützung bezüglich der arabischen Quellen danke ich insbesondere Bashar Abbas, Alya Bahar und Manfred Sing.

Damit aus der Dissertation ein Buchmanuskript wurde, habe ich von vielen Seiten Unterstützung erfahren. Verbunden bin ich für gewissenhaftes und nimmermüdes Korrekturlesen Johannes Wischmeyer, Susanne Krause, Emmanuel Delille, Mareike Menne, Renate Adam, Hans-Martin und Ingrid Hohendorf, Julia Hauser, Maria und Matthias Kleimann, Johanna Möller, Julia Kerfin, Frauke Kersten, Aika Meyer, Silvia Hoffmann, Bernhard Gissibl, Manfred Sing, Thomas Deierling, Sara Mehlmer und Benan Sarlayan.

Meiner Familie verdanke ich die Neugier und Offenheit, sich über Ostwestfalen hinaus für fremde Kulturen zu interessieren. Thomas kann ich nicht genug danken für die Unterstützung in allen Höhen und Tiefen meiner Promotion, für alle Diskussionen über die Arbeit und für die umfassende Versorgung in den letzten Wochen ihrer Fertigstellung. 


\section{Der Libanon vom Osmanischen Reich zum Mandatsregime}

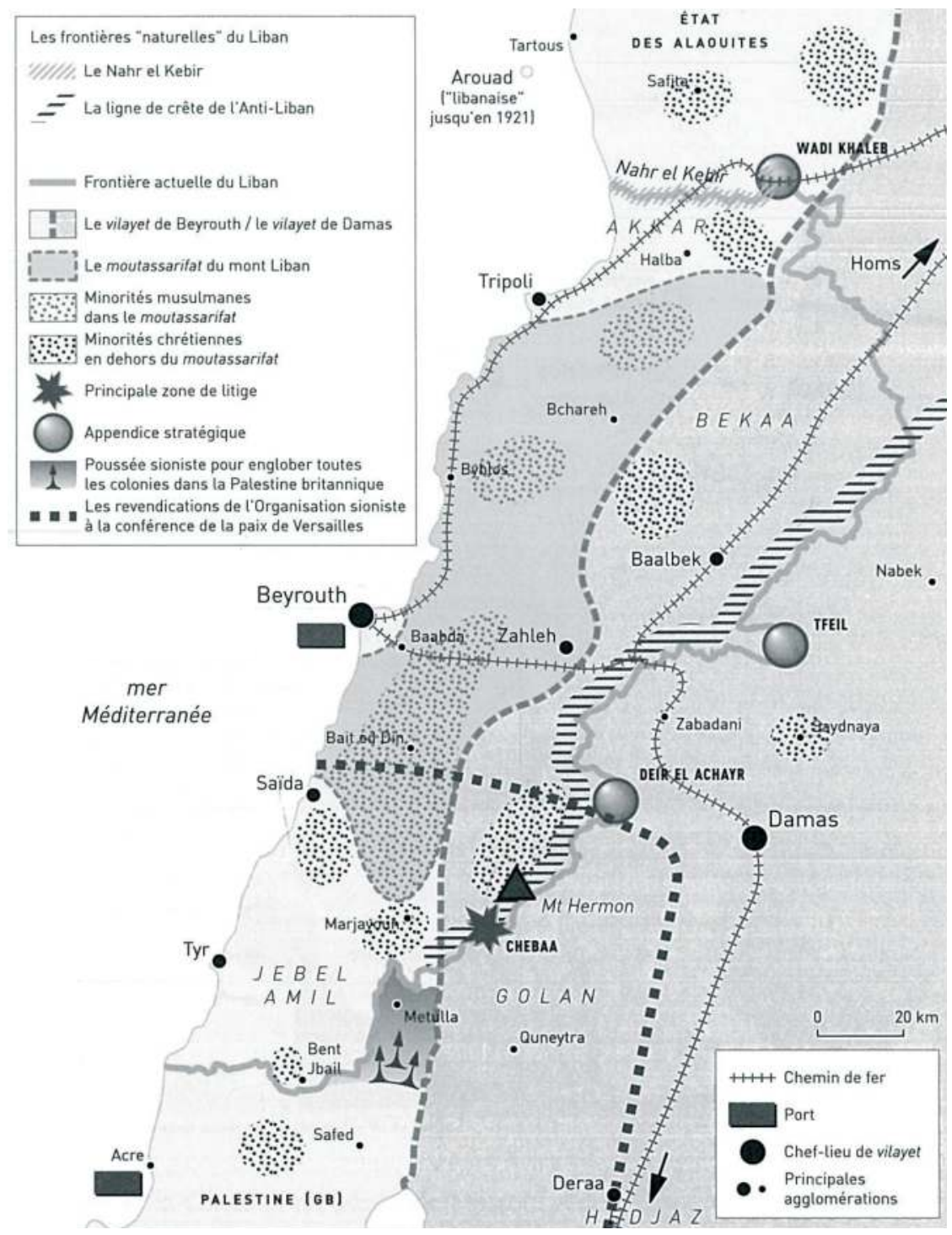

Karte: Du Mont Liban au Grand Liban.

Quelle: Fabrice Balanche, Atlas du Proche-Orient arabe, Paris 2012, S. 28. 



\section{Einleitung}

Im Archiv des von Jesuiten geführten Collège Notre Dame de Jamhour ${ }^{1}$ in der Nähe von Beirut stieß ich auf ein schreibmaschinengetipptes Manuskript aus dem Jahr 1975, zu Beginn des libanesischen Bürgerkrieges. Darin hatten Schüler Interviews mit Nachbarn und Verwandten festgehalten, die sie nach deren Schulzeit zwischen 1890 und 1920 befragt hatten. Der Schüler Samir Abouda hatte notiert:

L'USJ [L'Université Saint-Joseph ${ }^{2}$ ], telle que la voyait [sic] les élèves d'autrefois, méritait fort bien le titre que lui avait donné Maurice Barrès, ce nom étant: ১Phare de l'Orient ${ }^{3}$.

Zum »Leuchtturm des Orients « stilisierte bereits im Jahr $1923^{4}$ der französisch-nationalistische Schriftsteller Maurice Barrès die Schule und Universität der Jesuiten in Beirut. Auch im hier angeführten Zitat 50 Jahre später findet diese bis heute bekannte Metapher ihren Widerhall. Der direkte Bezug Samir Aboudas auf Barrès' Metapher überrascht gleich durch dreierlei: die positive Bewertung des durch die Schule vermittelten französischen Bildungssystems durch ehemalige Schüler, die ebenfalls positive Rezeption des umstrittenen Schriftstellers Barrès ${ }^{5}$ durch seinen libanesischen Interviewpartner und die Aktualität dieses Themas über Generationen hinweg.

Das Bild des Leuchtturms, der als Lichtquelle meist der einzige zuverlässige Orientierungspunkt und Richtungsweiser in der Dunkelheit ist, spiegelt eindringlich die Idee der Zivilisierungsmission (französisch mission civilisatrice) wider. Zivilisierungsmissionen waren seit dem späten 19. Jahrhundert Bestandteil aller imperialen Projekte europäischer wie auch einiger außer-

1 Diese französischsprachige Schule wurde in den 1950er Jahren in Jamhour eröffnet, als die ursprüngliche, gleichnamige Schule im Zentrum von Beirut die wachsende Schülerzahl nicht mehr fassen konnte.

2 Diesen Namen trug sowohl die von den Jesuiten geführte Université Saint-Joseph in Beirut als auch die ihr angeschlossene Sekundarschule, um die es in diesem Satz geht.

3 Samir Abouda, 3.1, in: La vie scolaire au Liban de 1890 à 1920 environ. Enquête faite l'été 1975 par des élèves du Collège Notre-Dame de Jamhour, S. 43. NDJ, Rapport d'élèves 1975.

4 Ursprünglich bezog Maurice Barrès diesen Satz auf die Universität der Jesuiten in Beirut. Vgl. Enquête aux pays du Levant, Paris 1923, S. 33.

5 Bezüglich Maurice Barrès' teils mystisch-bewundernder, teils kolonialistischer Wahrnehmung des Orients vgl. Bernard Heyberger, Barrès Maurice, in: François Pouillon (Hg.), Dictionnaire des orientalistes de langue française, Paris 2008, S. 50-52. 
europäischer Gesellschaften, doch wurde ein zivilisatorischer Sendungsanspruch von Frankreich besonders vehement für sich beansprucht: unter Berufung auf die französische Sprache als Trägerin universeller Werte waren viele französische Gruppen und Individuen davon überzeugt, die eigene Kultur bringe Licht und Fortschritt in `dunkle‘, als rückständig wahrgenommene Regionen der Welt. Als besonders wirksame Stätten und Vehikel galten Bildungseinrichtungen wie Schulen oder Universitäten, da diese die französische Kultur und Sprache durch das Angebot höherer Bildung flächendeckend und über lange Lebensabschnitte hinweg verbreiten konnten.

Während diese Idee und ihre Praxis im Kontext der europäischen »Verschulung der Welt $\ll^{6}$ in allen kolonialen Gebieten Frankreichs weltweit implementiert wurde und oftmals auch auf Ablehnung stie $\beta^{7}$, zeichnete sich der Libanon ${ }^{8}$ dadurch aus, dass hier bestimmte Gesellschaftsschichten, die besonders unter den Christen aufgrund zahlreicher Verbindungen zu Europa stark vertreten waren, die französischen Schulen oft mit großem Interesse aufnahmen. Erst mit der Errichtung des kolonialen Mandatsregimes Frankreichs Mitte des 20. Jahrhunderts wurden mehr Libanesen aus Gründen politischer, wirtschaftlicher und sozialer Integration gezwungen, eine französische Bildungsstätte zu frequentieren. Dabei wurde die dahinterstehende Idee der französischen Zivilisierungsmission von einigen Libanesen übernommen, von anderen dagegen rigoros abgelehnt und von wieder anderen nur zu bestimmten Zwecken selektiv angeeignet und adaptiert. Hierbei spielten wirtschaftliche und politische asymmetrische Machtverhältnisse eine entscheidende Rolle. Die unterschiedlichen Haltungen der Libanesen spiegeln die enge Verflechtung von Bildung, Sprache, kolonialer Herrschaft, politischer oder religiöser Identität und sozialer Differenzierung wider, durch welche die Bildungseinrichtungen einerseits inter- und intrakulturelles Kon-

6 Vgl. Jürgen Osterhammel, Die Verwandlung der Welt. Eine Geschichte des 19. Jahrhunderts, München 2011, S. 1129.

7 Vgl. Denise Bouche, Histoire de la colonisation française, Paris 1991, S. 245; Nicola Cooper, Making Indo-China French: Promoting the Empire through Education, in: Martin Evans, Culture and Empire: An Overview, in: Ders. (Hg.), Empire and Culture. The French Experience 1830-1940, London 2004, S. 131-147, S. 132. In Afrika kam es nach dem Ersten Weltkrieg zu einem stärkeren Interesse an französischer Bildung. Vgl. Pascal Le Pautremat, La politique musulmane de la France au XX $X^{e}$ siècle. De l'Hexagone aux terres d'Islam. Espoirs, réussites, échecs, Paris 2003, S. 315.

8 Die Bezeichnung Libanon wird im Folgenden auch für die Zeit vor der Gründung des Staates Libanon in seinen heutigen Ausmaßen im Jahr 1920 verwendet. Auch wenn es während des Osmanischen Reiches den Libanon als Land oder Provinz noch nicht gab, ist damit für die Zeit des Osmanischen Reiches das Gebiet bezeichnet, welches dem Gebiet des heutigen Libanons entspricht. Dazu gehörten zur Zeit des Osmanischen Reiches das mutașarrifīya (Provinz) des Libanongebirges (Ğabal Lubnān), die Küstenstädte Beirut, Tripoli und Saida sowie die vier ehemaligen osmanischen Verwaltungsbezirke von Hasbaya, Rashaya, Baalbek und Akkar. Vgl. Fawwaz Traboulsi, A History of Modern Lebanon, London 2007, S. 80. 
fliktpotential schürten, andererseits aber auch als integrative Faktoren am Aufbau des neuen libanesischen Staates beteiligt waren.

Dieser komplexen Verflechtungsgeschichte geht die vorliegende Studie nach, wobei die Frage im Zentrum steht, inwiefern Schulen unter französischer Trägerschaft im Libanon zwischen 1909 und 1943 als Orte der Zivilisierungsmission fungierten und $\mathrm{zu}$ welchen Zwecken sie von verschiedenen Regierungs- und zivilgesellschaftlichen Instanzen in Frankreich und im Libanon genutzt wurden. Der Begriff Ort wird hier bewusst verwendet, um auf die Bedeutung des konkreten Raums hinzuweisen, in welchem die genannten Interaktionen stattfanden ${ }^{9}$. Das bedeutet allerdings nicht, dass der Konstruktionscharakter des Raumes und dessen Bedeutung als sozialer Raum, in welchem Machtbeziehungen konstituiert und in Frage gestellt werden, vernachlässigt wird, wie die soziologischen Raumtheorien in Anschluss an Pierre Bourdieu ${ }^{10}$ und in jüngster Zeit auch die historische Bildungsforschung ${ }^{11}$ betonen.

Untersucht wird erstmals die gesamte ideologische Bandbreite französischer Bildungseinrichtungen im Libanon, das heißt katholische, jüdische, laizistische und protestantische Schulen. Die Untersuchung erfolgt auf drei Ebenen: Erstens wird die Beziehung der Schulen mit französischen Regierungsvertretern und zivilgesellschaftlichen Gruppen, insbesondere mit der Kulturabteilung des Außenministeriums, dem Erziehungsministerium, den Konsulaten im Libanon und dem Hochkommissariat sowie mit Vertretern von Wissenschaft, Wirtschaft und Kirche, in den Blick genommen. Zweitens wird die Interaktion der Schulen mit der libanesischen Bevölkerung analysiert, wozu auch die Einbeziehung anderer lokaler und ausländischer Bildungseinrichtungen gehört. Drittens werden die pädagogischen, sozialpolitischen und kulturellen Wandlungsprozesse innerhalb der Schulen selbst untersucht, das heißt politische Diskussionen innerhalb der Lehrerschaft, Konflikte über Lehrinhalte und -methoden mit den Schülern oder die Rezeption und Adaptation pädagogischer Reformen. Auf allen drei Untersuchungsebenen - imperiale Einflussnahme der französischen Regierung auf die Schulen, Aneignung und Zurückweisung der Schulen durch die libanesische Bevölkerung und Mittlerrolle der Schulen selbst - steht die Frage der Haltung der Schulen selbst im Mittelpunkt der Analyse.

9 Auf die konkrete Örtlichkeit der Schule hat auch Anthony Giddens hingewiesen. Er betont außerdem deren Abgeschlossenheit nach außen, ein Aspekt der in dieser Studie in Frage gestellt wird. Vgl. Anthony GidDens, Die Konstitution der Gesellschaft. Grundzüge einer Theorie der Strukturierung, Frankfurt am Main/New York 1995, S. 188-192.

10 Vgl. Pierre Bourdieu, Sozialer Raum und symbolische Macht, in: Ders., Rede und Antwort, Frankfurt am Main 1992, S. 135-154; Martina Löw, Raumsoziologie, Frankfurt am Main 2001, S. $180-183$.

11 Vgl. Eckhardt Fuchs / Christoph LüTH, Transnationale Bildungsbemühungen und die Konstruktion des Raumes in historischer Perspektive, in: Bildung und Erziehung 6, 2008, S. 1-10. 


\section{Forschungsgegenstand}

Die vorliegende Arbeit hat die Historisierung und Dekonstruktion der Idee der Zivilisierungsmission als Ausgangspunkt kolonialer Aushandlungsprozesse über Bildung zwischen Franzosen und Libanesen zum Gegenstand. Dabei geht es um die Analyse der historischen Prozesse, die zur Entwicklung dieser Idee beigetragen haben sowie der unterschiedlichen Bedeutungen, die verschiedene Akteure ihr in unterschiedlichen Kontexten zuschrieben ${ }^{12}$.

Die Idee der Zivilisierungsmission ist ein Phänomen, das nicht nur französische Kolonialpolitik bestimmte, sondern ein zentrales Element kolonialer Herrschaft im 19. und 20. Jahrhundert allgemein bildete. In diesem Sinne hat Jürgen Osterhammel sie als handlungsleitende Überzeugung von der Überlegenheit der eigenen Kultur und den damit verbundenen praktischen Auswirkungen definiert ${ }^{13}$. In der vorliegenden Studie wird die Zivilisierungsmission konkreter noch als bei Osterhammel als koloniale Praxis und in diesem Sinne gleichberechtigt neben der diskursiven Ausgestaltung einer zivilisatorischen Überlegenheit behandelt.

Außerdem wendet sich diese Arbeit, indem sie nach der spezifischen historischen Genese und Entwicklung der Zivilisierungsmission in Frankreich und in von Frankreich dominierten außereuropäischen Gebieten fragt, bewusst gegen eine zu starke Homogenisierung der Zivilisierungsmission als eines omnipräsenten Bestandteils aller kolonialen Ideologien. In der Tat sticht die Idee der mission civilisatrice dadurch hervor, dass sie als bereits zeitgenössisch kurrenter Begriff in der Rechtfertigung auswärtiger Kulturund Kolonialpolitik Frankreichs eine zentralere Rolle gespielt hat als in den Diskursen und Praktiken anderer imperialer Staaten ${ }^{14}$.

Darüber hinaus ist es aber notwendig, auch diese Interpretationsebene weiter auszudifferenzieren, um zu einer Dekonstruktion der Zivilisierungsmission zu gelangen. Gerade aufgrund der Anfang des 20. Jahrhunderts in Frankreich zahlreich auftauchenden Konflikte zwischen klerikalen und anti-

12 Zum Begriff der Dekonstruktion in der Geschichtswissenschaft, speziell in der außereuropäischen Geschichte, vgl. Jürgen Osterhammel, Transkulturell vergleichende Geschichtswissenschaft, in: Heinz-Gerhard HaupT / Jürgen Kocka (Hg.), Geschichte und Vergleich. Ansätze und Ergebnisse international vergleichender Geschichtsschreibung, Frankfurt am Main/New York 1996, S. 271-313, S. 276.

13 Vgl. Ders., Europe, the »West« and the Civilizing Mission. The 2005 Annual Lecture, London 2006, S. 8; Jacques FrémEAux, Les empires coloniaux dans le processus de mondialisation, Paris 2002, S. 244.

14 Vgl. Evans 2004, S. 10; Jürgen Osterhammel, »The Great Work of Uplifting Mankind«. Zivilisierungsmission und Moderne, in: Boris BARTH/Jürgen OsterhAMmEL (Hg.), Zivilisierungsmissionen, Konstanz 2005, S. 363-425, S. 383; Philippe Beneton, Histoire de mots. Culture et civilisation, Paris 1975, S. 49-51; Annabelle Sreberny-Mohammad, The Many Cultural Faces of Imperialism, in: Peter Golding / Phil Harris (Hg.): Beyond Cultural Imperialism. Globalization, Communication and the New International Order, London u.a. 1997, S. 49-68, S. 61. 
klerikalen, monarchistischen und republikanischen Kräften ist es notwendig, nach deren unterschiedlichen Vorstellungen der mission civilisatrice zu fragen. In der Tat gab es, auch wenn diese von einem breiten gesellschaftlichen Konsens in Frankreich getragen wurden, erhebliche Unterschiede im Verständnis der mission civilisatrice zwischen unterschiedlichen zivilgesellschaftlichen Gruppen, die in Frankreich, aber auch in der französischen Bildungspolitik außerhalb Frankreichs agierten.

Diese sind von der Forschung bisher nicht ausreichend gewürdigt worden, weshalb diese Arbeit sich das Ziel setzt, erstmals die unterschiedliche Ausgestaltung der Idee der Zivilisierungsmission von ideologisch so weit auseinander stehenden Gruppen wie französischen Katholiken, Laizisten, Protestanten und Juden im Libanon integrativ in den Blick zu nehmen und nach ihren Unterschieden, aber auch Gemeinsamkeiten zu fragen: kam es im gemeinsamen Agieren außerhalb Europas vielleicht sogar zu einer Übereinstimmung zwischen diesen Gruppen, die in Frankreich nie erfolgt wäre?

Vor diesem Hintergrund wurden für die Analyse zentrale Dachorganisationen und Missionsorden und ihre Bildungseinrichtungen ausgewählt, die ein unterschiedliches Verständnis von französischer Bildungsarbeit und der mit ihr verbundenen Zivilisierungsmission aufwiesen und zudem divergierende Beziehungen zum französischen und osmanischen bzw. libanesischen Staat hatten. Darüber hinaus stellten die ausgewählten Einrichtungen nicht nur spezifische Varianten französischer Bildung im Libanon dar, sondern stachen unter den bis zu 300 französischen Bildungseinrichtungen während der Mandatszeit ${ }^{15}$ hervor, weil sie im Untersuchungszeitraum die höchsten Schülerzahlen verzeichneten und über eine hohe kulturelle Reichweite verfügten. Nicht nur Schüler aus dem Libanon, sondern auch aus der gesamten arabischen Welt frequentierten sie.

Der räumliche Hauptakzent der Arbeit liegt auf den Schulen in Beirut, da sich insbesondere die Tätigkeit der laizistischen Organisation Mission laïque française $^{16}$ im Untersuchungszeitraum auf die Hauptstadt beschränkte. Zum anderen ist dieser räumliche Fokus praktisch durch das größtenteils nur noch in Beirut vorhandene Archivmaterial der einzelnen Schulen begründet. Zwei Schulen und ihre Archive konnten aber auch außerhalb Beiruts ausfindig gemacht werden. Querverweise zu französischen Bildungseinrichtungen in anderen Städten und Dörfern werden zudem in die Untersuchung integriert, um ein möglichst flächendeckendes Bild der französisch-libanesischen Schullandschaft zu vermitteln. Unter den katholischen Kongregatio-

15 In Syrien und Libanon zusammen gab es in der Mandatszeit über 400 französische Schulen. Vgl. MAE/Nantes, IP 130, »Renseignements statistiques«, 1936: Die Statistik dieses Jahres zählte 294 französische Schulen im Libanon und 435 in beiden Mandatsgebieten zusammen. Zur Anzahl der Schulen im Untersuchungszeitraum vgl. die Tabellen im Anhang.

16 Im Folgenden teils mit Mission laïque abgekürzt. 
nen sind neben den Jesuiten, die über eine sehr lange Tradition der Präsenz in der Levante verfügten und zudem stark international orientiert waren, die Lazaristen Gegenstand der Analyse, welche mit den Jesuiten in ständiger Konkurrenz lagen und ebenso wie die Frères des Écoles chrétiennes vor allem auf Frankreich ausgerichtet waren ${ }^{17}$.

Dabei können die Jesuiten auf die längste Präsenz im Libanon zurückblicken. Missionare dieses 1534 von Ignatius von Loyola gegründeten Ordens wurden bereits im 16. Jahrhundert in das Land der Zedern entsandt, um sich auf Geheiß des Papstes ein Bild der Situation der dortigen mit Rom unierten katholischen Gläubigen, der Maroniten, zu verschaffen und deren Bindung an Rom zu festigen ${ }^{18}$. Nachdem diese Mission auf positive Resonanz gestoßen war, errichteten die Jesuiten dann im 17. Jahrhundert mehrere Ordensniederlassungen wie auch Missionsschulen in Syrien, Ägypten und im Libanon, unter anderem in dem Ort Ayntoura (französisch Antoura). Im Jahr 1870 siedelten die Jesuiten als Reaktion auf den Aufschwung der Stadt Beirut ihr Priesterseminar, das zunächst in Ghazir errichtet worden war, und eine Schule in der Hafenstadt an, wobei sie der Schule 1875 die Université SaintJoseph angliederten, nach dem 1866 gegründeten Syrian Protestant College, welche ab 1920 den Titel American University of Beirut trug, die zweite Universität im Libanon. Die Jesuiten haben das intellektuelle Leben im Land stark mitbestimmt. Im Libanon unterhielten sie eine Vielzahl von Schulen, die sie nicht nur in den Städten, sondern auch in den Bergdörfern der Provinz des Libanongebirges (arabisch Ğabal Lubnān, französisch Mont Liban). Auf diese Art und Weise erreichten sie mit ihrem Bildungsangebot eine große und vielschichtige Klientel ${ }^{19}$.

Die Lazaristen waren ein weiterer Orden mit ausgedehntem Aktionsradius im Libanon. Im Jahr 1625 von dem Priester Vincent de Paul in Paris unter dem Namen Congrégation de la Mission mit dem ausdrücklichen Ziel der Armenpflege und der Mission gegründet, expandierte der Orden bald weltweit. Auf den Libanon erweiterten die Lazaristen ihr Tätigkeitsfeld allerdings erst im 18. Jahrhundert, wo sie zunächst einige Einrichtungen der Jesuiten übernahmen und sich dann Mitte des 19. Jahrhunderts in Beirut niederließen ${ }^{20}$. Selbst nach der Rückkehr der Jesuiten konnte der Lazaristenorden

17 Besonders ab dem Ersten Weltkrieg waren die Lazaristen von einem zunehmenden französischen Nationalgefühl geprägt. Vgl. Jérôme BocQuet, Missionnaires français en terre d'Islam: Damas (1860-1914), Paris 2005, S. 132.

18 Vgl. Charles SJ Libois, La Compagnie de Jésus au »Levant«. La Province du Proche-Orient. Notices historiques, Beirut 2009, S. 59.

19 Besonders beeindruckend war die Anzahl der vom Jesuitenpater Joseph Delore gegründeten Schulen. Vgl. Lévon Nordiguian, Les petites écoles du Mont-Liban: Joseph Delore, s.j. (1873-1944), Beirut 2003.

20 Vgl. Pierre Corcket, Les Lazaristes et les Filles de la Charité au Proche-Orient, Beirut 1983, S. 244. 
die Schule in Ayntoura halten, diejenige ihrer Einrichtungen im Libanon mit der größten Schülerzahl, aber auch mit zunehmend höheren elitären Ansprüchen $^{21}$. Der außerdem untersuchte Orden der Frères des Écoles chrétiennes wurde zwischen 1680 und 1685 von dem Kanoniker Jean-Baptiste de la Salle explizit mit dem Ziel gegründet, Schulen speziell für arme Kinder einzurichten. Die Frères des Écoles chrétiennes gründeten nicht nur Schulen in ganz Europa, sondern auch in Nordafrika und im Nahen Osten, unter anderem in Palästina und dem Libanon. Zunächst reisten die ersten Mitglieder dieses Ordens im Jahr 1890 auf Bitten der Lazaristen nach Beirut, um diese in ihrer Arbeit zu unterstützen, eröffneten aber später mit dem Collège français $d u$ Sacré-Cour die erste eigene Schule im Libanon.

Ihre komparative Analyse verspricht neue Einblicke in das unterschiedliche und oft paradoxe Verhältnis katholischer Orden zur französischen Nation. So waren die Lazaristen und die Frères des Écoles chrétiennes von den französischen Gesetzen zur Zurückdrängung der katholischen Orden in der Periode von 1890 bis 1910 weniger stark betroffen als die Jesuiten ${ }^{22}$, deren Schulen schon ab 1880 von der laizistischen Regierung der Dritten Republik in Frankreich verboten worden waren. Paradoxerweise förderte die Regierung den Jesuitenorden, wie auch die anderen Kongregationen, in der Levante zur gleichen Zeit jedoch finanziell weiter ${ }^{23}$. In dieser Zeit begann die ambivalente Beziehung zwischen der laizistischen Republik und den Jesuiten, die als Reaktion darauf ihren Dienst an Frankreich zunehmend herausstellten ${ }^{24}$. Während für Jesuiten und Lazaristen die Erziehungsarbeit eine Aufgabe unter vielen darstellte, waren die Frères des Écoles chrétiennes explizit mit dem Fokus auf Bildung gegründet worden.

Dadurch eröffnet sich eine weitere relevante Vergleichsebene, um die je unterschiedlichen Ausprägungen der mission civilisatrice erfassen zu können: der Umgang mit kultureller Differenz. Alle drei Orden unterschieden sich in der Tat signifikant in ihrem Verhältnis zur arabischen Sprache. Während die Jesuiten, die auch wissenschaftliche Studien über die arabische Welt betrieben, in der Regel auch Wert auf deren Sprache legten, beherrschten viele Angehörige der Lazaristen und der Frères des Écoles chrétiennes das

21 Vgl. Victor Hachem, Antoura, de 1657 à nos jours. Une histoire du Liban, Antoura 2003.

22 Beispielsweise gehörten die Lazaristen und den Frères des Écoles chrétiennes zu den fünf Kongregationen, die nach dem Gesetz zur Vereinigungsfreiheit von 1901 weiter bestehen bleiben durften. Vgl. Jérôme Bocquet, Les Lois anticongréganistses et leurs effets au Levant, in: Cabanel, Patrick/ Durand, Jean-Dominique (Hg.), Le grand exil des congrégations religieuses françaises 1901-1914, Paris 2005, S. 386-414, S. 386.

23 Vgl. Patrick Cabanel (Hg.), Une France en Méditerranée. Ecoles, langue et culture françaises, $\mathrm{XIX}^{\mathrm{e}}-\mathrm{XX}^{\mathrm{e}}$ siècles, Paris 2006.

24 Vgl. Dominique Avon/Philippe Rocher, Les Jésuites et la société française, XIX $-X^{\mathrm{e}}$ siècles, Toulouse 2001, S. 75-82. 
Arabische nicht oder nur schlecht. In ihren Lehrinhalten hingegen unterschieden sich die Orden weniger stark, da alle die französische Zivilisation der arabischen als überlegen präsentierten.

Um des Weiteren nach geschlechtsspezifischen Ausprägungen der mission civilisatrice zu fragen, werden die weiblichen Orden der Filles de la Charité und der Scurs de Saint-Joesph de l'Apparation mit in die Untersuchung einbezogen. Der Frauenorden der Filles de la Charité wurde um das Jahr 1630 von Vincent de Paul, dem Gründer des Lazaristenordens, ins Leben gerufen, um Frauen zu ermutigen, in klösterlicher Gemeinschaft zu leben und in der Krankenpflege tätig zu sein. Die Filles de la Charité unterstanden dem Lazaristenorden und wurden vornehmlich im Ausland eingesetzt, unter anderem im Nahen Osten. Nach der Ankunft der ersten Schwestern in der heutigen Türkei im Jahr 1839 weiteten die Filles de la Charité von da aus ihre Tätigkeit nach Ägypten und den Libanon aus. Im Jahr 1847 errichtete Sœur Gélas die erste Gemeinschaft der Filles de la Charité in Beirut ${ }^{25}$. Darüber hinaus wurden die Filles de la Charité in Palästina aktiv und rekrutierten schon bald einheimische Novizinnen.

Der eigenständige Frauenorden Sœurs de Saint-Joseph de l'Apparation wurde 1832 in Südfrankreich von der Adeligen Émilie de Viliar ins Leben gerufen, die sich mit einigen Gefährtinnen der Armut und dem Zölibat verschrieb $^{26}$. Die Gemeinschaft wuchs schnell und wurde bald auch außerhalb Frankreichs aktiv. Mitte des 19. Jahrhunderts wurden die Schwestern auf Bitten der Jesuiten in der Levante tätig, wie aus der Ordenschronik hervorgeht ${ }^{27}$. Wie auch die Filles de la Charité breiteten sich die Sours de Saint Joseph de l'Apparition im gesamten Nahen Osten aus, wo sie Krankenhäuser und Schulen für Kinder aus wohlhabenden und armen Bevölkerungsschichten einrichteten. Dabei richteten sie ein duales System ein, nach dem die finanziell besser gestellten Eltern für ihre Kinder Schulgeld zahlten, um damit zusätzlich die Plätze der sozial benachteiligten Schüler zu finanzieren. Dieses Finanzierungssystem hielt sich erfolgreich bis Mitte des 20. Jahrhunderts. Auch diese beiden weiblichen Orden standen in einer Konkurrenzsituation zueinander ${ }^{28}$.

Um innerhalb der christlichen Institutionen die Bandbreite der Vorstellungen zu eruieren, tritt neben die katholischen Schulen, die die Mehrheit der französischen Bildungsstätten bildeten, die exemplarische Analyse einer

25 Vgl. CORCKet 1983.

26 Vgl. Sarah Curtis, Civilizing Habits. Women Missionaries and the Revival of French Empire, Oxford 2010, S. 101-175.

27 Vgl. SJA, »À propos de la fondation de Beyrouth«.

28 Vgl. ebd.: »Elles s'étaient mises sous la protection du Délégue Apostolique Mgr. Villardel et sous la direction des Pères Jésuites, il n'en fallait pas davantage pour être mal vues du Consulat de France, favorable aux Lazaristes «. 
protestantischen Schule in Beirut. Dieses Collège protestant français wurde von der protestantischen Organisation Association française pour la défense et la gestion des intérêts protestants en Syrie et dans le Moyen Orient (ab 1929 Euvres protestantes françaises de Syrie et du Liban ${ }^{29}$ ) ab 1928 in Beirut aufgebaut. Die protestantische Organisation wurde als späteste der hier untersuchten Institutionen gegründet. Schon im 19. Jahrhundert hatten französische Protestanten, besonders aus dem Elsass, verschiedene karitative Initiativen im Orient unterhalten, sich dabei aber nicht gegen die bereits seit längerem dort ansässigen deutschen und britischen Protestanten in Syrien und Palästina durchsetzen können.

Als mit dem Zusammenbruch des Osmanischen Reiches nach dem Ersten Weltkrieg die deutschen Protestanten allerdings die nun französischen Mandatsgebiete verlassen mussten, übernahmen die Euvres protestantes françaises deren Aufgaben. So ließ sich 1927 das von dieser Organisation gegründete Collège protestant français in den ehemaligen Räumen der Kaiserswerther Diakonissen nieder ${ }^{30}$. Neben der Unterstützung durch die französische Regierung finanzierte sich diese Dachorganisation durch Zuschüsse und Spenden. Als einzige der hier untersuchten Organisationen expandierten die Euvres protestantes françaises im Untersuchungszeitraum nicht ${ }^{31}$. Hier ist es interessant, nach den Auswirkungen des Transfers der Minderheitenposition der Protestanten aus Frankreich in den Libanon zu fragen.

Das Bild wird weiter ergänzt durch die Hinzunahme der laizistischen Organisation Mission lä̈que française, deren Schulen die Analyse einer spezifisch laizistischen, durch die Dritte Republik geprägte, Vorstellung der mission civilisatrice ermöglicht. Die Initiative zur Gründung dieser Organisation 1902 in Paris ging von Pierre Deschamps aus, der als junger Lehrer in Madagaskar arbeitete und die Lehrsituation in den dortigen französischen Schulen als zu stark auf Frankreich ausgerichtet kritisierte ${ }^{32}$. Ihm schwebte stattdessen eine Schulform vor, die der indigenen Kultur besser gerecht würde. Zurück in Paris fand er die Unterstützung einiger stark laizistisch orientierter Politiker und Professoren, mit denen er sich zusammenschloss und die Mission lä̈que française gründete, deren Ziel die weltweite Verbreitung einer explizit laizistischen französischen Bildung war. Allerdings haben die Studien von Talal Asad auch verdeutlicht, dass die Idee des Säkularismus

29 Im Folgenden teils mit Euvres protestantes abgekürzt.

30 Vgl. Wilfried MAsson, La politique de la France à l'égard des missions catholiques et protestantes allemandes à Beyrouth 1918-1929, Magisterarbeit Lyon 1995.

31 Vgl. Jean-Paul Eyrard/Georges KreBs, Le Protestantisme français et le Levant de 1856 à nos jours, Straßburg 2007.

32 Vgl. André Thévenin, La Mission laïque française à travers son histoire, 1902-2002, Paris 2002. 
eindeutig aus einem religiös-christlichen Kontext hervorgegangen sind und diesen wieder produzieren ${ }^{33}$, was bedeutet, dass man den Laizismus der Mission laïque gar nicht von der Existenz des Religiösen trennen kann.

Mit großer Wahrscheinlichkeit erhielt die Organisation in Folge ihrer späteren Aktivitäten einen deutlich stärkeren kolonialistischen Impetus als Deschamps ursprünglich intendiert hatte. Nach der ersten Schulgründung in Thessaloniki im Jahr 1906 eröffnete die Mission laïque ihre Schule in Beirut. Von der französischen Regierung wurde die laizistische Organisation erst in den 1920er Jahren verstärkt unterstützt und konnte daraufhin auch Schulen in Ägypten, in Syrien und später in Nordafrika gründen. Besonders interessant ist die Frage, wie sich dieses spezifische Verständnis außerhalb Frankreichs veränderte. Das Wirken dieser Organisation im Libanon und ihr reichlich überliefertes Archivmaterial wurde bisher von der Forschung nicht berücksichtigt, doch lässt sich daran verdeutlichen, dass neben der traditionellen katholischen Verbindung zwischen Frankreich und dem Libanon auch andere Milieus als Interaktionskanäle fungierten.

Schließlich integriert die Untersuchung die Einrichtungen der jüdischen Organisation Alliance israélite universelle $e^{34}$, die von Frankreich aus agierte und Auskunft über das spezifisch jüdische Verständnis der Idee der Zivilisierungsmission geben kann. Diese Organisation wurde 1860 von jüdischen liberalen Geschäftsleuten und Intellektuellen gegründet ${ }^{35}$. In der Folge verschrieb sie sich der Hilfe für Juden in aller Welt unter Berufung auf die Werte der Französischen Revolution. Ihren Glaubensgeschwistern in der arabischen Welt wollte die Alliance israélite denselben privilegierten Status verschaffen, den Juden seit 1791 in Frankreich genossen. Nach den ersten Schulen in Marokko eröffnete die Organisation schon 1867 auch im Libanon und in Syrien Bildungseinrichtungen. Später gründete die Alliance israélite in allen Regionen des Osmanischen Reiches weitere Schulen, wurde aber erst im 20. Jahrhundert von der französischen Regierung unterstützt ${ }^{36}$.

Eine solche breit angelegte und komparative Untersuchung gibt nicht nur Einblick in bisher unerforschte Dimensionen staatlicher und zivilgesellschaftlicher französischer Bildungsinitiativen im Libanon, sondern wirft

33 »Thus the insistence on a sharp separation between the religious and the secular goes the with the paradoxal claim that the latter continually produces the former«. Talal AsAD, Religion, Nation-State, Secularism, in: Hartmut Lehmann/Peter van der Veer (Hg.), Nation and Religion. Perspectives on Europe and Asia, Princeton, New Jersey 1999, S. 178-196, S. 186.

34 Im Folgenden teils mit Alliance israélite abgekürzt.

35 Vgl. den Band zum 150-jährigen Bestehen der »Alliance israélite« von André KASPI (Hg.), Histoire de l'Alliance israélite universelle de 1860 à nos jours, Paris 2010, S. 28-41; vgl. auch André Chouraqi, L'Alliance israélite universelle et la renaissance juive contemporaine (1860-1960), Paris 1965.

36 Vgl. Aron Rodrigue, De l'instruction à l'émancipation. Les enseignants de l'Alliance israélite universelle et les Juifs d'Orient 1860-1939, Paris 1989. 
darüber hinaus neues Licht auf das historische Verhältnis der ambivalenten Wechselbeziehungen von Kirche bzw. Religion und Staat in Frankreich, von Kolonien und Mandatsregimen in der imperialen Bildungspolitik sowie auf politische und soziale Emanzipationsprozesse im Nahen Osten unter europäischer Herrschaft. Bezüglich des Libanons ist es besonders relevant, nach der wechselseitigen Einflussnahme zwischen französischer Bildungspolitik und dem das Land bis heute kennzeichnenden konfessionellen System, das von einer kontinuierlich herrschenden kleinen Elite dominiert wird, zu fragen.

Die untersuchte Zeitspanne zeichnet sich durch den steigenden Einfluss Frankreichs auf das politische Regime des späten Osmanischen Reiches sowie des anschließenden französischen Völkerbundmandats über den Libanon aus. Anders als vergleichbare Studien zum Schulwesen im Libanon ${ }^{37}$ beschränke ich mich deshalb nicht auf eine Regierungsepoche, sondern frage nach den Kontinuitäten und Brüchen zwischen den unterschiedlichen politischen Regimen und deren jeweiligem Einfluss auf das französischsprachige Schulwesen. Für den Libanon bedeutet dies, dass er zu Beginn des Untersuchungszeitraums noch nicht als politische Einheit existierte, sondern aus verschiedenen osmanischen Verwaltungs- und Regierungseinheiten bestand und der eher historisch gewachsenen als geographisch exakt zu bemessenden Region Großsyrien (arabisch Bilād aš- ̌̌ām) zugerechnet wurde. Dazu zählten neben dem Libanon auch das heutige Syrien, Israel, Jordanien und Palästina. Erst 1920 entstand mit dem französischen Völkerbundmandat der libanesische Staat in seinem heutigen Ausmaß.

Die Untersuchung beginnt im Jahr 1909 und bezeichnet einen Einschnitt im Libanon, in Frankreich sowie in der franko-libanesischen Bildungsgeschichte. Die Jungtürkische Revolution in der Endphase des zerfallenden Osmanischen Reiches bedeutete auch für die Regionen des Libanon die Ankündigung von Reformen. Im französischen Kontext verankerte die Schaffung eines Bureau des Euvres françaises à l'Étranger im Juli 1909 die auswärtige Bildungspolitik zentral im französischen Außenministerium ${ }^{38}$; 1920 wurde diese Sektion in Service des Euvres françaises à l'Étranger (SOFE) umbenannt. Auf der lokalen Ebene sollte die Ankunft der Mission laïque française in Beirut als Vorbote einer neuen französischen Politik im Libanon auch die Schullandschaft vor Ort erkennbar verändern. Der Endpunkt des Untersuchungszeitraums fällt mit dem Jahr 1943 auf das Ende des Völkerbundmandats, das Frankreich von 1920 bis 1943 im Libanon besaß. Auch wenn die kulturelle Arbeit sowohl der französischen Regierung als

37 Vgl. Forschungsstand.

38 Vgl. Jean Riffier, Les œuvres françaises en Syrie (1860-1923), Paris 2000, S. 9. 
auch der einzelnen Schulen von einer großen Kontinuität geprägt war, die über diese politischen Einschnitte hinausging, bildete die finanzielle und rechtliche Unterstützung der Schulen durch die Regierungsebene ein zentrales Element der Bildungsarbeit und rechtfertigt die Orientierung an diesen Zäsuren.

Ein knapper historischer Abriss der Präsenz französischer Schulen im Libanon vermag $\mathrm{zu}$ verdeutlichen, in welchem politischen und religiösen Spannungsfeld sich die Bildungspolitik dieser Schulen in der ersten Hälfte des 20. Jahrhunderts bewegte. In der Tat reicht die Präsenz französischer Bildungseinrichtungen im Nahen Osten weit in die Zeit vor dem französischen Völkerbundmandat zurück: Erste vereinzelte katholische Orden ließen sich, wie schon angedeutet, bereits im 17. Jahrhundert auf dem Gebiet des späteren Libanon nieder, um dort zu missionieren und ihre Schulen zu errichten ${ }^{39}$. Erst als zu Beginn des 19. Jahrhunderts protestantische Missionare aus Amerika in großer Anzahl in den Nahen Osten und also auch in den Libanon kamen und damit in Konkurrenz zu den katholischen Orden traten ${ }^{40}$, wuchs die Zahl der aus Frankreich in den Libanon entsandten katholischen Missionare rasch stark $\mathrm{an}^{41}$. Die spätere Präsenz britischer, russischer, deutscher und italienischer Missionare und ihrer Schulen sowie die Zunahme zwischenstaatlicher Spannungen in Europa, wie zwischen Frankreich und Deutschland, verstärkte dieses Phänomen noch ${ }^{42}$. Dabei wurden die unterschiedlichen Missionsgesellschaften von ihren Heimatregierungen als wertvolle Agenten imperialer Machtpolitik angesehen und dementsprechend unterstützt ${ }^{43}$. In dieser Hinsicht verspricht die Arbeit neue komparative Einblicke in das komplexe Verhältnis zwischen christlicher Mission und laizistischem französi-

39 Vgl. Salim Daccache, Catholic Missions in the Middle East, in: Habib Badr (Hg.), Christianity. A History in the Middle East, Beirut 2005, S. 688-712.

40 Vgl. Ussama Makdisi, Reclaimimg the Land of the Bible: Missionaries, Secularism, and Evangelical Modernity, in: The American Historical Review 102 (1997), H. 3, S. 680-713; Heleen Murre-VAn den Berg, »Simply by Giving to them Macaroni...«. Anti-Roman Catholic Polemics in Early Protestant Misisons in the Middle East, 1820-1860, in: Michael Marten/Martin TAmcke (Hg.), Christian Witness between Continuity and New Beginnings. Modern Historical Missions to the Middle East, Berlin 2006, S. 63-80.

41 Vgl. Samir Khalaf, Cultural Resistance. Global and Local Encounters in the Middle East, London 2001, S. 131.

42 Vgl. Jens Hanssen, Fin de siècle Beirut. The Making of an Ottoman Provincial Capital, Oxford 2005, S. 164; Wilfried MAsson, La politique de la France à l'égard des missions catholiques et protestantes allemandes à Beyrouth 1928-1929, Magisterarbeit Lyon 1995, S. 13.

43 Vgl. Khalaf 2001, S. 120; Vgl. auch die älteren Arbeiten, die trotz ihres wenig differenzierenden Ansatzes für diese These weiterhin gültig sind: John P. Spagnolo, The Definition of a Style of Imperialism: The Internal Politics of the French Educational Investment in Ottoman Beirut, in: French Historical Studies 3-4 (1973), S. 563-584; William I. SHORRocK, French Imperialism in the Middle East. The Failure of Policy in Syria and Lebanon 1900-1914, Madison, Wisconsin 1976. 
schen Kolonialstaat ${ }^{44}$ und ergänzt es durch jüdische und zivilgesellschaftlich laizistische Positionen.

In dem von imperialistischen Machtkämpfen geprägten außenpolitischen Klima versuchte Frankreich zunächst, sich im Nahen Osten gegen Großbritannien durchzusetzen und seine Schlüsselposition in Ägypten zu sichern, die aber nach der Besetzung Ägyptens durch die Engländer im Jahr 1882 endgültig verloren war ${ }^{45}$. Als Konsequenz daraus verlagerte Frankreich seine außenpolitischen Interessen zunehmend auf Syrien und das heutige Gebiet des Libanons. Dort konnte Frankreich sich zudem der Unterstützung der christlichen Bevölkerung, insbesondere der Maroniten, einer mit Rom unierten katholischen Ostkirche sicher $\operatorname{sein}^{46}$. Seine kulturelle Vormachtstellung konnte Frankreich in dieser Region allerdings erst ab 1850 festigen, denn bis zu diesem Zeitpunkt war dort unter der Vorherrschaft Italiens das Italienische lingua franca ${ }^{47}$. Auch wenn die außenpolitische Konkurrenz zu den anderen europäischen Mächten mit Kolonialinteressen weiterhin bestand insbesondere mit Großbritannien, für dessen geopolitische Interessen der Nahe Osten einen strategisch wichtigen Stützpunkt für den Seeweg nach Indien darstellte ${ }^{48}$-, konnte sich Frankreich Ende des 19. Jahrhunderts im wirtschaftlichen, militärischen und politischen Bereich die Vorrangstellung in Syrien und Libanon sichern ${ }^{49}$. An dieser Entwicklung hatten die französischen Schulen einen gewichtigen Anteil.

Indem Frankreich im Jahr 1920 vom Völkerbund ein Mandat für Syrien und den Libanon erhielt, wurde der bis zum Ende des Osmanischen Reiches indirekte französische Einfluss in diesen Landstrichen offiziell anerkannt. So standen im Nahen Osten nach dem Ersten Weltkrieg 200.000 km² und 3,5 Millionen Einwohner unter französischer Kontrolle ${ }^{50}$. Vom Völker-

44 Vgl. James P. Daughton, An Empire Divided. Religion, Republicanism, and the Making of French Colonialism, 1880-1914, Oxford 2006. Anhand des Verhältnisses katholischer Missionare und des französischen Kolonialstaates in Indochina, Polynesien und Madagaskar konnte der Autor zeigen, dass vor Ort pragmatische Bündnisse oft wichtiger waren als ideologische Unterschiede, dass letztere aber auch hitzige Debatten über das Gesicht Frankreichs in der Welt auslösten. Vgl. auch die Aufsätze in Philippe Delisle (Hg.), L'anticléricalisme dans les colonies françaises sous la Troisième République, Paris 2009.

45 Vgl. Henry Laurens, La présence française au Proche-Orient du XVII ${ }^{\mathrm{e}}$ siècle à la Première Guerre mondiale, in: Bernard Delpal/Bernard Hours/Claude Prudhomme (Hg.), FranceLevant. De la fin du XVII ${ }^{\mathrm{e}}$ siècle à la Première Guerre mondiale, Paris 2005, S. 9-20, S. 12-14.

46 Vgl. Nasri Salhab, La France et les Maronites, Beirut 1997, S. 98.

47 Vgl. Sélim Авоu, Le bilinguisme arabe-français au Liban. Essai d'anthropologie culturelle, Paris 1962, S. 188-193.

48 Vgl. Henry Laurens, La France, l’Angleterre et les Etats-Unis dans la Méditerranée et le monde arabe, in: Relations Internationales 87 (1996), S. 277-292, S. 286.

49 Vgl. Jacques ThoBIE, Intérêts et impérialisme français dans l'empire ottoman (1895-1914), Paris 1977.

50 Auch hier war Frankreich wieder im Nachteil gegenüber Großbritannien, welches $550000 \mathrm{~km}^{2}$ und etwas mehr als 5000000 Einwohner beherrschte. Vgl. FrÉmEAux 2002, S. 66. 
bund mit dem Auftrag betraut, beide Länder auf dem Weg zur Unabhängigkeit zu begleiten, initiierte die französische Regierung zwar einerseits die Gründung eines libanesischen Staates 1920, behielt sich aber andererseits die Stellung als koloniale Macht im Libanon weiterhin vor und herrschte direkter als beispielsweise die Briten in ihren Mandatsgebieten in Irak und Palästina $^{51}$. Von besonderem Interesse ist hier, im Vergleich mit dem Vorgehen in französischen Kolonien, nach den Spezifika auswärtiger Bildungspolitik in einem Regime zu fragen, das von seiner Definition her zeitlich begrenzt und weniger umfassend war.

Von den unterschiedlichen libanesischen Bevölkerungsgruppen befürworteten die meisten Katholiken ausdrücklich die französische Mandatsherrschaft. Schließlich verschaffte ihnen diese politische Neuordnung eine - wenn auch weitaus geringer als gewünschte - Bevölkerungsmehrheit im Libanon. Insbesondere die Maroniten erhielten zudem viele zentrale Posten in der neu aufgebauten Mandatsverwaltung. Andere Bevölkerungsgruppen hingegen, insbesondere die Muslime, kritisierten die Entscheidung des Völkerbundes heftig, hatten sie sich doch für eine Vereinigung mit Syrien für ein großarabisches Reich ausgesprochen ${ }^{52}$. Die quasi-koloniale Herrschaft Frankreichs endete erst mit der libanesischen Unabhängigkeitserklärung im Jahr 1943 und fand mit dem Abzug der französischen Truppen aus dem Libanon 1946 ihr offizielles Ende. Während der Mandatszeit erstarkten, unter anderem als Reaktion auf die Fremdherrschaft, die verschiedenen arabischen nationalistischen Bewegungen, die schließlich nach dem Mandatsende die Regierung mit übernahmen.

Bereits vor der Übernahme der Mandatsverwaltung waren französische Schulen schon mehr als Orte der Wissensvermittlung, denn sie wirkten auch als Instrumente der französischen Außenpolitik. Um die zentrale Frage zu beantworten, inwiefern die französischen Schulen im Libanon zu Orten der Zivilisierungsmission wurden, wird im Folgenden untersucht, wie schulische Bildungseinrichtungen sowohl von den unterschiedlichen französischen als auch libanesischen Akteuren für ihre jeweiligen politischen, sozialen und kulturellen Interessen genutzt wurden. Um wertvolle und oft nur schwer zu erreichende Einblicke in die zentrale Rolle der Schulen als kulturelle Mediatoren oder »Broker« zu erlangen, werden zunächst die in den Schulen vermittelten Inhalte, dann die administrative und organisatorische Struktur und schließlich die politische und soziale Funktion der unterschiedlichen Bildungseinrichtungen analysiert.

51 Vgl. Kais Firro, Inventing Lebanon. Nationalism and the State under the Mandate, London 2003; Nadine Méouchy / Peter Sluglett (Hg.), The British and French Mandates in Comparative Perspectives, Leiden 2004.

52 Vgl. Traboulsi 2007, S. 80-87. 
Aus diesem Grund verfährt die Arbeit wie eingangs bereits kurz skizziert auf drei Analyseebenen. Erstens wird im historisch-politischen Rahmen der Grad der Einflussnahme Frankreichs auf die französischen Bildungseinrichtungen im Libanon beleuchtet. Hierbei bilden die französische Regierung und deren Vertretung, die Mandatsregierung in Beirut, das Untersuchungszentrum, auch wenn der Einfluss politischer und sozialer Wandlungsprozesse innerhalb der französischen Zivilgesellschaft ebenfalls berücksichtigt wird. Von besonderem Interesse ist hier die Frage, inwiefern die Schulen konkret als Vehikel der auswärtigen Kulturpolitik genutzt wurden, und wie sich diese Nutzung innerhalb des Untersuchungszeitraums wandelte. Dabei soll die Hypothese erhärtet werden, dass die französischen Schulen, unabhängig von ihrer jeweiligen konfessionellen Zugehörigkeit (oder Konfessionslosigkeit), gefördert wurden, um den Anspruch der kulturellen Überlegenheit Frankreichs umzusetzen und zudem eine direkte Einflussnahme auf die libanesische Bevölkerung zu ermöglichen. War ihr Ziel also, die »school instruction« als, wie Mitchell dies für die englische Schulpolitik in Ägypten beschrieben hat, »a means of transforming every youth in the country into an industrious and obedient political subject ${ }^{53} \mathrm{zu}$ verwenden oder muss diese Annahme stärker differenziert werden?

Zweitens wird der Einfluss der einzelnen Dachorganisationen auf den institutionellen Aufbau und die ideologische Ausrichtung der unter ihrer Trägerschaft stehenden französischsprachigen Schulen im Libanon untersucht. Dabei stehen die in diesen Bildungseinrichtungen vorherrschenden politischen, sozialen, religiösen und pädagogischen Ansichten im Mittelpunkt sowie die Frage, wie diese durch die Interaktion mit französischen und libanesischen Partnern verändert wurden. In der Tat befanden sich die Bildungseinrichtungen in einem gewissen Abhängigkeitsverhältnis zur französischen Regierung, sie waren aber auf die Akzeptanz durch die libanesische Bevölkerung genauso angewiesen, weshalb die Schulen ihre Diskurse und Praktiken auch den Erwartungen und kulturell-religiösen Sensibilitäten ihrer Klientel anpassten. Die Haltungen sowohl von Personengruppen wie Lehrerkollegien als auch von Individuen wie Schuldirektoren oder auch einzelnen Lehrkräften bilden hierfür die Untersuchungsbasis. Außerdem werden die von den Schulen ausgehenden Widerstände gegen die politischen Systeme in Frankreich und im Libanon analysiert. Dieser Themenkomplex umfasst die Reaktionen angesichts der Umwandlung des indirekten kulturellen Einflusses Frankreichs im Libanon in die faktische französische Herrschaft seit dem Jahr 1920.

53 Timothy Mitchell, Colonising Egypt, Berkeley, California 2003, S. X-XI. 
Des Weiteren wird die Frage beantwortet, inwiefern die französischsprachigen Schulen in der Folgezeit zu Unterstützern des Mandatsregimes oder zu Wegbereitern des libanesischen Staates und damit letztlich der libanesischen Unabhängigkeit und des libanesischen Nationalismus in seinen unterschiedlichen Spielarten wurden. Dabei darf aber nicht die Autonomie der Schulen und ihrer Lehrer ${ }^{54}$ vergessen werden. Schließlich waren die Verantwortlichen und die Lehrer dieser Schulen auch Akteure mit dezidierten pädagogischen und ideologischen Vorstellungen, welche sie in den Schulen im Libanon umzusetzen suchten. Hierin gab es zwischen den verschiedenen Einrichtungen signifikante Unterschiede, welche sich aber in manchen Fällen in der Praxis im Libanon auflösten und durch welche sich die Institutionen einander stärker annäherten als in ihrem Herkunftskontext.

Die dritte Untersuchungsebene konzentriert sich auf die Rezeptionsebene des Bildungsangebots der französischsprachigen Schulen im Libanon. Die libanesische Bevölkerung wird dabei nicht nur in der passiven Empfängerrolle, sondern dezidiert als aktive Mitgestalterin des Angebots der Bildungseinrichtungen verstanden. Die Motive und Gründe für ihr Engagement sowie die von den libanesischen Gruppen und Individuen angewandten Formen der aktiven Partizipation im französischsprachigen Schulwesen stehen hier im Mittelpunkt. Schnell wird deutlich, dass die Schulen keineswegs nur als Vehikel zur Umsetzung und Bejahung der mission civilisatrice benutzt wurden. Sie dienten auch der religiösen, sozialen und wirtschaftlichen Positionierung der libanesischen Klientel ${ }^{55}$ im zerfallenden Osmanischen Reich beziehungsweise im neu geschaffenen libanesischen Staat. Gleichzeitig gab es Widerstände aus libanesischen Kreisen gegen die französischsprachigen Schulen. Tatsächlich war die Deutungshoheit der französischen Kulturpolitik keinesfalls umfassend. Ein genauer Blick auf die kulturellen und sozialen Aneignungspraktiken im Kontext laizistischer und religiöser Missionsschulen zeigt, dass dieser mit der Zivilisierungsmission verbundene universelle Anspruch durch spezifische Interessen innerhalb der libanesischen Bevölkerung sehr differenziert aufgenommen wurde. Dabei fällt auf, dass die materiellen und sozialen Erwägungen der Libanesen bezüglich aller Schulen sehr ähnlich waren, während sich die Unterschiede zwischen den Klientelen der verschiedenen Einrichtungen auf der religiösen und kulturellen Ebene zeigten.

54 Die weibliche Form dieses Berufs wird in der Arbeit nicht jedes Mal mit genannt. Wenn der Begriff »Lehrer« allgemein verwendet wird, schließt er Lehrer und Lehrerinnen mit ein.

55 Der Begriff $» K l i e n t e l \ll$ mag wegen seiner ökonomischen Konnotation überraschen, wird aber trotzdem im Folgenden verwendet, da er von den hier untersuchten Akteuren in den Quellen selbst verwendet wurde und da die Beziehung zwischen Schulen, Eltern und Regierungsautoritäten in der Tat stark von ökonomischen Gesichtspunkten beeinflusst war. 
Aufgrund des reichhaltigen und bisher nicht erforschten Quellenmaterials steht die eigene gesellschaftspolitische Positionierung der französischen Schulen im Libanon im Zentrum dieser Studie: Ihre Aktivitäten und Diskurse, Erfolge und Niederlagen in der Bildungsarbeit spiegeln dabei oft diejenigen der französischen Politiker sowie der libanesischen Interessengruppen wider. Deshalb stehen alle drei Untersuchungsebenen in wechselseitig wirkenden Verhältnissen zueinander, welche über Diskurse zur Zivilisierungsmission und darauf bezogene kulturelle und soziale Praktiken im Schulkontext greifbar werden. Mit dieser weiten Perspektive soll der Begriff der Zivilisierungsmission in seiner Vielschichtigkeit eingefangen und für die französische Bildungspolitik im Libanon erstmals umfassend untersucht werden.

Damit fügt sich diese Arbeit ebenso in die innerhalb der Geschichtswissenschaft aktuelle Debatte über die Aushandlungsprozesse von Machtverhältnissen in kolonialen Kontexten wie in diejenige über die Idee der Zivilisierungsmission und deren Kulturtransfer als zentralem Gegenstand dieser Aushandlungen ein. Der neue Beitrag dieser Arbeit liegt dabei in der vergleichenden Untersuchung der ideologisch ganz unterschiedlich ausgerichteten französischen Schulen und ihren spezifischen Interaktionen mit der libanesischen Bevölkerung und den französischen Autoritäten und damit nicht zuletzt in einer notwendigen weiteren Differenzierung der Idee der Zivilisierungsmission.

\section{Forschungsstand}

Die vorliegende Studie versteht sich als Beitrag zu den in der Geschichtswissenschaft aktuellen Debatten zu den Themen der Zivilisierungsmission und des Bildungswesens im kolonialen Kontext, speziell in der arabischen Welt. Dabei stehen diese drei Forschungsfelder in einem engen Zusammenhang. Mit der Frage der Zivilisierungsmission hat sich die historische Forschung der letzten Jahre intensiv beschäftigt ${ }^{56}$. Insbesondere Jürgen Osterhammel hat sie in seinen wegweisenden Arbeiten als Phänomen beschrieben, das sich seit Ende des 18. Jahrhunderts aus der Überzeugung der eigenen kulturellen Überlegenheit in den europäischen und nordamerikanischen Gesellschaften entwickelt hatte. In dieser Zeit des entstehenden Kolonialismus und Imperialismus leiteten die westlichen Mächte aus dieser Überlegenheitshaltung das Recht und die Pflicht ab, ihre Kultur und die damit verbundenen Werte in die Welt zu tragen ${ }^{57}$. Die Idee der Zivilisierungsmission wurde so zum selbstver-

56 Vgl. einen Forschungsüberblick in: Osterhammel 2005, S. 363-425.

57 Vgl. ebd., S. 363. 
ständlichen Bestandteil der kolonialen Ideologie, wie Michael Mann gezeigt hat $^{58}$, wirkte aber, wie Marc Frey anhand der USA deutlich gemacht hat, auch über die Zeit der direkten kolonialen Kontrolle hinaus ${ }^{59}$.

Die Forschung hat aber zu Recht die besondere Bedeutung der Zivilisierungsmission für Frankreich auf der nationalen und Regierungsebene betont: insbesondere die Betonung der französischen Sprache als >natürlicheく Trägerin universeller Werte hat diese Idee zwar nicht zu einem in sich geschlossenen Konzept werden lassen, aber unter vielen französischen Gruppen in der Regierung und in der Gesellschaft die Überzeugung von der spezifischen Mission ihrer Kultur wachsen lassen ${ }^{60}$. Insbesondere die Regierungen der laizistisch geprägten Dritten Republik haben diese Idee auf nationaler und internationaler Ebene vorangetrieben und konnten so die christlichen Wurzeln der Zivilisierungsmission, aber auch die Werte der französischen Nation in eine säkulare Form gießen ${ }^{61}$.

Im Kontext des Kolonialismus hat die Dritte Republik ihre Vorreiterrolle in dieser Hinsicht besonders betont, um so auch den Widerspruch zwischen Demokratie und gewalttätigem Erwerb von Kolonialgebiet zu überwinden ${ }^{62}$. Bezüglich des Völkerbundmandats für Syrien und Libanon stilisierte sich der französische Staat sogar Elizabeth Thompson zufolge als »Mother France [...] for her Syrian and Lebanese children, deemed not yet mature to sustain themselves $\ll^{63}$.

58 Michael Mann, Touchbearers upon the path of progress, in: Harald Fischer-Tiné/Michael Mann (Hg.), Colonialism as Civilizing Mission. Cultural Ideology in British India, London 2004, S. 1-25, S. 4.

59 Vgl. Marc Frey, Indoktrination, Entwicklungspolitik und »State Building«. Die Vereinigten Staaten in Südostasien 1945-1961, in: Boris BARTH / Jürgen Osterhammel (Hg.), Zivilisierungsmissionen, Konstanz 2005, S. 335-362.

60 Vgl. Dino Costantini, Mission civilisatrice. Le rôle de l'histoire coloniale dans la construction de l'identité politique française, Paris 2004, S. 58; Evans 2004, S. 10. Für den Vergleich französischer und britischer Sprachpolitik siehe Almut Steinвach, Sprachpolitik im Britischen Empire: Herrschaftssprache und Integration in Ceylon und den Föderierten Malaiischen Staaten, München 2009, S. 20; vgl. Bob W. White, Talk About School: Education and the Colonial Project in French and British Africa (1860-1960), in: Comparative Education 32 (1996), H. 1, S. 9-25, S. 21.

61 Vgl. Osterhammel 2006, S. 8: »[...] since it gave the name to a specific doctrine of the Third Republic«; vgl. auch Nicolas Bancel/Pascal Blanchard/Françoise Verges, La République coloniale, Paris 2003, S. 74: »En France, la mission civilisatrice [...] dès 1895 devient l'idéologie officielle de la République «.

62 Vgl. Alice L. Conklin, A Mission to Civilize. The Republican Idea of Empire in France and West Africa 1895-1930, Stanford 1997, S. 2.

63 Vgl. Elizabeth Thompson, Colonial Citizens. Republican Rights, Paternal Privilege, and Gender in French Syria and Lebanon, New York 2000, S. 58; vgl. auch Benjamin Thomas White, Rhetorical Hierarchies in France and Syria During the Mandate, in: Chronos. Revue d'Histoire de l’Université de Balamand 17 (2008), S. 105-121. 
Die in der vorliegenden Arbeit vorgenommene Analyse der französischen Schulen im Libanon bestätigt zum einen die Bedeutung der Zivilisierungsmission auf der staatlichen Ebene, fragt aber darüber hinaus auch danach, wie sie konkret sowohl im zivilgesellschaftlichen Bereich als auch in der individuellen Begegnung im Libanon sowie auch in Frankreich vollzogen wurde, beispielsweise indem sie als Argument in Briefen und Reden Verwendung fand. Zudem will die Studie nach den Unterschieden zwischen der exportierten Idee und der Praxis vor Ort fragen.

Die zu diesem Themenkomplex bereits vorliegenden Studien verdeutlichen, dass sich die Ansprüche der Zivilisierungsmission nicht nur auf die kolonialen Territorien richteten. Diese Idee wurde gerade von Eliten auch auf randständige Gruppen in der eigenen Gesellschaft bezogen. Betroffen waren davon entweder sozial benachteiligte Gruppen, wie Harald Fischer-Tiné für Großbritannien nachgewiesen hat ${ }^{64}$, oder rebellierende Regionen und Bevölkerungsgruppen, wie von Anne-Marie Thiesse für Frankreich untersucht wurde $^{65}$. Zusammenfassend kann festgehalten werden, dass die Unterscheidung der kolonialen Interaktionsräume in »Kolonisierer« und »Kolonisierte« oder im Falle der vorliegenden Arbeit in »Zivilisierer« und »Zivilisierte« in der historischen Praxis stark aufgelöst wurde ${ }^{66}$.

Die in Europa gereiften Vorstellungen vom Wert der eigenen Kultur wurden von staatlichen und zivilgesellschaftlichen Akteuren insbesondere im Bildungswesen oft auf die Situation in den Kolonien übertragen, wie Fanny Colonna für die Schulen in Algerien nachgewiesen hat ${ }^{67}$. Dass sich das Projekt der Zivilisierungsmission aber nicht nur auf die indigene Bevölkerung, sondern auch auf die europäischen »subalternen « Individuen in den kolonialen Gesellschaften bezog, zeigte jüngst Harald Fischer-Tiné ${ }^{68}$. Aus diesem Grund kann die Zivilisierungsmission, soweit der gegenwärtige Forschungs-

64 Harald Fischer-Tiné, Englands interne Zivilisierungsmission. Arbeitshäuser für Europäer im kolonialen Indien (ca. 1860-1914), in: Boris BArth / Jürgen Osterhammel (Hg.), Zivilisierungsmissionen, Konstanz 2005, S. 169-198.

65 Anne-Marie Thiesse, Ils apprenaient la France. L'exaltation des régions dans le discours patriotique, Paris 1997; Eugen Weber, Peasants into Frenchmen. The Modernization of Rural France 1870-1914, Stanford, California 2007.

66 Diese Begriffe werden hier in Anführungszeichen gesetzt, da die neueste Forschung zu Recht deutlich gemacht hat, dass die Bezeichnungen sowohl eurozentristisch sind als auch in ihrer Essentialisierung nicht der historischen Realität entsprechen. Vgl. Frederick CoOPER/Ann Laura Stoler, Between Metropole and Colony. Rethinking a Research Agenda, in: Dies. (Hg.), Tensions of Empire. Colonial Cultures in a Bourgeois World, Berkeley, California 1997, S. 1-56.

67 Vgl. Fanny ColonnA, Educating Conformity in French Colonial Algeria, in: Frederick Cooper / Ann Laura Stoler (Hg.), Tensions of Empire. Colonial Cultures in a Bourgeois World, Berkeley, California, 1997, S. 346-370.

68 Vgl. Harald Fischer-Tiné, Low and Licentious Europeans. Race, Class and »White Subalternity« in Colonial India, Neu Delhi 2009. 
stand, sowohl innerhalb der westeuropäischen als auch in Bezug auf koloniale Gesellschaften in mehrfacher Hinsicht als Elitenprojekt verstanden werden $^{69}$. Demgegenüber ist es unabdingbar, ergänzend dazu auch die Gruppen in den Blick zu nehmen, die durch ihre Tätigkeit in Kolonialgebieten ihren sozialen Status verbessern konnten, wie dies am Beispiel einiger französischer Lehrer im Libanon untersucht werden soll.

Die Forschung hat den Begriff der Zivilisierungsmission außerdem insofern bereits ausgeweitet, als sie auf dieses Phänomen auch jenseits der Beziehungen zwischen westeuropäischen Staaten und den von diesen beanspruchten kolonialen Gebieten hingewiesen hat. So waren bereits Intellektuelle und Politiker des Osmanischen Reiches überzeugt davon, dass das städtische Zentrum gegenüber der ländlichen Peripherie ${ }^{70}$, die gebildete Schicht mit Blick auf die »Unwissenden « oder auf die »dekadente osmanische Zivilisation $\aleph^{71}$, eine Zivilisierungsmission zu leisten habe. Auf diese Weise nahmen sich diese Reformer zwar den Westen grundsätzlich zum erziehungspolitischen Vorbild, manche aber taten die europäische Kultur als dekadent oder unpassend für die arabische Welt $a b^{72}$. In der vorliegenden Arbeit wird auch hierauf Bezug genommen, indem gezeigt wird, dass sich die Libanesen selbst bereits aus unterschiedlichen Motiven heraus der Idee der Zivilisierungsmission bedient hatten.

Abschließend ist $\mathrm{zu}$ betonen, dass in den oben genannten Studien offen bleibt, welche Formen sozialen Wandels durch Diskurse und kulturelle wie soziale Praktiken mit Bezug zur Zivilisierungsmission angestoßen und wie diese im Verbund mit lokalen kulturellen Mustern umgesetzt wurden. Gerade diese Verflechtung des Begriffs der Zivilisierungsmission auf den unterschiedlichsten Ebenen und in jeweils lokal und kulturell unterschiedlichen Ausprägungen will die vorliegende Studie aufzeigen. Dadurch werden die bisherigen Forschungsergebnisse insofern ergänzt, als sie nicht nur die Diskussion der eigenen Zivilisation und die Perzeption der westlichen Kultur im arabischen Kontext untersucht, sondern diesen Diskussionskomplex zusätzlich in seiner Interaktion mit den französischen Schulen analysiert. Ohne

69 Vgl. Osterhammel 2005, S. 370.

70 Vgl. Frederick Cooper, Colonialism in Question. Theory, Knowledge, History, Berkeley, California 2005, S. 28; Birgit SchÄBLER, Von »wilden Barbaren« zur »Blüte der Zivilisation«: Zur Transformation eines Konzeptes und zur Neubewertung des frühen arabischen Nationalismus, in: Dietmar Rothermund (Hg.), Aneignung und Selbstbehauptung. Antworten auf die europäische Expansion, München 1999, S. 85-109; Birgit SchÄBlER, Civilizing Others. Global Modernity and the Local Boundaries (French/German, Ottoman, and Arab) of Savagery, in: Dies./Leif Stenberg (Hg.), Globalization and the Muslim World: Culture, Religion, and Modernity, Syracuse 2004, S. 3-29.

71 Vgl. Keith David Watenpaugh, Being Modern in the Middle East. Revolution, Nationalism, Colonialism, and the Arab Middle Class, Princeton 2006, S. 1-11.

72 Vgl. Nazik Saba Yared, Secularism and the Arab World (1850-1939), London 2002. 
die Berücksichtigung dieser Interaktion kann weder die französische noch die libanesische innergesellschaftliche Entwicklung adäquat erklärt werden.

Das Bildungswesen im kolonialen Kontext, welches die Forschung seit den 1970er Jahren beschäftigt, hat in jüngster Zeit verstärkt die Aufmerksamkeit der historischen Forschung auf sich gezogen. Stärker als die Pionierarbeiten aus dem Bereich der Kulturimperialismusforschung, welche die kulturelle Dimension kolonialer Expansion betonten und in Abgrenzung zur zuvor vorherrschenden apologetischen Herangehensweise in der Forschung besonders die negativen Seiten solcher kulturellen Einflüsse auf Bildungseinrichtungen hervorhoben ${ }^{73}$, analysieren neuere Arbeiten die vielschichtigen Interaktionen zwischen Europäern und der indigenen Bevölkerung in den Schulen vor Ort ${ }^{74}$. Diese Studien lassen zwar nicht die oft verheerenden Folgen außer Acht, die die Umgestaltung des einheimischen Bildungswesens für den kulturellen Reichtum in den Kolonien bedeutete ${ }^{75}$, differenzieren ihre Ergebnisse jedoch mit Blick auf die Handlungsspielräume der Akteure vor Ort. Nicht nur Akteure auf Seiten der Kolonialmacht, sondern auch solche in den Kolonien wussten ihre Diskurse und Praktiken dem jeweiligen politischen Kontext anzupassen und ihre Interessen im Rahmen der Möglichkeiten einer Machtasymmetrie zumindest in einem gewissen Umfang zu vertreten ${ }^{76}$.

73 Vgl. für einen Forschungsüberblick zum kulturellen Imperialismus Ryan Dunch, Beyond Cultural Imperialism. Cultural Theories, Christian Missions, and Global Modernity, in: History and Theory 41 (2002), S. 301-325; Peter Golding/Phil Harris (Hg.): Beyond Cultural Imperialism. Globalization, Communication and the New International Order, London 1997; vgl. Ferner die trotz ihres Alters sehr hilfreichen Arbeiten von Philip G. Altbach/Gail P. Kelly (Hg.), Education and Colonialism, New York 1978. Für die allgemeine Entwicklung der Kolonialhistoriographie vgl. Wolfgang ReInHARD, Kleine Geschichte des Kolonialismus, Stuttgart 2008; Frederick COOPER 2005, S. 33-58, hier vor allem S. 33-35.

74 Vgl. Alice L. Conklin/Julia Clancy-Smith, Introduction: Writing Colonial Histories, in: French Historical Studies 27 (2004), S. 497-505, S. 501; Rita Sмiтн KipP, Emancipating Each Other. Dutch Colonial Missionaries' Encounter with Karo Women in Sumatra, 1900-1942, in: Julia Clancy-Smith/Frances Gouda (Hg.), Domesticating the Empire. Gender and Family Life in French and Dutch Colonialism, Charlottesville/London 1998, S. 211-235; Julia CLANCYSмітн, L'éducation des jeunes filles musulmanes en Tunisie. Missionnaires religieux et laïques, in: Florence Rochefort (Hg.), Le pouvoir du genre. Laïcités et religions, 1905-2005, Toulouse 2007, S. 127-143; Paul SEDRA, From Mission to Modernity. Evangelicals, Reformers and Education in Nineteenth-Century Egypt, London/New York 2011; Jana TschuRENEV, Incorporation and Differentiation: Popular Education and the Imperial Civilizing Mission in the Early Nineteenth Century India, in: Carey Watt/Michael Mann (Hg.), Civilizing Missions in Colonial and Postcolonial South Asia. From Improvement to Development, London 2011, S. 93-124; Julia Hauser, Waisen gewinnen. Mission zwischen Programmatik und Praxis in der Erziehungsanstalt der Kaiserswerther Diakonissen in Beirut seit 1860, in: WerkstattGeschichte 57 (2011), S. 9-30.

75 Vgl. Cooper 2004, S. 131-147; Mitchell 2003.

76 Vgl. Harald Fischer-Tiné, Vom Wissen zur Macht. Koloniale und »nationale« Bildungsmodelle in Britisch Indien, ca. 1781-1920, in: Karin Preisendanz/ Dietmar Rothermund (Hg.), Südasien in der »Neuzeit«. Geschichte und Gesellschaft, 1500-2000, Wien 2003, S. 90-109; Peter WiEN, 
Die vorliegende Arbeit teilt diesen Ansatz und legt durch die Darstellung des spezifischen historischen Spannungsfeldes Schulen - französische Regierung - libanesische Bevölkerung eine weitere Fallstudie der frankoarabischen Verflechtung vor. Auch wenn die französische Herrschaftspraxis im Libanon, entgegen den völkerrechtlichen Vorgaben des Völkerbundmandats, in vielen Aspekten einer kolonialen Konstellation entsprach, unterschied sich die Bildungssituation in einigen Punkten von derjenigen in Kolonien im engeren Sinn ${ }^{77}$. Dies gilt zum Beispiel für den Umgang mit der Vergangenheit des kolonialen Gebietes im Geschichtsunterricht ${ }^{78}$. Dementsprechend verdeutlicht der Vergleich mit kolonialen Bildungssituationen wie in Algerien und Indochina die Vielschichtigkeit des libanesischen Falles und stellt dessen Besonderheiten heraus.

Hilfreich für diese Arbeit waren außerdem Studien, die in den letzten Jahren in Frankreich und dem angelsächsischen Raum über Bildungseinrichtungen im Nahen Osten entstanden sind. Neben einigen Arbeiten zu britischen und amerikanischen Institutionen ${ }^{79}$ wurden vor allem die französischen katholischen Schulen und ihre vornehmlich katholische arabische Klientel untersucht. Die Studien von Chantal Verdeil über die Jesuiten im Libanon bis zum Ersten Weltkrieg sowie von Jérôme Bocquet über die Lazaristen in Syrien im 19. und 20. Jahrhundert sind dabei zentral für die nachfolgende Analyse, da sie die Position der katholischen Schulen zwischen den Erwartungen der französischen Regierung und der lokalen Bevölkerung ausleuch$\operatorname{ten}^{80}$. Forschungsarbeiten von Karène Sanchez und Dominique Trimbur zu den französischen Orden in Palästina sowie von Frédéric Abécassis zu den

Who is »liberal« in 1930s Iraq? Education as a Contested Terrain in a Nascent Public Sphere, in: Christoph Schumann (Hg.), Nationalism and liberal Thought in the Arab East. Ideology and Practice, London/New York 2010, S. 31-47; Osama ABI-Mershed (Hg.), Trajectories of Education in the Arab World. Legacies and Challenges, London/New York 2010.

77 Vgl. Bouche 1991, S. 271-272; Le Pautremat 2003, S. 23, 310; Yvette Katan Bensamoun/ Rama Chalak, Le Maghreb. De l'empire ottoman à la fin de la colonisation française, Paris 2007, S. 245-269.

78 Vgl. COOPER 2004, S. 141-142.

79 Vgl. jüngst Betty Anderson, The American Univerity of Beirut. Arab Nationalism and Liberal Education, Austin 2011.

80 Vgl. Chantal Verdeil, La Mission jésuite du Mont-Liban et de Syrie (1830-1964), Paris 2011 ; DiEs., Un établissement catholique dans la société pluriconfessionelle de la fin de l'Empire ottoman: l'université Saint Joseph de Beyrouth, in: Anne-Laure Dupont (Hg.), Islam et éducation au temps des réformes modernes. Systèmes scolaires et enjeux de l'enseignement au Proche-Orient et en Afrique du Nord aux XIX ${ }^{\mathrm{e}}$ et $\mathrm{XX}^{\mathrm{e}}$ siècles, Paris 2007, S. 28-38 (Cahiers de la Méditerranée 75); Dies., Les écoles d'Orient. Le réseau scolaire congrégationiste (1880-1914), in: Bernard Delpal/Bernard Hours/Claude Prudhomme (Hg.), France - Levant. De la fin du XVII ${ }^{\mathrm{e}}$ siècle à la Première Guerre mondiale, Paris 2005, S. 145-166; Dies., Les jésuites de Syrie (1830-1864): une mission auprès des chrétiens d'Orient au début des réformes ottomanes, Diss. Paris 2003; Jérôme BocQuet, La France, L'Église et le Baas. Un siècle de présence française en Syrie (de 1918 à nos jours), Paris 2008; ders., 2005. 
katholischen, laizistischen und jüdischen französischen Schulen in Ägypten zwischen 1920 und 1960 zeigen viele Parallelen, besonders hinsichtlich der Dynamik der Schulen zwischen französischer und lokaler Einflussnahme sowie in ihrer Funktion als Ausbildungsstätten für Eliten ${ }^{81}$. Sie führen aber auch zu der Frage nach der spezifischen kulturellen und politischen Situation im Libanon, insbesondere im Hinblick auf die engen Beziehungen der Maroniten, einer mit Rom unierten katholischen Religionsgemeinschaft, zu Frankreich.

Die Mehrzahl dieser Arbeiten beschränkt sich allerdings auf die Analyse einer einzigen Schule. Die ambivalente Beziehung katholischer Schulen zum laizistischen französischen Staat wird jeweils nur aus der Perspektive der Schulen selbst aufgezeigt, was die analytische Perspektive stark einschränkt. Eine Untersuchung der laizistischen, protestantischen und jüdischen französischsprachigen Schulen im Vergleich mit den katholischen Einrichtungen, wie ich sie in dieser Arbeit vornehme, ermöglicht dagegen neue Einblicke in die Ansichten und Haltungen der nicht-katholischen frankophonen Bevölkerung im Libanon und damit eine neue Sichtweise der französisch-libanesischen Beziehungen ${ }^{82}$. Darüber hinaus umfasst der Untersuchungszeitraum, in dem die unterschiedlichen französischsprachigen Schulen im Libanon verglichen werden, regimeübergreifend die Regierung des Osmanischen Reichs und die Periode des französischen Völkerbundmandats. Diese Langzeitperspektive ist besonders vielversprechend, da sie die Fragestellung nach den vielen Kontinuitäten, welche Forscher über die unterschiedlichen syrischen und libanesischen Regimes hinweg benannt haben ${ }^{83}$, auch in Bezug auf Bildung und speziell die französischen Schulen erlaubt.

In ihrer kürzlich erschienenen Arbeit hat Jennifer eine Reihe vor allem französischer, aber auch amerikanischer und britischer Schulen als Instrumente der Kulturpolitik in Syrien und dem Libanon in der letzten Dekade

81 Vgl. Dominique Trimbur, La revanche des congrégations? Politique anticléricale et présence catholique française en Palestine au début du XX $\mathrm{X}^{\mathrm{e}}$ siècle, in: Jean-Pierre Luizard (Hg.), Le choc colonial et l'islam. Les politiques religieuses des puissances coloniales en terre d'islam, Paris 2006, S. 121-135; Karène SAChez-Summerer, Langue(s) et religion(s) en Palestine mandataire au sein d'institutions éducatives catholiques. Établissements des Frères des Écoles chrétiennes et Sœur de Saint-Joseph de l'Apparition 1922-1940, in: Documents pour l'histoire du Français langue étrangère ou seconde 37 (2006), S. 93-132; Frédéric ABÉCASsIs, L'enseignement étranger en Égypte et les élites locales 1920-1960. Francophonie et identités nationales, Diss. AixMarseille, 2000.

82 Das von Burrows 1986 postulierte Forschungsdesiderat zu dieser Frage ist bis heute nicht eingelöst. Vgl. Matthew Burrows, »Mission civilisatrice«: French Cultural Policy in the Middle East, 1860-1914, in: The Historical Journal 29 (1986), 1, S. 109-135.

83 Vgl. prominent Khourys Studie zu der Kontinuität der Position der Notabeln während osmanischer und Mandatszeit in Syrien. Philip S. Khoury, Syria and the French Mandate. The Politics of Arab Nationalism 1920-1945, London 1987. 
des französischen Mandats von 1936-1946 untersucht ${ }^{84}$. Mit der Anlage ihrer Analyse betont sie die Bedeutung der Schulen für die politischen Aushandlungsprozesse zwischen westlichen Staaten und libanesischen sowie syrischen Aktivisten und Parteien, kann aber wegen der Breite ihres geographischen und institutionellen Fokus nicht in allen Aspekten die Rolle der Schulen in ihrer Vielschichtigkeit thematisieren. Wenig überzeugend ist Duecks Kritik an der Fokussierung auf die Idee der Zivilisierungsmission zur Analyse des Bildungswesens in den Mandatsregimen, durch die ihrer Meinung nach zu stark von den »confines of tutor-tutee power dynamic $\ll^{85}$ ausgegangen werde. Die Analyse des in dieser Studie verarbeiteten Archivmaterials zeigt dagegen sehr deutlich die Relevanz der Zivilisierungsmission als Aushandlungsprodukt französischer und libanesischer Interessengruppen.

\section{Theoretische Herangehensweise}

Diese Arbeit verbindet verschiedene theoretische Herangehensweisen, um von der Makroebene ausgehend eine differenzierte Analyse der französischen Schulen im Libanon bis hin zur Mikroebene durchzuführen. Den übergreifenden theoretischen Rahmen dieser Studie bilden dabei die Postcolonial Studies, die den Einfluss der kolonialen Strukturen auf >Mutterland und `Kolonien ‘ jenseits direkter kolonialer Machtverhältnisse in den Fokus rücken. Ursprünglich aus der Literaturwissenschaft kommend, hat der postkoloniale Ansatz auch in der Geschichtswissenschaft in vielen Werken Eingang gefunden, die sich mit Kolonialgeschichte befassen ${ }^{86}$. Diese Forschungsrichtung wurde maßgeblich durch das Werk Orientalism von Edward Said geprägt, in welchem dieser die Konstruktion des Orients als Wissensund Machtobjekt Europas aufzeigt ${ }^{87}$. Aus eben diesem Grund sei die wissenschaftliche Auseinandersetzung Europas mit dem Orient, so Said, im Monolog erstarrt: dieses Vorgehen habe die Bevölkerung des Orients entmündigt und ihr die Möglichkeit zur Selbstrepräsentation genommen, weshalb sie nur noch von außen, also vom Westen, repräsentiert werden könne. Schließlich, so Said weiter, seien diese Fremdrepräsentationen nie interessenlos gewesen,

\footnotetext{
84 Vgl. Jennifer Dueck, The Claims of Culture at Empire's End. Syria and Lebanon under French Rule, Oxford 2010.

85 Vgl. ebd., S. 8.

86 Vgl. beispielsweise die sehr gelungene Studie über die Beziehung zwischen Sexualität und kolonialer Herrschaft am Beispiel der niederländischen Kolonien in Südostasien von Ann Laura Stoler, Carnal Knowledge and Imperial Power. Race and the Intimate in Colonial Rule, Berkeley/California u.a. 2005.

87 Vgl. Edward W. SAID, Orientalism, New York 1979.
} 
sondern Teil der kolonialen Machtverhältnisse, die zudem der Selbstvergewisserung Europas gedient hätten ${ }^{88}$.

Trotz aller - in großen Teilen durchaus angemessenen - Kritik an Saids Thesen geben diese wichtigen Anregungen für die vorliegende Arbeit, insbesondere dort, wo es um die Beschreibung der verschiedenen französischen Wahrnehmungen des Orients geht, die er sehr treffsicher analysiert hat. Edward Said, der selbst als Kind britische Schulen in Jerusalem und Kairo besucht hatte, hat den Einflüsse westlicher Bildungsinstitutionen und -inhalte auf Schüler im Nahen Osten zwar in seiner Autobiographie ${ }^{89}$ beschrieben, aber nicht zum Thema seiner Forschung gemacht; gleichwohl sind seine Überlegungen und die Kritik daran für die vorliegende Arbeit durchaus weiterführend. Allerdings stellt die hier vertretene These von der Aushandlung kolonialer Bildung zwischen Franzosen und Libanesen die Said'sche Dekonstruktion europäischer Blicke auf den Orient als imperiale und von der realen Begegnung losgelöste Haltungen auch in Frage.

Saids Werk wurde in mehrfacher Hinsicht kritisiert. Neben den Vorwürfen der Übertreibung, der unsauberen Anwendung theoretischer Paradigmen und der zu starken persönlichen Positionierung Saids ${ }^{90}$, ist dem Literaturprofessor vor allem die mangelnde Differenzierung seines dekonstruktivistischen Ansatzes vorgehalten worden. Zum einen wird seiner OrientalismusKritik vorgeworfen, ein zu statisches Bild des einen Orients gezeichnet zu haben, indem sie nicht zwischen verschiedenen Orientalismen und Orientbildern differenziere ${ }^{91}$. In der Tat hatten auch die in dieser Arbeit untersuchten französischen Akteure bei aller Gemeinsamkeit unterschiedliche Bilder vom Libanon. Auf diese Weise habe Said, so ein zweiter wichtiger Kritikpunkt, den Orient zwar als passives Objekt der Europäer dekonstruiert, zugleich aber auch den arabischen Akteuren jegliche Handlungsmöglichkeit abgesprochen $^{92}$. Außerdem habe diese pauschale Darstellung zur Folge, dass der Westen ebenfalls als ein zu monolithischer Block erscheine, der nur an Macht

88 Für diese konzise Zusammenfassung der Hauptthesen der Kritik an Orientalism siehe Harald Fischer-Tiné, Postkoloniale Studien, in: Europäische Geschichte Online (EGO), hg. vom Institut für Europäische Geschichte (IEG), Mainz 2010. URL: http://www.ieg-ego.eu/fischertineh2010-de (15.06.2011). Für eine breitete historische Einbettung siehe Robert C. Young, Postcolonialism. An Historical Introduction, Oxford 2010, S.383-394.

89 Vgl. Edward SAID, Out of Place. A Memoir, New York 2000, S. 36-48.

90 Eine Kritik, die ihrerseits sehr persönlich wurde - vgl. Bernard LEwIS, The Question of Orientalism, in: Ders., Islam and the West, New York 1993, S. 99-118; John M. MacKenzie, Orientalism, History, Theory and the Arts, Manchester 1995, S. 4-7.

91 So Michael F. Klinkenberg, Das Orientbild in der französischen Literatur und Malerei vom 17. Jahrhundert bis zum fin de siècle, Heidelberg 2009, S. 11.

92 Vgl. Hartmut Fähndrich, Orientalismus und Orientalismus. Überlegungen zu Edward Said, Michel Foucault und westlichen »Islamstudien«, in: Die Welt des Islams 28 (1988), S. 178-186, hier S. 181-183. 
und Hegemonie interessiert sei ${ }^{93}$. Generell habe Said die Vormachtstellung Europas stark überbewertet und dabei ausgeblendet, dass die Europäer in den Kolonien, wie Homi Bhabha hervorgehoben hat, auch von Ängsten und Unsicherheiten geprägt waren ${ }^{94}$. Außerdem habe der Autor von Orientalism die Rolle der einheimischen Vermittler ignoriert und damit zu wenig die Grauzonen zwischen den verschiedenen Kategorien beachtet ${ }^{95}$. Einige der hier untersuchten libanesischen Akteure im Umfeld der französischen Schulen untermauern diesen Befund.

Der syrische Philosoph Sadiq Jalal al-'Azm schließlich warf Said vor, in teleologischer Weise den institutionellen Orientalismus konstruiert zu haben. Indem er diesen mit dem europäischen Expansionismus gleichsetze, den er wiederum aus dem akademischen Orientalismus, d.h. der wissenschaftlichen Beschäftigung mit dem Orient, herleite, sei er den von ihm kritisierten Legitimationsdiskursen der Orientalisten selbst zum Opfer gefallen ${ }^{96}$. Al-Azm weist außerdem darauf hin, dass Saids starke Betonung der essentialistischen Trennung zwischen Orient und Okzident im Orient zu einem »Orientalisme à l'envers«, also zu einem umgekehrten Orientalismus geführt habe, der seinerseits ebenfalls Ost und West essentialisierend darstelle ${ }^{97}$. Bei aller berechtigten Kritik an Saids Forschungsansatz ist jedoch unbestritten, dass die von ihm beschriebenen Paradigmen das Denken und Handeln der französischen und libanesischen Akteure trotz allem stark beeinflussten. So haben beispielsweise die von Said untersuchten Werke französischer Schriftsteller in erheblichem Maß sowohl die französischen Lehrer im Libanon als auch deren libanesische Schüler geprägt. Das von Said entworfene OrientalismusKonzept ist also nicht ungültig, sondern kann als ein Paradigma neben anderen gelten, auf das sich unterschiedliche Akteure in kolonialen Handlungskontexten beziehen.

Teils ist Said seinen Kritikern selbst entgegen gekommen, indem er sich in seinem Buch Culture and Imperialism »that response to Western dominance« gewidmet hat ${ }^{98}$. Zum anderen kann den genannten Diskussionspunkten mit dem Ansatz der Entangled Histories begegnet werden, wie ihn zuletzt Sha-

93 Vgl. Daniel Martin VARISCo, Reading Orientalism. Said and the Unsaid, Seattle/London 2007, S. XIII und S. 23-24.

94 Vgl. FisCHER-Tiné 2010.

95 Vgl. Jürgen Osterhammel, Wissen als Macht. Deutungen interkulturellen Nichtverstehens bei Tzvetan Todorov und Edward Said, in: Jürgen Osterhammel, Geschichtswissenschaft jenseits des Nationalstaats. Studien zu Beziehungsgeschichte und Zivilisationsvergleich, Göttingen 2001, S. 240-265, S. 259.

96 Vgl. Sadiq Jalal AL-Azm, Ces interdits qui nous hantent. Islam, censure, orientalisme, Marseille 2008, S. 154-155.

97 Vgl. ebd, S. 168. Ursprünglich hat Al-Azm diese Kritik auf Englisch veröffentlicht, vgl. Sadiq AL-Azm, Orientalism in Reverse, in: Khamsin 8 (1981), S. 5-26.

98 Vgl. Edward SAID, Culture and Imperialism, London 1994, S. xii. 
lini Randeria und Sebastian Conrad für die Verflechtung zwischen Europa und der außereuropäischen Welt aus dem auf Europa konzentrierten Theorem der Histoire croisée heraus entwickelt haben. Der Ansatz der Entangeld Histories betont die konstituierende Rolle dieser Verflechtung für die »Metropolen« und für die »Kolonien« im Sinne einer »Geschichte des Austausches und der Interaktion $«{ }^{99}$. Leider wurde dieser Ansatz bis heute über eine vielversprechende Programmatik heraus nicht wesentlich weiter entwickelt.

Mit dem Paradigma der Histoire croisée wandten sich die Historiker Michael Werner und Bénédicte Zimmermann unter anderem gegen das Konzept der Transferforschung, welches Werner mit Michel Espagne selbst entworfen hatte ${ }^{100}$. Die besonders bei der Untersuchung von kultur- und bildungshistorischen Phänomenen angewandte Transferforschung geht davon aus, dass die Konstitution nationaler und kultureller Identitäten nicht ohne den Austausch und die Übernahme von Überzeugungen und Praktiken zwischen verschiedenen politischen und kulturellen Entitäten zu verstehen ist. Auch wenn Werners und Zimmermanns Kritikpunkte am Kulturtransfermodell gerade im europäisch-außereuropäischen Verhältnis unbedingt berücksichtigt werden müssen - wichtig ist hier vor allem der Vorwurf, es operiere mit zu statischen Entitäten, sowie die Kritik an der Nähe zur Modernisierungstheorie ${ }^{101}$-, erweist sich das Konzept des Transfers für den vorliegenden Untersuchungsgegenstand als sinnvoll ${ }^{102}$. Der Ansatz profitiert weiterhin davon, dass er mittlerweile über europäische Fragen hinaus auch im globalen Kontext diskutiert wird ${ }^{103}$.

99 Vgl. Shalini Randeria/ Sebastian ConRad, Geteilte Geschichte - Europa in einer postkolonialen Welt, in: Shalini Randeria/Sebastian Conrad (Hg.), Jenseits des Eurozentrismus. Postkoloniale Perspektiven in den Geschichts- und Kulturwissenschaften, Frankfurt am Main/New York 2002, S. 9-49, S. 17.

100 Vgl. Michael Werner/Bénédicte Zimmermann, Vergleich, Transfer, Verflechtung. Der Ansatz der Histoire croisée und die Herausforderung des Transnationalen, in: Geschichte und Gesellschaft 28 (2002), S. 607-636.

101 Vgl. dieses Gebot zur Vorsicht bei Jürgen Osterhammel, Transferanalyse und Vergleich im Fernverhältnis, in: Hartmut KaElBle/Jürgen Schriewer (Hg.), Vergleich und Transfer. Komparatistik in den Sozial-, Geschichts- und Kulturwissenschaften, Frankfurt am Main/New York 2003, S. 439-465, hier 448-449. Siehe auch Christiane EISENBERG, Kulturtransfer als historischer Prozeß. Ein Beitrag zur Komparatistik, in: Hartmut KaELbLE/Jürgen Schriewer (Hg.) 2003, S. 399-417. Marcelo Caruso und Jürgen Schriewer sprechen statt von Transfer von Diffusionsdynamiken und bieten damit ein zumindest bedenkenswertes alternatives Konzept. Vgl. Jürgen Schriewer/Marcelo CARuso, Globale Diffusionsdynamik und kontextspezifische Aneignung: Konzepte und Ansätze historischer Internationalisierungsforschung, in: Dies. (Hg.), Nationalerziehung und Universalmethode. Frühe Formen schulorganisatorischer Globalisierung, Leipzig 2005 (Comparativ 15 (2005), H. 1), S. 7-30, S. 17.

102 Vgl. auch Esther MöLlER/Johannes WischmeYer, Transnationale Bildungsräume - Koordinaten eines Forschungskonzepts, in: Dies. (Hg.), Transnationale Bildungsräume. Wissenstransfers im Schnittfeld von Kultur, Politik und Religion, Göttingen 2013, S. 7-20.

103 Vgl. Jörg Feuchter, Cultural Transfers in Dispute. An Introduction, in: Jörg Feuchter/Friedhelm Hoffmann/Bee Yun (Hg.), Cultural Transfers in Dispute. Representations in Asia, 
Zum einen ist das Konzept für die vorliegende Arbeit hilfreich, weil die französischsprachigen Schulen im Libanon mit der bewussten Absicht zum Transfer des französischen Bildungswesens auf der Grundlage der Zivilisierungsmission eingerichtet wurden, auch wenn diese Absicht in den früheren Jahrhunderten mehr die christlichen und weniger die französischen Inhalte in den Vordergrund stellte. Zum anderen konnte dieser Transfer nur mit dem Interesse und Einverständnis einiger libanesischer Gemeinschaften und Akteure stattfinden. Dieser bis dato von der Forschung eher vernachlässigte »Wille zum Import « ${ }^{104}$ als Voraussetzung zum Kulturtransfer wird in den Arbeiten zur Transferforschung in letzter Zeit zunehmend betont ${ }^{105}$.

Neben einer genauen Analyse der Voraussetzungen des Transfers in der »gebenden« Gesellschaft sollten nach Osterhammel in der »empfangenen« Gesellschaft in einem kolonial dominierten Kontext besonders folgende Bedingungen beachtet werden: die »Beschaffenheit der einheimischen Traditionen«, die »spezifischen Entwicklungen innerhalb dieser Traditionen am Vorabend eines mehr als nur punktuellen Kontakts mit dem Westen«, die »Art und Weise der Vermittlung und Präsentation westlichen Wissens«, schließlich die »jeweiligen politischen Handlungsspielräume ([semi-] kolonial, selbständig etc.)《 und die »kulturellen Reaktionsmöglichkeiten [...] der Empfänger und Verwerter westlichen Wissens an der außereuropäischen Peripherie $\ll^{106}$.

Darüber hinaus ist es wichtig, auch die Akteure und ihre jeweiligen Handlungskontexte im Blick zu behalten. So untersuchen Michael Werner und Michel Espagne, »wie sich die Akteure verschiedener Kulturen selbst zueinander in Beziehung gesetzt haben ${ }^{107}$, indem sie $» d i e$ gesellschaftlichen Voraussetzungen für die Verbreitung von Wissen, die konkreten Interessen der Vermittler und die Rolle, welche der Transfer bei der Ausbildung von Identitäten spielen konnte $\ll^{108}$, analysieren. Für Christophe Charle sind die »characte-

Europa and the Arab World since the Middle Ages, Frankfurt/New York 2011, S. 15-37; vgl. auch die Beiträge in MöLler/WischmeYer (Hg.) 2005.

104 Vgl. Matthias Middell, Kulturtransfer und Historische Komparatistik - Thesen zu ihrem Verhältnis, in: Comparativ 10 (2000), S. 7-41, S. 21.

105 Vgl. Johannes PAulmann, Internationaler Vergleich und interkultureller Transfer. Zwei Forschungsansätze zur europäischen Geschichte des 18. bis 20. Jahrhunderts, in: Historische Zeitschrift 267 (1998), S. 649- 685, S. 674; Hans-Jürgen LüSEBRInK, Interkulturelle Kommunikation. Interaktion, Fremdwahrnehmung, Kulturtransfer, Stuttgart /Weimar 2008, S. 129-138.

106 Vgl. Jürgen Osterhammel, Vorbemerkung: Westliches Wissen und die Geschichte nichteuropäischer Zivilisationen, in: Wolfgang KütTLER/Jörn RüsEn/Ernst Schulin (Hg.), Geschichtsdiskurs, Bd. 4: Krisenbewusstsein, Katastrophenerfahrungen und Innovationen 1880-1945, Frankfurt am Main 1997, S. 307-313, S. 308.

107 Siehe die Zusammenfassung des Ansatzes des Kulturtransfers in Middell 2000, S. 38.

108 Paulmann 1998, S. 675; siehe auch Michel Espagne, Die Rolle der Mittler im Kulturtransfer, in: Hans-Jürgen LüsEBRInK/Rolf REICHARDT (Hg.), Kulturtransfer im Epochenumbruch. Frankreich - Deutschland 1770-1815, Leipzig 1997, S. 309-329. 
ristics of these mediators and networks «, »their number, their social cohesion, or their position in the cultural field $\aleph^{109}$ von Bedeutung. Insbesondere im kolonialen Kontext gibt es bisher nur wenige Vorschläge zur Untersuchung der an Transferprozessen beteiligten Akteure. Die Vertreter der Entangled Histories betonen lediglich, dass »die strikte Gegenüberstellung von Kolonialherren und Kolonisierten« nicht der historischen Realität entspreche und es bei allen Akteuren um die Konstruktion einer Identität in der Auseinandersetzung miteinander und mit dem Herkunftskontext gehe ${ }^{110}$.

Um in diesem Sinne zu einer Differenzierung insbesondere des Begriffs der Zivilisierungsmission zu gelangen, ist ein Rückgriff auf Studien zur kolonialen Erziehung nützlich. Hier wird die Bedeutung der Lehrer als Vermittler kolonialer Machtverhältnisse, aber auch als Widerständler gegen diese betont ${ }^{111}$. Außerdem ist das im amerikanischen Kontext entstandene Paradigma der »Cultural Brokers« hilfreich ${ }^{112}$. Speziell für transnationale Beziehungen zwischen Europa und der arabischen Welt haben Bernard Heyberger und Chantal Verdeil eine Untersuchung von »hommes de l'entre-deux« vorgelegt, die zwischen den westlichen und östlichen Ufern des Mittelmeers ansässig waren ${ }^{113}$.

Im Zentrum dieser Arbeit steht die Antwort auf die Frage, wie sich die unterschiedlichen Akteure die französische mission civilisatrice aneigneten, sie ablehnten oder veränderten. Während die Zivilisierungsmission die historische Form des Transfers darstellte, die in dieser Epoche weit verbreitet war, bezeichnet ihr spezifisches französisches Verständnis und ihre Erklärungsmuster den Inhalt dieses Transfers. Wie bereits deutlich wurde, handelt es sich bei der mission civilisatrice um einen stark ideologisch aufgeladenen Begriff, dessen historische Konsequenzen nicht einseitig kausal erklärbar sind. Vielmehr ist sie Gegenstand eines komplexen kulturellen und sozialen Aneignungsprozesses mit unterschiedlichen Zuschreibungen. Mit dem Ziel,

109 Christophe Charle, Introduction to Part I, in: Ders. u.a. (Hg.), Transnational Intellectual Networks. Forms of Academic Knowledge and the Search for Cultural Identities, Frankfurt/New York 2004, S. 197-204, S. 199.

110 Vgl. Randeria/Conrad 2002, S. 25, 27, 31.

111 Vgl. Gail P. Kelly, Teachers and the Transmission of State Knowledge: A Case Study of Colonial Vietnam, in: Philip G. Altbach/Robert F. Arnove/Gail P. Kelly (Hg.), Comparative Education, New York 1982, S. 176-194, hier 176-177.

112 Vgl. die Einleitung und die verschiedenen Fallstudien in Mark HÄBERLEIN/Alexander KeESE (Hg.): Sprachgrenzen - Sprach-kontakte - kulturelle Vermittler. Kommunikation zwischen Europäern und Außereuropäern (16.-20. Jahrhundert), Stuttgart 2010; als eine der Ersten in die Wissenschaft eingeführt hat den Begriff des »Cultural Broker« Margaret Connell Szasz (Hg.), Between Indian and White Worlds. The Cultural Broker, Norman u.a. 1994.

113 Vgl. Bernard Heyberger/Chantal Verdeil, Introduction, in: Dies. (Hg.), Hommes de l'entredeux. Parcours individuels et portraits de groupe sur la frontière de la Méditerranée, Paris 2009, S. 7-20. 
dieser vielschichtigen Situation gerecht zu werden, wird die Zivilisierungsmission in dieser Arbeit gleichzeitig als Diskurs und als kulturelle und soziale Praxis untersucht.

Die passende Beschreibung der Zivilisierungsmission als dem »klebrigen zähen Diskursiven « ${ }^{114}$, um die Worte Phillip Sarasins zu entleihen, verlangt nach einer Analyse, für die sich der Ansatz der historischen Diskursanalyse als sinnvoll erweist. Von Michel Foucault initiiert und von Willibald Steinmetz $^{115}$, Gareth Stedman Jones ${ }^{116}$, Achim Landwehr ${ }^{17}$ und anderen Wissenschaftlern weiterentwickelt und zur praktischen Anwendung gebracht, dient die historische Diskursanalyse als Hilfsmittel, um die Idee der Zivilisierungsmission in der Verwendung im Umfeld französischen Schulen im Libanon zu dekonstruieren. Diskurs wird hier nach Michel Foucault als »(zumindest für eine bestimmte Zeit) mit einem Wahrheitswert geladen [...], an die unterschiedlichen Machtmechanismen und -institutionen gebunden $\aleph^{118}$ definiert.

Die beiden Elemente Wahrheit und Macht erweisen sich für die Analyse des Forschungsgegenstandes als pertinent. Zum einen haben die französischen und einige libanesische Akteure, indem sie Frankreich die Durchführung einer Zivilisierungsmission zuschrieben, diese als wahr konstruiert. Zum anderen haben sie sich damit in die Machtstrukturen integriert, welche die Dominanz Frankreichs im Libanon legitimierte, diese aber gleichzeitig auch hinterfragte und kritisierte. Diese Erkenntnisse ergeben sich aus der Häufung der diskursiven Bezugnahme der Akteure auf die Zivilisierungsmission an den historischen Wendepunkten der Jahre 1920, 1925, 1930 und 1935, welche eine Veränderung der politischen und sozialen Verhältnisse nach sich zogen ${ }^{119}$. Da französische Regierungsvertreter den Begriff der mission civilisatrice in ihren Ansprachen und ihrer Korrespondenz selten verwendeten, die zivilgesellschaftlichen Akteure dagegen sehr viel häufiger, argumentiere ich, dass die Regierung die Funktion der Trägerin der Zivilisierungsmission innehatte, und sich die zivilgesellschaftlichen Akteure durch den häufigen Wortgebrauch ihre Zustimmung zur Regierung in Beziehung setzten und diese in der Regel unterstützten. Das bedeutet allerdings nicht,

114 Philipp SARasin, Geschichtswissenschaft und Diskursanalyse, Frankfurt am Main 2003, S. 7.

115 Vgl. Willibald Steinmetz, Das Sagbare und das Machbare. Zum Wandel politischer Handlungsspielräume. England 1780-1867, Stuttgart 1993.

116 Vgl. Gareth Stedman Jones, Languages of Class. Studies in English Working Class History 1832-1982, Cambridge 1983, S. 7-8. Zur Kritik an Stones’ Ansatz, dem die spätere feministische Geschichtswissenschaft Idealismus vorgeworfen hat, vgl. Joan Wallach Scott, On Gender, Language and Working-Class History, in: International Labour and Working Class History 31 (1987), S. 1-13.

117 Vgl. Achim LandweHr, Historische Diskursanalyse, Frankfurt am Main 2008.

118 Michel Foucault, Sexualität und Wahrheit, Bd. 1: Der Wille zum Wissen, Frankfurt am Main 1997, S. 8. Für eine koloniale Sichtweise auf das Denken Foucaults siehe STOLER 2005, S. $140-161$.

119 Vgl. Kapitel 1.1, 2.1, 3.1, 5.1, 6.1, 7.1. 
dass der Begriff bei Konflikten verschwand, sondern dass er dann gerade verwendet wurde, um die Differenzen zumindest diskursiv zu überbrücken.

Weil die Individuen und Gruppen zwar alle dieselben Begriffe verwendeten, aber darunter oft unterschiedliche Dinge verstanden, ist die Kennzeichnung der mission civilisatrice als »leerer Signifikant« sinnvoll. Diesen Begriff hat der postmarxistisch geprägte Politikwissenschaftler Ernesto Laclau entwickelt, um damit die Dehnbarkeit universeller Konzepte wie Freiheit, Demokratie etc. und deren Nutzung durch zum Teil ideologisch konträr stehende Parteien zu beschreiben ${ }^{120}$. Aus diesem Grund können begriffsbezogene Diskurse auch dazu beitragen, dass sich ihre Sprecher Dritten gegenüber als gemeinsame Teilnehmer des gleichen Diskurses wahrnehmen ${ }^{121}$. Dieses Phänomen lässt sich sehr gut am Fall der ideologisch verschieden ausgerichteten französischen Schulen und ihrer Beziehungen zur libanesischen Gesellschaft zeigen.

Die Herangehensweise der historischen Diskursanalyse ist darüber hinaus ein hilfreiches Instrumentarium, um das vielleicht wünschenswerte, aber nicht zu realisierende Untersuchungsvorhaben zu umgehen, nämlich rekonstruieren zu wollen, was die unterschiedlichen Akteure mit dem Bezug auf die Zivilisierungsmission »wirklich gemeint haben« könnten. Hier greift der positivistische Ansatz der historischen Diskursanalyse, welchem es nicht mehr um den »eigentlichen Kern« hinter den Erscheinungen, sondern um die Umstände ihres Auftauchens geht ${ }^{122}$. Damit soll aber nicht das Subjekt als aktiv Handelnder im historischen Kontext negiert werden ${ }^{123}$. Im Gegenteil gehe ich in Anlehnung an die nach den Strukturalisten wieder akzeptierte Existenz eines Subjekts ${ }^{124}$ davon aus, dass die hier untersuchten Akteure die Freiheit hatten, sich für oder gegen die Nutzung des Diskurses zu entscheiden, und sich darüber hinaus dieser unterschiedlichen Diskurse auch teils instrumentell, je nach Bedarf bedienen konnten. Auch wenn beispielsweise die libanesischen zivilgesellschaftlichen Akteure gewissen Machtzwängen unterworfen waren, haben sie die Idee der Zivilisierungsmission genutzt, um mit deren Hilfe ihre Position in ihren sozialen Räumen zu sichern oder zu verbessern.

120 Ernesto Laclau, Emanzipation und Differenz, Wien 2002, S. 70.

121 Vgl. Sarasin 2003, S. 48.

122 Vgl. Landwehr 2008, S. 92. Allerdings würde ich eine derart radikale positivistische Sicht auf die Geschichte, wie sie Landwehr vertritt, nicht unterstützen.

123 Dieser Vorwurf ist der historischen Diskursanalyse in den letzten Jahren wiederholt aufgekommen. Allerdings betonen alle ihre neueren Vertreter in unterschiedlichem Grad, dass sie das Subjekt nicht negieren.

124 Vgl. Sarasin 2003, S. 54. 
Dies ist zugleich das entscheidende Argument dafür, neben der diskursiven Definition, die Zivilisierungsmission als kulturelle und soziale Praxis zu untersuchen. Der in diesem Zusammenhang verwendete Begriff der Praxis wurde vorrangig von Pierre Bourdieu entwickelt, der sowohl in verschiedenen ländlichen Gesellschaften (der algerischen Kabylei, dem französischen Béarn) als auch in der Institution der Schule Strategien entdeckte, mit deren Hilfe sich Individuen im sozialen Raum positionieren. Den Schulen kam dabei insofern eine besondere Bedeutung zu, als Bourdieu in ihnen einen Ort der Reproduktion sozialer Verhältnisse und damit der Herrschaft der sozialen Elite sah ${ }^{125}$. Deswegen ist die Analyse von Sprachpraktiken, sozialem Handeln mittels Ehemaligennetzwerken und Praktiken mit ähnlicher sozialer Funktion innerhalb der französischen Schulen im Libanon sinnvoll; ging es im Kontext der Schulen doch an zentraler Stelle um die Herausbildung und Bewahrung einer sozialen Elite, die sich durch bestimmte Distinktionsmerkmale vom Rest der Gesellschaft unterscheiden sollte. In diesem Zusammenhang ist es interessant zu vergleichen, inwiefern die Merkmale einer frankophonen Elite auch für die arabophone Elite gelten. Stellten die verschiedenen Sprachgruppen unterschiedliche Bezüge zum Diskurs der Zivilisierungsmission her? Wie Michel de Certeau und Alf Lüdtke im Anschluss an Bourdieu betonen und noch stärker als dieser herausgestellt haben, können sich Individuen tatsächlich in Herrschaftsverhältnisse einfügen, sich diesen aber auch genauso gut widersetzen. In der Tat wirkt koloniale Bildung nicht nur systemstabilisierend, sondern hat, wie die postkoloniale Forschung betont hat, paradoxerweise auch zum Widerstand gegen die koloniale Herrschaft erzogen ${ }^{126}$.

Für eine weitere Analyse sind die Begriffe Strategie und Taktik hilfreich, die Michel de Certeau im Anschluss an Clausewitz entwickelt hat. Strategien, so de Certeau, werden von denjenigen entworfen, die Macht über einen bestimmten sozialen Raum haben, während Taktiken von denen angewendet werden, welche sich innerhalb dieses Raumes befinden und unter den vorgesetzten Bedingungen agieren müssen ${ }^{127}$. Am Beispiel kolonialer Bildung konkretisiert, verfügten die Europäer also zunächst über Strategien um ihre Herrschaft auszuüben, während die einheimische Bevölkerung aufgrund der Machtasymmetrie begrenztere Taktiken zur Verfügung hatte, um sich der europäischen Herrschaft zu beugen oder zu widersetzen.

125 Pierre Bourdieu/Jean-Claude PASSERon, La reproduction. Éléments pour une théorie du système de l'enseignement, Paris 1970.

126 Vgl. Aimé CÉsAire, Discours sur le colonialisme, Paris 1955, S. 14; Peter Vermeeren, La formation des élites marocaines et tunisiennes. Des nationalistes aux islamistes, 1920-2000, Paris 2002, S. 26.

127 Michel de Certeau, L'invention du quotidien. 1. Arts de faire, Paris 1990, S. 59-63. 
Allerdings könne es de Certeau zufolge auch zur Umwandlung von Strategien in Taktiken kommen, wie er am Beispiel christianisierter Völker in Südamerika zeigt ${ }^{128}$.

Verschiedene Praktiken französischer Regierungsmitglieder wie schulischer Akteure im Libanon erscheinen als Formen dieser Umwandlung. Das zeigt sich zum Beispiel in den Stipendienprogrammen. Allerdings gab es auch andere Themen und Praktiken, die von manchen libanesischen Partnern der Schulen abgelehnt wurden. Dazu gehörte zum Beispiel der aus Frankreich >importierteく Laizismus der Misison lä̈que françiase, den die Klientel der Schule nur in Anpassung an die libanesischen Verhältnisse akzeptierte. Die Kolonialhistoriographie hat die Begriffe der Aneignung, Mimikry, Abwehr, Zurückweisung und Selbstbehauptung entwickelt, um so die Vielfältigkeit der Reaktionen innerhalb der kolonialen Gesellschaft auf einen Machtanspruch zu zeigen ${ }^{129}$. In diesem Sinne soll in der vorliegenden Arbeit auch die Aneignung beziehungsweise der Widerstand der französischen Akteure gegen Strategien der französischen Regierung in den Schulen untersucht werden. Denn auch deren Verhältnis zu den Herrschenden war durch »Kooperation und zugleich Differenz und Reibung « ${ }^{130}$ geprägt.

Die vorangegangenen Überlegungen verdeutlichen, dass die Aneignung als »Kunst der Schwachen ${ }^{131}$ wie auch die Begriffe der Strategie und der Taktik nicht nur auf eine der drei Akteursgruppen, die im Fokus der Arbeit stehen - Französische Regierung, libanesische Bevölkerung, Französische Schulen im Libanon - sondern abwechselnd auf alle drei zutreffen und Identitäten und soziale Positionen immer wieder neu, sowohl über Diskurse als auch über kulturelle und dass soziale Praktiken in Bezug auf die Zivilisierungsmission verhandelt wurden.

128 Vgl. ebd., S. 62.

129 Vgl. Homi Bнавна, Of Mimkry and Men. The Ambivalence of Colonial Discourse, in: Ders. (Hg.), The Location of Culture, London 2008, S. 121-131; Dietmar Rothermund, Einleitung, in: Ders. (Hg.), Aneignung und Selbstbehauptung. Antworten auf die europäische Expansion, München 1999, S. 1-14; Karl-Heinz KoHL, Abwehr und Verlangen. Zur Geschichte der Ethnologie, Frankfurt am Main 1987.

130 Alf LüdtKe, Einleitung: Herrschaft als soziale Praxis, in: Ders. (Hg.), Herrschaft als soziale Praxis, Göttingen 1991, S. 9-63, S. 12-13. In diesem Sinne hat Lüdtke den Begriff des »Eigensinns« entwickelt.

131 So der Titel eines Aufsatzes von Marian Füssel, der sich mit dem Begriff der Aneignung bei Bourdieu, Certeau und Alf Lüdtke beschäftigt: Marian Füssel, Die Kunst der Schwachen. Zum Begriff der »Aneignung « in der Geschichtswissenschaft, in: Sozial.Geschichte 21 (2003), H. 3, S. 7-28. Vorreiter dieser Idee war James Scotт, Weapons of the Weak. Everyday Forms of Peasant Resistance, New Haven 1987. 


\section{Quellen}

Der nachfolgend durchgeführten Analyse liegen vier Datenkorpora zugrunde. Das erste Korpus umfasst Unterlagen staatlicher Institutionen und Nationalarchive - vor allem aus Frankreich, aber auch aus dem Libanon. Die Basis des zweiten Korpus bilden Materialien der Kongregationen und Organisationen aus Pariser Archiven, die Bildungseinrichtungen im Libanon betrieben haben. Das dritte Datenkorpus besteht aus Unterlagen aus den Archiven französischer, vor allem katholischer Schulen im Libanon. Diese Einblicke wurden ergänzt durch Interviews mit einigen ehemaligen Schülern und Lehrern dieser Schulen sowie durch deren Memoiren und persönliche Aufzeichnungen.

Die den Libanon betreffenden Materialien staatlicher Institutionen und aus Nationalarchiven stammen aus den Archiven des französischen Außenministeriums in Paris und Nantes. Die Pariser Akten umfassen wegen des durch den Umzug des Archivs vom Quai d'Orsay nach La Courneuve erschwerten Zugangs nur einige Ordner der den Libanon und Syrien betreffenden »Handelskorrespondenzen" (Correspondance politique et commerciale) zwischen 1918 und 1940 sowie einen Teil der Dokumente aus der Zeit des Vichy-Regimes in beiden Gebieten. In den Archiven in Nantes konnten dagegen die Akten des französischen Generalkonsulats in Beirut für die Zeit von 1900 bis 1943 und die Akten des speziell für die Schulen zuständigen Ressorts Service des Euvres françaises à l'Étranger innerhalb des französischen Außenministeriums sowie der Bestand des Kultusministeriums des französischen Hochkommissariats für Syrien und den Libanon in der Mandatszeit vollständig eingesehen werden. In den Archiven des französischen Erziehungsministeriums, die sich im französischen Nationalarchiv befinden, wurden die Akten französischer Lehrer, die für ihren Dienst im Libanon freigestellt wurden, sowie die Akten der Akademie in Paris, welche für die Lehrer und Schulen in Paris zuständig war, geprüft. In Beirut wurde Einblick in das Nationalarchiv genommen. Hier wurden leider nur sehr wenige Dokumente bereitgestellt. Es bleibt offen, ob dies an dem tatsächlichen Bestand der Archive oder an der mangelnden Bereitschaft der Archive lag, das Material zur Verfügung zu stellen.

Außerhalb der Staatsebene gehören die Archivbestände der einzelnen Organisationen und Kongregationen zum Quellenkorpus, die ihren Sitz in Paris haben. Das betrifft zum einen die katholischen Archive der Jesuiten, Lazaristen und der Filles de la Charité. Während mir das Archiv der Sœeurs de Saint-Joseph de l'Apparition in Paris leider verschlossen blieb, konnte ich einen kurzen Blick in das Archiv der Filles de la Charité in Paris werfen. Das Archiv der Jesuiten in Vanves bei Paris bietet die Korrespondenz des Ordens und ihrer Schulen im Libanon mit dem Mutterorden sowie mit dem Delegier- 
ten der Université Saint-Joseph bei der französischen Regierung, Louis Jalabert, und darüber hinaus Berichte und Dokumente über die Tätigkeiten der Jesuiten im Libanon. Das Archiv der Lazaristen in Paris enthält ebenfalls die Korrespondenzen zwischen den Orden im Libanon und in Paris sowie wertvolle Dokumente über die Aktivitäten ihrer Schulen, beispielsweise der Alumnivereinigungen. Außerdem bietet dieses Archiv einige Akten über die dem Orden angeschlossenen Frauenkongregation Filles de la Charité, deren eigenes Ordensarchiv in Paris erst langsam der Forschung zugänglich wird, und deshalb so wertvoll ist, weil es die vollständige Korrespondenz zwischen den Einrichtungen im Nahen Osten und dem Mutterhaus in Paris enthält.

Neben den katholischen Orden basiert diese Studie auch auf den Archiven der jüdischen Alliance israélite universelle in Paris, welche Korrespondenzen zwischen Beirut und Paris sowie viele Zeitschriften über die Arbeit der Alliance israélite im Nahen Osten bereitstellen.

Ein zentraler Fokus dieser Arbeit beruht auf den Archiven der laizistischen Organisation Mission laïque française, die sich im Sitz der Organisation und im Nationalarchiv in Paris befinden. Sie enthalten neben Berichten über Anzahl und Namen der Schüler und Stipendiaten, über Finanzen und Ausstattung der Schulen, auch unzählige Briefe zwischen den Direktoren der Mission laïque in Beirut und der Zentrale in Paris sowie Korrespondenzen mit dem Hochkommissariat oder der französischen Regierung sowie mit Eltern und libanesischen Persönlichkeiten. Schließlich konnte ich glücklicherweise Einblick in das Archiv der Euvres protestantes françaises gewinnen, welches sich im Privatbesitz bei Paris befindet und Informationen und Briefe der Schulen enthält.

Hatte schon der Zutritt zu einigen Archiven dieser Institutionen in Frankreich viel Fingerspitzengefühl und Glück verlangt, bedeutete der Einblick in die Archive im Libanon noch eine größere Herausforderung, da zu der lückenhaften Überlieferungslage und teilweise mangelhaften archivalischen Erschließung noch ein wenig transparenter Zugang kam, zumal die meisten Archive der Schulen in privatem Besitz der Einrichtungen selbst standen. Nach einer Phase der Vertrauensgewinnung war es mir aber glücklicherweise möglich, Zugang zu einigen Schul-Archiven, die der Öffentlichkeit in der Regel verschlossen bleiben, zu erlangen. Auf diese Weise bekam ich Einsicht in die Archive der Jesuiten in Beirut, der Schule der Jesuiten in Jamhour, der Schule der Frères des écoles chrétiennes, und, zu einem begrenzten Ausmaß, der Schule der Sceurs de Saint Joseph de l'Apparation in Beirut. Weiterhin konnte ich die Archive der Filles de la charité in Beirut und des Collège Saint-Joseph der Lazaristen in Ayntoura einsehen. Zu diesem Material zählen Berichte über Aktivitäten und Auseinandersetzungen in den Schulen, Korrespondenzen mit französischen und libanesischen Regierungsvertretern sowie Anliegen von Eltern. Die beiden Schulen der Mission laïque française 
in Beirut, welche aus der Jungen- und der Mädchenschule im hier untersuchten Zeitraum hervorgegangen sind, verfügen leider über kein Archivmaterial.

Schließlich hatte ich die Gelegenheit, einige ehemalige Schüler und Lehrer dieser französischen Schulen im Libanon zu interviewen. Auch wenn die Verwertbarkeit von Materialien, die mit den Methoden der oral history gewonnen werden, kritisch und mit Vorsicht behandelt werden muss, waren die Interviews ein unabdingbarer Wegweiser in einem Forschungsbereich mit äußerst lückenhaftem Archivmaterial. Nicht nur ist das, was erinnert und erzählt wird, per se eine Quelle eigenen Rechts; die Gespräche lieferten auch wertvolle Informationen über Lehrernamen, Schulbücher und Mitschüler/ innen. Darüber hinaus ermöglichen die Interviews Einblicke in das Innenleben des Collége protestant français in Beirut, der Schule der Université Saint-Joseph der Jesuiten in Beirut, der Mädchenschule der Mission laïque française in Beirut, der Schule der Frères des Écoles chrétiennes in Beirut, der Schule der Lazaristen in Antoura und der Schule der Sceurs de Saint Joseph de l'Apparition in Saida. Interviews mit einem ehemaligen Schüler der Schule der islamischen Wohlfahrtsorganisation Ğam'īyat al-Maqāṣid al-hayrīya al-islāmīya (kurz Maqāṣid, im folgenden Maqasid) sowie mit einer ehemaligen Schülerin der Syrian Protestant School, erlaubten eine interessante vergleichende Perspektive auf das libanesische Schulwesen, weil so die Schulen in das gesamte libanesische Bildungswesen eingebunden werden konnten. Weitere Einblicke ermöglichten in diesem Korpus die Memoiren ehemaliger Schüler und Lehrer französischsprachiger, aber auch anderer ausländischer und lokaler Schulen im Libanon.

\section{Aufbau der Arbeit}

Die Arbeit ist, mit Ausnahme des ersten Kapitels, chronologisch aufgebaut, um die Dynamik der Positionen der Schulen angesichts sich wandelnder politischer und sozialer Verhältnisse in Frankreich und im Libanon einzufangen. Das erste Kapitel fällt hierbei insofern aus dem Rahmen, als es anhand einer Einführung in die Definition und Geschichte der Idee der Zivilisierungsmission in Frankreich den ideologischen Rahmen auslotet, innerhalb dessen die Akteure im Libanon tätig wurden. Dieser einmalige Bruch in der Analyse ist notwendig, um den Weg der französischen Institutionen und ihrer Akteure nachzuvollziehen.

$\mathrm{Ab}$ dem zweiten Kapitel wendet sich die Arbeit dem Fokus der Untersuchung, also den Akteuren im Libanon zu. Die Kapitel zwei bis sieben sind anhand von Zäsuren strukturiert, welche auf der realhistorischen, aber auch auf der diskursiven und praktischen Ebene einschneidende Veränderungen für Funktion und Ausgestaltung der Schulen bedeuteten. Die Kapi- 
tel sind thematisch angeordnet, das heißt, die Unterkapitel widmen sich Themen, welche in dieser Zeit besonders virulent waren. Manche Themen waren natürlich über die gesamte Zeitspanne hinweg von Bedeutung für die französischen und libanesischen Institutionen und Individuen, aber sie werden innerhalb der Arbeit dort platziert, wo sie am offensichtlichsten auftreten.

Kapitel zwei widmet sich der Situation der französischen Schulen am Ende des Osmanischen Reiches 1909-1920, Es fragt nach den Veränderungen der Bildungslandschaft durch die Ankunft der Mission laïque und zeigt anhand dieser Einrichtung die Bedingungen und Mechanismen der Integration der Schulen in die libanesische Gesellschaft. Kapitel drei fokussiert den Beginn des französischen Mandats im Libanon in den Jahren zwischen 1920 und 1924. Es untersucht den ambivalenten politischen Status des Mandats, welcher sich par excellence im Bildungswesen zeigte. Es zeigt außerdem auf der diskursiven und praktischen Ebene, wie die französischen Schulen sowie manche libanesischen Institutionen und Individuen durch die Betonung der Zivilisierungsmission Unterstützung durch die französische Regierung zu erlangen, ohne von dieser ganz abhängig zu sein.

Kapitel vier widmet sich der Funktion der französischen und arabischen Sprache im Spannungsverhältnis zwischen Machtinstrument und sozialer Distinktion und argumentiert, dass beide Sprachen bei den unterschiedlichen Interessengruppen der französischen Schulen die Funktion sozialer Distinktion erfüllten, während die französische Sprache zusätzlich als die Herrschaftssprache galt. Kapitel fünf befragt den Wechsel in der Mandatspolitik ab 1925 hinsichtlich seiner Auswirkungen auf das Schulwesen und argumentiert, dass das Mitsprachrecht der Libanesen in manchen Schulen von diesem Zeitpunkt an sehr viel stärker wurde.

Kapitel sechs lenkt den Fokus auf die Bedeutung der wirtschaftlichen und kulturellen Entwicklungen für die Schulen und fragt außer nach den Auswirkungen des Höhepunkts des Kolonialismus auch nach den Praktiken, durch welche sich sowohl die Schulen als auch die libanesischen Akteure im Mandatsregime etablierten. Kapitel sieben analysiert die Zeitspanne ab 1935, in der sich das Ende der Mandatsmacht im Libanon und auch in den französischen Schulen ankündigte, und zeigt auf, dass sich die französischen Schulen nur unter großen Mühen diesen neuen Bedingungen anpassten konnten.

\section{Transkription}

Eine einheitliche Wiedergabe der Eigennamen stellt aufgrund der unterschiedlichen Schreibweisen von Namen in französischen, deutschen und englischen Umschriftsystemen eine Schwierigkeit dar, insbesondere wenn Namen in den Quellen in unterschiedlichen Sprachen auftauchen. Die Unter- 
schiede werden durch ein Bemühen um Einheit so gering wie möglich gehalten. Für die Umschrift der arabischen Begriffe und Namen wird auf die Umschrift der Deutschen Morgenländischen Gesellschaft (DMG) zurückgegriffen. Dabei erfolgt bei den Namen nach der Erstnennung in korrekter Transkription eine vereinfachte Bezeichnung. Bei den in europäischen Sprachen häufig verwendeten Personen- oder Ortsbezeichnungen wird diese Schreibweise benutzt, gleiches gilt für Libanesen, die ihren Namen selbst in europäischer Form schrieben. 


\section{Das Projekt der mission civilisatrice in Frankreich}

Die französischen Schulen und ihre Lehrer, die sich im Libanon niederließen, nahmen nicht nur materielle Dinge wie Unterrichtsmaterial und ihr persönliches Hab und Gut aus Frankreich mit in das fremde Land. Vielmehr waren sie auch, bewusst oder unbewusst, mit einem >geistigen Gepäckı ausgestattet, das ihre Tätigkeit begründete oder begleitete: die Idee der Zivilisierungsmission.

In diesem Kapitel geht es um den historischen Kontext in Frankreich, innerhalb dessen diese Idee entstand. Das Wort Projekt ist dabei bewusst gewählt, um die Prozesshaftigkeit dieser Situation anzudeuten: Auch wenn ihr Ursprung in Frankreich lag, wurde die Idee der Zivilisierungsmission von den hier untersuchten Akteuren im Libanon verwendet und weiterentwickelt. Dieses Kapitel will der vielschichtigen Verankerung der mission civilisatrice in Frankreich Rechnung tragen. Es argumentiert, dass die Schulen die Idee der Zivilisierungsmission sowohl in ihrer Bedeutung als regierungspolitische Leitlinie der Dritten Französischen Republik als auch als gesellschaftliches Produkt verstanden und praktiziert haben und dass diese Idee darüber hinaus auch in gewissem Maß von den Lehrern geteilt wurde.

Um die in der Einleitung vorgestellten Kategorien des entsendenden Landes innerhalb des Kulturtransfers im Folgenden zu untersuchen, wird das Analyseraster von der Regierungsebene auf die Frage der Schule und schließlich auf die Untersuchung der individuellen Akteure schrittweise verfeinert. Der erste Teil behandelt die mission civilisatrice als gesellschaftliches Produkt der Dritten Republik. Es wird deutlich, dass sich die Schulen des Diskurses von der Überlegenheit und der Mission der französischen Zivilisation bedient haben, um ihre Zugehörigkeit zur französischen Regierung und Gesellschaft zu manifestieren. Außerdem identifizierten sie sich mit dieser Idee. Der zweite Teil erklärt die zentrale Rolle der Bildungseinrichtungen in Frankreich für die Idee der Zivilisierungsmission. Der dritte Teil widmet sich schließlich den einzelnen Lehrern der französischen Schulen im Libanon als Träger der Zivilisierungsmission und zeigt, dass für die individuellen Akteure diese Idee nur ein Motiv unter anderen war, um im Libanon tätig zu werden. 


\section{Kulturelle Expansion als politisches und gesellschaftliches Produkt}

Indem die französischen Schulen im Libanon sich auf die mission civilisatrice als Motiv für ihre Tätigkeit beriefen, reagierten sie auf den zentralen Stellenwert, den diese Idee für die französische Regierung und innerhalb der französischen Gesellschaft einnahm.

Dabei begriff sich die französische Regierung als selbstverständlicher Träger dieser Zivilisierungsmission, während die Institutionen einem stärkeren Legitimationsdruck unterworfen waren. In der Folge beriefen sie sich auf diese Idee, um von der Regierung sowohl ideelle als auch finanzielle Unterstützung zu erhalten. Dabei interpretierten die verschiedenen Organisationen civilisation und mission civilisatrice durchaus uneinheitlich. Sie bestätigten damit die Idee der Zivilisierungsmission als ein Konzept, das Unterschiede nivelliert. In der Tat konnte die französische Regierung unter der Formel der Zivilisierungsmission sowohl die Ideen des Christentums als auch der Revolution vereinigen und sich der Unterstützung der unterschiedlichen Anhänger dieser Denkrichtungen sicher sein ${ }^{1}$. Aus diesem Grund möchte ich von einem Dachkonzept sprechen, das in der Interaktion der französischen Regierung mit der Gesellschaft entstanden ist und dessen sich die Führung der Republik dann bedient hat.

Diese Dynamik auf politischer Ebene geht auf Napoleon zurück². Seine Ägyptenexpedition wird von vielen als Geburtsstunde der mission civilisatrice angesehen ${ }^{3}$. Über das geostrategische Ziel - die Unterbindung des englisch-indischen Handels - hinaus wollte Napoleon durch diese Expedition deutlich machen, dass er die französische Zivilisation in die Tradition der großen Weltzivilisationen stelle und seine »Zivilisierungsmission« sogar dazu beitrage, die alte ägyptische Tradition wieder lebendig zu machen ${ }^{4}$. In

1 Vgl. BANCEL u. a. 2003, S. 58: »La mission civilisatrice est un mélange d'emprunts à la mission chrétienne que la France, fille aînée de l'Église, se doit d'accomplir et à la mission de la Révolution française d'apporter le bonheur au monde«.

2 Norbert Elias datiert den Perspektivenwechsel innerhalb der französischen Gesellschaft auf den Zeitpunkt der Revolution zurück: auf einmal galt »der Prozess der Zivilisation (anders als zum Zeitpunkt seiner Genese) im Inneren der eigenen Gesellschaft als beendet « und bekam seinen neuen »Sinn als Rechtfertigungsbegriff der nationalen Ausbreitungs- und Kolonisationsbestrebungen Frankreichs«. Vgl. Norbert Elias, Über den Prozess der Zivilisation. Soziogenetische und psychogenetische Untersuchungen, Bd. I: Wandlungen des Verhaltens in den weltlichen Oberschichten des Abendlandes, Frankfurt am Main 1976, S. 63.

3 Vgl. Conklin 1997, S. 17; Henry Laurens, L'expédition d'Égypte 1798-1801, Paris 1997.

4 Allerdings darf auch nicht die Tatsache vergessen werden, dass Napoleon durch diese Expedition sein neues Imperium legitimieren wollte. Die Bedeutung der Ägyptenexpedition Bonapartes für Frankreich wird auch dadurch klar, dass sich die französischen Mandatsträger im 20. Jahrhundert noch einmal auf sie bezogen. Vgl. Ulrike Freitag, Geschichtsschreibung in Syrien 1920-1990. Zwischen Wissenschaft und Ideologie, Hamburg 1991, S. 83. 
Ägypten und in der Region wurde seine Politik von der Bevölkerung kritisch aufgenommen. Im Gegensatz zum Rheinland, wo seine Zivilisierungsmission weitaus mehr Erfolg hatte ${ }^{5}$, lehnten im Nahen Osten viele Religionsgemeinschaften seine Politik ab. Weil Bonaparte die Freundschaft zum Islam betonte, blieben auch viele Christen ihm gegenüber, bis zu seiner militärischen Niederlage, reserviert ${ }^{6}$. Außerdem sorgte Napoleons Invasion dauerhaft für Unfrieden zwischen den religiösen Gemeinschaften, weil sich von da an jede von ihnen unter die Schutzmacht einer europäischen Nation stellte? Wie Osterhammel gezeigt hat, kann Napoleon als der erste »staatliche Zivilisierer« bezeichnet werden, unter dem durch das »Zusammenrücken eines interventionistischen Staates und eines transformativen Kulturverständnisses« die Zivilisierungsmission zur Staatssache wurde ${ }^{8}$.

Während des zweiten Kaiserreichs wurde die civilisation durch die ersten kolonialen Eroberungen, z. B. Algeriens 1830, in der kolonialen Ideologie verankert ${ }^{9}$. Aber vor allem in der Dritten Republik avancierte die Idee der Zivilisierungsmission zu einer offiziellen Ideologie. Auch hier spielte der Kolonialismus eine wichtige Rolle. So sprach im Juli 1885 der gerade gestürzte Ministerpräsident Jules Ferry im Zusammenhang des französischen Einsatzes in Tonkin von dem »devoir de civilisation« der »races supérieures « gegenüber den »races inférieures $\aleph^{10}$. Interessanterweise wird diese Idee der Zivilisierungspflicht in einem Kontext bemüht, in dem die innen- und außenpolitischen Umstände in keiner Weise eine Superiorität Frankreichs nahelegten. Außenpolitisch war die mission civilisatrice sowohl gegen den immerwährenden Konkurrenten Großbritannien ${ }^{11}$ als auch gegen das neu entstandene Deutschland ${ }^{12}$ gerichtet, gegen das Frankreich gerade den Krieg verloren hatte. So behaupteten einige Intellektuelle und Politiker,

5 Vgl. Michael Broers, Le Fardeau du Franc. Aufklärung zu Pferde - eine Zivilisierungsmission in Napoleons Europa?, in: Boris BARTh/Jürgen Osterhammel (Hg.), Zivilisierungsmissionen, Konstanz 2005, S. 73-99.

6 Vgl. Laurens 2005, S. 9-20, S. 12.

7 Vgl. für Syrien die Studie von Leila Fawaz, La campagne de Bonaparte en Syrie et ses conséquences locales, in: Revue du monde musulman et de la Méditerranée 52 (1989), H. 2-3, S. 77-83.

8 Osterhammel 2006, S. 15.

9 Vgl. Costantini 2004, S. 86. Als Frankreich 1848 offiziell die Sklaverei abschaffte, machte es sich unter Berufung auf seine Universalität zur Pflicht, diese Überzeugung in jene Länder zu bringen, die diese Praxis noch hätten. Denker wie Tocqueville legten dafür das philosophische Fundament. Vgl. Costantini 2004, S. 59.

10 Jules Ferry, La République des Citoyens, Bd. II, hg. von Odile Rudelle, Paris 1996, S. 295-315 (Parlamentssitzung vom 28.07.1885).

11 Osterhammel 2005, S. 369.

12 Freitag 1991, S. 86. 
dass das französische Bemühen um Einfluss in der Levante auch eine Kompensation der an Deutschland verlorenen Provinzen Elsass und Lothringen darstellte ${ }^{13}$.

Vor allem bedienten sich die Vertreter der Dritten Republik der mission civilisatrice, um die eigene Identität des Staates zu definieren ${ }^{14}$. Schließlich war diese mit dem Dilemma konfrontiert, sich als demokratische Republik von der Außenpolitik des Empire absetzen zu müssen. Innenpolitisch war die junge Republik vielen Spannungen zwischen Monarchisten und Republikanern, zwischen klerikalen und anti-klerikalen Parteien ausgesetzt. Bancel, Blanchard, Vergès und Freitag betonen deshalb die christlichen Wurzeln der mission civilisatrice ${ }^{15}$ und die Tatsache, dass die laizistisch ausgerichtete Republik ihrer Bevölkerung durch sie eine alternative sakrale Dimension anbot $^{16}$.

Allerdings handelte es sich bei der Mission civilisatrice um mehr als um eine staatspolitische Leitlinie der Regierung, nämlich auch um eine Idee, die auf breiten gesellschaftlichen Konsens stieß. Parallel zur ersten staatlichen Verwendung der Idee der Zivilisierungsmission um 1800 wandelte sich auch in den intellektuellen Diskussionen das Verständnis von Zivilisation. Seit der Aufklärung, die die Religion und Gott als alleinige höchste Instanzen in Frage stellte, hatten Überlegungen zur Zivilisation an Bedeutung gewonnen. Dabei war die wichtigste Neuerung, dass civilisation in einem universalistischen Sinn zunächst nur im Singular gebraucht wurde. Erst nach der Französischen Revolution bekam der Begriff eine Pluralform und eine nationale Ausdifferenzierung, wie zum Beispiel La civilisation française ${ }^{17}$. Die Idee eines Nebeneinanders verschiedener Zivilisationen veränderte sich dann rasch in Richtung der Vorstellung einer Hierarchie der Zivilisationen. Stark beeinflusst wurde diese Meinung von den Ideen des Sozialdarwinismus ${ }^{18}$. So formulierte der wichtigste Theoretiker der kolonialen Gesetzgebung Arthur Girault 1895: »L'extinction progressive des races inférieures devant les races civilisées, ou, si l'on ne veut pas de ces mots, cet écrasement des faibles par les forts est la condition même du progrès $\aleph^{19}$.

13 Vgl. Barrès 1923, S. 124. Auf die Kolonien im Allgemeinen als Ausgleich des militärischen Verlustes bezog sich der Kolonialminister Albert Sarraut in seinem Werk La mise en valeur des colonies françaises, Paris 1923, S. 28-29.

14 Laut Conklin 1997, S. 2, war die mission civilisatrice der Rahmen, den die Dritte Republik sich gab und innerhalb dessen sie ihre Aktivitäten in den Kolonien als legitim darstellen konnte.

15 Bancel u. a. 2003, S. 68.

16 Freitag 1991, S. 84-85.

17 Allerdings existierten beide Formen in der Folge nebeneinander und ergänzten sich sogar. Vgl. Beneton 1975, S. 42-43.

18 Vgl. Costantini 2004, S. 78-79.

19 Zitiert in: Costantini 2004, S. 79. 
Auf die Idee einer Hierarchie der Zivilisationen griffen Autoren der Zeit auch in ihren Beschreibungen arabischer Gesellschaften zurück. So sprach der französische Journalist und Nahostreisende Gabriel Charmes von dem »degré de civilisation«, den Frankreich in Syrien zu erhöhen habe ${ }^{20}$. Allerdings gab es auch eine gegenläufige Tendenz, die die Zivilisation der Araber betonte und aufwertete. So beschrieb André Bruneau, der Ende der 1920er Jahre Lehrer der Schule der Mission laïque in Beirut war, dass jede der civilisations einmal la civilisation gewesen sei; auf Griechen und Römer sei die Phase der »civilisation des arabes« gefolgt, während im Westen die Barbaren ihre Kultur verbreiteten ${ }^{21}$. Diese These erinnert stark an Gustave Le Bons Werk La civilisation des Arabes von 1884, in dem er betonte, dass die Araber lange Zeit die höchst entwickelte Zivilisation besaßen und sogar Europa zivilisiert hätten: »Ils ont été nos civilisateurs pendant 600 ans « ${ }^{22}$. Allerdings stellte diese Einsicht, da sie sich auf die Vergangenheit bezog, keine Konkurrenz zur europäischen Zivilisation mehr dar. Im Gegenteil: sie legitimierte das Überlegenheitsbewusstsein und die Notwendigkeit der Zivilisierung Anderer. Dafür spricht das von Henry Laurens festgestellte gesteigerte Interesse im Frankreich der Dritten Republik am Islam: In dieser Zeit hätten sowohl Intellektuelle als auch Politiker realisiert, dass die arabischen und islamischen Länder eine nicht zu unterschätzende Größe waren, mit der man sich auseinandersetzen müsse ${ }^{23}$.

Auch während des französischen Mandats sprachen die Autoren von der »tradition d'expansion civilisatrice $«{ }^{24}$ Frankreichs in Syrien, und Hochkommissar Weygand betonte, dass Frankreichs Aufgabe in Syrien und Libanon beendet sei, wenn es »guidé leur évolution ${ }^{25}$ habe. Auf dem Höhepunkt des französischen Kolonialismus 1920 bis 1930 veränderten sich in der Tat die Vorstellungen des Zivilisationsmodells noch einmal, und anstelle des Sozialdarwinismus, der als zu gewalttätig erachtet wurde, betonten koloniale Ideologen wie Georges Hardy nun stärker die moralische Überlegenheit und die »Mise en valeur«, die den Kolonien zugutekäme ${ }^{26}$.

20 Gabriel Charmes, Voyage en Syrie. Impressions et Souvenirs, Paris 1891, S. 121.

21 André Bruneau, Traditions et politique de la France au Levant, Paris 1932, S. 248.

22 Gustave Le Bon, La civilisation des arabes, Paris 1884, S. 632.

23 Vgl. Henry Laurens, Orientales II. La Troisième République et l'Islam, Paris 2004, S. 65. Die geschilderten Werke erinnern aber auch an die Überzeugung einiger schottischer Aufklärer, die europäische Geschichte habe schon zweimal den Prozess der Zivilisierung vollzogen. Vgl. Wilfried NipPEL, Griechen, Barbaren und »Wilde«. Alte Geschichte und Sozialanthropologie, Frankfurt am Main 1990, S. 69-70.

24 Siehe z. B. René Ristelhueber, Les Traditions Françaises au Liban, Paris 1925, S. V.

25 Capitaine N. Bourdon, Les Druzes. Histoire du Liban et de la Montagne Haouranaise, Préface du Général Weygand, Paris 1930, S. VII.

26 Costantini 2004, S. 80. 
Die Idee der mission civilisatrice war nicht nur unter den Gelehrten, sondern in allen Gesellschaftsschichten präsent. Ähnliche Ansichten fanden sich auch in den französischen Lexika der Zeit wieder ${ }^{27}$. Ferner hoben die Schulbücher, die in dieser Zeit benutzt wurden, insbesondere ab dem Ersten Weltkrieg die herausragende Rolle Frankreichs in der Welt hervor ${ }^{28}$. Auch in den Kolonien wurden diese Bücher vermehrt eingesetzt. So formulierte ein französisches Schulbuch aus Hanoi von 1925, dass die französische Zivilisation die höchste sei ${ }^{29}$.

Was das französische Verständnis der Zivilisierungsmission von dem anderer Gesellschaften der Zeit unterschied, liegt neben der schon erwähnten Bedeutung der Sprache in dem Anspruch des Universalismus ${ }^{30}$. Costantini zufolge wurde mit der Französischen Revolution auch die Idee der »Universalität der Republik« geboren, die von der Dritten Republik später stark genutzt werden sollte. Auf diese Universalisierung nahmen die französischen Schulen im Libanon eindeutig Bezug. Besonders die Mission laïque betonte die Universalität der französischen Kultur, die partikulare Tendenzen unwichtig mache:

La culture française ne s'y prête-t-elle pas? Elle est, de l'aveu même d'éminentes personnalités étrangères, la plus pénétrée peut-être d'humanité; le particularisme national s'y montre moins qu'ailleurs; elle n'altère pas le sentiment national de ses élèves étrangers ${ }^{31}$.

27 Beispielsweise formulierte Lalande in seinem »Vocabulaire technique et critique de la Philosophie«, das 1926 in erster Auflage erschien, zwei Definitionen von civilisation. Die erste konstatiert eine komplexe Gesamtheit von sozialen Phänomenen mit Eigenschaften, die für alle Teile einer Gesellschaft gelten, und somit die verschiedenen Gesellschaften auf eine Ebene stellen. Die zweite Definition hat eine absolute Dimension: Lalande bezeichnet die Zivilisation, im Gegensatz zur Barbarei, als die Gemeinschaft der Zivilisationen, die als die höchsten angesehen werden, und zwar nicht wegen einer bestimmten Eigenschaft oder gar wegen ihrer Rasse, sondern wegen ihres technischen und wissenschaftlichen Fortschritts. Vgl. André Lalande, Vocabulaire technique et critique de la Philosophie, Paris 1962, S. 141-142.

28 Vgl. SAid 1994, S. 218.

29 Zitiert in: Nicola Cooper, France in Indochina. Colonial Encounters, Oxford 2001, S. 54. Sogar Gesellschaftsspiele für Kinder spiegelten diese Ansichten wider, wie das Beispiel des Brettspiels »Course de l'empire français« belegt, bei welchem die Kinder die verschiedenen Stationen der Eroberung der Kolonien durch Frankreich nachempfanden. Vgl. Alice L. ConkLin/Clancy-Smith, Julia, Introduction: Writing Colonial Histories, in: French Historical Studies 27 (2004), H. 3, S. 497-505.

30 Costantini 2004, S. 58. In der Tat zeigen Studien anderer Formen der Zivilisierungsmissionen diesen Anspruch auf Allgemeingültigkeit nicht, wie Steinbach für die imperiale Sprachpolitik Großbritanniens gezeigt hat. Vgl. Almut SteinBach, Sprachpolitik im Britischen Empire: Herrschaftssprache und Integration in Ceylon und den Föderierten Malaiischen Staaten, München 2009, S. 20.

31 Revue de l'enseignement français hors de France 31 (1934), S. 106-107. 
Der Anspruch des Universalismus blieb auch im 20. Jahrhundert bestehen und legitimierte nach Ansicht kolonialer Ideologen wie Albert Sarraut die spezifische Aufgabe Frankreichs zu kolonisieren ${ }^{32}$. Aber von der Legitimation Frankreichs, Werte wie Freiheit und Laizismus weiterzugeben, waren auch französische Politiker außerhalb der kolonialen Lobby überzeugt ${ }^{33}$. So hat Dueck herausgearbeitet, dass französische Schriftsteller wie André Malraux, André Gide, Albert Camus und Marguerite Duras, die als politisch links eingeordnet werden, zwar in den 1920er und 1930er Jahren die wirtschaftliche Abhängigkeit der Kolonien von Frankreich, nicht aber die französische Administration oder Erziehung in den Kolonien kritisierten ${ }^{34}$.

Die Schulen hatten die Idee der Zivilisierungsmission als offizielles Leitbild der Republik und als Konsens der Gesellschaft verinnerlicht. Allerdings stellte diese Idee nicht für alle Schulen die gleiche Priorität dar. Für die Mission laïque française bildete die Zivilisierungsmission eindeutig das Hauptmotiv ihres Engagements. Schon 1906, also kurz nach ihrer Gründung, bekannte sich die Zeitschrift Revue de l'enseignement colonial ${ }^{35}$, das Hauptorgan der Organisation, zum »CEuvre civilisatrice«, das über die französische Kultur und mit Hilfe der französischen Regierung realisiert würde ${ }^{36}$. Gleichzeitig werden in diesem Artikel auch schon die Widersprüche deutlich, die die Organisation kennzeichneten: Einerseits wollte sie die französische Sprache und Kultur den Gesellschaften bringen, die sich durch vermeintlichen kulturellen und sprachlichen Stillstand auszeichneten, andererseits wollte sie niemandem die französische Sprache aufzwingen, weil das brutal und wenig wirksam sei. Ziel war also eine Kontaktzone ${ }^{37}$, in der die »unterentwickelten« Kulturen sich sozusagen automatisch durch den Kontakt mit der französischen Kultur entwickeln würden:

En vertu du principe qui nous porte autant à civiliser qu'à exploiter, nous n'imposerons pas notre langue aux indigènes de nos colonies, car: 1. Ce serait continuer la conquête brutale alors que notre devoir est d'entreprendre la conquête des cœurs et des volontés; 2. Nous ferions d'ailleurs fausse route pour notre œuvre civilisatrice, car un peuple ne se développe pas bien qu'avec sa langue, résumé de sa civilisation, expression de

32 Costantini 2004, S. 89.

33 So die beiden Politiker der radikalen Partei Bayet und Viollette auf dem Kongress der nationalen Liga für Menschenrechte 1931. Zitiert in: Costantini 2004, S. 90.

34 Jennifer Dueck, Stories of Pride and Shame: Left-Wing Writers and the French Mission to Civilize an Empire, in: Chronos. Revue d'Histoire de l'Université de Balamand 15 (2007), S. 107-130, hier S. 115-122.

35 Die Zeitschrift wurde kurze Zeit später in Revue de l'enseignement français hors de France umbenannt.

36 Vgl. MLF/Paris, Revue de l'enseignement colonial 1906, S. 38/39.

37 Diesen Begriff prägte Mary Louise Pratt in ihrem Buch Imperial Eye. Travel Writing and Transculturation, London 1992, S. 8. 
ses aptitudes, de ses goûts, de ses besoins moraux, intellectuels, esthétiques etc. Cela ne veut pas dire que nous n'enseignerons pas du tout le français, que nous ne ferons l'éducation des indigènes qu'avec leurs différentes langues et que nous condamnerons celles-ci à leur pauvreté naturelle et à une immobilité qui leur serait funeste. Une langue, comme tout être vivant, naît, grandit, évolue, continue à vivre ou [...] meurt. [...] À notre contact, au contact de notre civilisation et de ses diverses aspirations, il est donc possible et même probable que les langues indigènes s'enrichisseront de termes nouveaux et que leur syntaxes se modifieront [...] cela arrive aux langues des peuples les plus libres et les plus civilisés ${ }^{38}$.

Für die Mission laïque hatte die Idee der Zivilisierungsmission eine viel exklusivere Bedeutung als für die katholischen Schulen. Letztere bekannten sich ebenfalls zur mission civilisatrice, allerdings bildete sie nicht das einzige Ziel ihrer Aktivitäten, sondern einen Aspekt neben ihrer christlichen Missionstätigkeit. Dabei stand der Bezug auf die mission civilisatrice für die Orden nicht in Konkurrenz zu ihrer primären Aufgabe, das Christentum zu verbreiten beziehungsweise die orientalischen Christen zu stärken oder zur lateinischen Kirche zurückzuführen. Im Gegenteil, so formulierte ein Jesuit 1931: Es gebe das »élément, à la fois spirituel, civilisateur et hospitalier, qui est l'action missionnaire $«^{39}$. Beide Anliegen bildeten für ihn eine Einheit und konnten sich gegenseitig ergänzen.

Ähnlich zentral wie die Mission lä̈que verstand die Alliance israélite universelle die mission civilisatrice. Der Unterschied zwischen beiden Institutionen lag darin, dass sich die Alliance israélite nur auf die jüdische Gemeinschaft bezog. Sie formulierte als ihr Ziel die Reformierung und Modernisierung der orientalischen Juden mit Hilfe westlicher Kultur und Philosophie:

[...] la double préoccupation de notre activité scolaire: Intégrer par tous les moyens le judaïsme à la civilisation moderne, briser les cloisons qui sont susceptibles de l'isoler, mais à condition d'allier harmonieusement l'esprit occidental aux formes éternelles du judaïsme ${ }^{40}$.

38 Revue de l'enseignement colonial 1906, S. 38/39. Die Mission laïque française hatte somit eindeutig zum Ziel, »to strengthen the use of the French language [...] as a vehicle for spreading French culture and civilization «. Randi DegulLhem, Turning Syrians into Frenchmen: the Cultural Politics of a French Non-Governmental Organization in Mandate Syria (1920-67) - The French Secular Mission schools, in: Islam and Christian-Muslim Relations 13 (2002), S. 449460, S. 450; siehe auch Burrows 1986, S. 126: »[...] the [...] Mission laïque française did heavily subscribe to such belief in the French Mission civilisatrice«.

$39 \mathrm{SJ} /$ Vanves, RPO, 105, »Pour la participation des missions catholiques à l'Exposition coloniale internationale de 1931 «.

40 AIU/Paris, Paix et Droit, I/Januar 1936, S. 11-12, S. 11. 
Die orientalischen Juden waren laut den Verantwortlichen der Alliance israélite materiell und moralisch zurückgeblieben ${ }^{41}$, eine Zuschreibung, die die Argumentation der französischen Zivilisierungsmission widerspiegelt. Gleichzeitig betonte die Alliance israélite ihren Beitrag zur Verbreitung der französischen Zivilisation. So bezeichnete Direktor Penso 1919 die Alliance israélite als »instrument d'expansion pour la culture française « ${ }^{42}$. Die Organisation hielt sich für besonders geeignet, diese Ausdehnung durchzuführen, waren ihre Gründer doch selbst französische Juden, die sich zum französischen Staat und zur französischen Kultur seit der Emanzipierung der Juden 1791 besonders zugehörig fühlten ${ }^{43}$.

Die Verantwortlichen des Collège protestant français, das im Oktober 1927 seine Türen öffnete, sahen sich ebenfalls als Träger der mission civilisatrice. So hatte sich der protestantische Senator Eccard schon 1926 nach seiner Reise durch den Libanon »pour le maintien et la diffusion de la civilisation française $\aleph^{44}$ ausgesprochen. Neben der Betonung der protestantischen Ausrichtung der Schule formulierte ein Prospekt aus den späten 1920er Jahren ganz deutlich: „C'est aussi un Collège français qui contribuera à répandre autour de lui l'influence et la culture française ${ }^{45}$.

Während die vorgestellten Institutionen bezüglich der Zivilisierungsmission eine sehr ähnliche Einschätzung teilten, wies ihr Verständnis von Zivilisation sowohl Gemeinsamkeiten als auch Unterschiede auf ${ }^{46}$. Damit trugen sie der Tatsache Rechnung, dass der Begriff Zivilisation, wie Beneton gezeigt hat, für die unterschiedlichsten Ideen benutzt werden konnte: »[L]e mot est un creuset où chaque école politique coule son idéologie « ${ }^{47}$. In jedem Fall aber war der Ausdruck civilisation für die Institutionen positiv besetzt ${ }^{48}$. Alle Institutionen sprachen von civilisation und von civilisation française und konstruierten damit ein gemeinsames Verständnis, das sie aber jeweils noch ausdifferenzierten.

41 Vgl. z. B. die Einschätzung in den Bulletins de l'Alliance Israélite Universelle 64 (1902), S. 61, die die Situation der Juden in Saida beschreibt: »Quel autre remède que l'école pour améliorer la situation matérielle et morale de cette pauvre population, pour la relever à ses propres yeux, pour lui donner un peu de dignité [...]«.

42 AIU/Paris, »Liban VIE 81«, Brief von Penso an den Präsidenten der Alliance israélite in Paris, Beirut, 03.07.1919.

43 Vgl. Michael A. Meyer, Response to Modernity. A History of the Reform Movement in Judaism, Detroit 1995.

44 So ein Satz seines Abschlussberichts, abgedruckt in Jean-Paul EyrARD/ Afaf Khoury / Georges KreBs, Le Collège protestant français de Beyrouth. 80 ans d'excellence, Beirut 2006, S. 40.

45 Défap/Paris, »Rapport sur les œuvres protestantes françaises de Syrie et du Liban« (ca. 1929).

46 Die Organisationen verstanden »civilisation« sowohl als Zustand als auch als Bewegung, wie es der französische Begriff offen lässt. Vgl. Beneton 1975, S. 44.

47 Ebd., S. 45.

48 Ebd., S. 43. 
Die Akteure der Alliance israélite sprachen besonders oft von der »civilisation moderne $«^{49}$, die sie synonym zur $»$ civilisation française $\ll^{50}$ oder auch zur »civilisation occidentale $\aleph^{51}$ setzten. Für die Alliance israélite war der Begriff der Moderne, der sie sich zugehörig fühlten, zentral. Damit konstruierten sie die Vorstellung eines modernen Frankreichs, das dem »zurückgebliebenen Orient« gegenüber stehe. So sprach die Zeitschrift Paix et Droit der Alliance israélite 1932 von der »somnolence du monde musulman«, die auch die orientalischen Juden in die Dekadenz geführt habe und aus der nur die französische Sprache und Kultur heraushelfen könne ${ }^{52}$. Ähnlich lautete der Diskurs der Mission laïque, deren Akteure aber oft einfach nur von der civilisation française sprachen beziehungsweise das Adjektiv ganz wegließen. In den Artikeln ihrer Zeitschrift wird besonders die Idee einer Hierarchie der Zivilisationen entwickelt, an deren Spitze die französische Zivilisation stehe. Diese könne die anderen, unter ihr stehenden Zivilisationen inspirieren, welche dann auf der Leiter der Zivilisationen aufsteigen:

À notre contact, au contact de notre civilisation et de ses diverses aspirations, il est donc possible et même probable que les langues indigènes s'enricheront de termes nouveaux et que leur syntaxes se modifieront [...] cela arrive aux langues des peuples les plus libres et les plus civilisés ${ }^{53}$.

Wie das praktisch aussah, zeigte sich in den Plänen der Mission lä̈que 1907, ausländische Kinder für den Sommer nach Frankreich zu holen, um diese zu späteren Handelspartnern Frankreichs zu machen. Dabei sollte mit Algeriern und Tunesiern begonnen werden, denn diese hätten sich schon entwickelt und seien nun in der Lage, an der Seite Frankreichs von despotischen zu demokratischen Gesellschaften zu avancieren ${ }^{54}$.

49 AIU/Paris, Bulletins de l'Alliance Israélite Universelle, 64/1902, S. 92; Paix et Droit, Janaur 1936, S. 11.

50 AIU/Paris, Paix et Droit, Oktober-Dezember 1939, S. 8, wo sie mit »civilisation de Racine et de Pascal« umschrieben wird.

51 Siehe die Rede des Schuldirektors der AIU in Beirut Sidi während der Schuljahresendfeier am 02.06.1925: $»[. .$.$] quel est encore le secret de notre succès? Pour faire bénéficier nos coréligion-$ naires d'Orient des progrès des temps modernes, pour les faire entrer dans le plan de la civilisation occidentale, l'Alliance israélite s'est servie d'un instrument qui a fait ses preuves, de la langue française, véhicule incomparable d'idées généreuses et de sentiments nobles [...]«. AIU/ Paris, »Liban IXE 96b «.

52 AIU/Paris, Paix et Droit, Juni 1932.

53 Revue de l'Enseignement colonial français 1906, S. 38-39.

$54 »[. .$.$] ne s'approchent-ils pas du degré de civilisation où, après avoir obéi à leur propre évolution,$ ils peuvent, d'aucuns au moins, entrer avec les Européens dans la même voie de progrès et de la condition des sujets qui est celle des sociétés à formes despotiques s'élever à celle des collaborateurs, d'associés, de citoyens qui est celle des sociétés à formes démocratiques? « Revue de l'enseignement colonial 3 (Juni 1907), S. 74-75. 
In Absetzung von dem säkular geprägten Verständnis der Zivilisation benutzten die christlichen Institutionen oft den Begriff der civilisation chrétienne, welche sie dem Islam gegenüberstellten ${ }^{55}$. Die christliche Zivilisation bildete aber für sie meistens eine Einheit mit der civilisation française oder der civilisation ${ }^{56}$ im Allgemeinen. So bemerkt eine Schrift der Sours de Saint-Joseph de l'Apparition über das Kreuz in ihrer Schule, dieses sei ein »symbole de l'influence chrétienne et de la civilisation française que rien ne peut remplacer ${ }^{57}$.

Wie Beneton treffend bemerkt, wurde der Begriff civilisation von den unterschiedlichen Strömungen des dem Fortschrittsdenken verhafteten Jahrhunderts genutzt: Während er für die Kirche Religion und Glaube bedeutete, repräsentierte er für die Wissenschaftler Fortschritt der Technik und des Wissens $^{58}$. Beneton hat aber außer Acht gelassen, dass der Bezug der Katholiken auf die Zivilisation nicht selbstverständlich war. Als François Guizot, der französische Gelehrte und Politiker, 1828 seine ersten Vorlesungen über die »Histoire de la civilisation en Europe« hielt, reagierten die Katholiken mit Empörung, weil Guizot die Zivilisation und nicht das Christentum als Analysekategorie verwendete und weil er darüber hinaus die katholische Kirche, und besonders die Jesuiten, für ihren Widerstand gegen den Fortschritt, den Guizot als Element der Zivilisation ansah, kritisierte ${ }^{59}$. Nachdem der Protestant Guizot aber ab 1850 die katholische Kirche seiner Wertschätzung und seiner Unterstützung versichert hatte, brachten ihm deren Vertreter ihre Glückwünsche und Sympathien entgegen ${ }^{60}$.

Eine andere wichtige Voraussetzung für das Einstimmen der katholischen Orden in den Diskurs der civilisation française bildete der Schulterschluss der katholischen Kirche mit dem republikanischen französischen Staat. Eine erste öffentliche Geste in dieser Richtung war 1890 das Bekenntnis Kardi-

55 Vgl. für die Jesuiten SJ/Vanves, RPO, 21, »Mission de Syrie«, ca. 1927: »[...] L'école fait donc pénétrer dans l'Islam la civilisation chrétienne«. Vgl. auch Louis JALABERT, Les causes du malaise syrien, in: L’Orient, 01.06.1926. Archiv der Zeitung L'Orient-Le Jour/Beirut.

56 Vgl. für die Jesuiten SJ/Vanves, RPO, 105, »Exposition coloniale«: »Les catholiques de France, en particulier, mais aussi tous les français, même indifférents en matière religieuse - qui sont justement fiers de la place éminente que tient la France dans la grande œuvre d'expansion de la civilisation«.

57 Luce Camuzet, L'œuvre de Syrie des Sœurs de Saint-Joseph de l'Apparition, Paris 1931, S. 32.

58 Beneton 1975, S. 46.

59 Vgl. z. B. François Guızot, Histoire de la civilisation en Europe depuis la chute de l'empire romain jusqu'à la révolution française, Paris 1871, S. 19: »Qui niera pourtant que le christianisme n'ait été dès lors une immense crise de la civilisation?«; S. 346-347: »[...] le développement de la civilisation moderne, la liberté de l'esprit humain, toutes ces forces contre lesquelles les jésuites étaient appelés à lutter [...]«.

60 Vgl. Laurent Theis, François Guizot, un protestant très politique, in: Bulletin de la Société de l'Histoire du Protestantisme français 155 (2009), S. 831-840, S. 839. 
nal Lavigeries, Kardinal von Alger, zur Republik ${ }^{61}$. Erst danach näherten sich der Staat und die katholische Kirche langsam einander an. Für die Jesuiten, die 1880 und 1901 vom französischen Staat verboten wurden, sollte es allerdings bis nach dem Ersten Weltkrieg, in welchem sie für Frankreich kämpften, dauern, bis sie wieder in den Staat integriert wurden ${ }^{62}$. Die zunehmenden Verweise der Jesuiten auf den Begriff der mission civilisatrice ab 1920 bestätigen diese Annäherung ${ }^{63}$.

Die Organisationen stimmten auch in einer anderen Sache überein: Sie alle sprachen von ihrer Mission, die sie im Libanon zu erfüllen hätten, und sie nutzten diesen Begriff als Legitimation ihres Handelns. Der Begriff Mission entstammt eindeutig dem religiösen Kontext. Zwar meint er ursprünglich nur einen Auftrag oder die Aufforderung zu einer bestimmten Handlung (von lat. mittere $=$ entsenden) und wurde und wird deshalb auch für bestimmte politische, wirtschaftliche oder kulturelle Aufträge verwendet. Allerdings ist er in Europa vor allem durch seine religiöse Verwendung geprägt, die die Arbeit der Kirchen oder bestimmter religiöser Gruppen definiert: Unter Berufung auf die im Neuen Testament überlieferte Aufforderung Jesu, »Gehet hin in alle Welt und predigt das Evangelium aller Kreatur « ${ }^{64}$ haben diese seit ihrer Entstehung die Mission als Bekehrung zum Christentum praktiziert und kirchenrechtlich festgesetzt ${ }^{65}$. Aus diesem Auftrag erklärt sich das Sendungsbewusstsein der Missionare.

Für die katholischen und protestantischen Institutionen verwundert der Bezug zur Mission nicht. Die katholischen Orden hatten vom Vatikan den Auftrag der christlichen Missionierung erhalten ${ }^{66}$. Deshalb war die Konversion von Nicht-Christen und die Erhaltung der vorhandenen Katholiken, vor allem gegen die Konkurrenz der amerikanischen protestantischen Missionare, das ausgesprochene Ziel ihrer Arbeit. Da sich die Muslime, um die es zu Beginn ging, als »schwer bekehrbar« erwiesen hatten ${ }^{67}$, lag der neue Fokus auf den libanesischen nicht-katholischen Christen, die als »nominale Christen bezeichnet wurden, was bedeutete, dass man sie zum »wahren« Christen-

61 Vgl. Daniel Moulinet, Genèse de la laïcité. À travers les textes fondamentaux de 1801 à 1959 , Paris 2005, S. 121: »Le toast d'Alger prononcé par le cardinal Lavigerie (12 novembre 1890)«.

62 Vgl. Avon/Rocher 2001, S. 10.

63 Vgl. Kapitel 3, 5, 6 und 7.

64 Die Bibel, Markus-Evangelium 15, 16.

65 Vgl. Bernd Hausberger, Mission: Kontinuität und Grenzen eines universalen Anspruchs, in: Ders. (Hg.), Im Zeichen des Kreuzes. Mission, Macht und Kulturtransfer seit dem Mittelalter, Wien 2004, S. 9-25.

66 Vgl. für die Lazaristen LAZ/ Paris, »Beyrouth Correspondance 1896-1918«, Brief von Boury, Beirut, 18.02.1902, über den Lazaristen M. Baroudi: »il est devenu un excellent missionaire«.

67 Vgl. Samir Khalaf, Cultural Resistence. Global and local Encounters in the Middle East, London 2001, S. 127. 
tum zurückführen musste ${ }^{68}$. Aus diesem Grund kamen zu der direkten Mission die karitativen Tätigkeiten ${ }^{69}$. In diesem Sinne bezeichnet der Bericht der Filles de la Charité die Schule als »l'œuvre par excellence et c'est par elles surtout que nous espérons étendre l'influence religieuse parmi les dissidents et amener les indigènes à une foi plus éclairée ${ }^{70}{ }^{2}$. Dafür schien der Libanon ein geeignetes Terrain zu sein: »Le Liban est un champ de mission véritable et fructueux», urteilte 1907 ein Lazarist in Beirut ${ }^{71}$. Allerdings entbrannten auch innerhalb des Ordens heftige Diskussionen darüber, wie direkt diese Bekehrungsbemühungen aussehen sollten ${ }^{72}$.

Innerhalb des Jesuitenordens hatte es ähnliche Diskussionen gegeben. Trotzdem definierten sich auch die Jesuiten weiterhin als Missionare, deren Auftrag im Libanon es war, die Nicht-Christen zu bekehren, die NichtKatholiken mit den Katholiken zu vereinigen und die Katholiken zu stär$\mathrm{ken}^{73}$. Ähnlich lautete die Motivation des Ordens der Frères des Écoles chrétiennes: "pour la gloire de Dieu et le bien des âmes $\aleph^{74}$.

Auch die protestantische Institution Euvres protestantes françaises bezeichnete ihre Arbeit als $»$ mission protestante $«{ }^{75}$. In diesem Sinne wurde auch schon in den Werbeprospekten für die Schule in Beirut in den 1920er Jahren deren religiöse Ausrichtung an erster Stelle genannt: „C'est un collège protestant $\ll^{76}$. Allerdings betonten die Verantwortlichen schon sehr schnell, dass es nicht um eine »évangélisation directe« gehe, sondern eher um eine

68 Wie Chantal Verdeil für die Jesuiten in Beirut herausgearbeitet hat, hatten diese ab dem späten 19. Jahrhundert »renoncé à toute forme de prosélytisme à l'égard des non-chrétiens«. VERDEIL 2007, S. 37.

69 Dazu gehörten bei den Filles de la Charité »externat, internat, orphelinat, ouvroir, hôpital, dispensaire, école normale [...]«. CoRCKet 1983, S. 248.

70 LAZ/Paris, »Moyen Orient - Filles de la Charité «, »Rapport 1924«.

71 LAZ/Paris, »Beyrouth Correspondance 1896-1918«, Brief von Dinet, Beirut, 13.06.1908.

72 Ebd., Brief von Ouanès, Beirut, 19.02.1902. Er wiegt die Vorteile der Konzentration auf die Schule oder auf die reine Mission ab: »[...] tout le monde ici, clergé et laïcs apprécient beaucoup cette œuvre et la préfèrent pour le pays aux Missions proprement dites «.

$73 \mathrm{Vgl}$. SJ/Vanves, »Fonds Jalabert«, 1-1 C, »Deux conférences de L. Jalabert à l'Université catholique du Louvain les 10 et 11 décembre 1935«, »Caractéres de la mission des Jésuites en Syrie et au Liban«.

74 Georges Rigault, Histoire générale de l'Institut des Frères des Écoles chrétiennes, Bd. VIII, Paris 1937, S. 383. Wie nah Missionierung und Erziehung beieinander lagen, zeigen auch die Schriften über den katholischen Frauenorden Sœurs de Saint-Joseph de l'Apparition, dessen »œuvres missionaires« als »mission éducatrice« bezeichnet wurden. Vgl. Pr. Testas, La vie militante de la Bienheureuse Mère Emilie de Vialar. Fondatrice de la Congrégation des Sœurs de Saint-Joseph de l'Apparition 1797-1856, Marseille 1938, S. 9; S. 15.

75 PPFL, »Comptes rendus du Conseil d'administration«, Sitzung vom 08.05.1929: »[...] question d'organiser un pavillon spécial pour les Missions Protestantes«.

76 Défap/ Paris, »Fédération protestante de France, Les œuvres protestantes françaises en Syrie. A Beyrouth et dans le Djebel Druse«, ohne Datum, S. 3. 
Vernetzung mit den örtlichen und amerikanischen Protestanten sowie um deren Interessenvertretung vor dem französischen Hochkommissariat ${ }^{77}$.

Den Begriff der Mission bei der areligiösen Mission laïque française anzutreffen, überrascht nur auf den ersten Blick. Vielmehr repräsentierte die Organisation die Bedeutungsübertragung, die in der Dritten Französischen Republik von der Religion auf den Laizismus vollzogen worden war $^{78}$. In der Tat stellte sich die Mission laïque schon bei ihrer Namensgebung bewusst in die semantische Tradition der christlichen Missionen. Diese Wahl rechtfertigten ihre Begründer mit dem gleichen Elan und derselben Intensität, mit denen sie ihre Werte verbreiten wollten: »[M]ais si nous nous sommes appelés de ce nom, c'est pour annoncer que les laïcs propageront l'esprit laïque avec autant d'ardeur et de dévouement que les prêtres propagent l'esprit clérical « ${ }^{79}$. Ob bewusst oder unbewusst, benutzten die Publikationen der Mission laïque eindeutig religiöses Vokabular, wie diese Passage der Revue de l'enseignement du français hors de France 1920 zeigt:

La Mission laïque est la mission d'une foi vraiment universelle, parce que sans $d o g$ mes révélés, sans orthodoxie imposée, elle ne porte avec elle que les vérités qui peuvent unir tous les hommes dans la communauté de la conscience et de la raison. [...] La Mission laïque envoie aux peuples d'Orient, qui si volontiers se tournent vers nous dans l'attente de la bonne nouvelle ${ }^{80}$.

Außerdem sprachen die Verantwortlichen der Mission lä̈que wiederholt von »nos missionnaires «, manchmal sogar ohne den Zusatz »laïques « ${ }^{81} .1928$ bezeichnete Direktor Ruche sich und seine Mitstreiter als »missionnaires de la culture française $\ll^{82}$.

In ganz ähnlicher Richtung ist die Arbeit der Alliance israélite universelle einzuordnen. Deren Verantwortliche und Akteure stellten sich zwar nicht so explizit in die Tradition der christlichen Missionare, was vor allem daran $\mathrm{zu}$ liegen scheint, dass das Judentum keine Mission kennt ${ }^{83}$. Trotzdem sprachen auch die Verantwortlichen der Alliance israélite von der Mission, auf die ihre Lehrer in Paris vorbereitet wurden. Ebenso nahmen sie darauf Bezug im Hinblick auf ihre ehemaligen Schüler in Beirut, die sich ihrer »mission«

77 Vgl. den Text des Pastors Jean Bianquis, »Les œuvres des missions protestantes françaises en Syrie« vom Juli 1928, zitiert in: EYrard/KREBS 2007, S. 153.

78 Vgl. Bancel u.a. 2003, S. 68.

79 MLF/Paris, Bulletin de la Mission laïque française 3 (Juni 1907), S. 88.

80 Revue de l'enseignement français hors de France 17 (1920), H. 1, S. 3 (Hervorhebung E.M.).

81 AN/Paris. 60 AJ 120, Brief von Besnard aus Alexandria, 04.01.1913.

82 AN/Paris, 60 AJ 131, Brief von Ruche an Besnard, Beirut, 27.10.1928.

83 Vgl. Elizabeth AntéBI, Les Missionnaires juifs de la France 1860-1939, Paris 1999, S. 11. 
bewusst seien ${ }^{84}$. In diesem Sinne kann man also mit Elizabeth Antébi von den »Missionnaires juifs de la France« sprechen, deren Mission die Juden aber nicht bekehren, sondern von ihrer Unmündigkeit emanzipieren wollte ${ }^{85}$.

Insofern kann also das von Hausberger bezüglich der christlichen Missionare aufgestellte Postulat von der gegenseitigen Beeinflussung weltlicher und religiöser Kräfte auch auf nicht-christliche Missionen erweitert wer$\mathrm{den}^{86}$. Diese große Offenheit gegenüber unterschiedlichen Einflüssen liegt einerseits in der Natur des Missionskonzepts, das, »um seine universelle Gültigkeit $\mathrm{zu}$ beweisen ${ }^{87}$, die eigenen Grenzen stets offen halten muss, und andererseits daran, dass die Mission selbst »gezielten Wissens- und Kulturtransfer« betreibt, » folglich immer grenzüberschreitend « ist und sich erst »in einer Praxis der Interaktion und interkulturellen Kommunikation zwischen Missionsträgern und Missionierten « entwickelt ${ }^{88}$.

\section{Zivilisierung durch Bildung:}

\section{Schulen im Fokus der auswärtigen Kulturpolitik}

Als idealen Ort für die Realisierung ihrer Zivilisierungsmission wählten alle Organisationen, die hier untersucht werden, den institutionellen Rahmen der Schule. Dieser Fokus entsprach der zentralen Rolle, die die Erziehung in der in- und auswärtigen Kulturpolitik der Dritten Französischen Republik bekleidete. Die Schule war der Ort der konkurrierenden Ideologien in Frankreich, welche die Organisationen, die hier untersucht werden, vertraten: Deren Repräsentanten bemühten sich, soviel Einfluss wie möglich an diesem privilegierten Ort zu bekommen, an dem sie die Bürger schon von Kindesbeinen an formen konnten. Deshalb wurde die Schule auch als der Ort wahrgenommen, an dem sich das Schicksal der französischen Nation entscheiden würde.

Bis zur Entstehung der Dritten Republik hatten in Frankreich die katholischen Orden das Schulwesen weitestgehend dominiert ${ }^{89}$. Deren Einfluss wollten die Vertreter der Republik, die 1875 ins Leben gerufen wurde, maßgeblich eindämmen und durch ein staatlich gefördertes - und kontrolliertes - Schulsystem ersetzen, das die republikanischen Werte verbreiten sollte.

84 Vgl. AIU/Paris, Paix et Droit, April 1931, S. 7: »À Beyrouth, une jeunesse consciente de sa mission, vit et agit«.

85 Vgl. AntÉBi 1999, S. 11-12.

86 Hausberger 2004, S. 19.

87 Ebd., S. 10.

88 Ebd., S. 11.

89 Vgl. Françoise Mayeur, Histoire générale de l'enseignement et de l'éducation en France, Bd. III: De la Révolution à l'École républicaine, Paris 1981, S. 406. 
Außerdem war die Regierung in Paris überzeugt, durch diese Vereinheitlichung die »unzivilisierten « Regionen in Frankreich an das »zivilisierte« Zentrum anzubinden. Wie Fanny Colonna überzeugend gezeigt hat, galt für diese Regionen wie für die französischen Kolonien der gleiche zivilisatorische Anspruch ${ }^{90}$. Für die Vertreter der Republik war die Schule deshalb die Institution, die die Kinder zu Bürgern und Verfechtern der Republik erziehen sollte. Dazu gehörte auch eine Vereinheitlichung und Disziplinierung durch die französische Sprache und durch einen gemeinsamen Wertekanon ${ }^{91}$. Während viele Lehrer der Mission lä̈que zu der für Frankreich so spezifischen Gruppe der instituteurs militants, der militanten Grundschullehrer, gehörten, die die republikanischen Ideen unterstützten ${ }^{92}$, verbreiteten viele katholische Orden in ihren Schulen ein christliches, mindestens bis 1914 oft auch antidemokratisches Weltbild ${ }^{93}$.

Nach den ersten Reformen Mitte des 19. Jahrhunderts, die die Ausweitung der Schulpflicht und der Lehrfreiheit zum Ziel hatten, waren es vor allem die Reformen des Erziehungsministers Jules Ferry Anfang der 1880er Jahre, die die Schulsituation in Frankreich wesentlich veränderten. Er machte nicht nur die Grundschule laizistisch und ihren Besuch verpflichtend und umsonst, sondern erhöhte maßgeblich das Budget des Erziehungsministeriums ${ }^{94}$. Im erbitterten Kampf zwischen klerikalen und anti-klerikalen Kräften konnten die Republikaner 1905 durch das Gesetz zur Trennung von Staat und Kirche einen klaren Sieg erringen. Während die katholischen Orden für eine enge Verbindung zwischen Staat und Kirche eintraten, unterstützten die anderen Institutionen die Trennung beider Entitäten.

Die nicht-katholischen Organisationen begrüßten deswegen, dass durch die Gesetze von 1901 und 1905 alle religiösen Gruppierungen den Status einer »Association« erhielten: Diese Entwicklung dämmte den Einfluss der dominanten katholischen Kirche massiv ein und gab zudem den protestantischen und jüdischen Gemeinschaften eine neue Legitimation ${ }^{95}$. Die Gesetze zwangen in der Tat viele katholischen Orden, ihre Schulen zu schließen. Diese Situation veränderte die Schullandkarte gewaltig und wirkte sich auch auf die Kolonien und französischen Einflussgebiete aus, da viele Ordensleute dorthin ins Exil gingen ${ }^{96}$. Das Bildungswesen nahm aber auch in der außenpolitischen Position Frankreichs eine bedeutende Stellung ein. So erklärte

\footnotetext{
90 Vgl. Colonna 1997, S. 361.

91 Zur Uniformierung und Disziplinierung der Gesellschaft durch die Institution Schule vgl. Michel Foucault, Surveiller et punir. Naissance de la prison, Paris 1975, S. 163-199.

92 Vgl. Jacques Ouzouf/Mona Ouzouf, La République des instituteurs, Paris 1992, S. 134-135.

93 Vgl. Avon/Rocher 2001, S. 82.

94 Vgl. Jean-Michel Gaillard, Un siècle d'école républicaine, Paris 2000, S. 175.

$95 \mathrm{Vgl}$. Jean-Pierre Rioux/Jean-François Sirineldi, Le temps des masses. Le vingtième siècle, Paris 2005, S. 42-48.

96 Vgl. Cabanel/Durand (Hg.) 2005.
} 
sich die militärische Niederlage Frankreichs gegen Preußen 1879 laut Ernest Renan und anderen Denkern durch die Überlegenheit Deutschlands im Bereich der Erziehung ${ }^{97}$. Auch im kolonialen Kontext betonten Politiker wie der Kolonialminister Albert Sarraut 1923 die Schlüsselstellung der Erziehung, um mit den anderen Kolonialmächten mithalten zu können ${ }^{98}$.

Die zentrale Rolle der Bildung für die Entwicklung eines bestimmten Weltbildes findet sich bei den hier untersuchten Institutionen wieder. Innerhalb des Ordens der Lazaristen gab es zwar Anfang des 20. Jahrhunderts noch Auseinandersetzungen darüber, ob man sich nicht lieber auf die Mission statt allein auf die Schulen konzentrieren solle ${ }^{99}$. Letztlich konnten sich aber die Stimmen durchsetzen, die in Übereinstimmung mit allen anderen Organisationen davon überzeugt waren, ihre Ideen am besten durch die Schule verbreiten zu können. So bemerkte ein Jesuit 1927, dass die Schule ein gutes Mittel sei, um unauffällig und ungehindert in nicht-christliche Dörfer gehen und sich dort niederlassen zu können, ohne sofort den Verdacht der Missionierung zu wecken:

De plus par l'école le missionnaire a accès dans les villages, il a une raison toute naturelle d'entrer en relation avec les familles schismatiques et infidèles, sans exciter la méfiance d'un fanatisme soupçonneux. L'apostolat est multiplié de toute la profonde influence que le missionnaire peut acquérir de la sorte ${ }^{100}$.

Gleichzeitig, so der Verfasser weiter, sei die Schule der Ort, wo Bekehrungen geschehen: »Aussi est-ci autour de l'école que se font les conversions ${ }^{101}$. Die Schule wurde von der katholischen Kirche schließlich auch als das Mittel gesehen, mit dem die Laizisten ihren Einfluss verbreiteten und dem deshalb mit dem verstärkten Engagement der katholischen Schulen im Nahen Osten begegnet werden musste: »Mais l'armée la plus efficace du laïcisme,

97 Vgl. Gaillard 2000, S. 171.

98 SARRAut 1923, S. 95.

99 Der Grund für diese Entscheidung lag in der Konkurrenz der anderen, vor allem der protestantischen Schulen, und in der Erkenntnis begründet, dass die Bekehrungen von Libanesen die späte Frucht des Schulbesuchs sei: »Nos missionnaires reconnaissent que souvent, à l'heure de la mort, des conversions se produisent, qui sont le fruit de l'éducation du collège. Serait-il sage, au moment où les protestants redoublent d'énergie et où la Franc-maçonnerie commence à pénétrer dans des régions jusqu'ici respectées, de nous désintéresser de l'éducation de la jeunesse [...]?« LAZ/Paris, »Compte-rendu du Conseil de Province tenu à Beyrouth le 28 novembre $1905 \ll$.

100 SJ/Vanves, RPO, 21, »La mission de Syrie, environ 1927«.

101 Auch wenn andere jesuitische Quellen dieser sehr optimistischen Sichtweise widersprechen und die Frage der Bekehrungsmöglichkeiten einschränken beziehungsweise ablehnen, macht dieses Zitat doch die Hoffnungen und das Gewicht deutlich, das die Jesuiten mit der Implementierung ihrer Schulen verbanden. Vgl. Verdeil 2007, S. 37. 
c'est l'école ${ }^{102}$. In der Tat konzentrierten sich auch die Gründer der Mission laïque française, Pierre Foncin und Pierre Deschamps, beide selbst im Erziehungsbereich tätig, auf die Schule als Ort, um ihr Projekt der »éducation progressive ${ }^{103}$ der indigenen Bevölkerung unter der Berücksichtigung ihrer Kultur zu realisieren. Die Alliance israélite universelle glaubte ebenfalls an die Schule als das beste Medium, um ihre Mission zu verbreiten, wie Rodrigue herausgearbeitet hat:

La mission civilisatrice du maître consistait à répandre les valeurs de la civilisation occidentale telle que la concevait l'idéologie émancipatrice du judaïsme européen. Une fois occidentalisé et civilisé, le Juif deviendrait, dans le pays où il vivait, un citoyen honnête et vertueux ${ }^{104}$.

Die französischen Protestanten verfolgten als Christen eine ähnliche Strategie wie die katholischen Orden. Auch sie sahen die Schule als idealen Ort, um ihre Präsenz zu zeigen und ihre protestantische Lehre zu verbreiten. Ebenso heißt es in einem Brief der libanesischen Protestanten an den Senator Eccard, der 1926 die Möglichkeiten einer französischen protestantischen Schule im Libanon eruierte: »Il est incontestable que le moyen le plus efficace pour inculquer les principes du protestantisme français est l'ÉCOLE [sic], surtout l'école supérieure « ${ }^{105}$.

Mit ihrem Fokus auf die Schule reproduzierten die Institutionen die zentrale Stellung des Bildungswesens in Frankreich selbst. Aus diesem Grund kann die enge Verflechtung in der kolonialen Bildungs- und Sozialpolitik zwischen `Mutterland überzeugend demonstriert wurde ${ }^{106}$, auch für die Beziehung zwischen Frankreich und dem Libanon bestätigt werden.

$102 \mathrm{LAZ/Paris,} \mathrm{Lettre} \mathrm{pastorale} \mathrm{au} \mathrm{clergé} \mathrm{et} \mathrm{au} \mathrm{peuple} \mathrm{latin} \mathrm{du} \mathrm{vicariat} \mathrm{apostolique} \mathrm{d'Alep} \mathrm{pour} \mathrm{le}$ carême de 1911: Religion et laïcisme en face du problème de l'éducation populaire, Beirut 1911, S. 30.

103 So Foncin, zitiert in THÉvenin 2002, S. 28.

104 Rodrigue 1989, S. 76.

105 Brief der »Native Evangelical Church Beirut« an Eccard, zitiert in Eyrard/Khoury/Krebs 2006, S. 38.

106 Vgl. Fischer-Tiné 2009, S. 13, 372. 


\section{Die Verortung auf der Akteursebene:}

Lehrer als Träger der Zivilisierungsmission

Um ihre Zivilisierungsmission mit Hilfe der Schulen realisieren zu können, waren die Institutionen auf Lehrer angewiesen, die diese Arbeit im Alltag ausführten. Um die Analyse der Zivilisierungsmission konkret auf der Akteursebene zu verorten, soll deshalb gefragt werden, ob die Lehrer selbst sich als Träger dieser Idee verstanden ${ }^{107}$. Die Analyse der Lehrer der Mission lä̈que ist dabei besonders interessant, weil es über sie noch keine historischen Studien gibt ${ }^{108}$ und weil die Archive der Mission lä̈qu ausführliche Informationen über die Biographien der einzelnen Lehrer enthalten ${ }^{109}$. Die Lehrer der anderen Institutionen werden vergleichend zur Analyse hinzugezogen. Um die Analysekriterien der Transferforschung auf die Lehrer der französischen Schulen im Libanon anzuwenden, untersucht dieses Kapitel ihre Herkunft, ihre Ausbildung, ihre Vorkenntnisse über Sprache und Kultur des Libanons sowie ihre Motive und Perspektiven. Da die meisten Lehrer der französischen Schulen im Untersuchungszeitraum Franzosen waren und über diese Akteure die meisten Dokumente vorliegen, widmet sich das Kapitel vor allem den französischen Lehrern. Vorhandene Informationen zu ihren arabischen Kollegen werden aber vergleichend integriert.

Die Herkunft als ein Element der Identität der Lehrer ist deshalb von großem Interesse, weil sie erstens die Haltung der Institutionen gegenüber ihren Akteuren aufdeckt: Sollten nur Franzosen die französische Zivilisation überbringen oder war im Gegenteil eine Aneignung dieser Mission durch NichtFranzosen erwünscht oder wurde zumindest geduldet? Zweitens hilft diese Frage zu eruieren, ob es Netzwerke ${ }^{110}$ gab, anhand derer die Lehrer angeworben wurden.

Die Schulen der Mission lä̈que wiesen zwar einen erheblichen Anteil an arabischen Lehrern auf, aber die Mehrzahl der Lehrer waren Franzosen. Leider listet das überlieferte Verzeichnis des Lehrkörpers nur die Franzosen und Französinnen auf. Eine Aufstellung der Schule von Januar 1924 belegt aber,

107 Vgl. auch Esther MöLlER, Lehrer als Träger der Zivilisierungsmission? Die französischen Schulen im Libanon 1909-1943 als transnationale Bildungsräume aus der Akteursperspektive, in: Dies./Johannes Wischmeyer (Hg.), Transnationale Bildungsräume. Wissenstransfers im Schnittfeld von Kultur, Politik und Religion, Göttingen 2013, S. 171-187.

108 Vgl. Simon Duteil, Parcours parallèles et construction d'une identité. Les enseignants français dans les colonies françaises sous la Troisième République. Les enseignants formés à l'école Jules Ferry de la Mission laïque française (1902-1914), DEA Le Havre 2003.

109 Sie verfügen über Einzelakten zu verschiedenen Lehrern sowie über ein Dossier mit Kurzbiographien, die zumindest die (in Frankreich eingestellten) französischen Lehrer fast vollständig abzudecken scheinen.

110 »Netzwerk« wird hier nicht verstanden im Sinne der Netzwerktheorie, sondern in seinem unmittelbaren Verständnis als Beziehungsgeflecht zwischen Individuen. 
dass neben 19 Mitgliedern des französischen Personals auch 16 Mitglieder des »arabischen Personals« an der Schule arbeiteten ${ }^{111}$. Lässt man die verschiedenen Hausangestellten außer Betracht, ist zu vermuten, dass circa zwei Drittel der Lehrer französischer und ein Drittel arabischer Herkunft waren. Geographisch gesehen kamen die französischen Lehrer der Mission laïque aus ganz Frankreich. Das heißt, dass sie keinem exklusiven Netzwerk entstammten, zumal sie auch in unterschiedlichen Lehrerseminaren ausgebildet worden waren. Eine gewisse geographische Konzentration lässt sich allerdings im Département der Manche in der Normandie ausmachen: Hier waren fünf Lehrer derselben Generation geboren worden und hatten zum Teil auch ihre Ausbildung und erste Arbeitserfahrungen gemacht ${ }^{112}$. Sie entstammten demselben Département und der gleichen Generation wie Edmond Besnard, Generalsekretär der Mission laïque von 1906 bis 1946, der sie möglicherweise rekrutiert hat.

Ähnliche Verbindungen lassen sich bei einigen Lehrern ausmachen, die an demselben Lehrerseminar ausgebildet worden waren oder an derselben Schule unterrichtet hatten und die dann auch zur gleichen Zeit im Libanon tätig waren ${ }^{113}$. Hier ist $\mathrm{zu}$ vermuten, dass sich die Lehrer gemeinsam entschlossen haben, in den Libanon zu gehen beziehungsweise einander dazu ermutigten $^{114}$. Noch häufiger ist dieses Phänomen aber für die Lehrer festzustellen, die vor ihrer Zeit in Beirut in einer anderen französischen Schule im Ausland unterrichtet hatten. Beispielsweise hatte Emile Mathieu, Direktor der Mission lä̈que in Beirut von 1921 bis 1925, gemeinsam mit einem Lehrer und einem Verwaltungsangestellten an der Schule der Mission lä̈que in Thessaloniki gearbeitet, bevor diese mit ihm und seiner Frau an die Schule in Beirut gingen ${ }^{115}$. Familiäre Beziehungen spielten keine herausragende Rolle: Abgesehen von den zahlreichen Lehrerehepaaren gab es im Untersuchungs-

111 Vgl. AN/ Paris, 60 AJ 128, »État d'émargement du personnel«.

112 Diese Lehrer waren René Latrouite (Direktor von 1938 bis 1946), Jean Lehéricy (Verwalter von 1922-1948), Germaine Compère (Lehrerin ab 1922), Paul Lehéricy (Lehrer von 1919 bis 1925), Eugénie Lehéricy (Lehrerin von 1919 bis 1925). Paul Leroux stammte ebenfalls aus der Manche, aber gehörte einer späteren Generation an (Lehrer von 1945 bis 1948). Vgl. MLF/ Paris, »Liste du personnel«.

113 Beispielsweise hatten Pioger und Chevrier um 1920-1923 gemeinsam das Lycée und die Universität in Rennes besucht; außerdem waren Mathieu und Rousseau zur gleichen Zeit in der Marne-Gegend als Lehrer tätig; schließlich war Duval vor seiner Zeit im Libanon Lehrer in Guincamp gewesen, wo auch Deschamps unterrichtet hatte. Vgl. MLF/Paris, »Liste du personnelk.

114 So berichtet Roger Lefèvre, der 1946 an die Schule der Mission laïque ging, seine Nachbarn seien dort schon als Lehrer tätig. Roger LEFÈVRE, Itinéraire d'un jeune enseignant entre trois guerres et trois continents, Paris 2004, S. 111.

115 Es handelt sich um die Herren Vaporiu, Guillot und das Ehepaar Lehéricy. 
zeitraum nur zwei nachweisbare Fälle, in denen mehrere Mitglieder einer Familie gemeinsam in den Libanon gingen ${ }^{116}$.

Nicht alle französischen Lehrer kamen direkt aus Frankreich nach Beirut; einige hatten vorher in anderen französischen Gebieten gearbeitet ${ }^{117}$. Außerdem wurden einige Kollegen in Beirut selbst rekrutiert. So konnten die Schulen sowohl Kosten sparen als auch pragmatisch und schnell nach Bedarf rekrutieren. Diese Erkenntnis warnt davor, eine allzu gradlinige Verbindung zwischen Heimatland und dem Libanon zu ziehen. Vielmehr wird deutlich, dass die Lehrer aus ganz verschiedenen Kontexten und Erfahrungen heraus an die französischen Schulen im Libanon kamen.

Was die Herkunft der arabischen Lehrer der Mission laïque betrifft, waren diese größtenteils Libanesen und Christen ${ }^{118}$. Auch hier schien es gewisse Netzwerke zu geben, durch welche sie rekrutiert wurden. Beispielsweise stammten Assaf bey Kfoury (arabisch Assāf Bey Kfūrī) und Georges Kfoury (arabisch Ğūrğ Kfūrī) aus der nordlibanesischen, christlich dominierten Stadt Zahlé ${ }^{119}$. Während über Assaf bey Kfoury keine weiteren Informationen bekannt sind, war Georges Kfoury Journalist und Schriftsteller ${ }^{120}$. Abgesehen von Georges Kfoury, der die Abteilung der »arabischen Studien« (études arabes) leitete, wurden im Untersuchungszeitraum die leitenden Funktionen innerhalb der Schule von »Metropol«-Franzosen bekleidet. Eine Ausnahme bildete die langjährige Direktorin der Mädchenschule (1932-1958), Lucie Lévy, eine 1895 bei Oran in Algerien geborene Jüdin, die aber die französische Staatsangehörigkeit besa $\aleph^{121}$.

116 Das waren zum einen »Madeleine Hoffman, née Ruche« und Germain Victor Hoffman, die Schwester und der Schwager des Direktors Lucien Ruche, die 1925 mit ihm in den Libanon aufbrachen. Die andere Familie waren die Brüder Jean und Paul Lehéricy mit ihren Ehefrauen, die aber zu unterschiedlichen Zeitpunkten (1919 bzw. 1922 und 1925) nach Beirut gingen. Vgl. MLF/Paris, »Liste du personnel«.

117 Vgl. Kapitel 3.4.

118 Vgl. für die 1930er Jahre AN/Paris, 60 AJ 136, »Personnel recruté sur place«.

119 Für Assaf Bey Kfoury vgl. MLF/Paris, »Dossiers du personnel«, G 4200 A/ 026-13; für Georges Kfoury siehe AN/Paris, 60 AJ 131, Artikel einer nicht näher spezifizierten libanesischen Zeitung.

120 Vgl. Murāği` Bašīr QABaṬī, Halīl Taqī ad-Dīn f̄̄ sīratihi wa-adabihi, Beirut 2006 [Halīl Taqī ad-Dīn: Über seine Biographie und seine Literatur], S. 9.

121 Zur Diskussion um den ambivalenten Status der Juden in Algerien vgl. Patrick WEIL, Le statut des musulmans en Algérie coloniale. Une nationalité française dénaturée, in: La Documentation française (Hg.), La Justice en Algérie 1830-1962, Paris 2005, S. 95-109, Fußnote 22: seit 1871 besaßen die Juden in den französischen Gebieten, die vor 1870 besetzt wurden, die französische Staatsangehörigkeit. Nach dem Gesetz vom 07.10.1940 wurde den algerischen Juden die französische Staatsangehörigkeit wieder aberkannt. Vgl. André KAsPI, Vichy et les Juifs, in: Jean-François SiRINELli (Hg.), Dictionnaire historique de la vie politique française au $\mathrm{XX}^{\mathrm{e}}$ siècle, Paris 1995, S. 1243-1248, S. 1244. Im Gegensatz zu anderen jüdischen Lehrern bei der Mission laïque wurde Lévy aber unter der Vichy-Regierung nicht entlassen. Vgl. MAE/ Nantes, IP, 170: 1941, Brief des Direktors Latrouite an den Leiter des Erziehungsministeriums des Hochkommissars in Beirut, Bounoure, Beirut, 20.05.1941. 
Damit wies die Herkunft der Lehrer der Mission laïque starke Parallelen zu denen der katholischen Schulen auf. Zwar muss man noch einmal zwischen den verschiedenen Orden unterscheiden, aber ihre Mitglieder im Libanon in der ersten Hälfte des 20. Jahrhunderts waren vor allem französischer Herkunft. Damit unterschied sich die Situation stark von den vorhergehenden Jahrzehnten, in denen die Orden sehr viel internationaler besetzt gewesen waren. Diese neue Tendenz war vor allem eine Folge des gewachsenen Nationalismus in Europa, wie Jérôme Bocquet für die Lazaristen gezeigt hat ${ }^{122}$. Sie galt auch für die Jesuiten, obwohl sich diese immer als »internationalen Orden « definierten ${ }^{123}$. Gerade der Jesuitenpater Louis Jalabert, der während der Mandatszeit die von seinem Orden geführte Beiruter Université Saint-Joseph in Paris vertrat, repräsentierte die stark nationalistische Ausrichtung der französischen Patres im Libanon ${ }^{124}$. Bei den Frères des Écoles chrétiennes in Beirut gab es interessanterweise auch im 20. Jahrhundert eine Gruppe von Ordensbrüdern aus anderen europäischen Ländern, die aber in Frankreich ausgebildet worden waren und dort die französische Staatsangehörigkeit erhalten hatten ${ }^{125}$.

Mit der Mission laïque verband die katholischen Schulen in struktureller Hinsicht weiterhin, dass sie zwar über einen erheblichen Anteil an libanesischen Lehrern verfügten, die Leitungspositionen in der Zeit von 1909 bis 1943 aber ausschließlich mit Franzosen besetzten. Bei den Lazaristen war der Prozentsatz der libanesischen Brüder und Lehrer, die als »collaborateurs « bezeichnet wurden, Anfang des 20. Jahrhunderts anscheinend sehr hoch, denn zu der Zeit gab es bei einem Treffen der Provinz von Beirut eine Diskussion über ihren Stellenwert ${ }^{126}$. Die Teilnehmer bewerteten diesen hohen Anteil als negativ. Es wurde sogar von einem »abandon«, also einer

122 Für die Lazaristen vgl. Jérôme Bocquet, Missionnaires français et allemands au Levant: les Lazaristes français de Damas et l'Allemagne, du voyage de Guillaume II à l'instauration du mandat, in: Dominique Trimbur (Hg.), Europäer in der Levante. Zwischen Politik, Wissenschaft und Religion (19. und 20. Jahrhundert), München 2004, S. 57-75. Er hat untersucht, dass die deutschen Lazaristen in Syrien nicht nur zahlenmäßig weniger wurden, sondern auch immer stärkere Konflikte mit ihren französischen Brüdern hatten.

123 Vgl. Peter Claus Hartmann, Die Jesuiten, München 2001, S. 86. Für die Selbstwahrnehmung der Jesuiten vgl. das Interview der Verfasserin mit dem Jesuiten Charles Libois, Beirut, 05.11.2007, der die Lazaristen und Frères des écoles chrétiennes als viel »französischer« bezeichnete.

124 Vgl. Dominique Avon, La cause du Liban selon le jésuite Louis Jalabert (1914-1934), in: Evelyne Farcy-Magdenel (Hg.), Le rôle de la France dans les opérations extérieures: influence, ingérence et/ou mandat. L'exemple du Liban, Montpellier 2007, S. 69-80.

125 Vgl. das Interview der Verfasserin mit Frère Michel in Beirut, 08.12. 2007, der ursprünglich aus Tschechien kam, aber in Frankreich ausgebildet und französischer Staatsbürger worden war. Vgl. auch FEC, »Registre des frères«.

126 LAZ/ Paris, »Beyrouth Correspondance 1896-1918«, »Compte-rendu du Conseil de Province tenu à Beyrouth le 28 novembre 1905«. 
Vernachlässigung durch den französischen Mutterorden gesprochen ${ }^{127}$. Diese Diskussion macht deutlich, dass es nicht Ziel des Ordens war, so viele arabische Brüder oder Lehrer wie möglich zu gewinnen.

Auch der den Lazaristen angeschlossene Frauenorden Filles de la Charité hatte zu Beginn des 20. Jahrhunderts mehr französische als arabische Schwestern $^{128}$. Allerdings muss hier betont werden, dass es schwierig ist, zu identifizieren, ob die Ordensschwestern als Lehrerinnen oder in einem anderen Bereich aktiv waren ${ }^{129}$. Im Gegensatz zur Mission laïque stammten die arabischen Lehrerinnen und Lehrer der katholischen Schulen aber nicht nur aus dem Libanon, sondern auch aus den angrenzenden Regionen Syrien, Ägypten und Palästina ${ }^{130}$. Diese Gebiete gehörten zu derselben Provinz des Ordens, innerhalb derer eine große Mobilität herrschte ${ }^{131}$.

Das Profil der Lehrer der protestantischen französischen Schule ähnelte dem der Mission laïque, denn sie waren, bis auf die Arabischlehrer ${ }^{132}$, ausschließlich französische Staatsangehörige. So formulierten die Euvres protestantes françaises in einem Brief an die Académie de Paris, durch den sie neue Lehrerinnen zu rekrutieren hofften, als zwei Bedingungen, die diese zu erfüllen hatten, die französische Staatsangehörigkeit und die protestantische Konfession beziehungsweise religiöse Neutralität ${ }^{133}$.

127 Ebd., Brief von Boury, Beirut, 19.05.1903: »En ce moment, les œuvres sont, en plusieurs maisons, entre les mains des confrères indigènes. Il est absolument nécessaire d'envoyer quelques sujets jeunes, de bonne espérance, qui apprennent l'arabe pour pouvoir rendre service. Ainsi, à Beyrouth tout le ministère est, pour ainsi dire, abandonné à Bahri [Name nicht gut leserlich, E.M.] et Ouanès qui ne peuvent pas se sentir; et il m'est impossible de les changer. De même, et surtout, à Tripoli. On a dû vous écrire sur l'esprit qui anime MMr Jérémie Aoun et R. Koury: ce n'est pas rassurant $\ll$.

128 Vgl. FDC, »G B 2 Beyrouth«.

129 Vgl. z.B. FDC, »G B 6 Personnel de Communauté. Ras Beyrouth-Maison St. Joseph«. Zwar ist auf den vorgefertigten Listen bei manchen Schwestern die Rubrik »Brevet?« mit »Oui« ausgefüllt, was bedeutet, dass sie die Voraussetzung zur Grundschullehrerin mitbrachten, aber ob sie als solche tätig waren, bleibt offen. Bezüglich der Sœurs de Saint-Joseph de 1'Apparition kann keine verbindliche Aussage gemacht werden, aber es ist davon auszugehen, dass ihre Situation ähnlich der der Filles de la Charité war.

130 Für die Filles de la Charité vgl. deren Mitgliederlisten in: FDC, u.a. »Beyrouth-Immaculé, Personnel de 1906 à 1908«, »Ras-Beyrouth, Personnel de 1903 à 1909«.

131 Vgl. Interview der Verfasserin mit Sœur Madeleine, Beirut, 13.12.2007: Kurz nach dem Ersten Weltkrieg in Haifa in Palästina geboren, ging sie für ihr Noviziat bei den Filles de la Charité nach Beirut.

132 Laut Eyrard / Khoury / Krebs 2006, S. 97, gab es ab 1927 eine Arabischlehrerin, Asma Homsi, und ab 1928 zwei Arabischlehrer für die höheren Klassen sowie eine Koordinatorin des Arabischunterrichts, eine sogenannte »directrice des études d'arabe«.

133 »Etre française. Etre protestante ou, dans le cas contraire, s'engager à observer la plus stricte neutralité du point de vue religieux«. AN/Paris, aj 16, 6986, Brief der Euvres protestantes françaises de Syrie et de Liban an den Sekretär der Académie de Paris, Paris, 10.06.1939. 
Einen Sonderfall stellten die Schulen der Alliance israélite universelle im Libanon dar. Keiner ihrer Lehrer hatte die französische Staatsangehörigkeit, vielmehr wurden sie in den Ländern rekrutiert, in denen die Alliance israélite Schulen unterhielt, und für die Ausbildung nach Paris geholt ${ }^{134}$. Danach gingen sie als Lehrer der Organisation in ihr eigenes oder ein anderes Land, in dem die Alliance israélite Schulen betrieb, zurück ${ }^{135}$. Die Verantwortlichen der Alliance israélite betonten, dass ihre Lehrer zwar nicht in ihrem Pass, aber in ihrer Seele französisch seien. Damit wurden diese von >Objekten $<$ der Zivilisierungsmission zu deren Trägern:

Faut-il parler de notre personnel enseignant? Formés dès leur plus jeune âge dans la civilisation de Racine et de Pascal, préparés à leur mission à l'ombre de notre propriété d'Auteil où les voix d'Helvétius, de d'Alembert et de Diderot ne se sont pas encore tues, nos instituteurs sont français par toutes les fibres de leur âme, même quand ils ne le sont pas par leur état civi1 ${ }^{136}$.

Die Alliance israélite musste zu dieser Maßnahme greifen, weil sie unter Lehrermangel litt ${ }^{137}$, aber sie wandelte den Mangel in eine Tugend um und betonte, dass die einheimischen Lehrer besser als französische Lehrer die Kultur des Landes und der Menschen kannten und deshalb weniger einen Kulturschock erleiden oder einen solchen verursachen würden:

Par leur connaissance intime des mœurs et des exigences du pays, ils risquent moins que les Occidentaux de froisser les susceptibilités religieuses des communautés, de heurter certains préjugés ou de s’étonner de certaines superstitions ${ }^{138}$.

Allerdings ist zu fragen, ob nicht ihr gesamtes Projekt - nämlich die Emanzipation der französischen Juden in die Welt zu sexportieren $<$ - in der Gefahr eines solchen Kulturschocks stand. Außerdem wurden die Lehrer oft in Gegenden entsandt, die sie nicht kannten und in denen sie sich ebenso fremd fühlten wie französische Lehrer: »Comme les professeurs de France, ceux de

134 Interessanterweise unterschied der Direktor der Schule der Alliance israélite in Beirut aber 1919 trotzdem zwischen den Lehrern der Alliance israélite und den »professeurs du pays «. Vgl. AIU/Paris, »Liban VIE 80-81«, Brief von Penso an den Präsidenten der Alliance israélite in Paris, Beirut, 31.10.1919: „Comme vous n'avez pas nommé des remplaçants à Monsieur Laredo et Mademoiselle Bardasch j’ai dû engager des professeurs du pays«.

135 Diese Ausbildung wird weiter unten näher erläutert.

136 AIU/Paris, Paix et Droit, Oktober-Dezember 1939, S. 8.

137 Burrows 1986, S. 123.

138 AIU/Paris, Bulletin de l'Alliance Israélite Universelle 63 (1901), S. 101. 
l'Alliance souffrent des mêmes difficultés, différences de langues, de climat, de mœurs, de milieu social, etc. ${ }^{139}$.

Die vergleichende Analyse zur Herkunft der Lehrer der französischen Schulen hat gezeigt, dass bis auf die Alliance israélite in allen Schulen die französischen Lehrer sowohl in der Anzahl als auch in ihren Positionen dominant waren. Das bedeutet, dass die Mission laïque, obwohl sie als ihr Ziel die Förderung der fremden Kulturen formuliert hatte, sich nicht an schon praktizierten Modellen wie dem der Alliance israélite orientiert hat, um die arabischen Lehrer stärker zu fördern.

Ein weiteres wichtiges Element für die Untersuchung der Lehrer als Träger der Zivilisierungsmission ist die Frage ihrer Ausbildung und beruflichen Vorerfahrung. Anhand der Analyse der verschiedenen Schulen wird deutlich, dass die französischen Lehrer umso stärker pädagogisch professionell ausgebildet und (vor-) erfahren waren, je später sich ihre Institution im Libanon etablierte. Die Professionalisierung der arabischen Lehrer hingegen wurde aus verschiedenen ideologischen und politischen Gründen im gesamten Untersuchungszeitraum be- und verhindert ${ }^{140}$.

Die französischen Lehrer der Mission laïque spiegeln zu großen Teilen die gestiegene Professionalisierung des Lehrkörpers durch die Schulpolitik der Dritten Republik in Frankreich wider, bezeugen aber auch einen gewissen Ermessensspielraum der Institution bei der Rekrutierung. Darüber hinaus repräsentieren viele von ihnen die laizistische und demokratische Bildungspolitik der französischen Republik ${ }^{141}$. Die von der Mission lä̈que angestellten Grundschullehrer hatten meistens die entsprechende Ausbildung an einer École normale, dem staatlichen Lehrerseminar, in Frankreich absolviert. Andere hingegen hatten nur das Abitur in Frankreich abgelegt. Diese Écoles normales waren durch die Gesetze von 1830 für Männer und von 1879 für Frauen in ganz Frankreich flächendeckend errichtet worden ${ }^{142}$. Im Zuge der Trennung von Staat und Kirche wurden sie zu Propagandastätten der laizistischen Republik ${ }^{143}$. Interessanterweise hat keiner der Lehrer, die in den Libanon gingen, die Schule besucht, die die Mission lä̈que unter dem Namen »Écoles Jules Ferry« 1902 speziell gegründet hatte, um schon diplomierte

139 Deshalb, so Direktor Penso 1919, halte er es für legitim, dass sie ähnlich wie diese eine finanzielle Entschädigung (den »quart colonial«) erhielten. AIU/ Paris, »Liban VIE 81b«, Brief von Penso an den Präsidenten der Alliance israélite in Paris, Beirut, 24.12.1919.

140 Vgl. Kapitel 5.2.

141 Viele der Lehrer kamen aus einfachen Verhältnissen und hatten durch die Schulreformen und die Ausbildungsstätten für Lehrer Eintritt in das Bildungssystem gefunden. Ein gutes Beispiel dafür ist Pierre Deschamps, der erste Direktor in Beirut.

142 Vgl. Mayeur 1981, S. 533.

143 So haben französische Grundschullehrer, die vor 1914 aktiv waren, angegeben, in dieser Hinsicht viel gelernt zu haben, insgesamt aber schlecht auf ihre Arbeit vorbereitet worden zu sein. Vgl. Ouzouf/ Ouzouf 1992, S. 339. 
Lehrer für den kolonialen Schuldienst auszubilden ${ }^{144}$. Deshalb ist zu fragen, ob der Libanon einen Sonderstatus innerhalb der französischen kolonialen Einflussgebiete einnahm ${ }^{145}$.

Entsprach die Situation der Grundschullehrer der Mission laïque weitgehend dem französischen Modell, sah die Ausbildungssituation der Lehrer im Sekundarschulbereich etwas anders aus: Manche waren eigentlich nur ausgebildete Grundschullehrer oder verfügten nur über ihr Abitur, andere hatten in Frankreich eine Licence, das Diplom nach drei Jahren Studium, absolviert $^{146}$. Viele von ihnen hatten vor ihrer Zeit im Libanon schon als Lehrer gearbeitet, allerdings in ganz verschiedenen Einrichtungen und Positionen. Grund für diese Diversität war wahrscheinlich der Umstand, dass die Mission lä̈que zeitweise unter Lehrermangel litt und nicht immer das benötigte adäquate Personal zur Verfügung hatte ${ }^{147}$.

Hingegen ist bei den Direktoren der Schulen der Mission lä̈que im Untersuchungszeitraum eine Steigerung des Ausbildungsniveaus festzustellen: Hatten die ersten Direktoren in den meisten Fällen nur das Lehrerseminar besucht und an diesem unterrichtet, schlossen ihre Nachfolger die Universität mindestens mit einer Licence $\mathrm{ab}^{148}$. Zwei von den insgesamt 11 Direktoren im Untersuchungszeitraum besaßen die Agrégation (um an der Universität und im Gymnasium zu arbeiten) ${ }^{149}$. Außerdem hatten alle Direktoren des Untersuchungszeitraums bis auf zwei vor ihrer Tätigkeit in Beirut in anderen Ländern als Frankreich unterrichtet, davon meistens in anderen arabischen Ländern beziehungsweise in Griechenland ${ }^{150}$. Gleiches gilt für die Direk-

144 Vgl. DuteIL 2003.

145 Vgl. Kapitel 3.4.

146 Vgl. MLF, »Liste du personnel«.

147 Vgl. z.B. AN/Paris, 60 AJ 122, Brief von Lehéricy an Besnard, Beirut, 06.10.1920, bezüglich eines Lehrers für die »Section commerciale«: »Nous cherchons, mais très difficile on en manque $\ll$.

148 Vgl. MLF/Paris »Liste du personnel«. Der erste Direktor hatte die höchste Stufe der republikanischen Bildungsstationen, die École normale supérieure in Saint-Cloud, besucht. Sein Nachfolger, Émile Chaufour, hatte eine Licence in Englisch und Deutsch und die Qualifikation, in den Écoles normales zu unterrichten. Nach einigen Vertretung kam als neuer Direktor Émile Mathieu, der nur über ein Brevet supérieur und ein Certificat d'aptitude pédagogique verfügte.

149 Mathieus Nachfolger Lucien Ruche hatte eine Agrégation (die höchstmögliche Qualifikation an der Universität) in Deutsch. Sein Nachfolger, Jacques Grandjouan, verfügte ebenfalls über eine Agrégation, und zwar in Grammatik. Interessanterweise hatte der letzte Direktor der Mission laïque in der Mandatszeit, René Latrouite, wieder nur die normale Lehrerausbildung absolviert.

150 Deschamps war vorher in Madagaskar, Chaufour in Alexandria, Matthieu in Thessaloniki, Ruche in Tunis, Constantine und Alger, Grandjouan in Casablanca und Latrouite in Damaskus. Vgl. MLF/Paris, »Liste du personnel«; für Ruche vgl. AN/Paris, F 17/25346: »Ruche, Lucien Charles«. 
torinnen der Mädchenschule der Mission lä̈que ${ }^{151}$. Man kann also bezüglich der Lehrer der Mission laïque feststellen, dass deren Ausbildung zum großen Teil den Richtlinien entsprach, mit denen sie auch in Frankreich als Lehrer oder Direktoren arbeiten konnten. Allerdings gab es auch Ausnahmen von der Regel. Vor allem im technischen Bereich kamen die Lehrer oft aus der entsprechenden Profession und hatten keine Vorerfahrung im Schuldienst $\mathrm{t}^{152}$.

Die Situation der Lehrer des Collège protestant français glich jener der Mission laïque ${ }^{153}$. Die in den Archiven nachweisbaren Lehrer hatten ihre Grund- oder Sekundarschullehrerausbildung in Frankreich absolviert, diesbezüglich schien es noch weniger Ausnahmen als bei der Mission laïque zu geben ${ }^{154}$. Die meisten von ihnen hatten auch schon in Frankreich als Lehrer und Lehrerinnen gearbeitet ${ }^{155}$. Wie die anderen Schulen rekrutierte aber auch das Collège protestant français vor Ort und profitierte damit von der starken Präsenz französischer Lehrerinnen, deren Ehemänner als Mandatsfunktionäre in den Libanon gekommen waren ${ }^{156}$.

Auch wenn es hinsichtlich der Ausbildung der indigenen Lehrer Parallelen zu den katholischen Schulen gab, unterschieden sich diese bezüglich der französischen Lehrer massiv von den laizistischen und protestantischen Schulen. Die französischen Lehrer der katholischen Schulen, die in der Regel Ordensmitglieder waren, wurden nicht nur - wie die der Alliance israélite - innerhalb der Institution formiert. Sie erhielten zudem in der Regel keine spezifische Ausbildung als Lehrer, sondern arbeiteten im Rahmen ihrer Ordenszugehörigkeit als solche. Das wurde durch die politischen Umstände noch einmal verschärft, da es seit dem »Gesetz über die Assoziationen« von 1901 für die katholischen Orden in Frankreich immer schwieriger und schließlich unmöglich wurde, zu unterrichten und damit auch ihren Nachwuchs auszubilden ${ }^{157}$.

151 Die erste Direktorin Eugénie Grall hatte nur in Frankreich unterrichtet. Aber ihre Nachfolgerin Marie Digrado war vorher in Alexandria tätig gewesen und Lucie Lévy kam aus Oran nach Beirut.

152 Siehe zum Beispiel André Ragon, ausgebildeter Zeichner, der sich 1913 um eine Stelle als »professeur d'enseignement technique et industriel« bei der MLF bewarb, aber schon 1914 wieder kündigte. Vgl. MLF/Paris, »Dossiers de personnel«, G 4200 A/038.3.

153 Es ist zu vermuten, dass die Lehrer sogar noch besser qualifiziert waren, auch wenn hier flächendeckende Informationen fehlen. Die Qualität der Lehrer war einer der Aspekte, den die Eltern besonders am Collège protestant français schätzten. Vgl. Interview der Verfasserin mit May Saykali, Beirut, 13.11.2008.

154 Vgl. PPFL, »Comptes-rendus du Conseil d'Administration 1925-1950«.

155 Dass die Organisation sehr gute, aber nicht höchstausgebildete Lehrer suchte, beweist der Vermerk der Verwaltungsrats von 1927: eine Agrégation sei nicht notwendig für eine Anstellung. Vgl. PPFL, »Compte rendu du Conseil d'Administration du 17.07.1927«.

156 Vgl. ebd.

157 Vgl. Mona Ouzouf, L’École, l’Église et la République (1871-1914), Paris 1982, S. 233. 
Außerdem darf nicht außer Acht gelassen werden, dass die katholischen Orden schon sehr viel länger als die anderen Institutionen ihre Schulen im Libanon unterhielten und deswegen einer anderen Epoche der Bildungsentwicklung entstammten. Wie das Register einer Schule der Frères des Écoles chrétiennes in Beirut deutlich macht, haben die Brüder, deren Funktion Professeur war, in der Regel nur das Brevet élémentaire, also den ersten qualifizierenden Schulabschluss, absolviert ${ }^{158}$. Ähnlich zeigen die Mitgliederlisten des Frauenordens Filles de la Charité keine besondere Zusatzausbildung der Nonnen an, die als Lehrerinnen arbeiteten ${ }^{159}$.

Die Ausbildung der Lehrer der Alliance israélite glich derjenigen der Mission laïque insofern, als sie in einem Lehrerseminar formiert wurden, welches dem französischen Modell nachempfunden war und auch die Inhalte und Methoden der staatlichen Lehrerausbildungsstätten übernommen hatte ${ }^{160}$. Die zukünftigen Lehrer wurden aus ihrem Heimatland für zwei oder drei Jahre nach Paris (für die Männer) oder nach Versailles (für die Frauen) an die École normale israélite orientale geschickt. Diese Einrichtung war 1865, also 5 Jahre nach der Gründung der Alliance israélite, von dieser ins Leben gerufen worden, um ihre eigenen Lehrer auszubilden ${ }^{161}$. Da die Alliance israélite nur Grundschulen unterhielt, waren Diplome, die über dieses Lehrerseminar hinausgingen, nicht notwendig. In dieser Schule erhielten die Kandidatinnen und Kandidaten zusätzlich zu dem staatlichen Programm noch Unterricht in hebräischer Sprache und jüdischer Geschichte, die sie dann selbst auch zu lehren hatten ${ }^{162}$. Für die Lehrer der Alliance israélite wie für ihre Kollegen in den anderen französischen Schulen galt, dass einige schon über Vorerfahrungen als Lehrer verfügten, andere im Libanon erst ihre Karriere begannen ${ }^{163}$.

Entscheidend für die Untersuchung der französischen Lehrer als Träger der mission civilisatrice ist außerdem die Frage nach ihrer Kenntnis der Sprache und Kultur des Libanons. Da der Arabischunterricht an den franzö-

158 Vgl. FEC, »Registre de personnel religieux«.

159 Vgl. die Listen der verschiedenen Standorte der Konvente, in: FDC.

160 Ein gutes Beispiel ist die Verwendung des Manuel général, eine der ältesten pädagogischen Zeitschriften in der Dritten Republik. Bei seiner Inspektionsreise vermisste Pariente es in der der Schule der Alliance israélite in Beirut - ein sicheres Zeichen dafür, dass es laut der Organisation zum Standard gehörte. Vgl. AIU/Paris, »Liban VIE 80-81«, »Rapport sur les Ecoles de l'Alliance Israélite à Beyrouth«. Zum Manuel général vgl. Ouzouf/Ouzouf 1992, S. 342.

161 Vgl. Albert H. NAvon, Les 70 ans de l'École Normale Israélite Orientale (1865-1935), Paris 1935, S. 15.

162 AIU/Paris, »École Normale Israélite Orientale. Rapport sur l'année scolaire 1938-1939«, S. 1: »À leur sortie de l'École, les élèves subissent un examen d'hébreu, d'histoire juive et d'exégèse biblique. Un diplôme spécial est délivré pour cette épreuve«.

163 Beispielsweise war die Lehrerin Jamilé Chalom vorher bei der Alliance israélite in Fès in Marokko tätig gewesen. Vgl. AIU/Paris, »Liban VIE 81b « Brief von Penso an den Präsidenten der Alliance israélite in Paris, Beirut, 09.11.1919. Direktor Émile Penso selbst hingegen fing in Beirut mit seiner Arbeit als Lehrer an. 
sischen Schulen im Libanon fast ausschließlich von Muttersprachlern gegeben wurde, benötigte zwar keiner der französischen Lehrer die arabische Sprache für seinen Unterricht, aber eine Kenntnis der Sprache und Kultur gehörte prinzipiell zu der Vorbereitung auf ihren Dienst im Libanon. Wie die Ausführungen allerdings zeigen werden, verfügten die Lehrer der meisten Schulen nur über sehr wenige dieser Kenntnisse.

Auf ihrem Kongress 1906 hatte die Mission lä̈que betont, dass die Lehrer die fremden Kulturen, in welchen sie unterrichten wollten, zuerst gründlich kennen lernen müssten:

En ce qui concerne l'éducation intellectuelle: Que les éducateurs européens se livrent à une étude approfondie de la mentalité indigène; qu'ils respectent en ce qu'elle a d'original, de particulier à la race; l'activité intellectuelle en ce qui concerne les productions de l'esprit s'appliquent à des objets qui ne soient pas étrangers à leur civilisation afin d'aider l'évolution et les progrès de celle-ci; que cependant les éducateurs européens s'efforcent de faire connaître la science occidentale et ses applications; Qu'en conséquence: l'enseignement soit varié, c'est-à dire que chaque colonie ait son plan d'éducation adapté à ses besoins et à la mentalité des indigènes ${ }^{164}$.

Angesichts des hier von der Mission lä̈que konstruierten Unterschiedes zwischen der französischen und den anderen Kulturen ist zu vermuten, dass die Auflösung dieses Gegensatzes das Ende der Zivilisierungsmission bedeutet hätte und die Lehrer vielleicht deswegen so wenig auf die Kultur des Libanon vorbereitet wurden ${ }^{165}$. Darüber hinaus macht das Zitat deutlich, dass es nicht um ein gegenseitiges und gleichberechtigtes Kennenlernen der Angehörigen zweier Kulturen, sondern um eine Begegnung mit dem Ziel der Zivilisierung ging. Anscheinend war aber die vorherige Kenntnis des Libanon kein notwendiges Einstellungskriterium, denn die wenigsten Lehrer hatten vorher im Nahen Osten oder überhaupt im Ausland gelebt. Ähnlich schien die Frage der Beherrschung der arabischen Sprache gehandhabt zu werden: Laut der Liste du personnel verfügte nur ein französischer Lehrer über ein Zertifikat der arabischen Sprache, und zwei andere beherrschten den syrischen arabischen Dialekt ${ }^{166}$.

164 MLF/Paris, Bulletin de la Mission laïque française 1906, S. 13.

165 Osterhammel weist zu Recht darauf hin, dass der Begriff der Zivilisierungsmission wertlos ist ohne seinen »inferior counterpart«, die Barbarei. Vgl. Osterhammel 2006, S. 7.

166 Über ein Diplom der Schule für orientalische Sprachen in Paris (für Arabisch, Persisch und Türkisch) verfügte Jean Lecerf (Lehrer von 1926-1929). Nach seiner Zeit in Beirut war Lecerf für zwei Jahre an der Schule der Mission laïque in Damaskus tätig, bevor er als Wissenschaftler am Institut français d'archéologie et d'art musulmans, das ab 1930 nur noch Institut français hieß, in Damaskus angestellt wurde. Vgl Renaud AVEZ, L'Institut français de Damas au palais Azem (1922-1946) à travers les archives, Damaskus 1993, S. 51. Zur Person Lecerfs siehe außerdem Alain Messaoudi, Lecerf Jean (Orléans, 1894-Paris, 1980) Arabisant, 
Innerhalb der Mission laïque française spielte für die Rekrutierung der einfachen Lehrer die Frage, ob ihre Lehrer Arabisch sprachen oder die arabische Kultur kannten, also keine Rolle. Trotzdem ermutigte die Leitung in Paris die Lehrer, im Libanon Arabisch zu lernen - ein Wunsch, dem von Seiten der Lehrer anscheinend nur sehr zögerlich entsprochen wurde. Schon ab 1911 ist vermerkt, dass ein einheimischer Lehrer, Assaf bey Kfoury, seinen französischen Kollegen Arabischunterricht gab - laut dem Direktor mit guter Resonanz: »Le cours [...] est bien suivi« ${ }^{167}$. Für die Absolvierung dieses Kurses bekamen die französischen Lehrer sogar eine Zusatzprämie vertraglich zugesichert, wenn sie, nach tunesischem Vorbild, zwei Prüfungen für Arabisch absolvierten ${ }^{168}$. Aber anscheinend, so ein Brief von Deschamps von 1919, waren die Lehrer dafür nicht sehr motiviert und wollten in ihrer Freizeit lieber mit Privatstunden ihr Gehalt aufbessern ${ }^{169}$. Dieser finanzielle Gesichtspunkt mag ein Grund für ihr mangelndes Interesse gewesen sein. Und so schienen im Schuljahr 1926-1927 nur drei Lehrer diesen Arabischkurs zu besuchen ${ }^{170}$. Im November/Dezember 1933 hatten sich aber einige Lehrer für den Arabischkurs eingeschrieben, den das französische Hochkommissariat anbot ${ }^{171}$.

Für die Wahl der Direktoren wurde diese Frage nicht explizit diskutiert, aber die Verantwortlichen der Mission lä̈que scheinen auf diese Vorerfahrung im Verlauf des Untersuchungszeitraums verstärkt Wert gelegt zu haben. Die meisten der Direktoren der Schule der Mission lä̈que in Beirut hatten, vor allem von den 1920er Jahren an, vor ihrer Zeit im Libanon in einem ande-

in: François Poulllon (Hg.), Dictionnaire des orientalistes de langue française, Paris 2008, S. 573-575. Den syrischen Dialekt beherrschte Elias Muard (Assistenzlehrer von 1921-1928), der vor seiner Einstellung bei der MLF schon in anderen französischen Schulen im Libanon gearbeitet hatte. Vgl. MLF/Paris, »Liste du personnel«. Zur Erhärtung der These, dass fast keiner der Lehrer Arabisch sprach, dient der Aufruf des Generalsekretärs der Mission laïque an den Direktor der Schule in Beirut 1925, wenn jemand einen Franzosen kenne, der Arabisch spreche, solle er zu ihm geschickt werden: "si en attendant vous découvriez un Français sachant bien l'arabe et disposé à collaborer avec nous, je vous serais reconnaissant de me le faire savoir«. AN/ Paris, 60 AJ 128, Brief des Generalsekretärs an den Direktor in Beirut, 09.11.1925. 1935 scheint Rebours (Lehrer von 1922 bis 1936) der einzige französische Lehrer gewesen zu sein, der Arabisch sprach. Vgl. AN/Paris, 60 AJ 137, Brief von Ruche an Besnard, Beirut, 28.02.1935.

167 AN/Paris, 60 AJ 119, Brief von Dupouey an den Präsidenten der Mission laïque, Beirut, 13.11.1911.

168 Siehe den Vertrag des Lehrers J. Delhomme vom 17.05.1910. MLF/Paris, »Dossiers de personnel«, G 4200 A/ 014.6 (Delhomme).

169 AN/Paris, 60 AJ 122, »Questions urgentes posées par Deschamps« (Dossier 1919-1920): »Il faut remarquer que les professeurs, étant donné le taux actuel des indemnités, aimeront mieux donner des leçons particulières que d'apprendre l'arabe«.

170 AN/Paris, 60 AJ 129, »État trimestriel des élèves«. Danach waren die Schüler »Madame Baur, M. Lafarque, M. Rousseau«. Zu diesem Arabischkurs beglückwünschte die Zentrale der Mission laïque in Paris die Schule in Beirut. Vgl. AN/Paris, 60 AJ 129, Brief an Ruche, 16.12.1926.

171 AN/Paris, 60 AJ 136, »Rapports mensuels«, November-Dezember 1933. 
ren arabischen Land gelebt und gearbeitet und waren daher mit dieser Kultur vertraut. Allerdings sprachen laut den Akten nur zwei dieser Direktoren Arabisch: Ruche, Direktor von 1925 bis 1935, verfügte über ein »Certificat d'arabe parlé (Mention bien) « des Hochkommissariats ${ }^{172}$, und Grandjouan, im Amt von 1935 bis 1938, legte 1936 eine Arabischprüfung ab ${ }^{173}$.

Bei den katholischen Orden sah die Situation etwas anders aus. Allerdings muss auch berücksichtigt werden, dass diese nicht nur französischsprachige Schulen unterhielten, in denen Französisch die offizielle Sprache war, sondern auch in der Mission und in karitativen Einrichtungen wie Krankenhäusern aktiv waren, wo sie nicht damit rechnen konnten, dass ihr Gegenüber die französische Sprache beherrschte. Von daher waren die Ordensleute darauf angewiesen, Arabisch zu sprechen, was sich auch auf die Schulen auswirkte, wenn sie dorthin delegiert wurden. Allerdings fand der Anspruch aller Orden an ihre Mitglieder, Arabisch zu sprechen, nur bei den Jesuiten starke Resonanz in der Praxis.

Innerhalb des Jesuitenordens wurde viel Wert darauf gelegt, dass die Patres das Arabische beherrschten. Deshalb wurde im Libanon zweimal jährlich für die nicht-arabischen Jesuiten ein biennum arabe abgehalten, eine Art Intensivkurs, der meistens im Sommer stattfand ${ }^{174}$. Auch der Orden der Lazaristen betonte die Wichtigkeit dieser Sprache, damit die Ordensbrüder, da sie nach der Schließung der Priesterseminare nicht mehr nach Frankreich zurückkehren konnten, auch an anderen Orten in der arabischen Welt arbeiten konnten ${ }^{175}$. Allerdings scheint diese Vorstellung nur teilweise in die Tat umgesetzt worden zu sein. In zahlreichen Briefen berichteten Lazaristen an den Mutterorden in Paris von ihren Schwierigkeiten vor allem in den Bergdörfern, wo sie mit den Bewohnern Arabisch sprechen mussten und deren Beichte auf Arabisch kaum verstanden:

172 Vgl. AN/Paris, F 17/25346: Ruche, Lucien Charles, »Notice individuelle 1935-1936«.

173 Vgl. AN/Paris, 60 AJ 139, »Certificat« über Arabischprüfung Grandjouans beim französischen Hochkommissariat, Juni 1937: er hat 13,75 Punkte von 20 erhalten.

174 SJ/Vanves, RPO, 15, »M. Ley 138: Proche Orient - Visites 1925-1956, »Rapport sur la Mission de Syrie Décembre 1934«. Nachdem dieser Kurs erst in Bikfaya in den libanesischen Bergen stattgefunden hatte, wurde er später nach Damaskus verlegt.

175 LAZ/ Paris, »Beyrouth Correspondance 1898-1918«, »Compte-rendu du Conseil de Province tenu à Beyrouth le 28 novembre 1905«: »Autrefois, les confrères pouvaient rentrer en France; maintenant que cette porte leur est fermée, il faut ou qu'ils apprennent la langue, ou qu'ils se résignent à devenir inutile le jour où, pour une raison ou pour une autre, ils se trouvent hors d'état de continuer à travailler dans les collèges. Désirent-ils d'ailleurs y passer toute leur vie, ils ne pourront y remplir leur mission, être à la fois professeurs et directeurs, que par la connaissance de la langue«. 
La langue arabe que je commence à bégayer un peu ne m'offre maintenant que [...] difficultés, augmentées de la responsabilité de conscience qui me pèse à chaque confession que je ne parviens pas malgré tous mes efforts à bien comprendre ${ }^{176}$.

Ein Lazarist berichtete daher, welche Erholung die Abhaltung einer Einkehrwoche in der Schule der Lazaristen von Ayntoura bedeutet hatte: »[C]'était pour moi comme une résurrection de retrouver ma chère langue française $«{ }^{177}$. Da die Lazaristen des Collège Saint-Vincent in Damaskus überhaupt kein oder nur ein dialektales Arabisch sprachen ${ }^{178}$, ist anzunehmen, dass die Situation im Libanon ähnlich weit von den Vorstellungen Bourys entfernt war ${ }^{179}$. Ein Grund für die Schwierigkeiten mancher Lazaristen, Arabisch zu lernen, war auch, dass sie nicht wussten, wie lange sie in der Region bleiben würden $^{180}$. Auch die Frères des Écoles chrétiennes besaßen zwar, "pour donner à leurs Ecoles d'Orient des maîtres qui connaissent la langue étrangère«, ähnlich wie die Jesuiten ein »Noviciat qui prépare tous les jeunes Novices qui doivent aller enseigner dans le Levant ${ }^{181}$. Aber in der Praxis sprachen nur wenige von ihnen Arabisch ${ }^{182}$.

Was die Arabischkenntnisse des Frauenordens Filles de la Charité angeht, die den Lazaristen angegliedert sind, können keine belastbaren Aussagen getroffen werden. Auch sie scheinen Arabischunterricht erhalten zu haben, ob und wie er gefruchtet hat, ist aus den Archiven nicht ersichtlich ${ }^{183}$. Interessanterweise weisen die Formulare, die alle Informationen der Ordensschwestern enthalten, eine Sparte zu den »langues«-Kenntnissen auf ${ }^{184}$, aber diese ist in den meisten Fällen nicht ausgefüllt, was entweder daraufhin deutet, dass die Schwestern keine anderen Sprachen beherrschten oder diese Frage

176 LAZ/Paris, »Tripoli Correspondance 1892-1913«, Brief von Thomas, »en mission«, 08.03. 1909.

177 Ebd.

178 Bocquet 2008, S. 63.

179 Bezüglich der Frères des Écoles chrétiennes liegen keine Dokumente über die Arabischkenntnisse der Ordensbrüder vor. Allerdings berichtete ein Ordensbruder, Frère Michel, der in den 1940er Jahren nach Beirut gekommen war, in einem Interview in Beirut am 08.12.2007, dass er die arabische Sprache nicht beherrschte (und beherrscht).

180 Vgl. LAZ/Paris, »Beyrouth Correspondance 1896-1918«, Brief von Romon, Beirut, 01.12.1908.

181 AN/Paris, aj 16/4734. Dieses Noviziat befand sich in St. Maurice im Département Isère.

182 Vgl. Interview der Verfasserin mit Frère Michel, Beirut, 08.12.2007.

183 Vgl. LAZ/Paris, »Beyrouth Correspondance 1896-1918«, Brief von Romon, Beirut, 29.09.1907. Er beschreibt den Arabischlehrer der Schwestern als »un bon prêtre du district de Batroun«. Romon weiter : »Nos sœurs payent le professeur et je lui donne le logement et la table, car il n'a pas pied à terre en ville. Tout d'abord, nous ne l'admettions pas à nos récréations, mais depuis qu'on m'a envoyé des Confrères pour apprendre l'arabe, ils ont eux-mêmes manifesté le désir de l'y admettre pour se former avec lui à la prononciation«.

184 Diese Sparte enthält zum Beispiel das Formular der Frères des Écoles chrétiennes nicht. 
nicht so wichtig erschien ${ }^{185}$. Rose Ferali, eine ehemalige Schülerin der Sours de Saint-Joseph de Lyon, die eine kleine Schule in Deir el-Harf in den libanesischen Bergen unterhielten, erklärte, dass die französischen Schwestern für das Gespräch mit nicht frankophonen Eltern ihrer Schülerinnen auf Dolmetscher zurückgriffen ${ }^{186}$.

Die Situation in den Schulen der Alliance israélite kann insofern nicht genau rekonstruiert werden, als hier genaue Informationen fehlen. Da ihre Lehrer aus den Ländern des Mittelmeerraums kamen, in denen die Organisation Schulen unterhielt, ist zu vermuten, dass diese Akteure vertrauter mit der Sprache und Kultur des Libanons waren als die Lehrer der anderen französischen Schulen. Allerdings berichteten die Direktoren immer gesondert von den Arabischlehrern, die sie rekrutierten ${ }^{187}$. In den Dokumenten der protestantischen Schule hingegen wird zwar der Respekt vor der arabischen Sprache und Kultur der Schüler betont, es fehlen jedoch Hinweise auf die Fähigkeit der Lehrer, diese beherrschen zu müssen. Der protestantische französische Lehrer Phillipe Bianquis, der zwar an der amerikanischen Universität unterrichtete, aber in den Gremien der Institutionen saß, die das Collège protestant français verwalteten, erwähnte 1926 seinen Privat-Arabischlehrer ${ }^{188}$.

So muss insgesamt davon ausgegangen werden, dass, abgesehen von einigen Schulen der katholischen Orden, relativ wenig französische Lehrer und Lehrerinnen die arabische Sprache beherrschten. Da viele von ihnen in der colonie française lebten und außerhalb des Schulalltags, in dem ausschließlich Französisch gesprochen wurde, auch hauptsächlich mit Franzosen Umgang pflegten ${ }^{189}$, hinderte sie die sprachliche Unkenntnis zwar nicht am Überleben im Libanon, aber schränkte ihre Kommunikationspartner und -felder auf frankophone Sprecher ein.

Wichtig in diesem Zusammenhang ist die Frage, inwiefern die arabischen Lehrer und Angestellten der französischen Schulen die französische Sprache beherrschten. Da die meisten von ihnen laut den Dokumenten Französisch sprachen, gab es innerhalb der Schulen geringe Kommunikationsbarrieren zwischen den verschiedenen Akteuren. Aber es gibt in den Dokumenten der Mission lä̈que auch den Hinweis auf wenige nicht französisch sprechende

185 Vgl. in FDC die Formulare für die unterschiedlichen Häuser in Beirut, Beurges, Tripoli, Broumana, Zghorta.

186 Vgl. Interview der Verfasserin mit Rose Ferali, Beirut, 05.12.2007.

187 Vgl. AIU/Paris, »Liban VIE 80-81«: »M. Barzilai, Professeur d'arabe, enseigne en même temps un peu d'hébreu et de français. C'est un ancien élève de l'école de Beyrouth. Parle peu le français«.

188 So schrieb er in einem Brief an seine Eltern: »Je termine pour aujourd'hui, car mon professeur d'arabe vient d'arriver«. PPFL, Brief von Phillipe Bianquis an seine Eltern, Beirut, 11.02.1926.

189 Viele Lehrer wohnten zum Beispiel im Schulgebäude. Vgl. Interview der Verfasserin mit Claudine Arnac, Paris, 27.03.2009. 
Lehrer. So kommentierte der Direktor der Mission laïque in Beirut 1925 ein Anliegen der Lehrerin für Arabisch, Englisch und Grammatik, Marie Noomie: $»[I] 1$ est regrettable que Mlle Noomie ne parle pas du tout français $«{ }^{190}$. Auch die Schule der Alliance israélite in Saida hatte Lehrer, die wenig Französisch sprachen: »M. Barzilai [...] parle peu le français « ${ }^{191}$. Diese Aussagen zeigen also die relativ uneingeschränkte Kommunikation zwischen den Angehörigen der verschiedenen Kulturen innerhalb der französischen Schulen. Andererseits wurde auch der Unterschied zwischen der dominierten und der dominanten Kultur betont, weil die Libanesen Französisch sprechen, aber die Franzosen nicht die arabische Sprache beherrschen mussten.

Schließlich ist die Analyse der Motive und Perspektiven der Lehrer für ihr Engagement im Libanon pertinent, um die Frage ihrer Unterstützung der Zivilisierungsmission weiter zu klären. Ihre Motive sind sehr schwer zu eruieren, weil nur wenige Dokumente sie explizit benennen und weil die Ausgangssituationen der Lehrer sehr heterogen waren. Gerade die zwei Weltkriege, die im Untersuchungszeitraum liegen, haben außerdem zu Brüchen in den Lebensläufen beigetragen. Deshalb wird im Folgenden die Analyse nicht nach Institutionen geordnet, sondern nach den Faktoren, von denen die Motive der Akteure abhängig gewesen sein konnten: erstens die Frage der Freiwilligkeit ihres Dienstes, zweitens die Dauer ihres Aufenthaltes, drittens ihre intimen Bindungen an das Land und viertens pragmatische beziehungsweise persönliche Gründe.

Was die Frage der Freiwilligkeit betrifft, kann zwischen den Lehrern der katholischen Schulen und der Alliance israélite auf der einen Seite und den Lehrern der Mission lä̈que und der protestantischen Schule auf der anderen Seite unterschieden werden. Die Akteure der ersten Gruppe wurden in der Regel von ihren Organisationen in ein bestimmtes Land geschickt, und aufgrund ihrer Zugehörigkeit zu dieser Institution (die Ordensleute wegen ihres Gelübdes, die Lehrer der Alliance israélite, weil sie von dieser auf deren Kosten ausgebildet worden waren) mussten sie dieser Anordnung Folge leisten ${ }^{192}$. Die Lehrer der Mission lä̈que und der Euvres protestantes hingegen hatten

190 AN/Paris, 60 AJ 128, Brief von Marie Noomie an den Direktor, Beirut, 21.10.1925, Kommentar Ruches am Rand des Briefes. Vor allem viele der zahlreichen Hausangestellten (in der Küche, für die Reinigung etc.) der MLF scheinen nicht Französisch gesprochen zu haben, denn auf ihren Gehaltszetteln unterschrieben sie auf Arabisch. Nur sehr wenige Lehrer scheinen nicht Französisch gesprochen zu haben.

191 AIU/Paris, »Liban VIE 80-81«, »Inspection Pariente 1905 sur les écoles de Jaffa-CaiffaSaida-Tibériade-Beyrouth«, »Rapport sur l'École mixte de l'Alliance Israélite Universelle à Saida«.

192 Vgl. für die Alliance israélite AIU/Paris, »Liban VIE 80-81«, Brief von Penso an den Präsidenten der Alliance israélite in Paris, Beirut, 09.11.1919: »Mlle Chemtob de Damas. Cette institutrice se trouve actuellement au Caire. Je lui écris par le même courrier pour lui annoncer sa nomination à Beyrouth et pour la prier de rentrer le plus tôt possible pour prendre possession de son nouveau poste $\ll$. 
ihre Ausbildung in der Regel schon beendet und traten aus eigenen Stücken an die Organisationen heran und baten um Einstellung ${ }^{193}$. Allerdings wurde diesen Bitten nicht immer entsprochen: So wünschten erstaunlich viele Lehrer der Mission lä̈que, nach Ägypten zu kommen, wurden aber nach Beirut beordert ${ }^{194}$.

Sowohl freiwillig als auch unfreiwillig im Libanon waren die détachés militaires, die Wehrdienstverpflichteten, die statt als Soldat als Lehrer ihren Wehrdienst absolvierten und die um Anstellung im Nahen Osten gebeten hatten ${ }^{195}$. Die Zahl dieser >Zivildienstleistenden< war in allen Schulen, bis auf die der Alliance israélite, sehr hoch und lag bei circa zehn Personen pro Schuljahr. Alle Schulen bemühten sich um viele détachés militaires, weil diese sehr kostengünstig waren ${ }^{196}$. Interessant ist, dass einige dieser détachés sich nach Ablauf ihrer Wehrpflichtzeit (in der Regel zwei Jahre) entschieden, noch länger an der französischen Schule im Libanon, der sie zugeteilt worden waren, zu bleiben ${ }^{197}$.

Was die Dauer des Aufenthalts der Akteure im Libanon angeht, kann keine allgemeingültige Aussage getroffen werden. Tendenziell blieben die Mitglieder der katholischen Orden sehr lange in der Levante, während die Lehrer der Alliance israélite oft wechselten und die der Mission lä̈que ganz unterschiedlich lange blieben.

193 Vgl. für die protestantische Schule die Kandidatur von einer »Mlle Bauer« 1935. Vgl. PPFL, »Dossier Mlle Bauer (professeur au CPF)«. Für die Mission laïque siehe die zahlreichen Bewerbungen an den Generalsekretär. Vgl. MLF, »dossiers de personnel«.

194 Vgl. z. B. die Biographie von Marie Justine Digrado in: MLF/Paris, »Marie Justine Digrado (numéro de dossier G 4200 A/ 015-4)«. Damit unterschied sich die Situation Anfang des 20. Jahrhunderts von der Zeit nach dem Zweiten Weltkrieg, als Beirut ein beliebtes Ziel von Lehrern war, die ins Ausland gehen wollten.

195 Vgl. AN/Paris, 60 AJ 131, Brief des französischen Kriegsministers an den französischen Außenminister, Paris, 08.07.1930. Vor allem die katholischen Orden versuchten auf diese Weise, ihre eingezogenen Ordensbrüder wieder zum Orden zu holen. Vgl. MAE/Nantes, IP, 162: 1940, »Militaires détachés«.

196 Zwischen den verschiedenen Schulen herrschte eine große Konkurrenz um die Anzahl der »détachés militaires«. Vgl. AN/ Paris, 60 AJ 132, Brief des Direktors an Besnard, Beirut, 16.03.1930: »Par contre les Révérends Pères Jésuites ont pour le seul collège de Beyrouth (appelé Université Saint Joseph) 18 professeurs militaires détachés et les frères pour leur seul collège ont 6. Il paraît ainsi que l'Université St. Joseph de Beyrouth ainsi que les Jésuites de Homs, Alep et Bicfaya peuvent avoir des professeurs à très bon marché - et qu'il est bien dommage que ne nous puissions trouver une combinaison qui nous permette pareilles économies«.

197 Vgl. zum Beispiel Fernand Fichard, der 1937-38 seinen `Zivildienst in Beirut absolvierte und danach bis 1951 (ausgenommen seiner Zeit als Soldat während des Zweiten Weltkrieges) als Lehrer der Mission laïque in Beirut tätig blieb. Vgl. MLF/Paris, »Liste du personnel«. Für die Jesuiten siehe zum Beispiel SJ/Vanves, »Fonds Jalabert«, 7-1/B, Brief von Sautier an Jalabert, Beirut, 14.09.1937. 
Für die Mission lä̈que ist festzustellen, dass deren französische Lehrer während der Mandatszeit deutlich länger im Libanon blieben als zur Zeit des Osmanischen Reiches ${ }^{198}$. Dies mag der Tatsache geschuldet sein, dass mehr Ehepartner der Akteure im Libanon eine langfristige Anstellung fanden, kann aber auch damit zusammenhängen, dass die Schule der Mission laïque in der Mandatszeit schon etablierter war als in den Anfangsjahren und den Lehrern deshalb eine größere Stabilität bieten konnte. Neben Lehrkräften, die einige Jahre in Beirut blieben und dann nach Frankreich zurückkehrten, gab es eine Gruppe von Lehrern, die ein paar Jahre in Beirut verbrachten und von hier in andere Länder gingen, um dort entweder an einer Schule der Mission lä̈que oder in einem anderen Rahmen zu arbeiten ${ }^{199}$. Eine dritte Gruppe schließlich blieb sehr lange in Beirut, in einigen Fällen bis zu zwanzig Jahren, und etliche von ihnen beantragten eine Verlängerung ihres Vertrages ${ }^{200}$.

Damit glichen diese Akteure den Lehrern der katholischen Schulen, die zwar durchaus innerhalb ihrer Provinz wechselten, aber oft auch sehr lange im Libanon blieben. So zitierte die französische Autorin Miriam Harry, die Ende der 1920er Jahre eine Reise durch den Libanon machte, die Verbundenheit des französischen Direktors der Schule der Lazaristen in Ayntoura mit dem Libanon folgendermaßen: »Et pourtant, il n'y en a pas un de nous qui voudrait partir. Moi le premier, j'ai fait un beau bail avec ce pays, devenu ma seconde patrie ${ }^{201}$. Die Mitglieder der katholischen Frauenorden blieben in der Regel besonders lange im Libanon. So zeigt eine Auflistung der Schwestern des Ordens Filles de la Charité, dass die französischen Schwestern meistens im Libanon verstorben sind beziehungsweise innerhalb der Region versetzt wurden und dann dort starben ${ }^{202}$. Am mobilsten waren die Lehrer der Alliance israélite, die oft nach ein paar Jahren ihre Wirkungsstätte wechselten.

Die Frage der emotionalen Verbindung zum Libanon in Form von Eheschließungen oder Freundschaften soll als weiteres Argument für die Motive der Lehrer geprüft werden. Für alle Ordensmitglieder galt selbstverständlich der Zölibat. Doch auch in den anderen Schulen führte der Aufenthalt im Libanon selten zu Ehen mit Libanesen oder Libanesinnen. So gab es in den Schulen der Mission lä̈que, der Alliance israélite und der Euvres protestantes viele ledige Lehrer. Aus dem Umfeld der Alliance israélite und der Mission lä̈que sind sogar Diskussionen darüber überliefert, ob es für ihre

198 Vgl. die Zahlen in MLF/Paris, »Liste du personnel «.

199 Die häufigsten Ziele waren Thessaloniki, Kairo, Aleppo und Damaskus.

200 Vgl. die Zahlen in MLF/Paris, »Liste du personnel «.

201 Myriam Harry, Terre d'Adonis. Au pays des Maronites et des Druses, Paris 1930, S. 194.

202 Vgl. FDC, Listen der Ordensangehörigen. 
Arbeit besser sei, dass die Lehrer ledig oder verheiratet seien ${ }^{203}$. Bei der Alliance israélite gab es sehr viele Eheschließungen innerhalb der eigenen community. Zum Beispiel wurde die Jungenschule der Alliance israélite in einer Stadt oft von dem Ehemann, die Mädchenschule von der Ehefrau geleitet ${ }^{204}$. Das Collège protestant français rekrutierte in Frankreich in der Anfangszeit fast nur ledige Lehrerinnen, während die verheirateten Lehrerinnen vor Ort eingestellt wurden ${ }^{205}$.

Erstaunlicherweise sind von den hundert Lehrern, die das Register der Mission laïque für Beirut zählt, nur drei Lehrer vermerkt, die einen Ehepartner aus der Levante hatten: Diane Potier-Boès heiratete, allerdings erst wohl während ihrer Zeit an der Schule der Mission laïque in Kairo, einen Ägypter; Elias Muard ehelichte eine Syrerin, und die Ehefrau des Verwalters Jean Lehéricy stammte aus Konstantinopel ${ }^{206}$. Allerdings waren manche Lehrer mit Partnern aus anderen Kontinenten verheiratet. Deschamps' Ehefrau stammte aus Madagaskar, wo er zu Beginn seiner Karriere tätig gewesen war $^{207}$. Direktor Ruche hatte in seiner Zeit in Tunesien seine Ehefrau kennengelernt, welche in Tunesien geboren, aber französischen Ursprungs war $^{208}$. Mit den wenigen Eheschließungen mit Libanesen oder Libanesinnen unterschieden sich die Lehrkräfte der französischen Schulen folglich von vielen ihrer Landsleute im Libanon, die, im Gegensatz zu der Situation in Nordafrika, oft eine gemischte Ehe eingingen ${ }^{209}$.

$203 \mathrm{Zu}$ Beginn des Mandats sprach sich Deschamps eindeutig gegen ledige Lehrerinnen aus, wegen der Gefahr der »Versuchung« durch die Soldaten; vgl. AN/Paris, 60 AJ 122, Brief von Deschamps an Besnard, Guincamp, 18.07.1919: »Plus qu'autrefois, il ne nous faut pas de professeurs femmes célibataires; la présence de l'armée achèvera la démoralisation [de] la société syrienne«. Allerdings, so Deschamps ein Jahr später, sollten die Ehemänner am besten auch Lehrer sein, um mit ihren Frauen versetzt werden zu können; vgl. AN/Paris, 60 AJ 119, Brief von Deschamps an den Präsidenten der Mission laïque, Beirut, 06.01.1920: »Je crois bon de vous signaler l'inconvénient qu'il y a à envoyer à Beyrouth des institutrices dont le mari n'est pas instituteur; dans le cas où l'œuvre de la Mission se développerait, certaines mutations peuvent devenir nécessaires [...]; il convient donc de ne pas avoir dans notre personnel d'agents qui ne puissent être déplacés si les besoins de l'œuvre l'exigent«.

204 Siehe das Ehepaar Penso, das nach Aleppo versetzt wurde und davon ausging, diese Praxis würde beibehalten: »Ce télégramme ne fait aucune allusion à la situation qu'aura ma future femme Mademoiselle Esther Pitchon. Je pense qu'il est entendu qu'elle sera chargée de la direction de l'école des filles d'Alep«. AIU/Paris, »Liban VIE 80-81«, Brief von Penso an den Präsidenten der Alliance israélite in Paris, Beirut, 22.12.1919.

205 Vgl. PPFL, »Dossiers de professeurs «.

206 Diane Potier-Boès war von 1936 bis 1938 Lehrerin der MLF in Beirut, bevor sie an die Schule der MLF in Kairo wechselte. Vgl. MLF/Paris, »Liste du personnel«.

207 Vgl. André Thévenin, Pierre Deschamps. Premier missionnaire laïque, Paris 2002, S. 75.

208 Vgl. AN/Paris, F 17/25346: Ruche, Lucien Charles, »Inspection générale 1920/1921, Tunis«. Da Ruches Ehefrau mit Mädchennamen Susanne Brulé hieß, ist zu vermuten, dass sie einer der französischen Kolonistenfamilien in Tunesien entstammte.

209 Vgl. Pierre Fournié/Jean-Louis Riccioli, La France et le Proche-Orient 1916-1946. Une chronique photographique de la présence française en Syrie et au Liban, en Palestine, au Hedjaz et en Cilicie, Paris 1996, S. 268. 
Viel eher als eine enge Verbindung der Lehrer zum Libanon waren pragmatische und persönliche Gründe ausschlaggebend für ihr Engagement in der Levante. Dazu gehörten erstens die Karrierechancen, zweitens die Vergütung im Ausland und drittens die Abenteuerlust. Die Sorge um die Karriere betraf vor allem die Lehrer der Mission lä̈que und der CEuvres protestantes. Diese bemühten sich sehr darum, den Anschluss an das französische Bildungssystem nicht zu verpassen und kümmerten sich auch im Libanon um ihre Rente in Frankreich. Keiner der Lehrer erlitt durch den Aufenthalt im Ausland Einbußen. Die in Frankreich rekrutierten Lehrer wurden vom Erziehungsministerium freigestellt ${ }^{210}$, ihre Arbeit im Libanon wie eine Tätigkeit in Frankreich angerechnet, und sie wurden auch während sie im Libanon weilten in den französischen Besoldungsklassen höher gestuft. Um den Lehrern jede diesbezügliche Sorge zu nehmen, betonte der Verwaltungsrat der Eeuvres protestantes 1926, dass die Leitung der protestantischen französischen Schule in Beirut keinen Karriereeinbruch in Frankreich bedeuten dürfe:

[...] il faudrait qu'il soit bien entendu avec le Ministre de l'Instruction Publique que ce séjour de quelques années en Syrie ne nuira pas à l'avancement de l'universitaire qui acceptera la direction de l'institut de Beyrouth ${ }^{211}$.

Für manche Lehrer konnte die Arbeit im Libanon sogar insofern einen Karrieresprung bedeuten, als ihnen der Beamtenstatus, welchen sie in Frankreich trotz der erforderlichen Diplome nicht bekommen hatten, nun zuteilwurde $^{212}$. Andere wenige Lehrer erhielten nun die feste Anstellung, die sie in Frankreich nicht vorweisen konnten. Dabei waren ihnen oft Beziehungen zu Verantwortlichen der Mission lä̈que in Frankreich zu Hilfe gekommen ${ }^{213}$. Damit konnten diese Akteure ihren sozialen Status verbessern, gehörten sie doch gewisser Weise zu den »white subalterns«, die in Europa aus den unteren sozialen Schichten kamen ${ }^{214}$. Anders als das in anderen kolonialen Kontexten oft der Fall war, konnten diese Akteure also im Libanon ihren sozialen Status eindeutig verbessern.

210 Vgl. z. B. MAE/Nantes, SOFE 375, Brief des Außenministeriums an das Erziehungsministerium, Paris, 02.11.1939.

211 PPFL, »Compte-rendu du Conseil d'Administration du 31.05.1927«.

212 So wurde Georges Meyzaud, der vor seiner Anstellung bei der Mission laïque 1935-1936 an verschiedenen Schulen im Ausland tätig gewesen war, 1939 in das französische Beamtentum aufgenommen Vgl. MLF, »Liste du personnel«.

213 Beispielsweise wurde der Lehrer Delhomme, der von 1909 bis 1914 bei der Mission laïque in Beirut arbeitete, bei der Vertragsunterzeichnung von seinem Bruder begleitet, der für ihn bürgte. Vgl. MLF, »Dossiers de personnel«, Delhomme (G 4200 A/ 014.6).

214 Vgl. Fischer-Tiné 2009, S. 4. Wie Fischer-Tiné deutlich macht, war diese Gruppe der »Low Europeans«, wie sie zeitgenössisch genannt wurden, viel größer als bisher von der Forschung wahrgenommen. 
Eine letzte kleine Gruppe umfasste die Akteure, die, wie Elias Muard bei der Mission läque, zwischen den »Welten lebten«, d.h. in Frankreich geboren worden waren und schon eine lange Zeit im Orient verbracht hatten. Die Biographie dieses Lehrers spiegelt die nur schwer zu fassende Identität der »Hommes de l'entre-deux« wider, die, wie Bernard Heyberger und Chantal Verdeil treffend schildern, deutlich machen, dass die Unterscheidung zwischen >Orient $<$ und >Okzident in der historischen Realität oft nicht einfach festzumachen ist ${ }^{215}$. Ähnliches gilt für die Lehrer der Alliance israélite universelle. Für die die Mehrheit der Lehrer bedeutete die Arbeit im Libanon aber wohl nur einen Ortswechsel, während auf eine Minderheit auch das Sprichwort Disraelis vom »Osten als Karriere« zutraf ${ }^{216}$.

Ein zweiter pragmatischer Grund, der manche Lehrer motivierte, in den Libanon zu gehen, war die Zusatzprämie, die die Arbeit im Ausland für ihr Gehalt bedeutete ${ }^{217}$. Da das Leben in Beirut aber, verglichen mit anderen Städten im Nahen Osten, teuer war ${ }^{218}$, konnten sich die Lehrer im Libanon zwar nicht wirklich finanziell bereichern, aber dennoch ein angenehmes Leben führen. Das gilt allerdings nicht für die Lehrer der Alliance israélite, die anscheinend sehr wenig Geld zur Verfügung hatten ${ }^{219}$. Bezüglich der katholischen Orden waren Gründe dieser Art ebenfalls nicht relevant, da keine Hinweise dafür vorliegen, dass der Aufenthalt im Libanon Voraussetung für eine etwaige Karriere innerhalb des Ordens gewesen ist.

Ein dritter Grund für das Engagement im Libanon lag in der Abenteuerlust der Lehrer. Ihr Motiv war häufig nicht die Zivilisierungsmission, sondern ihr Interesse an fremden Ländern und am Reisen ${ }^{220}$. Viele Lehrer waren in der Tat sehr jung, da sie mit Anfang zwanzig ihren Dienst im Libanon antraten. Deshalb spielte auch das Bedürfnis, sich von der Großfamilie zu emanzipieren und eine eigene Identität aufzubauen, eine wichtige Rolle, wie die Memoiren von Roger Lefèvre veranschaulichen: »[N]ous allons [...] commencer une vie nouvelle, totalement indépendante! Notre vie de famille à nous et sans les autres! ২Enfin seuls $<[\ldots] \ll^{221}$.

215 Vgl. Heyberger/Verdeil 2009, S. 11.

216 Benjamin Disraeli: »The East is a career«, zitiert in Edward SAID, Orientalism, New York 1979, S. XIII.

217 Vgl. AN/Paris, 60 AJ 122, »Questions urgentes posées par Deschamps« (Dossier 1919-1920).

218 So Deschamps 1909: »La vie est plus chère que nous ne pensions«. AN/Paris, 60 AJ 118, Brief von Deschamps an Besnard, Beirut, 10.06.1909. 16 Jahre später betonte Ruche den preislichen Unterschied zwischen Beirut und Ägypten: »Inutile de faire la comparaison avec l'Égypte«. AN/ Paris, 60 AJ 129, Brief von Ruche an Besnard, Beirut, 02.02.1927.

219 Vgl. AIU/Paris, »Liban VIE 81a«, Brief von Penso an Jacques Nehama in Thessaloniki, Beirut, 03.05.1916.

220 Vgl. Interview der Verfasserin mit Claudine Arnac, Paris, 27.03.2009.

221 LefÈVRe 2005, S. 113. 
Auch wenn die Zivilisierungsmission nicht das primäre Motiv der Akteure war, wird anhand der Archivmaterialien deutlich, dass sie deren ideologisches Fundament meistens teilten. Sowohl die Direktoren der Schulen der Mission laïque als auch der Alliance israélite beschwerten sich kontinuierlich über das »orientalische Verhalten« der Libanesen, das diese zu übertriebener Selbstdarstellung, Unzuverlässigkeit und mangelnder Strebsamkeit verleite $^{222}$. In diesen Diskursen über den »Caractère oriental« ist der Orientalismus zu erkennen, den Edward Said in der Literatur französischer und britischer Schriftsteller, aber auch in der Politik dieser Länder beschrieben hat. Dabei gingen diese Essentialisierungen auch bei den Lehrern mit Macht- und Überlegenheitsansprüchen des Westens über den Orient Hand in Hand ${ }^{223}$. Insofern ist das Verständnis von der Ideologie eines Superioritätsanspruches des Westens zwischen den Institutionen und ihren Akteuren dasselbe. In manchen Fällen kam es sogar zur Entwicklung extremerer Positionen vor Ort, die von der Zentrale in Frankreich eingedämmt werden mussten $^{224}$. Diese Aussagen machen deutlich, dass ein Aufenthalt im Libanon nicht automatisch eine Position der Überlegenheit der französischen Akteure gegenüber der libanesischen Kultur relativierte oder nivellierte.

Die Zivilisierungsmission bildete zwar das Fundament, aber nicht das primäre Motiv der Lehrer, an eine der französischen Schulen im Libanon zu gehen. Die Untersuchung hat außerdem deutlich gemacht, dass die Biographien der Lehrer der verschiedenen Institutionen, aber auch innerhalb der einzelnen Institutionen, sehr heterogen waren und es deshalb sehr schwierig ist, eine Typologie des französischen Lehrers im Libanon zu erstellen. Damit entspricht die Heterogenität des Lehrkörpers aber dem Projekt der mission civilisatrice allgemein, das nur auf den ersten Blick kongruent und homogen erscheint. Für die Heranziehung der Akteure als Analysekategorie spricht deshalb, dass dadurch das Bild von der Zivilisierungsmission der französischen Schulen im Libanon als ein kohärentes Gebilde korrigiert und so differenzierter betrachtet werden kann. Ferner zeigen die Ausführungen, dass die Idee der mission civilisatrice im Frankreich der Dritten Republik von

222 Auch diese Einschätzungen ziehen sich durch den gesamten Untersuchungszeitraum. So urteilte Deschamps 1909: „C'est la part du caractère oriental: il faut paraître«. AN/Paris, 60 AJ 118, Brief von Deschamps an Besnard, Beirut, 10.06.1909; ähnlich äußerte sich Direktor Mathieu 1924: »[...] un des travers du caractère oriental, le goût exagéré des discours, qui sont pris trop facilement pour les actes«. AN/Paris, 60 AJ 127, Brief von Mathieu an Besnard, Beirut, 31.10.1924; 1923 betonte Mathieu die Abneigung des »Orientalen« gegenüber dem Internat: »L'oriental répugne à l'internat français; d'autre part, les parents n'aiment pas que leurs enfants sortent trop souvent seuls«, und knüpfte damit wieder an den Diskurs über den Orient als Gegenteil des Rationalen und Geordneten an. AN/Paris, 60 AJ 129, »Rapports mensuels«, Oktober 1923.

223 Allerdings sollte betont werden, dass die französischen Akteure auch mit dem Widerstand der libanesischen Akteure umzugehen hatten, der in den nächsten Kapiteln behandelt wird.

224 Vgl. Kapitel 3.4. 
der Regierung als staatspolitische Leitlinie vorangetrieben, aber auch auf der Ebene der Zivilgesellschaft aktiv rezipiert wurde. Damit wird die Definition der Zivilisierungsmission als Eliteprodukt nicht aufgehoben, aber etwas relativiert, weil auch Lehrer, die nicht zur sozialen Elite gehörten, sich ihrer annahmen. Schließlich macht dieser Analysezugang deutlich, dass, mit wenigen Ausnahmen, der Abstand zwischen den französischen Lehrern und der libanesischen Kultur, auf die sie trafen, auch mit den unterschiedlichen Variablen (Zeit, familiäre Bindung, Motivation des Aufenthalts) bestehen blieb.

Das Kapitel hat somit deutlich machen können, dass die Idee der Zivilisierungsmission, die die französischen Schulen im Libanon antrieb, ihre Wurzeln in der französischen Gesellschaft hatte. Darüber hinaus wurde auch ersichtlich, dass die Schulen und ihre Lehrer sehr unterschiedliche Vorstellungen von Zivilisation und Zivilisierungsmission hatten. Diese Spannweite der Möglichkeiten machte den Bezug auf diese Ideen für die französischen Schulen so attraktiv. 



\section{Une ou Deux France? Die französische Schullandschaft im Libanon 1909}

Im ersten Kapitel wurden die Ausgangsvoraussetzungen der Schulen, die in der zentralen Bedeutung der mission civilisatrice für die französische Gesellschaft lagen, herausgestellt. Nun folgt die Studie dem Weg der hier untersuchten Akteure und richtet den Blick auf die Arbeit der Organisationen im Libanon am Ende des Osmanischen Reiches. Dabei lautet die zentrale Frage dieses Kapitels, inwiefern es um 1909 zu einer Neuausrichtung der Schullandschaft im Libanon kam. Die antiklerikalen Schulgesetze in Frankreich und die Jungtürkenrevolution im Osmanischen Reich begünstigten die Ankunft der Mission laïque française in Beirut, die ein ganz neues Modell französischer Bildung anbot. Wie integrierte sich diese Organisation als Teil der expandierenden und von Konkurrenz geprägten Erziehungseinrichtungen in der Stadt, und wie reagierten die bestehenden Schulen auf den Neuankömmling? Vereinigten sich die antiklerikalen und klerikalen französischen Kräfte nun zu »Une France en Méditerannée « ${ }^{1}$ oder bestanden »Les Deux France $\ll^{2}$ auch im Libanon weiter? Das Kapitel macht anhand der Etablierung der laizistischen Organisation deutlich, dass es zum einen zu einer Neuausrichtung der französischen Schullandschaft im Libanon kam, dass diese aber auch von Kontinuitäten und Gemeinsamkeiten der ideologisch so unterschiedlichen französischen Bildungseinrichtungen geprägt war. Die konkreten Bedingungen und Faktoren für die Niederlassung der Schulen in der Region sollen erstens anhand des diskursiven Rückgriffs auf die Tradition der französischen Präsenz in der Region, zweitens durch die Unterstützung der Schulen auf Regierungsebene, drittens mithilfe der Offenheit in der libanesischen Gesellschaft und viertens anhand der Abgrenzungsprozesse zu bestehenden Schulen im Libanon untersucht werden.

Mit der Betonung dieser Rahmenbedingungen stützt sich die Analyse auf die Herangehensweise der Transferforschung, welche besonders die Voraussetzungen des Transferprozesses innerhalb der »aufnehmenden" Gesellschaft betont. In der Tat war nicht nur, wie manche Autoren darstel-

1 Vgl. Patrick Cabanel (Hg.), Une France en Méditerranée. Écoles, langue et culture françaises, $\mathrm{XIX}^{\mathrm{e}}-\mathrm{XX}^{\mathrm{e}}$ siècles, Paris 2006.

2 Dieser ursprünglich von Jules Michelet verwendete Begriff für die Beschreibung der französischen Gesellschaft im 19. Jahrhundert zwischen den konkurrierenden Einflüssen von Katholischer Kirche und Französischer Revolution wurde auch für die Frage der französischen auswärtigen Kulturpolitik prägend. Vgl. DAUGHTON 2006. 
$\operatorname{len}^{3}$, die steigende politische, wirtschaftliche und kulturelle Vormachtstellung Frankreichs im Osmanischen Reich verantwortlich für die Niederlassung französischer Schulen. Im Sinne der neuesten Studien zu Bildung in imperialen Kontexten betont diese Arbeit darüber hinaus die vorhandene Offenheit innerhalb der osmanischen Gesellschaft gegenüber diesen Schulen, die allerdings auch, zum Teil heftige, Kritik einschloss, als notwendige Voraussetzung für die Arbeit der Schulen. Diese Offenheit betraf sowohl Regierungskreise, die sich von französischen Ideen und Bildungseinrichtungen inspirieren ließen, als auch die Zivilgesellschaft. Unter Einbeziehung der oben erläuterten Kritik am Konzept des Transfers sollen deshalb die multiplen Dynamiken aufgezeigt werden, die sowohl französische als auch libanesische Akteure in ihrer Auseinandersetzung mit eigener und fremder Kultur bewegten.

\section{Rückbezug auf die französische Tradition im Libanon}

Im Folgenden wird der diskursive Rückgriff der Schulen auf die Tradition französischer Präsenz im Libanon als zentraler Faktor für ihre dortige Niederlassung analysiert. Auf diese Weise konnten die Bildungseinrichtungen zum einen ihre eigene Existenz und Aktivität legitimieren und zum anderen ihr Handeln vor den politischen Instanzen rechtfertigen. Außerdem wird deutlich, dass trotz der Betonung ihrer Unterschiedlichkeit die verschiedenen französischen Schulen dieser gemeinsame diskursive Bezug verband. So bediente sich die Mission laïque trotz ihrer Kritik an der starken Präsenz der katholischen Schulen in der Levante genau derselben Argumentation. Auch die jüdischen und protestantischen Institutionen formulierten den Diskurs der französischen Tradition im Libanon. Wie die im ersten Kapitel analysierte mission civilisatrice fungierte das Argument als ein »leerer Signifikant«, den alle Schulen für sich beanspruchten. Indem sie den Diskurs der französischen Tradition in der Levante aufnahmen, erhoben sie seinen Wahrheitsanspruch und banden ihn an konkrete politische Machtverhältnisse an: Die Schulen versuchten zum einen, ihre Position als die »wahre französische Position « zu präsentieren und konstruierten gleichzeitig ihre Zugehörigkeit zu dem Gesamtprojekt französische Zivilisierungsmission. Damit betonten sie ihre Bindung an die französischen, aber, oft unbewusst, auch an die osmanischen Machtverhältnisse, von denen dieses Projekt abhängig war. Den sich ändernden Machtverhältnissen mussten die Schulen ihren Diskurs anpassen, da sich, um mit Michel Foucault zu sprechen, die Dispositi-

3 Vgl. z.B. Jacques Thobie, Les intérêts culturels français dans l'empire ottoman finissant. L'enseignement laïque et en partenariat, Paris 2008, S. 43. 
onen des Wissens änderten ${ }^{4}$. Das meint nicht einfach eine Veränderung des erkennenden Subjekts (die Franzosen) und des zu erkennenden Objektes (die Frage der französischen Tradition im Libanon), sondern der »jeweiligen Erfahrungsstruktur ${ }^{5}$, die Subjekt und Objekt umgreift. Im vorliegenden Fall bedeutet das, dass sich die äußeren politischen Rahmenbedingungen (jungtürkische Revolution, steigende Abhängigkeit des Osmanischen Reiches von Frankreich) wandelten und damit eine neue Positionierung der französischen Akteure vor Ort und in Frankreich sowie eine Legitimierung ihres Handelns gegenüber den unterschiedlichen französischen und osmanischen Instanzen erforderlich machten.

Während die Vertreter der Mission laïque sich ebenso wie die anderen Institutionen auf den jahrhundertealten Einfluss Frankreichs im Orient beriefen, stellten sie gleichzeitig die Position der katholischen französischen Orden im Nahen Osten in Frage. Sie versuchten einerseits, deren Bedeutung herunterzuspielen, indem sie nicht die katholischen Orden, sondern die Politik der französischen Regierungen und die französischen Wissenschaftseinrichtungen allgemein an die erste Stelle der Faktoren setzten, die für Frankreichs Einfluss im Orient verantwortlich seien:

La France jouit depuis des siècles en Orient d'une situation privilégiée. [...] Tout en rendant hommage aux écoles congrégationistes pour la diffusion de notre langue, il $\mathrm{y}$ aurait donc injustice à ne vouloir considérer que ce facteur dans l'établissement de notre influence ${ }^{6}$.

Andererseits mussten sie auch anerkennen, dass diese Symbiose zwischen »katholisch« und »französisch« im Nahen Osten sehr wirkmächtig war:

Ce serait à notre avis une erreur dangereuse [...] que de croire que ces deux mots: Français et catholiques, s'ils ont été longtemps synonymes doivent le rester toujours, et de lier les destinées de l'influence française en Orient aux destinées de l'idée catholique?.

Damit kritisierte die Mission laïque auch die ambivalente Außenpolitik der Dritten Republik, die im Ausland die katholischen Orden unterstützte, im Inland deren Rechte aber gleichzeitig massiv einschränkte ${ }^{8}$. Diese Poli-

4 Michel Foucault, Die Geburt der Klinik. Eine Archäologie des ärztlichen Blickes, Frankfurt am Main 1988, S. 150 f., hat in diesem Buch die Veränderung der Diskurse an der Beziehung zwischen Arzt und Patienten analysiert.

5 Michael Maset, Diskurs, Macht und Geschichte: Foucaults Analysetechniken und die historische Forschung, Frankfurt am Main 2002, S. 126.

6 MLF/Paris, Bulletin de la Mission laïque française 1906, S. 66.

7 Ebd., S. 66-67.

8 Vgl. Trimbur 2006; Daughton 2006, S. 5-21. 
tik war stark von dem berühmten Bonmot inspiriert, das dem Politiker Gambetta zugeschrieben wird, das aber eigentlich von Paul Bert stammte: »L'anticléricalisme n'est pas un article d'exportation «'. Trotz ihrer Kritik unterstützten die Verantwortlichen der Mission lä̈que diese Haltung und erklärten sie zum Prinzip ihrer Institution. So nahm der Präsident der Mission laïque, Aulard, 1907 bei einem Vortrag in Thessaloniki, wo die Organisation ihre erste Schule gegründet hatte, bewusst auf den Satz Gambettas Bezug und betonte:

Qu'il soit bien entendu d'abord, a-t-il dit, que nous n'apportons ici aucune hostilité contre personne. Si souvent qu'ait été cité le mot de Gambetta: ।l'anticléricalisme n'est pas un article d'exportation<, la Mission laïque le peut reprendre à son compte ${ }^{10}$.

Die Mission laïque passte somit ihr Programm dem neuen kulturellen Kontext an und betonte, im Gegensatz zu ihren Aussagen in Frankreich, dass sie keinerlei Kritik an der Religion der Menschen in der Levante übe. Die Akteure der Mission lä̈que mussten sich zudem sehr um das Vertrauen der Menschen bemühen, da sie auf keine jahrhundertealte Präsenz in der Region bauen konnten und der Laizismus oder Säkularismus in seiner europäischen Form nur von einer Minderheit von Intellektuellen vertreten wurde ${ }^{11}$. Ferner waren die ersten Versuche einer laizistischen französischen Schule in Beirut, die offiziell noch nicht unter ihrer Schirmherrschaft gestanden hatten, kläglich gescheitert und hatten diesen Schultyp stark diskreditiert ${ }^{12}$.

Die jahrhundertealte Tradition aber war gerade das Gewicht, das die katholischen Schulen in die Wagschale werfen konnten, um ihre Präsenz in der Region zu rechtfertigen. Deswegen betonten sie auch, dass die Mission laïque erst sehr viel später als sie selber in die Levante gekommen war. So wird in der Geschichte der Frères des Écoles chrétiennes der Erfolg der französischen Schulen im Orient, den 1912 ein französischer Inspektor attestierte, bewusst auf die katholischen Schulen konzentriert: »Les religieux français

9 Um den ursprünglichen Autor und Kontext dieses Satzes rankt eine rege wissenschaftliche Diskussion. Vgl. Jean-Louis Triaud, Une laïcité coloniale. L'administration française et l'islam en Afrique de l'ouest (1860-1960), in: Christine Peyrard (Hg.), Politique, religion et laïcité, Aixen-Provence 2009, S. 121-143, S. 121.

10 MAE/Nantes, »Beyrouth Consulat Général«, 359, »Notes de Salonique«, in: Stambul, 25.10.1907.

11 Vgl. Yared 2002; Azzam Tamini, The Origins of Arab Secularism, in: Azzam Tamini/John Esposito (Hg.), Islam and Secularism in the Middle East, New York 2000, S. 13-28, S. 17.

12 Für die laizistischen Schulprojekte Oliviers (1896-1904) und Augiers (1903-1909) vgl. Jacques TновіE, La Préhistoire de l'enseignement läque français à Beyrouth (1897-1909), in: Walid Arbid/Simone Dreyfus/Edmond Jouve (Hg.), La Francophonie au Liban. Actes du sixième colloque international francophone du Canton de Payrac et du Pays du Quercy, Paris 1997, S. 159-197. 
ont acquis ces résultats en un temps où les travaux, d'ailleurs méritoires, de la >Mission laïque`sur le pourtour de la Méditerranée orientale commençaient à peine $\ll^{13}$. In der Tat setzten die katholischen Schulen oftmals, wie von der Mission laïque kritisiert, französische und katholische Präsenz gleich, wenn sie davon sprachen, dass Frankreich seit vier Jahrzehnten großen Einfluss in Syrien habe: »Rappelons-nous d'autre part l'influence réelle et constante que la France exerce depuis quatre siècles en Syrie ${ }^{14}$.

Um weiterhin als Vertreter dieses Einflusses agieren zu können, wehrten sich die katholischen Orden Anfang des 20. Jahrhunderts vehement gegen die Ankunft der Mission lä̈que. Sie konstruierten eine Parallele zwischen Frankreich und dem Libanon, die beide von dem Schreckensgespenst des Laizismus heimgesucht würden: »Le Liban, comme notre pauvre France, est à un tournant de l'histoire; les esprits se montrent poussés par la secte maudite; l'indifférence religieuse gagne [...] $\ll^{15}$, schrieb ein Lazarist 1907 nach Paris. Ein wichtiger Grund für die Betonung der Tradition französischer Präsenz im Libanon lag für die katholischen Orden auch in der Sicherheit, die ihnen die militärische und politische Einflussnahme Frankreichs immer gab. Dies wurde ihnen besonders deutlich in Zeiten, in denen dieses Gewicht nicht mehr garantiert schien, wie im Zuge der antiklerikalen Gesetzgebung in Frankreich Amfang des 20. Jahrhunderts. In solchen Situationen verwiesen sie verstärkt auf die Tradition des französischen Einflusses in Syrien und Libanon ${ }^{16}$. Die Verbundenheit mit der militärischen und politischen Präsenz Frankreichs führte allerdings auch manchmal zu einem Gefühl der Scham, wenn Frankreich nach Ansicht der Orden nicht energisch genug für die Christen des Libanons eintrat ${ }^{17}$.

Während die katholischen Orden die französische Präsenz im Libanon mit dem Christentum gleichsetzten, stellten auch die Verantwortlichen der Alliance israélite universelle ihre traditionelle Rolle als Mediatoren Frankreichs

13 Georges Rigault, Histoire de l'Institut des Frères des Écoles chrétiennes, Bd. VIII, Paris 1937, S. 481.

$14 \mathrm{SJ} /$ Vanves, RPO, 62, »L'Enseignement à l'université Saint-Joseph. Le point de vue de l'élève«, 30.10.1931 (Autor P. J. Honiskiss).

15 Vgl. LAZ/Paris, »Tripoli Correspondance 1892-1913«, Brief von Thomas aus Tripoli, 31.05.1907: »Le Liban, comme notre pauvre France, est à un tournant de l'histoire; les esprits se montrent poussés par la secte maudite; l'indifférence religieuse gagne [...]«.

16 Vgl. LAZ/Paris, »Beyrouth Correspondance 1896-1918«, Brief von Boury, Beirut, 14.09.1903: „Au point de vue de l'existence de nos œuvres, l'avenir paraît sombre. Nous vivons ici des secours de la France. Qu'elle vienne à nous manquer, et je ne sais trop ce que nous deviendrons, surtout nos sœurs«.

17 Ebd.: »La France lâche la Syrie! le Liban! les Maronites. Le moment est très critique pour notre influence. Si la France n'intervient pas énergiquement, les Maronites vont faire appel aux Anglais. On dit que le patriarche est décidé à en finir avec une protection dont il ne retire que des déboires«. 
im Libanon heraus. So unterstrich eine Publikation des Kongresses der Alliance israélite 1960 in Paris, dass die jüdische Organisation »von Anfang an dabei gewesen sei«:

[A]ppuyés par la représentation diplomatique et consulaire de la France, dont ils appelaient l'attention sur la situation des juifs du pays chaque fois que la nécessité s'en présentait, les directeurs étaient devenus des agents de liaison entre la communauté juive et les autorités consulaires et autochtones. Ils sont parvenus ainsi à être considérés comme des personnalités diplomatiques ${ }^{18}$.

Mit dieser Darstellung der Tradition französischer Präsenz im Libanon reproduzierten die verschiedenen Institutionen und ihre Akteure den Diskurs einer reichhaltigen französischen Literatur über den Orient, die in Frankreich in der ersten Hälfte des 20. Jahrhunderts zirkulierte und sehr populär war $^{19}$. Die Forschung hat im Anschluss an Said zu Recht deutlich gemacht, wie stark die Beschreibung des Fremden auch Aufschluss über das Eigene gibt $^{20}$. Diese Dimension steht aber im Folgenden weniger im Fokus als die starke Prägung der Schulvertreter in ihrer Wahrnehmung und Beschreibung des Libanons durch die Reiseliteratur.

Die Autoren dieser Reiseberichte über den Orient waren französische Schriftsteller des 18. und vor allem des 19. Jahrhunderts, die zum Kanon der französischen Literatur gehörten, und von denen viele ihre Reise in den Orient schriftlich festgehalten hatten. Prominente Autoren wie Gustave Flaubert und Alphonse de Lamartine stellten die französische Präsenz im Libanon als selbstverständlich dar, auch wenn sie sie unterschiedlich beurteilten ${ }^{21}$. Dabei bedienten sie sich selber auch anderer Reiseberichte älterer Autoren und schrieben so die Kontinuität der französischen Präsenz im Libanon

18 Jacques Preciado, L'œuvre de l'Alliance Israélite Universelle au Liban, Congrès de l'AIU, Paris 1960, S. 2.

19 Bis heute hat dieser Diskurs in manchen Werken überlebt. Vgl. z. B. Pierre Dufour, La France au Levant, Paris 2001, S. 13, der sogar von einer jahrtausendealten Präsenz Frankreichs in der Levante spricht: »La France, qui entretient depuis près d'un millénaire des rapports commerciaux et culturels féconds avec les États du Levant, est maintes fois impliquée dans les problèmes du Proche-Orient [...]

20 Vgl. Klinkenberg 2009, S. 149; Felix Konrad, Von der `Türkengefahr zu Exotismus und Orientalismus: Der Islam als Antithese Europas (1453-1914)?, in: Europäische Geschichte Online (EGO), hg. vom Institut für Europäische Geschichte (IEG), Mainz 2010. URL: http://www.iegego.eu/konradf-2010-de (14.03.2012).

21 Flaubert beschreibt in sehr kritischen Worten den französischen Konsul in Damaskus 1850. Vgl. Gustave Flaubert, Reise in den Orient. Ägypten, Nubien, Palästina, Libanon. Aus dem Französischen von Reinhold Werner und André Stoll, Frankfurt am Main 1985, S. 284. Lamartine hingegen, der von 1830-1832 dort war, bewunderte den Orient, auch wenn er die kolonialen Absichten Frankreichs teilte. Vgl. Denise Brahimi, Volney et Lamartine. Les jeux de l'Orient et de la différence, in: Ilana Zinguer (Hg.), Miroirs de l'Altérité et Voyages au ProcheOrient, Genf 1991, S. 289-293. 
fort $^{22}$. Dieser Intertext wurde von den Schulen wiederum reproduziert. Beispielsweise zitiert die Chronik der Lazaristenschule in Ayntoura Lamartines Beschreibung ihrer Schule. Darin nahm er mehrmals Bezug auf die Reiseberichte Constantin François Volneys aus dem 18. Jahrhundert:

[...] d'orangers magnifiques, cités déjà par Volney comme les plus beaux et les plus anciens de la Syrie; ils [...] portent sur leurs troncs les noms de Volney et de voyageurs anglais qui avaient, comme nous, passé quelques moments à leurs pieds ${ }^{23}$.

Auch die Mission laïque und die anderen französischen Schulen rezipierten diese Werke, die sie in ihren Schulbibliotheken führten ${ }^{24}$. Damit reproduzierten die Schulen die Konstruktion Lamartines eines Bildes vom »imaginary Orient«, der nach Edward Said Europa gegenüber schwach und unterlegen war, »as if it were a personal (or at the very least a French) province ready to be disposed of by European powers $\ll^{25}$.

Die Vertreter der französischen Schulen waren aber nicht nur Reproduzenten dieser Diskurse. Insbesondere die Jesuiten verfassten viele Reise- und Erfahrungsberichte sowie wissenschaftliche Abhandlungen über den Nahen Osten. Mit dem dreifachen Ziel, Unterstützung zu erlangen, Wissen zu verbreiten und mit dem Orden beziehungsweise den Christen in der Heimat in Kontakt zu bleiben ${ }^{26}$, trugen die Jesuiten maßgeblich zur Verbreitung von Informationen über den Orient in Europa bei ${ }^{27}$.

$\mathrm{Zu}$ den >orientalistischen Autoren, die sowohl in Frankreich als auch von den Schulen im Libanon intensiv rezipiert wurden, zählte ferner der Schriftsteller und Wissenschaftler Ernest Renan. Auch wenn Renans Hauptinteresse nicht der französischen Präsenz im Orient galt, sondern der wertenden Gegenüberstellung von Islam und westlicher Zivilisation und Wissenschaft ${ }^{28}$,

22 Wie Achim Landwehr in seinem Werk Die Erschaffung Venedigs. Raum, Bevölkerung, Mythos 1570-1750, Paderborn u.a. 2007, deutlich gemacht hat, erklärt sich die oft wörtliche Wiederholung eines vormaligen Reiseberichts durch die Reisenden aus deren Bedürfnis heraus, sich und ihre Leserschaft dieses Wissens zu vergewissern.

23 Alphonse de Lamartine, Voyage en Orient, zitiert in: Victor Hachem, Antoura de 1657 à nos jours. Une histoire du Liban, Antoura 2003, S. 99.

24 Für die Mission laïque siehe AN/Paris, 60 AJ 123, »Commande bibliothèque«: Direktor Mathieu bestellte 1919-1920 Bücher von Nerval, Chateaubriand, Lamartine und Renan.

25 SAID 1978, S. 177-178.

26 Vgl. Bernard Heyberger/Chantal Verdeil, Sprirituality and Scholarship: The Holy Land in Jesuit Eyes (Seventeenth to Nineteenth Century), in: Heleen Murre-van den Berg (Hg.), New Faith in Ancient Lands. Western Missions in the Middle East in the Nineteenth and Early Twentieth Centuries, Leiden/Boston 2006, S. 19-41, S. 20.

27 Besonders rührig und einflussreich war für Libanon und Syrien der belgische Jesuitenpater Henri Lammens, vgl. Kapitel 5.4.

28 Vgl. Klinkenberg 2009, S. 509-516. In der berühmten Auseinandersetzung mit dem muslimischen Gelehrten Ğamāl ad-Dīn al-Afg̉ānī hatte Renan behauptet, es habe keine genuin arabische Philosophie und Wissenschaft gegeben, weil die Philosophen keine Araber waren, son- 
präsentierte er sich als Teil und als Nutznießer der französischen Position im Orient. Im Vorwort seiner Mission de Phénicie von 1860 über die Ausgrabungen in Baalbek unterstreicht er die hilfreiche Präsenz der französischen Soldaten für seine Grabungsarbeiten: »[...] ces commissions scientifiques que la France, en sa noble préoccupation des choses de l'esprit, a toujours associées à ses expéditons militaires [... $\ll^{29}$. Hier stellt sich Renan eindeutig in die Linie der Ägyptenexpedition Napoleons, die neben einer Armee auch viele Wissenschaftler mit sich geführt hatte ${ }^{30}$.

Ein besonders prominenter Vertreter der Betonung der französischen Tradition im Libanon war Anfang des 20. Jahrhunderts der Schriftsteller und politische Aktivist Maurice Barrès. Er träumte zwar von der Schaffung einer »franko-orientalischen Zivilisation«, war aber von der Überlegenheit Frankreichs überzeugt und sah im Orient nur die Inkarnation einer christlichen Mystik, die er selber suchte ${ }^{31}$. Ein ausgesprochenes Lob hatte er für die katholischen Schulen übrig, beispielsweise bezeichnete er die Arbeit der Frères des Écoles chrétiennes als »plus puissante force d'expansion spirituelle et parfois de développement économique ${ }^{32}$. Außerdem hob er den paradoxen Verdienst der Orden hervor, die, obwohl in Frankreich ausgeschlossen, ihrer Heimat doch dienten: »Originaires d'un territoire français dont vous fûtes chassés par la force, vous avez acquis un territoire moral à la France $\ll^{33}$. Auch Barrès wurde von den französischen Schulen im Libanon rezipiert. So waren die Frères des Écoles chrétiennes voll des Lobes für diesen »auteur qui a si bien décrit notre Orient brisé $\ll^{34}$.

dern nur auf Arabisch schrieben beziehungsweise sogar aus dem Griechischen übersetzten. Seiner These von den »Semiten«, die im Gegensatz zu den Indoeuropäern nur kopierten, entgegnete al-Afḡānī, dass als arabischer Philosoph gelten könne, wer, unabhängig von seiner »Rasse«, auf Arabisch schreibe. Vgl. Ernest RENAN, L'Islamisme et la science, conférence donnée à la Sorbonne le 29 mars 1883, avec la réponse d'al-Afghani, Montpellier 2005. Zur eurozentrischen Position Renans in diesem Streit vgl. Birgit SchäBler, Religion, Rasse und Wissenschaft. Ernest Renan im Disput mit Jamal al-Din al-Afghani, in: Themenportal Europäische Geschichte 2007. URL: http://www.europa.clio-online.de/2007/Article=274 (14.03.2012).

29 Ernest Renan, Mission de Phénicie, Paris 1864, S. 2. Wie Ignaz Goldziher, Renan als Orientalist. Gedenkrede am 27. November 1893, hg. v. Friedrich NiEwöHNER, Zürich 2000, S. 82-83 herausgestellt hat, traf Renan, der im Auftrag Napoleons III. diese Expedition unternahm, im Libanon selber auf sehr viel Widerstand, über den er in seiner Erzählung aber schweigt.

30 Vgl. Napoléon Bonaparte, Campagnes d'Égypte et de Syrie, hg. von Henry Laurens, Paris 1998, S. 24.

31 Vgl. Heyberger 2008, S. 50-53.

32 Maurice BARrÈs, Faut-il autoriser les congrégations? Les Frères des Écoles chrétiennes. Rapport fait au nom de la Commission des Affaires étrangères de la Chambre des Députés, Paris 1923, S. 6.

33 BARRÈs 1923, S. 123.

34 FEC, L'Essor, Juli 1924, S. 32-34. 
Überraschend ist, dass die Schulbücher, die in Frankreich selbst Anfang des 20. Jahrhunderts verwendet wurden, wenig Bezug auf diese Reisberichte nahmen. Zwar wurden die Bücher von Lamartine, Flaubert, Renan und Barrès vorgestellt, aber nicht diejenigen über den Orient ${ }^{35}$. Diese Nichterwähnung warnt davor, die Betonung der Beziehung zum Orient in den Schulen in Frankreich zu überschätzen. Hingegen behandelten die französischen Schulen im Libanon diese Themen aber sehr wohl. So mussten sich die Schüler für das französische Abitur in Beirut 1943 unter dem Thema »L'Orient dans Lamartine« der Aufgabe widmen: »Déterminez en quoi et comment le voyage d'Orient a [...] surélevé l'inspiration lamartinienne « ${ }^{36}$.

In der französischen Gesellschaft des 19. und frühen 20. Jahrhunderts war die Tradition der französischen Präsenz im Libanon ebenfalls ein prominentes Thema, auf das neben den Literaten auch viele französische Historiker, Geographen und Wirtschaftswissenschaftler hinwiesen. Einige von ihnen gehörten dem Kreis des Comité de l'Asie française an, welches, ähnlich wie die parti colonial für die französischen Kolonien allgemein, das französische Engagement in Syrien in wirtschaftlicher, militärischer und kultureller Hinsicht in Syrien vorantrieb ${ }^{37}$ und dazu auch die französischen, insbesondere katholischen Schulen zählte ${ }^{38}$. Eine treibende Kraft der Gruppe war Robert de Caix, der später für das Hochkommissariat in Beirut arbeitete ${ }^{39}$. Andere hatten an dem 1919 in Marseille abgehaltenen Congrès français de la Syrie teilgenommen, der demselben Ziel diente und der unter anderem die Arbeiten von Jesuiten aus Beirut miteinbezog ${ }^{40}$. In diesem Zusammen-

35 Vgl. z.B. Charles-Marc Des Granges, Morceaux choisis des auteurs français, Deuxième cycle, Paris 1918. Keiner der gewählten Werkausschnitte von Lamartine, Guizot, Renan, Flaubert und Pierre Loti behandelt den Orient. Gleiches gilt für andere Schulbücher der Zeit, die untersucht wurden.

36 LAZ/Antoura, »Cahier de Sujets de Devoirs Français. Dissertations littéraires, morales, explications de textes [...]«, geführt von E. Joppin. Es wäre interessant zu untersuchen, inwiefern die Schüler dadurch nicht nur zum Orientalismus, sondern zum »Self-Orientalism« gezwungen wurden, da sie über sich als »Orientalen« und damit Teil der Inspiration Lamartines schreiben mussten. Das Konzept des »Self-Orientalism« ist bis jetzt vor allem in den Ostasienwissenschaften diskutiert worden, denen es auch entstammt. Vgl. den grundlegenden Aufsatz von Arif Dirlik, Chinese History and the Question of Orientalism, in: History and Theory 35 (1996), H. 4, S. 96-118.

37 Vgl. Christopher Maurice Andrew/Alexander Sydney Kanya-Forstner, The Climax of French Imperial Expansion 1914-1924, Stanford, California 1981, S. 102-103.

381912 war der Kanzler der Université Saint-Joseph nach Frankreich gereist und hatte für die Erweiterung der Fakultäten unter anderem die Unterstützung dieses Komitees bekommen. Vgl. Jean Ducruet/Henri Awit, L'Université Saint-Joseph de Beyrouth et ses institutions (18752002), Beirut 2002, S. 40.

39 Vgl. Meir ZAmir, The Formation of Modern Lebanon, London 1985, S. 45-46.

40 Vgl. Chambre de commerce de Marseille (Hg.), Congrès français de la Syrie, Marseille, les 3, 4 et 5 janvier 1919. Éléments d'une bibliographie française de la Syrie (Géographie, Ethnographie, Histoire, Archéologie, Langues, Littératures, Religions), réunis par Paul Masson, Correspondant de l'Institut/ Professeur à l'Université d'Aix-Marseille, Marseille 1919. Diese Bib- 
hang war die Konkurrenz mit anderen westlichen Mächten ein zentraler Aspekt. So betonte eine Arbeit von Verney und Dambmann von 1900, die sich mit den industriellen und wirtschaftlichen Aspekten der ausländischen Mächte befasste, »ce que les relations commerciales avec la France étaient jadis $\aleph^{41}$. Auf diese Art und Weise versuchten die Wissenschaftler, die wirtschaftlichen und strategischen Interessen Frankreichs im Nahen Osten als einen selbstverständlichen Anspruch, von welchem beide Regionen profitieren würden, darzustellen.

Im Gegensatz dazu hatte Guizot während der Restauration 1827 bezüglich des Orients interessanterweise weniger das französische als das europäische oder okzidentale Element hervorgehoben ${ }^{42}$. So waren die Kreuzzüge für ihn Ausdruck des Kampfes zwischen Islam und Christentum, aber auch der Beginn der Vermischung von Okzident und Orient: »L'Occident et l'Orient se connurent, se visitèrent, se mêlèrent ${ }^{43}$. Die starke Betonung der französischen Beziehungen mit der Levante, auch in politischer Hinsicht, wurde aber erst in der Dritten Republik wirksam, wie Henry Laurens herausgearbeitet hat: Diese Region stellte einerseits die Inkarnation der französischen mission civilisatrice unter den christlichen Gemeinschaften dar. Andererseits galt sie als eine besonders sensible Zone, in der die "politique musulmane« der Regierung greifen musste, um die französische Angst vor einer drohenden arabisch-nationalistischen Bewegung vom Nahen Osten bis nach Nordafrika einzudämmen ${ }^{44}$. Gerade nach der jungtürkischen Revolution 1909 setzte sich in Paris die Erkenntnis durch, dass die Bewahrung und Ausweitung des französischen Einflusses nicht durch eine reine »clientélisation des populations chrétiennes« geschehen könne, sondern einer breiteren Untertsützung im Orient bedürfe ${ }^{45}$.

Der Bezug auf die Tradition der französischen Präsenz in der Region wurde in den zahlreichen Publikationen in der Mandatszeit ${ }^{46}$ fortgeführt. So finden sich einige Arbeiten, die herausstellen, dass Frankreich schon seit den Kreuzzügen, wenn nicht seit Karl dem Großen, im Libanon präsent und mit diesem seither »intimement mêlé« ${ }^{47}$ sei. Dieses Kontinuitätsdiskur-

liographie für die Teilnehmer des Kongresses beinhaltete unter anderem die »Mélanges de la Faculté orientale (Université Saint Joseph, Beyrouth, 6 vol., 1906-14)« sowie von Henri Lammens, Quarante ans d'autonomie au Liban, 1902.

41 Noel Verney/George Dambmann, Les Puissances étrangères dans le Levant, en Syrie et en Palestine. Influences politiques et économiques, Finances, Travaux Publics, Industrie et Agriculture, Commerce et Navigation, Paris/Lyon 1900, S. XI.

42 Vgl. Guizot 1871, S. 227-228.

43 Ebd., S. 236.

44 Le Pautremat 2003, S. 23.

45 Henry Laurens, Orientales II. La IIIe République et l'Islam, Paris 2004, S. 55, 62.

46 Für eine Übersicht der in dieser Zeit in Frankreich produzierten Werke vgl. Joseph A. DaGHER, L'Orient dans la littérature française d'après-guerre 1919-1933, Beirut 1937.

47 So Carl Roederer/Paul Roederer, La Syrie et la France, Paris 1917, S. 4. 
ses seit dem frühen Mittelalter, wie ihn zum Beispiel 1925 Ristelhueber ${ }^{48}$ und 1939 Charles-Roux ${ }^{49}$, beides ehemalige französische Diplomaten in der Levante, präsentierten, bediente sich auch die französische Mandatsregierung als Legitimierungsstrategie. So schrieb Hochkommissar Weygand, in Syrien und Libanon von 1923 bis 1924, im Vorwort eines Buches von Bouron: »[...] la France saura, comme toujours, gagner des cœurs capables de reconnaissance $\ll^{50}$.

Die französischen Schulen im Libanon besaßen viele dieser Bücher ${ }^{51}$. Auch wenn die Lehrer vermutlich nicht allen darin vertretenen Thesen und Ideen zustimmten, trugen sie damit doch zu ihrer Verbreitung bei. In der Tat entstand dieser Diskurs einer französischen Tradition im Orient selbstverständlich nicht im luftleeren Raum, sondern im Austausch mit der Bevölkerung im Libanon. Dort traf dieser Diskurs sowohl auf scharfe Kritik als auch auf große Zustimmung. Im Gegensatz zu anderen Regionen unter französischer Vorherrschaft gab es im Libanon eine Bevölkerungsgruppe, die die dortige französische Präsenz aktiv unterstützte. Dieser Gruppe gehörten mehrheitlich die christlichen Maroniten an. In ihrer eigenen Historiographie haben sie die privilegierten Beziehungen mit Frankreich, die ihnen von anderen Gemeinschaften vorgeworfen wurden, nie geleugnet, sondern $»$ repeatedly justified and flouted $\aleph^{52}$. Damit unterschieden sich die Maroniten sehr deutlich von anderen Bevölkerungsgruppen, die eine Tradition französischer Präsenz in ihrer Region entweder sehr differenziert und kritisch betrachteten oder sogar leugneten ${ }^{53}$.

48 René Ristelhueber, Les traditions françaises au Liban, Paris 1925.

49 Vgl. François Charles-Roux, France et chrétiens d'Orient, Paris 1939: das erste Kapitel hat die Überschrift »Les origines. Charlemagne et la Terre-Sainte«, das zweite Kapitel lautet »Les croisades. La Syrie franque«.

50 Maxime Weygand, Préface, in: Capitaine N. BOURON, Les Druzes. Histoire du Liban et de la Montagne Haouranaise, Préface du Général Weygand, Paris 1930, S. IX. (Hervorhebung im Zitat durch E.M.).

51 Bezüglich des Buches von Ristelhueber siehe AN/Paris, 60 AJ 122, Brief Deschamps an Besnard, Marseille, 05.02.1919. Gleichzeitig machte sich Deschamps darüber lustig, dass zu dem Zeitpunkt fast jeder ein Buch über dieses Thema schreiben würde: »Ai acheté ce soir deux livres qui peuvent figurer dans la bibliothèque de la mission: Traditions françaises par Ristelhueber (il va falloir que je me mette moi aussi à faire des livres; c'est épatant tout le monde en fait; à quand le tien?)«. Zur Frage der Geschichtsbücher im Libanon vgl. auch Kapitel 5.4.

52 Joseph Mounwad, The Image of France in Maronite Tradition, in: The Beirut Review, o.J., S. 85-95, S. 85. Wie das Werk von Nasri SAlHaB, La France et les Maronites, Beirut 1997, zeigt, hält dieses Narrativ bis heute an.

53 Eine gute Übersicht dieser verschiedenen Positionen Anfang des 20. Jahrhunderts liefert Traboulsi 2008, S. 80-86. 
Ein frühes Zeugnis für die Herausstellung der langen Tradition französischer Präsenz im Libanon ist die Schrift des maronitischen Patriarchen Nicolas Murad, der die Beziehung zwischen Frankreich und den Maroniten auf »depuis 1249 « zurückverfolgte ${ }^{54}$. In dieser Tradition beschrieb der libanesische maronitische Autor Paul Jouplain (französisches Pseudonym von Būlus Nuğaīm) 1908 Frankreich als »protectrice des chrétiens d'Orient ${ }^{55}$. Auch wenn er Frankreich besondere Hilfe bei der Schaffung des »Grand Liban« gestattete, lehnte er ein französisches Mandat $\mathrm{bb}^{56}$.

Wie verschiedene Forscher deutlich gemacht haben, bestimmte die Betonung der historischen Beziehungspunkte die ideologische Zugehörigkeit des jeweiligen Sprechers: So erhofften sich die Maroniten, die die Beziehungen mit Frankreich besonders hervorhoben, den Beistand Frankreichs gegen eine Vereinigung mit Syrien oder der arabischen Welt sowie gegen eine Aufgabe ihrer Privilegien als französische Protégés ${ }^{57}$. Die Definition der Länge und Intensität der Tradition französischer Präsenz im Libanon stellte also immer ein politisches Statement ihres Autors dar: Je länger die Tradition zurückgeführt wurde, desto mehr warb ihr Autor für eine direkte Einflussnahme Frankreichs im Libanon.

$54 \mathrm{Vgl}$. notice historique sur l'origine de la nation maronite et sur ses rapports avec la France, sur la nation druze et sur les diverses populations du Mont Liban, par S.G. Mgr. Nicolas Murad, archevêque maronite de Laodicée, représentant de sa nation près le Saint Siège, Paris 1844, S. 22: »Lorsque, dans l'année 1249, Saint Louis aborda en Chypre déjà une colonie considérable de Maronites [...] et dès lors se conclut, entre la nation maronite et la France, une alliance morale dont le souvenir est resté profondément gravé dans l'esprit de ces populations«. Bernard Heyberger bezeichnet Murad als ein Beispiel der Maroniten, die nach der Französischen Revolution die reaktionären französischen katholischen Strömungen aufnahmen. Vgl. Bernard HeYBERGER, Les Européens vus par les Libanais (XVI ${ }^{\mathrm{e}}-\mathrm{XIX}^{\mathrm{e}}$ siècles), in: Bernard HeYBerger / CarstenMichael Walbiner (Hg.), Les Européens vus par les Libanais à l'époque ottomane, Würzburg 2002, S. 1-22, S. 15.

55 Paul Jouplain, La Question du Liban. Étude d'Histoire Diplomatique et de Droit International, Paris 1908, S. VII. Zu dem Autoren vgl. Marwan Buheiry, Bulus Nujaym and the Grand Liban Ideal 1908-1919, in: Marwan Buheiry (Hg.), Intellectual Life in the Arab East, 1890-1939, American University of Beirut 1981, S. 62-83, S. 79.

56 Vgl. Axel Havemann, Geschichte und Geschichtsschreibung im Libanon des 19. und 20. Jahrhunderts. Formen und Funktionen des historischen Selbstverständnisses, Würzburg 2002, S. 153.

57 Vgl. Ahmad Beydoun, Identité confessionnelle et temps social chez les historiens libanais contemporains, Beirut 1984, S. 569; Asher Kaufman, Phoenicianism: The Formation of an Identity in Lebanon in 1920, in: Middle Eastern Studies 37 (2001), H. 1, S. 173-194, S. 185. 


\section{Unterstützung der Schulen auf Regierungsebene}

Neben dem Rückbezug auf die französische Tradition im Orient lag eine weitere notwendige Rahmenbedingung der Schulen in der Unterstützung durch die Regierungsebenen, sowohl in Frankreich als auch im Libanon. Während die katholischen und jüdischen Schulen diese Unterstützung, wenn auch mit Einschränkungen, schon genossen, musste sich die Mission laïque diese neu erwerben und ist daher als Forschungsgegenstand besonders gut geeignet, um diesen Prozess der staatlichen Sanktionierung zu untersuchen.

Als eine französische Organisation, die auf finanzielle Unterstützung durch einen zahlungskräftigen Geldgeber angewiesen war, konnte und wollte die Mission lä̈que nicht ohne die Unterstützung der französischen Regierung ihre Aktivitäten im Osmanischen Reich beginnen. Deshalb kam ihr zum einen zugute, dass diese Region seit einigen Jahrzehnten unter steigender französischer Einflussnahme stand, deren Hauptinteresse in Großsyrien lag. Zum anderen musste die Mission lä̈que aber auch den Moment abwarten, in dem die Regierungen ein dezidiert laizistisches Projekt unterstützen würden.

Spätestens seit der Besatzung Ägyptens durch die britische Armee 1882 hatte sich Frankreich, das ebenfalls großes Interesse an der Nilregion gehabt hatte, vor allem auf die Region von Syrien, Libanon und Palästina konzentriert $^{58}$. In dieser Region konnten verschiedene französische Sektoren in der Folge ihren Einfluss immer stärker ausbauen. Ökonomisch entwickelten sich französische Firmen, Banken und der französische Staat zu den Hauptinvestoren und -nutznießern der osmanischen Wirtschaft ${ }^{59}$. Besonders enge Beziehungen entwickelten sich zwischen Händlern und Banken in Lyon und der Seidenindustrie im Libanon, in die auch die Jesuiten eingebunden waren ${ }^{60}$. Als militärische Größe hatte sich Frankreich seit den Unruhen in Damaskus und im Ğabal Lubnān 1860 aktiv in der Region politisch engagiert ${ }^{61}$. Dabei hatte sich die französische Armee wie auch die anderen europäischen Ver-

58 Vgl. Henry Laurens, La présence française au Proche-Orient du XVII ${ }^{\mathrm{e}}$ siècle à la Première Guerre mondiale, in: Bernard Delpal/Bernard Hours/Claude Prudhomme (Hg.), FranceLevant. De la fin du XVII ${ }^{\mathrm{e}}$ siècle à la Première Guerre mondiale, Paris 2005, S. 9-20, S. 15.

59 Vgl. Jacques ThoBIE, Intérêts et impérialisme français dans l'empire ottoman (1895-1914), Paris 1977, S. 210.

60 Vgl. Roger Owen, The Middle East in the World Economy 1800-1914, London/ New York 1993, S. 153-154; Dominique Chevallier, La société du Mont Liban à l'époque de la révolution industrielle en Europe, Paris 1971, S. 221, 229; Michel SeUrat, Le rôle de Lyon dans l'installation du mandat français en Syrie. Intérêts économiques et culturels, luttes d'opinion (1915-1925), in: Ders., L'État de Barbarie, Paris 1977, S. 173-224.

61 Vgl. Samir Kassir, Histoire de Beyrouth, Paris 2003, S. 114. 
treter auf die Seite der Maroniten gestellt, die sie als unschuldige Opfer ansahen, obwohl mittlerweile unbestritten ist, dass nicht die Drusen die alleinige Schuld an den Auseinandersetzungen trugen ${ }^{62}$.

Mit dem wirtschaftlichen und militärischen Einfluss hatten sich auch die politischen und juristischen Ansprüche Frankreichs im Libanon erhöht. Seit den ersten Kapitulationen zwischen dem französischen König François I. und dem osmanischen Sultan Suleiman, die zunächst nur die juristische Unterstellung französischer Händler unter die französische Gerichtsbarkeit bedeutet hatten, hatte Frankreich diese Privilegien stetig auf orientalische Christen ausweiten können ${ }^{63}$. Die Schaffung des mutașarrifĩya (Provinz) des Ğabal Lubnān als von Konstantinopel stark autonome Provinz durch das Règlement organique von 1864, in der Folge der Auseinandersetzung von 1860, bildete einen der Höhepunkte französischer beziehungsweise europäischer Einflussnahme in der Levante. Der Mutașarrif (Gouverneur) dieser Provinz musste ein Christ sein, der von den europäischen Mächten ernannt wurde, wobei Frankreich eine führende Rolle in seiner Designation zukam ${ }^{64}$. Vor allem anderen bildete Frankreich aber, nachdem es Mitte des 19. Jahrhunderts Italien abgelöst hatte, zunehmend eine kulturelle Macht in der Levante, an welcher die katholischen Missionare, vor allem aus Frankreich und Italien, einen großen Anteil hatten ${ }^{65}$. In diesem Zusammenhang kam es bis zum Abbruch der diplomatischen Beziehungen 1904 in Folge der antiklerikalen Politik in Frankreich zu einer engen Zusammenarbeit zwischen der französischen Regierung und dem Vatikan ${ }^{66}$.

Paradoxerweise kann anhand der Mission lä̈que française als neuer kultureller Größe in dem bis dato von der Kirche dominierten Feld gezeigt werden, wie unabdingbar der französische Einfluss in Beirut Anfang des 20. Jahrhunderts für das Wirken der Schulen war. Jacques Thobie, der bisher als einziger umfassender zu den Anfängen der säkularen Schule in Beirut geforscht hat, reduziert die Gründe allerdings zu stark auf die französischen Interessen in der Region: »Beyrouth est au cœur d'une région où les intérêts français, tant économiques que culturels, sont d'une grande densité « ${ }^{67}$. Vielmehr

62 Die Ereignisse von 1860 bleiben bis heute eines der umstrittenen und noch lange nicht abschlieBend erforschten Themen der libanesischen Geschichte. Vgl. Ussama MAKDISI, The Culture of Sectarianism. Community, History, and Violence in Nineteenth-Century Ottoman Lebanon, Berkeley, California 2000, S. 167-169.

63 Vgl. William I. Sновяоск, French Imperialism in the Middle East. The Failure of Policy in Syria and Lebanon 1900-1914, Madison, Wisconson 1976, S. 13.

64 Vgl. Kamal SaliBi, The Modern History of Lebanon, New York 1965, S. 113-118.

65 Vgl. Burrows 1986, S. 133.

66 Vgl. SHORRock 1976, S. 35-45.

67 THовіе 2008, S. 43. Er betont zwar den Wunsch der Mission laïque, das »quasi monopole de fait de l'enseignement religieux français en Syrie« zu beenden, aber diese franko-französischen Gründe sind nicht ausreichend. Thobie ist bis jetzt der einzige, der zur Mission laïque in Beirut, allerdings nur bis 1914, publiziert hat. 
bedurfte es, neben dem Interesse und der Unterstützung durch die osmanische Regierung und Gesellschaft, einer bestimmten positiven Ausgangslage in Paris. In der Tat mehrten sich, auch wenn die Unterstützung der Ordensschulen anhielt, die Stimmen innerhalb der Regierung für eine stärkere Förderung laizistischer Bildungseinrichtungen im Orient ${ }^{68}$. Außerdem kam der Mission laïque zugute, dass innerhalb des Außenministeriums eine strukturelle Stärkung der auswärtigen Bildungspolitik erfolgte: Im Juli 1909 wurde dort das Bureau des Écoles et des Euvres françaises gegründet, 1920 in Service des Euvres françaises à l'Étranger umbenannt ${ }^{69}$. Dessen Budget stieg schnell an und ermöglichte schon 1909 der Schule der Mission laïque ein Budget von $35000 \mathrm{Francs}^{70}$. Das war mehr als die einzelnen Schulen der katholischen Orden durch die Regierung erhielten ${ }^{71}$.

$\mathrm{Zu}$ diesem Zwecke hatten diverse Inspektionsreisen in die Levante im Namen der Mission lä̈que française und des französischen Außenministeriums in den Jahren 1904, 1906, 1907 und 1909 ${ }^{72}$ stattgefunden und das Ergebnis präsentiert, dass die Situation für eine laizistische Schule günstig sei ${ }^{73}$. Laut Pierre Deschamps, dem Mitbegründer und ersten Direktor der Mission laïque in Beirut, war für die Niederlassung in Beirut der ausschlaggebende Grund die Unterstützung der französischen Regierung gewesen, die sich zu der Zeit »en pleine lutte anticléricale« befand: »[...] la Mission laïque apparut à beaucoup comme une arme qui portait le combat hors de France. [...] on voulut voir en elle un moyen de supplanter un jour les missions religieuses $\aleph^{74}$.

68 Vgl. Jean Riffier, Les œuvres françaises en Syrie (1860-1923), Paris 2000, S. 147-166; vgl. auch die älteren, aber für die französische Perspektive immer noch wichtigen Arbeiten zu dem Thema: William Shorrock, Anti-Clericalism and French Policy in the Ottoman Empire, 190014, in: European Studies Review 4 (1974), H. 1, S. 33-55; John P. Spagnolo, The Definition of a Style of Imperialism. The International Politics of the French Educational Investment in Ottoman Beirut, in: French Historical Studies 3 (1973), H. 4, S. 563-584.

69 Vgl. Colette DE Bonnay-BARBIER, Le Service des CEuvres françaises à l'étranger du Ministre des Affaires étrangères entre les deux guerres mondiales, Paris 1983 (unveröffentlichte Magisterarbeit).

70 Vgl. Riffier 2000, S. 162.

71 Für diese Einrichtungen liegen Zahlen von 1906 vor: Lediglich die medizinische Fakultät der Jesuiten in Beirut erhielt mit 93000 Francs als einzelne Institution mehr Geld, ansonsten beliefen sich die Subventionen der katholischen Schulen auf Summen zwischen 1000 und 10000 Francs. Vgl. MAE/Nantes, »Beyrouth Consulat A«, 177. Wie Riffier 2000, S. 159-161, waren die katholischen Einrichtungen für die französische Regierung günstiger, weil sie auch von den Institutionen der katholischen Kirche, der »Propagande de la Foi« und dem »Euvre des Écoles d'Orient« finanzielle Unterstützung erhielten.

72 Vgl. Thévenin 2002, S. 77.

73 Vgl. Thobie 2008, S. 40-42.

74 Pierre Deschamps, Promenade archéologique, abgedruckt in: Dialogues 35/36/37, Éléments pour une histoire de la Mission laïque française 1902-1982, 1982, S. 81-99, S. 98. 
Der französische Generalkonsul in Beirut, der 1905 eine laizistische Schule noch gutgeheißen hatte, riet zwar 1909 davon $\mathrm{ab}^{75}$, aber seine Bedenken wurden nicht erhört. Deschamps selber stimmte diesem Projekt nach seiner Inspektionsreise in den Libanon im Juni 1909 nur zögerlich zu. Zwar hielt der Verwaltungsrat in Paris fest, dass »la conclusion [...] de M. Deschamps est qu'il y a une place à prendre pour la Mission laïque à Beyrouth et qu'il faut la prendre $\aleph^{76}$. In einem autobiographischen Text von 1953 machte er aber deutlich, dass der Nahe Osten nicht seine erste Wahl gewesen war: »La Mission laïque [...] a fondé plusieurs établissements, non pas dans les colonies comme je l'avais pensé, mais dans le Proche-Orient « ${ }^{77}$. In der Unterstützung einer laizistischen Schule in Beirut fanden sich also sowohl die Interessen der Mission lä̈que française als auch der französischen Regierung wieder ${ }^{78}$. Das bedeutet allerdings nicht, dass damit aller Widerstand gegen eine Förderung laizistischer Schulen in der Levante innerhalb der französischen Regierung zum Schweigen gekommen war. Bis zum Ende der Mandatszeit hielt der Kampf zwischen Gegnern und Verfechtern dieser Politik in den unterschiedlichen französischen Regierungsgremien an.

Abgesehen von der französischen Hilfe benötigte die Mission laïque aber unbedingt die Unterstützung der osmanischen Regierung. Da die Organisation ihre ersten Schulen in Beirut errichtete, musste sie sich unmittelbarer mit der Hohen Pforte auseinandersetzen. Die Stadt war stärker von Konstantinopel abhängig als die relativ unabhängige Provinz Ğabal Lubnān. In Beirut traf die ausländischen Schulen auch massiver die restriktive Politik der Hohen Pforte, welche einen zu großen Einfluss dieser Schulen und damit der sie unterstützenden westlichen Mächte fürchtete.

Die große Konkurrenz um die Hoheit der Bildung und deren enge Verbindung mit nationalstaatlichen Interessen zeigte sich exemplarisch in dem Konflikt der osmanischen Regierung mit den medizinischen Fakultäten des von amerikanischen Missionaren gegründeten Syrian Protestant College und der Universität Saint-Joseph der Jesuiten in Beirut: Hier wurden die Entscheidungen des Ortes und des Komitees der Abschlussprüfungen zur Frage der Hoheit über Bildung und staatliche Macht ${ }^{79}$. Das Gefühl der Bedrohung durch die westlichen Mächte und deren Schulen war laut Fortna einer der Gründe für die Errichtung des Vilayets (Großprovinz, arabisch wilāya) von

75 MAE/Nantes, Brief/ Notiz [anscheinend des Consul Général], Beirut, 22.06.1909.

$76 \mathrm{MLF} /$ Paris, »Procès-verbaux du Conseil d’Administration«, Sitzung vom 08.07.1909.

77 Deschamps 1982, S. 99.

78 Vgl. MLF/Paris, »Procès-verbaux du Conseil d'Administration«, Sitzungen der Jahre 19071909.

79 Neben Spagnolo 1973 vgl. unter Hinzunahme osmanischer Quellen und mit Betonung der osmanischen Perspektive Adil Baktiaya, The Ottoman-French Domination Struggle Over The Syrian-Lebanon Territory: The Case of St. Joseph Medical School, in: International Journal of Turcologia 3 (2008), H. 6, S. 68-93, S. 73 (= BAKTiaya 2008). 
Beirut $1888^{80}$. In der Folge bemühte sich der Gouverneur verstärkt, allerdings nur wenig erfolgreich, um ein Bildungsprogramm, das die Eltern von den Missionarsschulen, welche in der Regel finanziell besser ausgestattet waren und zudem als attraktiv und smodern galten, weg und zu den staatlichen Schulen hin brachte - ein wahrer Bildungskampf begann ${ }^{81}$.

Als die Mission lä̈que française im Oktober 1909 ihre Schule in Beirut eröffnete, befand sich der Libanon in einer Phase politischer und sozialer Umwälzungen. Im Juli 1908 hatten einige Offiziere des Komitees für Einheit und Fortschritt, auch als jungtürkische Bewegung bekannt, eine erfolgreiche Militärrevolte gegen den osmanischen Sultan Abdülhamid II. geführt und 1909 seine Abdankung erreicht. Die Regierungsübernahme der Jungtürken führte auch im Vilayet von Beirut zu einer Neubesetzung des Amtes des Vali (Verwalter des Vilayets, arabisch wālī) durch den den Jungtürken wohlgesonnenen Nazim Pascha im September $1908^{82}$. Unter vielen Notabeln der Stadt löste die politische Veränderung zunächst Zustimmung aus, weil sie das Vorhaben der Jungtürken unterstützten, das Reich zu reformieren, aber seine Einheit beizubehalten ${ }^{83}$. Diese Übereinstimmung wandelte sich aber spätestens 1912, als die Jungtürken nach dem »Umsturzversuch konservativer Kreise um Sultan Abdülhamid II. vom April $1909 «^{84}$ erneut die Macht an sich nahmen und ihre Zentralisierungs- und Turkisierungspolitik noch radikaler vorantrieben ${ }^{85}$. In der Folge verstärkte sich, unter anderem als Protest gegen diese Politik, in der gesamten Region der arabische Nationalismus, welcher in Beirut eines seiner Zentren hatte ${ }^{86}$.

Etwas anders verlief die Entwicklung im Ğabal Lubnān, das stark unter europäischem, besonders französischem Schutz stand. Hier kam es erst Ende 1912 zu wichtigen Veränderungen: Zum einen erreichten die maronitischen Notabeln eine Reform des Règlement organique und damit eine noch größere

80 Vgl. Benjamin Fortna, Imperial Classroom. Islam, the State, and Education in the Late Ottoman Empire, Oxford 2002, S. 51.

81 Vgl. ebd., S. 52-56; Jens Hanssen, Fin de siècle Beirut. The Making of an Ottoman Provincial Capital, Oxford 2005, S. 164.

82 Vgl. Kamal SAliBi, Beirut under the Young Turks: As Depicted in the Politial Memoires of Salīm 'Alī Salām (1868-1938), in: Jacques Berque/Dominique Chevallier (Hg.), Les Arabes par leurs archives (XVIe-XXe siècles), Paris 1976, S. 193-215, hier 199-200.

83 Für die allgemeine Beziehung der Jungtürken und der Araber vgl. Hasan KaYALI, Arabs and Young Turks. Ottomanism, Arabism, and Islamism in the Ottoman Empire, 1908-1918, Berkeley, California 1997. Er betont, dass diese Beziehung von der Historiographie schlechter dargestellt wurde als sie wirklich war.

84 Gudrun KRÄMER, Geschichte Palästinas. Von der osmanischen Eroberung bis zur Gründung des Staates Israel, München 2003, S. 151.

85 Für den konkreten Fall eines arabischen Notabeln siehe den Beiruter Sunniten Salīm 'Alī Salām. Erst ab 1912 wandte er sich von der jungtürkischen Regierung ab. Vgl. SALIBI 1976.

86 Vgl. Salibi 1965, S. 157. 
Autonomie ihrer Provinz von der Hohen Pforte, zum anderen wurde mit dem neuen Mutașarrif Ohannès Pascha ein Kompromisskandidat zwischen Istanbul und Paris ernannt ${ }^{87}$.

Es scheint kein Zufall zu sein, dass die Mission lä̈que gerade zum Zeitpunkt der Machtübernahme der Jungtürken im Osmanischen Reich aktiv wurde. Bis jetzt hat die Forschung diese frappierende Parallele ignoriert. Dabei fällt auf, dass die Mission lä̈que ihre erste Schule in Thessaloniki 1907 in der Heimatstadt der Jungtürken eröffnete ${ }^{88}$ und in Beirut 1909 tätig wurde, also nach der konstitutionellen Revolution. Da die Archive aber über die konkreten Beziehungen zwischen der Mission laïque und den Jungtürken keine weiteren Auskünfte geben, können nur Vermutungen formuliert werden. Eine erste Verbindung zwischen den beiden Gruppen bestand über das Freimaurertum, zu dem sich trotz mancher Differenzen zwischen Freimaurern und Jungtürken ${ }^{89}$ viele Mitglieder des Komitees für Einheit und Fortschritt ${ }^{90}$ als auch mehrere Akteure der Mission laïque ${ }^{91}$ bekannten. Außerdem waren die Jungtürken sehr stark von der französischen Kultur und besonders vom Vorbild der Französischen Revolution geprägt ${ }^{92}$.

Allerdings spiegelte sich die Spaltung der jungtürkischen Bewegung nach 1902 in eine Mehrheitsgruppe, die die Zusammenarbeit mit Großbritannien und Frankreich akzeptierte, und eine Minderheitsgruppe, die einen stärkeren Nationalismus forderte, auch in der unterschiedlichen Bewertung ausländischer Schulen und Institutionen im Osmanischen Reich wieder ${ }^{93}$. Schließlich kam der Mission laïque aber zugute, dass seit der Machtübernahme des Komitees für Einheit und Fortschritt die Erziehung höchste Priorität erhal-

87 Vgl. Ohannès Pacha Kouyoumdian, Le Liban à la veille et au début de la grande guerre. Mémoires d'un gouverneur, Paris 2003, S. 8-9.

88 Vgl. ThÉVEnin 2002, S. 81.

89 Vgl. M. Şükrü HanioğLu, Notes on the Young Turks and the Freemasons, 1875-1908, in: Middle Eastern Studies 58 (1989), H. 2. S. 186-197, S. 193.

90 Vgl. Elie Kedouri, Young Turks, Freemasons and Jews, in: Middle Eastern Studies 7 (1971), H. 1, S. 89-104, S. 98.

91 Auch wenn diese Tatsache bekannt ist, gibt es wenige konkrete Angaben, da die Zugehörigkeit zu einer Freimaurerloge zum einen geheim war und zum anderen von vielen Mythen umrankt war und ist, was oft zu Fehleinschätzungen geführt hat. Sicher ist, dass Deschamps in späten Jahren Freimaurer wurde. Vgl. André ThÉvenin, Pierre Deschamps (1873-1958). Premier missionnaire laïque, Paris, o.J., S. 75. In den Anfangsjahren gehörte auf jeden Fall der zweite Direktor in Beirut, Émile Chaufour, einer Loge an. Das zeigt sich an dem Lorbeerkranz und der römischen Zahl eins, die im »Livre du personnel« hinter seinem Namen vermerkt sind. Laut Ouzouf / Ouzouf 1992, S. 279, bekamen Lehrer, die Freimaurer gewesen waren, bei ihrer Beerdigung einen Kranz von ihren Mitbrüdern auf das Grab gelegt.

92 Vgl. Kedouri 1971, S. 102; M. Şükrü HanioĞLu, The Young Turks in Opposition, New York/Oxford 1995, S. 16-18.

93 Vgl. M. Şükrü HanioĞLu, Preparation for a Revolution. The Young Turks, 1902-1908, Oxford 2001, S. 316. 
ten hatte ${ }^{94}$. Da es jedoch wenige Verbindungen zwischen den Jungtürken in Paris und denjenigen in Thessaloniki gegeben zu haben schien ${ }^{95}$, wurden die Kontakte zwischen der Mission laïque und den Jungtürken im Libanon wohl nicht in Frankreich geknüpft.

Das Interesse der Jungtürken am revolutionären Frankreich und an freimaurerischen Ideen stellte einen weiteren Grund für deren Ablehnung durch die katholischen Orden, insbesondere die Jesuiten, dar. Vor allem der Jesuitenpater Louis Cheikho (arabisch Luwīs Šayhū) verfasste viele Schriften gegen die Freimaurer ${ }^{96}$. Die Akteure der Alliance israélite universelle zeigten sich hingegen sehr angetan von der jungtürkischen Revolution. Ihr Bulletin berichtete 1908:

On a pu voir dans la capitale et dans les centres importants de la province, aussi bien à Salonique, à Smyrne qu'à Beyrouth ou à Damas, des manifestations grandioses organisées par toutes les parties de la population, musulmans, juifs et chrétiens, pour proclamer solennellement l'attachement unanime à l'ère nouvelle, jurer fidélité à la Constitution et exprimer les plus magnifiques espérances de paix et d'union sociale $^{97}$.

Diese Begeisterung lag zum einen an dem relativ hohen Anteil von Juden innerhalb der jungtürkischen Bewegung ${ }^{98}$ und zum anderen an der Hoffnung auf Reformen, die auch den Status der Juden im Osmanischen Reich verbessern würde ${ }^{99}$. Die Offenheit der Jungtürken ließ zudem Deschamps zu der Überzeugung gelangen, dass die osmanische Regierung eine laizistische Schule in Beirut unterstützen würde. Dafür würde sie ihr den benötigten Firman (imperiales Dekret) geben beziehungsweise die Mission lä̈que dürfte diesen Firman von einer anderen laizistischen französischen Schule in Bei-

94 Vgl. Kayali 1997, S. 76.

95 Vgl. den Brief von G. Lowther an C. Hardinge, Konstantinopel, 29.05.1910, abgedruckt in: Kedouri 1971, S. 94.

96 Vgl. Monica Corrado, The Essentials of Freemasonry (al-khulâsa al-mâsûniyya), an Annoted Translation of Luwîs Shaykhû's Article on Freemasonry, in: AHL (Archeology \& History in Lebanon), Winter 2007, S. 34-65; Anne-Laure DUPONT, Usages et acculturation de la Francmaçonnerie dans les milieux intellectuels arabes à la fin du XIXe siècle à travers l'exemple de Jurji Zaydan (1861-1914), in: Cahiers de la Méditerranée 72 (2006), S. 16. URL: http://cdlm. revues.org/index1175.html (18.08.2010). Zur Person Cheikhos vgl. auch Leyla DAKHLI, Une génération d'intellectuels arabes. Syrie Liban 1908-1940, Paris 2009, S. 236-237 (=DAKHLI 2009a).

97 AIU/Paris, Bulletin de l'Alliance Israélite Universelle 70 (1908), »Israélites de Turquie«, S. 73-77, S. 73.

98 Vgl. Kedouri 1971, S. 90.

99 Vgl. Kirsten E. Schulze, The Jews of Lebanon. Between Coexistence and Conflict, Brighton 2009, S. 16. 
rut, die vor der Schließung stand, erhalten ${ }^{100}$. Deswegen akzeptierte er auch nach kurzem Zögern die Bitte der Mission laïque, der erste Direktor dieser Schule zu werden und mit seiner Familie nach Beirut zu ziehen ${ }^{101}$.

Das konkrete Interesse der neuen osmanischen Regierung gegenüber der Mission laïque manifestierte sich auch im November 1909, als ein osmanisches Komitee aus 12 Notabeln auf Anregung des Valis der Stadt Beirut die Mission lä̈que um Kooperation für eine »Kunstgewerbeschule« (École des Arts et Métiers) bat ${ }^{102}$. Nach einigen Verhandlungen, in denen deutlich wurde, dass sowohl das Komitee als auch die Mission lä̈que die Oberhand über diese Schule haben wollten, entschied der Vorstand der Mission laïque im März 1910, dieses Projekt zu beenden ${ }^{103}$. Damit entsprach er der Ansicht des französischen Außenministers, der einem zu starken osmanischen Einfluss eine Absage erteilt hatte:

Tout en reconnaissant l'intérêt que présenterait à Beyrouth l'ouverture d'une école professionnelle, je ne puis en principe approuver un projet qui aboutirait en réalité à »ottomaniser « ou tout au moins à »Franco-ottomaniser« l'œuvre que nous avons entreprise à Beyrouth. J'estime que cette œuvre doit rester essentiellement française et qu'il vaut mieux lui conserver des proportions même modestes que de la voir s'agrandir en acceptant leur participation, sinon le contrôle, d'un comité ottoman ${ }^{104}$.

Diese Episode knüpfte an ein erstes Projekt des Valis von Beirut 1905, Khalil Pascha (arabisch Hualīl Bāša), an, der ein »institut d'enseignement technique« nach französischem Vorbild und mit französischen Lehrern errichten wollte ${ }^{105}$.

Dieses Beispiel macht deutlich, dass eine Kooperation mit Frankreich im Schulbereich von osmanischer Seite aus bestand, aber von Frankreich nicht akzeptiert wurde, weil es den französischen Akteuren um die Wahrung ihres

100 »Et puis n'oublions pas que si, pour le Liban, aucune demande d'autorisation n'est nécessaire, il n'en est pas de même à Beyrouth. Sans doute, cette autorisation serait accordée sans difficulté, mais il est plus pratique, plus rapide de se substituer à Augier«. AN/Paris, $60 \mathrm{AJ}$ 118, Brief von Deschamps an Besnard, Beirut, 10.06.1909. Zwar war der Vali von Beirut von dieser Praxis wenig begeistert, aber akzeptierte schließlich die Erklärung der Übernahme. Vgl. TноBIE 2009, S. 49-50.

101 Sein Zögern lag laut Bericht des Verwaltungsrats daran, dass er nicht wusste, ob seine Kinder in Beirut eine gute Schule besuchen könnten. Daraufhin köderte ihn die Leitung der Mission laïque mit dem Versprechen, »de faire élever ses enfants à Beyrouth, dans notre Collège même, où il y aura lieu de créer une section européenne«. MLF/Paris, »Compte-rendus du Conseil d'administration«, Sitzung vom 08.07.1909.

102 Ebd., Sitzung vom 18.11.1909.

103 Vgl. THовіе 2008, S. 50-56.

104 MAE/Nantes, »Beyrouth Consulat Général A«, 352, Brief des Außenministers Stéphane Pichon an den französischen Botschafter in Konstantinopel, Paris, 12.03.1910.

105 Ebd., Brief des Generalkonsuls an den Botschafter, Beirut, 29.11.1905. 
dominierenden Einflusses ging. Außerdem zeigt sich sehr klar die französische Abwehr einer Vermischung der Kulturen oder Bildungssysteme, wie sie in den späteren Jahren ernsthaft diskutiert wurde.

In der Einschätzung der osmanischen »Machtlosigkeit« kam es in der Folge zu Differenzen zwischen der Mission laïque in Paris und Deschamps als »man on the spot«. Ein Streit entbrannte, als zur Eröffnung der Mädchenschule im Herbst 1910 der Vorstand der Mission laïque in Paris trotz Deschamps' Einwänden wieder keinen Firman beantragte. Deschamps hatte Sorge, dass die Jungtürken die Schule wieder schließen würden, weil sie über keine Erlaubnis verfüge ${ }^{106}$. Er beschuldigte außerdem die französische Regierung, die Mission lä̈que in diesem Punkt schlecht beraten zu haben, eventuell sogar mit Absicht ${ }^{107}$. Deschamps selbst rief dagegen zu einer respektvolleren Haltung gegenüber der osmanischen Regierung auf: Die Mission lä̈que sollte zeigen, dass sie nicht wie die christlichen Schulen Proselytismus betreibe, sondern, »que nous pouvons être pour lui des auxiliaires dont il n'a rien à redouter ${ }^{108}$. Die weitere Entwicklung gab Deschamps recht, denn Ende 1910 erhielt die französische Botschaft einen Brief des osmanischen Erziehungsministers, in dem dieser daran erinnerte, dass nur autorisierte Schulen im Osmanischen Reich Zeugnisse ausstellen dürften. Allerdings wurde die Frage nicht weiterverfolgt und erledigte sich mit dem Ende des osmanischen Regimes.

\section{Mechanismen der Integration in die lokale Gesellschaft}

Neben der Akzeptanz und Unterstützung durch die französischen und osmanischen Autoritäten bedurften die französischen Schulen für ihre Integration in die Gesellschaft der Unterstützung der Bevölkerung, und insbesondere der einflussreichen Notabeln. Auch die Mühen und Strategien, die eine ausländische Institution unternehmen musste, um sich in die lokale Gesellschaft zu integrieren, lassen sich besonders gut an der Mission lä̈que als >Neuling in der Beiruter Schullandschaft untersuchen.

Die Mission lä̈que befand sich zunächst im Nachteil gegenüber den französischen Schulen der katholischen Orden und der Alliance israélite, die seit Ende des 18. beziehungsweise des 19. Jahrhunderts im Libanon ansässig und in die Gesellschaft integriert waren. Diese hatten von der Schulpolitik der

\footnotetext{
106 Vgl. AN/Paris, 60 AJ 118, Brief von Aulard an Deschamps, Jouy-en-Josas, 23.08.1910.

107 »I1 y a des moments où je pense que nos adversaires n'auraient pas mieux agi pour nous nuire que le Ministère en nous conseillant de ne pas demander le firman«. Brief von Deschamps an Besnard, Beitmery, 10.08.1910, abgedruckt in: Dialogues 35/36/37, Éléments pour une histoire de la Mission laïque française 1902-1982, S. 100-102, S. 101.

108 Ebd.
} 
Hohen Pforte profitiert, die Orden auch von der Unterstützung durch den lokalen Klerus, vor allem der maronitischen Kirche, sowie von der Akzeptanz der Bevölkerung ${ }^{109}$. Gleiches galt für die Schulen anderer nationaler und religiöser Provenienz, wie Ussama Makdisi anhand der amerikanischen Missionare im Libanon deutlich gemacht hat ${ }^{110}$. Allerdings hatten sich die katholischen Schulen besonders im Libanongebirge niedergelassen, dessen christliche Gouverneure das »œuvre civilisatrice des nombreux établissements d'éducation entretenue et patronnée par elle [Frankreich] « schätzten ${ }^{111}$.

In Beirut konnten die französischen katholischen Schulen und die der Alliance israélite sich ebenfalls etablieren, aber hier trafen sie auch auf die Konkurrenz anderer ausländischer und lokaler Schulen. In nicht christlich dominierten Städten und Gegenden wurden die katholischen Schulen zudem massiv kritisiert und ihnen wurde Proselytismus und Zusammenarbeit mit der politischen Macht Frankreich vorgeworfen. Repräsentativ für die Mischung aus Faszination und Kritik, die viele Nicht-Katholiken angesichts der französischen katholischen Schulen empfanden, ist der muslimische Gelehrte Husayn al-Ğisr (1845-1909) aus Tripoli: Er erkannte »die Überlegenheit des Westens [...] [im] Streben des Volkes nach Bildung und Wissenschaft« sowie dessen »materielle Überlegenheit«, »doch gleichzeitig warnte er vor dem Verfall, der durch die Übernahme westlicher Sitten [...] hervorgerufen würde ${ }^{112}$. In anderen, stärker städtisch und mitelleständisch geprägten, Milieus überwogen in dieser Zeit hingegen die Kritik an der eigenen Zivilisation und der Wunsch nach deren Erneuerung durch Imitation des Westens ${ }^{113}$.

Die vielfältigen Positionen gegenüber dem Westen zeigten sich zudem in der Einstellung arabischer Intellektueller gegenüber dem Konzept des Säkularismus. Während einige Christen wie der Beiruter Ğūrğ̄̇ Zaydān die radikale Einführung des Säkularismus in die Politik, die Religion und das Denken ihrer Gesellschaft forderten, erklärten auch muslimische Intellektuelle wie der Damaszener Muhammad Kurd 'Alī die Trennung von Staat und Kirche für notwendig. Allerdings gingen die Muslime in ihrer Kritik an der Religion in der Regel nicht so weit wie ihre christlichen Kollegen, sondern beanstandeten vor allem den Fanatismus und die Ungebildetheit ihrer Gelehrten ${ }^{114}$.

109 Für die Integration der Jesuiten in die libanesische Gesellschaft vgl. VERDEIL 2003.

110 Ussama Makdisi, Artillery of Heaven. American Missionaries and the Failed Conversion of the Middle East, Ithaca/London 2008, S. 217.

111 Siehe beispielhaft die Memoiren Ohannès Pacha Kouyoumdjians. Vgl. Kouyoumdjian 2003, S. 21.

112 Johannes EBERT, Religion und Reform in der arabischen Provinz. Husayn al-Gisr at-Traboulsi (1845-1909) - Ein islamischer Gelehrter zwischen Tradition und Reform, Frankfurt am Main 1991, S. 113, 117.

113 Vgl. SCHÄBLER 2003; Watenpaugh 2006.

114 Vgl. YARED 2002, S. 195. 
Diese Strömungen versuchten sich die Verantwortlichen der Mission laïque zu Nutze zu machen, indem sie auf die Beiruter Kreise setzten, die mit dem bisherigen Bildungsangebot in der Stadt nicht zufrieden waren. Zu diesem Zweck bauten sie bewusst ein Netzwerk aus Kontakten auf, das sich auf Beiruter Freimaurer und sunnitische Notabeln der Stadt stützte. Die erste Kontaktaufnahme lief allerdings über den Weg des Freimaurertums. Gleich nach seiner Ankunft im Sommer 1909 besuchte Deschamps die als Freimaurer bekannten Beiruter Familien. Dazu gehörte die bekannte griechisch-orthodoxe Händlerfamilie Sursuq (arabisch Șurșuq) ${ }^{115}$, die er als erste aufsuchte: »Vu Sursock, le vénérable de la Loge Liban; il est très bien; et, paraît-il, est quelqu'un « ${ }^{116}$. An Sursuqs Reaktion wird deutlich, dass die Beiruter Freimaurer einer laizistischen Schule nicht ablehnend, aber auch nicht sehr euphorisch gegenüber standen:

Il m'assure, et autres avec lui, qu'un établissement laïque peut réussir ici, mais il faut qu'il soit sérieux! C'est l'éternel refrain.- Et par sérieux, ils entendent d'abord un établissement bien aménagé (c'est la part du caractère oriental: il faut paraître), et ils ne manquent pas de me dire: il nous faudra beaucoup d'argent, en avez-vous?- Je réponds un peu à côté; oui, nous en avons; mais pas autant que si nous en aurons davantage; c'est-à-dire, oui, nous en avons, mais pas assez pour nous installer d'une manière définitive, dans un local à nous, construit pour nous $[\ldots]^{117}$.

Die von Sursuq betonte Notwendigkeit einer finanziell gut ausgestatteten Schule nennt ein wichtiges Argument für die Akzeptanz einer Einrichtung. Wie die Analyse der anderen ausländischen Schulen der Zeit zeigen wird, machten deren beachtliche finanzielle Mittel sie besonders attraktiv.

Sursuq bot Deschamps seine Hilfe an und nannte ihm weitere Kontaktpersonen: »Il m'a promis de m'aider et a commencé, en me remettant un mot par Farès Mischrik [sic!] que j'irai voir demain « ${ }^{118}$. Der Genannte, Fāris Mušriq, war ein anderer bekannter Freimaurer und Großmeister der Loge Sannine. Er hatte sich Anfang des 20. Jahrhunderts sehr kritisch gegenüber Frankreichs Patronage zugunsten der Maroniten geäußert und gedroht, dass alle griechisch-orthodoxen Mitglieder seiner Loge zu einer schottischen Loge überwechseln würde, wenn Frankreich diese Patronage nicht beendete ${ }^{119}$.

115 Manchmal schrieb sich diese Familie auch Sursock. Bezüglich ihrer zentralen Rolle in Beirut siehe Fruma ZACHS, The Making of a Syrian Identity. Intellectuals and Merchants in Nineteenth-Century Beirut, Leiden/Boston 2005, S. 238-239; Dorothe Sommer, Les premières loges écossaises en Grande Syrie, in: Cahiers de la Méditerranée 72 (2006), S. 321-330, S. 324.

116 AN/Paris, 60 AJ 118, Brief von Deschamps an Besnard, Beirut, 10.06.1909.

117 Ebd.

118 Ebd.

119 Vgl. Souad Stim, Le rôle de la franc-maçonnerie dans le développement des nouvelles idées au Levant, in: Delpal u.a. (Hg.) 2005, S. 211-222, S. 220. 
Von Sursuq vermittelt, besuchte Deschamps Mušriq in Zahlé120. Dieser Kontakt hielt sich bis in die Mandatszeit, als Mušriq als Mitglied des Elternrats der Mission lä̈que, des sogenannten Comité de patronage aktiv war ${ }^{121}$. Der französische Generalkonsul in Beirut hieß diese Verbindung nicht gut. Es erzürnte ihn, dass es ein erstes Zusammentreffen von Vertretern der Mission laïque mit Mušriq und einem anderen griechisch-orthodoxen Freimaurer, Nağīb Țarād, bereits 1907 in Paris gegeben hatte ${ }^{122}$. In seinem Bericht über dieses Treffen an das Außenministerium äußerte sich der französische Generalkonsul in Beirut sehr negativ über Mušriq, weil dieser die Nähe zwischen Frankreich und den Maroniten kritisierte. Für den Generalkonsul war Mušriq deshalb »suspect de quelque particularité « ${ }^{123}$.

Über die libanesischen Freimaurer hinaus suchte die Mission lä̈que auch den Kontakt zu den französischen Freimaurern im Libanon ${ }^{124}$ oder wurde von diesen aufgesucht ${ }^{125}$. Allerdings beschränkten sich die Kontakte Deschamps' bald nicht mehr auf diese Kreise. Schon 1911 berichtete er von seiner Bekanntschaft mit dem sunnitisch-muslimischen Notabeln 'Umar Da'uq (arabisch ('Umar Dā'ūq) (1874-1949)'126. Da'uq, ein Beiruter Geschäftsmann und einflussreicher Politiker, war zu diesem Zeitpunkt sowohl Mitglied des Beiruter Stadtrates als auch der sunnitischen Wohlfahrtsorganisation Maqasid ${ }^{127}$. In der zweiten Hälfte des 19. Jahrhunderts hatte diese Organisation Schulen gegründet, um der Vorherrschaft der europäischen und christlichen Schu-

$120 »[\ldots]$ j’ai vu Farès Muschneck [sic], à Zahlé (dans le Liban)«. AN/Paris, 60 118, Brief von Deschamps an »Monsieur le Président«, Beirut, 19.06.1909.

121 Vgl. Kapitel 5.2.

122 MAE/Nantes, »Beyrouth Consulat Général A«, 207: »1907 Allocations établissements religieux et laïques«, Briefentwurf des Consul Général nach Konstantinopel, 16.06.1907.

123 Ebd., Brief des Generalkonsuls an das französische Außenministerium, Beirut, 10.06.1907.

124 Vgl. AN/Paris, 60 AJ 118, Brief von Deschamps an Besnard, Beirut, 10.06.1909, in dem er von einem Franzosen namens Romégon berichtete, der bei der Post arbeite: »[...] il est déjà avec nous, il le sera encore plus; il est maçon et se démène beaucoup; et puis il est agent de la poste française, le successeur de l'oncle Barbasson et un personnage dans la Colonie [...]

125 Vgl. AN/Paris, 60 AJ 120, Brief von Le Baut an Besnard, [Ort unleserlich] »chez le Dr. Zein«, 02.08.1913: »M. Bernet et le Dr. Zein ont provoqué une réunion pour la première quinzaine de septembre en vue de recueillir des adhésions à la Mission. Cette réunion [...] réunirait les membres des autres loges de Syrie, délégués à cette inauguration, et serait privée. Je vois qu'il n'y a aucun inconvénient à ce qu'elle ait lieu en ce moment, si toutefois vous en voyiez, je ferai fixer une autre date. Je demanderais surtout à ceux qui voudront s'inscrire comme membres de la Mission de Syrie de faire de la propagande pour l'établissement de Beyrouth. Des frères, les maronites [...] parcourent le Liban et le Vilayet de Damas préparant leur rentrée. Les Jésuites font beaucoup de propagande pour leur nouveau cours industriel, il serait bon que nous essayons de notre côté de faire quelque chose«.

126 Vgl. AN/Paris, 60 AJ 119, Brief von Dupouey an den Präsidenten der Mission laïque, Beirut, 13.11.1911.

127 Vgl. Carla EdDÉ, L'émergence de la capitale libanaise à l'ombre du mandat français. Les premiers pas (1918-1924), Diss. Aix-Marseille/Beirut 2008, S. 517. 
len zuvorzukommen und einige, islamisch geprägte Schulen, allerdings mit einem modernen Curriculum, anzubieten ${ }^{128}$. Die Schule in Beirut entstand 1878.

Da Da'uq war weder Freimaurer ${ }^{129}$ noch ein Unterstützer des Laizismus war und dazu, wie die meisten sunnitischen Notabeln, nicht zum traditionellen frankophonen und frankophilen Milieu in Beirut ${ }^{130}$, ist es vielleicht über den Kommerz zu einer Begegnung gekommen, da viele Freimaurer Händler waren ${ }^{131}$. Es steht zu vermuten, dass er sich von der Kooperation mit der Mission laïque gewisse Vorteile für sein geschäftliches und privates Leben erhoffte. In der Tat half Dauq der Mission lä̈que in Geld- und Immobilienangelegenheiten ${ }^{132}$ und formulierte im Gegenzug diverse Anliegen. So sollte Deschamps sich beim französischen Außenministerium für seinen Verwandten Ahmad Da'uq (arabisch Aḥmad Dā'ūq) einsetzen, weil dieser in einer französischen Handwerkerschule seine Ausbildung machen wollte. Der französische Generalkonsul unterstützte dieses Anliegen, weil »le requérant appartient à une famille musulmane qui compte parmi les notables de la ville $\ll^{133}$.

Während Deschamps und Da'uq anscheinend sehr gut miteinander auskamen, gingen Deschamps' Nachfolger Dupouey 1911 die Forderungen Da uqs zu weit. Auch wenn die Zentrale der Mission laïque in Paris bedauerte, dass Da uq nicht mehr so kooperativ sei wie zu Dechamps' Zeiten, mahnte sie Dupouey erstens zur Vorsicht, dass er keine Verleumdung betreibe, und zweitens zur Nachsicht, da sie auf Da uq angewiesen seien: Schließlich sei Da uq »un de ceux [...] qui ont le plus d'influence sur leurs coreligionnaires $\aleph^{134}$.

128 Vgl. 'Ișām Muḥammad Šabārū, Ğam'īyat al-maqāṣid al-ḩayrīya al-islāmīya fī Bayrūt [Die islamische wohltätige Gesellschaft in Beirut] (1295-1421/1878-2000), Beirut 2000, S. 29; Michael Johnson, Factional Politics in Lebanon: the Case of the Islamic Society of Benevolent Institutions (al-Maqāsid) in Beirut, in: Middle Eastern Studies 14 (1978), H. 1, S. 56-75, S. 58; Donald J. Cioeta, Islamic Benevolent Societies and Public Education in Ottoman Syria, 18751882, in: The Islamic Quarterly 26 (1982), H. 2, S. 40-62.

129 Gespräch der Verfasserin mit Prof. Carla Eddé am 10.11.2008 in Beirut.

130 Die sunnitischen Notabeln kooperierten erst ab den 1920er Jahren mit der Mandatsmacht. Vgl. Carla EDDÉ, Étude de la composition du conseil municipal beyrouthin (1918-1953). Renouvellement des élites urbaines ou consolidation des notables?, in: Agnès FAvier (Hg.), Municipalités et pouvoirs locaux au Liban, Beirut 2001, S. 79-102.

131 Vgl. Sommer 2006, S. 324.

132 So berichtete der französische Generalkonsul, dass er im August 1909 mit Da uq zum griechischen Konsulat gegangen sei, um zu sehen, wann dieses frei würde. Vgl. MAE/Nantes, »Beyrouth Consulat Général A«, 352, Notiz des »Consul Général de France en Syrie«, Beirut, 16.08.1909.

133 Ebd., Brief von Deschamps an den Generalkonsul, Beirut, 04.06.1910.

134 Vgl. AN/Paris, 60 AJ 119, Brief von Dupouey an Besnard, Beirut, 16.10.1911; Antwort aus Paris vom 26.10.1911. 
Diese Episode macht deutlich, dass die Verbindungen zwischen der Mission laïque und den Beiruter Notabeln sehr fragil waren und stark von persönlichen Beziehungen abhingen.

Eine andere sunnitisch-muslimische Familie, die schnell Kontakt mit der Mission lä̈que aufnahm, war die Familie Fakhuri (arabisch Fāhūūī). Muhammad Fakhuri (arabisch Muhammad al-Fāhūīī), ein Beiruter Apotheker, war ebenfalls in der Maqasid aktiv, wo er 1909-1912 und 1918-1926 Vorstandsmitglied, 1926 bis 1931 Vizepräsident sowie schließlich 19311933 deren Präsident war ${ }^{135}$. Während der Kontakt zu den Beiruter Freimaurern sich aus einer ähnlichen ideologischen Überzeugung erklären lässt, ist es sehr viel schwieriger, gemeinsame Punkte zwischen der Mission laïque als dezidiert laizistische Organisation und der Maqasid, einer eindeutig islamischen Wohlfahrtsorganisation, zu finden. Ein nicht zu unterschätzender Grund scheint die Persönlichkeit Pierre Deschamps' gewesen zu sein. Er betonte stets, dass ihm der Austausch mit der lokalen Bevölkerung immer äußerst wichtig gewesen sei ${ }^{136}$, was ihn deutlich von manchen seiner Nachfolger unterschied.

Zusammenfassend kann festgehalten werden, dass die Mission lä̈que sich ähnlich wie die katholischen Schulen vor ihr an lokale Würden- und Einflussträger wandte. Während die Orden die Notabeln aber vor allem im maronitischen Milieu suchten, baute die Mission lä̈que über andere Wege ihr Netzwerk auf. Ihre Ansprechpersonen waren, wie die Sursuqs, schon teilweise mit der französischen Erziehung in Berührung gekommen, während dieser Kontakt für andere Notabeln ganz neu war. Gemeinsam war diesen Notabeln, dass sie nicht zur traditionellen Klientel Frankreichs gehörten, da sie nicht der maronitischen, sondern vor allem den griechisch-orthodoxen und muslimisch-sunnitischen Gemeinschaften entstammten. In der Tat betrug der Anteil muslimischer Schüler in der Mission lä̈que im Schuljahr 19111912 34,4\%, während die großen katholischen Schulen im Libanon ungefähr $10 \%$ muslimische und nur sehr wenige griechisch-orthodoxe Schüler hat$\operatorname{ten}^{137}$. Die griechisch-orthodoxen und sunnitischen Religionsgruppen stellten zudem die alteingesessene Stadtbevölkerung von Beirut, wo sich die Mission laïque zuerst niederlie $\beta^{138}$.

135 Vgl. Michael Johnson, Class and Client in Beirut. The Sunni Muslim Community and the Lebanese State, London 1986, S. 22; Johnson 1978, S. 59.

136 Vgl. Deschamps 1982, S. 95.

137 Vgl. Thobie 2008, S.70. Der Autor beruft sich auf den Bericht, den Maurice Pernot im Auftrag der französischen Regierung über die Situation der französischen Schulen im Orient 1912 erstellte. Demnach betrug der Anteil muslimischer Schüler der Lazaristen in Ayntoura 13,3\%, bei den Jesuiten in Beirut sogar nur 7,6\%. Vgl. auch VerdeIL 2007, S. 35.

138 Vgl. ZACHs 2005, S. 50-67. 
Auch wenn die Unterstützung durch lokale Notabeln sehr wichtig war, benötigten die französischen Schulen aber ebenso ein Interesse der breiten Bevölkerung, welche ihre Kinder auf diese Schulen schicken würde. Das lässt sich an der Mission laïque besonders prägnant zeigen, da diese Organisation sowohl eindeutige Verfechter als auch harte Kritiker fand. Allgemein profitierte die Organisation stark von der hohen Bedeutung, die der Bildung innerhalb der Gesellschaften des Osmanischen Reiches in dieser Zeit zukam: »Education was not an abstract or a statistical issue but rather one which was seen to have an enormous impact on society as a whole, and [...] on the individuals that comprise it $^{139}$. Indes fielen die Reaktionen innerhalb der Bevölkerung auf die Mission laïque sehr verschieden aus. Einige Zeitschriften äußerten sich positiv über diese neue Schule. So berichtete die Zeitschrift al-Muqtațaf 1910, dass die Mission laïque die Religion ihrer Schüler respektiere und sich zudem darum bemühe, alles Trennende zwischen den Schülern zugunsten einer Einheit abzubauen:

Das französische laizistische College (al-kullīya al-'almānīya) in Beirut hat uns sein Jahrbuch geschenkt, in dem seine Abteilungen, Bedingungen, Richtlinien und Kurse erklärt werden. Vorangestellt ist eine Einleitung, in der dargelegt wird, dass der Zweck der laizistischen Mission in ihrem Dienst an Frankreich außerhalb Frankreichs in seinen Kolonien und in fremden Ländern sowie in der Verbreitung seiner Sprache und Grundsätze liegt, wobei sie gleichzeitig Fürsorge für die Ehrerbietung gegenüber allen Religionen ohne Unterschied trägt. Diejenigen, die diese Arbeit verrichten, glauben, dass sich dieser Dienst nicht auf etwas stützen darf, das zu Trennung und Zwietracht führt, sondern auf solche Mittel, die die Herzen zusammenführen und die Bande der Brüderschaft und Versöhnung zwischen den Menschen stärken. Deshalb wurde eine patriotische Erziehung zur Grundlage des Unterrichts in dieser Schule gemacht, nicht die Sichtweisen einer bestimmten Religion werden gelehrt. Nichtsdestotrotz genießen die Schüler volle Freiheit bei der Verrichtung ihrer religiösen Pflichten und treffen dabei auf keinerlei Hindernisse, sondern es werden ihnen alle notwendigen Mittel zur Verrichtung dieser Pflichten bereitgestellt.

In seinem ersten Jahr umfasste das College vier Abteilungen: die Abteilung für Allgemeinbildung, die Abteilung für die Vorbereitung zur Schule für Medizin, die Abteilung für das Handwerk und die kaufmännische Abteilung. Und es besteht die Absicht, einen landwirtschaftlichen Zweig in der Bekaa-Ebene zu gründen, die berühmt für ihre fruchtbare Erde ist, so dass es sich ihr ziemen würde, wenn dies verwirklicht würde ${ }^{140}$.

139 FORTNA 2002, S. 55.

140 »Kitāb al-kullīya al-'almānīya al-fransawīya«, in: al-Muqtațaf 37 (1910), S. 810. 
Auch wenn der Autor dieses Artikels vor allem die Ziele der Mission laïque präsentiert, wird seine Sympathie für deren Ziele deutlich. Al-Muqtațf gehörte zu den progressiven und liberalen Zeitungen dieser Zeit. 1876 von zwei Christen, die zu der Zeit dem amerikanischen Syrian Protestant College in Beirut als Lehrkräfte angehörten, in Beirut gegründet, wurde die Zeitung 1885 nach Kairo verlegt und berichtete von da aus über alle Themen politischer, kultureller und religiöser Brisanz. Vor allem säkularen Intellektuellen, sowohl christlichen als auch muslimischen, bot die Zeitschrift ein Forum, um über die Fragen der Zeit zu diskutieren, während sie vom traditionellen Klerus sehr kritisch gesehen wurde ${ }^{141}$.

Demgegenüber gab es in der Bevölkerung auch harsche Kritik an der laizistischen französischen Schule. Ein ehemaliger Schüler einer katholischen Schule verfasste 1911 ein Pamphlet gegen die Zeitschrift der ehemaligen Schüler der Mission laïque, die den Namen Le Lien trug ${ }^{142}$. Dieses Pamphlet war in der katholischen Druckerei von Beirut gedruckt worden, die den Jesuiten gehörte, welche sich ebenfalls sehr negativ über die Mission laïque äußerten ${ }^{143}$. Aber auch im muslimischen Milieu stieß die Mission laïque auf große Schwierigkeiten, besonders bei der Rekrutierung von Schülerinnen ${ }^{144}$. Deshalb schlug die erste Direktorin, Marie Digrado, vor, zunächst vor allem christliche und dann die eigentlich als Zielgruppe geltenden muslimischen Schülerinnen zu erreichen. Die Leitung in Paris allerdings beharrte auf den Muslimen als primäre Klientel und bat Digrado, die schwierige Anfangsphase durchzuhalten ${ }^{145}$.

In den ersten Jahren bis zum Ersten Weltkrieg schwankte die Zahl der Schüler an den zwei laizistischen Schulen zwischen 150 und 250. Neben den muslimisch-sunnitischen und griechisch-orthodoxen Gemeinschaften nahm die israelitische Konfession den dritten Platz einnahm ${ }^{146}$. Damit unterschied sich die Klientel der Mission laïque in Beirut stark von der ihrer Schulen in Ägypten und später auch in Syrien, die entgegen ihres Wunsches mehrheitlich jüdische Schüler verzeichneten ${ }^{147}$.

141 Vgl. Dagmar Glass, Der Muqtataf und seine Öffentlichkeit. Aufklärung, Räsonnement und Meinungsstreit in der frühen arabischen Zeitschriftenkommunikation, Würzburg 2004, Bd. II, S. S.633-644.

142 Zitiert in: Spagnolo 1973, S. 581.

143 Vgl. SJ/Vanves, RPO 62: »USJ Collège Secondaire 1877-1957«, Notizblatt »Budget Affaires étrangères 1913?«. Allerdings hält der Autor den Einfluss der laizistischen Einrichtungen zu dem Zeitpunkt noch für gering.

144 Vgl. AN/Paris, 60 AJ 120, Bericht von Besnard aus Alexandria, 04.01.1913.

145 Vgl. ebd., Brief von Besnard an Digrado, Paris, 18.06.1913.

146 Vgl. Thobie 2008, S. 72. Vgl. auch die Tabellen im Anhang.

147 Für Ägypten vgl. AbÉCAssis 2000, S. 88; für Syrien vgl. Randi DeguiLhem, Impérialisme, colonisation intellectuelle et politique culturelle de la Mission Laïque française en Syrie sous Mandat, in: Nadine Méouchy/Peter Sluglett (Hg.), The British and French Mandates in Comparative Perspectives, Leiden 2004, S. 321-343, S. 334. 
Von der Forschung oft vernachlässigt wurde die Frage der Gründe, die die Eltern für ihre Entscheidung nannten, ihren Nachwuchs auf die Schule der Mission lä̈que zu schicken. Inwiefern reagierte die Mission laïque auf diese Wünsche und Forderungen? Aus den Archiven lassen sich vor allem zwei verschiedene Gründe herausarbeiten, die die Eltern für ihre Wahl angaben: die religiöse Neutralität der Mission laïque und das Erlernen des Französischen als Handelssprache. Der erste Direktor Deschamps sammelte die Briefe von Libanesen, die ihr Interesse an seiner Schule bekundeten. Da die Verfasser ein bestimmtes Anliegen hatten, formulierten sie ihren Brief sehr positiv, was aber nicht unbedingt Aufschluss über ihre allgemeine Einstellung zur französischen Kultur geben kann. In der Tat, so belegt die neueste Forschung zum Osmanischen Reich, aber auch zur kolonialen Bildungsgeschichte im Allgemeinen, hatten die lokalen Bevölkerungen in ganz unterschiedlichen Abstufungen Interesse an europäischer Bildung beziehungsweise wehrten sich gegen diese. Außerdem zeigte ihre Haltung oft ein großes $\mathrm{Ma} ß$ an pragmatischen und zweckgebundenen Motiven ${ }^{148}$.

In ihren Briefen nannten die Libanesen als Gründe für ihr Interesse zum einen die religiös neutrale Haltung, die sie sich von der Schule erhofften. So wandten sich die Bewohner des Dorfes Metn im Libanongebirge, dessen einzige Schule von einem englischen Protestanten mit starkem missionarischem Eifer betrieben wurde, 1910 an Deschamps. Ihre Forderung war eindeutig: »Nous sommes disposés à accomplir tout ce que vous demandez à ce propos; et nos élèves sont au-delà de cent! « $^{149}$ Als Reaktion auf diese Klage über massive Missionierung betonte die Mission laïque, wie schon 1907 in Thessaloniki, auch in Beirut ihre religiöse Neutralität. Sie passte ihr Programm den Bedürfnissen der Bevölkerung an und legte jeglichen öffentlichen antireligiösen Diskurs ab. In ihrem Prospekt von 1909 versprach die Schule den Eltern »que leurs enfants trouveront, dans son collège, non seulement la tolérance la plus scrupuleuse, mais le respect le plus sincère de leurs croyances et de leurs opinions $\aleph^{150}$. Wie wichtig den Libanesen diese Zusage war, zeigte sich auch an dem zitierten Artikel von al-Muqtataf, der den Respekt der Mission laïque gegenüber allen Religionen besonders betont.

Ein anderer Grund, der in den Elternbriefen formuliert wurde, war die Notwendigkeit, die französische Sprache für den Handel zu beherrschen sowie das Interesse der Bevölkerung an Schulen mit einem praktischen, technischen, vor allem aber wirtschaftlichen Zweig. So ist in den Protokollen

148 Bzgl. des Osmanischen Reiches vgl. ForTna 2002, S. 50-60; für die Kolonialgeschichte allgemein vgl. RotHERMUND 1999, S. 4-6.

149 MAE/Nantes, »Beyrouth Consulat Général A«, Brief der Bewohner von Metn an Deschamps, 31.10.1910.

150 Mission laïque française, Collège français de Beyrouth. Cours préparatoires. Cours professionnels, Beirut 1909, zitiert in: Тновіе 2009, S. 46. 
des Verwaltungsrats der Mission lä̈que vom November 1909, also kurz nach der Gründung der Schule in Beirut, vermerkt, dass eine Gruppe von Abgeordneten der Stadt Beirut die Mission laïque um den Aufbau eines technischen Zweiges in ihrer Schule gebeten habe, was die Zentrale aber aus finanziellen Gründen ablehnte ${ }^{151}$. Eine ähnliche Anfrage kam 1909 von der Ligue ottomane de l'enseignement in Konstantinopel ${ }^{152}$ und 1912 von den Bewohnern aus Adana, die die Mission lä̈que um den Aufbau einer Schule in ihrer Stadt baten, da Französischkenntnisse unablässig für den Handel seien ${ }^{153}$. Eine Statistik der Schule der Mission laïque in Beirut von 1913-1914 bestätigt das besondere Interesse ihrer Klientel an wirtschaftlichen Fächern: Von den 273 befragten Schülern gaben 105 Schüler »Commerce« als Berufsziel an, $34 »$ Industrie« und $24 »$ Médecine, Pharmacie $\ll^{154}$.

Auch wenn die Mission lä̈que die meisten der beschriebenen Anfragen ablehnte, ging sie doch auf die von der Bevölkerung formulierten Interessen ein, wie der Prospekt ihrer Schule in Beirut von 1909 zeigt. Sehr ausführlich werden die Ausbildungszweige beschrieben, die die Mission lä̈que ab 1909 neben den normalen Schulklassen anbot: eine höhere Handelsschule, ein industrieller Zweig, eine Klasse, die auf die Zulassungsprüfungen für das Medizinstudium an der französischen Universität Saint-Joseph in Beirut vorbereitete ${ }^{155}$. Entgegen der Aussage des Prospekts waren einige der Ausbildungszweige, vor allem die Vorbereitungskurse für die Medizinprüfung ${ }^{156}$, aber zu dem Zeitpunkt noch gar nicht etabliert. Mit der Ankündigung ging die Mission laïque also zum einen auf das Interesse der Bevölkerung ein, die sich nicht im Umfeld der Jesuiten befand, aber dort Einlass finden wollte. Zum anderen entsprach die Öffnung des Medizinstudiums an der Université Saint-Joseph für Nicht-Katholiken auch dem Vorhaben der französischen Regierung. Obwohl schließlich »an agreement was worked out so that the entrance examinations were administered by a jury picked jointly by the

151 MLF/Paris, »Procès-Verbaux du Conseil d'Administration«, Sitzung vom 18.11.1909.

152 Allerdings lautete die Vorgabe, die Mission laïque solle sich an dem Modell einer englischen Schule, welche im Dokument nicht näher definiert wird, orientieren. Vgl. MLF/Paris, »ProcèsVerbaux du Conseil d'Administration«, Sitzung vom 25.03.1909. Da der Verwaltungsrat dadurch die Chance sah, in Konstantinopel etwas für »le développement de l'influence française« zu unternehmen, bat er um weitere Details, aber anscheinend blieb es lediglich bei den Plänen.

153 AN/Paris, 60 AJ 120, Brief eines Lehrers bei den Jesuiten und eines Lehrers an der nationalen armenischen Schule an Dupouey, Adana, 09.10.1912.

154 Ebd., »Statistique des élèves 1913-1914«.

155 MAE/Nantes, »Beyrouth Consulat Général A«, Prospectus du Collège français de Beyrouth (1909), S. 2-4.

156 Siehe zum Beispiel AN/Paris, 60 AJ 119, Brief von Dupouey an den Präsidenten der Mission laïque, Beirut, 11.12.1911: »Le jour où le baccalauréat sera exigible à l'entrée de la Faculté française de médecine de Beyrouth (et il ne faut pas renoncer à cette juste ambition), le Collège des Jésuites devra abdiquer beaucoup de sa puissance«. 
French Consulate General in Beirut and the Jesuits ${ }^{157}$, blieb die Universität unter starker Kontrolle der Jesuiten ${ }^{158}$, was die nicht-katholische Bevölkerung auch während der Mandatszeit stark beklagen würde.

\section{Zwischen Abgrenzung und Anpassung: \\ Die Konfrontation der Mission lä̈que française mit den Beiruter Schulen}

Die Stimmen aus der Bevölkerung haben deutlich gemacht, dass die Mission laïque 1909 nicht in einen »schulleeren Raum« kam. Im Gegenteil waren der Libanon und Beirut voller nationaler, lokaler und ausländischer Schulen. Nicht ohne Grund wurde Beirut um die Jahrhundertwende »Die Stadt der Schulen « genannt ${ }^{159}$. In der Tat lernten in den frühen 1880er Jahren 12.452 Schülerinnen und Schüler unter 517 Lehrern in Beirut, was bei einer Gesamtbevölkerung von ca. 70000 (1863) einen hohen Prozentsatz ausmacht ${ }^{160} .1888$ unterrichteten die ausländischen Schulen davon allein 5000 Schüler, welche zu 99\% osmanische Staatsbürger waren ${ }^{161}$. Welche waren diese ausländischen und einheimischen Schulen, und warum schien es trotz der Schuldichte noch eine Lücke für die Mission läque zu geben? Wie reagierten die älteren Schulen auf die französische laizistische Schule? Im Folgenden werden die staatlichen, die privaten lokalen und die anderen ausländischen und französischen Schulen in ihrer Beziehung zur Mission lä̈que dargestellt. Auf diese Weise wird die neueste Forschung zu Bildung im späten Osmanischen Reich von Fortna, Somel und Hanssen gewinnbringend erweitert. Diese Autoren überwinden überzeugend die Auseinandersetzungen der zwei Forschungsrichtungen bezüglich der »ewigen Frage« des westlichen Einflusses im Nahen Osten, die sich seit Jahrzehnten gegenüberstehen und noch heute Anhänger haben ${ }^{162}$ und betonen demgegenüber, dass man zum einen

157 Spagnolo 1973, S. 575.

158 Vgl. Baktiaya 2008, S. 87.

159 So die Gelehrten M.T. Khairallah 1912 und Martin Hartmann 1913, zitiert in: Martin Strohmeier, Muslim Education in the Vilayet of Beirut, 1880-1918, in: Caesar E. Farah (Hg.), Decision Making and Change in the Ottoman Empire, Kirksville, Missouri 1993, S. 215-241, S. 218.

160 Vgl. Hanssen 2005, S. 163; die Zahl der Gesamtbevölkerung findet sich bei Hanssen 2005, S. 141.

161 Fortna 2002, S. 53.

162 Das eine Lager beruft sich auf Albert Hourani und proklamiert die Bedeutung des westlichen Einflusses im Osmanischen Reich, besonders der Missionare, als primäre Quelle der Reformbewegungen, sowohl auf der staatlichen als auch auf der kulturellen (in Form der nahḍa-Bewegung) Ebene. Vgl. Albert Hourani, Arabic Thought in the Liberal Age, 17981939, Cambridge 1983, Preface; vgl. auch Hisham Sharabi, Arab Intellectuals and the West. The Formative Years, 1875-1914, Baltimore/London 1970, S. 2: »The rise of the intellectuals 
die Frage der Erziehung im Osmanischen Reich nicht nur in Beziehung zum Westen sehen sollte ${ }^{163}$, und dass zum anderen die Perspektive der lokalen Akteure gewinnbringend sei ${ }^{164}$. Diese Ansätze sollen mit der Untersuchung der Pluralität der Schulen im Libanon weiter untermauert werden.

Auch wenn spätestens seit der Revolution der Jungtürken die Erziehung eines der Hauptinteressen der Regierung war, blieb die Situation der staatlichen Schulen im Osmanischen Reich ein Kritikpunkt und wurde von vielen als defizitär beschrieben. Die Tanzimat-Reformen von 1839 bis 1878, die die Modernisierung des Osmanischen Reiches zum Ziel hatten, betrafen auch die staatlichen Schulen: Durch die Durchsetzung eines staatlichen Bildungsmonopols sollten kompetente und willige Staatsdiener geformt werden, aus denen man die Beamten für den Staatsapparat $z u$ rekrutieren gedachte ${ }^{165}$. In diesem Punkt ähnelten die Zielsetzungen der osmanischen Schulen stark denen der europäischen Schulen in dieser Zeit ${ }^{166}$. Außerdem wurde auf das Erlernen der europäischen Sprachen in den staatlichen Schulen Wert gelegt, um die Schüler als spätere Diplomaten und Übersetzer im Kontakt mit den europäischen Staaten einsetzen zu können ${ }^{167}$. Schließlich hofften die Reformer, dass die Schulabsolventen auf diese Art und Weise die Ideale der Tanzimat verinnerlichen und in die Gesellschaft einbringen würden ${ }^{168}$.

and the elaboration of ideological functions must be seen as a manifestation of the process of education and enlightenment brought about by increasing contact with Europe«; S. 15: »Christians aspired to be liberated one day by France, Britain, or some other European power«. Das andere Lager weist den Einfluss der westlichen Ideen und Akteure auf die Reformbewegungen im Osmanischen Reich zurück und betont stattdessen die Eigeninitiative osmanischer Akteure, entweder aus christlichen oder islamischen Motiven heraus. In seinem Buch »The Arab Awakening« von 1938, S. 36-37, widerspricht der arabische Politiker und Historiker christlich-libanesischer Herkunft George Antonius der Idee eines exklusiven westlichen Einflusses auf die Reformbewegungen Mitte des 19. Jahrhunderts, die für ihn vor allem von den arabischen Christen ausgingen. Noch vehementer wendet sich, mit der Betonung der islamischen Komponente, Tibawi gegen die Idee massiver westlicher Beeinflussung des osmanischen Erziehungswesens. Vgl. A. L. Tibawi, Islamic Education. Its Traditions and Modernization into the Arab National Systems, London 1979, S. 64.

163 Vgl. Benjamin ForTnA, Islamic Morality in Late Ottoman »Secular Schools«, in: International Journal of Middle East Studies 32 (2000), H. 3, S. 369-393, S. 388-389.

164 Vgl. Hanssen 2005, S. 164.

165 Siehe das Zitat der offiziellen Mitteilung des osmanischen Rats für gerichtliche Erlässe vom 19.02.1846, die als Ziel der Erziehungsreformen nannte »to raise well-mannered and wellinformed servants for their employment at the important services of the Ottoman government«, in Selçuk Akşin Somel, The Modernization of Public Education in the Ottoman Empire 1839-1908. Islamization, Autocracy and Discipline, Leiden 2001, S. 24, Fußnote 13.

166 Vgl. Randi Degullhem, Exporter la France laïque dans la Méditerranée ottomane, in: Patrick Cabanel (Hg.), Une France en Méditerranée. Écoles, langue et culture françaises, $\mathrm{XIX}^{\mathrm{e}}-\mathrm{XX}^{\mathrm{e}}$ siècles, Paris 2006, S. 179-190, S. 180-181.

167 Vgl. Robert Mantran (Hg.), Histoire de l'Empire ottoman, Paris 1989, S. 717-718.

168 Vgl. Randi Degullhem, State Civil Education in Late Ottoman Damascus. A Unifying or a Separating Force?, in: Thomas Philipp/Birgit SchäBler (Hg.), The Syrian Land. Processes of 
Aus diesen Gründen wurde durch das Schulgesetz von 1869 eine dreijährige Schulpflicht für alle männlichen Osmanen beschlossen, und neben der traditionellen islamischen medrese, den ausländischen christlichen und jüdischen Missionsschulen und den einheimischen millet $^{169}$-Schulen der unterschiedlichen nicht-muslimischen Gemeinschaften entstanden die staatlichen osmanischen Schulen: in einem fünfgliedrigen System gab es nun Grundschulen (ibtidà'’oya), Volksschulen (rušdìya), vorbereitende Schulen ( $i^{`} d \bar{a} d \bar{\imath} y a$ ), Sekundarschulen (sultān̄īya) und die Universitäten ${ }^{170}$. Benjamin Fortna hat aber auf die vielen Kontinuitäten zwischen traditionellen und den $>$ modernen S Schulen hingewiesen ${ }^{171}$. Das staatliche Schulsystem verbreitete sich außerdem nicht flächendeckend, insbesondere in den Provinzen und Dörfern gab es in vielen Fällen keine staatlichen Schulen. Beispielsweise hatten Beirut, Aleppo und Bagdad 1869 jeweils zwei rušdīya-Schulen, in denen sich die Schüler entweder auf eine militärische oder eine VerwaltungsKarriere vorbereiten konnten ${ }^{172}$.

In den existierenden Schulen blieben die Lehrpläne oft defizitär und enthielten beispielsweise in manchen Schulen gar keine arabische Sprache und Geschichte ${ }^{173}$. Das lag vor allem daran, dass die osmanische Regierung, entgegen offizieller Verlautbarungen, die Erziehung nicht als Priorität behandelte. Das Prestige der öffentlichen Schulen wurde weiterhin dadurch geschmälert, dass sie vor allem von armen Schülern, insbesondere aus muslimischen Familien, besucht wurden, während die Christen, auch die ärmeren, ihre Kinder auf eine der vielen christlichen privaten, in- oder ausländischen, Schulen schickten ${ }^{174}$. Während die Schulreformen der Tanzimat-Zeit noch stark von der Idee der Erneuerung der eigenen Kultur durch den Einfluss des Westens geprägt waren, war das Ziel der Schulpolitik unter Abdülhamid II. eindeutig die Übernahme westlicher Lehrinhalte und -methoden, um die Zukunft des Osmanischen Reiches zu sichern ${ }^{175}$. Die Errichtung Beiruts als Provinzhauptstadt 1888 bedeutete auch in Erziehungsfragen eine stärkere

Integration and Fragmentation, Bilad al-Sham from the $18^{\text {th }}$ to the $20^{\text {th }}$ Century, Stuttgart 1998 , S. 221-250, S. 222.

169 Immer mehr dieser offiziell anerkannten religiösen Gemeinschaften erhielten ab dem 19. Jahrhundert durch das Osmanische Reich eine Autorisierung und konnten in der Folge auch Schulen errichten. Vgl. FoRTNA 2002, S. 71-75.

170 Vgl. Cioeta 1982, S. 42; Mustafa Gencer, Bildungspolitik, Modernisierung und kulturelle Interaktion. Deutsch-türkische Beziehungen (1908-1918), Münster 2002, S. 63-66.

171 Vgl. Benjamin Fortna, Education and Autobiography at the End of the Ottoman Empire, in: Die Welt des Islams 41 (2001), H. 1, S. 1-31, S. 16-17.

172 Vgl. CiOETA 1982, S. 42.

173 Vgl. Deguilhem 1998, S. 234.

174 Vgl. Selçuk Akşin Somel, Christian Community Schools during the Ottoman Reform Period, in: Elizabeth Özdalga (Hg.), Late Ottoman Society. The Intellectual Legacy, London 2005, S. 254-273, S. 271.

175 Fortna 2002, S. 4. 
Einbindung in das osmanische staatliche System: der neue Gouverneur gründete eine Internatsschule ( $i^{\prime} d \bar{a} d \bar{l} y a$ ), welche die Absolventen auf das Studium in Konstantinopel vorbereiten sollte ${ }^{176}$. Galt schon unter Abdülhamid II. der Bildung eine große Aufmerksamkeit, wurde diese unter den Jungtürken noch einmal verstärkt. Das zeigte sich unter anderem in der Erhöhung der Haushaltsmittel für das Schulwesen um 50\% im ersten Jahr und um 100\% im zweiten Jahr nach der Revolution ${ }^{177}$. Allerdings scheiterte die Erziehungspolitik Abdülhamids II. sowie die der Jungtürken, und besonders die nichtmuslimischen Gemeinschaften des Osmanischen Reiches, allen voran die Armenier und Griechisch-Orthodoxen, bevorzugten ihre eigenen Schulen.

Neben den staatlichen Schulen stellten die privaten Lehreinrichtungen im Libanon eine wichtige Größe in der libanesischen Schullandschaft dar und wurden deshalb von den französischen Schulen besonders observiert. Allein in der Stadt Beirut gab es beispielsweise 188966 private Schulen der verschiedenen religiösen Gemeinschaften, von denen die protestantischen und die muslimischen Einrichtungen den größten Anteil ausmachten ${ }^{178}$.

Ihr besonderes Augenmerk richteten die französischen Schuldirektoren auf die Kullìya 'uțmānìya (osmanische Oberschule), eine muslimische Privatschule in Beirut, deren Erfolg sie mit Neid erfüllte. Sie waren empört, dass der französische Konsul diese Schule unterstützte ${ }^{179}$. Besonders die Mission lä̈qu sah die Gefahr, dass diese Schule ihnen die muslimische Klientel streitig machen würde ${ }^{180}$. Aus diesem Grund ließ der Direktor der Mission lä̈que die Anfrage der Kullīya 'uțmānīya, ihnen ein oder zwei Französischlehrer zur Verfügung zu stellen, auch zunächst unbeantwortet ${ }^{181}$. Diese Ver-

176 Vgl. Hanssen 2005, S. 177-178. Diese Schule inkorporierte dann 1889 die reformorientierte Madrasat al-sultanīya. Vgl. ebd., S. 181.

177 Vgl. Cevat Kara, Menschlichkeit, Wohlfahrt und Gesundheit als Ideale spätosmanischer Bildung (1876-1918), in: Marianne Heimbach-Steims/Rotraud Wielandt (Hg.), Was ist Humanität? Interdisziplinäre und interreligiöse Perspektiven, Würzburg 2008, S. 283-299, S. 286-287.

178 Vgl. Naim Aтıуен, Schools of Beirut, in: Beirut College for Women (Hg), Beirut - Crossroads of Cultures, Beirut 1970, S. 133-166: Neben 32 protestantischen (12 für Jungen und 20 für Mädchen) und 24 muslimischen (21 für Jungen und drei für Mädchen) Schulen zählte die Stadt zu dem Zeitpunkt neun griechisch-orthodoxe, sechs jüdische, sechs maronitische, vier melkitische und 18 römisch-katholische Einrichtungen.

179 Vgl. AN/Paris, 60 AJ 119, Brief von Dupouey an Aulard, Beirut, 20.10.1911.

180 Vgl. MAE/Nantes, »Beyrouth Consulat Général A«, 352, Brief des Konsuls aus Beirut, 10.11.1911: »[la Kulliya] vient de changer de local et de se réorganiser et ne permettra plus, je crois, au Collège de la Mission laïque de compter sur les Musulmans convaincus, qui s'adresseraient à lui plutôt qu'aux écoles chrétiennes, mais lui préférant naturellement un collège musulman«.

181 AN/Paris, 60 AJ 119, Brief Dupouey an Aulard, Beirut, 20.10.1911: »Accueil courtois, cigarettes, café, saluts prolongés, à la musulmane. On m'a fait visiter l'école; on m'a accablé de protestations d'amitié ; on m'a même demandé de procurer, si je puis, au Collège Osmanieh un ou deux professeurs de français«. 
weigerung der Kooperation lag anscheinend auch daran, dass, so beschwerte sich Dupouey im Oktober 1911, 'Umar Da'uq Schüler von der Mission laïque abwarb und sie zur Kullīya 'uțmānīya schickte:

Monsieur Omar Daouk [die Schreibweise der Mission laïque für 'Umar Da'uq] nous a fait pendant les vacances et nous fait encore une guerre acharnée. Tous les jeunes musulmans qu'il peut atteindre- et ils sont nombreux- il les dirige vers le Collège Osmanieh [die Kullīya 'uțmānīya] [...]. Nous avions l'an dernier cent élèves musulmans; nous n'en avons plus que cinquante-six ${ }^{182}$.

In der Tat war die Kullīya 'uțmānīya im Mai 1911 in eine Sekundarschule umgewandelt worden und dadurch noch attraktiver für die Beiruter Muslime geworden. Sie legte Wert auf den Unterricht in französischer Sprache, und die Schüler konnten sogar das französische Abitur ablegen, um an französischen Universitäten zu studieren ${ }^{183}$. Die Kullīya 'uțmānīya hatte bis zu ihrer vorläufigen Schließung kurz vor dem Ersten Weltkrieg viel Erfolg und wurde zu einem Zentrum des arabischen Widerstands gegen die Turkisierungspolitik des Komitees für Einheit und Fortschritt ${ }^{184}$. Die Archive der Mission laïque erwähnen diese Schule später interessanterweise nicht mehr. Daraus kann man schließen, dass sich die Verantwortlichen der laizistischen Schule mit der Kullīya 'utmānīya versöhnt haben, denn 1913-1914 stellten deren Schüler die größte Gruppe der Neuzugänge an der Mission lä̈que dar ${ }^{185}$.

Die schon erwähnten Schulen der sunnitischen Wohlfahrtsorganisation Maqasid wurden erst später zu einer Institution, die die französischen Laizisten als Konkurrenz empfanden. Das mag damit zusammenhängen, dass diese Organisation zwar eine große Strahlkraft hatte und in vielen Städten des Nahen Ostens wie Damaskus und Jaffa Nachahmer fand, aber lange mit finanziellen Engpässen zu kämpfen hatte ${ }^{186}$ und erst nach dem Ersten Weltkrieg über mehr Möglichkeiten verfügten. Interessanterweise nahm die Mission laïque aber auch keine Notiz von den lokalen säkularen Schulen, die unabhängig von jeder europäischen Initiative entstanden waren. Sowohl in Beirut $^{187}$ als auch Damaskus ${ }^{188}$ gründeten reformorientierte Gelehrte Schulen, die den Kindern als Alternative zu den religiös geprägten Schulen neben

182 Ebd., Brief Dupoeuy an Besnard, Beirut, 16.10.1911.

183 Vgl. Strohmeier 1993, S. 227.

184 Vgl. ebd., S. 228.

185 Vgl. AN/Paris, 60 AJ 120, »Statistique des élèves 1913-1914«.

186 Vgl. CiOETA 1982, S. 46.

187 Am berühmtesten ist al-madrasat al-wațanīya von Buțus al-Bustānī, die er 1863 mit dem Ziel gründete, zu einer überkonfessionellen, nationalen Einheit beizutragen. Vgl. YARED 2002, S. 95.

188 Vgl. Randi Deguilhem, L'école secondaire Matktab 'Anbar à Damas, in: Revue du monde musulman et de la Méditerranée 52 (1989), H. 2-3, S. 199-205. 
einer soliden Ausbildung auch die Idee einer überkonfessionellen, nationalen Einheit vermitteln sollten ${ }^{189}$. Da deren Klientel anscheinend um 1909 nicht in der Reichweite der Mission lä̈que lag, bezog sich diese nicht auf jene säkularen Schulen.

Neben staatlichen und privaten einheimischen Schulen gab es in Beirut und im Libanon darüber hinaus eine große Anzahl ausländischer und vor allem französischer Schulen unterschiedlicher Couleur. Das Scheitern zweier laizistischer Schulprojekte durch die Franzosen Olivier und Augier Anfang des 20. Jahrhunderts spielte sicher eine wichtige Rolle für die Entscheidung der Mission laïque, nach Beirut zu gehen ${ }^{190}$. Die Mission laïque dachte zunächst an eine Kooperation mit Augier, verweigerte sich dann aber seiner Bitte, für seine Schule die Schirmherrschaft zu übernehmen, weil sie weder dessen Schulden noch dessen schlechten Ruf übernehmen wollte. So berichtete Deschamps 1909 aus Beirut: »Il est hors de doute que nous pouvons nous installer à Beyrouth sans tenir compte de l'existence d'Augier; son école se meurt; il est perclu de dettes; on le considère comme un bon garçon, mais il n'a aucune situation personnelle ${ }^{191}$.

Da Pierre Deschamps bei seinem Besuch in Beirut im Juni 1909 aber feststellen konnte, dass Augier keine Konkurrenz für die Mission laïque darstellen würde, schlug er vor, dessen Schule zu übernehmen, um sich so die Prozedur der Bitte um ein Firman zur Eröffnung der Schule zu ersparen ${ }^{192}$. In diesem Zusammenhang betonte Deschamps auch den Unterschied zwischen Beirut und »le Liban « ${ }^{193}$, also dem Ğabal Lubnān, welcher für ausländische Schulen sehr viel einfacher zu betreten war - ein Grund, warum sich die katholischen Schulen vor allem in dieser Gegend niedergelassen hatten.

Im Gegensatz zu der Mission lä̈que française erfuhren die katholischen Orden die volle Unterstützung des französischen Konsulats in Beirut wie auch der französischen Regierung ${ }^{194}$. Die Alliance israélite universelle hingegen erhielt erst kurz vor 1914 die ersten Subventionen des Quai d'Orsay ${ }^{195}$. Allerdings blieb ihre Situation schwierig, denn oft beschwerten sich die Inspektoren der Alliance israélite über den angeblichen Geiz und

189 Vgl. Hanssen 2005, S. 169, 170.

190 Die Projekte waren vor allem aus persönlichen und finanziellen Gründen gescheitert. Vgl. THobie 1997, S. 159-197.

191 AN/ Paris, 60 AJ 118, Brief von Deschamps an Besnard, Beirut, 10.06.1909. Allerdings zollte Besnard Augier noch mehr Respekt als es die Verantwortlichen der MLF in Paris taten, die in ihrer Sitzung vom 06.10.1910 betonten, dass Augier mit der MLF nichts zu tun habe. Vgl. MLF/Paris, »Procès-Verbaux des réunions du Conseil d'Administration 1907-1919«.

192 Vgl. AN/Paris, 60 AJJ 118, Brief von Deschamps an Besnard, 10.06.1909.

193 Vgl. ebd.: »Et puis n'oublions pas que si, pour le Liban, aucune demande d'autorisation n'est nécessaire, il n'en est pas de même à Beyrouth«.

194 Vgl. RifFier, 2000, S. 142.

195 Vgl. Burrows 1986, S. 125. 
die vermeintliche Apathie der jüdischen Bevölkerung im Libanon ${ }^{196}$, außerdem hatte die Alliance israélite viele Konflikte mit dem lokalen orthodoxen Judentum ${ }^{197}$. Aber sie erfuhr durchaus die Unterstützung des Valis von Beirut. Als der Großrabbiner von Saida mit Unterstützung des Gouverneurs die Schule der Alliance israélite schließen wollte, machte sich der Vali für ihren Erhalt stark ${ }^{198}$.

Darüber hinaus gab es im Libanon während des Osmanischen Reiches viele Missionarsschulen, von denen die der französischen katholischen Orden die meisten Schulen darstellten, gefolgt von amerikanischen und britischen protestantischen, russischen, italienischen und deutschen Schulen ${ }^{199}$. Diese Schulen waren bei großen Teilen der christlichen Bevölkerung sehr beliebt, wie die zahlreichen Briefe der Eltern an die Schulen belegen ${ }^{200}$. Auch die jüdischen Eltern waren sehr von den katholischen Schulen angetan. Gerade innerhalb der besserverdienenden Beiruter Gemeinde galt es als »affaire de mode«, sein Kind nach der jüdischen Grundschule auf eine der katholischen Schulen der Stadt zu schicken, wie eine Lehrerin der Alliance israélite 1904 beklagte $^{201}$. Zwischen katholischen und protestantischen Schulen hingegen herrschte eine »bitter rivalry $«^{202}$. Wegen der »concurrence protestante» unterrichteten die Jesuiten in ihren Schulen sogar Englisch ${ }^{203}$. Fast um jedes Dorf im Libanongebirge lieferten sie sich eine Schlacht.

196 Siehe zum Beispiel den Bericht des Inspektors Pariente über die Schule der AIU in Beirut 1905: »L'école de l'Alliance n'est plus suffisamment appréciée par la majorité de nos coreligionnaires de Beyrouth. La faculté d'y entrer sans bourse déliée y est certainement pour quelque chose. Il est à noter qu'ici les parents ne sauraient arguer du payement de la gabelle ou impôt sur la viande dont bénéficierait l'école«. AIU/Paris, »Liban VIE 80-81«, »Inspection Pariente 1905 sur écoles de Jaffa-Caiffa-Saida-Tibériade-Beyrouth«.

197 Vgl. AIU/Paris, »Liban 1 B/1«, Beschwerdebrief des Großrabbiners Danon über den Lehrer Sémach an den Präsidenten der Alliance israélite, Beirut, 25.08.1910.

198 Vgl. AIU/Paris, »Liban VIE 80-81«, »Inspection Pariente 1905 sur les écoles de Jaffa-CaiffaSaida-Tibériade-Beyrouth «.

199 Theodor Hanf, Erziehungswesen in Gesellschaft und Politik des Libanon, Bielefeld 1969, S. 69.

200 Beispielsweise bat ein römisch-katholischer Mann aus Zahlé namens Salīm Nāṣīf die Jesuiten in Tanail am Ende des Osmanischen Reiches um die Aufnahme eines Kindes mit dem Namen Tawfīq Sa’d, dessen Vormund er war. Vgl. SJ/Beirut, »Beirut, 12 C. 10 Tanail I Ministères Écoles«. Außerdem baten viele Eltern in ihren Briefen an den französischen Generalkonsul um ein Stipendium speziell in einer der katholischen Schulen. Vgl. MAE/Nantes, »Beyrouth Consulat Général A«, 191, »Demandes de bourses«, Brief von Elie R. Rizcallah an den Generalkonsul vom 15.07.1903.

201 AIU/Paris, »Liban VE 43-65«, Brief von Madame Elmaleh an den Präsidenten der AIU, Beirut, 31.12.1904.

202 Samir Khalaf, Cultural Resistance. Global and Local Encounters in the Middle East, London 2001, S. 131.

203 SJ/Beirut, 11.A.26, »Compte-rendu des séances sur l'organisation des écoles de la Mission« (1897). 
Ähnlich aggressiv wie auf die protestantischen Schulen reagierten die französischen katholischen Schulen Anfang des 20. Jahrhunderts auf die Ankunft der Mission laïque, die sie als Freimaurer zu disqualifizieren versuchten. So stellte ein Brief des römischen Abgesandten in Aleppo an die Bevölkerung in Syrien 1911 die Existenz der laizistischen Schulen als Kampf für die Kirche dar:

L'Église a gagné, à travers les siècles, des batailles non moins terribles que celles que lui livre en ce moment le laïcisme maçonique. Mais pour vaincre, il faut lutter, car Dieu n'est pas tenu de faire des miracles pour suppléer à notre indolence ${ }^{204}$.

Er betonte die Qualität der katholischen Schulen und dass sie den laizistischen Schulen weder in Fragen der Hygiene, noch des Lehrpersonals, noch der Disziplin und Moral nachständen. Da die Gefahr aber anscheinend sehr groß war, dass Familien, die bis dahin treue Kunden der katholischen Schulen gewesen waren, zu den laizistischen Schulen wechseln würden, wurde ihnen mit dem Ausschluss von den Sakramenten gedroht:

Nous renouvelons, de la manière la plus solennelle, la défense de nos vénérés prédécesseurs de fréquenter les écoles acatholiques. [...] Avec la défense, nous renouvelons la censure ecclésiastique relative, en vertu de laquelle les désobéissants ne pourront être absous et admis aux sacrements sans une autorisation spéciale de Nous et que nous n'accorderons que difficilement, pour quelque circonstance particulière qui atténuerait la gravité du pêché. La défense et la censure concernent naturellement les parents surtout, ou ceux qui tiennent leur place et ont la responsabilité de la bonne éducation à donner à la jeunesse. Cela n'empêche pas cependant qu'elles ne visent aussi les enfants eux-mêmes, dans le cas possible où leur influence ne serait pas étrangère au choix de l'école ${ }^{205}$.

In ihrer Verurteilung setzten die katholischen Orden die laizistischen Schulen oft mit den protestantischen Einrichtungen gleich, ihren traditionellen Feinden. So formulierte ein Lazarist aus Beirut im August 1909: „L'œuvre de nos écoles gratuites du Liban [qui] devient de plus en plus importante à cause de la concurrence des protestantes et plus encore à cause de la propagande franc-maçonne ${ }^{206}$. Auch die Jesuiten waren sehr skeptisch gegenüber den laizistischen Schulen, wie die ersten Direktoren der Mission laïque,

204 »Lettre pastorale au clergé et au peuple latin du vicariat apostolique d'Alep pour le carême de 1911: Religion et laïcisme en face du problème de l'éducation populaire, Beyrouth 1911«, S. 23. Gefunden in LAZ/Paris.

205 Ebd., S. 32-33.

206 LAZ/Paris, »Beyrouth Correspondance 1896-1918«, Brief von Ouanès aus Beirut, August 1909. 
Deschamps und Dupouey bei ihren Besuchen bei der Université Saint-Joseph zu spüren bekamen: Während Rektor Cattin Deschamps 1909, angeblich aus Zeitgründen, die Jesuitenschule nicht zeigen konnte ${ }^{207}$, wollte er Dupouey 1911 durchaus treffen, aber nur privat und nicht in der Schule der Mission laïque $^{208}$. In ihrer Zeitschrift al-Baši $\underline{\text { r }}$ kritisierten die Jesuiten die Organisation vehement ${ }^{209}$. Die sehr kritische Reaktion der Mission laïque in Paris auf dieses Treffen, das dann im Hause Dupoueys stattfand, macht deutlich, dass auch die Mission laïque Distanz zu den Jesuiten halten wollte ${ }^{210}$. In der Tat sorgte der Besuch, so berichtete Dupouey nicht ohne Stolz, für einigen Aufruhr in der Stadt: »La visite du P. Cattin a été très observée, très commentée, et l'effet produit a été si grand que les Jésuites ont essayé un peu puérilement de répandre le bruit que cette visite n'avait jamais eu lieu« ${ }^{211}$. Dieses Zitat zeigt sehr deutlich, wie die Feindschaft zwischen laizistischen und katholischen Vertretern in Frankreich auch im Libanon nachwirkte.

Neben den französischen katholischen Schulen wurden auch die anderen ausländischen Schulen von manchen Akteuren der Mission laïque als Konkurrenz empfunden. So notierte Dupouey, der Direktor der Mission laïque in Beirut zwischen 1911 und 1913, 1912 auf einen Zeitungsartikel über das amerikanische Syrian Protestant College: „Voilà l'ennemi! « ${ }^{212}$ Allerdings teilten nicht alle Mitglieder der Mission lä̈que diese Abneigung gegen die amerikanische protestantische Schule. Deschamps beurteilte diese sehr viel positiver, schrieb sogar:

[...] j'ai visité ce matin le collège américain. Ce dernier est grand, beau, admirable; peu religieux, presque laïque; indépendant à l'égard de toute secte protestante, mais faisant quand même de la Bible la base de l'éducation morale. Rien de ce qui s'y fait ne m'a cependant surpris; ils ont des hommes et de l'argent, voilà leur secret. M. Bliss, le directeur, m’a gardé assez longtemps $[\ldots]^{213}$.

Die katholischen Schulen empfanden die Konkurrenz mit der amerikanischen Universität noch sehr viel deutlicher. Seit Beginn des 18. Jahrhunderts hatte sich der Kampf der verschiedenen ausländischen christlichen Schulen um

207 »J'ai vu aussi le Père Cattin qui m'eut fait visiter son collège s'il n'eut été un peu tard«. AN/ Paris, 69 AJ 118, Brief von Deschamps an Besnard, Beirut, 10.06.1909.

208 Vgl. AN/Paris, 60 AJ 119, Brief von Dupouey an Aulard, Beirut, 20.10.1911.

209 Vgl. MAE/Nantes, »Beyrouth Consulat Général A«, 359, Übersetzung eines Artikels der von den Jesuiten herausgegebenen Zeitung al-Bashir vom 5. Juli 1909 »au sujet d'un article du Journal La Sabela«.

210 »Vous me blâmez, par exemple, d'avoir reçu chez moi le P. Cattin«. AN/Paris, 60 AJ 119, Brief von Dupouey an Besnard, Beirut, 27.11.1911.

211 Ebd., Brief von Dupouey an Besnard, Beirut, 27.11.1911.

212 AN/Paris, 60 AJ 120, Brief von Dupouey an Aulard, Beirut, 08.01.1912.

213 AN/Paris, 60 AJ 118, Brief von Deschamps an Besnard, Beirut, 10.06.1909. 
die libanesischen Schüler und deren Konversion verstärkt. Wie in den libanesischen Dörfern, standen in Beirut die Jesuiten-Universität und das Syrian Protestant College in starker Konkurrenz zueinander ${ }^{214}$. Als Deschamps die Schule besuchte, hatte es allerdings gerade einen Aufstand muslimischer Studenten gegen das Syrian Protestant College gegeben, in dem diese sich gegen die Pflicht erhoben, am täglichen christlichen Gottesdienst teilnehmen zu müssen ${ }^{215}$. Sie wurden der Universität verwiesen, was für ein sehr negatives Bild des College sorgte. Unter Umständen war dies neben seiner versöhnlichen Grundeinstellung ein Grund, warum Deschamps sich 1909 weniger um ihre Konkurrenz sorgte. Ein anderer Grund mag gewesen sein, dass die osmanische Regierung der amerikanischen Universität wie auch den amerikanischen Schulen weniger Privilegien zugestand als den französischen Schulen ${ }^{216}$.

Die Untersuchung der Anfänge der Mission laïque française in Beirut hat deutlich gemacht, dass diese nur aufgrund spezifischer Umstände auf internationaler, nationaler, regionaler und lokaler Ebene eine Chance hatte, sich zu dem Zeitpunkt in der Region niederzulassen. Zwar gab es einige Individuen und Gruppen in den Regierungsebenen und in der Bevölkerung, die einer solchen französischen laizistischen Schule positiv gegenüber standen, aber auch der Widerstand gegen diese spezifische beziehungsweise grundsätzlich gegen jede ausländische Einrichtung war groß. Da 1909 aber eine reformorientierte Regierung in Konstantinopel sowie ein Netzwerk aus Notabeln der Mission laïque den Weg ebneten, suchten auch bestimmte Bevölkerungsgruppen, die sich bis dato nicht in den anderen ausländischen Schulen wohlgefühlt hatten, diese Schule auf.

Nachdem sich die Mission laïque nach vielen Anfangsschwierigkeiten in die libanesische Gesellschaft integriert hatte, kam es durch den Ersten Weltkrieg für die laizistischen, aber auch für die anderen französischen Schulen zu einem tiefen Einschnitt. Nur die Alliance israélite universelle war von dieser vierjährigen \Leerstelleく nicht betroffen. Zum einen wurden viele Lehrer als Soldaten eingezogen. Zum anderen mussten die katholischen Orden, wie auch die Mission lä̈que française, die ironischerweise mit ihnen gleichgesetzt wurde, als Franzosen und damit Feinde des mit Deutschland verbündeten osmanischen Reiches den Libanon verlassen. Zum ersten Mal war der Direktor der Mission laïque erleichtert über diese Verwechslung:

214 Vgl. KassiR 2003, S. 220-241.

215 Vgl. Anne-Laure Dupont, Une école missionnaire et étrangère dans la tourmente de la révolution constitutionnelle ottomane, in: Cahiers de la Méditerranée 75 (2007), S. $39-57$.

216 Vgl. Adil Baktiaya, Syrian Protestant College's Struggle Legitimacy as Reflected in Archival Sources, in: International Review of Turcology 1 (2008), H. 2, S. 25-41, S. 35-36 (= BAKTIAYA 2008 a). 
Notre titre de >Mission Laïque a-t-il créé une confusion, ou bien bénéficions-nous d'une faveur spéciale, [...] c'est sur une lettre pressante du Pape au Sultan que la Consigne a été levée pour les religieux, au nombre desquels nous avons été compris, ce dont, pour une fois du moins, nous nous félicitons sans scrupules ${ }^{217}$.

Bleiben durften nur die Schulen der Alliance israélite universelle, da ihre Angehörigen keine Franzosen waren ${ }^{218}$. Deshalb konnte die Organisation viele ihrer Schüler, die zu einer ausländischen Schule gewechselt hatten, wieder übernehmen:

À quelque chose, malheur est bon, dit-on. La fermeture des écoles laïques et congrégationistes, de nationalités étrangères, a amené certains de nos coreligionnaires aisés, imbus de préjugés, qui n'ont jamais voulus, par ignorance de votre œuvre, nous confier l'éducation et l'instruction de leurs enfants, à placer ceux-ci dans vos institutions. [...] Beaucoup de nos coreligionnaires m'ont exprimé leur reconnaissance à l'Alliance ${ }^{219}$.

Aus demselben Grund bildete die Alliance israélite auch zum Ende des Ersten Weltkrieges die Ansprechpartnerin der französischen Behörden, die sich mit dem Aufbau des libanesischen Schulsystems unter französischer Führung beschäftigten ${ }^{220}$. Durch das Verbot der katholischen Kongregationen, welche bis dahin die privilegierten Kontaktgruppen der französischen Regierung im osmanischen Reich dargestellt hatten, boten sich für die jüdische Organisation eine ungeahnte Nähe zur Regierung und neue Gestaltungsmöglichkeiten für Form und Inhalt der Bildungsprogramme. Doch die Hoffnung der Organisation, von da an der bevorzugte Partner Frankreichs zu werden, sollte sich nicht erfüllen. Denn schon bald nach dem Ende des Ersten Weltkrieges kehrten die anderen französischen Schulen in den Libanon zurück.

Auch wenn die meisten französischen Schulen während des Ersten Weltkrieges im Libanon geschlossen blieben und deshalb keine finanzielle Unterstützung aus Paris erhielten, bedeutete das nicht, dass die französische Regierung bis zur Mandatszeit untätig blieb. Im Gegenteil, schon ab 1915 verhandelten britische und französische Vertreter der beiden Regierungen über die Zukunft des Osmanischen Reiches und die Aufteilung seiner Regionen unter sich. Bei diesen Gesprächen spielte die Frage der Bildung eine sehr wichtige Rolle. Zum einen waren beide Parteien daran interessiert, die Regi-

217 AN/Paris, 60 AJ 120, Brief von Chaufour an den Präsidenten der Mission laïque, Alexandria, 30.09.1914.

218 AIU/Paris, »Liban VIE 81a«, »Lettre de fin d'année«, Beirut, 02.10.1915.

219 Ebd. Vgl. auch Preciado 1960, S. 2: »Tous les établissements français d'enseignement ont dû alors fermer leurs portes, à l'exception de ceux de l'Alliance«.

220 AIU/Paris, »Liban VIE 80-81«, Brief von Penso an den Präsidenten der Alliance israélite in Paris, Beirut, 15.06.1919. 
onen, in denen sie bisher Schulen unterstützt hatten, auch weiterhin zu ihrem Einflussbereich zählen zu können. Zum anderen warf vor allem Frankreich diese Schulen als Gewicht in die Waagschale, um seine territorialen Ansprüche zu rechtfertigen ${ }^{221}$. 


\section{Koloniale Bildung ohne Kolonie: Die französischen Schulen nach dem Ersten Weltkrieg}

Das Ende des Osmanischen Reiches und der Beginn des Mandatsregimes im Libanon zwangen auch die französischen Schulen, ihre Rolle innerhalb der neu entstandenen französischen Herrschaft im Libanon erneut zu definieren. Ziel dieses Kapitels ist deshalb zu untersuchen, inwiefern die Idee der Zivilisierungsmission von Mandatsvertretern, französischen Schulen und Libanesen genutzt wurde, um die Aufgaben von Bildung im neuen Regime festzulegen. Dabei wird deutlich, dass Bildungspolitik im Mandatsregime viele Parallelen zu kolonialen Regimen aufwies, sich aber auch davon unterschied. Die von dieser Politik betroffenen Personen und Institutionen nahmen aus verschiedenen Gründen Bezug auf die mission civilisatrice, um an dieser Bildungspolitik zu partizipieren und um bestimmte Forderungen durchzusetzen. Die Bezugnahme konnte aber auch in Form von Widerstand geschehen, wie das Beispiel der Mission lä̈que française und verschiedener libanesischer Gruppen zeigt. Die französischen Schulen befanden sich damit mit Beginn des Mandats noch stärker als zuvor in einem Spannungsfeld zwischen Vereinnahmung durch die französischen Autoritäten einerseits und notwendigem Eingehen auf die Forderungen der Bevölkerung. Wie sie beiden Seiten gerecht zu werden und mit ihren eigenen Vorstellungen von Bildung unter dem Mandat in Einklang zu verbringen versuchten, untersucht dieses Kapitel.

Um diese unterschiedlichen Aspekte französischer Bildungspolitik zu beleuchten, werden im Folgenden sowohl die Diskurse als auch die konkreten Praktiken der Regierungsvertreter, der Schulen und ihrer Lehrer und einzelner libanesischer Gruppen und Individuen analysiert. Im ersten Teil wird die Verkörperung und Inszenzierung der mission civilisatrice durch die französischen Schulen, aber auch durch libanesische Akteure als Indikator ihrer Beziehung zur Mandatsmacht untersucht. Das zweite Unterkapitel widmet sich der Idee der Zivilisierungsmission als oberstes Prinzip der Bildungspolitik des Mandats, welches aus gleichzeitiger Förderung und Kontrolle der libanesischen Schullandschaft bestand, aber als französisch-libanesische Partnerschaft deklariert wurde. Welche Folgen diese ambivalente Politik hatte, die nur eine sehr begrenzte Entwicklung des libanesischen Bildungssystems vorsah, zeigt die Frage der Vereinheitlichung der Schulabschlüsse zwischen Orientierung am französischen Modell und schleppender Entwicklung eines libanesischen Prüfungssystems im dritten Teil. Der vierte Teil widmet sich Transferprozessen von Bildungswissen und -erfahrung und rekonstruiert, 
wie sowohl die Mandatsbeamten in der Bildungsbehörde als auch die französischen Schulen versuchten, ihre Aufgabe im Libanon durch Abgrenzung zu der französischen Bildungspolitik in den Kolonien näher zu erfassen.

Das französische Mandat hatte die Niederlage des Osmanischen Reiches als Verbündeten des Deutschen Reiches während des Ersten Weltkriegs zur Voraussetzung. Elizabeth Thompson hat zu Recht auf die großen Leiden hingewiesen, die dieser Krieg durch Hungersnöte und Tod vieler Soldaten über die Menschen in Syrien und Libanon brachte und ihre sozioökonomischen Strukturen stark erschütterte ${ }^{1} 1918$ hatte die französische Armee gemeinsam mit den Briten den Libanon besetzt und schon mit dem Aufbau eines Mandats begonnen. Die zahlenmäßige Überlegenheit des britischen Militärs beheizte den Machtkampf zwischen beiden Ländern um den Erhalt und Ausbau ihrer Machtpositionen in der Region zusätzlich².

Schon während des Ersten Weltkrieges, genauer gesagt seit 1915, waren die britischen und französischen Militärs in der Region stationiert. Außerdem hatten sich am 16. Mai 1916 beide Regierungen in dem von ihren Vertretern Mark Sykes und Georges Picot verhandelten geheimen und sogenannten »Sykes-Picot-Abkommen« auf eine Aufteilung der Provinzen des Osmanischen Reiches, von dessen Zerfall sie ausgingen, geeinigt: Frankreich sollte Syrien und Libanon, Großbritannien Irak und Jordanien zugeteilt bekommen, während Palästina als internationales Gebiet verwaltet werden sollte ${ }^{3}$.

Allerdings machten die weiteren Entwicklungen die Idee einer einfachen französischen Übernahme Syriens und Libanons zunichte. Zunächst beschloss Großbritannien aufgrund seiner militärischen Überlegenheit, Frankreichs Ansprüche vor allem in Syrien zurückschrauben, und brachte das syrische Territorium in die Verhandlungen mit dem Herrscher des Hedjaz, Sherif Hussein (arabisch Husayn), Statthalter von Mekka, mit ein ${ }^{4}$. Zudem hatte die 1919 vom amerikanischen Senat beauftragte King-Crane-Commission, welche die Bevölkerung dieser Region zu ihrer Zugehörigkeit nach dem Ende des Osmanischen Reiches befragte, zum Ergebnis, dass außer im Libanon sich die Mehrheit der Bevölkerung gegen ein französisches Protektorat

1 Vgl. Тномрson 2000, S. 21: Zeitgenössischen Schätzungen zufolge starben im Ersten Weltkrieg allein im Libanon 150.000 bis 300.000 Menschen, und in Syrien und Libanon zusammen 300.000 bis 450.000 Menschen.

2 Peter Sluglett, Les Mandats / The Mandates. Some Reflections on the Nature of the British Presence in Iraq (1914-1932) and the French Presence in Syria (1918-1946), in: Nadine Méouchy/ Peter Sluglett (Hg.), The British and French Mandates in Comparative Perspective, Leiden 2004, S. 103-128, hier 111-115.

3 Vgl. Gérard Khoury, La France et l'Orient arabe. Naissance du Liban moderne 1914-1920, Paris 1993, S. 89-93; Henry Laurens, L'Orient arabe. Arabisme et islamisme de 1789 à 1945, Paris 2002, S. 142-145.

4 Vgl. Anne-Lucie Chaigne-Oudin, La France et les rivalités occidentales au Levant. Syrie-Liban 1918-1939, Paris 2006, S. 43; Khoury 1987, S. 34-40. Aus unterschiedlichen strategischen Gründen erkannte Großbritannien dann aber Frankreichs Ansprüche auf Syrien an. 
und stattdessen für ein Mandat der USA aussprach, welches diese an Faysal (arabisch Fayșal), den Sohn Husseins, übergeben sollten. Allerdings wurde dieses Ergebnis nie in die weiteren Verhandlungen des Völkerbundes mit einbezogen, weil die USA sich im Sommer 1919 von der Friedenskonferenz zurückzogen 5 .

Aber auch im Libanon selbst stand nicht die gesamte Bevölkerung hinter der Idee einer französischen Protektion: diese wurde vor allem von einer Gruppe von Maroniten um Emile Eddé (arabisch Imīl Iddah), vertreten, die ihre Position bei den Friedensverhandlungen in Paris am 15. Februar 1919 vorbrachten ${ }^{6}$. Sie warben für einen unabhängigen Libanon, in dem die Christen eine Mehrheit bildeten und der von Frankreich protegiert würde. Aus diesen Ideen entwickelte sich die Stömung des Libanismus, dessen Anhänger die Idee des Libanons als eigene staatliche Entität und christliches Refugium entwickelten ${ }^{7}$. Ihnen gegenüber standen die Vertreter einer Vereinigung des Libanons mit allen arabischen Staaten unter Faysal, die sich vor allem, aber nicht ausschließlich in den muslimischen Milieus zusammensetzten. Eine letzte Gruppe von Libanesen setzte sich schließlich für die Vereinigung des Libanons mit Syrien im Sinne der Wiedererrichtung des Bilād-aš-Šàm, des historischen Großsyriens ein, das die heutigen Gebiete von Syrien, Libanon und Palästina umschloss. Zu ihren prominenten Verfechtern gehörten das Comité central syrien um den frankophonen Dichter Choukri Ghanem (arabisch Šukrī Ġānim) und andere Persönlichkeiten aus unterschiedlichen religiösen Gemeinschaften ${ }^{8}$. Diese Aufsplitterung in Libanisten, syrische und arabische Nationalisten unterschied den Libanon von den politischen Strömungen und Bewegungen in den arabischen Nachbarländern, wo die politischen Gruppen in der Zwischenkriegszeit über alle Differenzen hinweg den arabischen Nationalismus verfochten?.

5 Vgl. Shorrock 1976, S. 166; James Gelvin, The Ironic Legacy of the King-Crane-Commission, in: David W. Lesch (Hg.), The Middle East and the United States. A Historical and Political Reassessment, Boulder, Colorado 2007, S. 13-29.

6 Vgl. Khoury 1993, S. 181.

7 Diese ursprünglich vom belgischen Jesuitenpater Henri Lammens entwickelte Idee wurde von maronitischen Denkern wie Michel Chiha aufgenommen und weiterentwickelt. Vgl. Meir ZAmiR, Lebanon's Quest. The Road to Statehood 1926-1939, London/New York 2000, S. 37; Kais Firro, Inventing Lebanon. Nationalism and the State under the Mandate, London 2003, S. 23-41.

8 Vgl. Khoury 1993, S. 179-187.

9 Vgl. C. Ernest DAwn, The Formation of Pan-Arab Ideology in the Interwar Years, in: International Journal of Middle Eastern Studies 20 (1988), S. 67-91, S. 67. Neuere Arbeiten betonen allerdings auch die Diversität der politischen Strömungen in den anderen arabischen Ländern der Region. Vgl. für Syrien z.B. Christoph Schumann, Radikalnationalismus in Syrien und Libanon. Politische Sozialisation und Elitenbildung 1930-1958, Hamburg 2001, S. 256-258; für den Irak vgl. Peter WIEN, Who is »liberal« in 1930s Iraq? Education as a Contested Terrain in a Nascent Public Sphere, in: Christoph Schumann (Hg.), Nationalism and Liberal Thought in the Arab East. Ideology and Practice, New York 2010, S. 31-46, S. 43. 
Trotz der verschiedenen Widerstände konnte Frankreich aber seine Forderungen durchsetzen und auf der Konferenz von San Remo vom 19. bis 26. April 1920 die Gebiete von Syrien und Libanon für sich beanspruchen. Diese Regelung veränderte einige Punkte des Sykes-Picot-Abkommens ${ }^{10}$. Vom während der Pariser Friedensverhandlungen 1920 gegründeten Völkerbund wurden die Mandate im Nahen Osten für Frankreich und Großbritannien allerdings erst am 24. Juli 1922 beschlossen und in Artikel 22 der Völkerbundvereinbarung festgehalten ${ }^{11}$ sowie nach dem Vertrag von Lausanne im Juli 1923 in die Tat umgesetzt.

Diese Entscheidung traf auf den Widerstand unterschiedlicher libanesicher Gruppen. Auch wenn die Maroniten um den Patriarchen Hoyek (arabisch al-Hawayik) ${ }^{12}$ ihren Wunsch nach einem christlich dominierten Libanon erfüllt sahen, war diese Mehrheit aufgrund des größeren Gebietes, das Frankreich hinzunahm nicht so stabil wie erhofft: nur 55\% der Libanesen waren 1921 Christen, gegen einen Prozentsatz von 80\% im Jahr 1914'3. Aus diesem Grund protestierten Maroniten wie Soliman Kanann gegen die Regelung und attestierten der französischen Regierung Naivität, wenn diese glaube, durch die neuen Grenzen die Muslime für da Mandat gewinnen zu können: »Si la politique française continue comme jusqu'ici, vous aboutirez à la ruine et à la disparition du Liban, sans pouvoir les combler par des sympathies nouvelles auprès des musulmans $\aleph^{14}$. Die syrischen und arabischen Nationalisten behielten ihre ablehnende Haltung bei, nur manche würden sich später mit dem Mandat und der Gründung des Staates Libanon versöhnen ${ }^{15}$.

Gleichzeitig mit der Mandatsaufteilung beschloss die französische Regierung auch, den Libanon als eigenständigen Staat zu kreieren. Deswegen kam es am 1. September 1920 zur Ausrufung des État du Grand Liban durch den französischen General Henri Gouraud ${ }^{16}$. In diesem Prozess erhielt der Bil-

10 Die wichtigste Änderung war, dass Großbritannien nun auch Palästina als Mandatsgebiet erhielt, während allein Jerusalem als international verwaltete Stadt geführt werden sollte. Grund für diese Modifikation war unter anderem die Balfour Declaration von 1917, welche den Juden in Israel eine Heimat versprach. Da die Briten Faysal gleichzeitig ein arabisches Königreich versprochen hatten, war ein territorialer Konflikt von diesem Zeitpunkt an nahezu unausweichlich. Vgl. LaURENS 2002, S. 150-152.

11 Siehe den Vertrag unter URL: http://avalon.law.yale.edu/20th_century/leagcov.asp\#art22 (28.03.2012).

12 TRabulsi 2007, S. 81, mahnt zu Recht, die Maroniten nicht zu sehr zu vereinheitlichen.

13 Vgl. Nadine Picaudou, La décennie qui ébranla le Moyen-Orient. 1914-1923, Bruxelles 1992, S. 127.

14 Le Liban. Requête présentée au Parlement français par Soliman Kanaan, membre du Conseil Administratif du Liban, représentant élu du peuple libanais, Rome: Imprimerie pontificale en l'institut Pie IX, 1921.

15 Vgl. Kapitel 5.

16 Vgl. Khoury 1993, S. 397-399. 
dungsbereich besondere Aufmerksamkeit. Die Schulen stellten neben den Waisenhäusern, Asylen und Krankenhäusern »nos meilleurs moyens de propagande« dar, so ein französischer Regierungsvertreter kurz nach dem $\mathrm{Krieg}^{17}$. Wie in anderen kolonialen Systemen versuchten die Franzosen über das Bildungswesen eines der Schlüsselelemente staatlicher Kontrolle zu erlangen $^{18}$, bauten aber auch auf der Tradition der französischen Schulen im Libanon auf.

Auf diese Art und Weise wurde das Bildungswesen zu einer der tragenden Säulen des Mandats neben dem Militär, der Wirtschaft und der Verwaltung ${ }^{19}$. Ungeachtet seiner eingeschränkten offiziellen Rechte organisierte das französische Hochkommissariat schon seit Ende 1918, also lange vor der Ratifizierung des Mandats durch den Völkerbund, den Bildungssektor im Libanon neu. Es nutzte das Machtvakuum, das in dieser Zeit bestand, um durch die Schulen Tatsachen zu schaffen, die ein französisches Mandat unterstützten. Ziel Frankreichs war es, wie Jean Riffier sehr treffend formuliert hat, zu demonstrieren, dass Syrien und Libanon schon längst zu Frankreich »gehörten«. Gerade gegenüber dem militärisch überlegenen Rivalen Großbritannien initiierte es diesen "processus par lequel [...] la France n'a plus, en 1919, à proclamer pour elle mais bien à faire constater à tous [...] que la Syrie est déjà depuis longtemps sienne $\ll^{20}$.

Allerdings wurde der Aufbau des Schulwesens von großem Zögern, Unwissen und vielen Meinungsverschiedenheiten zwischen den Entscheidungsträgern begleitet. Zum einen wurden weitaus weniger französische Funktionäre von Paris in den Libanon entsandt als beispielsweise in das Protektoratsgebiet Marokko ${ }^{21}$. Zum anderen fehlte den Verantwortlichen ein Modell, wie sie die Bildungspolitik im Libanon organisieren sollten. Die unsichere Bildungssituation der frühen Mandatsjahre wurde noch dadurch verstärkt, dass der Hochkommissar eine Parallelstruktur von französischer und libanesischer Regierung schuf: wie für die anderen Sektoren des öffentlichen Lebens auch gab es im Libanon sowohl einen »Bildungsbeauftragten" (den Conseiller pour l'Instruction Publique), der dem Hochkommissariat unterstellt war, als auch ein »Erziehungsministerium « (Ministère de l'Instruction Publique) des am 1. September 1920 proklamierten Staates Großlibanon (Grand Liban). Beson-

17 MAE/Nantes, IP, 02: 1919-1920, »Note«.

18 Vgl. Mitchell 2003, S. 157.

19 Vgl. Edmond Chidiac, La France au Levant. Le bilan économique du Mandat français en Syrie et au Liban 1920-1946, Diss. Paris 2002, S. 340.

20 RifFIER 2000, S. 345.

21 Carla Eddé, Au temps du mandat français sur la Syrie et le Liban, in: Fabrice Denise/Lévon Nordiguian (Hg.), Une aventure archéologique. Antoine Poidelbard, photographe et aviateur, Marseille 2004, S. 75-89, S. 80: gegenüber 6700 Funktionären in Marokko verfügte der Libanon nur über 326 französische Funktionäre. 
ders in der Anfangszeit kam es zu Überschneidungen der Kompetenzen beider Instanzen. Allerdings setzte sich das Hochkommissariat in der Folge als maßgebliche Instanz durch ${ }^{22}$.

Die Errichtung des französischen Mandats im Libanon bedeutete im Bereich des Bildungswesens einerseits eine Fortsetzung der Schulpolitik des späten Osmanischen Reiches und andererseits eine deutliche Veränderung hin zu einer größeren Vereinheitlichung und Orientierung an dem französischen Schulmodell. Dabei lag die Priorität der Mandatsautoritäten eindeutig bei den privaten, besonders bei den französischen katholischen Privatschulen. Die privaten Institutionen besaßen zwar nach Artikel 10 der Mandatscharta das Recht, weiterhin ihre Schulen zu unterhalten, aber Artikel 8 sah auch die Entwicklung eines staatlichen Schulsystems vor ${ }^{23}$.

Im Libanon ignorierte Frankreich diese Mandatsvorschrift sogar noch deutlicher als in Syrien. Dort wurde zumindest ab den späten 1920er Jahren das staatliche Schulsystem eindeutig gestärkt ${ }^{24}$. Zwar eröffnete das Hochkommissariat auch im Libanon die staatlichen Schulen wieder, insbesondere in den Gebieten, wo es wenige Privatschulen gab ${ }^{25}$, jedoch waren im Dezember 1919 nur 189 staatliche Schulen erneut funktionsfähig. Dem standen 728 wiedereröffnete private Schulen gegenüber, die vor allem in der Trägerschaft lokaler religiöser Gemeinschaften wie der maronitischen Kirche, der griechisch-orthodoxen Kirche, der sunnitischen Gemeinschaft, aber auch weniger überkonfessioneller Gruppen standen ${ }^{26}$.

Darüber hinaus kam es im Libanon zu einer starken konfessionellen Differenzierung der Schülerschaft: während die christlichen Gemeinschaften vor allem die privaten Schulen besuchten, wurden die staatlichen Schulen mehr-

22 Das Machtverhältnis zeigte sich unter anderem darin, dass der Protest eines Libanesen gegen den ersten ernannten libanesischen Erziehungsminister, der nicht die Freiheit der katholischen Schulen garantieren würde, insofern Gehör fand, als Maurice Chéhab kurzerhand abgesetzt und Rachid Bey Nakhlé ernannt wurde. Vgl. MAE/Nantes, IP, 02: 1919-1920, »Note«.

23 Vgl. die Mandatscharta, z.B. in Edmond Chidiac (Hg.), Rapports annuels du Ministère des Affaires étrangères à la Société des Nations sur la situation de la Syrie et du Liban, Beirut 2008, S. 287-292, S. 289. Die Mandatsmacht erklärte ihre Politik damit, dass die staatlichen Schulen so niveaulos und materiell verkommen seien, dass es unrentabel wäre, in sie zu investieren: »Avant la guerre, il n'existait en Syrie qu'un très petit nombre d'écoles officielles turques, sans valeur. L'enseignement était tout entier donné par les écoles privées locales de différents rites, relevant des évêques [...], par des écoles françaises subventionnées et par des écoles étrangères [...]«. MAE/Nantes, IP, 02: 1919-1920, »Notes sur les écoles privées. Janvier 1920«.

24 Vgl. Bocquet 2008, S. 70, 90.

25 Vgl. Hanf 1969, S. 78: Diese Gegenden waren die Bekaa-Ebene, der Nord- und der Südlibanon.

26 MAE/Nantes, IP, 02: 1919-1920, »Note sur les écoles privées janvier 1920« (ohne Autor, wahrscheinlich Chevalley). Nach dem Ausscheiden Chevalleys reduzierte sich die Zahl der staatlichen Schulen noch einmal drastisch, während die Zahl der privaten Schulen stieg: 1921 gab es 129 staatliche Schulen im Libanon. Vgl. Annette Renée Chapman-Adisho, Mission Civilisatrice to Mandate. The French and Education in Syria and Lebanon, M.A. Thesis Louisville, Kentucky 1998, S. 76-77. Vgl. auch die Tabelle im Anhang. 
heitlich von Muslimen genutzt ${ }^{27}$. Insgesamt besuchten mehr christliche als muslimische Schüler eine Schule ${ }^{28}$. Das französische Vorgehen im Libanon unterschied sich außerdem eindeutig von der englischen Mandatsverwaltung in Palästina und im Irak: Dort wurden die staatlichen Schulen stärker gefördert, weil die britische Mandatsmacht nicht wie die französische einen moralischen Impetus vertrat und deshalb viel weniger direkt intervenierte. Stattdessen setzte sie auf die arabischen Kräfte und Institutionen, um Finanzen zu sparen, einen rechtlichen status quo zu wahren und die Unabhängigkeit der Länder früher anzuvisieren ${ }^{29}$.

\section{Verkörperung und Inszenierung der mission civilisatrice}

Die erste Reaktion der französischen Bildungseinrichtungen sowie der libanesischen Schulen und Individuen auf das Mandat, war eine Hervorhebung der Idee der Zivilisierungsmission in den Reden und Briefen, die sie an die Mandatsmacht richteten. Diese Diskurse sollen im Folgenden mit den konkreten Praktiken der Verkörperung und Inszenzierung der mission civilisatrice in den Schulen in Beziehung gesetzt werden, um die Haltung der schulischen Akteure zur Mandatsmacht zu eruieren. Neben der Vergabe von Stipendien und der Vollziehung nationalstaatlicher Rituale wie der französischen Nationahymne handelt es sich dabei vor allem um die Besuche französischer Regierungsvertreter und Künstler, die von der Forschung bisher nie systematisch untersucht wurden.

Diese doppelte Analyse zeigt ein interessantes Bild: während die Mission laïque trotz einer starken Betonung der mission civilisatrice eine etwas distanzierte Beziehung zur Mandatsmacht unterhielt, wie die Ausgestaltung der Besuche zeigen wird, pflegten die katholischen Schulen eine sehr enge Beziehung zu der Mandatsmacht, was sowohl ihre Herausstellung der Zivilisierungsmission als auch die vielen Besuche französischer Persönlichkeiten deutlich machen. Die Alliance israélite universelle bejahte uneingeschränkt sowohl Diskurs als auch Praxis, wurde aber von der Regierung nicht auf dieselbe Art und Weise berücksichtigt.

27 Vgl. MAE/Nantes, IP, 29: Im Schuljahr 1923-1924 besuchten 6725 muslimische und 1363 christliche Schüler eine staatliche Schule. Diese Zahlen änderten sich auch in den nachfolgendenJahren nicht deutlich.

28 Vgl. Chidiac 2002, S. 268.

29 Vgl. Chapman-Adisho 1998, S. 77-78; Roland Löffler, Protestanten in Palästina. Religionspolitik, Sozialer Protestantismus und Mission in den deutschen evangelischen und anglikanischen Institutionen des Heiligen Landes 1917-1939, Stuttgart 2008, S. 114; SLuglett 2004, S. 116-123. 
Darüber hinaus verfolgten Franzosen und Libanesen aber auch konkrete Ziele, für die sie sich durch den Bezug auf diesen Diskurs beim Hochkommissariat Unterstützung sichern wollten.

Die Akteure der Mission laïque nahmen zu Beginn des Mandats sehr direkt Bezug auf die Idee der Zivilisierungsmission, wobei schwieriger als bei den anderen Schulen auszumachen ist, ob diese Bezugnahme gleich blieb oder anstieg. Sicher jedoch ist, dass die Institution sich zu Beginn der Mandatszeit ganz klar mit dem französischen Mandat identifizierte. So hieß es in »Notre programme« von 1920:

Dans l'œuvre immense de reconstruction qui est commencée [...] quel peut être le rôle de la France et de l'esprit français? De tous côtés, les vieilles nations qui se réveillent, les jeunes nations qui naissent à l'indépendance ont les yeux tournés vers la «grande éducatrice des peuples». Elles l'interrogent, elles attendent qu'elle se fasse leur guide.

Il faut répondre à cet appel. Il ne s'agit pas de conquête, ni de domination. L'impérialisme, intellectuel ou autre, n'est pas à craindre de la France. Elle a donné son sang; on lui demande de donner son âme, en répandant sa pensée, afin que se prépare et forme, dans la concorde et dans la paix, l'humanité fraternelle qui doit être l'humanité de demain, Il s'agit de culture, d'après les principes et l'idéal de cette civilisation française, libérale et démocratique, si profondément humaine qu'il semble, vraiment, que l'on ne soit homme que dans la mesure où l'on a pu s'en imprégner. C'est pour prendre sa part de la tâche qui s'impose si impérieusement que la Mission laïque française a décidé de publier cette revue ${ }^{30}$.

Auch in offiziellen Schreiben an die französischen Regierungsvertreter sprachen die Entscheidungsträger der Institution 1919 von ihrer »action civilisatrice ${ }^{31}$ oder 1923 von den Schulen der Mission laïque als »foyers de culture française $\ll{ }^{32}$. Gerade angesichts der Tatsache, dass viele Regierungsvertreter zu Beginn des Mandats der Mission laïque sehr wenig Beachtung schenkten, liegt es nahe, in dieser diskursiven Bezugnahme eine Strategie der Organisation zu sehen, mit der sie darauf setzte, an der offiziellen Bildungspolitik beteiligt zu werden. So bemühten sich der Generalsekretär, Edmond Besnard, und der Direktor der Mission laïque in Beirut, Pierre Deschamps, Mitte des Jahres 1919 sehr um eine Unterstützung durch den Quai d'Orsay, bekamen aber erst nach einem erneuten Schreiben eine Antwort und einen Termin mit dem Hochkommissar im Libanon, General Gouraud ${ }^{33}$.

30 Revue de l'enseignement français hors de France 17 (1920), H. 1, S. 1.

31 AN/Paris, 60 AJ 121, Brief von Deschamps an das französische Hochkommissariat, 26.06.1919.

$32 \mathrm{MLF} /$ Paris, »Fonds de Russie«, 03/942, »Note à M. Daladier«.

$33 \mathrm{Vgl}$. AN/Paris, 60 AJ 122, Briefe von Besnard an den französischen Außenminister, Paris, 24.06.1919, 03.07.1919. Über das Ergebnis dieses Treffens ist nichts bekannt. 
Analysiert man die Besuche der laizistischen Schule durch französische Regierungsvertreter, wird allerdings die beidseitige Distanz deutlich. Im Mai 1920 besuchte Gouraud die Schule der Mission laïque in Beirut. Dem Bericht Deschamps' darüber ist zu entnehmen, dass eine höfliche, aber distanzierte Atmosphäre dieses Treffen bestimmte ${ }^{34}$. Sein Nachfolger General Maxime Weygand stattete, erst ein halbes Jahr nach seiner Ankunft, im Dezember 1923 der Mission lä̈que einen Besuch ab. Außerdem war dieser, so Direktor Mathieu in einem Brief an den Generalsekretär seiner Organisation, auf Drängen des Kultusbeauftragten Duthoit auf Gleichbehandlung zustande gekommen, nachdem Weygand schon alle Schulen außer der amerikanischen Universität und der Mission laïque besucht hatte ${ }^{35}$. Allerdings reagierte die Mission laïque auch selbst kritisch auf eine zu große Nähe zur Mandatsmacht, die sie in den Augen der nicht-katholischen Syrer suspekt machen würde. So schrieb der Generalsekretär an das französische Außenministerium:

Il nous paraît impossible, en tout cas fort dangereux, et pour le succès de notre œuvre et pour l'influence française, que nous apparaissions comme les agents de la politique française en Syrie. Ce serait le plus sûr moyen de nous rendre suspects aux yeux des non-catholiques qui constituent la grande majorité des Syriens et de nous enlever toute autorite ${ }^{36}$.

Darüber hinaus war Deschamps selbst der Errichtung des Mandats gegenüber sehr skeptisch eingestellt. Seiner Meinung nach wurden von den französischen Funktionären viele Fehlentscheidungen getroffen, die nur sehr schwer wieder zu korrigieren seien. So schrieb er drei Monate vor der Schlacht von Maysaloun, in welcher Frankreich den König des kurzlebigen arabischen Reiches Faysal besiegen würde:

[...] il semble bien qu'on s'achemine vers une campagne dans l'intérieur, qu'on envisage l'occupation de Damas. [...] Et la France va commettre ce crime, - on le lui fait commettre sans le lui dire; on la mettra en présence du fait accompli; du cadavre d'un peuple qui a eu confiance dans la Justice, - et de nombreux cadavres de nos soldats. Je voudrais me tromper; j'ai peur de ce que je dis,- et pourtant ${ }^{37}$ !

34 Vgl. AN/Paris, 60 AJ 123, Brief von Deschamps an den Präsidenten der Mission läque, Beirut, 12.05.1920.

35 Vgl. AN/Paris, 60 AJ 126, »Correspondance du directeur 1923-1924«, Brief von Mathieu an Besnard, Beirut, 06.12.1923.

$36 \mathrm{MAE} /$ Paris, CPC, 103, Brief von Besnard an »M. le directeur«, Paris, 06.06.1919.

37 AN/Paris, 60 AJ 122, Brief von Deschamps an Besnard, Beirut, 12.04.1920. 
Deschamps' Einschätzung der Situation unterschied sich stark von der anderer französischer Lehrer und Direktoren, aber auch von der anderer Mitglieder der Mission laïque. Obwohl die Organisation also deutlich auf die Zivilisierungsmission Bezug nahm, ging ihre Integration in die Bildungspolitik der Mandatsregierung eher zögerlich vonstatten.

Noch viel prominenter findet sich der Diskurs der mission civilisatrice in den Dokumenten der katholischen Schulen. Das gilt besonders für den Orden der Jesuiten: in ihren Schriften taucht ab 1920 vermehrt der Begriff der »action civilisatrice « auf ${ }^{38}$. Auch gegenüber der Mandatsmacht betonten die Jesuiten die $»$ seule vraie culture française $\ll^{39}$, als deren Mediatoren sie sich sahen. Die Besuche der ersten Hochkommissare belegen die enge und privilegierte Beziehung der katholischen Schulen zur Mandatsregierung. So besuchte Hochkommissar Georges Picot schon am 25. Januar 1919 die Schule der Frères des Écoles chrétiennes. Nicht lange bitten ließ sich auch sein Nachfolger Gouraud, der im Februar 1920 den Besuch des Cardinal Dubois bei den Frères vorbereitet hatte. Als er im Mai am Sportfest dieser Schule teilnahm, lobte er die Darbietungen der Schüler mit den Worten: „C'est [...] une véritable armée parfaitement organisée « ${ }^{40} .1923$ besuchte auch sein Nachfolger Weygand die Schule der Frères des Écoles chrétiennes, die ihm einen pompösen Empfang bereiteten ${ }^{41}$.

Wie Hochkommissar Gouraud waren auch seine Nachfolger Robert de Caix und Maxime Weygand Vertraute der katholischen französischen Orden $^{42}$. Die Unterstützung der Hochkommissare durch die Frères des Écoles chrétiennes zeigte sich unter anderem darin, dass sie die Reden der Mandatsvertreter in ihrer Schulzeitschrift abdruckten und positiv kommentierten $^{43}$. Sie unterstützten die Hochkommissare auch deshalb, weil diese die christliche französische Präsenz in der Levante verteidigten. So soll Gouraud nach der Schlacht von Maysaloun ausgerufen haben: »Saladin, nous sommes revenus « ${ }^{44}$ ! Mit dieser Anspielung auf den mamlukischen Kriegsherren und König, der die Herrschaft der Kreuzfahrer in der Levante beendet hatte, knüpfte Gouraud eindeutig an die christlich motivierte französische Präsenz

38 Siehe z.B. SJ/Vanves, RPO 15: »L'action civilisatrice des missionnaires catholiques«.

$39 \mathrm{SJ} /$ Vanves, »Fonds Jalabert«, 1/1 F, Notiz von Chanteur an Weygand, November 1924.

40 FEC, L'Essor, März 1921, S. 50-52.

41 Vgl. FEC, »Historique du Collège Français du Sacré-Cœur«.

42 Die Verbundenheit zeigte sich darüber hinaus an der Vermittlerrolle, welche die französischen Orden zwischen dem Hochkommissariat und der maronitischen Kirche einnahmen. Vgl. LAZ/ Antoura, Brief des Patriarchen Hoyek an Schuldirektor Sarloutte, 22.04.1923. In dem Brief drückte Hoyek seine Freude über die Ankunft Weygands aus und fragte Sarloutte: »Savez-vous quelque chose sur les idées et religion du nouveau Haut-Commissaire? «

43 Vgl. z.B. FEC, L'Essor, März 1921, S. 71-75: »Proclamation de l'indépendance du Liban«. In derselben Ausgabe zeigte die Zeitschrift Fotos von Gouraud als Militärverwalter in Marokko.

44 Vgl. Kassir 2003, S. 306. 
in der Region an und bekannte sich zu ihrer Rekonstruktion. Über die ideologische Überzeugung hinaus wählten die ersten Hochkommissare die Allianz mit den katholischen Orden aber auch aus strategischen Gründen: Zum einen genossen die Orden und ihre Schulen die Sympathie eines Großteils der (christlichen) Bevölkerung des Libanon ${ }^{45}$, und zum anderen konnten sie eine oft jahrhundertealte Präsenz im Land aufweisen, während derer sie sich fest etabliert hatten.

Die katholischen Schulen befürworteten diese Allianz und konnten die Sorge der Mission laïque, von Seiten der Libanesen zu stark mit der Mandatsmacht identifiziert zu werden, nicht teilen. Im Gegenteil befürchteten die Jesuiten, auch wenn sie zu Beginn des Mandats die privilegierten Ansprechpartner der Mandatsregierung darstellten, immer eine erneute Ausweisung oder ein Verbot, wie sie es Ende des 19. Jahrhunderts in Frankreich erfahren hatten ${ }^{46}$. Diese Sorge brachte sie schon 1920 dazu, ihre Zugehörigkeit zu der offiziellen Bildungspolitik zu betonen.

Auch bei den Vertretern der Alliance israélite universelle ist eine stärkere Verwendung des Diskurses der mission civilisatrice festzustellen. Die Referenzen häuften sich ab 1919 im internen Geschäftsverkehr, aber auch in der Kommunikation mit den französischen Autoritäten. So führte Direktor Sidi 1925 in seiner Rede anlässlich des Schulsommerfestes aus:

[...] quel est encore le secret de notre succès? Pour faire bénéficier nos coreligionnaires d'Orient des progrès des temps modernes, pour les faire entrer dans le plan de la civilisation occidentale, l'Alliance israélite s'est servie d'un instrument qui a fait ses preuves, de la langue française, véhicule incomparable d'idées généreuses et de sentiments nobles $[\ldots . .]^{47}$.

Wie in Kapitel zwei dargestellt, stellte die Alliance israélite während des Ersten Weltkriegs den Hauptansprechpartner der französischen Besatzungsmacht dar, wurde dieses Privilegs aber durch die Rückkehr der anderen französischen Schulen wieder enthoben ${ }^{48}$. Obwohl die Organisation ihre Zugehörigkeit zur Mandatsmacht betonte und deren Vertreter explizit zu unterschiedlichen Gelegenheiten einlud, reagierte die Mandatsregierung

45 In den christlichen Gemeinschaften, vor allem im Klerus, waren noch die Erfahrungen des französischen Erziehungswesens vor dem ersten Weltkrieg lebendig. Vgl. Hanf 1969, S. 75.

46 Vgl. Elizabeth Thомpson, Neither Conspiracy nor Hypocrisy. The Jesuits and the French Mandate in Syria and Lebanon, in: Eleanor H. Tejirian / Reeva S. Simon (Hg.), Altruism and Imperialism: Western Cultural and Religious Missions in the Middle East, New York 2002, S. 66-87, S. 66.

47 AIU/Paris, »Liban IXE, 96b«, Abschrift der Rede Sidis während des Schulfestes im Juni 1925.

48 In den Archiven der Organisation finden sich nach 1919/1920 keine dementsprechenden Dokumente mehr, und auch die Quellen der französischen Autoritäten verzeichnen keinerlei engere Kooperation mehr. 
etwas verhaltener als bei den anderen französischen Schulen. Alle Hochkommissare besuchten zwar die Schulen der Alliance israélite und sprachen ihnen, so die Berichte der Direktoren, ihre »sympathie à l'œuvre de l'Alliance $«{ }^{49}$ aus, aber aus den Archiven wird ersichtlich, dass sich die Lehrer der Alliance israélite stärker um den Kontakt bemühten als die Hochkommissare selbst ${ }^{50}$. Trotzdem blieb das eindeutige Bekenntnis der Organisation zur Beteiligung an der französischen Zivilisierungsmission bestehen. Laut Aron Rodrigue lag die erneuerte Zustimmung der Alliance israélite zur mission civilisatrice ab 1918 auch darin begründet, dass sich die französische Kolonialmacht in der Levante, im Gegensatz zu Nordafrika, erst sehr spät manifestierte ${ }^{51}$.

Die Inszenierung der mission civilisatrice funktionierte in allen französischen Schulen auch über die Verwendung der französischen nationalen Symbole, der Nationalhymne und der Flagge. Diese Praktiken zeigen nicht nur nur deutliche Parallelen zur Bildungspolitik in kolonialen Regimen, sondern geben darüber hinaus Aufschlus über die Positionierung der Schulen. Die Bildungsstätten benutzten die Symbole zum einen bei den Empfängen französischer Persönlichkeiten. Auf diese Weise verwendeten sie das »Kulturinventar« der französischen Republik, das vor allem in der Dritten Republik, insbesondere in den Schulen, gefestigt und zelebriert wurde ${ }^{52}$. Das Abspielen der Marseillaise beim Empfang französischer Persönlichkeiten kann noch als Ritual verstanden werden, das einem Politiker in einem fremden Land zuteil wird. Die Lehrer der Schulen formulierten aber darüber hinaus den Anspruch, dass der Libanon oder zumindest die französischen Schulen im Libanon ein Teil Frankreichs waren. Ähnlich argumentierte ein französischer Admiral, als er die Schüler der Alliance israélite universelle auf ein Kriegsschiff einlud und ihnen mitteilte: »À bord de mon bateau, vous vous trouvez sur une partie du $>$ sol français $\ll^{53}$.

Die Inszenierung der französischen Symbole geschah darüber hinaus bei Schulfesten, etwa beim Fest am Ende des Schuljahres. So berichtet die Chronik der Frères des Écoles chrétiennes, dass bei einem Schulfest 1921 die

49 AIU/Paris, »Liban 1 C 1«, Brief von Sidi an den Präsidenten der Alliance israélite, Beirut, 07.12.1924, in welchem er das Kompliment Weygands wiedergab.

50 Beispielsweise berichtete Penso, Hochkommissar Picot habe ihm versprochen, seine Schule bald zu besuchen; da es keine spätere Meldung gab, scheint dieser Besuch aber nicht stattgefunden zu haben. Vgl. AIU, »Liban VIE 81«, Brief von Penso an den Präsidenten der Alliance israélite in Paris, Beirut, 15.07.1919.

51 Rodrigue 1989, S. 174-175.

52 In Frankreich hatte es allerdings auch viele Proteste gegen diese Inszenierung gegeben. Vgl. Ouzouf/ Ouzouf 1992, S. 151-152.

53 AIU/Paris, »Liban VIE 80-81«, Brief von Penso an den Präsidenten der Alliance israélite in Paris, Beirut, 01.05.1919. 
Marseillaise »donnernd« gespielt wurde ${ }^{54}$. An diesem Beispiel zeigt sich sehr deutlich die Verflechtung der französischen Schulen im Libanon mit der Entwicklung in Frankreich selbst. In der Tat hatte sich die Marseillaise vom Kennzeichen der Revolutionäre und der Arbeiter durch das starke Einwirken der Regierung zum Symbol der ganzen französischen Nation entwickelt. Nach dem Ersten Weltkrieg allerdings kritisierten die Sozialisten und Kommunisten die Marseillaise heftig und zogen ihr die Internationale vor, bevor die Nationalhymne um 1934 auch wieder von den linken Parteien als ihr Symbol anerkannt wurde ${ }^{55}$. Das heißt, dass die Frères des Écoles chrétiennes 1921 ein klares profranzösisches, aber auch antikommunistisches Zeichen setzten. Interessanterweise berichten die Archive der Mission laïque in Beirut erst 1934 von dem Abspielen der Marseillaise bei einem Schulfest, was ihre Nähe zu den linksdemokratischen Parteien in Frankreich zeigt ${ }^{56}$.

Die Schulen integrierten diese Symbole über die Feste hinaus auch in den Alltag des Klassenzimmers. In allen französischen Institutionen ${ }^{57}$ mussten die Schüler den Text des Flaggengrußes (»salut au drapeau français«) aufsa$\operatorname{gen}^{58}$. Die Forschung hat herausgearbeitet, dass die »pratiques cérémonielles ritualisées « wie der Fahnengruß insbesondere in Ländern, die gerade die Unabhängigkeit erlangt hatten, dazu diente, eine nationale Einheit zu schaffen, welche die Unterschiede der >Rasse〈, Sprache oder Religion aufheben und durch die Zugehörigkeit und Loyalität zur Nation ersetzen sollte ${ }^{59}$. Bei diesen Ritualen wurden durch die künstlerische Gestaltung insbesondere die emotionalen Kapazitäten der Schüler angesprochen, was die Wirkung noch verstärken sollte ${ }^{60}$. Hier handelte es sich aber nicht um das Heimatland der Zöglinge, was die Parallele zu Bildung in kolonialen Regimen und das dort erforschte Phänomen der Verfremdung ${ }^{61}$ erneut verdeutlicht.

54 FEC, L'Essor, März 1921, S. 45.

55 Vgl. Michel Vovelle, La Marseillaise. La guerre ou la paix, in: Pierre Nora (Hg.), Lieux de mémoire, Bd. I, Paris 1997, S. 107-151, hier 138-145.

56 Vgl. AN/Paris, 60 AJ 136, Brief von Ruche an Besnard, Beirut, 29.06.1934.

$57 \mathrm{Ob}$ das auch auf die Alliance israélite zutrifft, konnte nicht ermittelt werden.

58 Für die Mission laïque siehe AN/Paris, 60 AJ 125, Brief von Mathieu an Besnard, Beirut, 06.03.1923: »J'ajouterai que M. Duval a pu faire chanter aux élèves de la division secondaire au début de l'année >Salut au drapeau de la France« sans soulever aucune protestation«. Da Mathieu in seinem Brief betont, dass dieses in seiner Schule noch ohne Proteste möglich war, wird deutlich, dass diese Praktiken von den Libanesen schon früh kritisiert wurden.

59 Arnaud Mercier, Efficacité du performatif dans les rituels politiques, in: Hermès 43 (2005), S. 31-37, S. 32.

60 Vgl. Yves-Henri Nouailhat, Identité européenne, identité nationale, identité régionale: rivalité ou complémentarité?, in: Jean-Pierre Wallot, (Hg.), Constructions identitaires et pratiques sociales, Ottawa 2002, S. 90-104, S. 102.

61 Внавна 2008, S. 121-131 erfasst das Phänomen unter dem Begriff der Ambivalenz der Mimkry. Das bekannteste Beispiel für den französischen Kontext ist die Geschichtslektion »Nos ancêtres les Gaulois«, die auch die afrikanischen Kinder lernen musste. Vgl. Denise Bouche, 
Aus diesem Grund mussten die Schulen auf unterschiedliche Sensibilitäten ihrer jeweiligen Klientel achten. Während in vielen katholischen französischen Schulen die Symbole der französischen Nation ohne Schwierigkeiten verwendet wurden, musste sich die Mission laïque mehr Gedanken um ihren Umgang damit machen. So wehrte der Generalsekretär der laizistischen Organisation in Paris, Edmond Besnard, 1924 sehr entschieden den Vorschlag des Direktors Mathieu in Beirut ab, die Wände des Versammlungsraumes der Schule mit Fotografien der Hochkommissare Gouraud und Weygand zu dekorieren ${ }^{62}$.

Neben den offiziellen französischen Vertretern der Regierung oder des Hochkommissariats wurden die Schulen seit Beginn des Mandats verstärkt auch von einer Reihe von französischen Persönlichkeiten aus dem kulturellen Bereich besucht. Da manche Persönlichkeiten alle, andere nur bestimmte Schulen aufsuchten, soll in einem weiteren Schritt der Untersuchung die These von der mission civilisatrice als leerem Signifikanten verifiziert werden. Gerade die schon aus osmanischer Zeit bekannte Praxis der Besuche als Symbol der mission civilisatrice schuf zwischen den Schulen zwar größere Gemeinsamkeiten, als sie diese von Frankreich kannten, ließ aber auch die Unterschiede klar hervortreten.

Die Persönlichkeiten, die alle Schulen besuchten, bildeten das »symbolische Allgemeingut $\ll^{63}$ der Erziehungseinrichtungen und des Hochkommissariats, welches diese Besuche koordinierte. Dazu gehörten der Schriftsteller Henry Bordeaux, der im Mai 1922 seine Tour durch die Schulen machte ${ }^{64}$, aber auch diverse französische Militärangehörige ${ }^{65}$.

Daneben gab es aber auch eine Gruppe von Besuchern, die wegen spezifischer Affinitäten nur bestimmte französische Schulen besuchten. Damit verstärkten sie die ideologische Zugehörigkeit der Schulen nach außen. Die katholischen Schulen und ihre Besucher betonten bewusst ihre christliche und französische Identität. Beispielsweise erhielten die Frères des Écoles chrétiennes, wie schon erwähnt, im Februar 1920 einen Besuch des französischen Kardinals Dubois, der die zweischneidige Identität dieser Schule sehr sichtbar machte. So rief er zum Schluss seines Besuches aus: »Vive la France

Autrefois notre pays s'appelait la Gaule...Remarques sur l'adaptation de l'enseignement au Sénégal, in: Cahiers d'études africaines 8 (1969), H. 29, S. 110-122.

62 Vgl. AN/Paris, 60 AJ 126, »Correspondance du Directeur 1923-1924«, Brief an Mathieu vom 05.07.1924.

63 Von »Kollektivsymbol« im Sinne der Literaturwissenschaft zu sprechen, erscheint insofern nicht sinnvoll, als dieser Begriff vor allem konkrete und abstrakte Dinge, aber nicht Personen umschließt.

64 Für die MLF siehe AN/Paris, 60 AJ 124, »rapports mensuels«, Mai 1922; für die Frères des Écoles chrétiennes siehe FEC, »Historique du Collège du Sacré-Coeur de Beyrouth«.

65 Für die Schule der Frères des Écoles chrétiennes siehe FEC, L'Essor, März 1921; für die Mission laïque siehe AN/Paris, 60 AJ 124, »Rapports mensuels«, 30.11.1921. 
catholique! $\ll^{66}$ und inszenierte damit ein Bild von Frankreich, das der politischen Realität im Mutterland nicht mehr entsprach. Demgegenüber betonten die Besuche französischer Persönlichkeiten der Mission lä̈que nicht explizit deren laizistische, antiklerikale Identität. Allerdings zeigten die Besucher André Lichtenberger, Autor mehrerer Bücher über den Sozialismus, im Mai $1922^{67}$ oder der französische Abgeordnete Sérot, bekennender Republikaner, im Oktober $1923^{68}$ eine Seite Frankreichs, die in den katholischen Schulen nicht sichtbar wurde.

Die Berichterstattung in den Beiruter Zeitungen der Zeit zeigt, dass diese Besuche von den Libanesen sehr genau verfolgt wurden ${ }^{69}$. Allerdings beschränkte sich die Reaktion der Libanesen nicht auf eine Rezeption dieser Inszenierung. Neben den französischen Akteuren und Institutionen gebrauchten auch sie in ihren Briefen an die französischen Schulen oder die französische Regierung zu Beginn des Mandats verstärkt den Diskurs der mission civilisatrice. Noch offensichtlicher als die französischen Schulen verbanden sie damit bestimmte Forderungen. Beispielsweise bat der Möbelhändler Schami Bey Durri aus Aleppo die Mission lä̈que 1921 um die Gründung einer laizistischen Schule in seiner Heimatstadt. Er hatte die Organisation auf der Beiruter Messe, der Foire de Beyrouth, kennengelernt und reproduzierte ihren Diskurs in seinem Brief:

Les raisons de création de cette mission sont très sublimes au point de mettre la paix entre les différentes cultures en Syrie. Les élèves qui étudieront dans les écoles laïques apprendront la fraternité humaine sans distinction de religion ou nationalité (c'est le moyen le plus proche pour la civilisation). Vous savez bien, Monsieur, que la ville d'Alep est la plus grande de Syrie. Il n'y a que des écoles créées par des religieux. Le monde musulman en souffre beaucoup, ils cherchent à trouver un endroit où ils pourront instruire les enfants sans s'occuper des religieux, mais ils n'en trouvent pas ${ }^{70}$.

Ebenso bat der griechisch-orthodoxe Pfarrer Kalouf aus Marcab in Syrien den Rektor der Schulbehörde in Paris um Unterstützung für eine Schule mit den Worten:

66 Vgl. FEC, »Historique du Collège français du Sacré-Cœur«.

67 Vgl. AN/Paris, 60 AJ 124, »Rapports mensuels«, Mai 1922.

68 Vgl. AN/Paris, 60 AJ 126, »Rapports mensuels«, Oktober 1923.

69 Beispielsweise wurden Jouvenels und Ruches Reden bei Jouvenels Besuch der Mission laïque in der Zeitung La Syrie abgedruckt. Vgl. AN/Paris, 60 AJ 128, »Rapports mensuels«, Dezember 1925.

70 AN/Paris, 60 AJ 123, »Correspondance du directeur«, Brief von Durri an den Direktor der MLF, Beirut, 08.05.1921. 
Cependant, ma fréquentation dans les milieux français, d'une part, et, d'autre part, ma conviction que nos écoles de Syrie en général sont appelées à servir la cause de la France en répandant l'usage de la langue française et de la littérature française, tout cela m'encourage à m'adresser à vous en votre qualité d'éminent représentant de la Science dans ce pays de lumière et de liberté, pour que vous m'accordiez votre appui dans l'exécution de la mission pour laquelle j'ai été envoyé. Les moyens ne vous manquent pas et vous connaissez certainement parmi vos relations personnelles ou bien dans les diverses corporations des bienfaiteurs que vous saurez intéresser à cette œuvre $\mathrm{e}^{71}$.

Manche Libanesen suchten auch verschiedene Möglichkeiten der Unterstützung: beispielsweise richtete Farid al-Hage, Direktor einer kleinen Schule in Kaitouly, seine Petitionen sowohl im Juli und Oktober $1920^{72}$ an die Mission laïque als auch Ende Oktober desselben Jahres ${ }^{73}$ an das Hochkommissariat.

Zusammengefasst diente der Rekurs der Libanesen auf den Diskurs der Zivilisierungsmission ganz unterschiedlichen Motiven, die in einer Frankreich gegenüber kooperativen oder feindlichen Art und Weise darauf abzielten, die Hierarchie der französischen und libanesischen Zivilisation entweder $\mathrm{zu}$ akzeptieren und zu unterstützen oder subversiv zu untergraben ${ }^{74}$.

\section{Bildungspolitik als französisch-libanesische Partnerschaft}

Die Idee der mission civilisatrice wurde nicht nur von den Schulen symbolisch inszeniert, um ihre Zugehörigkeit zum französischen Mandat zu zeigen, sie bestimmte auch die Bildungspolitik der Mandatsregierung. Indem die französische Mandatsmacht im Libanon die französischen wie auch die libanesischen Schulen sowohl förderte als auch kontrollierte und diese Haltung ebenso gegenüber den libanesischen Schülern einnahm, erhob sie die Idee der Zivilisierungsmission zum leitenden Prinzip ihrer Politik: sie setzte sich selbst als höchste Instanz, präsentierte sich aber nicht als despotische Herrscherin, sondern als fürsorgliche Begleiterin, indem sie signalisierte, die Bedürfnisse der Libanesen nach Bildung $\mathrm{zu}$ erfüllen und

71 AN/Paris, aj 16/6993, »Correspondance avec le Père Kalouf« 1922, Brief von Kalouf an den Rektor der Académie, Paris, 20.06.1922; Brief von Besnard an den Rektor der Académie, Paris, 02.08.1922.

72 AN/Paris, 60 AJ 123, Brief von Lehéricy an Besnard, Beirut, 14.10.1920.

73 MAE/Nantes, IP, 03, »Écoles ne relevant d'aucune communauté«.

74 Benjamin White hat diese Kategorien entwickelt, um die unterschiedlichen Aneignungen der Rhetorik eines Machtgefälles zwischen Frankreich und Syrien durch die Syrer zu charakterisieren. Diese Kategorien können auch auf den Libanon übertragen werden. Der einzige Unterschied bestand in dem größeren Anteil Frankreich freundlich gegenüber gesinnter Taktiken. Vgl. White 2008, S. 109. 
sie zu Partnern Frankreichs zu machen. Dieses Bild präsentierte die Mandatsregierung 1921 in einer großen Ausstellung, der Foire de Beyrouth: die Bildungseinrichtungen

attesteront des progrès faits, surtout dans la langue française par les enfants du pays, et, partant, leur désir de s'instruire et leur aptitude à devenir d'excellents collaborateurs pour les échanges et les rapports économiques entre la Syrie et les pays étrangers, en particulier la France ${ }^{75}$.

Damit weitete sie ihre Selbstdarstellung als Mutter, die sich ihrer vom Osmanischen Reich vernachlässigten Kinder annahm ${ }^{76}$, auch auf den Bereich der Bildung aus. Sie subventionierte und kontrollierte die Schulen, vergab Stipendien, vereinheitlichte das Abschluss- und Prüfungssystem und setzte dabei ihre eigenen Interessen an erste Stelle.

Wie reagierten die einzelnen Institutionen darauf? Wie der erste Teil der Analyse zeigen wird, beteiligten sich diese an der Durchdringung des Bildungssystems durch die Mandatsmacht, schufen sich aber auch geringe Freiräume, innerhalb derer sie autonom agieren konnten. Interessanterweise verwandelten die Schulen manche Strategien der Mandatsregierung in Taktiken zur Erfüllung ihrer eigenen Interessen. Ihre libanesische Klientel wiederum nutzte ihrerseits sowohl die Strategien der Regierung als auch der Schulen für die Bewahrung oder Verbesserung ihres eigenen sozialen Status. Damit wurden die von der Mandatsregierung initiierten Mechanismen teilweise ausgehebelt. Dieses komplexe Phänomen wird im zweiten Teil der Analyse anhand der Frage der Stipendien diskutiert.

Zunächst einmal ging es dem Hochkommissariat darum, das Monopol über die Schulen zu erlangen. Zu diesem Zweck verpflichtete Chevalley, der erste Bildungsbeauftragte des Hochkommissariats, Anfang 1920 alle Privatschulen, eine Erlaubnis einzuholen, um wieder eröffnen zu können. Dafür mussten die Institutionen Rechenschaft über ihre Gründung, ihre Größe und ihre Unterrichtsprogramme ablegen ${ }^{77}$. Ganz deutlich hieß es, dass »l'autorisation [...] ne pourra être donnée que par le Haut-commissariat français $\aleph^{78}$. Als Begründung wurde angegeben, dass weder der syrische noch der libanesische Staat dafür die nötige Administration besäßen. Seinen Machtanspruch setzte das Hochkommissariat auch um, indem es zu Beginn des Mandats viele lokale Schulen, die keine Erlaubnis besaßen, schließen

75 MAE/Nantes, IP, 03:1920, »Foire de Beyrouth«.

76 Vgl. Einleitung.

77 Vgl. MAE/Nantes, IP, 02, »Gouvernement arabe, 16.03.1920«.

78 AN/Beirut, Recueil des Actes administratifs du Haut-Commissariat de la République Française en Syrie et au Liban«, Band 1-4, 1919-1923, Beirut: Imprimerie Jeanne d’Arc. Arrêté Nr. 1107 »Concernant les écoles privées«. 
lie $3^{79}$. Diese Erlaubnis betraf aber auch die französischen Schulen. Während die katholischen Schulen zu Beginn des Mandats keine Schwierigkeiten hatten, wieder zu eröffnen, musste die Mission lä̈que viel länger auf eine endgültige Erlaubnis warten ${ }^{80}$ und konnte ihrerseits den lokalen Schulen, die an einer Kooperation interessiert waren, keine Partnerschaft anbieten ${ }^{81}$. Damit bremste das Hochkommissariat bewusst den wachsenden Einfluss der laizistischen Schule.

Nachdem die Privatschulen im Libanon anerkannt worden waren, wurden sie von den Angestellten des Kultusministeriums im Hochkommissariat kontrolliert. Dabei zeigten sich sehr früh die Probleme der Kompetenzüberschneidung zwischen libanesischen und französischen Inspektoren ${ }^{82}$. Diese Schwierigkeit bekam auch die Bevölkerung zu spüren: so beschwerten sich die Lehrer einer maronitischen Schule in dem Dorf al-Arbaniya im Libanongebirge, dass ein Vertreter der lokalen Regierung sie kontrollieren wollte, obwohl er dazu kein Recht habe ${ }^{83}$. In ihrem Schreiben an den Hochkommissar appellierten sie an die Tradition, nach der sie dem maronitischen Erzbischof unterstellt seien.

Ganz ignorieren konnte das Hochkommissariat die Forderungen der traditionellen Notabeln auch bezüglich der Kontrolle der Schulen in der Tat nicht. So rekrutierte Chevalley neben dem libanesischen Inspektor Sawaya 1920 eine französische Inspektorin, Marie Saule, und reagierte damit auf den Protest des muslimischen Klerus im Libanon, der keine männlichen Beamten in einer muslimischen Mädchenschule akzeptierte: »d'autre part, (il est nécessaire) de déposer d'urgence d'une inspectrice des écoles, le clergé musulman protestant de plus en plus contre l'accès de tout homme, même musulman, dans les écoles de filles « ${ }^{84}$.

79 Vgl. z.B. OIB, Bulletin officiel des actes administratifs du Haut-Commissariat Français 49 (1920), 04.12.1922.

80 So berichtete Deschamps Anfang 1920, er habe »exposé au Haut-Commissariat notre programme et prié qu'on me dise, avant que je réponde aux directeurs d'écoles qui s'étaient adressés à moi, si ce programme avait l'agrément du gouvernement«; aber auch nach einem Monat hatte er noch keine Antwort. AN/Paris, 60 AJ 122, Brief von Deschamps an den Präsidenten der MLF, Beirut, 23.01.1920.

81 Ebd., Brief von Lehéricy an Besnard, Beirut, 14.12.1920.

82 So traf es sich im April 1920, dass »en inspectant l'école de Zahrat Uloum (École privée de Beyrouth, subventionnée par le H.C.) M. Sawaya a appris que cette école avait été visitée deux jours avant par M. Nahas, Inspecteur des écoles officielles«. MAE/Nantes, IP, 02, Notiz vom 20.04.1920.

83 Ebd., Brief vom 16.05.1920.

84 MAE/Paris, CPC, 103, Telegramm des französischen Außenministeriums an Picot, Kairo/ Beirut, 28.03.1919. 
Die ersten Inspektionsberichte der Schulen im Libanon aus dem Schuljahr 1921-1922 zeigen, dass das Hochkommissariat auch die staatlichen Schulen kontrollierte, allerdings seltener und weniger ausführlich als die privaten Schulen ${ }^{85}$. In ihren Berichten beschrieb Saule neben den technischen Daten minutiös das Französischniveau der Schüler und den politischen Nutzen der insgesamt 78 Schulen, die sie besuchte ${ }^{86}$. So lautete beispielsweise ihr Urteil über die Schule der Sours de Saint-Joseph de l'Apparition in Abey: „très bonne influence sur les milieux druses $\ll^{87}$.

Finanzielle Subventionen waren für die Schulen nur zum Preis der Kontrolle durch die Inspektoren zu haben, wie Chevalley unumwunden zugab: »Le H.C. [Haut-Commissaire] ou les Affaires Étrangères qui subventionnent exercent un contrôle [...] $\ll^{88}$. Der Bericht des Hochkommissariats vom Juli 1920 erwähnt, dass sich einige griechisch-orthodoxe und muslimische Privatschulen gegen diese Politik wehrten und erst gar nicht bei der Verwaltung erschienen, um ihre Subventionen zu erhalten. Das heißt, dass es bereits von Beginn an Widerstand gegen die französische Bildungspolitik $\mathrm{gab}^{89}$. Allerdings gaben sie diese Blockade wenig später auf und nahmen die Subventionen an, da die Versorgungslage im Libanon nach dem Ersten Weltkrieg katastrophal war und jede materielle und finanzielle Hilfe das Überleben sicherte ${ }^{90}$.

Auch die französischen Schulen betrafen diese materiellen Sorgen. Bei der Mission laïque und der Alliance israélite kam erschwerend hinzu, dass sie ihre Lehrer selbst bezahlen mussten ${ }^{91}$. Aus diesem Grund nahmen die Schulen die finanzielle Unterstützung des Hochkommissariats nur zu gerne an, auch wenn die Mission laïque eine Gleichsetzung mit der Mandatsmacht durch die Bevölkerung um jeden Preis vermeiden wollte ${ }^{92}$.

85 Vgl. MAE/Nantes, IP, 07, »Fiches d'inspection«.

86 Vgl. ebd.

87 Ebd.

88 MAE/Nantes, IP, 02: 1919-1920, »Le Conseiller pour l'Instruction Publique à M. le Chef du Contrôle Administratif« (ohne Datum).

$89 »$ Le fait le plus notable est que les Grecs-Orthodoxes et les Musulmans montraient dans l'ensemble peu d'empressement à recevoir des subventions scolaires françaises, leur politique les rapprochant plutôt de l'Angleterre et de l'Amérique qui les payaient d'ailleurs plus largement«. MAE/Nantes, IP, 02, »Avis du chef du contrôle administratif«, Juli 1920.

90 Vgl. Thompson 2000, S. 19-23.

91 Die Mission laïque sah das auch deutlich als Nachteil gegenüber den katholischen Institutionen, deren Mitglieder unentgeltlich arbeiteten. Vgl. AN/Paris, 60 AJ 122, Brief von Deschamps an Besnard, 13.12.1918: »Je sais bien qu'un missionnaire catholique ne raisonnerait pas comme moi; la faiblesse des missionnaires laïques est qu'ils ont une famille, des intérêts matériels et qu'ils n'ont pas le droit de s'en abstraire. C'est bien gênant parfois quand les événements, comme aujourd'hui, exigent une action immédiate $\ll$.

92 AN/Paris, 60 AJ 122, Brief von Deschamps an Besnard, Guincamp, 19.04.1919. 
Die materielle Förderung zu Beginn des Mandats fiel eindeutig zu Gunsten der katholischen Orden aus ${ }^{93}$. Die reservierte Haltung des Hochkommissariats gegenüber der Mission laïque erklärt sich aber nicht nur durch die prokatholische Haltung der ersten Hochkommissare. Hinzu kam, dass Kultusbeauftragter Chevalley selbst ein, allerdings staatliches, laizistisches Schulwesen im Libanon und in Syrien aufbauen wollte ${ }^{94}$. In der Folge kam es zu einer starken Konkurrenz zwischen ihm und den Privatschulen der Mission lä̈que. Beide Seiten kannten sich bereits aus Ägypten, wo Chevalley 15 Jahre gearbeitet hatte und die laizistische Organisation seit 1907 Schulen unterhielt ${ }^{95}$. Von der Schule der Mission lä̈que in Kairo rekrutierte Chevalley auch deren Lehrerin Marie Saule als Inspektorin, worüber die Mission laïque sehr erbost war ${ }^{96}$. In verschiedenen Gesprächen erinnerte Chevalley Deschamps daran, dass die Mission lä̈que von der französischen Regierung abhängig sei und deshalb mit dieser kooperieren solle. Er führte aber auch aus, dass ihm die Feindseligkeit der Mission lä̈que durchaus nützlich sein könne, sie sei »de nature à dissiper les préventions qu'on pouvait avoir contre lui ${ }^{97}$. Diese Aussage bestätigt noch einmal die Vorbehalte im Hochkommissariat gegenüber ihm und seiner laizistischen Einstellung.

Darüber hinaus kommunizierte Chevalley mit ehemaligen Lehrern der Mission laïque in Beirut, um Informationen über die Institution zu erhalten. So traf er sich 1922 mit einem Lehrer, der die Schule der Mission lä̈que verlassen hatte, und notierte sich die Höhe seines Gehalts ${ }^{98}$. Es ist zu vermuten, dass er diese Informationen nutzte, um in späteren Jahren den einheimischen Lehrern in den staatlichen Schulen ein höheres Gehalt zu zahlen als in den privaten Einrichtungen ${ }^{99}$. Auf diese Weise wurde die Mission laïque in dop-

93 Vgl. MAE/Nantes, IP, 05: »Allucations extraordinaires«. Allerdings gab es für alle Schulen sehr bald weniger finanzielle Unterstützung: Das Budget des Service des Euvres françaises à l’Étranger sank von 15 Millionen Francs 1921 auf 10 Millionen Francs 1923 und berief sich ab 1924 sogar nur noch auf 8500000 Francs. Erst um 1930 erhielt die Mission laïque française mehr Subventionen, und ab 1937 bekamen auch die katholischen Schulen wieder verstärkte finanzielle Unterstützung. Vgl. Riffier 2000, S. 245.

94 Vgl. MAE/Nantes, IP, 02: 1920, »Enseignement official«.

95 Vgl. Abécassis 2000, S. 98-109: 1907 war eine Schule in Port-Said, 1909 in Kairo und 1910 in Alexandria errichtet worden. Über Chevalley waren keinerlei weitere Informationen aufzufinden, und er wird in der einschlägigen Literatur gar nicht erwähnt. Auch Walter BJöRkman, Das syrische Bildungswesen und seine Probleme, in: Die Welt des Islams, 23 (1941), H. 3-4, S. 133155, S. 134, Fußnote 9, belässt es bei der Nennung von Chevalleys Namen.

96 Saule war bis 1917 bei der Schule der Misison laïque in Ägypten angestellt gewesen, und es war 1920 wohl nicht klar, ob sie die Institution rechtmäßig verlassen hatte. Vgl. AN/Paris, 60 AJ 122, Brief von Deschamps an den Präsidenten der Mission laïque, Beirut, 10.02.1920.

97 Ebd., Brief Deschamps an Präsidenten der Mission lä̈que, Beirut, 10.02.1920, in dem er über sein Treffen mit Chevalley berichtete.

98 MAE/Nantes, IP, 14, »Note«.

99 Vgl. die Diskussion der Direktoren der privaten Schulen, wiedergegeben in AN/Paris, 60 AJ 136, Brief von Besnard an Ruche, Paris, 15.11.1934. 
pelter Hinsicht vom Hochkommissariat - sowohl von dem pro-katholischen Hochkommissar als auch von dem laizistisch eingestellten Kultusbeauftragten Chevalley - auf Abstand gehalten.

Mit der Förderung der Schulen wirkte das Hochkommissariat nicht nur auf diese ein, sondern verfügte darüber hinaus über ein Medium, um die libanesische Bevölkerung zu erreichen. So erfuhren die französischen Schulen seit der Besatzung durch das französische Militär erneut eine starke Zunahme der Schülerzahlen: »L'enseignement du français devient de jour en jour plus nécessaire et plus recherché. Il s'introduit de plus en plus, depuis l'occupation dans toutes les écoles primaires de notre ville si petites qu'elles soient $\ll^{100}$.

Stärker noch als während des Osmanischen Reiches frequentierten die Libanesen die französischen Schulen, weil diese die notwendigen Voraussetzungen boten, um danach im Mandatsregime eine Arbeit zu finden. Beispielsweise schrieb im Juni 1923 eine Delegation des Dorfes al-Ğāhilīya einen Brief in arabischer Sprache an die Mission laïque in Beirut, in ihrem Dorf eine Schule zu errichten, unter anderem wegen »unserer Notwendigkeit (ị̣tiyāğunā), dass sie die französische Sprache erlernen $\aleph^{101}$. Damit gewann der Schulbesuch erneut Bedeutung für den sozialen Aufstieg oder den Statuserhalt der libanesischen Klientel der Schulen. Auf diese Art und Weise wurden Franzosen und Libanesen gleichermaßen zu Nutznießern der französischen Schulen. Dass die Libanesen die ihnen gebotenen Möglichkeiten dabei manchmal stärker nutzten als es der Mandatsregierung recht war, illustriert die Einrichtung der Stipendien.

Das Hochkommissariat sah in der Vergabe von Stipendien für die Schüler der Privatschulen ein effektives Instrument, um seinen Einfluss in den Schulen und Familien zu verankern. Da besonders die ausländischen Privatschulen hohe Schulgelder forderten, waren viele Eltern auf finanzielle Unterstützung angewiesen. Deshalb erreichte die Kritik der libanesischen Bevölkerung an den zu hohen Schulgeldern auch die frankophilen Gemeinschaften. In mehreren Leserbriefen an die alteingesessenen Beiruter Zeitungen ${ }^{102}$ Lisān al-Hāl und al-Ahwāl beschwerten sich vor allem Vertreter der »Mittelklasse«, dass die Schulgelder massiv gestiegen, ihre Löhne

100 AIU/PAris, VIE 81, Brief von Penso an Präsidenten der AIU in Paris, Beirut, 30.01.1919.

101 AN/Paris, 60 AJ 12, Brief der Delegation an den Direktor der säkularen französischen Fakultät al-Ğāhilīya /20. oder 30.06.1922. Siehe den gesamten Brief in Kapitel 4.1. Die Tatsache, dass 17 Dorfbewohner den Brief unterschrieben hatten, unterstreicht das Gewicht ihres Anliegens. In ähnlicher Weise berichtet Adnan Haddad, sein Vater habe in den 1940er Jahren eigentlich abgelehnt, dass sein Sohn an den französischen Prüfungen teilnehme, dann aber doch zugestimmt, weil die Lehrer die gute Gelegenheit zur Qualifizierung betonten, die er nicht verpassen solle. Vgl. Adnan Haddad, Francophonie. Bilinguisme et culture, Beirut 2002, S. 29.

102 Vgl. Ami Ayalon, The Press in the Middle East. A History, New York/Oxford 1995, S. 89. 
aber gleich geblieben seien, und riefen den Hochkommissar zum Einschreiten auf ${ }^{103}$. Anscheinend war dieser gar nicht über die Erhöhungen der Schulgelder durch die Jesuiten informiert gewesen, und Gouraud versprach Hilfe durch die Vergabe von Stipendien ${ }^{104}$.

Allerdings erfand die Mandatsregierung das Stipendiensystem nicht neu, sondern knüpfte auch hier an eine Tradition aus der osmanischen Epoche an: schon vor dem Ersten Weltkrieg hatte der Quai d'Orsay durch die Vermittlung des französischen Generalkonsulats in Beirut Stipendien an indigene und französische Schüler vergeben. Diese Praxis schien sehr verbreitet gewesen zu sein, beispielsweise verzeichnet eine Liste des Generalkonsulats von 1902 vierzig $\gg$ Boursiers $\aleph^{105}$. Hingegen unterschied sich die Stipendienvergabe der Mandatszeit von derjenigen der osmanischen Epoche durch den Versuch einer verstärkten zentralen Verwaltung der Stipendien. Während die Anfragen vorher von Einzelpersonen geprüft worden waren, sollte nun eine zentrale Kommission dafür eingesetzt werden ${ }^{106}$. Zusätzlich wurden sogenannte »concours«, also Aufnahmeprüfungen, eingeführt, durch die sehr begabte Schüler ein Stipendium des Hochkommissariats erlangen konnten ${ }^{107}$. Durch dieses Auswahlverfahren sollte nicht nur die materielle Situation der Schüler verbessert werden, sondern auch deren mögliche Rekrutierung als künftige einheimische und frankreichtreue Funktionäre vorbereitet werden: »Ici encore nous gagnerons les âmes par l'amélioration de la vie matérielle $\ll^{108}$. Ein praktisches Beispiel für diese Rekrutierung liefert der Fall des Muḥammad Amīn Ayyūb, der als Stipendiat des Hochkommissariats 1921 nach Frankreich entsandt wurde, um dort an der Aufnahmeprüfung der École nationale d'agriculture teilzunehmen: Sollte er die Prüfung bestehen, würde die Mandatsverwaltung das Schulgeld in Frankreich übernehmen ${ }^{109}$.

Auf diese Weise konnten die französischen Autoritäten die libanesischen Schüler und Studenten an sich binden: gerade wenn ein Stipendiat mittellos war, konnte er, wie Bourdieu gezeigt hat, »jederzeit in das Nichts zurückgestoßen werden [...], aus dem ihn die Großzügigkeit des Staates erhoben

103 Vgl. die Leserbriefe in MAE/Nantes, IP, 02, vom Herbst 1920.

104 Ebd., »M. Samaya«.

105 Vgl. MAE/Nantes, »Beyrouth Consulat général Série A«, 191, »demande de bourses«.

$106 \mathrm{Vgl}$. MAE/Nantes, IP, 05, »Note sur la question des bourses«, 1920.

107 Wann dieser Concours genau eingeführt wurde, ist nicht zu sagen. 1925 berichtete der Direktor der AIU von ihm. Vielleicht wurde diese Institution 1922 gemeinsam mit der Einrichtung von vier verschiedenen Kategorien von Stipendien beschlossen. Vgl. dazu CHIDIAC 2002, S. 263.

108 MAE/Paris, 378, Brief von Drach an das Erziehungsministerium, Paris, 10.12.1922.

109 OIB, Bulletin officiel des actes administratifs du Haut-Commissariat français 1920-1921, Dekret Nr. 768 vom 17.05.1921. 
[hatte] $\ll^{110}$. Auf diese Weise wurde die mission civilisatrice auch zu einer sozialen Praxis der Mandatsmacht, die über die Position der Stipendiaten in der Gesellschaft entschied.

Eine weitere Erneuerung im Vergleich zur osmanischen Zeit bestand in der dezidiert politischen Ausrichtung der Vergabe. Durch die Stipendien sollten Angehörige bestimmter gesellschaftlicher und konfessioneller Gemeinschaften, die sich entweder für Frankreich eingesetzt hatten oder große Autorität besaßen, die besondere Gunst des Hochkommissariats erfahren ${ }^{111}$. Diese »bourses nettement politiques« scheinen zu Beginn des Mandats eine besonders große Rolle gespielt zu haben. Beispielsweise sollten sie 1920 gleich und ohne Prüfung durch eine Kommission verteilt werden ${ }^{112}$.

In diese Strategie wurde auch die Mission lä̈que schon zu Beginn des Mandats mit einbezogen. Im Februar 1920 berichtete Deschamps nach Paris: »On va nous donner des bourses druses; j'ai eu hier un long et intéressant entretien au Haut-Commissariat ‘ $^{113}$, denn die Drusen gehörten zu den Religionsgemeinschaften »que l'on cherche actuellement à attirer vers la France ${ }^{114}$. In der Tat hatte das Hochkommissariat seit 1919 enge Beziehungen mit den Drusen, die vor allem in Syrien lebten, aufgenommen und einige Familien für sich gewinnen können ${ }^{115}$. Angesichts der distanzierten Beziehung des Hochkommissariats zur Mission laïque zeigt diese Episode sehr deutlich, dass die Mandatsregierung zu Gunsten höherer politischer Ziele die Distanz überwand, und dass die Mission lä̈que ihrerseits bereit war, diese Strategie zu unterstützen.

110 Die von Pierre Bourdieu für die Praxis des Stipendiensystems im Frankreich der Dritten Republik konstatierte Politik trifft auch auf den Libanon zu. Vgl. Pierre Bourdieu, Von der königlichen Macht zur Staatsraison. Ein Modell der Genese des bürokratischen Feldes, in: Elke Ohnacker/Franz SchultheIs (Hg.), Pierre Bourdieu, Schwierige Interdisziplinarität. Zum Verhältnis von Soziologie und Geschichtswissenschaft, Münster 2004, S. 24-47, S. 34.

111 Dass allerdings auch zu osmanischen Zeiten die Stipendien nicht frei von politischen Erwägungen waren, zeigt eine Begebenheit von 1906: damals wurden der Sekundarschule der Jesuiten in Beirut die Stipendien entzogen, nachdem der Direktor der Schule dem französischen Inspektor Charlot, der im Auftrag des Außenministeriums die französischen Schulen im Orient besichtigte, den Zutritt verweigert hatte. Vgl. LAZ/Paris, »Beyrouth Correspondance 1896-1918«, Brief von E. Villette, Beirut, 07.10.1906.

112 Vgl. MAE/Nantes, IP, 05, »Note sur la question de bourses«, 1920.

113 AN/Paris, 60 AJ 122, Brief von Deschamps an Besnard, Beirut, 20.02.1920.

114 Ebd.

115 Vgl. Birgit SchäBlER, Aufstände im Drusenbergland. Ethnizität und Integration einer ländlichen Gesellschaft Syriens vom Osmanischen Reich bis zur staatlichen Unabhängigkeit, Gotha 1996, S. 210-214: Fāris al-Ațraš hatte schon 1919 Jungen aus seiner Familie mit der Unterstützung Picots auf eine französische Schule geschickt. Nach dem Aufstand 1926 wurde er für seine Treue zu Frankreich mit dem Kreuz der Ehrenlegion ausgezeichnet. 
Erst zwei Jahre später, mit dem Erlass Nummer 1573 vom 1. September 1922, schuf der Hochkommissar für das Stipendiensystem eine rechtliche Grundlage. Als wichtigstes Kriterium wurde das »résultat de l'examen « ${ }^{116}$ und die finanzielle Situation der Eltern genannt, denen es nicht möglich war, »[...] de subvenir en totalité ou en partie à l'éducation de leurs enfants«. Als drittes Kriterium wurde aber auch die Treue gegenüber Frankreich in die Entscheidung miteinbezogen: hatte der Kandidat oder seine Familie »rendu des services à la France et à la Syrie«? Die Entscheidungshoheit lag eindeutig beim Hochkommissariat: »Tout boursier qui quitte l'établissement où il était placé pour en fréquenter un autre, sans y avoir été autorisé préalablement par le Conseiller de l'Instruction Publique, perd le bénéfice de sa bourse « ${ }^{117}$.

Von diesen Stipendien profitierte die Mission lä̈que anfänglich sehr viel weniger als andere Schulen: Im Oktober 1922 zählten ihre Schulen in Beirut zwei »Boursiers de l'Instruction Publique« und $12 »$ Boursiers politiques du Haut-Commissariat français«. Der Grund für ihre Förderung findet sich als Randnotiz auf dem Bescheid: Diese Kinder stammten entweder aus einflussreichen Familien,-- beispielsweise wurden die Schüler Malek Abdelkader und Malek Mohamed mit einem Stipendium bedacht, weil sie »Fils d'un cheikh influent (wakf musulman) « waren ${ }^{118}$. Oder sie besaßen die drusische Religionszugehörigkeit, welche dem Hochkommissar förderungswürdig erschien, dazu zählte Khalil Taqi ad-Din (arabisch Halīl Taqī ad-Dīn) ${ }^{119}$, der nach seiner Schulzeit als Präsident der Ehemaligenvereinigung der laizistischen Schule eine wichtige Rolle spielen würde. Da zu diesem Zeitpunkt 340 Schüler durch Stipendien des Hochkommissariats mit einem Volumen von 69.280.50 Francs allein im Januar 1923 gefördert wurden ${ }^{120}$, bedeutet das, dass andere Schulen sehr viel stärker mit Stipendien bedacht wurden. Dies galt vor allem für die katholischen französischen Schulen. Ein gutes Indiz für die besondere Gunst des Hochkommissars gegenüber den Jesuiten ist der Brief des Conseiller de l'Instruction Publique an den Direktor der Université Saint-Joseph vom 13. Juni 1921, in dem er dessen Schüler Michel Chahoub aufforderte, so schnell wie möglich die Erneuerung seines Stipendiums zu erbitten ${ }^{121}$.

116 AN/Beirut, Recueil des Actes administratifs du Haut-Commissariat de la République Française en Syrie et au Liban, Bd. 1-4, 1919-1923, Arrêté Nr. 1573.

117 Ebd.

118 Vgl. AN/Paris, 60 AJ 125, »Boursiers politiques du H.C.F.«. Ein Wakf (arabisch waqf) bezeichnet eine religiöse Stiftung, wie sie im Islam seit der Zeit Mohammads existiert. Vgl. Amy SingER, Charity in Islamic Societies, Cambridge 2008, S. 90-91.

119 Vgl. ebd.

120 Vgl. MAE/Paris, 378, Telegramm des Service des Euvres françaises an den Hochkommissar, 30.01.1923. Vgl. auch Chidiac 2002, S. 263.

121 MAE/Nantes, IP, 05, »Bourses«, »Concours«. Diese Aufforderungen sind in den Dokumenten der anderen Schulen nicht zu finden. 
Insgesamt aber kann man einen stetigen Anstieg der an die Mission lä̈que vergebenen Stipendien aus den Mitteln des Hochkommissariats erkennen. Im Mai 1923 verfügte die Mission lä̈que schon über fünf Bourses du HautCommissariat français ${ }^{122}$, und im zweiten Trimester des Schuljahres 19261927 wurden schließlich 22 Stipendien der Mandatsverwaltung an die laizistische Schule vergeben ${ }^{123}$. Da diese Epoche, wie später zu zeigen sein wird, von einer stärkeren Hinwendung des Hochkommissariats zu der Mission lä̈que gekennzeichnet war, illustriert das Beispiel sehr eindrücklich, dass die Anzahl der vergebenen Stipendien an die Gunst und an die politischen Erwägungen der Mandatsverwaltung gekoppelt war.

Während die Mandatsmacht die Stipendien also als Mittel ihrer Politik einsetzte, um frankreichtreue Libanesen zu belohnen und mögliche Aufständische ruhigzustellen, nahmen die Schulen sie ihrerseits an, weil sie dadurch ihre Schüler unterstützen konnten und für die Familien noch attraktiver wurden. Aus diesem Grund stellten die Stipendien ein zentrales Element der Konkurrenz zwischen den französischen Schulen dar ${ }^{124}$. Um ihre Anziehungskraft noch zu steigern, boten die Schulen auch eigene Stipendien an, die sie entweder aus den Mitteln ihrer Organisation oder aus den Schulgeldern der anderen Schüler finanzierten ${ }^{125}$.

Die Libanesen wiederum wussten dieses Angebot zu nutzen und richteten zahlreiche Anfragen wegen einer Förderung an die Schulen. Diese Aneignung löste ihrerseits Widerstand in den französischen Einrichtungen aus. So bemerkte Direktor Ruche von der Mission laïque Ende der 1920er Jahre lakonisch bezüglich der Privilegien von 'Umar Da'uq: »N'y aurait-il pas lieu de limiter le nombre des bourses Omar Daouk? «126 Diese Spannung wiederholte sich seit der osmanischen Epoche. Manche libanesischen Eltern richteten ihre Bitte um ein Stipendium auch direkt an das Hochkommissariat. Sie umgingen damit die Rolle der Schulen als Vermittler und zeigten ihre Autonomie von dem etablierten System ${ }^{127}$.

Das Beispiel der Stipendien macht also deutlich, dass diese soziale Praxis als strategisches Element der Mandatsregierung, um ihre mission civilisatrice zu realisieren, von den Libanesen in eigene Taktiken umgewandelt wurde. Während sich die Mandatsmacht durch die Stipendien die Loyali-

122 AN/Paris, 60 AJ 125, Brief von Mathieu an Besnard, Beirut, 18.05.1923.

123 Vgl. AN/Paris, 60 AJ 129, »Beyrouth Bourses 1926-1927«. Im zweiten Trimester 1926-1927 erhielt die Mission laïque sogar insgesamt 22 Stipendien des Hochkommissariats. Vgl. ebd., »Beyrouh Bourses 1926-1927«.

124 Vgl. AN/Paris, 60 AJ 132, Brief von Ruche an Besnard, Beirut, 15.11.1929. Darin spricht er über die »Concurrence des Frères«, also der Frères des Écoles chrétiennes.

125 Für die Mission laïque siehe z.B. AN/Paris. 60 AJ 125, Brief von Mathieu an Besnard, Beirut, 18.05.1923: Zu diesem Zeitpunkt vergab die MLF insgesamt 23 eigene Stipendien.

126 AN/Paris, 60 AJ 133, »Bourses«.

127 MAE/Paris, CPC, 103, Brief von Ibrahim Abou-Khator, Zahlé, 07.01.1920. 
tät ihr besonders nah- und fernstehender Gruppen sichern wollte, nutzten die libanesischen Eltern diese finanzielle Unterstützung vor allem, um ihren Kindern eine gute Schulausbildung zu ermöglichen und ihre soziale Position in der Gesellschaft zu festigen oder zu verbessern. Die französischen Schulen nahmen bei diesem Aushandlungsprozess eine ambivalente Position ein, da sie einerseits die Stipendien der Mandatsregierung für die Verbesserung ihres Bildungsangebots nutzen und andererseits ihre libanesische Klientel unter Kontrolle behalten wollten.

\section{Lehren und Lernen für Frankreich:}

\section{Die ambivalente Vereinheitlichung von Abschlüssen und Prüfungen}

Ein weiterer Bereich der Bildungspolitik, in dem sich die Zivilisierungsmission der Mandatsregierung realisierte, betraf die Vereinheitlichung der Schulabschlüsse der staatlichen und privaten Schulen. Die französische Administration verfolgte damit das Ziel, ein zusätzliches Mittel der Kontrolle zu gewinnen: die Prüfungen »servent au contrôle des études, et nous devrons en tenir le plus grand compte dans l'allocation des subventions à l'avenir « ${ }^{128}$. Interessanterweise gibt die Analyse dieses Themas aber auch Aufschluss über die Wechselwirkungen zwischen der Entwicklung des Bildungssystems im Libanon und Frankreich, wie sie andere Studien zur kolonialen Bildung belegt haben ${ }^{129}$. Schließlich zeigte sich hier der erneute Versuch des Hochkommissariats, der ambivalenten Situation des Mandats zwischen Ausrichtung an Frankreich und Autonomie des Libanon Rechnung zu tragen. Deswegen lautete die Direktive des Kultusbeauftragten 1919-1920, dass die Mandatsverwaltung zwar die Schulabschlüsse vereinheitlichen und am französischen Modell ausrichten solle, dass die Schulen aber in der Wahl ihrer Curricula frei seien: »[...] de façon que ces écoles demeurent à la fois libres (dans leurs programmes et organisation) et dépendantes (en ce qui concerne les examens et subventions) $\ll^{130}$. Faktisch aber bedeutete dies selbstverständlich, dass sich die Schulen an den französischen Curricula orientierten mussten, damit ihre Schüler die Prüfungen bestehen konnten.

Im Bereich der Abschlüsse scheinen sich Chevalleys Ideen trotz seiner Differenzen mit dem Hochkommissar durchgesetzt zu haben. Nach ihm sollten ohne großes Aufheben (»sans discussions et déclarations officielles«) die

128 MAE/Nantes, IP, 03, »C.E.P. Beyrouth 1920«.

129 Vgl. Fischer-Tiné 2005, S. 197-198; Jana Tschurenev, Imperial Experiments in Education: Monitorial Schooling in India, 1789-1835, Diss. Berlin, 2008, S. 87.

130 MAE/Nantes, IP, 02: 1919-1920, »Le Conseiller pour l'Instruction Publique à M. le Chef du Contrôle Administratif« (ohne Datum). 
französischen Prüfungen analog zu Ägypten übernommen werden ${ }^{131}$. Auch bei den Abschlüssen und Prüfungen schloss der Kultusbeauftragte des Hochkommissariats an Traditionen und Praktiken aus der osmanischen Zeit an. Schon damals hatte die Jesuiten-Universität in Frankreich anerkannte Universitätsabschlüsse vergeben ${ }^{132}$. Im Primar- und Sekundarschulbereich war es allerdings bei den Plänen für die Durchsetzung französischer Abschlüsse geblieben. Auf diese Überlegungen aus der osmanischen Zeit griff die Mandatsverwaltung zurück und konsultierte die Diskussionen von 1913 bezüglich der Möglichkeit, die Prüfungen des französischen Abiturs in Beirut abzuhalten ${ }^{133}$.

Die ersten Entscheidungen 1919/1920 fielen zunächst aber nur für die Privatschulen. Hinsichtlich aller Abschlussprüfungen sollte es sowohl eine »Section A«, die mit den Anforderungen in Frankreich übereinstimmte, als auch eine »Section $\mathrm{B} \ll$ geben, die für andere lebende Sprachen galt, die aber dieselben Inhalte abfragte. Die arabische Sprache war dabei nur eine unter vielen, wie zum Beispiel das Armenische, Griechische, Italienische, Englische $^{134}$, obwohl das Arabische neben dem Französischen offizielle Sprache der Libanesen in der Mandatszeit war. Einen Unterschied zu den französischen Abschlüssen sollte es insofern geben, als dem Brevet élémentaire, der Prüfung für die späteren Grundschullehrer, eine Prüfung über die aptitude de l'enseignement en Orient beigefügt wurde ${ }^{135}$.

Die Elementarabschlüsse Certificat d'études primaires (C.E.P.) und Brevet élémentaire, die mit den Prüfungen in Frankreich übereinstimmten ${ }^{136}$, konnten als erste festgelegt werden: schon im Juli 1919 fanden dafür die ersten Prüfungen in Beirut statt. Diese Prüfungen standen wie in Frankreich am Abschluss der siebenjährigen Primarschule. Während der Dritten Republik gab es zwar heftige Diskussionen um den Status dieses Diploms, aber es bildete keine Konkurrenz zu den Prüfungen des komplett davon getrennten Sekundarschulwesens ${ }^{137}$. Deswegen kam es auch in Beirut zu keinen Auseinandersetzungen über seine Durchführung zwischen den verschiedenen französischen Vertretern. Zu diesem Zeitpunkt waren erst sehr wenige französische Schulen wieder in Betrieb, und die Schulen der Alliance israélite waren den Quellen nach die einzigen, die an den Verhandlungen teilnahmen. Direk-

131 Ebd., »Note sur les écoles privées«.

132 Vgl. Ducruet/Awit 2002, S. 39-40: seit 1900 erhielten die Studenten der medizinischen Fakultät ein Diplom der Universität von Lyon.

133 MAE/Nantes, IP, 03: 1920, »Baccalauréat«, »Documents provenant du Consulat de France [...] de 1914«.

134 MAE/Nantes, IP, 02, »Note sur les écoles privées«.

135 Ebd.

136 Vgl. Philippe Savoie, Quelle histoire pour le certificat d'études?, in: Histoire de l'éducation 85 (2000), S. 49-72.

137 Ebd., S. 51-52. 
tor Penso berichtete im Anschluss, dass seine Schüler einige Schwierigkeiten mit der Prüfung hatten, da ihre bisherigen Curricula damit nicht übereinstimmten $^{138}$. Seine Aussage belegt, dass es nach dem Ersten Weltkrieg in der Tat eine Veränderung der Curricula im Libanon gab.

Im Juli 1920 nahm mit 75 Schülern schon eine sehr viel größere Zahl von Absolventen der Privatschulen an den Prüfungen teil: Unter ihnen befanden sich eine Schülerin der Mission lä̈que, einige Schülerinnen katholischer französischer Schulen, aber auch lokaler katholischer und orthodoxer Einrichtungen ${ }^{139}$. Die Tatsache, dass die Prüfungen in den Gebäuden des Hochkommissariats stattfanden ${ }^{140}$, machte dessen Hoheit auch räumlich deutlich. Während die französischen und lokalen Schulen das System der Prüfungen für den Primarschulbereich, welches vom Hochkommissariat entwickelt worden war, annahmen und festigten, indem sie ihre Schüler auf diese Prüfungen vorbereiteten, war ihre Beteiligung an der Diskussion über die konkrete Ausgestaltung der Abiturprüfungen sehr viel aktiver und führte zu zahlreichen Kontroversen. Das hatte zum einen damit zu tun, dass die höheren Schulen für die Bildung von Eliten von deutlich höherer Bedeutung waren und die Schulen deshalb daran beteiligt werden wollten. Zum anderen spiegelten die Diskussionen um die Abiturprüfungen die Debatte wider, die auch in Frankreich zwischen Reformern und Verfechtern des traditionellen Systems stattgefunden hatte.

In Frankreich hatte es in der Dritten Republik eine heftige Debatte um die Vereinheitlichung des Schulsystems gegeben. Bis dahin bestand das Bildungssystem aus dem Primarschulwesen, des Enseignement primaire, das ein Basiswissen für spätere Händler, Soldaten und Angestellte vermittelte, einerseits und andererseits dem Sekundarschulwesen, dem enseignement secondaire, das der sozialen Elite vorbehalten war und zum Abitur führte ${ }^{141}$. Auch die Einführung einer Mittelstufe zwischen beiden, des Enseignement primaire supérieur, durch das Loi Guizot von 1833, hatte keine Brücke schlagen können. Die Dritte Republik investierte stark in diese neuen Schulen, die Kindern aus ärmeren Familien eine längere Schulbildung ermöglichte und in der Regel zu der Ausbildung zum Grundschullehrer führte ${ }^{142}$. Da diese Einrichtungen stark von den republikanischen und laizistischen Werten geprägt

138 AIU/Paris, »Liban VIE 81«, Brief von Penso an den Präsidenten der Alliance israélite in Paris, Beirut, 23.07.1919.

139 Vgl. MAE/Nantes, IP, 03: 1920, »Certificat d'études«: es handelte sich unter anderen um 12 Kandidatinnen der maronitischen Schule der »Sainte-Famille«, acht Schülerinnen der griechisch-orthodoxen Schule Zahrat al-ihssān und drei Schülern des griechisch-katholischen »Collège patriarcal«.

140 MAE/Nantes, IP, 03, »C.E.P. Beyrouth 1920«.

141 Vgl. Maurice Agulhon, La République. L'élan fondateur et la grande blessure (1880-1923), Paris 1990, S. 40-42.

142 Vgl. Agulhon 1990, S. 41; siehe auch die Biographien in Ouzouf/Ouzouf 1992. 
waren, erfuhren sie in katholischen und konservativen Kreisen heftige Kritik. Das Abitur stellte auch im Frankreich der 1920er Jahre das Privileg einer elitären Schicht dar, welcher sich die katholischen Schulen zugehörig fühlten ${ }^{143}$.

Auch in Dokumenten der libanesischen Bildungspolitik spiegelt sich dieser Diskurs. Die Einführung der Abiturprüfungen in Beirut zeugt von dem improvisierten und polyphonen Charakter, der die Bildungspolitik unter dem Mandat prägte. Bis zum Beginn des Mandats hatte es im Nahen Osten die französischen Abiturprüfungen nur in Alexandria gegeben. Während der Orden der Frères des Écoles chrétiennes im Mai 1920 um Abiturprüfungen in Beirut bat ${ }^{144}$, betonte der französische Erziehungsminister, dass er dieser Neueinrichtung nur zustimmen würde, wenn sie für sein Amt keine zusätzlichen Kosten verursachen würde ${ }^{145}$. Im Sommer 1920 fanden die ersten Prüfungen für das baccalauréat dann tatsächlich in Beirut statt ${ }^{146}$. Auch für die Organisation des Abiturs orientierte man sich an dem Modell aus Alexandria $^{147}$, was bedeutete, dass sich hier der Kultusbeauftragte Chevalley gegen den Hochkommissar Gouraud durchsetzte.

Die Anzahl der Kandidaten an den Abiturprüfungen war in den ersten Mandatsjahren noch sehr gering. 1922 nahmen ungefähr 20 Schülerinnen und Schüler an den Prüfungen teil ${ }^{148}$. Der Bericht des französischen Professors Jules Drach ${ }^{149}$, der in jenem Jahr Mitglied der Prüfungskommission war, ist für die Einstellung der Jury gegenüber den Kandidaten sehr aufschlussreich. Zunächst zeigt er, dass die Mitglieder der Jury keine Erfahrung mit der arabischen Welt aufweisen mussten. Außerdem betonte Drach die Bedeutung der französischen Schulen für Frankreichs Beziehung zum Libanon, denn mithilfe der Schulen könne man »chercher à gagner de nouvelles générations «. Damit teilte der Professor sowohl die Einstellung der französischen Regierung als auch der französischen Schulen selbst, die ihr Engagement an dem Nutzen für Frankreich ausrichtete. In diesem Sinne unterteilte er die Klientel der Schulen in »nützliche« und »unnütze« Schüler: erstere seien an den Lernstoffen interessiert und bildeten die späteren Fachkräfte, dank derer »nous pouvons avoir avec elle des échanges économiques importants

143 Vgl. Rioux/Sirinelli 2005, S. 35.

144 Vgl. MAE/Nantes, IP, 03, Brief eines Angehörigen der Frères des Écoles chrétiennes an »M. le conseiller«, Beirut, 08.05.1920.

145 Vgl. ebd., Brief des französischen Erziehungsministers an das Außenministerium, Paris, 07.02.1920.

146 Vgl. ebd.

147 MAE/Nantes, IP, 03, »Baccalauréat«, »Organisation de la session de 1920«.

148 Vgl. MAE/Paris, 378, Brief von Drach an das Erziehungsministerium, Paris/10.12.1922.

149 Jules Joseph Drach (1871-1949) war seit 1913 Professor für analytische Mechanik und höhere Analysis an der Sorbonne. Laut seiner Biographie hatte Drach keine Beziehung zum Nahen Osten. Das bedeutet, dass die Mitglieder der Prüfungskommission nicht speziell auf das Abitur in Beirut vorbereitet waren. Vgl. URL : http://www-history.mcs.st-and.ac.uk/Biographies/ Drach.html (16.01.2010). 
dans l'avenir et son action morale, aux confins du monde musulman d'Asie, peut nous être très précieuse«. Die anderen Schüler hingegen, insbesondere aus den muslimischen Gemeinschaften, würden nur aus Prestigegründen die französischen Schulen besuchen. Insgesamt ist Drachs Bericht stark von der Idee der Zivilisierungsmission geprägt, da es seiner Meinung nach wichtig sei, den »hungrigen « Syrern geistige Nahrung zu bringen und sie damit von ihrem Fanatismus zu entfernen:

Il s'agit là en somme de mettre à la mode parmi ses »oisifs« si nombreux en Orient un certain goût pour la littérature, la poésie, les arts, qui empêche l'empathie intellectuelle à les gagner à jamais. [...] Il est probable également qu'ils auront perdu un peu d'éclectisme et perdu un peu de fanatisme, de fanatisme religieux en particulier. Le fanatisme religieux est en effet la plaie de la Syrie où 29 religions s'arrachent les fidèles- et à ce propos je ne saurais trop insister sur la nécessité de marquer le caractère du mandat français [im Dokument unterstrichen, E.M.] - que tant d'intérêts tentent de défigurer ${ }^{150}$.

Aus diesem Grund sah das Hochkommissariat zunächst keinen Grund, das Abitur an den lokalen Kontext anzupassen. Dies hatte zwar der Orden der Frères des Écoles chrétiennes in dem genannten Antrag an die Mandatsverwaltung 1920 gefordert $^{151}$, aber sowohl dieser Brief als auch die Überlegungen Chevalleys für ein Baccalauréat franco-syrien blieben zunächst ohne Folgen.

Hingegen wurden parallel Ideen für ein libanesisches Abitur laut. 1920 schlug der Bürgermeister von Suq al-Gharb in der Nähe von Aley, Georges Attieh, 1920 ein Baccalauréat grand libanais vor $^{152}$. Diese Idee nahm der neue Bildungsbeauftragte des Hochkommissariats, Jeantry, im Juli 1921 erneut auf und begrub damit Chevalleys Pläne eines baccaulauréat francosyrien, das, so Jeantry, die Bereitstellung kompletter Abschlussprogramme durch die Staaten Syrien und Libanon benötige ${ }^{153}$. Aber erst 1924 entwickelte der wiederum neueingesetzte Bildungsbeauftragte des Hochkommissariats, Duthoit, konkrete Pläne für ein enseignement secondaire libanais und damit für ein libanesisches Abitur. Diese brachten ihm sogleich die Kritik der Jesuiten ein. Zwar sei es grundsätzlich richtig, so der Direktor der Jesuiten-Universität, Chanteur, ein syrisches und libanesisches Abitur einzurichten, aber die Priorität müsse weiterhin bei der französischen Sprache und Kultur lie-

150 Vgl. MAE/Paris, 378, Brief von Drach an das Erziehungsministerium, Paris/10.12.1922.

151 Vgl. MAE/Nantes, IP, 03: 1920, ohne Datum.

152 MAE/Nantes IP, 07, Brief von Georges Attieh, 16.12.1920. Attieh war später Lehrer der Mission laïque française, wurde aber während des Vichy-Regimes wieder entlassen. Vgl. Kap. 7.

153 Ebd., »Enseignement officiel«, Notiz für den Hochkommissar, Beirut, 06.07.1921. 
gen, und deshalb solle sich das syrische bzw. libanesische Abitur an den französischen Richtlinien orientieren:

Le programme envisagé devra en effet tenir compte à la fois de la culture française, de la culture arabe, et, dans une certaine mesure, de la culture anglaise. De ces trois éléments, lequel devra dominer? Évidemment la culture française. [...] De là un premier corollaire. Le fond du programme devra être emprunté au programme de l'Enseignement secondaire français ${ }^{154}$.

Ferner könne, so Chanteur, das Programm des Geschichtsunterrichts aus Frankreich übernommen werden, man müsse lediglich einen kurzen Rekurs zu Syrien hinzunehmen: »[...] en $4^{\text {ème }}[. .$.$] décentrer un peu le programme en$ partant de l'Histoire de la Syrie«. Ein positiver Aspekt, den Chanteur schließlich einem solchen syrischen bzw. libanesischen Abitur abgewinnen konnte, war, dass dadurch das Niveau der französischen Prüfungen in den Mandatsgebieten erhalten blieb:

Il aurait aussi l'inestimable avantage de pouvoir s'accorder aux réalités scolaires existantes et de ne pas troubler le fonctionnement des Écoles secondaires françaises qui pourraient continuer à donner, avec l'Instruction, la véritable éducation française ${ }^{155}$.

In einem Brief an Hochkommissar Weygand im November 1924 formulierte Chanteur seine Kritik an einem nicht an französischen Standards ausgerichteten Abitur noch sehr viel deutlicher. Er kritisierte den Niveauverlust des Programms von Duthoit und den Schaden, den die französische Kultur dadurch erleiden würde:

Cet enseignement nuira à la profonde, à la seule vraie culture française. [...] La France classique n'y reconnaîtra plus ses traits. Et du même coup ces esprits seront beaucoup plus accessibles aux suggestions anti-françaises de nos ennemis politiques du dedans et du dehors ${ }^{156}$.

Diese Debatte verweist deutlich auf die Auseinandersetzungen in Frankreich um die Vorherrschaft und Exklusivität des Sekundarschulbereichs, um die sich vor allem die Privatschulen bemühten. Bis 1930 waren genau diese Schulen schulgeldpflichtig und zudem sehr guten Schülern vorbehalten. In diesem Sinne beschrieb der von Chanteur verwendete Ausdruck »la France

$154 \mathrm{SJ} /$ Vanves, »Fonds Jalabert«, 1-1 F, »Note sur l'organisation de l'enseignement secondaire au Liban et en Syrie (P. Chanteur, ca. 1924)«.

155 Ebd.

$156 \mathrm{SJ} /$ Vanves, »Fonds Jalabert«, 1-1 F, Notiz von Chanteur an Weygand, November 1924. 
classique« sowohl den Schwerpunkt dieser Schulen auf den altsprachlichen Fächern ${ }^{157}$ als auch die Beibehaltung der alten Trennung von Primar- und Sekundarschulwesen. In jedem Fall ging es den Jesuiten um die Erhaltung des status quo des französischen Abiturs im Libanon.

Um die eigenen Aussagen noch zu bekräftigen und aus dem libanesischen Kontext heraus zu legitimieren, griff Chanteur in seinem Schreiben auf libanesische Persönlichkeiten zurück, die seine Meinung teilten: »Interrogez des hommes comme M. M. Chiha, Cardahi, ils vous diront où se trouvent les hommes les plus rapprochés de nous par tout leur être intime, par leur façon de penser, de sentir. «158 Michel Chiha (arabisch Mīšāl Šịhāa) (1891-1954), ein römisch-katholischer Bankier, Politiker und Journalist, der bei den Jesuiten in Beirut nicht nur die Schule besucht, sondern 1901 auch sein Studium beendet hatte, war zu Beginn der Mandatszeit in der Tat ein Verfechter des Großlibanons unter französischer Vormundschaft gewesen ${ }^{159}$. Er hatte eng mit dem Hochkommissariat, vor allem mit Robert de Caix, zusammengearbeitet, um die Gesetze und Rechtsklauseln des »État du Grand-Liban« zu entwickeln. Choukri Cardahi (arabisch Šukrī Qardāhīi) war ebenfalls ein ehemaliger Schüler und Student der Jesuiten, der später als Jurist und Autor von Büchern, unter anderem über Recht und Islam, bekannt wurde ${ }^{160}$. Diese Männer sympathisierten mit den Jesuiten, machten sich später aber auch für einen von Frankreich unabhängigen libanesischen Staat und für ein Auskommen der unterschiedlichen Gemeinschaften stark ${ }^{161}$. Insofern wurden sie von den Jesuiten nur teilweise zu Recht inkorporiert.

In den Dokumenten der Mission laïque finden sich die von Chanteur vorgebrachten Kritikpunkte nicht. Zwar waren auch viele laizistische Akteure von der Überlegenheit des Französischen überzeugt, aber der offizielle Diskurs der Organisation lautete immer, es sei notwendig, die arabische Sprache und Kultur gleichwertig mit der französischen zu fördern. So lässt sich auch das Schweigen der Quellen der Mission lä̈que bezüglich des libanesischen Abiturs erklären. Erst seit 1928, also zu einem Zeitpunkt, zu dem das libanesische Abitur Rechtsgültigkeit besaß, nahmen die verschiedenen Mitarbeiter

157 Vgl. Marie-Christine Kok-Escalle, Instaurer une culture par l'enseignement de l'histoire. France 1876-1912, Frankfurt am Main 1988, S. 61.

$158 \mathrm{Vgl} . \mathrm{SJ} /$ Vanves, »Fonds Jalabert«, 1-1 F, Notiz von Chanteur an Weygand, November 1924.

159 Vgl. Traboulsi 2007, S. 84. Allerdings wandte sich Chiha später dem konstitutionellen Block unter Bishara al-Khuri zu, der für eine Rückkehr der von den Franzosen suspendierten Verfassung und der Grundrechte kämpfte. Diese Vision dominierte in der 1933 von ihm gegründeten Zeitung L'Orient. Vgl. DAKHLI 2009a, S. 251.

1601921 verfasste er ein Buch über das Mandat: »Le Mandat de la France sur la Syrie et le Liban«, Paris 1921. Später schrieb er »Droit et morale. Le droit moderne et la législation de l'islam au regard de la morale«, Beirut 1950.

161 Vgl. Firro 2003, S. 31. 
der Institution dazu Stellung ${ }^{162}$. Seit dem Jahr 1926, in dem die libanesische Regierung durch eine eigene Verfassung weitere Kompetenzen zugeschrieben bekommen hatte, nahm das libanesische Erziehungsministerium zwar laut Gesetz die Staatsexamina ab ${ }^{163}$. Eine Art libanesisches Abitur neben dem syrischen Äquivalent scheint es aber erst seit dem Schuljahr 1927 / 1928 gegeben zu haben ${ }^{164}$. Allerdings handelte es sich tatsächlich nicht um ein libanesisches Abitur, sondern nur um eine Variante des französischen Abiturs, die zudem wenig Prestige besa $\beta^{165}$.

So unterstützt die Untersuchung des Abiturprüfungswesens zum einen die These von der improvisierten und uneinheitlichen Bildungspolitik der Mandatsmacht. Sie belegt zum anderen die Übertragung »metropolitaner« Debatten in den Libanon und zeigt schließlich die kolonialistische Haltung vieler französischer Akteure gegenüber den libanesischen Schülern und einem eigenständigem libanesischen Bildungssystem.

Diese ambivalente Haltung zeigte sich auch in der Debatte um die Lehrerseminare. Die Frage der Einrichtung der »Normalschulen«, der Écoles normales, in welchen die Lehrer der staatlichen Schulen ausgebildet werden sollten, schien deswegen so schwer zu lösen zu sein, weil das Hochkommissariat zum einen nicht einschätzen konnte, wie dauerhaft der Status des Mandats sein würde und inwiefern durch eine solche Ausbildung die libanesischen Lehrer und Lehrerinnen an das französische System gebunden wären. Zum anderen bildete diese französische Institution aber auch ein Sinnbild der laizistischen Republik und erfuhr deshalb ebenfalls harsche Kritik von Seiten der katholischen Mandatsverwalter ${ }^{166}$. Im Herbst 1919 wurden zunächst durch die Erziehungsbeauftragten Chevalley und Saule zwei Lehrerseminare eingerichtet, jeweils eines für Männer und für Frauen ${ }^{167}$. Die gesamte Organisation zog sich aber bis Mai 1920 hin, als der Verwaltungsdelegierte der französischen Besatzungszone dem Hochkommissar die Prüfungsfragen für die Aufnahmeprüfung der Écoles normales am 31. Mai und 14. Juni zusandte ${ }^{168}$.

162 Dann beklagten sie weniger den Verlust der französischen Sprache oder Kultur als vielmehr Missstände der Organisation, durch die die Mission laïque benachteiligt würde. Siehe zum Beispiel AN/Paris, 60 AJ 131, »L'arabe au baccalauréat libanais«: laut dem Arabischlehrer Kfoury sei die Fragestellung unklar gewesen und Schüler anderer Schulen seien schon vorher über die Aufgaben informiert gewesen.

163 Vgl. Hanf 1969, S. 76: »Die französischen Beamten behielten jedoch weiterhin einen Einfluss, der weit über das Maß dessen hinausging, das ihnen nach rein juristischen Gesichtspunkten zukam«.

164 Vgl. MAE/Paris, CPC, 378, Brief von Ponsot an das Außeninisterium, Beirut, 21.01.1928.

165 Vgl. Interview der Verfasserin mit Prof. Carla Eddé, Beirut, 15.11.2008.

166 Vgl. Jean-François Condette, Histoire de la formation des enseignants en France $\left(\mathrm{XIX}^{\mathrm{e}}-\mathrm{XX}^{\mathrm{e}}\right.$ siècles), Paris 2007, S. 63-157.

167 AN/Paris, 60 AJ 122, Brief von Deschamps an den Präsidenten der Mission laïque, Beirut, 28.11.1919.

168 MAE/Nantes, IP, 02, Brief vom 22.05.1920. 
1921 machte Inspektorin Saule dann unmissverständlich deutlich, dass diese libanesischen Schulen nur syrische und libanesische Kandidaten aufnehmen, denn $»[. .$.$] [Le] personnel français [...] ne saurait être assimilé au$ personnel syrien, à cause de sa valeur et à cause du rôle de guides et de conseillers que nos professeurs doivent jouer ici« ${ }^{169}$. Sie verstand die französischen Lehrer als Akteure der Zivilisierungsmission und wollte diese Hierarchie nicht durch ein gemischtes Lehrerseminar in Unordnung gebracht wissen. Während die katholischen Orden ${ }^{170}$ und die Alliance israélite ihre eigenen Lehrerseminare betrieben und sich deswegen kaum in die Debatte einbrachten, beteiligte sich die Mission lä̈que viel stärker. Deren Schuldirektor in Beirut berichtete von den verschiedenen Etappen der Diskussion ${ }^{171}$, was Generalsekretär Besnard zum Anlass nahm, erneut über die Idee einer Sektion der Mission lä̈que für die Lehrerausbildung nachzudenken. Diese Pläne hatte es schon vor dem Ersten Weltkrieg gegeben: im Juli 1909 hatte der Verwaltungsrat der Mission laïque in Paris die Möglichkeit diskutiert, eine laizistische École normale für die Lehrer im Libanon zu gründen ${ }^{172}$. Bezüglich der Lehrerseminare arbeitete die Mission lä̈que also stärker mit der Mandatsmacht zusammen als sie eigentlich beabsichtigt hatte.

Die Zusammenarbeit aller französischen Schulen mit der Mandatsmacht zeigte sich sehr deutlich in der Übernahme der französischen Curricula. Die spezielle Frage der französischen und arabischen Sprache als Kernelemente der Curricula wird Gegenstand des nächsten Kapitels sein. Auch bezüglich der Curricula waren die Schulen einerseits an die ambivalente Politik des Hochkommissariats gebunden, welches zwar die Prüfungen, nicht jedoch die Curricula bestimmen wollte, aber dies doch implizit tat. Andererseits besaßen sie dadurch immerhin geringe Freiräume, in denen sie eigene Akzente setzten. Chevalley schwebte für die staatlichen Schulen zwar ein frankosyrisches Curriculum vor, aber die Privatschulen sollten, solange es nötig sei, »pendant le temps qui sera nécessaire un enseignement purement français « anbieten ${ }^{173}$. De facto aber bildete auch das franko-syrische Curriculum nur eine vereinfachte Version der französischen Lehrpläne.

Dass die Vorstellungen des Hochkommissariats mit der Praxis der Schulen übereinstimmten, zeigt der Bericht des Direktors Deschamps von der Mission lä̈que im Mai 1920: »les programmes de l'enseignement français sont ceux des lycées et collèges de France«. Es gebe nur einen Unterschied

169 MAE/Nantes, IP, 07, »Écoles Normales«, »Rapport Mlle Saule, 22 juin 1921«.

170 Vgl. Kapitel 5.2.

1711922 berichtete der Direktor der Mission laïque das erste Mal von der Schließung der Écoles normales, welche 1927 Realität wurde. Zur weiteren Entwicklung der Lehrerseminare im Libanon der Mandatszeit vgl. Kapitel 5.2.

172 Vgl. MLF/Paris, »Procès-Verbaux du Conseil d'Administration«, Sitzung vom 08.07.1909.

$173 \mathrm{MAE} /$ Nantes, IP, 02, »Note sur l'organisation générale des écoles en Syrie«, 21.01.1920. 
bezüglich des Mathematikunterrichts und natürlich der arabischen Literatur, Geschichte und Geographie: »le programme de l'enseignement arabe comprend langue et littérature arabe, histoire et géographie du pays $\ll^{174}$. Den Mathematikunterricht passten die Schulen dem libanesischen Kontext an, weil ihre Schüler das Wissen in dieser Materie traditionell auswendig lernten und deshalb eine andere Herangehensweise benötigten als die Schüler in Frankreich ${ }^{175}$. Die Fächer arabische Literatur, Geschichte und Geographie allerdings bildeten, wie die nächsten Kapitel zeigen werden, die Kernelemente für die Herausbildung einer nationalen Identität, die die Mandatmacht mitbestimmen wollte, in denen die Schulen aber ihre Methoden und Inhalte bald dem lokalen Kontext anpassen mussten.

\section{Zur Mobilität von Bildung: Wissens- und Erfahrungstransfer aus den Kolonien}

Im schwierigen Prozess der Definition von Bildungsaufgaben im Mandatsregimen rekurrierten die verschiedenen Akteure im Umfeld der Schulen auf die französische Bildungspolitik in den Kolonien, insbesondere in Nordafrika. Dabei kam es aber nur bedingt zu einem Transfer aus den Kolonien. Während das Hochkommissariat sich zu Beginn des Mandats deutlich an der Kolonialsituation orientierte und diese Perspektive erst später dem lokalen Kontext anpasste, bemühten sich die Schulen von Anfang an darum, den »kolonialen Reflex«, dem manche ihrer Lehrer aufgrund ihrer Erfahrung in Nordafrika erlagen, zu vermeiden ${ }^{176}$. Dazu stifteten sie vor allem die Libanesen an, die jegliche Parallelsetzung ihres Landes mit den Kolonien verurteilten.

Die Orientierung des Hochkommissariats an Nordafrika, insbesondere an Marokko, wo Maréchal Luyautey die Politik geprägt hatte, betraf nicht nur den Bereich der administrativen und militärischen Verwaltung ${ }^{177}$. Auch bezüglich der Bildung gab es viele Parallelen, was zum großen Teil an der personellen Kontinuität des zweiten Hochkommissars, General Henri Gouraud, lag, der bis zum Ersten Weltkrieg in Marokko stationiert gewesen war $^{178}$. Mit Gouraud waren weitere Offiziere und Beamte aus Nordaf-

174 AN/Paris, 60 AJ 122, Brief von Besnard an Deschamps, Paris, 01.05.1920.

175 Vgl. AN/Paris, 60 AJ 137, Brief von Ruche an Besnard, Beirut, 22.11.1934.

176 Dieser von mir kreierte Begriff des kolonialen Reflexes soll deutlich machen, dass die Lehrer, die vor ihrem Aufenthalt in Libanon in einer französischen Kolonie tätig gewesen waren, reflexartig die gleiche Haltung gegenüber der Bevölkerung einnahmen und diese nicht näher reflektierten.

177 Vgl. dazu Edmund III Burke, A Comparative View of French Native Policy in Morocco and Syria, 1912-1925, in: Middle Eastern Studies 9 (1973), S. 175-186.

178 Ebd. 
rika nach Syrien und Libanon gekommen ${ }^{179}$. Auch in Frankreich unterstützten Fachleute die Orientierung der libanesischen Bildungspolitik an Lyauteys Modell, wie der Kommentar von Professor Drach zeigt, der 1920 in Beirut die Abiturprüfungen abgenommen hatte:

C'est un grand danger pour l'avenir même de la civilisation que le développement du monde musulman, tant qu'il garde son estime pour le guerrier et son mépris pour le sroumi<. Tout doit être tenté pour le désarmer moralement c'est, il semble, ce qu'on a bien compris au Maroc ${ }^{180}$.

Auch die medizinischen Berufe hielt er für sehr wichtig:

Le meilleur missionnaire de civilisation est un bon médecin. [...] Pour agir sur les musulmans, employons comme l'a fait le Maréchal Lyautey, l'Autorité du Coran et faisons des brochures de propagande hygiénique en arabe syrien ${ }^{181}$.

Drach konstruierte damit dieselbe asymmetrische Hierarchie zwischen französischer und libanesischer Kultur wie die Kolonialregierung in Algerien, welche überzeugt war »to shape cultural mediators who came from a $>$ barbarian< culture and were assigned to spread the legitimate culture $\ll^{182}$.

Diese Stimmen übertönten die Vorstellungen des ersten Bildungsbeauftragten Chevalley. Im Gegensatz zu Gouraud richteten sich seine Ideen an dem ihm aus eigener Erfahrung bekannten Bildungssystem in Ägypten aus. Gerade deshalb betonte er auch die Tatsache, dass Syrien keine Kolonie sei:

Si la Syrie était une colonie, un protectorat, ou un pays nettement conquis pour toujours, nous n'agirions peut-être pas ainsi. Mais elle n'est qu'un pays de mandat indéterminé. [...] L'exemple de l'Egypte, où nous n'avons sauvé notre situation que par l'action des écoles privées, heureusement soustraite à toute influence locale, est parfaitement instructif à cet égard ${ }^{183}$.

Sein Ziel war, den Libanon in den regionalen Kontext einzubetten und ein großes Netzwerk französischer Bildungseinrichtungen in der Levante zu schaffen. Damit sollte jegliche Verbindung mit der Bildungspolitik in Nordafrika gelöst werden. Chevalley wurde jedoch 1921 abgesetzt, während Gouraud bis $1923 \mathrm{im} \mathrm{Amt} \mathrm{blieb} \mathrm{und} \mathrm{damit} \mathrm{seine} \mathrm{Ideen} \mathrm{verfolgen} \mathrm{konnte.} \mathrm{Allerdings}$ musste auch der erste Hochkommissar sich den lokalen Verhältnissen anpas-

179 Vgl. AN/Paris, 60 AJ 124 (1921-1922), »Affaire Mougin«. Vgl. auch EdDÉ 2004, S. 80.

180 MAE/Paris, 378, Brief von Drach an den Erziehungsminister, Paris, 10.12.1922.

181 Ebd.

182 Colonna 1997, S. 361.

$183 \mathrm{MAE} /$ Nantes, IP, 02,»Note sur l'organisation générale des écoles en Syrie« (Chevalley). 
sen. Ursprünglich, so berichtete Deschamps der Mission laïque nach Paris, hatte Gouraud nach marokkanischem Vorbild eine école de fils de chefs gründen wollen, in der die Söhne der Drusen ausgebildet und an Frankreich gebunden werden sollten ${ }^{184}$. Um die religiöse Elite Nordafrikas auf die französische Seite zu ziehen, hatte Lyautey in der Tat in Marokko so genannte Collèges musulmans gegründet, in denen sowohl traditioneller Islamunterricht als auch eine europäische Bildung vermittelt wurden ${ }^{185}$. So kam es zur Herausbildung einer kleinen frankophonen muslimischen Elite und zu großen kulturellen Unterschieden zwischen den Bevölkerungsgruppen ${ }^{186}$. Für den Libanon konnte Gouraud diesen Plan allerdings nicht durchsetzen ${ }^{187}$.

Auf der Ebene der französischen Schulen kam es vor allem in personeller Hinsicht zu einem Transfer aus den Kolonien. Besonders innerhalb der Mission laïque française und der Alliance israélite universelle herrschte eine große Mobilität des Personals zwischen den Kolonien, insbesondere jenen in Nordafrika, und der Levante ${ }^{188}$. Die Lehrer der Mission laïque française hatten vor allem in staatlichen oder privaten französischen Schulen in Nordafrika unterrichtet und dort die koloniale Bildungssituation in einem arabischen Land kennengelernt ${ }^{189}$. Demgegenüber waren die Lehrer der Alliance israélite in ihren eigenen Schulen in Nordafrika tätig gewesen und hatten dadurch ein »trans-regional network of communication grounded in the lexicon of Republican France ${ }^{190}$ entwickelt. Dieser Unterschied ist dafür verantwortlich, dass die Vergleiche mit den Maghrebstaaten bei den jüdischen Schulen selbstverständlicher waren und weniger wertend ausfielen. Beispielsweise betonte Penso, Direktor der Alliance israélite in Beirut, 1919, dass die Probleme sich aus den unterschiedlichen Lebenshaltungskosten der Lehrer in der Stadt beziehungsweise auf dem Land ergäben - unabhängig von der geogra-

184 Vgl. AN/Paris, 60 AJ 122, Brief von Deschamps an Bienvenu-Martin, Beirut, 20.02.1920.

185 Vgl. Le Pautremat 2003, S. 87.

186 Vgl. Yvette Katan Bensamoun/Rama Chalak, Le Maghreb. De l'empire ottoman à la fin de la colonisation française, Paris 2007, S. 239: »Un des facteurs les plus importants du bouleversement des sociétés maghrébines fut l'école française. En fait, celle-ci, dont on prétendait faire un instrument d'assimilation et de progrès, accentua les contrastes entre les populations et même à l'intérieur des groupes ethniques. Le déracinement et l'acculturation d'un certain nombre d'autochtones passés par l'école française a souvent été évoqué. Celui des juifs fut particulièrement visible. Parmi les musulmans, une petite élite, plus ou moins francisée, témoigna de l'action scolaire de la France«.

187 Das Hochkommissariat trat nie mehr mit dieser Bitte an die Mission laïque heran.

188 Vgl. Kapitel 1.3.

189 Siehe die Angaben in Kapitel 1. Bezüglich dieser Schulen siehe die Erlebnisberichte ehemaliger Schüler in: Lina Hayoun/Effy TsELIKAs (Hg.), Les lycées français du soleil: Creusets cosmopolites du Maroc, de l'Algérie et de la Tunisie, Paris 2004. Die Mission laïque eröffnete erst 1927 in Marokko ihre erste Schule. Vgl. ThÉvenin 2002, S. 140.

190 Susan G. Miller, Gender and the Poetics of Emancipation: The Alliance Israélite Universelle in Northern Marocco, 1890-1912, in: Carl L. Brown/Matthew S. Gordon (Hg.), Franco-Arab Encounters. Studies in Memory of David C. Gordon, Beirut 1996, S. 229-252, S. 233. 
phischen Region: »Ceux de Salonique, de Smyrne, de Beyrouth, de Tanger, de Tunis, de Téhéran etc., ont des frais de représentation que ne supportent certainement pas leurs collègues de Monastir, de Saffed, je dirais même de Damas $\ll^{191}$.

In den Schulen der Mission lä̈que im Libanon hingegen kam es immer wieder zu »kolonialen Reflexen «, die die Zentrale in Paris stetig einzudämmen versuchte. So schlug Ruche 1931 vor, die Bezahlung der vor Ort rekrutierten Lehrerinnen ${ }^{192}$ sowie die Präsenz der Lehrer in den Sommerferien ${ }^{193}$ wie in Algerien zu handhaben. Für seinen Vorschlag, Arabisch als Fremdsprache anzusehen und erst ab der 6. Klasse zu unterrichten, wurde er von der Zentrale in Paris mit dem Hinweis zurechtgewiesen, der Libanon sei mit Nordafrika nicht zu vergleichen: »En Syrie, nous ne sommes pas dans une colonie française ni dans un pays de protectorat, et les enseignements qui peuvent convenir ici ne peuvent convenir là «194. Aus diesem Grund erhielt Ruches Nachfolger, Grandjouan, die Direktive, sich nicht wie sein Vorgänger zu gebärden, als sei er in einer französischen Kolonie:

Un dernier conseil: Votre prédécesseur arrivait, en 1925, de Tunis; quelques mesures intempestives qu'il prît à son arrivée le rendirent suspect parce qu'on lui attribuait l'état d'esprit d'un certain nombre de Français de la Régence qui n'avaient que mépris pour les Bicos. J'imagine qu'à votre égard, on se montrera plus juste, mais il vaut mieux se tenir sur ses gardes ${ }^{195}$.

Das hielt Grandjouan allerdings nicht davon ab, den Vergleich der libanesischen mit ägyptischen und marokkanischen Schülern auf qualitativer Ebene zu ziehen: Die Libanesen seien im Erlernen von bestimmten Techniken stärker als die $»$ Egyptiens et marocains musulmans ${ }^{196}$. Diese Einschätzung gleicht der von Edward Said dekonstruierten Sichtweise des Orientalismus, der auf essentialistische Weise »dem christlichen Okzident« das Rationale und »dem islamischen Orient« die Emotion zuteilt ${ }^{197}$. Gleichzeitig schwingt

191 AIU/Paris, »Liban VIE 80-81«, Brief von Penso an den Präsidenten der Alliance israélite, Beirut, 24.12.1919.

$192 »[. .$.$] d'adopter pour elles l'échelle de traitements de l'Algérie«. AN/Paris, 60$ AJ 133, Brief von Ruche an Besnard, Beirut, 21.03.1931.

193 »Dans les lycées d'Afrique du Nord, il est d'usage que le Censeur, l'Économe et le Surveillant Général prennent à tour de rôle la garde du Lycée pendant les vacances«. AN/Paris, 60 AJ 130, Brief von Ruche an Besnard, Beirut, 14.11.1927.

194 Ebd., »Réunion des professeurs«, Oktober 1927.

195 MLF/Paris, »Fonds de Russie«, 03/944, Brief von Besnard an Grandjouan, 14.11.1935. Allerdings ist hier seine Nutzung des Wortes »Bicos« (pejorativ für Nordafrikaner) zu hinterfragen: macht sie nicht sein Plädoyer für mehr Respekt gegenüber den Libanesen obsolet?

196 AN/Paris, 60 AJ 138, Brief von Grandjouan an Besnard, Beirut, 04.02.1936.

197 Vgl. SAID 1978, S. 42: »[...] no Westerner needed ever to see himself, mirrored in the eyes of the subject race, as anything but a vigorous, rational, ever-alert young Raj«. 
in Grandjouans Zitat wieder die Anspielung auf eine Hierarchie der Zivilisationen mit, innerhalb derer die Libanesen schon höher ständen als die Ägypter oder Marokkaner.

Darüber hinaus wurden die französischen Schulen aber auch konkret zu Orten, an denen die schwierige Position des Mandatsregimes im Vergleich zu den Kolonien in einem offenen Konflikt endete. Beispielsweise berichtete Direktor Mathieu im Schuljahr 1921-1922 sehr kritisch von der körperlichen Züchtigung eines Schülers, Sohn eines libanesischen muslimischen Politikers, durch einen französischen Angestellten des französischen Hochkommissariats, der vorher in Algerien tätig war und anscheinend, so Mathieu, seine Einstellung gegenüber den »Arabern« von dort mitgenommen habe:

Fonctionnaire algérien, avant d'entrer au service du Haut-Commissariat, je crains qu'il n'ait conservé de son ancien poste des idées très arrêtées sur la façon dont il convient d'agir avec `les arabes` et qu'il n'ait voulu délibérément les mettre en pratique ${ }^{198}$.

Die katholischen Orden waren von dieser Frage viel weniger betroffen. Ihr Personal bewegte sich vor allem innerhalb der Region des Nahen Ostens. Allerdings zog man auch hier durchaus Parallelen. 1935 berichtete der Repräsentant der Beiruter Jesuitenuniversität in Frankreich, Pater Jalabert, bei einer Konferenz an der katholischen Universität in Leuven in Belgien, dass die Jesuiten in Syrien und Libanon dieselben Schwierigkeiten wie in den französischen Kolonien hätten, nämlich dass die Unterstützung durch die französische Regierung rückläufig sei:

La présence de la France en Syrie et au Liban offre à l'apostolat des avantages par la sécurité [...], par la civilisation [...]. Mais, par ailleurs, cette présence n'est pas sans susciter des difficultés analogues à celles qu'elle a créées à l'apostolat en pays de colonie ou de protectorat ${ }^{199}$.

Das deutet darauf hin, dass den Jesuiten der Unterschied zwischen dem Mandat und der Kolonie sehr wohl bewusst war. Darüber hinaus finden sich in den Dokumenten der Orden implizite Vergleiche mit den Kolonien im Zusammenhang mit der Missionsarbeit, die die Menschen in den Kolonien herabsetzten. Beispielsweise führten die Schüler der Jesuitenschule in Beirut 1936 ein Theaterstück mit dem Namen »Comment Fou-Ki-Ri et Bamboula sont devenus chrétiens« auf. Dieses Stück bestand vor allem aus dem Dialog zwischen dem Chinesen »Fou-Ki-Ri« und dem Afrikaner »Bamboula«, des-

198 AN/Paris, 60 AJ 124 (1921-1922), »Affaire Mougin«.

$199 \mathrm{SJ} /$ Vanves, »Fonds Jalabert«, 1-1 C, »Deux conférences de L. Jalabert à l’Université catholique du Louvain les 10 et 11 décembre $1935 \ll$. 
sen Intention ein Aufruf zur Spende für Missionare und Priester war. Während die chinesische Figur recht gut Französisch spricht, benutzt die afrikanische ein nach rassistischen Darstellungen »afrikanisches Französisch«. So schrieb der Autor, wahrscheinlich ein Jesuit:

Fou-Ki-Ri: Dis-donc, alors au lieu de se disputer, on ferait mieux d'aller chez ceux qui ont beaucoup d'argent pour remplir les caisses vides. Bamboula: Oui moi prendre bô̂te pour les baptêmes toi boîte des séminaires ${ }^{200}$.

Dieses Theaterstück zeigt eindeutig eine Herabsetzung der chinesischen und afrikanischen Kulturen, die von Frankreich kolonisiert wurden. Gleichzeitig birgt es, da die Schauspieler junge Libanesen waren, wieder die Vorstellung von verschiedenen Zivilisationen, die in einem hierarchischen Zusammenhang miteinander stehen.

Trotz des partiellen Kulturtransfers zwischen den Kolonien und der Levante, welcher sich vor allem durch die personelle Mobilität der Akteure, die ihre Erfahrungen mitbrachten, erklärt, waren manche französischen Akteure auch darauf bedacht, den Unterschied zwischen beiden Regimen zu betonen und den »kolonialen Reflex« mancher ihrer Landsleute einzudämmen. Daran wurden die französischen Schulen auch von Seiten der Libanesen erinnert, wie der Brief eines libanesischen Notabeln an einen französischen Abgeordneten von 1925 bezeugt:

Ses principaux agents [de la puissance mandataire] [...] agirent comme s'ils avaient à découvrir la Syrie et le Liban qui leur étaient inconnus, et ils y établirent un système d'administration directe [...]. Au Liban [...] ils imposèrent un gouverneur français, comme dans les colonies, et ils y amenèrent des fonctionnaires coloniaux. Aussi le gouverneur actuel est-il un ancien gouverneur des colonies ${ }^{201}$.

Auch frankophone und frankophile libanesische Zeitungen wie L'Orient machten immer deutlich, dass zwischen ihnen und den französischen Kolonien ein großer Unterschied bestand ${ }^{202}$. In diesem Zusammenhang wäre eine Untersuchung der vielen Libanesen, die nach Afrika und Südamerika

200 SJ/Beirut, 11.D.15, »Fêtes de Divisions Petits Internes«.

201 SJ/Vanves, »Fonds Jalabert«, Kopie des Briefes eines libanesische Notabeln an Paul Boncour, Suq al-Gharb, 13.10.1925.

202 Vgl. L'Orient, 21.05.1926: »Pourquoi la France n'abandonnera pas la Syrie«. In diesem Artikel werden die Syrer höher als die Kolonisierten gestellt. Vgl. auch L'Orient, 06.06.1926: »L'œuvre française au Maroc«. In diesem Artikel wird Frankreich eindeutig nur in Bezug auf Marokko als »la plus grande puissance coloniale du monde« bezeichnet. 
emigrierten und dort unter französischer Kolonialherrschaft oft selbst eine kolonialistische Haltung entwickelten, sehr interessant ${ }^{203}$.

In manchen Fällen verwandelten die Libanesen die französische Haltung, ihr Land als Kolonie zu betrachten, sogar als Vorwurf gegen die Franzosen. So beschreibt die Libanesin Maud Fargeallah in ihren Memoiren einen französischen Offizier, der ihre Landsleute als »arriérés« bezeichnete und dem sie antwortete:

Sachez que les arriérés sont de votre espèce, vous les français vous n'êtes pas venus en conquérants, nous vous avons invités, je maudis le président Lebrun qui a envoyé chez nous des brutes comme vous. Vous aurez d'ailleurs de mes nouvelles, sale bandit ${ }^{204}$ !

Dieses Kapitel hat die zentrale Funktion der mission civilisatrice als Diskurs und soziale Praxis der Mandatsregierung, der französischen Schulen und der libanesischen Klientel dieser Schulen deutlich gemacht. Die Schulen und die Libanesen haben diesen Diskurs verwendet, weil sie entweder von dem Mandat begeistert waren, ihre Teilnahme an der französischen Bildungspolitik zeigen oder die Mandatsregierung um Unterstützung bitten wollten. Als soziale Praxis hat die Mandatsmacht sich der mission civilisatrice bedient, um die französischen Schulen, aber auch die Libanesen an sich zu binden. Die nur zögerlich vorangetriebene Vereinheitlichung der Abschlüsse und Ausarbeitung der Curricula sowie die geringe Abgrenzung von der Situation in Nordafrika zeugte von der ambivalenten Bildungspolitik, die die Mandatsregierung insgesamt betrieb. Die Libanesen ihrerseits haben diese Praktiken, zum Beispiel in Form der Stipendien, verwendet, weil sie auf diese Weise ihre soziale Position in der Gesellschaft festigen oder verbessern konnten. Die Schulen schließlich haben versucht, sich als Vermittler zwischen Mandatsregierung und libanesischer Bevölkerung zu etablieren.

Viele Grundsteine dieser Dreiecksbeziehung zwischen Mandatsregierung, libanesischer Bevölkerung und französischen Schulen wurden in den ersten Jahren des Mandats gelegt. In der Folge drifteten die unterschiedlichen Positionen allerdings noch stärker auseinander.

203 Eine erste Studie lieferten 1992 Hourani und Shehadi, die dieser Frage aber noch keinen großen Raum boten. Vgl. Albert Hourani/Nahim Shehadi (Hg.), The Lebanese and the World. A Century of Emigration, London 1992.

204 Ingrid Снамоun (Hg.), Visages d'une époque. Maud Fargeallah raconte, Paris 1989, S. 78. 



\section{Sprachen zwischen Mission und Distinktion im Mandatsregime}

Dieses Kapitel untersucht die französische und arabische Sprache als zentrales Element der Schulen zu Beginn des französischen Mandats im Libanon. In unterschiedlicher Gewichtung und auf verschiedenen Ebenen übten beide Sprachen die Funktionen als Machtinstrument, als Mittel sozialer Distinktion und als Identitätsmarker aus.

Zum einen war die französische Sprache fundamentaler Bestandteil der in den Schulen propagierten Idee der Zivilisierungsmission, da sie sowohl Symbol als auch Medium dieser Idee repräsentierte. Zwar wurde auch in anderen europäischen Ländern, beispielsweise in Großbritannien - wenn dort auch später als in Frankreich - der eigenen Sprache ein starkes »Zivilisierungspotential « attestiert, was sich laut deren Vertreter unter anderem an der Sprache Shakespeares zeigte ${ }^{1}$. Es scheint aber, dass in der französischen Tradition die Sprache unter Berufung auf die Französische Revolution noch stärker als universell verstanden wurde und ihr eine größere Bedeutung in ihrer Durchdringungskraft und -pflicht der Herzen der Menschen unter französischer Herrschaft zugeschrieben wurde als in der britischen Tradition ${ }^{2}$. Das galt für Frankreich selbst, wo die Regierung seit der Neuzeit das Französische als einzige legitime Sprache gegen die vielen regionalen Sprachen im Hexagon oft gewalttätig durchzusetzen versuchte, genauso wie für die französischen Kolonien ${ }^{3}$. Allerdings zeigte sich für letztere das besondere Paradox, dass die dortigen Menschen zwar Französisch sprechen, aber ihre Assimilation nicht zur - damit eigentlich verbundenen - Rechtsgleichheit mit den Franzosen führen ${ }^{4}$ sollte; dies war ein Grund warum um 1900 in den kolonialen Kreisen in Frankreich die Idee der Assimilation durch die der Assozia-

1 Vgl. Steinbach 2009, S. 25.

2 Das zeigt sehr deutlich am Konzept der Frankophonie, als deren Vorreiter der französische Geograph Onésime Réclus Ende des 19. Jahrhunderts gilt. Vgl. Luc Pinhas, Aux origines du discours francophone. Onésime Réclus et l'expansionnisme colonial français, in: Communication et Languages, 140 (2004), S. 69-82.

3 Vgl. Klaus Bochmann, Frankophonie als inneres Ordnungsprinzip der französischen Nation, in: Frankreich-Zentrum der Universität Leipzig/Institut français de LeipZIG (Hg.), Francophonie et Globalisation. Materialien zur V. Französischen Sommeruniversität, Leipzig 1997, S. 60-69, S. 65. Speziell für die Debatten um eine staatlich verordnete Einsprachigkeit in französischen Grundschulen im späten 19. Jahrhundert vgl. Pierre Boutan, La langue des Messieurs ... Histoire de l'enseignement français à l'école primaire, Paris 1996, S. 72-85.

Vgl. Bochman 1997, S. 65. 
tion der Kolonien ersetzt wurde 5 . Die in Frankreich verbreitete Vorstellung, die seit den ersten Sprachreformern um Joachim du Bellay im 16. Jahrhundert zu einem festen Bestandteil der französischen Kultur geworden war, fasste der Jesuit Louis Jalabert mit folgendem Satz zusammen: »on enseignât le français, et [...] avec notre langue, notre civilisation se répandît $\varkappa^{6}$. Die arabische Sprache und Kultur hatte innerhalb der Idee der Zivilisierungsmission ebenfalls einen wichtigen, aber als minderwertig konstruierten Stellenwert, der sich ebenfalls in der Sprachpolitik der französischen Regierung in den arabischen Ländern zeigte.

Unter den Denkern, die sich mit diesem Thema auseinandersetzten, hatte der französische Schriftsteller und Wissenschaftler Ernest Renan in seiner berühmten Rede über »L'Islam et la Science« an der Sorbonne 1883 das Arabische als »Sprache der Eroberung « bezeichnet ${ }^{7}$. Ein Jahr nach Renan rühmte der Sozialpsychologe Gustave Le Bon in seinem Werk »La civilisation des Arabes« zwar die arabische Sprache für ihre Durchsetzungskraft, allerdings schien ihm diese Universalität vor allem als Modell für die noch immer nicht erreichte sprachliche Homogenität Frankreichs zu dienen ${ }^{8}$. Außerdem zeigen seine Aktivitäten in der französischen Geographiegesellschaft, dass er sich für eine strikte Trennung der unterschiedlichen Kulturen aussprach und den Nicht-Europäern sehr wenig Mitspracherecht zugestand $^{9}$. Demgegenüber bezeichnete Paul Leroy-Beaulieu, Vertreter der Idee einer Hierarchie der Zivilisationen, 1897 mit Blick auf Algerien und Tunesien, das Arabische zwar als »instrument précieux qu'il faut se garder de détruire«, bezog das aber vor allem den funktionalen Nutzen dieser Sprache für die französische Herrschaft ${ }^{10}$.

Ähnlich widmete der belgische Jesuitenpater Henri Lammens, dessen Geschichtsabhandlungen über Syrien so zentral für die französische und maronitische Vision dieser Region war, der arabischen Sprache wenig Aufmerksamkeit, was sicher mit seiner Betonung Syriens als nicht-arabische Region zu tun hatte ${ }^{11}$. In seinem Werk »La Syrie« von 1921 erkannte er zwar

5 Vgl. Raymond F. Betts, Assimilation and Association in French Colonial Theory 1890-1914, New York/London 1961, S. 165.

$6 \mathrm{SJ} /$ Vanves, »Fonds Jalabert«, 1/1 C: »Deux conférences de L. Jalabert à l'Université catholique du Louvain les 10 et 11 décembre $1935 \ll$.

7 Vgl. RenAn 2005, S. 27.

8 Vgl. Le Bon 1884, S. 345.

9 Vgl. Benoît Marpeau, Gustave Le Bon. Parcours d'un intellectuel, Paris 2000, S. 82-84. Diese wissenschaftliche Darstellung ist sehr viel kritischer als die Erzählung von Michel KorPA, Gustave Le Bon. Hier et aujourd'hui, Chaintreaux 2011, S. 48-53, der Le Bon in stark rehabilitierender Weise als großen Bewunderer der Araber beschreibt.

10 Vgl. Paul Leroy-Beaulieu, L'Algérie et la Tunisie, Paris 1897, S. 264. Leroy-Beaulieu wollte die französische Sprache nur wenigen Arabern in Nordafrika zugänglich machen.

11 Vgl. Asher Kaufman, Henri Lammens and Syrian nationalism, in: Adel Beshara (Hg.), The Origins of Syrian Nationhood, London/New York 2011, S. 108-122, S. 110. 
die Schönheit der arabischen Sprache als die Sprache der Beduinen an, relativierte dieses Urteil aber implizit gleich danach durch eine sehr negative Beschreibung der Wüstenbewohner ${ }^{2}$. Sehr viel positiver fiel hingegen das Urteil des Orientalisten Louis Massignon und einiger französischer Dominikaner in Ägypten aus, die, in der Tradition der libanesischen Christen der nahda die Bedeutung des Arabischen hervorhoben ${ }^{13}$. Massignon war ein französischer Wissenschaftler, der sich besonders mit der islamischen Mystik beschäftigte und für eine islamisch-christliche Verständigung eintrat $^{14}$. Ihren Einfluss auf die Sprach- und »Islampolitik» der französischen Regierung zeigten diese Visionen, insbesondere von Leroy-Beaulieu und Massignon, der ab den 1920er Jahren auch in politischen Gremien tätig war, da die französische Regierung in der Tat aus strategischen Gründen die arabische Sprache und ihren Unterricht betonte - allerdings zunächst vor allem in Nordafrika, und auch dort nur in sehr begrenztem Maße ${ }^{15}$. Das brachte Massignon dazu, diese Politik auch in der Levante zu fordern und dabei die britische Sprachpolitik im Irak als Modell zu nennen ${ }^{16}$. Gerade in der Bildungspolitik im Nahen Osten zeichnete sich die britische Mandatsmacht im Gegensatz zu Frankreich dadurch aus, dass sie einen stärkeren Pragmatismus vertrat und beispielsweise im Irak und in Palästina den Unterricht auf Arabisch förderte ${ }^{17}$.

Zum anderen bildete die Sprache ein Kernelement der französischen Schulen in ihrer Funktion als Ausbildungsstätte junger Libanesen und stellte deshalb sowohl für die Regierung als auch für die Bevölkerung ein Machtinstrument dar. Darüber hinaus markierte die Frage der Sprache aber auch das Distinktionsmerkmal einer sozialen Elite innerhalb der französischen Schulen. In der Tat wurden Anzahl und Qualität der unterrichteten Sprachen in einer Schule immer wichtiger als Kriterium der libanesischen Eltern, ihre Kinder dorthin zu geben ${ }^{18}$. Wie Bourdieu und Passeron dies für Frankreich gezeigt haben, reproduzierte die Schule die sozialen Verhältnisse der libanesischen Gesellschaft auch vermittels der Sprache. Zwar sei die Sprache, die

12 Vgl. Lammens 1921, S. 34-37. Interessanterweise nahm Lammens hier Bezug auf Renan, zitierte dessen Bewunderung der Araber vor dem islamischen Zeitalter und verzieh diesem seine, wie Lammens ausführte, »naive Unkenntnis« der alten arabischen Literatur.

13 Vgl. Dominique Avon, Les Frères prêcheurs en Orient. Les dominicains du Caire (Années 1910-Années 1960), Paris 2005, S. 278-284.

14 Vgl. Hassan Elboudrari, Massignon Louis, in: François Poulllon (Hg.), Dictionnaire des orientalistes de langue française, Paris 2008, S. 660-661.

15 Vgl. Le Pautremat 2003, S. 314. Die relative Förderung des Arabischen macht Le Pautremat auch daran fest, dass diese Sprache ab 1935 in Algerien als Fremdsprache galt.

16 Vgl. Laurens 2004, S. 241.

17 Vgl. Sanchez-Summerer 2006, S. 106; Krämer 2003, S. 214.

18 Vgl. Deanna Ferree Womack, Lubnani, Libanais, Lebanese. Missionare Education, Language Policy and Identity Formation in Modern Lebanon, in: Studies in World Christianity 18 (2012), H. 1, S. 4-20, S. 11. 
in der Schule gelehrt wird, so Bourdieu und Passeron, zunächst für die Schüler aller sozialen Schichten eine Fremdsprache, die sie erlernen müssten, aber dieses werde den Kindern der privilegierten Schichten leichter gemacht als denen der ärmeren Familien, und so entwickle sich durch die Sprache eine, wenn auch versteckte, direkte Beziehung zwischen sozialer Herkunft und schulischem Erfolg ${ }^{19}$. Den beiden Soziologen zufolge resultiert daraus auch eine sehr unterschiedliche Haltung zur Sprache: so sei der Umgang der Schüler aus privilegierten Familien mit Sprache sehr viel ungezwungener und natürlicher als der der Schüler aus dem Arbeitermilieu ${ }^{20}$.

Innerhalb der französischen Schulen im Libanon erkoren privilegierte libanesische Klientelgruppen sowohl die französische als auch die arabische Sprache zu einem Merkmal sozialer Distinktion. Das zeigte sich zum einen ganz konkret in der Auszeichnung von Schülern mit herausragenden Noten in diesen Sprachen: sie erhielten eine Schleife als » marques de distinction ${ }^{21}$, wie Georgia Makhlouf in ihren Memoiren über die Schulzeit bei französischsprachigen Nonnen in Beirut berichtet. Dieser Prozess spiegelte aber auch die libanesische Gesellschaft wider, in der die französische Mandatsmacht eine fremde Sprache eingeführt und ihre Praxis zur Machtfrage erkoren hatte, da das Französische die einzige Kommunikationssprache mit der Mandatsregierung und ihren Institutionen darstellte. Darüber hinaus lagen hinter der französischen beziehungsweise arabischen Sprache verschiedene Identitätskonzepte, auf die die Schulen, teils bewusst und teils unbewusst, eingingen.

Die zentrale Frage dieses Kapitels lautet, wie sich die französischen Schulen innerhalb dieser verschiedenen Erwartungen positionierten. Wie die Ausführungen zeigen werden, kooperierten die Schulen einerseits mit der Mandatsmacht, um die französische Sprache als Mittel der machtpolitischen und kulturellen Durchdringung Frankreichs zu benutzen. Andererseits gingen sie aber auch auf die Interessen ihrer Klientel ein, die je nach Schultyp ver-

19 Vgl. Pierre Bourdieu/Jean-Claude Passeron, La reproduction. Éléments pour une théorie du système de l'enseignement, Paris 1970, S. 143-144. Natürlich ist Bourdieu für diese plakativen Thesen stark kritisiert worden, besonders radikal von dem Historiker und Philosophen Jacques Rancière, der ihm vorwarf, er zeige die Klassenstrukturen nicht auf, sondern schreibe sie erst fest. Vgl. Jacques Ranciére, Le philosophe et ses pauvres, Paris 1983, S. 261. Allerdings ist Rancières Ansatz, demgegenüber vor allem die Ausnahmen innerhalb des gesellschaftlichen Systems in den Blick zu nehmen, ebenfalls anzuzweifeln. Vgl. Ruth SonderEgGer, Wie emanzipatorisch ist Habitus-Forschung? Zu Rancières Kritik an Bourdieus Theorie des Habitus, in: Lithes. Zeitschrift für Literatur- und Theatersoziologie 2010, H. 3, S. 18-39, S. 31. Außerdem muss die Studie von Bourdieu und Passeron im Lichte ihrer Zeit gelesen werden, die von einer starken Öffnung des Universitätssystems für alle gesellschaftlichen Gruppen geprägt war. Vgl. Pierre Mounier, Pierre Bourdieu. Une introduction, Paris 2001, S. 134.

20 Vgl. Bourdieu/Passeron 1970, S. 148.

21 Vgl. Georgia Makhlouf, Eclats de mémoire. Beyrouth - Fragments d'enfance, Beirut 2005, S. 59. Sie selber war über die Auszeichnung eher beschämt als erfreut und wollte lieber wie ihre Freundinnen nicht hervorgehoben werden. 
schiedene Erwartungen an die französische beziehungsweise arabische Sprache formulierte. Ihre eigenen Einstellungen versuchten die Lehrer in diesen Prozess zu integrieren.

Während die vornehmlich katholische Klientel der katholischen Schulen die französische Sprache als Merkmal ihrer Identität und sozialen Distinktion ansah, galt das zu einem gewissen Teil auch für die muslimischen Eltern der laizistischen Schulen, die aber auch der arabischen Sprache diese Funktion gaben. Dabei ist interessant zu beobachten, dass die Mission lä̈que zwar die Bedeutung der arabischen Sprache betonte, aber in manchen Aspekten weniger dafür geeignet war, diese auch praktisch in die Tat umzusetzen als die katholischen Orden, welche die arabische Sprache in ihren schulinternen Diskursen größtenteils ignorierten, in der Praxis aber über mehr Erfahrung verfügten.

In der folgenden Analyse werden zunächst die französische und dann die arabische Sprache unter den Fragestellungen behandelt, welche Erwartungen die Mandatsmacht formulierte, wie die Vorstellungen der libanesischen Klientel aussahen und mit welchen Praktiken die Schulen diese zu erfüllen suchten. Dabei widmet sich das Kapitel dem von den Lehrern eingeschätzten Sprachniveau der Schüler, der Anzahl der unterrichteten Stunden, den Methoden und Lehrmitteln und deren Inhalten. Schließlich fragt es auch nach möglichen Widerständen der Schüler gegen diese Sprachpolitik.

\section{Das Französische als Macht- und Identitätsmarker}

Wie in anderen kolonialen Kontexten repräsentierte die französische Sprache auch im Libanon eine komplexe Beziehung zur politischen Macht, an der Europäer und Einheimische gleichermaßen teilhaben wollten. Ein Unterschied zu anderen Regionen unter französischem Einfluss bestand allerdings in der primär identitätsstiftenden Bedeutung des Französischen für eine bestimmte Gruppe von Libanesen, die sich vor allem aus Maroniten zusammensetzte, und deren Vorstellungen denen anderer libanesischer Gemeinschaften stark widersprachen: Mitglieder dieser Gruppe verstanden die französische Sprache nicht nur als Mittel sozialer oder kultureller Distinktion, sondern auch als Merkmal ihrer religiösen und nationalen Identität ${ }^{22}$.

Für das französische Hochkommissariat hatte die französische Sprache nicht nur Priorität vor dem Arabischen, sondern es sah es auch als seine Aufgabe, diesen Primat und damit die französische Herrschaft in den Köpfen der Libanesen zu verankern. Gouraud formulierte dies 1922 unmissverständlich:

22 Vgl. Yasir Suleiman, The Arabic Language and National Identity, Edinburgh 2003, S. 206;

WOMACK 2012, S. 15-16. 
La langue française devant devenir, aux termes du mandat, la première langue officielle du pays, l'enseignement de cette langue doit revêtir en Syrie un caractère éducatif et doit tendre, non seulement à répandre la connaissance pratique du langage, mais encore à pénétrer les esprits de nos idées ${ }^{23}$.

Der Bildungsbeauftragte Jeantry legitimierte diese Politik zusätzlich mit dem Interesse der Bevölkerung: »Le pays lui-même réclame la diffusion de notre langue qu'il considère comme un des meilleurs instruments de progrès et de civilisation: il est donc nécessaire de répondre à un désir unanimement exprimé $\ll^{24}$. Seine Hoheit über die Sprache manifestierte der Hochkommissar damit, dass er das Türkische, die Amtssprache des Osmanischen Reiches, durch das Französische als Amts- und Unterrichtssprache neben dem Arabischen ersetzte ${ }^{25}$. Wie in anderen kolonialen Kontexten demonstrierte die Mandatsregierung damit ihren Herrschaftsanspruch über das fremde Land auch in linguistischer Hinsicht und konnte gleichzeitig die indigene Kultur, die sich in der Sprache manifestierte, aus den öffentlichen Kontexten verbannen $^{26}$. Diese Vorgabe betraf natürlich auch die Schulen als zentrale Elemente des öffentlichen Lebens ${ }^{27}$.

Die katholischen Schulen teilten die Politik des Hochkommissariats, dem Französischen auch in ihren Schulen die Priorität zu geben. So warb die Broschüre der Schule der Frères des écoles chrétiennes in Beirut mit der Parole »le français qui est la langue officielle de l'école«, bevor sie als andere »langues vivantes« Latein, Englisch und Arabisch vorstellte ${ }^{28}$. Die französische Sprache wurde aber nicht nur als Basis des Unterrichts, sondern auch als die Sprache der Kultur und Konversation bezeichnet:

L'étude de la langue française est soignée d'une manière très spéciale: elle est la base de tout l'enseignement donné, c'est la langue de la conversation. Classiques et modernes, linguistique, connaissance approfondie de la langue, rien ne manque pour permettre à nos étudiants de faire, si Dieu le veut, de bons bacheliers $\ll^{29}$.

$23 \mathrm{MAE} /$ Nantes, IP, 04, »Écoles privées«, Brief von Gouraud an seinen Delegierten in Damaskus und im Drusengebiet, Beirut, 15.11.1922.

24 SJ/Beirut, 8.C.21, »Le Conseiller par intérim pour l'instruction publique du Haut-Commissariat au Révérend Père Delore, Université Saint-Joseph/Beyouth« (ohne Datum, ca. 1922).

25 MAE/Nantes, IP, 02 : 1919-1920, »Note sur les écoles privées«.

26 Für Indochina vgl. Cooper 2004, S. 138; für Algerien siehe Le Pautremat 2003, S. 27.

27 Vgl. Phillip G. Altbach/Gail P. Kelly, Introduction, in: Phillip G. Altbach/Gail P. Kelly (Hg.), Education and Colonialism, New York/London 1978, S. 1-49, S. 3: »In the colonial situation the school was detached from indigenous cultures in the languages and in the school values they taught $\ll$.

28 FEC, Palmarès, 1923-1924, S. 64: »Extrait du Prospectus Général«.

29 LAZ/Paris, Bulletin des Missions des Lazaristes, Juli 1931, S. 202-226: »Les Lazaristes en Syrie«. 
Auch die Schulen der Alliance israélite vertraten diesen Primat und überhöhten den Wert der französischen Sprache: »L'Alliance Israélite Universelle s'est servie d'un instrument qui a fait ses preuves, de la langue française, véhicule incomparable d'idées généreuses et de sentiments nobles « ${ }^{30}$. Damit reihten sie sich ein in den Kolonialismus der Dritten Republik, welcher sich auf die drei Größen »l'enseignement, l'école, la langue française« stützte, wobei allein die französische Sprache eine »patrie à part entière« darstellte ${ }^{31}$. Außerdem verteidigten die jüdischen Lehrer die besondere Stellung der französischen Sprache explizit auch gegenüber den Zionisten, die in dieser Zeit das Hebräische zur zentralen Sprache erhoben hatten ${ }^{32}$.

Die Position der Mission laïque fiel ambivalenter aus. Obwohl sie, wie später erläutert wird, betonte, dass in ihren Schulen die französische und arabische Sprache gleichberechtigt nebeneinander ständen, findet sich auch in den Dokumenten der Mission lä̈que ein besonderes Lob und eine ideologische Überhöhung des Französischen, das in sich die Logik und Klarheit des Denkens trage: »La Mission laïque enseigne avec la langue française, et par elle, la logique, qui donne à la pensée la clarté « ${ }^{33}$. Damit hatte die Mission laïque nach dem Ersten Weltkrieg eine »kolonialistische Wende« vollzogen. 1906 hatte man innerhalb der Organisation noch über das Recht diskutiert, anderen Kulturen die französische Sprache zu oktroyieren und beschlossen, dass die mission civilisatrice auf keinen Fall die indigene Sprache auslöschen dürfe ${ }^{34}$. Nach dem Ersten Weltkrieg gab die Mission laïque diese assoziationistische Idee auf und stand damit in einem gewissen Gegensatz zu der oben beschriebenen offiziellen französischen kolonialen Ideologie ${ }^{35}$.

30 AIU/Paris, »Paix et Droit. Organe de l’Alliance Israélite Universelle«, Januar 1921, S. 16: »Le Général Gouraud aux Écoles de l'Alliance de Beyrouth«.

31 ANTÉBI 1999, S. 14.

32 AIU/Paris, »Liban 1 B 4«, Brief des Großrabbiners des Grand Liban, Dr. S. Tagger, an die AIU in Paris, Beirut/30.06.1922: »Enfin le moment est arrivé à me rejoindre à mes collègues sépharadins pour propager l'utilité de la langue française et celle du pays malgré l'opposition des sionistes, et je suis ferme dans cette idée et sûr de franchir tout obstacle«. Zur Betonung des Hebräischen durch die Zionisten siehe Krämer 2003, S. 212; Malgorzata Maksymiak-Fugmann, Mapping Zionism. Ost und West in zionistischen Konzepten einer jüdischen Nation 1897-1914, Diss. Beer Sheva 2009, S. 108-121. Maksymiak-Fugmann macht aber auch auf die großen Unterschiede der Bewertung des Hebräischen zwischen und innerhalb der deutschen und polnischen Zionistenpresse aufmerksam.

33 Revue de l'enseignement français hors de France 17 (1920), 1, S. 5.

34 Revue de l'Enseignement colonial. Organe des écoles laïques françaises hors de France paraissant tous les deux mois publié par la Mission laïque française, »Compte-rendu du Congrès de la Mission Laïque (24-28 septembre 1906)«, S. 38f.

35 Vgl. Randi Degullhem, Turning Syrians into Frenchmen: the Cultural Politics of a French Non-Governmental Organization in Mandate Syria (1920-1967) - the French Secular Mission Schools, in: Islam and Christian-Muslim Relations 13 (2002), H. 4, S. 449-460, hier 452-453. Allerdings muss man, wie Deguilhem das in Ansätzen tut, deutlich zwischen verschiedenen Tendenzen innerhalb der Organisation unterscheiden. 
Auch große Teile der libanesischen Bevölkerung waren sich der Bedeutung der französischen Sprache als Machtinstrument des Mandats und deshalb als zentrale Fähigkeit für eine berufliche Perspektive bewusst und wollten sie deswegen erlernen. Den faktischen Anstieg der Schülerzahlen in den französischen Schulen im Libanon nach dem Ersten Weltkrieg erlebten die Schulen als das gewachsene Interesse der Bevölkerung an den Kompetenzen, die diese Schulen vermittelten: »L'enseignement du français devient de jour en jour plus nécessaire et plus recherché. Il s'introduit de plus en plus, depuis l'occupation dans toutes les écoles primaires de notre ville si petites qu'elles soient $\ll^{36}$.

Diese Bestretbung galt auch für die Muslime, wie der Bericht einer Schule der Filles de la Charité im Norden des Libanons belegt: "Le désir d'apprendre le français attire dans nos classes les enfants des schismatiques et des musulmans $\ll{ }^{37}$. Leider heiße das nicht, so bedauerten die Schwestern, dass sie auch die christliche Religion annähmen, höchstens habe sich ihre Sympathie dafür etwas erhöht.

Auch die Mission laïque erlebte das gewachsene Interesse der Libanesen an der französischen Sprache. Wie in dem auf Arabisch verfassten Brief eines Komitees des libanesischen Dorfes al-Ğāhilīya deutlich wurde, vermischte sich dabei das Interesse an den Werten der Schule mit der pragmatischen Notwendigkeit:

Sehr geehrter Herr Gelehrter, Direktor der französischen säkularen Fakultät in Beirut, nach dem, was wir im säkularen Studium gesehen haben, und wegen der guten Basis, die zu unserem Land passt, und unter Berufung auf unser Verlangen nach dieser Basis, die die Herzen unserer Söhne bepflanzen soll, verbunden mit unserer Notwendigkeit, dass sie die französische Sprache erlernen sollen, treten wir, die Leute des libanesischen Dorfes al-Ğāhilīya, vor Sie und erbitten den Aufbau einer Schule in unserem Dorf, wie dies in Rās-al-Matn geschehen ist. Und wir versprechen Ihnen eine genügende Anzahl von Schülern und auch, dass wir alle Bedingungen, die das System der Mission auferlegt, erfüllen, wie es sich gehört. Und wir haben die sichere Hoffnung, dass diese Vereinigung, die für ihre große menschliche Arbeit und ihre großen menschlichen Werte berühmt ist, unsere Bitte positiv beantworten wird. Damit ehren Sie uns und wir erinnern uns mit Lob und Danksagung immer daran ${ }^{38}$.

36 AIU/PAris, »VIE 81«, Brief von Penso an den Präsidenten der Alliance israélite in Paris, Beirut, 30.01.1919; für die Filles de la Charité siehe LAZ/Paris, »Filles de la Charité-Divers«, »Rapport général sur les Maisons des Filles de la Charité de la Province: Syrie, Palestine, Egypte, 1923, Tripoli/Miséricorde«: »Depuis l'occupation française, les parents attachent plus d'importance à l'étude du français; aussi les enfants sont plus nombreux dans les classes qu'avant la guerre «.

37 LAZ/Paris, »Filles de la Charité-Divers«, 1924, »Rapport général«.

38 AN/Paris, 60 AJ 121 »Bourse«, Brief der Notabeln aus al-Ğāhilīya/20. oder 30.06.1922. 
Weiterhin repräsentierte die französische Sprache vor allem für katholische, und im Speziellen maronitische Libanesen auch einen Teil ihrer distinkten Identität als Christen in einem muslimischen Umfeld. So schrieb Charles Corm, der maronitische Dichter und Vertreter der Idee der phönizischen und damit nicht-islamischen oder arabischen Wurzeln der Libanesen, auf Französisch. Auch wenn er anerkannte, dass Französisch nicht seine Muttersprache war, stellte sie doch das Medium dar, in dem er seine Ideen mitteilte ${ }^{39}$. Dafür wurde er stark kritisiert, unter anderem von dem ehemaligen Schüler der Mission laïque, Taqi ad-Din as-Sulh (arabisch Taqī ad-Dīn aṣ-Ṣulḥ), der in einem offenen Brief von 1934 seine Bestürzung ausdrückte, dass Corm das Arabische nicht als seine Sprache ansah ${ }^{40}$.

Darüber hinaus stellte die französische Sprache eindeutig ein Merkmal sozialer Distinktion für eine libanesische soziale Elite dar. Für die katholische Klientel verwundert es nicht, dass viele Schüler und ihre Eltern das Französische beherrschten, weil sie oft seit Generationen die französischen Schulen besuchten ${ }^{41}$. Außerdem wurde in vielen Familien von Schülern französischer Schulen Französisch gesprochen: »À Beyrouth, on parlait généralement le français en famille en même temps que l'arabe ou sans l'arabe $«{ }^{42}$. Auf diese Weise konnten sie während des Mandats an der dominanten französischen Kultur teilhaben ${ }^{43}$. In seinen Memoiren (auf Französisch) setzte der libanesische Politiker Charles Helou, der in den 1920er Jahren Schüler der Jesuiten in Beirut war, diese Tatsache in direkte Verbindung mit den französischen Autoritäten:

39 Asher Kaufman, >Tell Us Our History<: Charles Corm, Mount Lebanon and Lebanese Nationalism, in: Middle Eastern Studies 40 (2004), H. 3, S. 1-28, S. 20 (=2004b). Wie stark sich dieses Verständnis durch die Zeit rettete, zeigt die Beschreibung Corms durch einen libanesischen Autor 100 Jahre später: »Cette langue française dans laquelle il excella, il l'a apprise dans des écoles françaises dirigées par des Français qui, non seulement nous apprenaient et à lire et à écrire la langue de Montaigne, mais aussi et surtout à devenir des Libanais ouverts, tolérants et compréhensifs«. Salhab 1997, S. 111.

40 Taqi ad-Din as-Sulh, L’Exposition hebdomadaire/al-Márị̣ al-usbū'i, Beirut, 2. Juli 1934, S. 33-34, zitiert in: Mohamad Nasereddine, La littérature libanaise de langue française: de la recherche d'identité à l'expression d'angoisse, Diss. Paris 1987, S. 84. Allerdings erwähnt Kaufman auch eine Initiative von Charles Corm zur Stärkung der Solidarität zwischen libanesischen Schriftstellern 1934, an welchem mit Khalil Taqi ad-Din, Taqi ad-Din as-Sulh und Muḥammad Ğamīl Bayhum zwei Sunniten und ein Druse, und vor allem drei (ehemalige) Partner der Mission lä̈que, teilnahmen. Vgl. Asher Kaufman, Reviving Phoenicia. The Search for Identity in Lebanon, London/New York 2004, S. 186, Fn. 48 (=2004a).

41 Vgl. Interview der Verfasserin mit Camille Héchaïmé, Beirut, 24.10.2008.

42 Charles Helou, Mémoires, Bd. 1: Prime Jeunesse, Beirut 2002, S. 20; vgl. auch Interview der Verfasserin mit Camille Héchaïmé, Beirut, 24.10.2008.

43 Vgl. Bourdieu/Passeron 1970, S. 157. 
Semblait cultivé qui pouvait s'adresser directement aux fonctionaires du Mandat français, ou même aux autorités politiques en France: celui qui pouvait dialoguer avec les éducateurs et les missionnaires venus des différentes régions françaises ${ }^{44}$.

Da eine gute Kenntnis des Französischen auch dazu führte, dass die Schüler später an der französischen Universität in Beirut oder direkt in Frankreich studierten $^{45}$, trug sie zur Reproduktion der sozialen Elite bei. Die meisten Libanesen aus dieser Gruppe waren katholischer Konfession. Die Jesuiten unterstützten die Verbindung zwischen französischer Sprache und Elitenzugehörigkeit explizit. So notierte der Präfekt der Schule in Beirut angesichts einer französischen Theateraufführung 1935 bedauernd, die minder bemittelten (»de condition modeste et d'instruction médiocre «) Eltern, die kein Französisch sprächen, sollten auf Dauer nicht mit den gebildeten (»cultivés «) Eltern, die Französisch verstünden, vermischt werden, weil letztere unter der Ignoranz der ersten zu leiden hätten ${ }^{46}$.

$\mathrm{Zu}$ dieser katholischen Elite kamen während der Mandatszeit, besonders in Beirut, auch muslimische Notabeln hinzu, sodass Französisch zur »langue de référence des élites partout en Syrie et pas seulement au Liban $\aleph^{47}{ }^{4}$ wurde ${ }^{48}$. Aus diesem Grund beherrschten auch die nicht-katholischen Notabeln, mit denen die Mission laïque zusammenarbeitete, die französische Sprache, wovon ihre Teilnahme am Comité de patronage und ihre Briefe auf Französisch zeugen. Allerdings finden sich bei ihnen keine Bemerkungen zur Funktion des Französischen als identitätsstiftend, das ihnen in erster Linie als Medium der Kommunikation diente ${ }^{49}$.

Die große Verbreitung des Französischen bedeutete allerdings nicht automatisch, dass alle libanesischen Schüler der französischen Schulen diese Sprache beherrschten. Während die Archive der katholischen Schulen in der Tat nicht von Schwierigkeiten bezüglich der französischen Sprache berichten, hatten die Mission lä̈que und die Alliance israélite mit diesem Prob-

44 Helou 2002, S. 20.

45 Vgl. ebd.

46 SJ/Beirut, 3 A 30: »Collège de Beyrouth. Diaire du P. Préfet 1934-1947«, 03.06.1935: »Beaucoup de parents d'externes ne comprennent pas le français; alors la tenue de la salle en souffre. Il y a quelque chose à organiser au point de vue des invitations. Deux écueils à éviter: écarter les parents de condition modeste et d'instruction médiocre, alors qu'ils sont parents de nos élèves; et d'autre part, de grouper une salle un peu quelconque, dans laquelle les gens cultivés pâtissent de l'ignorance de leurs voisins«.

47 Kassir 2003, S. 314.

48 Aber auch die entstehenden Mittelklassen hatten sie sich zu Eigen gemacht. Vgl. WatenPaugh 2006, S. 3.

49 Vgl. Dueck 2010, S. 103, die den Mitgliedern der Maqasid-Schulen, von denen ja einige mit der Mission laïque zusammenarbeiteten, einen großen Pragmatismus im Umgang mit der französischen Kultur bescheinigt. 
lem zu kämpfen, weil, abgesehen von den Notabelnfamilien, ihre Schüler zu einem großen Anteil aus einem nicht-frankophonen Umfeld kamen: »La plupart des élèves qui nous sont confiés appartiennent à des milieux où notre langue n'est jamais prononcée $\aleph^{50}$. Besonders die Direktoren der Schule der Mission laïque beklagten sich in den ersten Jahren des Mandats, dass die Kenntnis der französischen Sprache vieler Schüler sehr gering oder nicht vorhanden sei. So berichtete Lehéricy im November 1921 von einer »[f]aiblesse générale des élèves en français: toutes les classes, sans exception, sont en ce sens intermédiaires « ${ }^{51}$. Auch im November 1924 monierte Direktor Mathieu noch, dass die Französischkenntnisse seiner Schüler, gerade in den unteren Klassen, oft sehr lückenhaft seien ${ }^{52}$.

Ähnlich sah die Situation in den Schulen der Alliance israélite aus, wie die Ermahnung des Hochkommissariats von 1922, dass auch die jüdischen Kinder das Französische beherrschen müssten, deutlich machte ${ }^{53}$. Die katholischen Schulen waren laut der Quellen mit diesem Problem weniger konfrontiert, das galt auch für die Schulen in den Bergen. Hatte ein Jesuit 1913 noch in seinem Tagebuch geschrieben, die Kenntnisse seiner Schüler in Tanail seien mangelhaft ${ }^{54}$, betonen die Aufzeichnungen von 1923 die guten Französischkenntnissen der Schüler ${ }^{55}$.

Die herausragende Stellung der französischen Sprache in allen Schulen zeigte sich aber nicht nur in den Diskursen, sondern auch in den sozialen Praktiken, sie zu realisieren. Außer im Arabischunterricht war es den Schülern verboten, ihre Muttersprache zu sprechen. Um dieses Verbot durchzusetzen, griffen alle Schulen auf die Methode des signal zurück, die in den Pausen eingesetzt wurde: ein Holzstab, versehen mit einem S an beiden Seiten, ging an den Schüler, der ein arabisches Wort sprach. Dieser musste es an den nächsten Schüler weitergeben, den er Arabisch sprechen hörte, und der Schüler, der den Holzstab am Ende der Pause in der Hand hielt, wurde bestraft. Diese Methode wurde in allen französischen Ordensschulen in der Levante praktiziert, um »l'omnipotence du français« zu demonstrieren ${ }^{56}$. $\mathrm{Zu}$ Recht ist darauf hingewiesen worden, dass hier ein Transfer der franzö-

50 AN/Paris, 60 AJ 128, Brief von Mathieu an Besnard, Beirut, 18.03.1925.

51 AN/Paris, 60 AJ 124, »Rapports mensuels«, November 1921.

52 Vgl. AN/Paris, 60 AJ 127, Brief von Mathieu an Besnard, Beirut, 05.11.1924.

53 Vgl. AIU/Paris, »Liban I B 4«, Brief des Großrabbiners des Grand Liban Tagger an den Großrabbiner von Paris, Lévy, Beirut/20.12.1922.

54 Vgl. SJ/Beirut,12.C.12, »Tanail École Normale«.

55 Vgl. SJ/Beirut, »Tanail Écoles«, »Bulletin de nouvelles (du P. Degivry, puis du P. Madam)«. Trotzdem gab es natürlich auch in den katholischen Einrichtungen Eltern, die kein Französisch sprachen.

56 Für die Schule der Lazaristen in Damaskus vgl. BocQuet 2008, S. 61. 
sischen Praxis stattgefunden hatte. Auch die Schulen der Dritten Republik bedienten sich des signal, um den Schülern in den Regionen mit einem anderen Dialekt die französische Sprache einzutrichtern ${ }^{57}$.

Der Fall der Mission lä̈que zeigt aber sehr eindrücklich, dass dieses Instrument nicht allein aus ideologischen und machtstrategischen Gründen, sondern auch als Mittel angesehen wurde, um das Französischniveau der Schüler zu heben. Im Gegensatz zu den katholischen Schulen, wo laut den Archiven die Methode des signal nie kritisch diskutiert wurde, gab es im Lehrerkollegium der Mission lä̈que lebhafte Auseinandersetzungen, ob dieses Instrument angemessen sei. Diese Diskussionen bestätigen die im ersten Kapitel postulierte stärkere Professionalisierung der Mission lä̈que française: Die explizit als Pädagogen geschulten Lehrer waren während ihrer Ausbildung in Frankreich für diese pädagogischen Themen stärker sensibilisiert worden als ihre Kollegen an den katholischen Schulen.

Auf der Suche nach einer Lösung, um die Schüler vom Arabisch sprechen abzuhalten, beschlossen die Lehrer zunächst, dass die Schüler, wenn sie in der Pause nicht Französisch sprachen, Geld bezahlen müssten, wovon Bücher für die Schulbibliothek gekauft würden. Nachdem dieses Vorgehen keinen Erfolg zeigte, besprach das Kollegium die Möglichkeit des signal, das von vielen Schulen im Land verwendet würde ${ }^{58}$. Um keine Front zwischen Franzosen und Libanesen entstehen zu lassen, sollten auch die Arabischlehrer sich an dieser Kontrolle beteiligen. Während einige Lehrer berichteten, dass ihre ersten Versuche gut funktionierten, waren andere Kollegen strikt dagegen. Deshalb beschloss man, zunächst verschiedene Modelle gelten zu lassen beziehungsweise einen Einfluss über die Notenvergabe auszuüben ${ }^{59}$. Einen Monat später kam aber die Diskussion über das signal wieder auf, und zwei Lehrer berichteten, dass diese Methode gut funktioniere ${ }^{60}$. Eine endgültige Entscheidung traf das Kollegium aber nicht. Diese Episode warnt einmal mehr davor, ein zu einheitliches und geschlossenes Bild der Allmacht der französischen Schulen zu zeichnen.

Die Bedeutung der französischen Sprache in den Einrichtungen lässt sich außerdem an der Anzahl der Stunden, die ihr dort zustand, messen: Auch wenn für die Anfangsjahre nur sehr lückenhafte Zahlen vorliegen, war die Anzahl der Französischstunden mit ungefähr acht Wochenstunden in allen

57 Vgl. Colonna 1997. Interessanterweise hat Michel Foucault in seiner Analyse der Schule der Frères des écoles chrétiennes in Frankreich im 19. Jahrhundert auch das »signal« als Disziplinierungsmaßnahme erwähnt, das aber nicht dieselbe Erscheinung hatte wie das hier beschriebene Objekt. Vgl. Foucault 1975, S. 195.

58 Vgl. AN/Paris, 60 AJ 124, »Rapports mensuels«, 27.10.1923.

59 Vgl. ebd.

60 Vgl. AN/Paris, 60 AJ 125, »Rapports mensuels«, November 1923. 
französischen Institutionen sehr hoch ${ }^{61}$. Das bedeutet, dass die Sprache auch quantitativ wie in einer Schule in Frankreich gelehrt wurde und nicht den Status einer Fremdsprache hatte.

Trotzdem musste die Sprache systematisch in den Schulen gelehrt werden. Schließlich sprachen nicht alle libanesischen Kinder Französisch in ihren Familien. Viele Bücher wurden aus Frankreich importiert, aber gerade für das Erlernen der Grammatik waren diese oft zu schwer oder ungeeignet. Aus diesem Grunde entwickelten die französischen Schulen auch selbst Methoden und Lehrinhalte. Die katholischen Orden, seit Jahrzehnten mit diesem Problem konfrontiert, hatten schon in früheren Zeiten eigene Bücher geschrieben ${ }^{62}$, zu Beginn des Mandats kamen noch einige neue hinzu. Speziell die Grammatiken sind ein interessantes Beispiel für die partielle Anpassung an den libanesischen Kontext: während die Regeln der französischen Grammatik wie in Frankreich erklärt wurden, stammten die Beispiele aus dem Umfeld der Schüler. So lautete ein Diktat aus der Petite Grammaire française, die der libanesische katholische Pfarrer Joseph Sfeir verfasst hatte: »Mon ami Eli demeure à Beyrouth en hiver avec son père Simon et sa mère Edma. En été, quelquefois, il fait avec sa sœur Alice une promenade à Bikfaïa et Chouaïr pour passer quelques semaines ${ }^{63}$. Neben den anderen Anpassungen in dieser Grammatik verwendete der Autor fast ausschließlich christliche Namen und viele Orte mit einer christlichen Mehrheit und zeichnete so eindeutig das Bild eines christlichen Libanons.

Die Mission laïque verfügte zu Beginn der 1920er Jahre noch nicht über solche Lehrmittel. Sie verwendete Bücher aus Frankreich und ließ sich darüber hinaus von den diversen pädagogischen Methoden der Zeit inspirieren, im Besonderen von der méthode directe $e^{64}$. Diese bestand darin, dass die Schüler nicht erst die Grammatik der Fremdsprache erlernten, sondern direkt zu sprechen begannen. Diese Methode, die in Europa entworfen, aber maßgeblich in den Kolonien eingesetzt und weiterentwickelt wurde ${ }^{65}$, entsprach auch dem Vorschlag des Hochkommissariats zu Beginn des Man-

61 Vgl. AN/Paris, 60 AJ 124, Brief von Mathieu an Besnard, Beirut, April 1922.

62 Am aktivsten waren hier wieder die Jesuiten. Siehe zum Beispiel das Schulbuch von Calmette, Cours complet de langue française, das in dem ordenseigenen Verlag »L'école (Rue des S.S. Pères)« erschien. Vgl. SJ/Vanves, »Fonds Jalabert«, 3-1 F.

63 Joseph Sfeir, Petite Grammaire française. Règles, Exercices, Analyses, Vocabulaires, Conjugaisons etc. Destinée spécialement aux enfants du Grand-Liban et de la Syrie, Beirut 1937, S. 12 .

64 Dafür verwendeten die Lehrer unter anderem das Buch »Deuxième année de Méthode Schweitzer, méthode directe pour l'enseignement de la langue françaises aux étrangères« von Joliet, das in Paris bei Colin erschien. Vgl. AN/Paris, 60 AJ 122, »Commande 1919-1920«.

65 Vgl. Pierre Singaravélou, Aux origines coloniales de la francophonie. Le rôle pionnier des associations et des sociétés savantes, in: Sylvie Guillaume (Hg.), Les associations dans la francophonie, Pessac 2006, S. 63-74, S. 73. 
dats: Die méthode directe habe sich als effektivstes Mittel erwiesen, um die Schüler schnell zur Konversation zu bringen und am Unterricht teilhaben zu lassen $^{66}$.

Das Gewicht der französischen Sprache wurde noch dadurch erhöht, dass außer arabischer Literatur, Geschichte und Geographie ${ }^{67}$ alle Fächer in französischer Sprache unterrichtet wurden. Die Dominanz der französischen Sprache manifestierte sich darüber hinaus in der französischen Literatur, die in den Schulen gelehrt wurde. Die libanesischen Schüler lasen und interpretierten dieselben französischen Klassiker wie ihre Altersgenossen in Frankreich. Auf dem vom Hochkommissariat ausgegebenen Curriculum standen:

La Fontaine: Fables. Fénelon: Fables. Buffon: Description d'Animaux. Corneille: Le Cid. Molière: Le Bourgeois Gentilhomme. Racine: Esther. Corneille: Horace. Molière: Les Femmes savantes. Racine: Les Plaideurs. Victor Hugo: Le mariage de Roland/ Aymerillo. Alphonse Daudet: Lettres de mon Moulin. Corneille: Cinna. Molière: L'Avare. Racine: Athalie. George Sand: La Mare au Diable. Michelet: Jeanne d'Arc. Théodore de Banville: Gringoire ${ }^{68}$.

Es ist interessant zu beobachten, dass es zwischen den französischen Schulen im Rahmen der ihnen gelassenen Freiheiten für die Auswahl der Werke auch Unterschiede gab. Abgesehen von den Autoren und Werken, die durch die Prüfungen in Frankreich vorgegeben waren, zogen die verschiedenen Schulen bestimmte Autoren und Strömungen vor und gaben damit auch ein politisches Statement ab. Das zeigte sich auch in den unterschiedlichen Schulbüchern und Verlagen, derer sich die Schulen bedienten. So legten die katholischen Schulen, insbesondere die Jesuiten, viel Wert auf die Autoren der Klassik, also des 17. und 18. Jahrhunderts, und vernachlässigten die Literatur der Romantik und Moderne des 19. und 20. Jahrhunderts. Diese Sichtweise fanden die Schüler in den Schulbüchern aus katholischen oder der Kirche nahe stehenden Schulbüchern, welche die katholischen Schulen verwendeten, wieder ${ }^{69}$. So urteilte Jean Calvet in seinen Morceaux choisis des auteurs français $d u X^{\mathrm{e}}$ au $X X^{\mathrm{e}}$ siècle über den romantischen Schriftsteller Victor Hugo eindeutig herablassend, dieser habe sich mit einer gewissen Blasiertheit für den Revolutionär der Poesie gehalten. Außerdem habe Hugo

$66 \mathrm{MAE} /$ Nantes, IP, 02, »Programmes«.

67 Laut Vorschrift fanden diese auf Arabisch statt, allerdings ist hier auch nach dem Unterschied zwischen Ideal und Realität zu fragen.

$68 \mathrm{MAE} /$ Nantes, IP, 02, »Programmes«, »Baccalauréat franco-syrien«, »Langue française«.

69 Die Jesuiten verwendeten viele Schulbücher des katholischen Verlages Vitte aus Lyon. Vgl. SJ/Vanves, »Fonds Jalabert«, 3-1 F. Über weitere Werke, die im Libanon während der Mandatszeit verwendet wurden, gibt eine Sammlung von ca. 15 Schulbüchern Auskunft, die aus einem Antiquariat in Beirut stammen und oft noch den Namen des Schülers beinhalten, der sie benutzte. 
hehre philosophische Ansprüche gehabt, sein System reduziere sich allerdings letztlich auf eine vage Fortschrittsreligion ${ }^{70}$. Ein Schulbuch der Littérature française aus dem religiösen Verlag Beauchesne setzte die Romantiker sogar mit Barbaren gleich ${ }^{71}$.

An der Mission laïque hingegen wurde die Literatur Victor Hugos unterrichtet $^{72}$. Aus diesem Grund kann das Urteil Daniel Panzacs über Victor Hugo als "un des auteurs les plus étudiés au Proche-Orient entre 1880 et 1930« für die Schulen nur begrenzt aufrechterhalten werden ${ }^{73}$. Ähnlich negativ urteilten die katholisch geprägten Schulbücher über Rousseau ${ }^{74}$, Voltaire ${ }^{75}$ und andere Vertreter einer rationalen und kirchenkritischen Strömung. Positiv urteilten sie hingegen über nationalistische Autoren wie Charles Maurras, den Ideengeber der royalistischen Action française ${ }^{76}$.

Die Präferenz der katholischen Schulen im Libanon für die klassischen Autoren und in der modernen Literatur für die katholischen und nationalistischen Schriftsteller lässt sich besonders deutlich an einer Schulzeitschrift der Frères des Écoles chrétiennes in Beirut festmachen. Die Publikation mit dem Namen L'Essor (»Der Aufschwung«) war Jeanne d'Arc gewidmet: »À Sainte Jeanne d'Arc: Noble Fille de France, Martyre de la Patrie, Gloire et modèle de la Jeunesse « ${ }^{77}$. Die Figur Jeanne d'Arcs war in der französischen Dritten Republik eine von allen politischen Lagern benutzte Identifikationsfigur. Nach ihrer Kanonisierung durch den Papst 1920 diente sie vor allem der katholischen Rechten als ideale Repräsentation eines christlichen Nationalismus $^{78}$, welche die Frères durch die Namensgebung unterstrichen. Es ist schwierig herauszufinden, welche Artikel von den Lehrern und welche von

70 Jean Calvet, Morceaux choisis des auteurs français du $\mathrm{X}^{\mathrm{e}}$ au XX $\mathrm{X}$ siècle, Classes de $3^{\mathrm{e}}, 2^{\mathrm{e}}$, et $1^{\mathrm{èr}}$, Nouvelle édition, Paris 1920/1935, S. 70: »Victor Hugo [...] prétendait avoir fait dans la poésie une révolution totale; il s'étend sur ce sujet avec emphase et avec quelque fatuité.«; S. 702: »Victor Hugo a de grandes prétentions philosophiques. Son systéme se ramène à une vague religion de progrès $[\ldots] \ll$.

71 Über Maurice Barrès heißt es nämlich: »Il est alors sous l'influence des »barbares, c'est-àdire des romantiques [...]«. Vgl. La littérature française par A. de Parvillez et M. Moncarey. Manuel pour la préparation au baccalauréat et aux divers Examens, Sixième édition, Paris 1922, S. 1207.

72 Vgl. AN/Paris, 60 AJ 125, Brief von Mathieu an Besnard, Beirut, 06.03.1923.

73 Vgl. Daniel PAnZAC, Révolution française et méditerranée musulmane. Deux siècles d'ambiguïté, in: Revue du monde musulman et de la Méditerranée 52 (1989), H. 2-3, S. 11-17, S. 13.

74 Vgl. Jean CAlvet, Manuel illustré d'histoire de la littérature française, Paris: J. de Girord Éditeurs, 1934, S. 549: »Rousseau est un déséquilibré. [...] Enfin ce déséquilibre, après avoir été la cause de bien des excentricités, tourna à la folie«.

75 Allerdings erkennt Calvet, bei allen Fehlern Voltaires, dessen »style qui fut si éminiment français« voller Stolz an. Vgl. CALvet 1934, S. 516.

76 Über ihn schrieb CALvET 1920/1935, S. 970: „C'est un penseur et un artiste, très écouté et très lu de la jeune génération«.

77 FEC, L'Essor. Bulletin de l'Académie de Jeanne d'Arc, März 1921.

78 Vgl. Michel Winock, Jeanne d'Arc, in: Pierre Nora (Hg.), Les lieux de mémoire, Bd. III: Les France, Paris 1992, S. 675-733, S. 700. 
den Schülern verfasst wurden, sicher ist aber, dass sie allesamt nur mit dem Einverständnis der Schulleitung veröffentlicht wurden. Zusätzlich zur Huldigung klassischer Autoren wie La Fontaine ${ }^{79}$ und Molière ${ }^{80}$ wurde der Theaterautor Edmond Rostand positiv dargestellt als ein Schriftsteller, den viele der Romantik vorzögen ${ }^{81}$. Aus dem 20. Jahrhundert wurden vor allem die nationalistischen Autoren Maurice Barrès ${ }^{82}$ und Henry Bordeaux ${ }^{83}$ für ihren Kampf für Religion und Vaterland gelobt ${ }^{84}$.

Interessanterweise veränderte sich die Perspektive Anfang der 1930er Jahre etwas, als die Zeitschrift auch »subversive« Autoren wie den Kritiker des Christentums Charles Baudelaire thematisierte. Allerdings betonte der Artikel der Schülerzeitschrift über Baudelaire, der Autor werde von vielen verurteilt, aber man dürfte nicht vergessen, wie sehr er in seinem Leben gelitten habe ${ }^{85}$. Dieser Interpretation haftet wegen der proklamierten christlichen Nächstenliebe etwas Überhebliches an, das Urteil fällt aber angesichts von Baudelaires Kritik am Christentum sehr milde aus. In ähnlicher Perspektive beschrieb dieselbe Zeitschrift 1931 die Biographie Paul Verlaines, der sich am Ende seines Lebens mit Christus versöhnt habe ${ }^{86}$. Auch wenn die anderen katholischen Schulen eine ähnliche Vision der französischen Literatur präsentierten, wurde in den Schulzeitschriften das nationalistische Element weniger stark betont als in dieser Einrichtung.

In den jüdischen, laizistischen und protestantischen Einrichtungen wurden dieselben französischen Klassiker gelesen wie in den katholischen französischen Schulen ${ }^{87}$. Überall mussten sich die Schüler durch die klassische Lektüre auf die Prüfungen vorbereiten. Besonders bezüglich der französi-

79 Vgl. FEC, L'Essor, Juli 1922, S. 29-31: »Un temple à La Fontaine«. Als Autor unterzeichnete Charles Kettaneh, höchstwahrscheinlich ein libanesischer Schüler.

80 Vgl. FEC, L'Essor, Juli 1922, S. 33-37: »Le Tricentenaire de Molière«. Der Autor wurde mit »Un membre d'honneur« bezeichnet.

81 Vgl. FEC, L’Essor, Juli 1927, S. 95-103, »Le théâtre de Rostand« (Autor M.N.).

82 Vgl. FEC, L'Essor, Februar 1924, S. 31-34: »Maurice Barrès« (ohne Autor). Allerdings bemerkt der Autor auch, Barrès habe einige unkorrigierbare Fehler gemacht. $\mathrm{Zu}$ den vielen verschiedenen Phasen Barrès' und seiner Perzeption in Frankreich und im Libanon vgl. Heyberger 2008, S. 50-52.

83 Vgl. FEC, L’Essor, Januar 1926, S. 54-59: »L'Orient dans la littérature française« von Marcel Noël. Es wird nicht klar, ob es sich bei diesem Autor, der an der Schule in Beirut als Lehrer oder Schüler tätig war, um den Schriftsteller handelt, der in Frankreich ein Vertreter der katholischen Rechten war.

84 Sicherlich bedingt durch die Verurteilung der Action française durch die katholische Kirche 1926 tauchte Charles Maurras zwar in der Zeitschrift nicht auf, aber dafür ihm nahe stehende Autoren. Vgl. Michel Winock, Le siècle des intellectuels, Paris 1999, S. 235.

85 FEC, L'Essor, Februar 1930, S.48-53.

86 FEC, L'Essor, Februar 1931, S. 93-101, S. 101. Der Artikel mit dem Titel »Paul Verlaine« wurde mit dem Pseudonym »Amicus« unterzeichnet.

87 Für die Mission laïque vgl. AN/Paris, 60 AJ 128, »Réunion des Professeurs«, Sitzung vom 15. März 1926. Die Lehrer beschlossen, dass ein Buch mit den Fabeln von La Fontaine für die Schüler der »Troisième« passend sei. 
schen Werke, die den Orient behandelten, gab es große Überschneidungen zwischen den Schulen, beispielsweise behandelten sie alle die Werke Lamartines $^{88}$. Das bedeutet, dass die in Frankreich verbreitete Wahrnehmung des Orients in den unterschiedlichen politischen Lagern auch in den französischen Institutionen im Libanon zirkulierte ${ }^{89}$.

Jedoch zeigten die nicht-katholischen Einrichtungen, vor allem die laizistischen und jüdischen Schulen, auch eine größere Tendenz zu religionskritischen und republikanischen Autoren und Werken. Das zeigte sich zum einen in der Verwendung von Material der französischen Schulbuchverlage, die die staatlichen Schulen der Dritten Republik belieferten, welches die Alliance israélite und die Mission lä̈que regelmäßig in Frankreich bestellten ${ }^{90}$. Darüber hinaus behandelte die Mission laïque auch religionskritische Werke wie Candide von Voltaire ${ }^{11}$. Außerdem bemängelten die Lehrer der laizistischen Schule, dass bei den Abschlussprüfungen das 18. und 19. Jahrhundert zu kurz kämen, das heißt, sie warfen den Prüfern, von denen viele aus dem katholischen Milieu kamen, vor, der Literatur der Aufklärung und der Romantik nicht genügend Bedeutung zu verschaffen ${ }^{92}$.

Die libanesischen Eltern und Partner der Schulen reagierten sehr unterschiedlich auf die Dominanz des französischen Literaturkanons. In dieser disparaten Rezeption liegt meiner Meinung nach der große Unterschied zwischen dem Libanon und anderen Regionen unter kolonialem französischem Einfluss. Grob vereinfacht verlief die Grenze vor allem konfessionell, also nicht zwischen Christen und Nicht-Christen, sondern zwischen sehr positiv eingestellten Maroniten und kritischeren Nicht-Maroniten. Frankophone katholische Autoren wie der schon erwähnte Charles Corm oder Georges Schéhadé, beide ehemalige Schüler katholischer Schulen, hoben die Vorbildfunktion der französischen Sprache und Schriftsteller für ihr Werk hervor ${ }^{93}$. Die Gedichte von Corm wurden auch in den Schulzeitschriften der Jesuiten, seiner ehemaligen Lehrer, abgedruck ${ }^{94}$. Außerdem berichtete Georges Schéhadé sehr positiv über den Bezug der Schüler der Frères des écoles chrétiennes auf Lamartine ${ }^{95}$. Auch in den geführten Interviews betonten viele

88 Vgl. FEC, L'Essor, Januar 1926, S. 54-59; MLF/Paris, 60 AJ 133, Liste der bestellten Bücher.

89 Vgl. Kapitel 1.1 und Kapitel 2.1.

90 Beispielsweise bestellte Direktor Penso von der Alliance israélite seine Bücher 1919 bei den Verlagen A. Colin et Cie, Gedalge et Cie, Ch. Delagrave und Delalain. Vgl. AIU/Paris, »Liban VIE 81«, Brief von Penso an den Präsidenten der Alliance israélite in Paris, Beirut, 01.08.1919. Auch Direktor Deschamps von der Mission laïque bestellte seine Bücher vor allem bei den Verlagen Colin und Hachtette. Vgl. MLF/Paris, 60 AJ 122, »Commande 1919-1920«.

91 Vgl. MLF/Paris, 60 AJ 128, »Réunion des Professeurs«, Sitzung vom 29. Januar 1926.

92 Vgl. ebd., Sitzung vom 20. November 1925.

93 So benannte Charles Corm sein Werk La Montagne inspirée nach dem Buch von Maurice Barrès, La Colline inspirée. Vgl. Kaufman 2001, S. 184.

94 Vgl. NDJ, L'U, Juni 1934, »L'Alphabet«.

95 Vgl. FEC, L'Essor, 1923, S. 11-14: »Séance de Réception«. 
ehemalige Schüler, dass die französische Sprache bis heute für sie positiv konnotiert sei ${ }^{96} .1927$ ging der Direktor der pro-französischen Beiruter Zeitung L'Orient sogar so weit, von Frankreich als »une culture, une civilisation, un idéal humain« zu sprechen, welche selbst dann existieren würden, wenn Frankreich als Staat verschwände ${ }^{97}$. Diese Überhöhung Frankreichs und die Tendenz zur Trennung zwischen Frankreich und der französischen Sprache, die hier positiv für Frankreich gedeutet wurde, fand sich auch in anderen kolonialen Kontexten wieder, allerdings oft in einer Frankreich gegenüber kritischen Art und Weise ${ }^{98}$. Den arabischen Nationalisten warf die Beiruter Zeitung zur selben Zeit vor, die westliche Kultur nur oberflächlich assimiliert, zu ihren Zwecken genutzt und dann als angeblich tyrannisch denunziert zu haben:

[...] cette prétendue élite [...]. N'ayant assimilé que très imparfaitement les méthodes et la culture occidentale, et pleine d'orgueil et de suffisance, elle croit tout savoir et tout prévoir. Elle a formé la classe des agitateurs. Éduqués dans les universités européennes et imbus d'idées égalitaires, ces agitateurs ont commencé par dénoncer cette prétendue de l'occidental ${ }^{99}$.

Dieser Artikel ist deshalb so interessant, weil er den Vorwurf des tafarnuğ, also der »rein äußerlichen Imitation der Europäer $\aleph^{100}$, welcher im 19. und 20. Jahrhundert stark frankophonen und frankophilen Arabern von ihren Landsleuten gemacht wurde, in gewisser Weise umdreht. Dieser Vorwurf wurde vor allem von den Verfechtern einer autochthonen Kultur vorgebracht, in der Regel arabisch nationalistisch geprägte Intellektuelle, die Übernahme der französischen Kultur und Sprache als Angriff auf ihre arabische Identität wahrnahmen ${ }^{101}$. Der zitierte Artikel des Libanesen hingegen verteidigte

96 Vgl. Interview der Verfasserin mit Victor Hachem, Beirut, 25.11.2008.

97 L'Orient, 20.04.1927, S. 1: »Les titres de la France. Discours prononcé par le Directeur de L'Orient à la réception officielle du Haut-Commissaire à l'Archevêché grec-catholique«.

98 So hat Miller für die Alliance israélite in Nordafrika herausgearbeitet: „To French language and culture, many said yes; but to the nation of France and the French people, it was a definite No.«. MilLeR 1996, S. 250.

99 Vgl. L'Orient, 21. und 22. 02.1926: »La Nouvelle Face de l’Orient« (ohne Autor).

$100 \mathrm{Zu}$ Definition und Herkunft des Begriffes siehe Rotraud Wielandt, Das Bild der Europäer in der modernen arabischen Erzähl- und Theaterliteratur, Wiesbaden 1980, S. 131, 193.

101 Vgl. HadDAD 2002, S. 29, der über seinen arabisch-nationalistisch eingestellten Vater berichtet: »Musulman pratiquant et arabe pur-sang, mon père, emporté par la politique nationaliste qui régnait à cette époque dans toute la ville de Tripoli, n'était pas très enthousiaste pour cette >francisation= tafarnos $<$ de son fils, sinon il la considérait non seulement comme une perte de temps, mais plutôt et surtout comme une atteinte à l'arabité. En effet, la génération de mon père avait vécu la colonisation comme étant un conflit de valeurs dont l'enjeu était la désintégration pure et simple des valeurs arabes par le double processus de l'assimilation et de la francisation, lequel trouvait dans la langue français son terrain d'élection«. 
die französische Sprache und Kultur gegen deren Ausnutzung durch andere Libanesen. Über die katholischen frankophonen Libanesen hinaus gab es aber auch ehemalige Schüler der Mission lä̈que, die, obwohl sie später auf Arabisch publizierten, in ihren Werken die französische Sprache positiv beurteilten, wie zum Beispiel Khalil Taqi ad-Din ${ }^{102}$. Dieser Druse aus dem Gebirge des Chouf, einer Gegend, in der traditionell viele Drusen lebten, war in den 1920er Jahren ${ }^{103}$ Schüler der Mission laïque in Beirut gewesen. Taqi ad-Din gehörte damit nicht zu den etablierten Beiruter Notabeln, die die Mehrheit der libanesischen Partner der Mission lä̈que ausmachten; sein Vater, Šayh Mạ̣mūd Taqī ad-Dīn, war ein unabhängiger Politiker und Intellektueller ${ }^{104}$. Nach seinem Abschluss studierte Khalil Jura an der Université Saint-Joseph in Beirut und arbeitete danach kurz als Lehrer an der französischen Schule der amerikanischen Universität, bevor er in die Politik einstieg: zunächst war er im Erziehungsministerium, später im diplomatischen Dienst tätig. Gleichzeitig wurde er ein sehr bekannter Schriftsteller ${ }^{105}$.

Den sehr positiven Stimmen gegenüber kritisierte der ehemalige griechisch-orthodoxe Bischof von Byblos Georges Khodr die Überhöhung der französischen Sprache durch die französischen Mönche, deren Schule er besucht hatte. Die Klarheit, die andere am Französischen rühmten, beschreibt er in seinen Memoiren als uninspirierend und zu offensichtlich:

Ils croyaient ferme en la prééminence de la clarté et n'hésitaient pas à persécuter leurs élèves pour les gagner à cette cause. Leur langage, évitant labyrinthes et méandres, ignorant les images, refusait tout déferlement et se répandait comme les rayons d'un soleil de fin de printemps ${ }^{106}$.

Diese deutliche Distanzierung lässt sich über die persönliche Empfindung des Autors hinaus auch mit der größeren Nähe zur arabischen Sprache erklären, die die griechisch-orthodoxe Gemeinschaft im Libanon im Gegensatz zu den Maroniten pflegte ${ }^{107}$. In der Tat empfanden viele Schüler die französi-

102 Amaya Martin Fernandez, National, linguistic, and religious identity of Lebanese Maronite Christians through their Arabic fictional texts during the period of the French mandate in Lebanon, Diss. Washington/D.C. 2009, S. 227.

103 Er hatte im Schuljahr 1925-1926 seinen Abschluss gemacht. Vgl. AN/Paris, 60 AJ 130, »Amicale des Anciens élèves«, Mai 1928.

104 Vgl. QABaȚī 2006, S. 7.

105 Vgl. M.T. Amyuni, Eintrag »Taqi al-Din Khalil (1906-87)«, in: Paul Starkey/Julie Scott MeiSAMI (Hg.), Encyclopedia of Arabic Literature, London 1998, Bd. 2, S. 758.

106 Georges KHodr, Et si je disais les chemins de mon enfance. Introduction de Maxime Eggerer, Paris 1997, S. 50.

107 Vgl. Bernard Heyberger, Chrétiens du monde arabe. Un archipel en terre d'islam, Paris 2003, S. 11. 
sche Literatur, die ihrem soziokulturellen Kontext nicht entsprach, als »alien to our traditional way of doing and thinking $\ll^{108}$.

In den Schulen selber kam es auch zu heftigeren Reaktionen. So weigerte sich 1923 ein Schüler der Mission lä̈que, ein Gedicht von Victor Hugo aufzusagen $^{109}$. Die Schüler nutzten die französische Literatur aber auch zu subversiven Zwecken: beispielsweise nahm Taqi ad-Din as-Sulh, ein Schüler der Mission laïque, der 1930 anlässlich der Feier der Märtyrer in Beirut eine Rede hielt, auf französische Werke Bezug, um das Mandatssystem zu kritisieren ${ }^{110}$.

Die Schüler spiegelten damit die Haltung der erwachsenen Kritiker des Mandats in Syrien und Libanon wider, die von der französischen Literatur beeinflusst waren. Im Gegensatz zu den Verteidigern der französischen Präsenz, die Autoren der Klassik als ihre Referenz benutzten, machten sich die Nationalisten die Schriftsteller der Französischen Revolution und der Romantik zu Eigen ${ }^{111}$. Die Vertreter der Mission laïque betonten diesen Umstand, um ihre Organisation im Gegensatz zu den katholischen Orden als Partner der arabischen Nationalisten zu etablieren ${ }^{112}$.

Die dargestellten Positionen illustrieren die Ambivalenz, die die mission civilisatrice der Schulen im Libanon, aber auch in anderen kolonialen Regionen Frankreichs in sich trug: die Lehrer lehrten eine Literatur, die auf den Prinzipien der Selbstbestimmung beruhte, aber waren Teil eines quasi-kolonialen Regimes, das die Selbstbestimmung der Libanesen und Syrer untersagte. Gerade diese Literatur aber wurde für viele arabische Nationalisten auch zur Inspiration ihres Aufstandes gegen die französischen Machthaber ${ }^{113}$. Das Phänomen ist aus anderen kolonialen Kontexten bekannt, in denen die indigenen Intellektuellen sich sowohl von der Literatur der Kolonialmacht inspirieren ließen als auch deren ambivalente Position kritisierten ${ }^{114}$.

108 Naim Atiyen, The Development of Education in Lebanon, in: Beirut College for Women (Hg.), Cultural Resources in Lebanon, Beirut 1969, S. 198-215, S. 199.

109 Vgl. AN/Paris, 60 AJ 125 Brief von Mathieu an Besnard, Beirut, 06.03.1923.

110 Vgl. AN/Paris, 60 AJ 132, Brief von Ruche an Besnard, Beirut, 29.05.1930.

111 Vgl. Schumann 2001, S. 220.

112 Édouard Herriot, Le centenaire de Lamartine, in: Revue de l'enseignement français hors de France 17 (1920), 1.

113 Beispielsweise haben sich die Aufständischen der syrischen Revolte gegen das Mandat 1925 der Ideen der Revolution in einer radikalisierten Weise bedient. Vgl. Lenka BokovA, La révolution française dans le discours de l'insurrection syrienne contre le mandat français (19251927), in: Revue du monde musulman et de la Méditerranée 52 (1989), H. 2-3, S. 207-217.

114 Vgl. die Arbeiten des Schriftstellers und Politikers Frantz Fanon aus der Martinique, z.B. Peau noire, masques blancs, Paris 1952. Bezüglich der Einsicht Fanons, dass die ehemaligen Kolonien nie gänzlich unabhängig vom Westen sein würden, vgl. auch SAID 1994, S. 20. 


\section{Arabischunterricht als Gratwanderung: Ignoranz oder nationales Bewusstsein?}

Die Position der arabischen Sprache in den französischen Schulen unterschied sich von der der französischen in vielerlei Hinsicht. Von einer bestimmten Gruppe von Eltern aus Fragen der Identität und der sozialen Distinktion sehr gefordert, von andern Eltern und Partnern und vom Hochkommissariat gering geschätzt, lavierten die französischen Schulen zwischen Ignoranz und dem Versuch, der arabischen Sprache einen zentralen Platz als Ausdruck des nationalen Bewusstseins zukommen zu lassen.

Im Gegensatz zur französischen Sprache gingen die Initiativen bezüglich der arabischen Sprache in den Schulen keineswegs von der französischen Regierung oder dem Hochkommissariat aus. Die Tatsache, dass nur wenige Funktionäre diese Sprache beherrschten ${ }^{115}$, war dabei nicht der ausschlaggebende Grund. Die Mandatsmacht maß ihr vielmehr keine Bedeutung bei, erkannte aber aus politischen Gründen die Notwendigkeit an, sie zu unterrichten. »Les jeunes gens ignorent presque l'arabe littéraire«, stellte der Kultusbeauftragte Jeantry zu Beginn des Mandats fest und folgerte daraus: "L'Enseignement de l'arabe doit être obligatoire dans nos écoles au même titre que le français $\aleph^{116}$. In der Folge beinhalteten die Berichte der Inspektoren immer eine Bemerkung zum Arabischunterricht aller besichtigten Schu$\mathrm{len}^{117}$. Zudem sollten die arabischen Lehrer in den staatlichen Grundschulen 25 Stunden unterrichten, im Gegensatz zu den französischen Lehrern, denen 10 Stunden zugedacht wurden ${ }^{118}$.

Der Einblick in die Praxis anhand des Schülerhefts einer staatlichen Beiruter Schule relativiert diese Vorgaben: Das wertvolle Dokument aus dem Schuljahr 1942-43 listet die arabische Sprache zwar an erster Stelle auf und zählt zu den acht dazugehörigen Fächern auch den Religions- und Moralunterricht, ordnet der französischen Sprache aber auch sechs Untersektionen $\mathrm{zu}^{119}$. Damit unterschied sich die Situation im Libanon nur gering von der in

115 Das zeigt die Tatsache, dass die Kenntnis des Arabischen nie als Einstellungsvoraussetzung genannt wurde und dass das Hochkommissariat 1925 interne Arabischkurse anbot. Der Lehrer war Jean Lecerf, der später als Lehrer bei der Mission laïque française in Beirut arbeitete. Vgl. MAE/Nantes, IP, 36: 1925, »Examens et concours divers«, Korrespondenz des Bildungsbeauftragten mit Direktor Ruche von der Mission laïque.

$116 \mathrm{SJ} /$ Beirut, 8.C.21, »Le conseiller pour l'Instruction Publique (Jeantry)«, ohne Datum (aber vor 1922).

117 Vgl. z. B. MAE/Nantes, IP, 69: 1929, »Rapports d'inspections«. Diese Tatsache legt den Schluss nahe, dass auch die französischen Inspektoren die arabische Sprache beherrschten oder einen Dolmetscher an ihrer Seite hatten.

118 MAE/Nantes, IP, 02, »Enseignement officiel, État du Grand Liban«, »Correspondance générale $\ll$.

119 Vgl. Notenheft von Afif Soubra an der madrasa ḥaụ̣ al-wilāya in Beirut: Zur arabischen Sprache gehörten Religionsunterricht (al-ta' līm ad-dīnī), Moral (al-aḩlāq), Aufsatz (al-inšàà), Dik- 
Algerien, wo die französischen Funktionäre ab 1920 den Stellenwert der arabischen Sprache sehr heruntergesetzt hatten, weil sie ein Erstarken des algerischen Nationalismus befürchteten ${ }^{120}$. Im Gegensatz zur Zeit vor dem Ersten Weltkrieg ${ }^{121}$ stellte Arabisch dort nun kein Abiturfach mehr dar, und auch die Herstellung von Lehrbüchern für Arabisch nahm ab.

Allerdings enthielten auch die Vorgaben des Hochkommissariats für die Abschlussprüfungen im Libanon nur wenige und sehr ungenaue Angaben zur arabischen Sprache, das heißt zu Grammatik und Literatur ${ }^{122}$. 1925 sollte nach Vorgaben des Bildungsministeriums im Gymnasium auch nur sechs beziehungsweise sieben Stunden im Gegensatz zu der ersten Fremdsprache mit sieben beziehungsweise neun und der zweiten Fremdsprache mit vier Stunden umfassen ${ }^{123}$. Die Tatsache, dass erst Ende der 1920er Jahre ein libanesisches Abitur entwickelt wurde, zeigt schließlich sehr deutlich, dass sich die Prüfungen und Abschlüsse bis dahin an den französischen Modellen orientierten, und diese waren für die arabische Sprache sehr vage und wenig entwickelt ${ }^{124}$.

Von zentraler Bedeutung für die Rolle der arabischen Sprache in den französischen Schulen waren vielmehr die Erwartungen der libanesischen Bevölkerung. Während die mehrheitlich katholischen Eltern der katholischen Institutionen in Einvernehmen mit diesen der arabischen Sprache in den meisten Fällen eine untergeordnete Rolle beimaß, bedeutete sie für den Großteil der Eltern der Mission laïque française sowohl einen wichtigen Bestandteil ihrer Identität als auch ihrer sozialen Distinktion. Eine Ausnahme stellten die Schulen der Jesuiten dar, weil viele der dortigen Lehrer und Pater in der Regel die arabische Sprache sehr gut beherrschten und auch in der literarischen Produktion sehr aktiv und für die Mandatszeit bestimmend waren. Allerdings war der Anteil des Arabischen in den Schulen des Ordens im Verhältnis dazu sehr gering. In vielen wohlhabenden katholischen libanesischen Familien wurde gar kein oder wenig Arabisch gesprochen ${ }^{125}$. Erst

tat (al-imlā’), Grammatik (al-qawā' id), Lesen (al-qirā’a), Sprechen (al-muḥādata), Schreiben (al-hațț). Die Fächer in französischer Sprache waren in Aufsatz (al-inšăà), Diktat (al-imlā'), Grammatik (al-qawā'id), Lesen (al-qirāa), Sprechen (al-muḥādata) und Schreiben (al-ḩațț) unterteilt.

$120 \mathrm{Vgl}$. Alain Messaoudi, The Teaching of Arabic in French Algeria and Contemporary France, in: French History 20 (2006), S. 297-317, S. 310-311.

121 Vgl. ebd., S. 306.

122 MAE/Nantes, IP, 02, »Note sur les écoles privées« (ca. 1919-1920).

123 Vgl. SJ/Beirut, 11.D.14, »Enseignement arabe«, Wizārat al-ma ārif al-'umūmīya, Ğadwal li-bayān hutț̣at ad-dirāsa li-t-ta līm at-tānawī [Bildungsministerium, Zeitplan zur Erläuterung des Unterrichtsplans in der Sekundarstufe]. Die Vorgaben des Ministeriums stammten vom Oktober 1925.

124 Vgl. Hanf 1969, S. 76-77.

125 Vgl. Helou 2002, S. 20; siehe auch Chamoun 1989, S. 32: »Je n'aimais pas et ne voulais pas apprendre l'arabe; aujourd'hui je le regrette«. 
später wurde der Sprache in diesem Milieu eine neue und größere Bedeutung beigemessen, was sich in der Rückschau mancher Zeitzeugen widerspiegelt $^{126}$. Zu Beginn des Mandats hingegen herrschte in vielen dieser Familien die Ansicht vor, Arabisch sei nur eine von außen, gleichzeitig mit dem Islam in den Libanon gebrachte Sprache, wie es ein Artikel der pro-französischen Zeitung L'Orient 1926 ausdrückte: »Contentons-nous de constater que l'arabe a été introduit dans ces pays, qu'il y a été imposé par l'envahisseur « ${ }^{127}$.

Allerdings gab es auch in den katholischen, frankophonen und frankophilen Gemeinschaften des Landes Familien oder Individuen, die die arabische Sprache sehr gut beherrschten, pflegten und propagierten. Innerhalb der maronitischen Gemeinschaft waren das zu diesem Zeitpunkt nur wenige, prominente Beispiele sind hier Said 'Aql (arabisch Sa'̄id 'Aql128, Ameen Rihani (arabisch Amīn ar-Rihānīī) ${ }^{129}$ und Bishara al-Khuri (arabisch Bišāra al-Hūrīi $)^{130}$. Innerhalb anderer katholischer und christlicher Gemeinschaften, insbesondere bei den Melkiten und Griechisch-Orthodoxen, gab es mehr Anhänger der arabischen Sprache. Sie knüpften an die Tradition der nahdaBewegung an, die, maßgeblich von arabischen Christen initiiert, die arabische Sprache reformieren, aber auch den Grundstein eines arabischen Nationalismus und einer gemeinsamen Basis von Muslimen und Nicht-Muslimen bilden sollte ${ }^{131}$. Prominente libanesische Vertreter dieser Bewegung waren im 19. Jahrhundert Buṭrus al-Bustān̄̄ und etwas später auch Ğūrŏī Zaydān ${ }^{132}$.

126 Vgl. Interview der Verfasserin mit Camille Héchaïmé, Beirut, 24.10.2008: Der Jesuit und ehemalige Schüler einer Jesuitenschule betonte, dass in seiner Familie beide Sprachen immer dieselbe Bedeutung hatten. Auch in den Biographien libanesischer maronitischer Politiker wird deren Bilinguismus betont. Vgl. Lyne LoHÉAC, Daoud Ammoun et la création de l'état libanais, Paris 1978, S. 27: »Dans ces collèges chrétiens est enseigné, parallèlement à l'arabe, le français. Cela a permis à Daoud Ammoun de maîtriser les deux langues: il écrira avec la même aisance des poèmes et des articles en arabe, ou des discours et des rapports en français.«; vgl. auch Jacques NAntet, Pierre Gemayel, Paris 1986, S. 12: »Tel est le milieu profondément chrétien [...] déjà tourné vers la France et où on parle aussi bien le français que l'arabe, dans lequel s'épanouit à l'école du village le petit Pierre«.

127 L'Orient, 18.11.1926, S. 1: »Les Faits du Jour«.

128 Vgl. Kaufman 2004b, S. 18-19.

129 Vgl. Kassir 2003, S. 394.

130 Vgl. Traboulsi 2007, S. 93.

131 Vgl. Axel Havemann, Geschichte und Geschichtsschreibung im Libanon des 19. und 20. Jahrhunderts. Formen und Funktionen des historischen Selbstverständnisses, Würzburg 2002, S. 81; Anne-Laure Dupont, Être un arabe moderne au temps de la >renaissance $<$ in: Bernard Heyberger, Chrétiens du monde arabe. Un archipel en terre d'islam, Paris 2003, S. 85-104, S. 85 .

132 Vgl. Anne-Laure Dupont, Gurgi Zaydan 1861-1914. Écrivain réformiste et témoin de la Renaissance arabe, Damaskus 2006, S. 119: „L'éducation que Zaydan décrit dans son autobiographie ressemble à celle d'un jeune bourgeois français, anglais ou américain de l'époque. Pour notre auteur, elle marquait la restauration d'une éducation authentiquement arabe. Il voulait être un 'adib', c'est-à-dire un homme capable de parler et d'écrire en bon arabe littéraire, curieux du monde, respectueux des convenances sociales et de la morale«. 
Von relevanterer Bedeutung als Kommunikations- und Unterrichtssprache sowie für die religiöse Erziehung war die arabische Sprache für die Libanesen, deren Kinder sich in den Schulen der Mission lä̈que wiederfanden. Diese Eltern betonten die Bedeutung der arabischen Sprache entweder wegen ihrer zentralen Rolle für den arabischen Nationalismus ${ }^{133}$ oder als heilige Sprache des Islams, in welcher der Koran verfasst war ${ }^{134}$. Aus diesen Gründen erhielt die Mission laïque Forderungen der Eltern, sich dieser Sprache besonders zu widmen: "[...] ne négligez pas dans votre programme la langue arabe, langue des Syriens $\ll^{135}$. Das bedeutet, dass die arabische Sprache für diese libanesischen Milieus dieselbe Funktion erfüllte wie die französische Sprache für die katholischen, speziell maronitischen Gemeinschaften. Auch wenn bezüglich der arabischen Sprache zwischen dem Hocharabischen, der Sprache des Korans und der Literatur, und dem Dialekt, der von den Sprechern gesprochen wurde, unterschieden werden muss, werden beide Formen im Folgenden unter dem Begriff der arabischen Sprache subsumiert, weil sie von den hier untersuchten Akteuren gleich bewertet wurden. Während die muslimischen Kinder in ihrem Alltagsleben libanesischen Dialekt sprachen, erlernten sie im Koranunterricht das Hocharabische ${ }^{136}$.

Darüber hinaus hatte sich aber, speziell in Beirut, eine Kultur entwickelt, die in der arabischen Sprache vor allem ein Merkmal sozialer Distinktion sah. Den arabophonen Wissenschaftler und Lehrer der Mission laïque, Jean Lecerf, brachte dies 1933 zu der enttäuschten Feststellung, dass die arabische Sprache in Beirut zu einer »langue de luxe« der »représentants de l'aristocratie de l'esprit« verkomme, die ihre Kenntnisse in Reden und Debatten präsentierten, während man in Damaskus Arabisch lerne, um die Sprache wirklich zu benutzen ${ }^{137}$. In der Tat spielte die arabische Sprache im heutigen Syrien eine größere Rolle spielte als im Libanon, unter anderem weil die dominanten politischen Gruppierungen, die arabischen Nationalisten, dort stärker auf die arabische Sprache rekurrierten als hier, wo zumindest die Anhänger des Libanismus das Französische stark machten ${ }^{138}$. Trotzdem

133 Vgl. Leyla DakhLi, Arabisme, nationalisme arabe et identifications transnationales arabes au $20^{\mathrm{e}}$ siècle, in: Vingtième Siècle. Revue d'Histoire 103 (2009), S. 13-25, S. 15 (=DAKHLi 2009b).

134 Vgl. Kaufman 2004b, S. 18.

135 AN/Paris, 60 AJ 123, Brief Lehéricy an Besnard, Beirut, 05.10.1920: diesen Ausspruch der libanesischen Gönner der Schule, 'Arif Diab und 'Umar Da'uq, kommentierte der Generalsekretär mit »Très important« und Lehéricy ergänzte: »J'ai déclaré à ces Messieurs qu'il serait tenu le plus grand compte d'un désir aussi justifié«.

136 Vgl. Tibawi 1979, S. 24.

137 Jean LECERF, L'arabe contemporain comme langue de civilisation, in: Revue africaine 74 (1933), S. 269-295, S. 286.

138 Die Aussage von Antonius 1938, S. 373, über das Arabische als »sole medium of the national life« nach der Einführung der Mandate in Syrien und Libanon kann in dieser Ausschließlichkeit höchstens für Syrien gelten. 
gab es auch im Libanon der 1920er und 1930er Jahre Intellektuelle, denen die Reform und Adaption des Arabischen an die neuen Begebenheiten eine dringende Angelegenheit war ${ }^{139}$.

Die meisten Eltern der Alliance israélite hingegen legten in dieser Zeit keinen Wert darauf, dass ihre Kinder die arabische Sprache erlernten. Der französische Hochkommissar betonte zwar 1922, dass die jüdischen Schulen unbedingt Französisch und Arabisch lehren sollten ${ }^{140}$, aber die Archive lassen zu Beginn des Mandats nur geringe Bemühungen des Personals erkennen, dies zu realisieren. Weder politisch noch religiös hatte diese Sprache Relevanz für die Gemeinschaft, die noch bis vor kurzem als Amtssprache das Osmanische gekannt hatte und für deren religiöse und kulturelle Identität das Hebräische langsam immer wichtiger wurde. So führte der Präsident der Alliance israélite 1932 in Paris aus: »Le français et l'hébreu, étroitement associés pour rendre au monde juif de l'Orient sa dignité compromise [...] $\ll^{141}$.

Die französischen Schulen versuchten, den formulierten Forderungen der Eltern gerecht zu werden. Während die Mission lä̈que der arabischen Sprache ganz eindeutig wegen der Forderungen ihrer Klientel einen besonderen Platz gab, reagierten die katholischen Schulen mit ihrer geringen Wertschätzung des Arabischen nicht nur auf die Erwartungen der Bevölkerung, sondern spiegelten darin auch ihre eigene Bewertung dieser Sprache für die Ausbildung der jungen Libanesen. Sie teilten ihren Standpunkt mit den Schulen der Alliance israélite. Interessanterweise, so wird dieser Abschnitt über die Praxis der Schulen zeigen, waren einige katholische Schulen aber in mancher Hinsicht besser ausgerüstet für den Arabischunterricht als die Mission lä̈que.

$\mathrm{Zu}$ Beginn des Mandats also betonte die Mission laïque den Platz der arabischen Sprache in ihrer Schule sehr viel stärker als die katholischen Schulen. So erklärte Direktor Mathieu 1922 das "principe d'égalité des deux langues $\aleph^{142}$. Erst zwanzig Jahre später fand sich ein solcher Satz in den Dokumenten der Jesuiten ${ }^{143} .1924$ hieß es dagegen in dem Schulprospekt der Université Saint-Joseph:

139 Vgl. Kaufman 2004a, S. 169-183; Dakhli 2009a, S. 293-300. Dakhli zeigt allerdings auch, dass die 1920er und 1930er Jahre nicht von großen und engagierten Debatten innerhalb der syrischen und libanesischen Intellektuellen geprägt war, deren Enthusiasmus und Vertrauen in die Zukunft einer skeptischeren Haltung gewichen war.

140 AIU/Paris, Brief des Großrabbiners des Grand Liban, Tagger, an den Großrabbiner von Paris, Lévy, Beirut, 20.12.1922: »Après que ladite ville a été annexée au Grand Liban, le gouvernement mandataire a fait remarquer que les enfants du pays ont besoin des langues françaises et arabes plus qu'une autre«.

141 AIU/Paris, Paix et Droit, 6/Juni 1932, S. 8-12: A.H. Navon, „L'École Normale Israélite Universelle (1867-1932)«, S. 8.

142 AN/Paris, 60 AJ 124, »Rapports sur professeurs étrangers«, Brief von Mathieu an Besnard, Beirut, April 1922.

143 Vgl. Kapitel 7.3. 
La langue arabe, étant la langue du pays, occupe avec la langue française une place importante dans l'enseignement. Les matières du cours d'arabe depuis les éléments jusqu'à la poétique et la rhétorique inclusivement ${ }^{144}$.

Diesen Text hatte die Schule der Jesuiten fast identisch aus ihren Prospekten von $1909^{145}$ und $1912^{146}$ übernommen, der neue Zusatz lautete lediglich: »[...] le programme suivi met à même les élèves d'écrire, après la Première, une composition en arabe littéraire«. Dieses Beispiel zeigt, dass sich in der Leitlinie der Jesuiten durch das Mandatsregime nichts Grundlegendes geändert hatte, dass sie sich aber nun verpflichtet sahen, eine Mindestgarantie ihres Arabischniveaus zu geben. Allerdings war der Unterricht in ihrer Schule, im Gegensatz zur Mission lä̈que, nicht verpflichtend: »Les élèves peuvent, à la place de la langue arabe, suivre le cours d'anglais ou d'une autre langue moderne s'ils y sont autorisés par leurs parents $«{ }^{147}$. Die geringe Bedeutung des Arabischen in ihren Schulen trotz des skizzierten ordensinternen Interesse der Jesuiten an dieser Sprache macht zum einen den Einfluss der Eltern deutlich und zeigt zum anderen den Unterschied zwischen den Bildungseinrichtungen und den internen Prioritäten der Jesuiten auf. Noch marginaler als in den Jesuitenschulen war der Platz des Arabischen in den Schulen der Frères des écoles chrétiennes, wo die arabische Sprache nicht nur im Schulprospekt an letzter Stelle auftauchte:

Pour satisfaire aux besoins spéciaux du pays, les programmes adoptés au Collège Français du Sacré-Cœur font une large part aux langues vivantes: outre le français qui est la langue officielle de l'établissement, tous les élèves apprennent obligatoirement le latin, l'anglais et l'arabe ${ }^{148}$.

Diese Gewichtung zeigte sich auch in der tatsächlichen Stundenzahl, die dem Arabischen in den Schulen zuteilwurde. In der Tat enthielt der Stundenplan der katholischen Schulen weniger Stunden Arabisch und mehr Stunden Französisch als der der Mission laïque. Der Lehrplan der Jesuiten sah 19211922 nachmittags von 14 bis 15 Uhr 30 den Arabischunterricht vor ${ }^{149}$, und 1924 vermerkte der Direktor der Jesuitenschule Chanteur, dass der französischen Sprache acht Stunden, der arabischen Sprache hingegen sechs Stunden

\footnotetext{
144 SJ/Beirut, 11.D.13, Schulprospekt von 1924.

145 Ebd., Schulprospekt von 1909.

146 Ebd., Schulprospekt von 1912.

147 Ebd., Schulprospekte von 1909, 1912 und 1924.

148 FEC, Palmarès, 1923-1924, S. 64.

149 SJ/Beirut, 3.A.28, »Diaire de Beyrouth 1919-1928«.
} 
gewidmet werden sollten ${ }^{150}$. Die Archive der Schulen der Frères des écoles chrétiennes enthalten keine Angaben zum Arabischunterricht, aber es ist zu vermuten, dass er wenige Stunden einnahm.

Viele französische Ordensschulen für Mädchen boten sogar so gut wie gar keinen Arabischunterricht $\mathrm{an}^{151}$. Hierin unterschieden sie sich von der Mädchenschule der Mission lä̈que, deren Cours élémentaire et moyen beispielsweise 1921 sechs Stunden Arabisch enthielt ${ }^{152}$. Auch in der Jungenschule der Mission lä̈que wurden der Sprache mehr Stunden als in den anderen Schulen gewidmet. Das geschah teilweise gegen den Widerstand der französischen Lehrer. So befand Direktor Mathieu in einem Brief an den Generalsekretär 1922 10-11 Stunden Arabisch pro Woche im Gegensatz zu acht oder sechs Stunden Französisch für zu viel ${ }^{153}$. Seine Versuche, dies zu ändern, wurden aber von den Eltern missbilligt und er musste sie revidieren.

Allerdings entsprachen die oben dargelegten Direktiven und Erklärungen nicht immer der Praxis in den Schulen. Das zeigt sich besonders deutlich bei der Mission lä̈que. Zunächst einmal waren die französischen Kinder vom Arabischunterricht freigestellt ${ }^{154}$. Das galt vor allem für die Schüler, deren Eltern aufgrund einer Anstellung in der Mandatsadministration nur drei oder vier Jahre im Libanon blieben. Sie durften sich auf das Abitur vorbereiten, ohne Arabisch als verpflichtende lebendige Sprache zu belegen ${ }^{155}$. Dass es Versuche, dem Arabischunterricht zu entkommen, auch bei den arabischsprachigen Schülern gab, zeigt die Anordnung der Mission lä̈que im Januar 1925, dass alle Kinder, die arabische Muttersprachler seien, diese Sprache auch zu lernen hätten: »J'ai toujours refusé de satisfaire aux demandes de dispense qui m’ont été assez fréquemment adressées «156. Auch in den katho-

$150 \mathrm{SJ} /$ Vanves, »Fonds Jalabert«, 1/1 F, »Note sur l'organisation de l'enseignement secondaire au Liban et en Syrie (P. Chanteur, ca. 1924)«.

151 Vgl. die Memoiren von Maud Fargellah, die Schülerin bei den »Sœurs de Besançon« war, in deren Schule der Arabischunterricht nur eine halbe Stunde pro Woche dauerte: Chamoun 1989, S. 32. Allerdings berichtet die Ägypterin Mary Kalil, die Anfang des 20. Jahrhunderts die französischsprachige Schule der Sœurs de Nazareth besuchte, vom täglichen Arabischunterricht: »J'ai été étonnée d'y voir que l'arabe était à l'honneur. Il y avait des cours d'arabe à trois heures de l'après-midi«. Jacques Keryell (Hg.), Louis Massignon, L'Hospitalité sacrée, Paris 1987, S. 89. Andererseits zeigt die späte Stunde, dass Arabisch auf keinen Fall eine Priorität des Unterrichts darstellte.

152 Vgl. AN/Paris, 60 AJ 124, »Rapports mensuels«, Dezember 1921.

153 Vgl. ebd., »Rapports sur professeurs étrangers«, Brief von Mathieu an Besnard, Beirut, April 1922.

154 Vgl. AN/Paris, 60 AJ 125, Brief von Mathieu an Besnard, Beirut, 02.12.1922. Darin berichtet er, dass eine französische Mutter um Ermäßigung des Schulgeldes bat, weil ihr Kind nachmittags nicht am Arabischunterricht teilnahm.

155 Vgl. AN/Paris, 60 AJ 127, »Correspondance«, Brief von Mathieu an Besnard, Beirut, 25.01.1925.

156 Vgl. ebd., Brief von Mathieu an Besnard, Beirut, 29.01.1925. 
lischen Schulen zeigten die Schüler oft kein großes Interesse für die arabische Sprache ${ }^{157}$.

Die Wahl renommierter Arabischlehrer war ein weiteres Element, mit dem die Schulen auf die Erwartungen der Bevölkerung einzugehen und sich von den anderen Schulen zu distinguieren versuchten. Laut dem Zeitzeugen Lecerf stellte die Frage ihrer Einstellung und Überwachung die weiterführenden Schulen wie die der Misison lä̈que vor die größte Herausforderung: »Rien n'est difficile comme le choix des professeurs et la surveillance de leurs travaux $\varkappa^{158}$. Die laizistische Schule konnte zu Beginn des Mandats Georges Kfoury, einen Literaten aus Zahlé, höchstwahrscheinlich der melkitischen Gemeinschaft zugehörig ${ }^{159}$, verpflichten. Einigen arabischsprachigen Zeitungsartikeln der Zeit aus Zahlé zufolge wurde er von der Bevölkerung sehr geschätzt:

Wir waren sehr vergnügt bei dem Treffen mit dem ausgezeichneten Schriftsteller Ğurğ Effendi al-Kfūrī, ein ehemaliger Kollege und Redakteur in der Zeitung al-Muhadddib (Der Erzieher). Jetzt ist er der Leiter des Arabischunterrichts (mudīr at-ta' līm al-'arabī) im französischen laizistischen College in Beirut. Er ist zur Erholung nach Zahlé gekommen. [...] Und bei dieser Gelegenheit können wir nicht anders als ein großes Lob über den Eifer auszusprechen, den er an den Tag legt, besonders bei der Anhebung des Niveaus im Arabischunterricht an dem genannten College. Es wurde sogar entsprechend der Neuheit seiner Zeit zum fortschrittlichsten Versuch unter den einheimischen und ausländischen Schulen bei der Unterrichtung der Heimatsprache, und dies ist ein gesegneter Einfluss des laizistischen College, der - selbst wenn er der einzige Einfluss unter allen den Auszeichnungen des College wäre - von dessen guten Absichten Zeugnis ablegt [...] und von den Söhnen des Vaterlandes erwünscht und von den Sprechern des >ḍāt< [das heißt des Arabischen, E.M.] gelobt wird ${ }^{160}$.

Kfourys Einfluss auf die nicht-muslimische libanesische Presselandschaft war auch einer der Gründe, warum die Mission laïque ihn einstellte: »[...] grâce à lui, j'ai pu et je pourrai encore faire marcher la presse, en particulier la presse non-musulmane. La presse musulmane nous est d'avance acquise $\ll^{161}$. Direktor Mathieu teilte Kfourys Wertschätzung auf pädagogischer Ebene. So lautete sein Urteil über den Arabischlehrer:

157 Vgl. Chamoun 1989, S. 32; Helou 2002, S. 20-21.

158 Jean LeCERF, La littérature arabe moderne et l'enseignement de la langue en Syrie, in: Revue africaine 72 (1931), S. 111-138, S. 122.

159 Laut QABAṬī 2006, S. 9, war Kfoury auch Politiker, aber leider konnten über seine Biographie keine weiteren Elemente in Erfahrung gebracht werden.

160 Vgl. AN/Paris, 60 AJ 131, Artikel »qudūm adīb (Ankunft eines Schriftstellers)« aus der Zeitung Zaḥla al-Fatāt, Zahlé, 22.05.1925.

161 AN/Paris, 60 AJ 123, Brief von Lehéricy an Besnard, Beirut, 12.11.1920. 
Il jouit d'une réelle autorité sur ses collègues qui reconnaissent la supériorité de ses [...] et de son expérience pédagogique. Il a le sens de l'ordre et de la méthode. [...] Il est à souhaiter que l'enseignement de l'arabe ne fut confié qu'à des maîtres de pareille valeur $^{162}$.

Auch für die Schüler hatte Kfoury eine wichtige Bedeutung, da er sie in die arabische Litertaur einführte. Khalil Taqi ad-Din und seine Kameraden schätzten ihn sehr, und diese Sympathie schien auf Gegenseitigkeit zu beruhen, denn Kfoury gab ihnen die Beinamen berühmter arabischer Literaten, beispielsweise erhielt Khalil Taqi ad-Din den Namen Ibn al-Muqaffa', und Taqi ad-Din as-Sulh wurde vom Lehrer als Ibn Haldūn bezeichnet ${ }^{163}$.

Anders als Kfoury beurteilte Direktor Mathieu einen anderen bekannten Schriftsteller und Journalist, Habib Riachy (arabisch Habīb ar-Riyāšīi), den er eingestellt hatte, sehr kritisch: dieser sei »persuadé qu'il est le meilleur professeur d'arabe de toute la Syrie ${ }{ }^{164}$. Leider interessiere er sich aber mehr für das öffentliche Leben als für den Unterricht. Andere Arabischlehrer kritisierte die Leitung der Mission lä̈que wegen ihrer zu laschen Disziplin $^{165}$. Dieses Phänomen findet sich auch in der Schule der Jesuiten wieder. Wie Charles Helou in seinen Memoiren berichtet, war Arabisch der einzige Unterricht, der von Laien gegeben wurde, die weder über die Strenge noch das Ansehen der Jesuiten und Maristen verfügten, welche Französisch unterrichteten $^{166}$.

Allerdings wird dieses Bild bezüglich der Jesuitenschule in Beirut dadurch modifiziert, dass deren ehemalige Schüler jedes Jahr einen Preis für den besten Aufsatz in arabischer Sprache vergaben. Parallel zu den Preisen für französische Sprache oder den Prix de la Sagesse gaben sie ein Thema in arabischer Sprache vor, in dem die Schüler ihre Kenntnisse unter Beweis stellen konnten. Die Themen kreisten häufig um die Frage des Vaterlandes (watan). 1911 lautete die Frage: »Wie und womit dient der Mensch seinem Vaterland? ${ }^{167} .1920$ waren die Schüler mit der Frage konfrontiert: »Welches sind die nützlichsten Mittel zur Verbesserung des Vaterlandes? «168 1921 lautete das Thema: »Die Pflichten für die Elite der Patrioten zur Erweckung des Vaterlandes $«^{169}$, 1922 wiederum »Die Bedeutung der Geschichte bei der

162 AN/Paris, 60 AJ 124, »Renseignements sur professeurs« (ca. 1922).

163 Vgl. QabaṬi 2006, S. 9. Der dritte Freund im Bunde, Muḥammad 'Alī Hamāda, erhielt den Beinamen Ibn Rušd.

164 AN/Paris, 60 AJ 124, »Renseignements sur professeurs« (ca. 1922).

165 Siehe die Kommentare über »M. Khoury« und »Mme Kfoury« in: Ebd.

166 Vgl. Helou 2002, S. 20.

167 NDJ, Distribution solennelle de prix, 1911: »Kayfa wa-bi-mād̄ā yaḩdamu al-mar’ wațanahu?«.

168 NDJ, Distribution solennelle de prix, 1920: »Mā anğa al-wasā'il ilā tarqiyat al-wațan?«.

169 NDJ, Distribution solennelle de prix, 1921: »Wāğibāt nuḩbat al-wațanīyīn fī inhāẹ al-wațan«. 
Erziehung der Individuen und bei der Verbesserung der Nationen ${ }^{170} .1923$ nahm die Aufgabenstellung Bezug auf die nahda und fragte nach der Rolle der Libanesen und Syrer in dieser Erneuerungsbewegung ${ }^{171} .1925$ lautete die Preisfrage: »Taugt die arabische Sprache, um die höchsten Wissenschaften zu lehren? «172 1926 wiederum sollten die Schüler auf die Frage antworten: »Siehst du einen Nutzen in Reisen und Ferien zu Lasten des Lebens fremder Völker, und welcher ist dieser « ${ }^{173}$ ?

Die Ehemaligen scheinen eine enge Verbindung zwischen der arabischen Sprache und der Frage der Heimat, des Vaterlandes gesehen zu haben. Diese Einsicht überrascht, weil viele der Alumni der Jesuitenschulen sich im Französischen sehr viel mehr ızuhause` gefühlt haben. Die häufige Thematisierung der Heimat (wațan) und Nation (umma) in diesen Aufgaben entsprach aber dem starken Gebrauch der Begriffe in den libanesischen und syrischen Gesellschaften nach dem Ersten Weltkrieg: auch wenn die Konzepte dadurch nicht eindeutiger und konsistenter wurden, gehörte die Frage der Nation zu den zentralen politischen Debatten der Zeit ${ }^{174}$ und also auch, wie die Zitate belegen, innerhalb der profranzösisch eingestellten Alumni der Jesuitenschule. Womöglich wollten die Ehemaligen mit diesen Zitaten auch an die stark christlich geprägte Bewegung der nahḍ anknüpfen, die die arabische Sprache zugunsten einer nationalen Identität förderte.

Eng mit der Wahl der Lehrer war die Frage der Methoden für den Arabischunterricht verbunden. Für die französischen Schulen bedeutete dieses Thema viele Schwierigkeiten, weil sie den Arabischunterricht praktisch in einheimische Hände geben mussten und deshalb wenig Kontrolle darüber hatten. Allen französischen Schulen mangelte es in diesem Bereich an Kenntnissen, auch wenn die katholischen Schulen noch über mehr Erfahrungen verfügten als die Mission lä̈que. Während erstere aber anscheinend ihre lokalen Lehrer schalten und walten ließen ${ }^{175}$, machten sich die Verantwortlichen der Mission lä̈que mehr Gedanken über die Methoden des Arabischunterrichts. Die aktuellen Methoden waren ihrer Meinung nach veraltet und

170 NDJ, Distribution solennelle de prix, 1922: »Maqām at-tārīh fĩ taţqîf al-afrād wa-tarqiyat al-umam«.

171 NDJ, Distribution solennelle de prix, 1923: »Dawr al-lubnānīyīn wa-s-sūrīyīn fi nahḍāt al-ādāb al-'arabīya al-hadītak.

172 NDJ, Distribution solennelle de prix, 1925: »Hal taṣluḥ al-lugiā al-'arabīya li-tadrīs al-'ulūm al-'ulyā?«.

173 NDJ, Distribution solennelle de prix, 1926: »Hal tarā fā'ida fī l-asfār wa-l-'uṭla 'alā hayāt al-umam al-ağnabīya. Wa-mā hīya?«.

174 Vgl. Schumann 2001, S. 254.

175 Vgl. für die Schule der Jesuiten in Beirut Helou 2002, S. 20; siehe auch die Memoiren von Shafiq Jabri, einem Schüler der Lazraristen in Damaskus, zitiert in: LeCERF 1931, S. 121: »Les professeurs, tous religieux, n'avaient pas alors une bonne méthode pour l'enseignement«. 
bedurften für ihre Modernisierung der Orientierung an den europäischen und »modernen« Unterrichtsmethoden, so Besnard:

Mais il nous a semblé que l'enseignement de l'arabe pouvait être modernisé pour être rendu plus rapide et plus efficace et qu'il serait très profitable aux professeurs indigènes qui le donnent dans nos établissements d'être initiés, s'ils ne le sont pas encore, aux méthodes occidentales et modernes d'enseignement des langues ${ }^{176}$.

Lecerf teilte diese Kritik, betonte aber gleichzeitig, dass sich auch in der arabischen Welt die Pädagogen und Intellektuellen um eine Reform bemühten, und dass die europäischen Schulen ihrerseits nicht immer viel täten, um eine Erneuerung der Methoden durchzuführen ${ }^{177}$. In der Tat folgten aus der von Besnard vorgegebenen Leitlinie anscheinend keine weiteren konkreten Schritte in Beirut. Die folgenden Lehrerkonferenzen beschäftigten sich zwar mit der Frage, wie man eine Harmonisierung zwischen den Französisch- und Arabischklassen erreichen könne, sprachen aber nicht über die Methoden und ihre Erneuerung ${ }^{178}$. Wie die Frage der Lehrerausbildung in Kapitel fünf zeigen wird, lag ein Hauptgrund für die mangelhaften Methoden im Arabischunterricht auch darin, dass die französischen Autoritäten eine lokale Lehrerausbildung verhinderten.

Ähnlich schwierig war die Frage der arabischen Literatur, die im Unterricht verwendet wurde. Die Archive enthalten nur sehr spärliche Informationen über die arabische Literatur, die in den französischen Schulen gelesen und kommentiert wurde. Interessanterweise ist hier wieder das Paradoxon festzustellen, dass die Jesuiten, die viel weniger Wert auf die arabische Sprache als Element ihrer Schulen legten, über einen größeren Bestand an Büchern zur arabischen Literatur verfügten als die Mission laïque française. Darin unterschieden sich die Jesuiten auch von den anderen katholischen Orden, die zwar oft schon ähnlich lange im Libanon erzieherisch tätig waren, die sich aber nicht wie die Societas Jesu wissenschaftlich mit der arabischen Kultur und Sprache beschäftigt hatten. Innerhalb des Ordens der Jesuiten hatte der libanesische Pater Louis Cheikho eine Anthologie der arabischen Literatur verfasst ${ }^{179}$, die auch in den staatlichen Schulen verwendet und sogar von den Schulen in Nordafrika importiert und genutzt wurde ${ }^{180} .1930$ legte ein weite-

176 Revue de l'enseignement français hors de France 18 (1921), H. 16: »Assemblée Générale Annuelle 18.12.1921《.

177 LECERF 1931, S. 123-125.

178 Siehe zum Beispiel AN/Paris, 60 AJ 123, »Réunion des professeurs«, Sitzung vom 29.12.1923. Die Diskussion der Lehrer kreiste um die Auszeichnung der Schüler für besondere Leistungen im Französisch- und Arabischunterricht.

179 Vgl. LECERF 1933, S. 276.

180 Vgl. MAE/Nantes, IP, 29/1924, »Publications«, Brief von Hochkommissar Weygand an die Leiterin der Filles de la Charité, Beirut, 14[?].08.1924. 
rer libanesischer Jesuit, Rafā's̄l Nahla, eine Anthologie (arabisch muhtarāt) arabischer Literatur vor, dessen Ziel explizit war, die Schüler und Studenten zu ermutigen, ihre Sprache zu erlernen, und der dafür eine Methode verwandte, die die Spannung und das Interesse der Studenten wecken sollte (tarīqat al-tašsīq $)^{181}$. Zu diesem Zweck präsentierte der Pater eine Auswahl von 100 Werken zeitgenössischer arabischer Literatur. Unter den ausgewählten Autoren fanden sich nicht nur christliche Namen wie Asad Rustum und Anīs Hūurī al-Maqdisī, beide Professoren der American University of Beirut, sondern auch viele muslimische und arabisch-nationalistische Schriftsteller wie der syrische Intellektuelle und Politiker Muhammad Kurd 'Alī, der ägyptische Autor Ṭāhā Husayn, der Gründer der ägyptischen Nationalbewegung Mustafā Kāmil Pascha und andere. Auch einige Frauen hatte er aufgenommen, darunter Salma Sayegh (arabisch Salma Șāyig̀), Labīya Hāšim und andere. Diese Anthologie geht interessanterweise über den Rahmen der üblichen literarischen und politischen Referenzen der Jesuiten hinaus.

Die Arabischlehrer der Mission lä̈que schienen, in einem sehr viel bescheideneren Umfang, ganz ähnlich wie die Jesuiten zu arbeiten und ihre eigenen Werke zu produzieren und zu unterrichten. Beispielsweise bestellte die Schule viele Exemplare des arabischsprachigen Werkes Das Genie von Riachy ${ }^{182}$. Leider ist über den Inhalt dieses Werkes nichts bekannt, zudem fehlen weitere Angaben über die Lehrmittel, die die Arabischlehrer verwendeten. Allerdings war in der laizistischen Schule die arabische Sprache schon viel früher ein Thema der Schulöffentlichkeit als in den katholischen Schulen. Beispielsweise organisierten Georges Kfoury und Khalil Taqi ad-Din im Frühjahr 1929 eine öffentliche Diskussion über die Frage der »adaptation de la langue arabe aux nécessités de la civilisation moderne et des rapports de l'arabe littéraire et de l'arabe parlé « ${ }^{183}$. Damit knüpften sie an eine lebhafte und ernste Debatte ihrer Zeit über die Frage der Modernisierung der arabischen Sprache an. Auch wenn viele Intellektuelle dieser Notwendigkeit zustimmten, sahen es vor allem die Muslime als problematisch an, die heilige Sprache des Korans zu verändern ${ }^{184}$. Die Tatsache, dass die Diskussion in der Mission lä̈que von einem Christen und einem Drusen veranstaltet wurde, war deshalb sicher unter anderem für die sehr unterschiedlichen Reaktionen auf die Veranstaltung verantwortlich ${ }^{185}$.

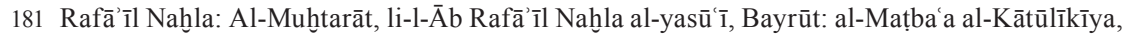
1930 [Eine Anthologie des Jesuiten Rafael Nakhlé, Beirut: Katholische Druckerei, 1930].

182 Vgl. AN/Paris, 60 AJ 133, Liste der bestellten Bücher, darunter das genannte Buch, das leider nur unter seinem französischen Titel »Le Génie« aufgelistet war.

183 Revue de l'enseignement français hors de France 26 (1929), H. 79, »Assemblée Générale extraordinaire«, 16.05.1929, S, 132-138, S. 137.

184 Vgl. Yared 2002, S. 181-187.

185 Vgl. Revue de l'enseignement français hors de France 26 (1929), H. 79, »Assemblée Générale extraordinnaire«, 16.05.1929, S. 132-138, S. 137. 
Vergleicht man darüber hinaus die bei den verschiedenen Schulfesten aufgeführten Theaterstücke, fällt auf, dass deren Inhalte ähnliche ideologische Positionen verrieten wie die im Unterricht behandelte französische Literatur. So wurden in den katholischen Schulen vor allem christliche Themen rezipiert. Beispielsweise führte die Theatergruppe der Frères des écoles chrétiennes in Beirut im Schuljahr 1926-1927 ein Theaterstück über christliche Helden in Arabien im 5. Jahrhundert auf ${ }^{186}$. Dem gegenüber wurden an der Schule der Mission lä̈que Stücke mit religiös neutralerem Inhalt präsentiert ${ }^{187}$.

Diese ideologische Aufladung der Wahl der Theaterstücke entsprach der großen sozio-kulturellen Bedeutung, die das Theater in Beirut, aber auch in anderen Metropolen des Nahen Ostens wie Kairo und Alexandria, schon seit der Jahrhundertwende auszeichnete: Gerade von einer aufsteigenden Mittelschicht wurde das Theater als Synonym für Zivilisation und Fortschritt und oft auch als Medium für die Forderung nach sozialen Reformen angesehen ${ }^{188}$. Wie in Frankreich wurde dem Theater auch von den arabischen Intellektuellen »an important literary, cultural and social role « zugedacht ${ }^{189}$. Dabei spielte die Kritik an religiösen Inhalten und Institutionen wie den Jesuiten eine wichtige Rolle ${ }^{190}$. In der Tat waren die Jesuiten in ihren Schulen im Nahen Osten, wie auch in Europa, in diesem Feld schon seit langem aktiv und sahen das Theater als ein bedeutendes Element ihrer Pädagogik an ${ }^{191}$. Die starke Beteiligung der Schulen an Theateraufführungen trug dazu bei, dass das Theater, obgleich bereits in der osmanischen Zeit praktiziert, durch den französischen Einfluss eine starke westliche Prägung erfuhr ${ }^{192}$.

Dass die arabische Sprache in den französischen Schulen viel wichtiger für die libanesische Öffentlichkeit als für die französische Mandatsmacht war, wird anhand mancher Prüfungen deutlich, die unter Einbeziehung die-

186 Vgl. FEC, L'Essor, Februar 1929.

1871922 berichtete Direktor Mathieu von dem Erfolg der Theateraufführung der Académie arabe bezüglich der zwei Stücke »Le chevalier noir« und »La Trahison écrasée« (da Mathieu kein Arabisch beherrschte, sind die Titel nur auf Französisch überliefert). Vgl. AN/Paris, 60 AJ 125, »Rapports mensuels«, Dezember 1922. Auch die Schüler der Alliance israélite führten 1916 einige Stücke auf Arabisch auf, deren Titel aber nicht überliefert wurden und denen wenig Bedeutung zukam. Vgl. AIU/Paris, »Liban VI E 81a, Penso«, Brief von Penso, Beirut, 22.08.1916.

188 Vgl. Ilham Khuri-Makdisi, Theater and Radical Politics in Beirut, Cairo, and Alexandria 1860-1914, in: Center for Contemporary Arab Studies (Hg), Occasional Papers, Georgetown University 2006, S. 32-33; Dies., The Eastern Mediterranean and the Making of Global Radicalism, 1860-1914, Berkeley, California, 2010.

189 Nazik Saba Yared, Arab Travellers and Western Civilization, London 1996, S. 181.

190 Vgl. Khuri-Makdisi, S. 26, 27.

191 Vgl. Hartmann 2008, S. 62.

192 Vgl. Nada Sehnaour, L'occidentalisation de la vie quotidienne à Beyrouth. 1860-1914, Beirut 1981, S. 168. 
ser Öffentlichkeit abgenommen wurden. Die Tatsache, dass die arabische Sprache im normalen Schulalltag dieser Schule keine große Bedeutung hatte, unterstreicht noch stärker die Bedeutung der Außenwirkung: So hatten die Frères des Écoles chrétiennes dieses Diplom mit dem Ziel »[...] ménager les études arabes « eingeführt ${ }^{193}$. Bemerkenswerterweise kamen sie damit der Mission laïque zuvor, die erst 1925 konkrete Überlegungen zum Arabischdiplom anstellte ${ }^{194}$. Da es keine offizielle Prüfung der arabischen Sprache gab, oblag sie den Schulen selbst.

Die libanesischen Jurymitglieder, die die Schulen für diese Prüfungen auswählten, waren entweder frankophile Persönlichkeiten, die bei verschiedenen französischen Institutionen ihr Land repräsentierten, oder Individuen, die die politische Orientierung der Schulen selber oder ihrer Klientel repräsentierten. Zur ersten Kategorie gehörte beispielsweise der christliche Scheikh Ibrahim Munzir (arabisch Ibrāhīm Mundir), ein libanesischer Politiker ${ }^{195}$. Er war 1923, $1924^{196}$ und $1927^{197}$ Jurymitglied bei der Schule der Frères des Écoles chrétiennes, wurde aber auch bei der Mission laïque aktiv $^{198}$. Direktor Ruche zog auch bewusst in Erwägung, dass Munzir schon in anderen Schulen aktiv war ${ }^{199}$. Innerhalb der zweiten Kategorie präsentierten sich bei den katholischen Schulen vor allem Verfechter eines autonomen Libanons mit christlicher Dominanz wie Said 'Aql bei den Frères des Écoles chrétiennes ${ }^{200}$. Bei der Mission laïque hingegen beteiligten sich an den Jurys auch Mitglieder, die einen arabischen Nationalismus vertraten, wie Prinzessin Nağla Abi-l-Lama', Schriftstellerin und Inhaberin der Zeitschrift al-Fağr (die Morgenröte) ${ }^{201}$ oder Badri Talih, der Präsident einer arabischen Gesellschaft an der amerikanischen Universität ${ }^{202}$.

193 FEC, »Historique du Collège«.

194 AN/Paris, 60 AJ 127, Brief von Mathieu an Besnard, Beirut, 16.03.1925.

195 Vgl. Zamir 2000, S. 66.

196 Vgl. FEC, Palmarès 1923-1924, S. 20.

197 FEC, Palmarès 1926-1927, S. 36.

198 Vgl. AN/Paris, 60 AJ 125, »Rapports mensuels«, Februar 1923. Mindestens ein Mitglied aus seiner Familie war auch Schüler der laizistischen Schule, nämlich Salih Munzir.

199 »[11] fait partie de jury semblables au Collège des frères et à l'Université américaine«. AN/ Paris, 60 AJ 127, Brief Mathieu an Besnard, Beirut, 16.03.1925.

200 Vgl. FEC, L'Essor, Februar 1924, S. 70-71: »La langue arabe au collège«.

201 Zur Geschichte dieser leider sehr kurzlebigen Zeitschrift siehe Souad Sum/Anne-Laure Dupont, La vie intellectuelle des femmes à Beyrouth dans les années 1920 à travers la revue Minerva, in: Anne-Laure Dupont/Catherine Mayeur-Jaouen (Hg.), Débats intellectuels au Moyen-Orient dans l'entre-deux-guerres, Revue des mondes musulmans et de la Méditerranée 95-98 (2002), S. 381-406.

202 Vgl. AN/Paris, 60 AJ 125, »Rapports mensuels«, Februar 1923. 
In ganz ähnlicher Manier funktionierten die sogenannten Académies de langue arabe, deren Mitglieder aus den besten Schülern in diesem Fach zusammengesetzt wurden. Diese funktionierten analog zu den Académies de langue française. Welche von beiden eher bestand, lässt sich aber nicht rekonstruieren. Auch der Ursprung dieser Akademien bleibt unklar. War das Modell die Académie française in Paris? Auf jeden Fall gab es in der Schule der Jesuiten schon 1888 eine Theateraufführung der Académie de littérature $\operatorname{arabe}^{203}$. Das bedeutet, dass es schon vor der Gründung der arabischen Akademie in Damaskus im Juni 1919 diese Form in den Schulen gegeben hatte ${ }^{204}$.

Aus dem Jahr 1923 sind sowohl von der Mission laïque als auch von der Schule der Frères des Écoles chrétiennes die Aktivitäten ihrer jeweiligen Académie arabe überliefert. Bei beiden wurden bekannte Beiruter Persönlichkeiten aus Politik und Literatur dazu gebeten ${ }^{205}$. Das zeigt zum einen, dass sich diese Persönlichkeiten bei den Gelegenheiten sin Szene setzten « und ihre Kenntnisse der arabischen Sprache präsentieren konnten. Zum anderen macht es deutlich, dass die Schulen ihrerseits diese Unterstützung suchten, um ihr Prestige bezüglich der arabischen Sprache und Kultur zu erhöhen. Allerdings war die Mission laïque dabei weniger erfolgreich als sie gehofft hatte. So lobte ein arabischsprachiger Zeitungsartikel über ein Schulfest Anfang der 1920er Jahre zwar das gute Arabischniveau mancher Schülerreden, monierte aber, dass die Schule nicht wie für die französische Sprache auch einen Preis für die arabische Sprache vergeben habe:

Die Feier gibt es jedes Jahr, dieses Jahr am Sonntagmittag. Anwesend waren der bevollmächtigte Kommissar [...] und die großen Männer der Gesandtschaft und der Šayh Muhammad al-Ǧisr, und der Rektor für Bildung und Herr Duthoit, der Berater für Bildung, und auch eine Gruppe der wichtigen Leute und Familien. Um 17 Uhr ist Herr Matthieu aufgestanden. Er ist der Rektor der Schule, und er hat eine lange Rede gehalten, er hat mit den Absolventen gesprochen und viele Ratschläge gegeben, dass sie gute Bücher zum Lesen wählen sollen. Und am Schluss hat er dem Bevollmächtigten gedankt für sein Kümmern um die Schule.

Es gab viele Reden von vielen Studenten auf zwei Sprachen, arabisch und französisch, Gedichte und Prosa, und zwischen diesen Reden gab es viele Lieder und $\mathrm{Mu}-$ sik von den kleinen Schülerinnen. Und die Leute waren voller Bewunderung. Beson-

203 Vgl. SJ/Vanves, RPO 62. Zwar gibt die erste Seite des Programms den Titel des Stückes auf Arabisch und Französisch wieder. Aber das restliche Programm ist ganz auf Französisch geschrieben und es ist fraglich, in welchem Maße diese Veranstaltung wirklich auf Arabisch stattgefunden hat.

204 Bocquet 2008, S. 41.

205 Für die Frères des Écoles chrétiennes siehe z.B. FEC, »Historique du Collège du Sacré-Cœur«: am 21.04.1923 präsidierte Habīb Pascha eine Sitzung der »Académie arabe«. 
dere Aufmerksamkeit hatten wir für die Studenten Ḥamāda, Badī‘ al-Mundir, der Sohn unseres Freundes, Šayḥ al-Mundir, und die Studentin Asma Qaleīlāt, diese haben eine arabische Rede gehalten, die sehr gut war. Und wir haben nicht nur eine Melodie gehört von den Künstlern; jeder war anders in seinem Vortrag. Wir gratulieren dem Lehrer Kfūrī, Chef der arabischen Sprache, und seinen Helfern für dieses wunderbare Ergebnis ${ }^{206}$.

Bis hierhin war der Artikel ins Französische übersetzt worden, aber der kritische Teil blieb unübersetzt:

Und wir hatten erwartet, dass die Leitung der Schule einen Preis für die arabische Sprache als Geschenk für die Bemühungen und den Fleiß vergibt, aber sie hat ihre Geschenke nur für die Fleißigen in französischer Sprache gegeben. Im Allgemeinen war das Ergebnis, das wir gesehen haben, sehr gut, und es gab nur einen Makel: dass die Reden ein bisschen lang waren, und auch das Programm war sehr lang, die Feier ist bis acht Uhr abends gegangen ${ }^{207}$.

Da mit dieser Kritik indirekt der Arabischunterricht Kfourys beanstandet wurde, ist zu vermuten, dass dieser, der in der Regel für alle Übersetzungen verantwortlich war, diesen Teil nicht übersetzt hat. Beide Aspekte geben Lecerfs Kritik an der paradoxen Situation in Beirut zu der Zeit Recht: die gebildeten Leute brillierten zwar rhetorisch in Arabisch, andererseits aber waren ihre politischen Rechte stark eingeschränkt ${ }^{208}$.

Die Untersuchung über den Platz der französischen und arabischen Sprache in den französischen Schulen zu Beginn der Mandatszeit hat deutlich gemacht, dass diese von den unterschiedlichen Akteuren mit bestimmten Bedeutungen versehen wurden. Galt die französische Sprache als Machtinstrument, mit dem sowohl die französische Regierung als auch die französischen Schulen ihren Einfluss im Libanon sichern wollten, war sie gleichzeitig ein Merkmal der Identität und sozialen Distinktion bestimmter libanesischer Gemeinschaften. Die arabische Sprache hingegen bedeutete für andere libanesische Gruppen ebenfalls ein Element ihrer Identität und sozialen Distinktion. Während die Mandatsregierung diesem Aspekt der Sprache nur ein sehr halbherziges Engagement entgegenbrachte, gaben die französischen Schulen ihr je nach Interessen ihrer Klientel viel oder weniger Bedeutung. Die Mission lä̈que bemühte sich sehr, diese Bedürfnisse zu befriedigen, war aber

206 AN/Paris, 60 AJ 131, Artikel »Haflat al-kullīya al-'almānīya (Fest der säkularen Fakultät)« in der Zeitung al-Aḥrār, Beirut, 27.06.1925.

207 Ebd.

208 Vgl. LeCERF 1933, S. 286. 
nicht immer erfolgreich. Da die katholischen und jüdischen Schulen stärker mit ihrer Klientel übereinstimmten, was Wertschätzung und Kenntnis der arabischen Sprache betraf, kam es hier zu weniger Problemen. 



\section{Wer bildet den Libanon? \\ Das Jahr 1925 als politische Zäsur}

Die Jahre 1924 und 1925 bedeuteten sowohl für Frankreich als auch für die französischen Mandatsgebiete im Nahen Osten einschneidende Veränderungen. Die Bildung des Libanon im doppelten Sinne des Unterrichtswesens und des staatlichen Aufbaus sowie dessen geistiges Fundament wurden neu verhandelt. Der Wahlsieg der Linken in Frankreich und der Aufstand gegen die Mandatsmacht in Syrien führten zu neuen politischen Konstellationen und Herangehensweisen von beiden Seiten, um das Verhältnis zwischen Frankreich und dem Libanon im Sinne der eigenen Interessen zu verändern: Die französische Regierung bemühte sich, allerdings nur halbherzig, um den Aufbau eigenstaatlicher Strukturen im Libanon und um die Erweiterung ihrer Einflusssphäre über die Maroniten hinaus, während sich im Libanon zum einen der Widerstand gegen die Mandatsherrschaft verhärtete und institutionalisierte und zum anderen einige sunnitische Familien ihren Widerstand gegen das Regime aufgaben und sich mit diesem arrangierten.

Ausgehend von diesen multiplen Anpassungs- und Verweigerungsprozessen soll in diesem Kapitel untersucht werden, ob sich die Schulen den neuen Verhältnissen anpassen konnten und inwiefern die von der französischen Regierung nun besonders gefördertere Mission lä̈que française darin eine bessere Alternative zu den anderen französischen Schulen bot. Die These lautet, dass es in dieser Zeit in der Tat zu Veränderungen in den französischen Schulen, insbesondere in der Mission lä̈que française, hin zu einer größeren Anpassung an die Verhältnisse im Libanon und an die Forderungen ihrer Klientel gab, dass diese Epoche aber auch das Scheitern eines adäquaten Bildungsangebotes deutlich machte.

Die Forschung hat zu Recht auf den Wendpunkt hingewiesen, welcher den Schulen der Mission lä̈que française eine neue Prominenz sowie den katholischen Schulen das Ende ihres Primats brachte'. In Frankreich hatte im Mai 1924 ein Bündnis aus linken Parteien, das Cartel des gauches, die Parlamentswahlen gewonnen. Dieses Bündnis bemühte sich, den republikanischen Laizismus, den die vorherige Regierung stark vernachlässigt hatte ${ }^{2}$, wieder konsequent zur Maxime ihrer Politik zu machen, auch im Bildungs-

Vgl. BocQuet 2008, S. 87.

2 Die vorherige Regierung hatte unter anderem wieder diplomatische Beziehungen zum Vatikan aufgebaut, nicht autorisierte Orden zurückkehren lassen, in Elsass-Lothringen das Konkordat aufrechterhalten. Vgl. Jean-Paul Brunet, Cartel des gauches, in: Jean-François Sirinelli (Hg.), Dictionnaire de la vie politique française au XX $\mathrm{X}^{\mathrm{e}}$ siècle, Paris 2003, S. 179-184, S. 179-180. 
bereich. Zu diesem Zweck führte sie verschiedene Reformen durch, die die Gleichheit der Bürger und der Geschlechter stärken sollten. So bemühte sich die Regierung, allerdings erfolglos, um die Einführung der école unique. Dieses Modell sollte den immer noch bestehenden Graben zwischen dem der sozialen Elite vorbehaltenen zahlungspflichtigen enseignement secondaire und dem von den weniger privilegierten Gesellschaftsschichten genutzten gebührenfreien enseignement primaire, zwischen welchen die Schüler nicht wechseln konnten, schließen ${ }^{3}$. Ferner glich die Regierung die Schulbildung für Mädchen derjenigen für Jungen $\mathrm{an}^{4}$. Schließlich wurden Latein und Griechisch als obligatorische Sprachen abgeschafft, indem das Erziehungsministerium im Abitur die Optionen A (Latein, Griechisch), A' (Latein und eine moderne Sprache) und B (zwei moderne Sprachen) bereitstellte ${ }^{5}$. Auch wenn die neue Koalition nicht lange hielt, sondern schon 1928 durch eine konservative Regierung abgelöst wurde, behielt diese die Änderungen im Bildungswesen bei. Diese Reformen sollten auch in den Schulen in den Mandatsgebieten, die auf das französische Abitur vorbereiteten, gelten.

Auch in juristischer Hinsicht verfolgte die linke französische Regierung in Syrien und Libanon einige Reformen wie die Landreform von 1924 oder die Entkonfessionalisierung des Personenstandrechts und einen Politikwechsel hin zu einer stärkeren Säkularisierung, was aber nur begrenzten Erfolg zeigte $^{6}$. Auf der höchsten administrativen Ebene rief der neue Premierminister Édouard Herriot im November 1924 Hochkommissar General Maxime Weygand zurück und ersetzte ihn durch General Maurice Sarrail ${ }^{7}$. Sarrail brach mit der Tradition seiner Vorgänger, die eindeutig eine pro-katholische Politik vertreten hatten. Sarrails neue Mandatspolitik wurde schon ein halbes Jahr nach seiner Ankunft auf die Probe gestellt, welche sich aber zu seinen Ungunsten entschied.

In Syrien organisierte eine Gruppe der Religionsgemeinschaft der Drusen im Sommer 1925 einen Aufstand gegen die Mandatsmacht, der im Drusengebiet (arabisch Ğabal ad-Durūz) begann und bis nach Damaskus zog ${ }^{8}$.

3 Vgl. Hervé Terral (Hg.), L'école de la République. Une anthologie (1878-1940), Paris 1999, S. 20.

4 Vgl. KoK-Escalle 1988, S. 63.

5 Vgl. Charles R. DAY, Schools and Work: Technical and Cocational Education in France since the Third Republic, Montreal 2001, S. 34.

6 Vgl. Jürgen Sтоцdт, Säkularisierungsinitiativen im Libanon 1920-1976, Magisterarbeit Universität Freiburg im Breisgau (o.J.), S. 65-85. Die zögerliche Haltung gegenüber Reformen resultierte unter anderem aus der Sorge, die frankophile libanesische Klientel nicht zu verärgern. Vgl. Firro 2003, S. 80-89.

7 Vgl. Pierre FourniÉ, Le mandat à l'épreuve des passions françaises: l'affaire Sarrail (1925), in: Nadine Méouchy (Hg.), France, Liban et Syrie 1918-1946. Les ambiguïtés et les dynamiques de la relation mandataire, Damas 2002, S. 125-168.

8 Über die genaue Bezeichnung und Bewertung dieses Aufstandes hat es viele Diskussionen gegeben. Vgl. Birgit Schäbler, Coming to Terms with Failed Revolutions: Historiography in 
Dieser Aufstand war ironischerweise von der Gemeinschaft initiiert worden, die Frankreich besonders an sich gebunden hatte ${ }^{9}$. Während sich die christlichen Minderheiten und die Alawiten wenig an der Revolte beteiligten, hielten die muslimische Handelsbourgeoisie, ein Teil der Landbesitzer und die Bauernschaft die Protestbewegung auch nach 1925 am Leben ${ }^{10}$. Auch wenn sie vor allem in den syrischen Gebieten für Unruhe und Kämpfe sorgte, waren die Auswirkungen auch im Libanon zu spüren ${ }^{11}$. Darauf reagierte Sarrail mit extremen militärischen Mitteln, indem er die Stadt Damaskus bombardieren ließ. Da diese Reaktion sowohl in der Levante als auch in Frankreich und international aufs schärfste kritisiert wurde, wurde er nach weniger als einem Jahr Amtszeit zurück nach Paris berufen und durch Henri de Jouvenel ersetzt $\mathrm{t}^{12}$.

De Jouvenel war als erster Hochkommissar kein Militärangehöriger, sondern Journalist und Schriftsteller. Seine Mandatspolitik war geprägt von dem Ziel, Syrien und Libanon zu mehr Unabhängigkeit zu verhelfen ${ }^{13}$ - gerade in der Konsequenz des Widerstandes in Syrien und der nicht adäquaten Reaktion Sarrails darauf sollte und wollte de Jouvenel neue Zeichen setzen. $\mathrm{Zu}$ diesem Zweck ermöglichte er mit der libanesischen Verfassung vom Mai 1926, dass der Libanon eine Republik wurde ${ }^{14}$ und initiierte die oben genannten Reformen, die ihm von allen Seiten Kritik einbrachten. In der Rückschau wird er oft als »a man who was ahead of his time « bezeichnet ${ }^{15}$. Dies war einer der Gründe, warum auch er schon im Juni 1926 nach Paris zurückgerufen wurde. Sein Nachfolger Henri Ponsot brachte das erste Mal Kontinuität für diesen Posten, denn seine Amtszeit währte von 1926 bis 1933.

In dem Aufstand in Syrien hatten neben dem Protest gegen das französische Mandat nationalistische Ambitionen eine große Rolle gespielt, auch wenn in der Masse der Bevölkerung traditionelle Loyalitäten zur Familie, zum Clan oder zur religiösen Gemeinschaft oft stärker blieben als die

Syria, France and Germany, in: Middle Eastern Studies 35 (1999), H. 1, S. 17-44; DAKHLI 2009a, S. 134-137. Ich wähle den Begriff »Aufstand« weil er am neutralsten erscheint. FirRo 2003, S. 71, macht aber auch darauf aufmerksam, dass es schon in den ersten fünf Jahren des Mandats viele ländliche Aufstände gegen die französische Regierung gab, und widerlegt damit die lange dominante These von der passiven Haltung der Landbevölkerung unter dem Mandat.

9 Vgl. Bocquet 2008, S. 77.

10 Vgl. Khoury 1987, S. 205-207.

11 Beispielsweise berichtete die Alliance israélite von einem Flüchtlingsstrom syrischer Juden nach Beirut. Vgl. AIU/Paris, »Liban IXE 96b«, Brief von Sidi an den Präsidenten der Alliance israélite, Beirut, 16.11.1925: »L'aspect de la ville ne se trouve modifiée que par l'arrivée de France de renforts et la présence d'un grand nombre de réfugiés venus de l'intérieur«.

12 Vgl. Fournié 2002, S. 167.

13 Vgl. Stoldt o.J., S. 76.

14 Vgl. Salibi 1965, S. 167-168. Syrien erhielt erst 1930 den Status der Republik, welchen sich die Regierung selbst gab.

15 ZAMIR 2000, S. 11. 
neuen Loyalitäten zum Staat oder zur Nation ${ }^{16}$. Wie in den anderen ehemaligen Nahostprovinzen des Osmanischen Reiches Irak, Palästina und Libanon gewann auch in Syrien der arabische Nationalismus, der seit der Jahrhundertwende aufgekommen war, in der Zwischenkriegszeit neue Anhänger und wurde, außer im Libanon, zur dominanten politischen Strömung in der Region $^{17}$. Das nationale Lager in Syrien spaltete sich aber angesichts der militärischen Überlegenheit Frankreichs bald in zwei Fraktionen ${ }^{18}$, die im Gegensatz zu der politischen Kräfteverteilung im Libanon aber beide explizit gegen das Mandat waren ${ }^{19}$.

Im Libanon gab es um 1925 ähnliche politische Lager, wenn auch die profranzösische Fraktion durch die Maroniten stärker vertreten war als in Syrien. Das zeigte sich unter anderem im Ergebnis der Wahlen vom Juni 1925, in denen, wenn auch unter massivem französischen Druck, Profranzösische und Befürworter des Konfessionalismus die Mehrheit erreich$\operatorname{ten}^{20}$. Neben den, hauptsächlich maronitischen, Vertretern des Libanismus, die erst in den 1930er Jahren für die Unabhängigkeit von Frankreich eintreten würden, und den Anhängern des arabischen Nationalismus, die sich für die Schaffung eines großen arabischen Staatsgebildes und die Einheit aller arabischen Staaten einsetzten und unter denen neben den Muslimen auch viele Angehörige der griechisch-orthodoxen Gemeinschaft waren, formierte sich ab 1928 eine Gruppe zur Vereinigung von Syrien und Libanon, die sich vor allem in den sognannten »Küstenkonferenzen« (arabisch Mu'tamarāt as-sāhil) sammelte und in der viele führende muslimische Familien vertreten waren ${ }^{21}$. Zwischen beiden Positionen gab es eine Gruppe von vornehmlich sunnitischen Notabeln, die sich ab 1925 mit der Mandatsmacht arrangierten und offizielle Positionen in Regierung und Verwaltung einnahmen, auch wenn sie weiterhin für eine Vereinigung von Syrien und Libanon eintraten $^{22}$. Die schier unübersichtliche politische Landschaft im Libanon wurde

16 Vgl. Khoury 1987, S. 217.

17 Vgl. Dawn 1988, S. 67. Dieser sehr informative Artikel betont allerdings sehr stark den Sozialismus als ideologische Kraft und vernachlässigt die Mitteklasse, die die neuere Forschung von Watenpaugh und anderen in den Mittelpunkt gerückt hat.

18 Die eine Fraktion wollte weiterhin absoluten Widerstand leisten, während die andere Fraktion für den Abzug der Mandatsmacht und die syrische Unabhängigkeit zu Verhandlungen mit Frankreich bereit war; aus dieser Gruppe gründete sich 1927 der Nationale Block (al-kutla al-wațanīya), der vor allem von den Panarabisten scharf kritisiert wurde. Vgl. Schumann 2001, S. 256-257.

19 Zur weiteren Entwicklung der Parteien in Syrien vgl. Kapitel 7.

20 Vgl. Firro 2003, S. 78.

21 Vgl. Raghid K. EL-Soln, Lebanese Arab Nationalists and Consociational Democracy during the French Period, in: Christoph Schumann (Hg.): Liberal Thought in the Eastern Mediterranean. Late $19^{\text {th }}$ Century until the 1960s, Leiden 2008, S. 217-238, hier 226-227.

22 Vgl. EdDÉ 2001, S. 92; Firro 2003, S. 134. Firro nennt die Familien Da uq, Bayhum und Adhab, die sich auch in der Mission laïque engagierten. 
zwischen 1926 und 1932 noch von der immerwährenden Rivalität zwischen den zwei Maroniten Eddé und Khuri bestimmt ${ }^{23}$. Während Khuri den Libanon in seinen Grenzen von 1920 erhalten wollte, dafür aber auf Kooperation mit den Sunniten setzte, optierte Eddé für die Reduzierung des libanesischen Staatsterritoriums, für die enge Anbindung des Libanons an Frankreich und für eine stark anti-arabische Haltung ${ }^{24}$. Abschließend muss unbedingt betont werden, dass die Machtkämpfe der unterschiedlichen Gruppen und religiösen Gemeinschaften, oft auch innerhalb dieser, häufig eine größere Rolle spielten als politische Überzeugungen ${ }^{25}$ : Aufgrund des konfessionellen Systems, in dem alle Ämter und Mandate nach der Religionszugehörigkeit festgelegt waren, sollten strategische Bündnisse über konfessionelle Grenzen hinweg den Gegner aus der eigenen Gemeinschaft schwächen ${ }^{26}$.

Interessanterweise erfolgte auch in dieser Zeit in der Direktion der Mission lä̈que française in Beirut ein personeller Wechsel, denn Émile Mathieu wurde von Lucien Ruche abgelöst. Mathieu wurde Direktor einer neuen Schule, welche die Mission lä̈que im syrischen Aleppo eröffnet hatte ${ }^{27}$. Da die Archive der Mission lä̈que keinerlei Dokumente über einen anstehenden Wechsel oder über personelle Debatten enthalten ${ }^{28}$, schien diese Entscheidung sehr kurzfristig gefallen und auf höherer Ebene getroffen worden zu sein. Möglicherweise stand sie in Verbindung zur Politik der neuen französischen Regierung, die im Nahen Osten die Zusammenarbeit mit den Muslimen stärken wollte. So attestierte in einer Notiz in Ruches Akte beim Erziehungsministerium ein gewisser G. Hardy Ruche »une connaissance approfondie des pays musulmans $\ll^{29}$. Es ist naheliegend, dass es sich bei dem Autor um Georges Hardy (1884-1972) handelte, einen bedeutenden Vertreter der staatlichen französischen kolonialen Erziehung, der lange Zeit in Nordafrika tätig war ${ }^{30}$. Aus diesem Grund ist zu vermuten, dass die französische Regierung Ruche besonders wegen seiner Vertrautheit mit den islamischen Ländern und seiner

23 Vgl. Salibi 1965, S. 175.

24 Vgl. Eyal Zisser, Lebanon. The Challenge of Independence, London/New York 2000, S. 17; Fadia Kiwan, La perception du Grand-Liban chez les maronites dans la période du mandat, in: Nadim Shehadi / Dana Haffar Mills (Hg.), Lebanon: A History of Conflict an Consensus, London 1988, S. 124-148, hier 130.

25 Vgl. Zamir 2000, S. 63.

26 Vgl. ebd., S. 63-84.

27 Dort blieb er sehr lange, wahrscheinlich bis zur Schließung der Schule aufgrund von politischen Unruhen 1945. Zur Person Mathieus vgl. MLF/Paris, »Liste du personnel«. Die Expansionspläne nach Syrien hatte die Mission laïque schon 1921 gehegt. Vgl. Revue de l'enseignement français hors de France 18 (1921), H. 16: Assemblée Générale Annuelle, 18.12.1921.

28 Zwar gibt es laut Index in den Archiven der Mission laïque française in Paris eine Personalakte über Ruche, aber leider war diese nicht aufzufinden.

29 AN/Paris, F 17/25346: Ruche, Lucien Charles, »Note«.

30 Siehe Hardys Biographie in der Einleitung zu seinem neu aufgelegten Buch: Georges HaRdY, Une conquête morale: l'enseignement en A.O.F., Paris 2005. 
Arabischkenntnisse ${ }^{31}$ in Beirut einsetzen wollte, um durch dessen umsichtiges Verhalten nicht weitere Muslime gegen Frankreich aufzubringen.

Aus den zwei Gründen, der stärkeren laizistischen Orientierung der Politik und dem Wunsch Frankreichs, weitere Aufstände zu unterbinden, erfuhr die Mission laïque française erhöhte Aufmerksamkeit durch die französische Regierung und ihre Vertretung in Beirut. Die Tatsache, dass die Präsidenten der Mission laïque verschiedene Regierungspositionen innehatten und der anti-klerikalen demokratischen Partei Parti radical angehörten, die ab 1924 Teil der Regierung war, förderte diese Unterstützung noch ${ }^{32}$. Paradoxerweise wählte das Hochkommissariat also eine laizistische Schule, die Neutralität propagierte, um eine bestimmte religiöse Gruppe, nämlich die muslimischen Gemeinschaften, verstärkt an sich zu binden. Diese waren Frankreich besonders kritisch gegenüber eingestellt und stellten den größten Anteil der arabischen Nationalisten. Da die französischen Akteure die Gruppen der Muslime und die der arabischen Nationalisten oft nicht klar trennten, wird es auch in dieser Arbeit teilweise zu einer Überschneidung der Bezeichnungen kommen.

Wie dieses Kapitel zeigen wird, kam es um 1925 nur sehr bedingt zu einer Anpassung der französischen Bildungseinrichtungen an die neuen Verhältnisse im Libanon, die Schulen beteiligten sich aber ebenso wie andere Gesellschaftsgruppen rege an den Debatten über die bildungs- und allgemeine politische Ausrichtung des Landes. Das erste Unterkapitel zeigt dies an Diskurs und Praxis der Zivilisierungsmission. Unterkapitel zwei widmet sich den libanesischen Akteuren als aktive Kollaborateure in den französischen Schulen selbst und problematisiert deren ambivalente Position zwischen Abhängigen und Vermittlern. Das dritte Unterkapitel untersucht die Mädchenschulen als besonderen Fokus der libanesischen Debatten in der zweiten Hälfte der 1920er Jahre und zeigt die Positionierungen der französischen und der libanesischen Akteure zwischen Emanzipierung und Beschränkung der Frauenbildung gleichermaßen. Unterkapitel vier macht schließlich anhand des Geschichts- und Geographieunterrichts deutlich, dass die Schulen einen zentralen Beitrag zur Konstruktion der libanesischen Geschichte leisteten, aber nicht dazu beitrugen, eine einheitliche Geschichtsvision zu entwerfen.

31 Vgl. Kapitel 1.3. Die dezidiert laizistische Einstellung Ruches mag ein weiterer Grund gewesen sein. In einem Brief nach Paris 1927 betont er seine neutrale Haltung gegenüber den Katholiken, bemerkt aber auch, dass man seinen Namen in einem Taufregister nur schwer finden könne. Vgl. AN/Paris, 60 AJ 130, Brief von Ruche an Besnard, Beirut, 03.11.1927.

32 Jean-Baptiste Bienvenu-Martin (Präsident von 1912 bis 1930) war von 1905 bis 1943 Senatsmitglied, und Édouard Herriot (Präsident 1930 von 1957), Generalsekretär der Parti Radical, war von 1905 bis 1940 und 1945 bis 1957 Bürgermeister von Lyon und unter anderem von 1926 bis 1928 französischer Bildungsminister. 


\section{Der Versuch einer Laizisierung der Zivilisierungsmission}

Um 1925 kam es trotz der geschildertern Umstände nur sehr bedingt zu einer stärkeren Laizisierung der Idee der Zivilisierungsmission. Die französischen Autoritäten weiteten sie zwar aus und betonten stärker die Zugehörigkeit aller Institutionen, durchschnitten aber, mit Ausnahme von Sarrail, mitnichten das Band mit den katholischen Kreisen. Ferner unterstützte die Klientel der Mission laïque zwar den Laizismus der Schule, aber nur zum Teil wegen ihrer ideologischen Überzeugung. Um ihrer Klientel gerecht zu werden, passte die Mission laïque wiederum ihr Verständnis von Laizismus stark dem lokalen Kontext an, behielt aber gleichzeitig ihre Sichtweise auf Religion aus Frankreich bei. Die französischen und libanesischen Katholiken schließlich kritisierten den Laizismus vehement.

Wenn im Folgenden von Laizismus die Rede ist, meint dieser eine spezifische Form des Säkularismus, welche in Frankreich geprägt wurde. Bezeichnet der Begriff Säkularismus sowohl die Trennung der religiösen von der weltlichen Sphäre als auch die langsame Zurückdrängung des Religiösen aus dem öffentlichen Raum (eine These, die in letzter Zeit wieder stark relativiert wurde ${ }^{33}$ ), fordert der Laizismus eine strikte Trennung beider Sphären und den Ausschluss des Religiösen aus dem öffentlichen Bereich ${ }^{34}$. Im Folgenden benutze ich die Begriffe Laizismus und Säkularismus synonym. Diese Herangehensweise wird ferner dadurch gerechtfertigt, dass die arabischsprachigen Dokumente der Zeit nur das Wort al-'almānīya (Säkularismus) verwendeten, und manchmal von der Schule der Mission lä̈que als »al-lāīk» sprachen und somit keine Trennung zwischen beiden Begriffen vornahmen.

Die Tatsache, dass die französische Regierung und ihre Vertretung in Beirut der Mission laïque und damit dem Laizismus, den sie vertraten, ab 1925 eine neue Aufmerksamkeit und Wertschätzung entgegen brachten, bedeutet nicht, dass alle Funktionäre nun zu Fürsprechern des Laizismus geworden waren ${ }^{35}$. Aber auf der diskursiven Ebene kam es zu einer Ausweitung ihres Verständnisses der Zivilisierungsmission. Die Regierungsvertreter in Paris betonten nun, dass alle Schulen, also auch die laizistischen, Teil der »même tâche civilisatrice« seien ${ }^{36}$. In seinem Brief an den neu designierten Hochkommissar Sarrail betonte Ministerpräsident Herriot aber auch den Respekt vor der jahrhundertelangen Arbeit der Missionare in der Levante

33 Vgl. José Casanova, Europas Angst vor der Religion, Berlin 2009, S. 83-93.

34 Vgl. Winfried Becker, Christliche Parteien im Frankreich des 19. und 20. Jahrhunderts, in: Benedikt Kranemann/Miriam Wijlens (Hg.), Religion und laïcité in Frankreich, Würzburg 2009, S. 17-33, hier 17-19.

35 Wie Fournié zeigt, war die Gruppe der antiklerikalen Funktionäre zwar gewachsen, aber verdrängte nicht vollständig die prokatholischen Beamten. Vgl. FourniÉ 2002, S. 136.

36 MAE/Paris, CPC, 378: 1922-1929, Brief von Herriot an Sarrail, 27.12.1924. 
und den dortigen Christen, den »populations anciennement attachées à la France $\ll^{37}$.

Die Politik Sarrails, der im Januar 1925 nach Beirut kam, zeigte, dass er diese Warnungen nicht sehr ernst nahm. Viel radikaler als seine Nachfolger kritisierte er die katholischen Schulen ${ }^{38}$. Außerdem brüskierte er den katholischen libanesischen Klerus, indem er sowohl den traditionellen Besuch beim maronitischen Patriarchen als auch die Teilnahme an der katholischen Messe, die zu Ehren jedes neuen Hochkommissars abgehalten wurde, ausschlug ${ }^{39}$. Umso mehr Gewicht bekam die Tatsache, dass Sarrail seinen ersten Besuch bei der Mission laïque absolvierte und seine Kinder an dieser Schule anmeldete ${ }^{40}$. Außerdem überreichte er der Schule eine Spende von 50000 Francs, die einzige finanzielle Unterstützung durch das Hochkommissariat, die jemals in den Archiven der Mission laïque auftauchte ${ }^{41}$. Auch General Vandenberg, französischer Gouverneur des Grand-Liban, stattete der laizistischen Schule im Oktober 1924 einen Besuch ab und pries den »libéralisme éclairé qui inspire l'œuvre de la Mission laïque $\ll^{42}$.

Trotz des offensichtlichen Wandels, der in der Vorgehensweise der französischen Autoritäten stattgefunden hatte, blieben die katholischen Schulen fester Bestandteil der Mandatspolitik. Als Sarrail Pläne entwickelte, das libanesische Hochschulwesen an die Mission lä̈que anzubinden, wurden diese von Paris sofort unterbunden. Der Hochkommissar wurde angehalten, an den katholischen Schulen nicht zu rütteln und den »caractère spécial de nos œuvres d'enseignement en Syrie« zu respektieren: »Antérieures au mandat, elles en constituent une des principales justifications et non pas une des conséquences « ${ }^{43}$. Auch wenn er schon nach wenigen Monaten zurück nach Paris beordert wurde, hatte sein Verhalten Wirkung erzielt, wie die Reaktion der katholischen Kreise im Libanon zeigen wird.

Sarrails Nachfolger Jouvenel beendete die privilegierte Unterstützung der Mission laïque. Zwar besuchte er auch die laizistische Schule und hielt eine positive Rede über die Einrichtung ${ }^{44}$. Sein Ansinnen war aber, alle französischen Schulen im Libanon in den Blick zu nehmen. Aus diesem Grund lud

37 Ebd.

38 Vgl. ebd., »Instruction Publique Dossier général«, 1922-1929. In einem Brief an das Außenministerium berichtete ein Mitglied der Frères des Écoles chrétiennes von seinem Besuch bei Sarrail, der das Niveau ihrer Lehrer kritisiert und jegliche Besuche abgelehnt hatte.

39 Vgl. Fournié 2002, S. 151.

40 AN/Paris, 60 AJ 127, »Rapports mensuels«, Januar 1925. Zur Tragweite und Tragik des kurzlebigen Hochkommissariats unter Sarrail siehe FourniÉ 2002.

41 Vgl. AN/Paris, 60 AJ 127, »Compte de Gestion«, Brief von Ruche an den Schatzmeister der Mission laïque, Beirut, 08.04.1926: »Subventions SARRAIL (sic) 50.000,00!«.

42 AN/Paris, 60 AJ 126, Brief von Mathieu an Besnard, Beirut, 31.10.1924.

43 MAE Paris, CPC 378: 1922-1929, Brief von Berthelot an Sarrail, Paris, 30.06.1925.

44 Vgl. AN/Paris, 60 AJ 128, »Rapports mensuels«, Dezember 1925. Laut Ruche wurde die Rede Jouvenels wie auch seine eigene in der Zeitung La Syrie wiedergegeben. 
er für den neu gegründeten »Conseil de l'Instruction Publique«, der sich mit den Fragen der Erziehung beschäftigte, auch die katholischen Schulen mit $e^{4}{ }^{45}$. Noch stärker als bei Sarrail und Jouvenel wird bei Hochkommissar Ponsot deutlich, dass er die Mission lä̈que nicht aus dem Grund unterstützte, weil er deren Laizismus teilte und für besonders fortschrittlich hielt, sondern als Kalkül, um die muslimische Bevölkerung zu erreichen. Beispielsweise richtete er sich Ende 1927 an die Mission lä̈que, um explizit muslimische Angestellte für die Banque de Syrie et du Grand Liban zu rekrutieren ${ }^{46}$.

Neben den Hochkommissaren spielte auch der Bildungsbeauftragte des Hochkommissariats eine entscheidende Rolle für die Frage des Laizismus in der Orientierung der Schulpolitik. Gabriel Bounoure, seit 1923 Duthoits Nachfolger, vertrat eine gemäßigtere Tendenz, er teilte nicht »l'anticléricalisme outrancier du général Sarrail $\ll{ }^{47}$. Allerdings machen die Archive der Mission lä̈que deutlich, dass er der laizistischen Organisation nicht so nahestand wie Jérôme Bocquet annimmt ${ }^{48}$. Zwar nahm er an vielen Veranstaltungen der laizistischen Schule teil ${ }^{49}$, aber es gab auch viele Unstimmigkeiten zwischen beiden Parteien ${ }^{50}$. In der Tat hielt er nicht nur zur Mission lä̈que seinen Abstand, sondern pflegte auch gute Beziehungen zu den französischen Ordensschulen $^{51}$. Unter anderem nahm sich der Jesuit Jalabert, der die Universität Saint-Joseph in Paris vertrat, in Frankreich seines Sohnes, Jean Bounoure, an, wofür ihm Bounoure sehr dankbar war ${ }^{52}$. So ergibt sich das Bild eines Mannes, der von keinem Lager vereinnahmt werden, sondern seine Handlungsspielräume behalten wollte.

45 Vgl. SJ/Vanves, »Fonds Jalabert«, 1-1 F, Brief von Jouvenel an den Rektor der Université SaintJoseph, Beirut, 11.01.1926.

46 Vgl. AN/Paris, 60 AJ 130, »Beyrouth Correspondance 1927-1928«.

47 Jérôme Bocquet, Gabriel Bounoure et les congrégations enseignantes, in: Gérard D. KHOURY (Hg.), Vergers d'exil. Gabriel Bounoure, Paris 2004, S. 205-221, S. 220.

48 Vgl. ebd., S. 215.

49 Vgl. AN/Paris, 60 AJ 126, Brief von Mathieu an Besnard, Beirut, 31.10.1924; vgl. auch AN/ Paris, 60 AJ 129, Brief von Ruche an Besnard, Beirut, 26.11.1926: Bounoure hatte Ruche auf eigene Initiative hin für die »palmes académiques« vorgeschlagen; vgl. auch AN/Paris, $60 \mathrm{AJ}$ 132, Brief von Ruche an Besnard, Beirut, 05.02.1930.

50 Vgl. z.B. AN/Paris, 60 AJ 130, »Beyrouth Correpondance 1927-1928«: Als es wegen nicht näher definierter Umstände zu Intrigen in Zusammenhang mit der Mission laïque und Bounoure kam, verkündete Generalsekretär Besnard, er werde Hochkommissar Ponsot, mit dem er indirekt kommuniziere, »demander de rappeler à $\mathrm{M}$. Bounoure les obligations de sa fonction«.

51 Vgl. SJ/Vanves, »Fonds Jalabert«, 26/S: die »Correspondance du P. Jalabert avec M. G. Bounoure janvier 1936-1939« zeugt von einer großen Vertrautheit zwischen dem Bildungsbeauftragten und dem Repräsentanten der Jesuiten, die auch einige Abmachungen wie die bezüglich der militaires détachés auf informellem Wege ermöglichte.

52 Vgl. ebd., Brief von Bounoure an Jalabert, Beirut, 26.12.1938: »Nous ne saurions oublier, ma femme et moi, le grand service que vous avez rendu à Jean. Nous en gardons une vive et profonde gratitude, non pas seulement à cause de la matérialité et de l'importance de ce bon office, mais encore et surtout à cause de la nuance si amicale du sentiment que vous y avez apporté $[\ldots] \ll$ 
Neben der Einstellung der Regierung waren die Erwartungen und Vorstellungen ihrer Klientel für das Laizismusverständnis der Mission laïque von entscheidender Bedeutung. Die Eltern, die sich zur Frage des Laizismus äußerten und diesen unterstützten ${ }^{53}$, können in ein pragmatisches und ein ideologisches Lager aufgeteilt werden. Auf der einen Seite gab es die Eltern aus muslimisch religiösen, politisch eher konservativen Familien, die sich des Laizismus pragmatisch bedienten, um ihre soziale Position im Libanon zu verbessern. Notabeln wie 'Umar Da'uq, der zur gleichen Zeit im Vorstand der Maqasid war ${ }^{54}$, hätte die Religion sogar lieber noch stärker in der laizistischen Schule verankert: er fragte 1920 an, ob der muslimische Scheikh, der Arabisch unterrichte, nicht auch den Kindern, die dies wünschten, Religionsunterricht erteilen könne ${ }^{55}$.

Die Eltern dieser Gruppe formulierten in einer Sitzung des Elternrates (Comité de patronage ${ }^{56}$ ) im November 1925: „Laïcisez la Faculté de Droit! «57. Dabei ging es ihnen aber nicht um die Implementierung des Laizismus innerhalb der libanesischen Gesellschaft. Vielmehr forderten sie, dass die juristische Fakultät der Université Saint-Joseph, welche von den Jesuiten geleitet wurde, nicht mehr nur den Schülern der Jesuiten nützen, sondern allen Gemeinschaften offen stehen solle. Das heißt, diese Väter forderten den Laizismus um seiner neuen finanziellen und sozialen Möglichkeiten für sie als Nicht-Katholiken willen. Damit transportierten sie die öffentlichen Beschwerden vieler sunnitischer Familien dieser Zeit, die das von ihnen als Ungleichgewicht empfundene Verhältnis zwischen Steuerzahlungen und Regierungsund Verwaltungspositionen, welche sie zu Gunsten der Maroniten verteilt sahen, anprangerten ${ }^{58}$, gewissermaßen direkt in den Klassenraum.

Diesem pragmatischen Lager stand die Gruppe von Eltern und Schülern gegenüber, die den Laizismus aus inhaltlicher Überzeugung unterstützte. Einige dieser Akteure waren Freimaurer, die mit der Mission lä̈que sympathisierten, weil sie sich für eine weniger zentrale Rolle der Religion im

53 Man darf in der Tat nicht vergessen, dass es viele Eltern gab, die zu der Frage keine spezifische Meinung hatten oder diese nicht dokumentiert haben.

54 'Umar Da'uq war seit 1908 Mitglied des Verwaltungsrates der Maqasid, 1913-1914 deren Präsident, 1931-1934 Vizepräisdent und von 1934 bis 1949 wieder Präsident. Von Beruf Uhrmacher, war Da'uq außerdem von 1912 bis 1949 Präsident der Handelskammer von Beirut. Schließlich gehörten die Da uqs zu den sieben bekanntesten Familien. Ihre Abstammung führten sie direkt auf den Propheten zurück. Vgl. EDdÉ 2008, S. 507.

55 Vgl. AN/Paris, 60 AJ 123, Brief von Lehéricy an Besnard, Beirut, 20.12.1920. Diese Anfrage lehnte der Generalsekretär strikt ab, da sie »contrairement à nos principes« sei und für die Zukunft gefährliche Folgen haben könnte.

56 »Elternrat« ist nicht ganz die korrekte Übersetzung des Begriffes »comité de patronage«, der noch umfassender eine Schirmherrschaft über die Schule bedeutete. Da aber die meisten Mitglieder des Komitees Eltern von Schülern waren, wird hier der Begriff Elternrat gewählt.

57 AN/Paris, 60 AJ 127, »Comité de patronage«, Sitzung vom 11.11.1925.

58 Vgl. Firro 2003, S. 134. 
öffentlichen Leben einsetzten. Dazu gehörte der Mandatskritiker Gibran Tuéni (arabisch Ğibrān Tuwaynī), der seine Zeitung al-Aḥrār der Mission laïque für Bekanntmachungen zur Verfügung stellte ${ }^{59}$. Ein anderer Freimaurer war Félix Farès (arabisch Fīlīks Fāris) ${ }^{60}$, der der Mission laïque von seiner neu gegründeten Gesellschaft »pour la propagande de l'enseignement laïc en Syrie« berichtete ${ }^{61}$.

Welchen Einfluss die Mission lä̈que auf die syrischen und libanesischen Freimaurer hatte, zeigt auch ein Brief des Großmeisters der Grande Loge de France an den damaligen Ministerpräsidenten und Außenminister Raymond Poincaré vom Mai $1923^{62}$. In diesem Brief berichtete er von der neu gegründeten Organisation der »libéraux du Grand Liban et de la Syrie«, deren Ziel die Verbreitung des laizistischen Bildungswesens in ihrem Land sei. Das dem Hochkommissariat unterbreitete Programm sehe zunächst 100 Schulen, dann Kurse an der »Université laïque française de Beyrouth« vor; die Schulen würden auf Französisch und Arabisch unterrichten, und Vorbild sei das Programm der Mission lä̈que française ${ }^{63}$. Diese Initiativen entsprachen dem Mitgliederboom, welchen die französischen Logen in Syrien und Libanon in dieser Zeit erfuhren ${ }^{64}$. Die Verbindung der Mission lä̈que mit den Freimaurern war also seit den Anfängen der laizistischen Schulen nicht abgebrochen und setzte sich auch während des Mandats fort ${ }^{65}$. Allerdings berichten die Protokolle der Elternratssitzungen nie offen von dieser Verbindung.

Ferner unterstützte eine Gruppe liberaler Intellektueller die Idee des Laizismus. Dazu zählte federführend Khalil Taqi ad-Din, der der Mission laïque auch nach seiner Schulzeit treu blieb. 1930 wollte er als Präsident der Ehemaligenvereinigung die Alumni-Zeitschrift der Schule unter einem deutlich laizistischen Vorzeichen neu herausgeben und unter den Abonnenten nicht nur die Ehemaligen, sondern alle "partisans de la laïcité et des idées libérales« wissen. Als Namen der Zeitschrift schwebte ihm La Revue laïque vor, denn das Ziel war die Verbreitung der laizistischen Prinzipien: »Le but de cette

59 Vgl. AN/Paris, 60 AJ 139, Brief von Besnard an Grandjouan, Paris, 10.11.1936.

60 Vgl. Makdisi-Khuri 2006, S. 5: Fāris, Besitzer der Zeitung Lisān al-ittiḥād, war vor dem Ersten Weltkrieg Anhänger der Jungtürken gewesen.

61 Vgl. AN/Paris, 60 AJ 127, Brief Mathieu an Besnard, Beirut, 05.01.1925.

62 Vgl. MAE/Paris, 378, Brief des Großmeisters an Poincaré, Paris, 05.05.1923.

63 Ebd.

64 Vgl. Thierry Millet, La Franc-maçonnerie en Syrie sous l'administration française (19201946), in: Cahiers de la Méditerranée 72 (2006), S. 4. URL: http://cdlm.revues.org/index1178. html (10.09.2010).

65 Beispielsweise berichtete Lehéricy 1920 von einem Stipendium, das die Freimaurerloge $»$ Le Liban« zur Verfügung stelle, aber nicht genug Geld habe, es ganz abzudecken. Lehéricy bat die Zentrale in Paris deshalb, dieses Anliegen der Freunde der Mission laïque zu unterstützen: »Un geste généreux de la Mission plairait aux franc-maçons de Beyrouth qui sont tous amis, et presque tous actifs amis, de notre œuvre«. AN/Paris, 60 AJ 124, »Bourses«, Brief Lehéricy an Besnard, Beirut, 20.10.1920. 
revue sera de propager les principes de laïcité parmi les populations de la Syrie et du Liban $\aleph^{66}$. Seinem Brief an den Direktor legte er auch einen Kostenvoranschlag bei.

Vielleicht war dieser zu hoch und das Projekt fand deshalb keine Fortführung. Es ist aber auch zu vermuten, dass den Verantwortlichen der Mission laïque ein zu offensives Auftreten Taqi ad-Dins nicht recht war, weil es die konservativen religiösen Vertreter irritieren würde. Als Druse und liberaler Intellektueller stand Taqi ad-Din im Gegensatz zu der Gruppe der sunnitisch konservativen Notabeln, die auf die Mission lä̈que großen Einfluss hatten. Letztere bestimmten maßgeblich die Praxis des Laizismus der Mission laïque. Im Mai 1928 hatte Taqi ad-Din im Rahmen der Ehemaligenaktivitäten einen Vortrag über Țāhā Ḥusayn gehalten. Der ägyptische Intellektuelle und Professor an der Universität von Kairo vertrat eine sehr liberale Auffassung des Islam und setzte sich für den Gebrauch westlicher Denkmuster wie des Laizismus und der kartesianischen Methode des Zweifels ein, um die islamische Tradition zu erneuern ${ }^{67}$. Diese Forderungen setzte er selbst in seinem Buch $F \bar{l}$ aš-ši 'r al-ğăhili (Zur vorislamischen Poesie), welches 1926 erschien und sich primär mit der Frage der Authentizität der vorislamischen Dichtung auseinandersetzte, um: Sein Ziel war nicht, die Glaubwürdigkeit des Korans in Frage zu stellen, aber er postulierte, die vorislamische Poesie sei a posteriori konstruiert worden, um die islamische Dichtung noch deutlicher von dieser absetzen zu können ${ }^{68}$. Das Werk löste eine große Polemik in Ägypten und der arabischen Welt aus und erneuerte die Kritik der konservativen religiösen Vertreter an seinem Denken ${ }^{69}$. Husayn wurde 1930 als Professor der Universität in Kairo entlassen ${ }^{70}$.

In seiner Rede bei der Mission laïque rühmte Taqi ad-Din Ḥusayns Werk, was ihm, wie ein Bericht des Ehemaligenkomitees belegt, sowohl viel Lob als auch Kritik in der Presse einbrachte: »[...] les idées émises par Khalil

66 AN/Paris, 60 AJ 133, Brief von Taqi ad-Din an Ruche, Beirut, 06.03.1930. Interessanterweise finden sich in den Quellen, die sich mit der Frage des Laizismus beschäftigen, keine Verweise auf die Türkei, die ja in dieser Zeit ein Beispiel für praktizierten staatlichen Säkularismus in der Region war.

67 Vgl. YARED 2002, S. 103. Țāhā Ḥusayn hatte während des Ersten Weltkrieges in Frankreich studiert und wurde 1919 an der Sorbonne mit einer Studie über Ibn Haldūn promoviert. Das heißt, dass er mit der französischen Kultur und Wissenschaft aus eigener Erfahrung vertraut war.

68 Vgl. Elizabeth Suzanne KASSAB, Contemporary Arab Thought. Cultural Critique in Comparative Perspective, New York 2010, S. 41. Daneben behandelte er auch die Frage, ob alles was im Koran steht, als Tatsache oder manches auch als Symbol zu bewerten sei.

69 Vgl. Jean Lacouture/Ghassan TuÉNi/Gérard Khoury, Un siècle pour rien. Le Moyen-Orient arabe de l'Empire ottoman à l'Empire américain, Beirut 2003, S. 345. 1927 brachte Husayn eine zweite Auflage des Buches heraus, in deren Einleitung er Stellung zu den Vorwürfen nahm und sich, aus Sicht mancher Kritiker, von den früheren Behauptungen distanzierte, aus Sicht anderer hingegen diese wiederholte und sogar verschärfte.

70 Vgl. Kassab 2010, S. 41-42. 
Takieddine [Khalil Taqi ad-Din] sont louées ou combattues « ${ }^{71}$. Auch in seinem eigenen literarischen Werk, das sich mit Themen wie der Beziehung zwischen Stadt und Land und dem Nationalismus befasste, erwähnt Taqi adDin die Religion nie, was die Vermutung nahelegt, dass er den Laizismus der Mission lä̈que positiv aufgenommen hatte ${ }^{72}$.

Aus diesem Grund muss man kritisch die Frage stellen, ob das Ziel der Organisation auch 20 Jahre nach ihrem Beginn in Beirut weiterhin lautete, »exporter la laïcité républicaine«, wie Randi Deguilhem in ihren Studien über die Mission laïque in Syrien postuliert hat ${ }^{73}$. Vielmehr praktizierte die laizistische Organisation ein ambivalentes Laizismuskonzept: Einerseits passten die Schulen der Mission laïque ihr Verständnis und ihre Praxis von Laizismus dem lokalen Kontext an, andererseits zeigte ihr Diskurs über die Religion im Libanon, dass sie ihre negative Sichtweise auf die Religion und deren politische Rolle aus Frankreich beibehalten hatten.

Diese Anpassung bedeutete allerdings nicht, dass die Schule der Mission laïque ihre Verwurzelung im französischen Laizismus und in der laizistischen Pädagogik völlig ignorierte. Auch in Beirut blieb sie, im Gegensatz zu den katholischen Schulen, der Tradition der republikanischen und laizistischen Pädagogik aus Frankreich verbunden und rezipierte und verbreitete diese. Über die institutionseigene Zeitschrift waren die Lehrer sehr genau über die Diskussionen der laizistisch geprägten Pädagogik in Frankreich informiert: Deren Artikel handelten von der von Ferdinand Buisson verfassten »conception laïque de l'enseignement $\aleph^{74}$ oder von den $»$ devoirs de l'éducateur laïque « ${ }^{75}$. Besonders um 1930 gab es viele Veröffentlichungen über das »Cinquentenaire de l'école laïque« und über die Beziehung zwischen Bildung und Laizismus ${ }^{76}$.

Der laizistische Bezug verschwand auch nicht aus der Praxis der Schule. 1929 hielt der Lehrer Jean Parisot in der Aula der Schule einen Vortrag über das Thema »Comment la France est devenue laïque «77. Höchstwahrscheinlich war es innerhalb dieser Vortragsreihe, dass Parisot die Jesuiten, den Papst und die Bibel stark kritisierte, wie eine Notiz in den Archiven des

71 AN/Paris, 60 AJ 130, »Amicale des anciens élèves«, Mai 1928, S. 2.

72 Vgl. Martin-Fernandez 2009, S. 293.

73 Randi Degullhem, Exporter la laïcité républicaine: la Mission laïque française en Syrie mandataire, pays multiconfessionnel, in: Pierre-Jean Luizard (Hg.), Le choc colonial et l'islam. Les politiques religieuses des puissances coloniales en terre d'islam, Paris 2006, S. 383-398, S. 398: »Elle [die Mission laïque] les [die indigene Bevölkerung] engage tous à rallier la laïcité«.

74 Revue de l'enseignement français hors de France 21 (1924), H. 39, S. 128-129: Journal Officiel, Ferdinand Buisson »La conception laïque de l'enseignement «.

75 Revue de l'enseignement français hors de France 26 (1929), H. 81, S. 224-225: »Devoirs de l'éducateur laïque«.

76 Revue de l'enseignement français hors de France 28 (1930), H. 92 und 93.

77 AN/Paris, 60 AJ 131, »Réunion des professeurs«, Januar 1929. 
Außenministeriums berichtet: Als Reaktion »seien 15 Schülerinnen von der Mädchenschule genommen worden und wüste Beschimpfungen in der katholischen Presse stünden bevor ${ }^{78}$.

Allerdings versuchte die Mission laïque nicht, ,französische Verhältnisse` auf den Libanon anwenden zu wollen. Im Gegenteil betonten die Verantwortlichen ihre absolute Neutralität gegenüber dem Glauben ihrer Schüler. Dazu gehörte auch, dass sie ihre Schüler nicht zum Laizismus bekehren wollten, wie ein Manifest 1920 betonte: »[...] elle ne veut faire du Mahométan un Chrétien ou un Libre-Penseur [... $\ll^{79}$. Interimsdirektor Lehéricy rechtfertigte diese Haltung auch mit der Forderung seiner libanesischen Klientel nach einer neutralen Schule: »S'ils ne veulent pas de la Congrégation qui divise en religion, ils ne veulent pas d'une école laïque qui ne serait pas totalement neutre ${ }^{80}$. Die Idee Ruches von 1927, die Schule der Mission laïque in Beirut nach Marcellin Berthelot, einem bekennenden Verfechter des Laizismus und wohl auch Freimaurer zu benennen, hielt die Zentrale der Organisation in Paris deswegen auch für zu heikel, um die Neutralität der Schule zu bewahren ${ }^{81}$.

An diesen Beispielen zeigt sich also einerseits ein größeres laizistisches Selbstbewusstsein der Mission lä̈que, andererseits werden aber auch dessen Grenzen offenbar. In der Praxis überwog sogar noch das Postulat des Respekts gegenüber dem der Neutralität. Auf diese Weise passte die Mission laïque ihr Verständnis von Laizismus dem lokalen Kontext an. So durften die Schüler ihre religiösen Rituale auch innerhalb der Schule praktizieren. Die Archive dokumentieren dies beispielsweise für das Fasten der muslimischen Schüler während des Ramadans 1922: »L'autorisation d'observer le ramadan a été accordée aux élèves internes qui en firent la demande $\left(9\right.$ en tout) $\ll^{82}$.

Allerdings hatte auch die Gewährung religiöser Praktiken ihre Grenzen. Das zeigte sich unter anderem an dem Umgang mit religiösen Feiertagen in der Schule der Mission laïque. Jede der Konfessionen, die innerhalb der Schülerschaft vertreten waren, hatte ihre eigenen Feiertage. Als sich im Mai 1923 die Feiertage der jeweiligen Konfessionen zu sehr häuften, beschloss Mathieu, den Schülern nicht freizugeben. Das bedeutete allerdings, so Mathieu in seinem Brief nach Paris, konsequenterweise auch, den traditionellen Feiertag des katholischen Pfingstmontags nicht freizugeben ${ }^{83}$. Auch

\footnotetext{
$78 \mathrm{Vgl}$. MAE/Nantes, SOFE, 223, »Note«, ohne Datum und Absender.

79 Revue de l'enseignement français hors de France 17 (1920), H. 1, S. 5.

80 AN/Paris, 60 AJ 123, Brief von Lehéricy an Besnard, ca. 22.10.1920.

81 Siehe die Diskussion in AN/Paris, 60 AJ 130, »Beyrouth Correspondance 1927-1928«.

82 AN/Paris, 60 AJ 124, »Rapports mensuels«, März 1922.

83 »Les fêtes du Rameau ont eu lieu les 17/18/19 mai; l'ascension orthodoxe tombait le 17 mai; La Pentecôte orthodoxe les 27 et 28 mai. Il n'a été donné aucun congé à ces fêtes religieuses trop fréquentes et il a paru par suite impossible de donner le congé traditionnel du Lundi de Pentecôte catholique le 21 mai«. AN/Paris, 60 AJ 125, »Rapports mensuels«, Mai 1923.
} 
1925 zeigten sich die Grenzen des Respekts gegenüber der Religion ihrer Zöglinge, als ein jüdischer Schüler aus Bagdad der Schule verwiesen wurde, weil er nur koscheres Fleisch essen wollte. Die Zentrale bestärkte den Direktor in seiner Entscheidung und führte als oberstes Prinzip die Aufrechterhaltung der Ordnung an: »Si nous devons [...] nous montrer large quand il s'agit de laisser les élèves libres de pratiquer leurs devoirs religieux, encore faut-il que ces pratiques ne puissent troubler le bon ordre de l'établissement et créer un précédent fâcheux $\ll^{84}$.

Wie wichtig die Toleranz der Mission lä̈que gegenüber der Religion ihrer Schüler für die Libanesen über die Zeit um 1925 heraus blieb, machte ein Zeitungsartikel von 1936 deutlich.

In der arabischsprachigen Zeitung an-Nahār, welche Ğibrān Tuwayn̄̄ gehörte, drückte der Autor Muḥammad Rafīq aš-Šahbī sein Erstaunen und seine Freude aus über die Bereitschaft der Mission laïque, ihre Schüler in die Moschee gehen zu lassen:

Die Studenten der säkularen Fakultät in der Moschee in Rās an-Nab'a [Stadtteil von Beirut, E.M.].

$\mathrm{Zu}$ uns ist folgendes aus der Feder des geehrten Besitzers der Unterschrift gekommen: Ich bin letzten Freitag in die Moschee Rās an-Nab a für die Verrichtung des Freitagsgebets gegangen und war sehr erstaunt, die Moschee übervoll mit Studenten vorzufinden. Sie saßen um den Scheikh herum und hörten aufmerksam und begierig zu, was er ihnen von den Dingen der Religion und des Lebens erzählte. Und als ich fragte, antwortete man mir, dies sei eine Gruppe von Studenten aus der laizistischen Schule.

Sie hatten beim Direktor um Erlaubnis gebeten, das Freitagsgebet in der Gruppe verrichten zu dürfen, und er hatte ihre Bitte mit Freude akzeptiert. Und da es sich um eine wohltätige Sache handelt, klein in der Form, aber groß in der Wirkung, machte sie tiefen Eindruck auf mich, und ich begann, ihren Geist zu verbreiten - denn den Leuten etwas einzuflüstern, ist ein kluger Schachzug -, ganz in der Hoffnung, dass die Direktoren der ausländischen Schulen das Verhalten ihres Kollegen, des Direktors der laizistischen Schule, nachahmen. Denn darin liegt ein guter Verwaltungsstil und ein freundliches Miteinander. Denn die Religion gehört Gott ${ }^{85}$, und wir alle gehören zum Vaterland ${ }^{86}$.

Dies bedeutet allerdings nicht, dass die religiösen Freiheiten vor allem den muslimischen Schülern gewährt wurden. Die Tatsache, dass die Mission

84 AN/Paris, 60 AJ 128, »Rapports mensuels«, Oktober 1925.

85 Hier scheint es sich um eine Abwandlung des ägyptischen Revolutionsslogans der Wafd-Partei von 1919 (»Gott gehört die Religion, uns allen das Vaterland (ad-dīn li-llah wa-l-wațan li-1-

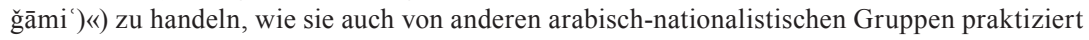
wurde. Vgl. KRÄMER 2003, S. 161.

86 AN/Paris, 60 AJ 138, Zeitungsartikel von an-Nahār, Datum unleserlich, vielleicht 01.02.1936. 
laïque nur christliche Arabischlehrer eingestellt hatte, weil die christlichen Eltern keinen muslimischen Arabischlehrer akzeptiert hatten ${ }^{87}$, bezeugt die Rücksichtnahme der Organisation auf die religiösen Gefühle aller Erziehungsberechtigten. In diesem Sinne protestierte Direktor Ruche in einem Schreiben 1928 an die Zentrale in Paris gegen die Politik des Hochkommissariats, den Laizismus vorwiegend auf die muslimischen Gemeinschaften anzuwenden: »On veut cantonner la laïcité dans la communauté musulmane et nous réserver les pays Druzes et musulmans $\ll^{88}$. Vielmehr hoffte die Mission laïque, ihre Klientel noch weiter auf das christliche Milieu ausweiten zu können und so in allen Gemeinschaften präsent zu sein ${ }^{89}$.

Trotz des Respekts, den die Mission lä̈que den religiösen Ritualen ihrer Klientel entgegenbrachte, passten viele ihrer Akteure ihre negative Einstellung gegenüber der Religion, die sie aus Frankreich mitgebracht hatten, nicht dem lokalen Kontext an. Auch in anderen kolonialen Kontexten kam es zu diesem Transfer der Perzeption von Religion ${ }^{90}$. Das zeigte sich zum einen in dem Unverständnis und Missfallen Ruches gegenüber dem Fastenmonat der Muslime, bei dem das Postulat des Respekts vor der Religion der Schüler reine Formalität blieb:

Cependant, le Coran n'impose pas aux étudiants l'obligation du jeûne! À plus forte raison à de jeunes enfants tels que la Division primaire [...]. Il serait souhaitable que le collège puisse s'affranchir de cette tradition: mais sera-ce jamais possible ? Les observances religieuses sont de plus en plus exactement pratiquées par toute la population ${ }^{91}$.

Neben dem persönlichen Befremden, das Ruche gegenüber dem muslimischen Gebot bezeugte, betonte er darüber hinaus die Ordnungs- und Disziplinprobleme, die durch das Fasten aufträten: »Le jeûne du Ramadan produit son effet désorganisateur habituel: absences fréquentes, travail négligé, discipline pénible.... $\ll^{92}$. Die negative Sichtweise auf Religion manifestierte sich zum anderen in den Aussagen der Lehrer dieser Schule über die Religionen im Libanon, die das Land spalten würden. Für diese Tatsache machte Ruche zum Teil die Mandatsregierung verantwortlich: »[...] c'est une politique maladroite que d'entretenir la division en communautés en partageant les postes, les influences, les champs d'action entre elles. [...] $\ll^{93}$. Allerdings

87 Vgl. AN/Paris, 60 AJ 128, Brief von Besnard an Ruche, 09.11.1925: »Les musulmans acceptaient de confier leurs enfants à des maîtres d'une autre religion; les chrétiens ne l'acceptaient pas«.

88 AN/Paris, 60 AJ 130, Brief von Ruche an Besnard, Beirut, 13.01.1928.

89 Zur konfessionellen Zusammensetzung der Schülerschaft siehe die Tabelle im Anhang.

90 Vgl. für Westafrika TRIaud 2009, S. 123.

91 AN/Paris, 60 AJ 124, »Rapports mensuels«, März 1922.

92 AN/Paris, 60 AJ 125, »Rapports mensuels«, April 1923.

93 AN/Paris, 60 AJ 130, Brief von Ruche an Besnard, Beirut, 13.01.1928. 
sahen die Akteure der Mission laïque die religiöse Aufsplitterung der libanesischen Gesellschaft auch als ein historisches Merkmal der arabischen Welt, »ces pays d'Orient si divisés par les croyances $«{ }^{94}$. Sich selbst präsentierte die Mission laïque in diesem Zusammenhang als die Lösung für dieses Problem, denn sie sei »un symbole de l'union entre tous par dessus les différences de sectes et de croyances $\iota^{95}$.

Diese negative Sicht auf die Religion muss in ihrer Kontinuität - der Argumentation im Kampf der Freidenker gegen die Katholiken um den Schulunterricht in Frankreich - gesehen werden. In diesem Kampf betonten die Freidenker gegenüber den Katholiken, die eine Dichotomie zwischen der Elite und dem gemeinen Volk propagierten, wie wichtig es sei »de resserrer d'abord un lien national fondant le lien social $\aleph^{96}$. Diese Sichtweise der Religion als Hindernis einer nationalen Identität entsprach auch den Vorstellungen vieler Freimaurer ${ }^{97}$.

Es kann aber auch sein, dass die Mission lä̈que mit der Betonung der Einheit auch auf Strömungen im Libanon reagierte, welche diese Einheit über religiöse Zugehörigkeiten hinweg beschworen und welche sich im Umfeld der laizistischen Schule befanden, nämlich die libanesischen Freimaurer und die Nationalisten. So berichtet Direktor Mathieu im Dezember 1922 anlässlich einer Aufführung eines arabischen Theaterstückes von der spontanen Rede Ibrahim Munzirs über »l'école laïque, son esprit, et les bienfaits qu'elle doit apporter dans un pays jusqu'ici divisé par tant de croyances et de religions différentes $\left\langle{ }^{98}\right.$. Auch wenn Reden dieser Art immer mit Vorsicht betrachtet werden müssen, weil sie in einem offiziellen Kontext mit starkem Hierarchiegefälle entstanden, entsprach die Idee einer Einheit über konfessionelle Grenzen hinweg sowohl dem Gedankengut der Freimaurer als auch der arabischen Nationalisten, die die gespaltenen Regionen und Länder unter der arabischen Kultur und Sprache zu einer Einheit zusammengefasst wissen wollten $^{99}$. Aus diesem Grund erscheint es sinnvoll, von einem gemeinsamen Diskurs zu sprechen, der die französischen und libanesischen Intellektuellen in einer »communauté de pensée, et de référence«, wie Leyla Dakhli dies formuliert hat, vereinte ${ }^{100}$.

94 MAE/Nantes, SOFE, 197, Brief von Besnard an den Präfekten, Paris, 8.06.1931.

95 Revue de l'enseignement français hors de France 18 (1921), H. 16, »Assemblée Générale Annuelle« 18.12.1921, S. 467.

96 Rioux/Sirinelli 2005, S. 48.

97 Vgl. Jacques Lemaire, Franc-maçonnerie et laïcité en France et en Belgique, in: Luis P. MarTIN (Hg.), Les franc-maçons dans la cité. Les cultures politiques de la Franc-maçonnerie en Europe XIX ${ }^{\mathrm{e}}-\mathrm{XX}^{\mathrm{e}}$ siècles, Rennes 2000, S. 97-123, S. 107.

98 AN/Paris, 60 AJ 125, »Rapports mensuels«, Dezember 1922.

99 Vgl. Dakhli 2009b, S. 13; Dawn 1988, S. 69-70.

100 Vgl. Dakhli 2009a, S. 304. 
Die katholischen Kreise im Libanon reagierten sehr kritisch und polemisch auf den Laizismus sowohl des Hochkommissariats als auch der Mission laïque. Ihre Kritik betraf gleichermaßen den Laizismus als Ideologie und war Ausdruck ihrer Furcht vor einem schwindenden Einfluss in der libanesischen Gesellschaft. So formulierte die maronitisch dominierte profranzösische Beiruter Tageszeitung L'Orient ${ }^{101}$, der Laizismus sei ein Konzept, das weder Muslimen noch Christen im Libanon entspreche: »Musulmans aussi bien que Chrétiens ont une horreur naturelle d'une doctrine pour laquelle Dieu peut être une quantité encombrante $\ll^{102}$. Zudem würde der Laizismus von den Muslimen nur genutzt, um das Christentum zurückzudrängen ${ }^{103}$. Damit traf die Zeitung trotz ihrer Polemik den wahren Kern der Intentionen einer gewissen Klientel der Mission lä̈que, ließ aber andere muslimische Stimmen außer Acht.

Ähnlich wie die Maroniten argumentierten die katholischen französischen Schulen im Libanon. Sie kritisierten zum einen die Verbindung zwischen Freimaurerei, Sarrail und Mission lä̈que française. So berichteten die Jesuiten vom Empfang Sarrails in Beirut, der vornehmlich von den Freimaurern ausgerichtet worden war und während desen die Mission laïque und eine lokale, nationalistisch ausgerichtete Schule bevorzugt behandelt worden wären:

Deux arcs de triomphe dressés par les soins d'un comité de couleur surtout maçonnique et sur l'un des deux arcs les armes de la Franc-maçonnerie qu'on eut cependant la pudeur de faire enlever la veille. Les présentations au Sérail eurent lieu vers $10 \mathrm{~h} 30$. Monseigner le Délégué fut présenté le premier, comme chef du Corps Diplomatique. Puis vinrent les écoles. La mission laïque fut accueillie avec une sympathie marquée et des paroles aimables et très encourageantes. Une directrice d'école syrienne, Mlle Kassab, qui par décret du Haut Commissariat avait vu sa boîte fermée pour des raisons graves même du point de vue purement français, car on y faisait une propagande antiFrançaise avouée, arriva à son tour escortée d'un certain nombre de ses élèves habillés en boy-scout et réclama justice contre une fermeture abritaire. Le Général lui dit : « Madame, votre requête est accordée, et votre école sera réouverte ${ }^{104}$.

Auf diese Weise unterstellten die Jesuiten Sarrail einerseits, dass er Freimaurer $\mathrm{sei}^{105}$, und andererseits stilisierten sie ihn zum Hochkommissar, der die Traditionen des Landes missachtete und sogar antifranzösische Bewegun-

101 Diese Zeitung unterstützte Emile Eddé sehr stark. Ayalon 1995, S. 89.

102 L'Orient, 28.03.1925, S. 2: „Vers une catastrophe (Gabriel Kabbaz)«.

103 Vgl. L’Orient, 25.03.1925, S. 2: »Les faits du jour: L'éloge du laïc«.

$104 \mathrm{SJ} /$ Vanves, $2 \mathrm{M}$, »Beirut, 16 janvier 1925«.

$105 \mathrm{SJ} /$ Vanves, »Fonds Jalabert«, 2 M, »Beirut, 16 janvier 1925«. Höchstwahrscheinlich war Sarrail aber kein Freimaurer. Vgl. FourniÉ 2002, S. 145. 
gen guthieß. Bei ihrem Kampf gegen die neue Politik des Hochkommissariats kooperierten die katholischen Schulen mit dem maronitischen Klerus. So setzte sich, auf Bitte des maronitischen Patriarchen, der Direktor der Lazaristenschule in Ayntoura dafür ein, dass Sarrail wieder abgesetzt und Weygand zurückkommen sollte ${ }^{106}$. Darüber hinaus reagierten die Orden mit Entsetzen auf die Bevorzugung der Mission lä̈que ${ }^{107}$. Als Gegenargument führten sie nicht nur ihre längere Tradition, sondern auch die höheren Schülerzahlen gegenüber der Mission lä̈que ins Feld ${ }^{108}$.

Die Akteure der Alliance israélite universelle äußerten sich nicht dezidiert zu der Frage des Laizismus. Um 1925 war ihre Beziehung mit der Mission laïque eher von Kooperation als von Konkurrenz geprägt, was sich zum Beispiel darin zeigt, dass Maurice Sidi, Direktor der Alliance israélite seinen Sohn an der Schule der Mission lä̈que angemeldet hatte und Mitglied des Elternbeirates der Schule war ${ }^{109}$. Außerdem gab es Formen der Kooperation ehemaliger Schüler der Alliance israélite, die von der Mission lä̈que übernommen wurden und der Schule dafür ihr Stipendium abtraten ${ }^{110}$.

Die Verantwortlichen des Collège protestant français hingegen, das 1927 eröffnet wurde, waren sich von Anfang an der Konkurrenz mit der Mission laïque um dasselbe nicht-katholische Publikum bewusst, bemühten sich aber, diese Konkurrenz nicht zu stark zu betonen ${ }^{111}$. Auch wenn die Schule dezidiert religiös konnotiert war, erlebte sie keine Konflikte mit Sarrail. Der Hochkommissar, der mit einer Protestantin verheiratet war, unterstützte die Organisation sogar beim Aufbau ihrer Arbeit im Libanon ${ }^{112}$. Abgesehen von der persönlichen Verbindung zum Protestantismus war Sarrail sich wohl bewusst, dass der französische Protestantismus immer von geringer Bedeutung im Libanon bleiben würde.

106 LAZ/Antoura, »Mandat français«, Brief des syrischen Patriarchen von Antiochien an Sarloutte, Paris, 02.09.1925; Brief von Raoul Brandon an Sarloutte, Paris, 04.02.1926.

107 SJ/Vanves, 25 B, Brief von Sautier an Jalabert, Beirut, 11.12.1924: »La Mission laïque, il est vrai, voit son budget de fonctionnement porté de 300 à 700000 Francs! C'est un indice - mais ce n'est pas la garantie du succès«.

108 Vgl. MAE/Paris, CPC, 378: 1922-1929, Brief der Frères des Écoles chrétiennes, Beirut: »Depuis, le Général Sarrail a présidé la fondation du Patronage des Anciens Élèves de la Mission Laïque, et il a même, paraît-il, donné à ces messieurs, à cette occasion, 50000 Francs, Le 4 mars, il a visité l'école musulmane de Tripoli, et sa visite a donné lieu à une grande manifestation contre les chrétiens «.

109 Vgl. AN/Paris, 60 AJ 128, »Bourses«. Der Sohn von Maurice Sidi bekam 1925 ein Stipendium; vgl. 60 AJ 135, Brief von Ruche an Besnard, Beirut, 12.03.1933.

110 Vgl. AN/Paris, 60 AJ 135, »Bourses«, Brief von Ruche an Besnard, Beirut, 08.10.1932; Brief der Schule von Sélim Tarrab an die Mission laïque, Beirut, 13.10.1932; Brief von Besnard an Ruche, Paris, 19.10.1932.

111 Vgl. z.B. die Wahl des Direktors: »Direction du collège. [...] Candidature de Monsieur Lecerf [...] écartée, car elle risquerait de susciter un conflit avec la Mission Laïque«. PFPL, »Comptesrendus du Conseil d'Administration 1925-1950«, Sitzung vom 31.01.1928.

112 Vgl. Eyrard/Krebs 2007, S. 353. 
Diese Beispiele zeigen, dass es von allen Seiten aus nur zu einer begrenzten Laizisierung der Zivilisierungsmission kam. Die hier vorgestellten Positionen unterschieden sich von der Situation 1909 insofern, als ein Teil der Klientel der Mission lä̈que ihre Forderungen nach Ausübung ihrer Religionspraktiken stärker formulierte. Außerdem fiel die Kritik der Katholiken sehr viel schärfer aus, weil sie nun eine Unterstützung des Laizismus durch den Hochkommissar und damit das Ende ihrer privilegierten Situation fürchteten. Schließlich reagierte Direktor Ruche als ein Vertreter des radikalen Laizismus der Dritten Republik längst nicht so tolerant wie Deschamps seinerzeit.

\section{Forderungen nach arabischer Partizipation}

Die politischen Emanzipationsbestrebungen in den Mandatsgebieten um 1925, deren offensichtlichster Ausdruck der syrische Aufstand war, bewirkten auf arabischer und französischer Seite ein neues Bewusstsein für die Integration der lokalen Gesellschaften in die Mandatspolitik, das sich auch im Bildungsbereich zeigte. Im Folgenden geht es um die in den französischen Schulen aktiven Libanesen, die im Sinne der neueren Kolonialgeschichte als Vermittler oder »Cultural Broker« von besonderem Interesse für das Verständnis kolonialer Prozesse sind. Die Protokolle der Elternratssitzungen der Mission laïque und andere von der Forschung bisher unbeachtete Dokumente liefern einen seltenen Einblick in ihre politischen, insbesondere aber ihre sozialen und ökonomischen Beweggründe für das Engagement in einer französischen Schule. Dabei spielt die Frage des sich in der Zeit immer stärker manifestierenden arabischen Nationalismus ${ }^{113}$ genauso eine Rolle wie die vielen Debatten unter den libanesischen Intellektuellen bezüglich der einzunehmenden Haltung gegenüber der Mandatsmacht ${ }^{14}$ und die schrittweise Institutionalisierung verschiedener Berufe wie der Lehrerausbildung.

In der Tat zeigen die Dokumente ein deutlicheres Auftreten der libanesischen Akteure insbesondere in der Schule der Mission laïque. Bei den ande-

113 So zeigte sich die nationalistische Bewegung am 20. Oktober 1927 in Beirut während des ersten Nationalistenkongresses mit libanesischen und syrischen Repräsentanten zum ersten Mal öffentlich. Vgl. Nadine MÉouchy, La presse de Syrie et du Liban entre les deux guerres (1918-1939), in: Anne-Laure Dupont / Catherine Mayeur-Jaouen (Hg.), Débats intellectuels au Moyen-Orient dans l'entre-deux-guerres, Revue des mondes musulmans et de la Méditerranée 95-98 (2002), S. 55-70, S. 58.

114 Gleichzeitig spaltete sich in dieser Zeit das politisch-intellektuelle Milieu in den Mandatsgebieten noch schärfer in Politiker und Intellektuelle auf. Außerdem differenzierten sich die Milieus stärker, zwischen Notabeln und dem Volk einerseits, andererseits zwischen radikalen und moderaten Politikern, die Verhandlungen mit der Mandatsmacht ablehnten beziehungsweise befürworteten. Vgl. DaKhli 2009a, S. 135. 
ren französischen Schulen ist diese Tendenz zur stärkeren Institutionalisierung der libanesischen Interessenvertretung weniger festzustellen. Das mag an der unterschiedlichen Quellenlage liegen ${ }^{115}$, scheint aber auch der Tatsache geschuldet zu sein, dass die Mission laïque stärker im Milieu der in dieser Zeit politisch sehr aktiven arabischen und syrischen Nationalisten integriert war als die anderen Schulen und dass sie besonders ihre Kompatibilität mit der libanesischen Gesellschaft betonte.

Die These dieses Kapitels lautet, dass libanesische Eltern und Lehrer offensiver ihre Forderungen formulierten, dass dies aber entgegen der Befürchtungen der Leitung der Mission lä̈que und der französischen Regierung nur bedingt mit dem arabischen Nationalismus zu tun hatte, sondern vor allem sozio-ökonomische Aspekte betraf. Während die Mission lä̈que vor Ort sehr stark auf die Wünsche der Eltern einging, blieb die Position der libanesischen Lehrer, welche sich mit ihren Forderungen auf die Zivilisierungsmission beriefen, prekär.

Der Elternrat, das sogenannte Comité de patronage, wurde 1924 auf Wunsch der libanesischen Eltern der Mission lä̈que wieder zum Leben erweckt. Auf diese Weise repräsentierte das Komitee die Verbindung aus Kontinuitäten und Brüchen, welche die Mission laïque und allgemein die französische Erziehungspolitik im Libanon zwischen Osmanischem Reich und Mandatsregime auszeichnete. In der Tat hatte es das erste Comité de patronage der Mission lä̈que schon 1912 gegeben $^{116}$. Viele seiner Mitglieder waren auch bei der Neubegründung unter dem Mandatsregime wieder anwesend. Neben den Kontinuitäten zeigten sich aber auch Brüche mit der osmanischen Zeit. So reagierte Generalsekretär Besnard überrascht darauf, dass Michel Tuéni (arabisch Mišāl Tuwaynī), ein Freund der Mission lä̈que der ersten Stunde, nicht auf der Mitgliederliste stand ${ }^{117}$. Mathieu erwiderte, dass niemand seinen Namen genannt hätte und dass Tuwaynī sich zudem durch den Erhalt erhöhter Entschädigungszahlungen nach dem Krieg diskreditiert habe $^{118}$. Ein Grund für seine Ablehnung kann auch darin gelegen haben, dass er als Unterzeichner einer Petition, welche sich für die Trennung von Libanon und Syrien einsetzte, von den syrischen und arabischen Nationalisten im Komitee nicht geschätzt wurde ${ }^{119}$.

115 Bezüglich der Mission laïque liegen vollständigere Dokumente über die einzelnen Aktivitäten innerhalb der Schule vor als bezüglich der anderen Schulen.

116 Vgl. z.B. AN/Paris, 60 AJ 120, Brief des Comité de patronage an den Präsidenten der Mission laïque, Beirut, 09.03.1913.

117 Michel Tuéni war während des Osmanischen Reiches für das französische Konsulat als Dragoman tätig gewesen. Vgl. SHorrock 1976, S. 91.

118 AN/Paris, 60 AJ 127, Brief von Mathieu an Besnard, Beirut, 09.10.1925. Als Grund wurde auch eine große Nähe zur osmanischen Regierung genannt.

119 Bezüglich dieser Petition, die vor allem von Beiruter Christen unterschrieben wurde, vgl. Kaufman 2004a, S. 84. 
Von der Zentrale der Mission laïque in Paris wurde die Gründung des Comité de patronage hinausgezögert, weil sie dessen politische Nutzung befürchteten. Zwar hatte Generalsekretär Besnard schon 1920 betont, wie wichtig und nützlich die enge Zusammenarbeit mit Libanesen sei, die das Terrain kennen:

Il est très désirable qu'il en soit formé un qui comprenne des Syriens, de tous les rites et de toutes les confessions, étant bien entendu que nous ne voulons pas faire de propagande ni pour ni contre aucune de ces religions qui se partagent le pays ${ }^{120}$.

Aber nachdem sich das Comité Mitte 1924 schon die ersten Male versammelt hatte, hatte die Zentrale in Paris Ende 1924 noch immer nicht die Zusammensetzung der Mitglieder abgesegnet. Auch im Frühjahr 1925 war Besnard noch sehr kritisch gegenüber manchem Mitglied, das er als "personnalité inquiétante« ansah ${ }^{121}$. Dazu zählte Georges Vayssié, den Herausgeber der frankophonen und frankophilen Zeitung La Syrie. Weil diese Zeitung vom Hochkommissariat unterstützt wurde, befürchtete Besnard unter Umständen mit Vayssié eine zu große Nähe zur Mandatsmacht. Trotz seiner Bedenken blieb Vayssié aber ein aktives Mitglied im Komitee, bis ein Zerwürfnis mit Ruche ihn zum Kritiker der Schule werden ließ ${ }^{122}$.

Besnard gab auch die Kritik der französischen Mandatsmacht an der Zusammensetzung des Komitees wieder. Das Hochkommissariat mahnte an, darin befänden sich Mitglieder, die entweder zum osmanischen Regime zurückkehren wollten oder als Pan-Arabisten in Wirklichkeit für Großbritannien arbeiteten ${ }^{123}$. Dieser Vorwurf der Kooperation mit den Engländern wurde auch später den Beteiligten des syrischen Aufstandes gegen Frankreich 1925 gemacht $^{124}$, er entsprach der generellen Anschuldigung der französischen Regierung gegen die arabischen Nationalisten. De Reffye, der Sekretär des Hochkommissariats, bat Mathieu deshalb darum, sich in Zukunft vor der Berufung von Mitgliedern des Elternrates bei der Mandatsregierung über sie zu erkundigen und beschwor gleichzeitig das generelle Interesse des

120 AN/Paris, 60 AJ 123, Brief von Besnard an die Schule in Beirut, Paris, 29.12.1920.

121 AN/Paris, 60 AJ 127, »Comité de patronage«, Notiz von Besnard.

122 Laut Ruche war die Tatsache, dass seine Tochter für das Abitur abgelehnt worden war, der Grund für seine Kritik an der Mission laïque, die er auch in seiner Zeitung formulierte. Vgl. AN/Paris, 60 AJ 133, Brief von Ruche an Besnard, Beirut, 13.06.1930. Interessanterweise berichtete Vayssiés Zeitung kurze Zeit darauf sehr positiv von der Arbeit der Frères des Écoles chrétiennes in Beirut. Vgl. die Wiedergabe des Artikels »Jeunes Promesses! Futures Moissons! « in FEC, L'Essor, Februar 1931, S. 5-6. Es ist zu vermuten, dass Vayssié auf diese Weise seine Kritik an der Mission laïque noch verstärkt hat.

123 AN/Paris, 60 AJ 127, Brief von Mathieu an Besnard, Beirut, 09.10.1924.

124 Vgl. Dakhli 2009a, S. 141. 
Hochkommissars an der Mission laïque sowie die Einheit der »compatriotes français« im Libanon, die nicht zerstört werden dürfe ${ }^{125}$.

Trotzdem oder gerade deshalb war das Interesse des Hochkommissariats an diesem Komitee sehr hoch. Das spiegelte sich in der relativ regelmäBigen Teilnahme der Hochkommissare an den Sitzungen wider. Ab Ende der 1920er Jahre kann man sogar eine noch stärkere Beteiligung der Mandatsvertreter feststellen ${ }^{126}$. Auf diese Weise wurde das Widerstandspotential des Komitees gegenüber dem Mandat stark relativiert, aber auch seine mögliche Gefahr bewiesen. Damit reagierte das Hochkommissariat gegenüber dem Elternrat ähnlich wie gegenüber dem Stadtrat von Beirut, zu dem er auch Kritiker des Mandats zuließ, um seine Generosität zu demonstrieren und gleichzeitig einen Zugang zu diesen Politikern zu behalten: »Ainsi, l'hostilité des élites, sunnites en particulier, ne semble pas avoir entraîné une mise à l'écart des charges municipales « ${ }^{127}$.

Um dieser Gefahr der Ablehnung durch die sunnitischen Eliten vorzubeugen, mahnte Generalsekretär Besnard den Direktor in Beirut eingehend, dass die Mitglieder des Komitees nur beratende Funktionen hätten und ihre politischen Debatten aus den Sitzungen heraushalten sollten. Er erinnerte ihn an die rein pädagogische Funktion und Mission der Schule: »Nous sommes une œuvre d'éducation formée sur des principes très clairs, et nous nous refusons à intervenir dans la politique des pays où nous sommes installés et à nous mêler aux luttes de partis et de personnes $\aleph^{128}$. Außerdem sah Besnard als Ziel des Komitees die Schaffung einer »atmosphère de sympathie« für die Schule, was sowohl für die libanesische Bevölkerung als auch für die Mandatsmacht gelten konnte. Allerdings waren die Sorgen aus Paris nur sehr begrenzt berechtigt. Lediglich ein Teil der Mitglieder waren dem Mandat gegenüber kritisch eingestellt, und das Hauptinteresse der libanesischen Mitglieder lag laut den Protokollen der Sitzungen eindeutig in der Konsolidierung ihrer sozialen Position innerhalb der libanesischen, insbesondere Beiruter Gesellschaft. Es überrascht nicht, dass ihre Vorstellungen dabei nicht immer denen der Direktoren und Lehrern der Mission lä̈que entsprachen.

Als sich der Elternrat 1924 wieder zusammensetzte, bestanden seine Mitglieder zu zwei Dritteln aus Libanesen und zu einem Drittel aus Franzosen. Trotz der numerischen Unterlegenheit besaßen die französischen Teilnehmer besondere Privilegien. So wurde das Komitee immer von einem Franzo-

125 Vgl. AN/Paris, 60 AJ 127, Brief von Mathieu an Besnard, Beirut, 09.10.1924.

126 Im Februar 1928 hatte sogar Hochkommissar Ponsot den Vorsitz des Komitees. Vgl. AN/ Paris, 60 AJ 130, »Comité de patronage«, Februar 1928. Ab den frühen 1930er Jahren nahm auch Bildungsbeauftragter Bounoure regelmäßig an den Sitzungen teil. Vgl. AN/Paris, 60 AJ 136, »Comité de patronage«, Sitzung vom 28.03.1934.

127 EDDÉ 2001, S. 84.

128 AN/Paris, 60 AJ 127, Brief von Besnard an Mathieu, Paris, 20.04.1925. 
sen geleitet, der erste Präsident war Édouard Soubret, ein im Libanon arbeitender französischer Ingenieur. Als dieser im Mai 1928 »aus persönlichen Gründen « ${ }^{129}$ für einige Zeit sein Amt aussetzte, wurde er vom französischen Generalkonsul Lafond ersetzt. Zu den französischen Mitgliedern zählte außerdem der Direktor der Schule als Schriftführer, der sowohl die Interessen der Schule als auch der Mission laïque vertrat. Die anderen Franzosen waren entweder Einzelpersonen, die im Libanon arbeiteten, oder Funktionäre des Hochkommissariats. Laut seinen Berichten war Mathieu verpflichtet gewesen, diese aufzunehmen, um die Mandatsregierung zu befriedigen $^{130}$. Die Mehrheit der französischen Mitglieder bekannte sich zudem zum Freimaurertum $^{131}$.

Die Gefahr einer nationalistischen Plattform war auch aufgrund der libanesischen Mitglieder des Komitees nur begrenzt gerechtfertigt. Die aktiven Mandatskritiker bildeten nur eine Gruppe neben frankophilen Notabeln, insbesondere Sunniten, und anderen weniger dezidiert politisch aktiven Mitgliedern. Die Freimaurer-Mitglieder Fāris Mušriq, Ğibrān Tuwaynī, Sa`̄̄e Sabbāğg, Muḥammad Ğamīl Bayhum und Amīr Amīn Arslān gehörten libanesischen Logen französischer Obedienz an ${ }^{132}$. Muhammad Ğamīl Bayhum wurde 1925 auf Vorschlag des Direktors der Mission laïque die Mitgliedschaft in diesem Rat angetragen, die er annahm ${ }^{133}$. Die Freimaurerzugehörigkeit der Mitglieder monierten weder die Zentrale der Mission laïque noch das Hochkommissariat, obwohl in den Logen trotz einer Bewunderung für Frankreich das französische Mandat stark kritisiert wurde ${ }^{134}$.

Ihre Kritik machten manche Mitglieder auch öffentlich. In seinen Zeitungen al-Ahrrar, 1923 gegründet, und an-Nahār, 1933 gegründet, ließ Ğibrān Tuwaynī »anti-French and pan-Arab sentiments « ${ }^{135}$ laut werden. Auch Muhammad Ğamīl Bayhum war ein strikter Gegner der Trennung Syriens und Libanons durch Frankreich ${ }^{136}$. Das zeigt, dass die Mission lä̈que in

129 Es wäre sehr interessant zu erfahren, ob noch andere, politische, Gründe hinter dieser Entscheidung lagen, aber leider schweigen die Quellen darüber. Vgl. AN/Paris, 60 AJ 130, Brief von Soubret an Ruche, Beirut, 28.05.1928: „Cette démission est motivée par des considérations d'ordre personnel $\ll$.

130 AN/Paris, 60 AJ 127, Brief von Mathieu an Besnard, Beirut, 09.10.1924.

131 Beispielsweise war Soubret Freimaurer der Loge Grand Orient Vgl. Achille RickeR/JeanAndré FAuchÉr, Histoire de la franc-maçonnerie en France, Paris 1967, S. 424: »Édouard Soubret, Ingénieur de Paris, membre du Conseil de l'ordre du Grand-Orient «.

132 Für Tuwaynī und Sabbāg siehe Millet 2006, Fußnote 22; für Bayhum siehe EdDÉ 2008, S. 512; für Mušriq siehe Kapitel 2.2; für Arslān siehe Éric Anduze, La franc-maçonnerie au MoyenOrient et au Maghreb fin XIX ${ }^{\mathrm{e}}$-début XX ${ }^{\mathrm{e}}$ siècle, Paris 2005, S. 503.

133 Vgl. Hassān Hallāe, Al-Mu'arih al-'Alāma Muḥammad Ğamīl Bayhum [Der Historiker und Gelehrte Muḥammad Ğamīl Bayhum], Beirut 1980, S. 37, 151.

134 Vgl. Millet 2006.

135 Ayalon 1995, S. 89.

136 Vgl. Havemann 2002, S. 172-174. 
einem Milieu respektiert wurde, das französischen Institutionen eigentlich kritisch gegenüber stand, und sich damit sehr von den anderen französischen Schulen unterschied. In der Tat stellte Tuwaynī seine Blätter der Schule kostenlos zur Verfügung ${ }^{137}$. Ein weiteres Indiz sind die von ihr abonnierten Zeitungen, die über pro-französische Blätter hinausgingen und auch muslimisch und nationalistisch dominierte Richtungen repräsentieren ${ }^{138}$.

Die andere große Gruppe innerhalb des Komitees bestand aus frankophilen Angehörigen einflussreicher sunnitischer Familien in Beirut ${ }^{139}$. Die Mitglieder gehörten zu den Sunniten, die den libanesischen Staat nach 1926 in seinen Grenzen akzeptiert hatten, auch wenn sie »continued to pay lipservice to pan-Arab unity $«^{140}$, wie der Historiker Firro anmerkt. Besonders kooperativ mit der Mandatsmacht zeigte sich Muhammad al-Fāhnūrīin ${ }^{141}$, ein bekannter Beiruter Apotheker, der ab Mitte der 1920er Jahre sowohl als Vizepräsident der Maqasid als auch als Politiker ein wichtiger Mann des öffentlichen Lebens war' ${ }^{142}$. Auch 'Abdallāh Bayhum, ein Parlamentsabgeordneter, gehörte zu dieser Gruppe ${ }^{143}$. Ähnlich kooperativ mit der Mandatsmacht zeigte sich 'Umar Da'uq, der der Mission lä̈que ebenfalls schon seit der osmanischen Epoche verbunden war. Schließlich bat Direktor Ruche 1927 Muḥammad al-Ğisr, einen frankophilen sunnitischen Politiker ${ }^{144}$, als Mitglied des Komitees hinzu, damit er Ruches Projekt der Lehrerausbildung unterstütze: »afin de le gagner pour la cause des écoles normales $«{ }^{145}$. Allerdings ließ sich al-Ğisr bei vielen Sitzungen entschuldigen, was sein begrenztes Interesse deutlich macht. Weiterhin nahmen die Vertreter anderer religiöser Gemeinschaften, die sich als Vermittler zwischen der Schule und ihren Gruppen präsentierten, an dem Komitee teil. Besonders aktiv war hier der jüdische Händler Joseph Farhi, eine prominente Person der jüdischen Gemeinde in Beirut ${ }^{146}$.

137 Vgl. AN/Paris, 60 AJ 135, »1932-1933«, Brief von Ruche an Besnard, Beirut, 25.03.1933.

138 Vgl. AN/Paris, 60 AJ 133, »Budget«, 1930-1931. Folgende Zeitungen sind als Abonnement aufgeführt: »La Syrie, L'Orient, El Balagh, El Abdul Jadid, El Fi Balad«. Die Zeitung alBalagh wurde stark von Schiiten genutzt. Vgl. Firro 2003, S. 165. Hinter dem Namen »E1 Abdul Jadid« könnte sich die Zeitung al-Aḥd al-ğadīd verbergen, die Riad as-Sulh und Khair ad-Din Adhab gehörte. Vgl. SEALE 2010, S. 185-187.

139 Von diesen Familien war nur die Familie Salām nicht vertreten, aber es kann vermutet werden, dass 'Umar Da'uq, ein enger Vertrauter Salīm 'Alī Salāms, dessen Repräsentant war. Vgl. JOHNSON 1986, S. 53.

140 Firro 2003, S. 39.

141 Fāhūūī hatte schon während des Osmanischen Reiches mit der Mission laïque zusammengearbeitet. Vgl. Kapitel 2.2. Bei den Wahlen von 1929 verlor Da uq gegen Fāhuūrī, nachdem er diesen nicht auf seine Seite hatte ziehen können. Vgl. ZAMIR 2000, S. 65.

142 Vgl. Johnson 1986, S. 56.

143 Vgl. Zamir 2000, S. 155; Johnson 1986, S. 63.

144 Vgl. SAlibi 1965, S. 174.

145 AN/Paris, 60 AJ 130, »Comité de patronage«, Sitzung vom 01.02.1927.

146 Vgl. Schulze 2009, S. 65-66. 
Schließlich frequentierten auch syrische und arabische Nationalisten das Komitee. Dazu zählte Riad as-Sulh (arabisch Riyād aṣ-Șulḥ), ein arabischer Nationalist und Gegner des französischen Mandats, der nach der Unabhängigkeit der erste Premierminister des Libanons wurde ${ }^{147}$. Nach seiner Rückkehr aus dem Exil, in das ihn die französische Regierung von 1925 bis 1929 verbannt hatte, wurde er Mitglied des Comité de patronage der Mission laïque. As-Sulh, der einige Familienmitglieder unter den Schülern hatte ${ }^{148}$, war aber keine Hauptfigur innerhalb des Komitees: er tauchte nur zu einigen Sitzungen auf, was unter anderem durch seine faktische Abwesenheit vom Libanon erklärt werden kann. Wenn er da war, äußerte er sich aber doch zu einigen Themen. 1931 lobte er die Haltung der Schule im Kontext der Boykotte gegen die Mandatsmacht ${ }^{149}$. In der Tat waren Riad as-Sulh und seine Cousins Taqi ad-Din - Schüler der Mission lä̈que - und Kāẓim aṣ-Ṣulḥ von den französischen Machthabern als Drahtzieher dieses Boykotts angeklagt worden ${ }^{150}$. Amīr Amīn Arslān, ein enger Freund Riad as-Sulhs ${ }^{151}$, der auch Mitglied des Elternrates war, kann zudem als Vertreter seiner Ansichten in dessen Abwesenheit gelten.

Diese Mitglieder sind besonders interessant, weil sie sich als Gegner des Mandats an einer französischen Institution beteiligten, die eindeutig mit dem Hochkommissariat kooperierte. Die Analyse der Themen, welche in den Sitzungen diskutiert wurden, zeigt aber deutlich, dass in diesem Rahmen politische oder gar nationalistische Themen nicht das Anliegen der libanesischen Mitglieder widerspiegelten. Vielmehr ging es den Libanesen vor allem um die gute materielle Ausstattung der Schule, deren soziale Integrität und letztlich um die Festigung ihres sozialen Status. Ihre Interessen schienen sowohl in der Repräsentation ihrer Familie und Gemeinschaft und schließlich in der Zusammenarbeit mit den französischen Institutionen zu liegen.

So sorgten sich die Eltern um den materiellen Zustand der Schule und fragten besorgt, ob die Neugründungen der Mission laïque in Syrien nicht einen negativen Einfluss auf die Finanzen der Schule in Beirut haben wür$\operatorname{den}^{152}$. Sie wünschten eine Schule, welche ihren Kindern beste Bedingungen

147 Vgl. Johnson 1986, S. 58; zu seinem Beitrag für die arabische Unabhängigkeitsbewegung siehe Patrick SeALe, The Struggle for Arab Independence. Riad el-Solh and the Makers of the Middle Modern East, Cambridge 2010.

148 Laut den Schülerlisten waren seine vier Töchter allerdings nicht darunter.

149 Vgl. AN/Paris, 60 AJ 133, Brief von Ruche an Besnard, Beirut, 06.06.1931. Leider wird aus dem Dokument nicht deutlich, welche Haltung die Schulleitung eingenommen hatte.

150 Vgl. Seale 2010, S. 258-259. Bezüglich des Boykotts vgl. Carla EddÉ, La mobilisation »populaire« à Beyrouth à l'époque du Mandat. Le cas des boykotts des trams et de l'électricité, in: Nadine Méouchy (Hg.), France, Syrie et Liban 1918-1946. Les ambiguïtés et les dynamiques de la relation mandataire, Damaskus 2002, S. 349-375.

151 Vgl. Seale 2010, S. 150-151.

152 Vgl. AN/Paris, 60 AJ 127, »Comité de patronage«, Sitzung vom 28.12.1924. 
bot. Eine weitere Sorge betraf die Mädchenschulen ${ }^{153}$. Ein Thema, das die libanesischen Väter ${ }^{154}$ außerdem massiv umtrieb, war die schon angesprochene Zulassung zu den Fakultäten der französischen Universität der Jesuiten in Beirut. Hier zeigt sich deutlich, dass dieses Thema von den Libanesen und nicht von den Franzosen ins Feld geführt wurde, denn in seinem Protokoll schrieb Ruche einmal, sichtlich genervt, von »l'éternelle question du baccaulauréat ${ }^{155}$. Vor allem die muslimischen Mitglieder kritisierten, dass die Schüler der Jesuiten bessere Voraussetzungen mitbrächten, dort genommen zu werden, und forderten eine Änderung dieser Verhältnisse. Eine Aufwertung des libanesischen Schulsystems erfolgte 1929 mit der Einführung des libanesischen Abiturs, das nun parallel zum französischen Abitur abgelegt werden konnte und mit der Zeit obligatorisch für die Erlangung des Sekundarabschlusses und ab 1932 ebenso wie das französische Abitur zum Studium des Rechts, der Medizin und der Pharmazie berechtigte ${ }^{156}$. Auch wenn ab den 1930er Jahren das libanesische Bildungsministerium immer mehr die Verantwortung für die staatlichen und lokalen privaten Schulen übernahm, behielten die französischen Schulen ihre Autonomie und, aufgrund ihrer finanziellen Mittel und Kontakte zur Mandatsregierung, ihr Prestige bei.

Das einzige Thema, das nationalistischen Forderungen nahe kam, war die Sorge um den Arabischunterricht. Mehrmals betonten die libanesischen Mitglieder, dass die Schule diesen auf keinen Fall vernachlässigen dürfe ${ }^{157}$. 1931 monierte Amīr Amīn Arslān, dass die Methoden des Arabischunterrichts veraltet seien. Direktor Ruche bestätigte, dass es unter den Schülern ein großes Desinteresse an der arabischen Sprache gebe, aber bezweifelte, dass dafür nur die Inkompetenz der Arabischlehrer verantwortlich sei. Stattdessen, so Ruche weiter, habe er den Eindruck, die Schüler würden den Unterricht in klassischem Arabisch als Zeitverschwendung empfinden. Er schloss aber mit dem Versprechen, dem Problem nachzugehen ${ }^{158}$. Obgleich das Thema der arabischen Sprache immer wieder aufkam, betonten die meis-

153 Vgl. Kapitel 5.3.

154 Der Elternrat zählte keine Frauen.

155 Vgl. AN/Paris, 60 AJ 130, »Comité de patronage«, Sitzung vom 18.06.1927.

156 Vgl. MAE/Nantes, SOFE, 377, »Conditions d'admission à la Faculté Française de Medécine de Beyrouth« (November 1932). Über unterschiedliche Kritierien für Jesuiten- und andere Schüler schweigt das Dokument allerdings. Vgl. auch Mirna Lattouf, Women, Education and Socialization in Modern Lebanon. $19^{\text {th }}$ and $20^{\text {th }}$ Centuries Social History, Lanham 2004, S. 87.

157 Vgl. AN/Paris, 60 AJ 130, »Comité de patronage«, Sitzung vom 20.11.1926. Auf die Kritik der Eltern, dass manche Ausbildungszweige nicht so viele Arabischstunden hätten wie die anderen und dass manche Schüler gar nicht zum Arabischunterricht kämen, antwortete Ruche, die Reduzierung der Arabischstunden in den Wirtschaftsklassen sei doch mit den Eltern abgesprochen worden, und die Schüler, die im Arabischunterricht fehlten, würden von ihm hart bestraft werden.

158 Vgl. AN/Paris, 60 AJ 134, »Comité de patronage«, Sitzung vom 25.03.1931. 
ten Mitglieder des Elternrates, dass sie der Schule in dieser Frage vertrauen würden ${ }^{159}$. Auch wenn die Protokolle mit Vorsicht gelesen werden müssen, weil sie aus der Feder des Direktors stammten, der ein erkenntnisgeleitetes Interesse hatte, entsteht der Eindruck, dass die Betonung der arabischen Sprache vor allem eine Art »nationalistischer Reflex« war, der immer dann wirkte, wenn die libanesischen Mitglieder den Eindruck hatten, ihnen würde eine fremde Meinung oktroyiert.

Wie wenig die libanesischen Mitglieder einen negativen Einfluss der Schule auf die moralische und nationale Identität ihrer Kinder fürchteten, zeigt sich auch anhand einer Diskussion 1929/1930 um die Frage der kulturellen Entwurzelung der Schüler. Bezeichnenderweise wurde diese Frage vom Direktor auf die Tagesordnung gesetzt, der sich von einem Vortrag Louis Massignons über diese Frage hatte anregen lassen ${ }^{160}$. In den Räumen der Mission lä̈que sprach dieser im Februar 1929 über »les conctacts culturels entre Orient et Occident « und thematisierte die Entwurzelung der jungen Syrer und Libanesen, die nach dem Besuch einer ausländischen Schule in ihr Milieu zurückkämen mit einem »cœur ulcéré de se trouver déracinés « ${ }^{161}$. In demselben Geist hatte Parisot, ein französischer Lehrer der Schule, die kulturelle Entwurzelung kritisiert, die die Mission lä̈que bei ihren Schülern hervorrufen würde. Als gutes Gegenbeispiel stellte er das zionistische Lycée Herzlia dar, welches er in Palästina besucht hatte, und befand: »Dans nos classes, on étudie la pédagogie de l'`Émiler. À Tel-Aviv, on l'applique «162. Mit der Anspielung auf das zentrale Werk Jean-Jaques Rousseaus, »Émile ou de l'éducation«, kritisierte er gleichzeitig den Anspruch der Mission laïque, pädagogisch fortschrittlicher zu sein als die katholischen Schulen. Direktor Ruche teilte die Kritik Parisots an den Methoden ihrer Schule, wie er in einem Brief an den Generalsekretär in Paris deutlich machte: »M. Parisot a bien mis en lumière la contradiction fondamentale des programmes et des examens auxquels nous devons préparer et des principes de notre action « ${ }^{163}$.

Ruche arbeitete daraufhin einen Fragenkatalog für die Mitglieder des Elternrates aus:

159 Vgl. AN/Paris, 60 AJ 130, »Comité de patronage«, Sitzung vom 16.04.1927: »Le Docteur Mohamed Haidar déclare qu'il a en effet été rassuré après une entrevue avec le Proviseur«.

160 AN/Paris, 60 AJ 132, »Comité de patronage«, Sitzung vom 07.02.1929.

161 Ebd., Sitzung vom 07.02.1929.

162 Jean Parisot, Visite au Lycée Herzlia à Tel-Aviv, in: Revue de l'enseignement français hors de France 26 (1929), H. 78, S. 104-112, S. 112. Dieser Artikel brachte Parisot von dem französischen Journalisten und Schriftsteller André Thérive den Vorwurf des Verrats an Frankreich ein. Dagegen verwehrte sich Parisot in einem weiteren Artikel, indem er betonte, dass die Kritik an den Methoden seiner Schule keine Kritik an Frankreich als Ganzes dargestellt habe. Vgl. Jean Parisot, Au confluent du Grand Morin et du Barada (Réponse à M. André Thérive), in: Revue de l'enseignement français hors de France 27 (1930), H. 82, S. 19-28.

163 AN/Paris, 60 AJ 132, Brief von Ruche an Besnard, Beirut, 22.01.1930. 
Connaissez-vous des parents ou des élèves qui ont pu se plaindre que nous leur ayons rendus >déracinés` les enfants qui nous ont été confiés. [...] N’y a-t-il pas des parents et des élèves qui ont eu à se féliciter au contraire de ce qui a été fait au Lycée pour éviter ce déracinement intellectuel et moral ${ }^{164}$ ?

Daraufhin antworteten die libanesischen Mitglieder des Comité, dass sie weniger eine kulturelle als eine soziale Entwurzelung befürchteten, und dass die weiterführende Schule einer Elite vorbehalten bleiben sollte ${ }^{165}$. Nachdem er diese Äußerungen in seinem Bericht festgehalten hatte, bemerkte Ruche, dies sei nicht ganz die Idee gewesen, um die es ihm beziehungsweise Massignon gegangen sei.

Anhand dieser faszinierenden Diskussion zeigen sich aber zum einen sehr gut die Probleme kultureller Übersetzung zwischen Angehörigen verschiedener Kulturen ${ }^{166}$. Zum anderen macht sie deutlich, dass die Sorgen der >Kolonisierer〈 um ein humanes Erziehungssystem nicht zwangsläufig denen der `Kolonisierten Komitees vor allem um die Zugehörigkeit zu einer sozialen Elite, die sie durch die Kooperation mit der Mission lä̈que gewinnen oder bewahren wollten. Die Tatsache, dass die Mitglieder des Elternrates die politischen oder nationalistischen Themen nicht in die Satzungen einbrachten, darf allerdings nicht über deren Relevanz hinwegtäuschen. Vielmehr hatten sie dafür andere Orte, während die Schule der Mission lä̈que für sie weniger einen Repräsentant der Mandatsmacht als ein Mittel sozialer Konsolidierung mit Hilfe besserer Bildungschancen für ihre Kinder darstellte. Auch in den anderen ausländischen und libanesischen Schulen gab es sicherlich solche Gremien der Interessenvertretung ${ }^{167}$, aber entweder waren sie nicht so stark institutionalisiert wie die der Mission laïque oder deren Protokolle wurden nicht überliefert.

Eine andere Gruppe libanesischer Akteure, die sich innerhalb der Schule der Mission laïque verstärkt zu Wort meldete und mehr Rechte einforderte, war die der libanesischen Lehrer. Auch dieser Umstand unterschied die laizistische Schule von den anderen, katholischen, protestantischen und jüdischen französischen Schulen, in denen die einheimischen Lehrer laut der vorhan-

164 Ebd., »Comité de patronage«, Sitzung vom 07.02.1929.

165 Ebd.

166 Vgl. Doris Bachmann-Medick, Dritter Raum. Annäherungen an ein Medium kultureller Übersetzung und Kartierung, in: Claudia Breger/Tobias Döring (Hg.), Figuren der/des Dritten. Erkundungen kultureller Zwischenräume, Amsterdam/Atlanta 1998, S. 19-36.

167 So berichtete Mathieu 1922, der Sekretär des »Comité du Collège Orthodoxe de Homs« hätte sich nach den Programmen der Mission laïque erkundigt, um seine Schüler darauf vorzubereiten. Vgl. AN/Paris. 60 AJ 124, »Rapports mensuels«, Mai 1922. Von der Schule der Jesuiten konnte nur für die Zeit nach dem Mandat die Existenz einer »réunion de parents d'élèves« bekannt. Vgl. NDJ, »Rapport d'élèves« 1975, S. 53. 
denen Archive keine erkennbaren Forderungen stellten. Die einzige überlieferte Begebenheit betraf die Schule der Jesuiten 1920, als der Rektor, sichtlich unangenehm berührt, Briefe seiner Lehrer, die als Laien arbeiteten, mit der Forderung um ein höheres Gehalt an den Hochkommissar weiterleitete ${ }^{168}$.

Bei der Mission laïque hingegen häuften sich die Protestbriefe der arabischen Lehrer an den Direktor, aber auch an die Zentrale der Organisation in Paris. Interessanterweise beriefen sie sich dabei auf die mission civilisatrice, insbesondere in ihrer laizistischen Ausprägung:

Si la situation qui nous est faite depuis déjà longtemps ne devait pas être modifiée [...] nous aurions en effet l'impression que nous ne pourrons jamais avoir chez vous le rang de collaborateurs et que nous ne sommes que des auxiliaires de passage avec lesquels on hésite à s'engager. Nous serions d'autant plus surpris que nous nous faisons une idée très haute de l'idée laïque fille de la France républicaine, et de nos devoirs et de notre dignité d'éducateurs ${ }^{169}$.

Das Hauptanliegen der Lehrer beinhaltete die Forderung nach gleichen Rechten wie ihre französischen Kollegen und einer höheren Bezahlung ${ }^{170}$. Die Direktion in Beirut und die Zentrale der Mission lä̈que in Paris reagierten nur sehr schleppend auf diese Ansprüche und erfüllten die Bitten der Lehrer lediglich teilweise ${ }^{171}$. So wurde ihr Lohn zwar erhöht, aber da diese Forderung über den gesamten Untersuchungszeitraum hinweg immer wieder auftauchte, ist zu vermuten, dass es sich um keine befriedigende Lösung handelte ${ }^{172}$. Ein interessantes Indiz dafür, dass die Organisation aber dennoch, vielleicht sogar unbewusst, für die Rolle der einheimischen Kräfte sen-

168 Vgl. MAE/Paris, CPC, 103, Brief von Cattin an Robert de Caix, Beirut, 03.05.1920: »[...] les lettres ci-jointes qui m'ont été adressées par les Professeurs laïcs de nos écoles d'enseignement supérieure. Il est inutile de vous dire combien une pareille démarche me cause de peine et me fait craindre pour l'avenir de nos principales œuvres françaises. Venant d'hommes dignes et éminents dont beaucoup pendant plus de 18 ans ont été sous mon administration et ne m'ont jamais tenu pareil langage, elle me fait considérer la situation comme grave. Je sais que le Général Gouraud s'est occupé de cette question des traitements avec toute la bienveillance possible. Mais je vous l'avoue, le retard apporté à la situation m'inquiète et fait sur ces Messsieurs la plus fâcheuse impression. En vous priant [...] de vouloir bien me manifester mes appréhensions à qui de droit, je vous présente l'hommage de mes respectueux sentiments «.

169 AN/Paris, 60 AJ 131, Brief der libanesischen Lehrer an Besnard, Beirut, 09.01.1925.

170 Vgl. AN/Paris, 60 AJ 125, Brief von Moukheibar an Besnard, Beirut, 29.06.1923; 60 AJ 125, Brief von Marie Noomie an Ruche, Beirut, 21.10.1925.

171 Vgl. AN/Paris, 60 AJ 131, »Statut du Personnel Local, Beyrouth Mai 1926«. Ihr Status unterschied sich weiterhin wesentlich von dem der französischen Lehrer: beispielsweise mussten sie zunächst ein Praktikum von drei Jahren absolvieren, zu welchem die Erlaubnis jedes Schuljahr erneuert werden musste.

1721937 schrieb die Direktorin der Mädchenschule, Lucie Lévy, einen Brief an Besnard und bat eindringlich um die Lohnerhöhung ihrer arabischen Kollegen. Vgl. AN/Paris, 60 AJ 139, Brief von Lévy an Besnard, Beirut, 29.01.1937. 
sibilisiert wurde, liegt in deren Bezeichnung in den Statistiken und Lohnabrechnungsblättern. Noch 1920 sprach die Direktion, von den arabischen Lehrern als "professeurs/personnel étranger«, im Gegensatz zu den »professeurs français«. Diese frankozentrische Sicht änderte sich aber 1922, als die Organisation dann zwischen »personnel français« und »personnel syrien« unterschied ${ }^{173}$.

Dass die arabischen Lehrer dennoch von der Leitung der Schule nicht als in allen Bereichen gleichberechtigte Kollegen angesehen wurden, zeigte sich auch anhand der Lehrerkonferenzen. Laut den Protokollen nahmen die libanesischen Kollegen an diesen nur teil, wenn es um Fragen der Vereinheitlichung der Disziplin oder der Führung von Heften etc. ging ${ }^{174}$. Außerdem urteilten die verschiedenen Direktoren der Mission laïque oft sehr negativ über die Ausbildung ihrer arabischen Kollegen ${ }^{175}$.

Dies war einer der Gründe, warum sich die Mission laïque ab Mitte der 1920er Jahre aktiv in die Lehrerausbildung im Libanon einbrachte. Hinzu kam, dass die Mandatsmacht sich um diese Frage nicht kümmerte, da sie einerseits der Entwicklung des staatlichen Schulsystems sehr wenig Beachtung schenkte und andererseits viele Privatschulen ihre Lehrer selbst ausbildeten. Das galt auch für die Jesuiten, die in Tanail über eine École normale verfügten ${ }^{176}$. Die Lehrerseminare, die das Hochkommissariat zu Beginn des Mandats eröffnet hatte, wurden 1927 wieder geschlossen ${ }^{177}$. Daraufhin bot die Schule der Mission laïque in Beirut an, deren Aufgabe zu übernehmen ${ }^{178}$. Direktor Ruche zufolge entsprach das auch dem Wunsch der Schüler der bisherigen École normale ${ }^{179}$. In der Folge zählte die laizistische Schule in der Tat einige Schüler, die sie zum Lehrer oder zur Lehrerin ausbildete. Auf dem Programm stand neben der allgemeinen Geschichte insbesondere die syrische Geschichte ${ }^{180}$. Allerdings stand dieser Schulzweig bald in der Kritik von Ğibrān Tuwaynī, der 1930 Erziehungsminister im Libanon geworden war ${ }^{181}$. Was Tuwaynīs Kritik genau beinhaltete, kann nicht rekonstruiert werden,

173 AN/Paris, 60 AJ 125, »État d'émargement du personnel«, Januar 1923.

174 Vgl. ebd., »Réunion des professeurs«, 30.11.1923. Außerdem nahmen auch die libanesischen Lehrer an einer Sitzung im Mai 1927 teil, als es um die »défauts que révèle dans la connaissance de la langue française un élève moyen du Lycée« ging. Wahrscheinlich sollten auch sie über die Vorgehensweise der Schule informiert werden. Vgl. AN/Paris, 60AJ 129, »Réunion des professeurs «, 25.05.1927.

175 Vgl. AN/Paris, 60 AJ 1924, »Renseignements sur professeurs«.

176 Vgl. Libois 2009, S. 155.

177 In Syrien hatte die Mandatsmacht übrigens gar keine Écoles normales errichtet, lediglich die Kandidaten aus dem Alawitenstaat durften das Lehrerseminar in Beirut besuchen. Vgl. CHIDIAC 2002, S. 261.

178 Vgl. AN/Paris, 60 AJ 130, Brief von Besnard an Ponsot, Paris, August 1927.

179 Vgl. ebd., Brief von Ruche an Besnard, Beirut, 09.10.1927.

180 Vgl. AN/Paris, 60 AJ 134, Brief von Ruche an Besnard, Beirut, 17.10.1931.

181 Vgl. AN/Paris, 60 AJ 133, Brief von Ruche an Besnard, Beirut, 20.10.1930. 
aber es ist zu vermuten, dass sein Misstrauen und die fehlende Unterstützung durch die französische Regierung dazu beigetragen haben, dass das Lehrerseminar an der Mission laïque bald nicht mehr von sich hören ließ. In der mangelhaft ausgearbeiteten Lehrerausbildung während der Mandatszeit mag darüber hinaus ein Grund dafür liegen, dass sich bis heute im Libanon, im Gegensatz zu den Berufsständen der Anwälte, Ärzte etc. kein Lehrerkorps entwickelt hat. In der Tat hatten die französische und libanesische Regierung im Anschluss an das osmanische System, in dem Lehrer vor allem in religiösen Institutionen ausgebildet worden waren ${ }^{182}$, keine neuen Formationszentren für Lehrende errichtet, sodass deren Ausbildung weiterhin oft aus privater Initiative geschah ${ }^{183}$.

\section{Die Brisanz der Mädchenbildung}

Neben dem stärkeren Engagement der arabischen Akteure war die Frage der Mädchenbildung Mitte der 1920er Jahre ein zentrales Thema der französischen wie auch der anderen ausländischen und lokalen Schulen im Libanon. Mit der gleichen Intensität spiegelten die Auseinandersetzungen um die Rolle der Frauen in den Schulen und in der Gesellschaft die Aushandlungsprozesse wider, die innerhalb des sich formierenden libanesischen Staates nicht nur bezüglich der Rollen der religiösen, sozialen und wirtschaftlichen Gemeinschaften und Schichten, sondern auch hinsichtlich der Geschlechter stattfanden. So wie das Mandatsregime den Männern und Frauen einerseits neue Handlungsmöglichkeiten bot, andererseits aber auch die alten patriarchalischen Strukturen perpetuierte ${ }^{184}$, trugen auch die französischen Schulen sowohl dazu bei, Ausbildung und agency ${ }^{185}$ der libanesischen Frauen zu stärken als auch dazu, dass diese in den familiären und gesellschaftlichen Strukturen blieben, die den Geschlechtern bestimmte Aufgaben zuwiesen ${ }^{186}$.

Anhand der verschiedenen französischen Schulen, die hier in den Blick genommen werden, zeigen sich sehr deutlich die vielen Gemeinsamkeiten und die wenigen Unterschiede sowohl zwischen den ideologisch so unterschiedlichen französischen Einrichtungen als auch zwischen ihren libane-

182 Vgl. Deguilhem 1998, S. 240.

183 Vgl. Lattouf 2004, S. 75.

184 Vgl. Joseph SuAd, Women between Nation and State in Lebanon, in: Norma Alarcón/Caren Kaplan/Minoo Moallem (Hg.), Between Woman and Nation. Nationalism, Transnational Feminisms and the State, Durham/London 1999, S. 162-181, S. 175.

185 Dieser aus der Handlungstheorie stammende Begriff wurde zu einem der Schlüsselbegriffe der neueren Kulturanthropologie. Vgl. Rothermund 1999, S. 2.

186 Mirna Lattouf hat darauf hingewiesen, dass die Frauen im Libanon zwar einerseits zu den bestausgebildeten Frauen der arabischen Welt gehörten, dass diese Tatsache aber oft über die Wirkmacht der patriarchalischen Strukturen hinwegtäuscht. Vgl. LatTouf 2004, S. 72. 
sischen Klientelen. Die Leiter und Lehrer der französischen Schulen betonten einerseits erstaunlich einmütig die Relevanz der mission civilisatrice für die Befreiung der Frauen im Libanon und hielten andererseits zur gleichen Zeit an einem Geschlechterbild fest, das der gesellschaftlichen Position der Frauen klare Grenzen setzte und sie vor allem auf die Aufgaben in Haus und Familie beschränkte. Damit teilten sie die Meinung der Mehrheit der libanesischen Eltern, die in den Schulgremien aktiv waren und in den Quellen zu Wort kommen: Diesen war an einer guten Ausbildung ihrer Töchter sehr gelegen. Das bisher unerforschte Beispiel der Mission lä̈que française ist dabei von besonderem Interesse, weil es die Erwartungen der größtenteils muslimischen Eltern innerhalb einer nicht-muslimischen, nicht einheimischen Einrichtung zeigt.

Die 1920er Jahre waren sowohl in Frankreich als auch im Libanon von großer Bedeutung für die Bildung der Mädchen. In Frankreich hatten die Gesetze von 1924 die Bildungssituation für Schülerinnen verbessert, indem auch diese nun Latein und Griechisch erlernen durften und damit das altsprachliche Abitur ablegen konnten ${ }^{187}$. Trotzdem blieben deren Lern- und Ausbildungsmöglichkeiten stärker eingeschränkt als die der Jungen, standen den Modernisierern des Bildungswesens doch die Vertreter der traditionellen Mädchenbildung gegenüber, welche die familiären Aufgaben der Frauen in den Vordergrund stellten ${ }^{188}$. Im kolonialen Diskurs kam den Frauen in dieser Zeit eine umfangreichere, aber auch ambivalente Rolle zu: sie sollten ein humanes Gesicht des französischen Kolonialismus bieten, aber in den Kolonien selbst auch die Männer kontrollieren, welche sich mit einheimischen Frauen verbanden oder die Administrationsaufgaben nicht streng genug befolgten ${ }^{189}$.

Im Libanon und in Syrien taten sich in dieser Zeit viele Frauen hervor, die für ihre Rechte kämpften. Sie verlegten Zeitungen, hielten literarische Salons ab, schrieben selber Bücher und nahmen so aktiv am gesellschaftlichen Leben teil ${ }^{190}$. Ihre Forderungen nach Mädchenbildung umfassten das Recht auf Bildung, die Teilnahme am öffentlichen Leben (wobei die Frage des Kopftuchs unterschiedliche Positionen fand) sowie die Gleichberechtigung im Sinne gleicher Rechte und Pflichten, wurden aber sehr unterschiedlich aufgenommen. Der letzte Anspruch war am stärksten umstritten, während bei den anderen beiden Postulaten vor allem die Art und Weise beziehungsweise der Umfang diskutiert wurde: bis zu welchem Alter und

187 Vgl. KoK-Escalle 1988, S. 63.

188 Vgl. MAYeur 1977, S. 443-444.

189 Vgl. Nicola J. CoOPER, Gendering the Colonial Enterprise. La Mère-Patrie and Maternalism in France and French Indochina, in: Harald Fischer-Tiné/Susanne Gehrmann (Hg.), Empires and Boundaries. Rethinking Race, Class, and Gender in Colonial Settings, New York 2009, S. 129-145.

190 Vgl. Slim/Dupont 2002; DakhLi 2009a, 197-219. 
Grad sollten Mädchen unterrichtet werden, sollte es koedukativen Unterricht geben ${ }^{191}$ ? Zum einen gab es liberale Milieus, die die Frauen unterstützten, zum anderen wurden sie von konservativen Religionsgelehrten stark kritisier $^{192}$.

Als Ausdruck beider Tendenzen entstanden oder erneuerten sich in dieser Zeit viele Mädchenschulen lokaler und ausländischer Provenienz. Auch wenn das osmanische Schulgesetz von 1913 den Grundschulbesuch von Jungen und Mädchen verpflichtend gemacht hatte ${ }^{193}$, gaben alle Eltern die sich dies leisten konnten, ihre Töchter in private Schulen, deren Zahl stark zunahm. Unter den lokalen Schulen tat sich die Maqasid mit neuen Mädchenschulen hervor ${ }^{194}$. Auf der universitären Ebene öffnete die American University of Beirut 1921/1922 zum ersten Mal ihre Tore für weibliche Studenten ${ }^{195}$. Der Anteil der Studentinnen verstärkte sich in den 1930er Jahren an den beiden Hochschulen der Stadt: so zählte die AUB 1938 unter 444 Studenten 104 Frauen $^{196}$, während der es an der Université Saint-Joseph 535 männliche und 43 weibliche Hörer gab ${ }^{197}$.

Außerdem wurde die französische Schullandschaft 1927 um das Collège protestant français erweitert. Trotz der zahlreichen Mädchenschulen in Beirut zu dieser Zeit waren sich die Vertreter der protestantischen Organisation Euvres protestantes françaises sicher, dass Bedarf für eine französische Einrichtung für Schülerinnen herrschte, deren Eltern ihre Töchter lieber nicht zu einer katholischen Schule schicken würden ${ }^{198}$. Dass die französischen Protestanten damit zur unmittelbaren Konkurrenz der Mädchenschule der Mission lä̈que française wurden, war ihnen bewusst, denn sie betonten

191 Vgl. zu den Diskussionen Werner EndE, Sollen Frauen schreiben lernen? Eine innerislamische Debatte und ihre Widerspiegelung in al-Manār, in: Dieter Bellmann (Hg.), Gedenkschrift Wolfgang Reuschel. Akten des III. Arabistischen Kolloquiums, Leipzig, 21.-22. November 1991, Stuttgart 1994, S. 49-57.

192 Für den Libanon und Syrien vgl. Leyla DAKHLI, Beyrouth-Damas, 1928: voile et dévoilement, in: Le Mouvement Social, April-Juni 2010, S. 123-140.

193 Vgl. Lattouf 2004, S. 73.

194 Vgl. Nadya Sbaiti, Lessons in History: Education and the Formation of National Society in Beirut, Lebanon, 1920s-1960s, Diss. Washington/D.C. 2008, S. 55: Beispielsweise wandelte die Maqasid eine sultaniya-Schule 1925-1926 in eine weiterführende Mädchenschule um.

195 Vgl. Aleksandra Majstorac-Kobiljski, Women Students at the American University of Beirut from the 1920s to the 1940s, in: Inger Marie OKkenhaug/Ingvild Flaskerud (Hg.), Gender, Religion and Change in the Middle East, Oxford/New York 2005, S. 67-84, S. 71. In diesem Studienjahr schrieben sich fünf Frauen für die Studiengänge Pharmazie beziehungsweise Zahnmedizin ein.

196 Vgl. BıöRKMAN 1941, S. 148.

197 Unter den Studentinnen absolvierten 30 Frauen die Hebammenschule, sieben waren in Medizin, zwei in Pharmazie und vier in Recht eingeschrieben. Vgl. MAE/Nantes, SOFE 376, »Euvres françaises des États du Levant sous Mandat français 1937«. Zu den Zahlen siehe auch die Tabelle im Anhang.

198 Vgl. PPFL, »Comptes-rendus du Conseil d'Administration«, Sitzung vom 16.10.1926: »[...] familles désirent éviter de confier leurs filles aux Écoles des Pères Jésuites et des Sœurs«. 
von Beginn an ihre Bemühungen, existierende Einrichtungen nicht zu brüskieren: »L'organisation de cet établissement [d'enseignement] demandera des études spéciales pour ne pas risquer de provoquer de l'opposition chez les établissements actuels ${ }^{199}$.

Die Schülerinnenzahlen der ersten Jahre zeigten allerdings, dass die französischen Laizisten und Protestanten eine sehr ähnliche Klientel anzogen: so waren 1933 zwar 22\% der Schülerinnen katholischer Konfession - also etwas mehr als bei der Mission laïque -, aber gleichzeitig zeigten die Sunnitinnen mit $16 \%$, die griechisch-orthodoxen und protestantischen Schülerinnen mit $36 \%$ und die Jüdinnen mit $21 \%$ eine ähnliche Verteilung wie die traditionelle Klientel der laizistischen Schule ${ }^{200}$. Letzten Endes erwies sich die Konkurrenz aber zwischen beiden Institutionen als weniger virulent als anfangs von beiden Seiten befürchtet ${ }^{201}$. So gab es nur wenige Eltern der Mission lä̈que, die wie Joseph Farhi ihre Töchter zu der neu eröffneten protestantischen Schule wechseln ließen ${ }^{202}$.

Die Frage nach der Rolle der Frau und ihrer Bildung beschäftigte die französischen und anderen ausländischen Missionare sowie Politiker und die arabischen Intellektuellen im Libanon schon seit dem 19. Jahrhundert ${ }^{203}$. Bis dahin hatten Mädchen in der Regel keinen Zugang zu formaler Bildung, sondern wurden höchstens im privaten Rahmen unterrichtet ${ }^{204}$. Noch prominenter als die Franzosen hatten die amerikanischen protestantischen Missionare, die seit Beginn des 19. Jahrhunderts vermehrt im Nahen Osten aktiv waren, den arabischen Frauen besondere Aufmerksamkeit als potentielle Rezipientinnen ihrer Arbeit geschenkt ${ }^{205}$. Das veranlasste die stark in Konkurrenzkategorien denkenden französischen katholischen Orden dazu, sich ebenfalls vermehrt um die Bildung der arabischen Mädchen zu bemühen ${ }^{206}$.

199 Ebd., Sitzung vom 21.02.1927.

200 Vgl. Eyrard/Krebs 2007, S. 157. Für die Zahlen der Misison laïque siehe die Tabelle im Anhang.

201 Für das Collège protestant français vgl. Eyrard/KReBs 2007, S. 147-148; die Vertreter der Mission laïque zeigten sich zwar vor der Eröffnung der protestantischen Schule sehr besorgt, vgl. z.B. AN/Paris, 60 AJ 130, Brief von Besnard an Ruche, Paris, 13.10.1927: »[...] l'ouverture du lycée protestant va nous faire un tort certain; mais nous n'y pouvons rien«. Allerdings gibt es für die Zeit nach der Eröffnung keine dieser Einträge mehr in den Quellen.

202 Vgl. AN/Paris, 60 AJ 136, Brief von Ruche an Besnard, Beirut, 23.10.1933.

203 Vgl. Khalaf 2001, S. 173-175.

204 Vgl. Lattouf 2004, S. 90.

205 Vgl. Heleen Murre-van den Berg, Nineteenth-Century Protestant Missions and Middle Eastern Women: an Overview, in: Inger Marie OKkenhaug/Ingvild Flaskerud (Hg.), Gender, Religion and Change in the Middle East, Oxford 2005, S. 103-122, S. 103; Ellen FleischmanN, Lost in Translation. Home Economics and the Sidon Girls' School of Lebanon, c. 1924-1932, in: Social Sciences and Missions 23 (2010), S. 32-62, S. 37.

206 Vgl. das halb wissenschaftliche, halb autobiographische Buch über den von Jesuiten gegründeten libanesischen Frauenschulorden Sœurs des Saints-Cœurs von Henri JALABERT, Histoire d'un siècle. Congrégation des Sœurs des Saints-Cœurs de Jésus et de Marie, Beirut 2001, 
Die Reaktion auf libanesischer Seite war ganz unterschiedlich. Zum einen gründeten sunnitische und griechisch-orthodoxe Kreise, die einem zu starken Einfluss der westlichen Bildung kritisch gegenüber standen, um 1880 ihre eigenen Mädchenschulen in Beirut ${ }^{207}$. Eine andere Alternative zu den Missionaren wollte die osmanische Regierung mit der Vermehrung staatlicher Schulen bieten: um 1869 gab es im Libanongebirge neben 10 Grundschulen für Jungen auch 7 Einrichtungen für Mädchen ${ }^{208}$. Zum anderen gab es aber auch viele arabische Intellektuelle, die das westliche Rollenmodell sehr bewunderten und in ihrem Land übernehmen wollten, entweder um der Frau einen gleichberechtigten Platz neben dem Mann zu geben oder damit die Frau ihren Platz in der Gesellschaft in der Rolle als Ehefrau und Mutter wahrnehme ${ }^{209}$. Der Unterschied der 1920er und 1930er Jahre zu dieser Zeit bestand darin, dass sich die Frauen stärker selber zu Wort meldeten und sich aktiv in die Gesellschaft einbrachten ${ }^{210}$. Außerdem hatten sich, ausgelöst durch den Ersten Weltkrieg und das Mandatsregime, für die Frauen in Syrien und Libanon trotz vieler Kontinuitäten auch neue Handlungsspielräume ergeben ${ }^{211}$.

Welche ambivalente Rolle die französischen Schulen in diesem Prozess der Neudefinition der Geschlechterrollen einnahmen, zeigt die vorliegende Untersuchung. Erstens waren die libanesischen Eltern bei ihren Töchtern noch vorsichtiger als bei ihren Söhnen, wenn es um den Besuch einer ausländischen Schule ging. Für die Töchter galt in besonderem Maße das Kriterium der sozialen Distinktion, das die Schule bieten sollte. Zweitens waren die Lehrer und Lehrerinnen der französischen Mädchenschulen, insbesondere der Mission laïque française trotz ihres Anspruches, die Rolle der Frau im Libanon zu modernisieren und ihr zur Emanzipation zu verhelfen, nicht fortschrittlicher als die lokalen Akteure. Drittens macht die Analyse der Erwartungen der Eltern und der Angebote der französischen Schulen deutlich, dass die französischen Schulen das patriarchalische System der libanesischen Gesellschaft weiterführten und unterstützten, dass sie aber parallel auch die Rolle und Handlungsmöglichkeiten der Frauen im Libanon stärkten.

S. 125-129. Der Autor zitiert mehrere Berichte der Schwestern über geradezu gewalttätige Kämpfe mit ihren protestantischen Konkurrentinnen um die libanesischen Mädchen.

207 Vgl. Magda Nammour, L'image de la femme occidentale dans la presse libanaise entre 1858 et 1914, in: Bernard Heyberger/Carsten-Michael Walbiner (Hg.), Les Européens vus par les Libanais à l'époque ottomane, Würzburg 2002, S. 141-173, S. 149.

208 Vgl. Lattouf 2004, S. 58.

209 Vergleiche die Diskussionen in der Zeitschrift al-Muqtataf. Vgl. Glass 2004, S. 526-556.

210 Vgl. Anne-Laure Dupont / Catherine MaYeur-JAOUEN, Monde nouveaux, voix nouvelles: États, sociétés, islam dans l'entre-deux-guerres, in: Dies. (Hg.), Débats intellectuels au Moyen-Orient dans l'entre-deux-guerres. Revue des mondes musulmans et de la Méditerranée 95-98 (2002), S. 9-39, S. 35.

211 Vgl. Thомpson 2000, S. 16. 
Die libanesischen Eltern waren um die Erziehung ihrer Töchter noch besorgter als um die ihrer Söhne. Es ist zu vermuten, dass dies einer der Gründe war, warum die Mission lä̈que große Schwierigkeiten hatte, Schülerinnen zu rekrutieren. Im Herbst 1925 zählte die Mädchenschule nur 75 Schülerinnen und darunter nur wenige Musliminnen, obwohl die islamischen Gemeinschaften in der Jungenschule die Mehrheit repräsentierten ${ }^{212}$. In der Tat gab es gerade in den muslimischen Familien starke Vorbehalte über den Sinn und Umfang der Mädchenbildung, und daraus resultierend eine starke Tendenz, die Tochter zu beschützen und in der Obhut des Vaters beziehungsweise des Ehemannes zu lassen ${ }^{213}$. Erst in den 1930er Jahren nahmen muslimische Frauen verstärkt am gesellschaftlichen Leben teil ${ }^{214}$. Dies könnte ein Grund dafür sein, dass in dieser Zeit auch die Anzahl der Schülerinnen bei der Mission laïque anstieg ${ }^{215}$.

Seit Mitte der 1920er Jahre fragte die Schulleitung besorgt bei den Sitzungen des Elternrates nach den möglichen Gründen für die geringen Schülerinnenzahlen. Als Ursache nannten die Väter erstens die Nähe der Mädchen- zur Jungenschule der Mission laïque sowie zweitens die Tatsache, dass der Schulhof der Mädchenschule von der Straße aus einzusehen sei ${ }^{216}$. Die Frage der Koedukation war in muslimischen Kreisen in dieser Zeit in der Tat sehr virulent ${ }^{217}$. Auf diese Argumente reagierte die Leitung der Mission laïque mit Unverständnis. Sie betonte zum einen, dass die Mädchenschule, als sie noch in einem anderen Gebäude weiter entfernt von den Jungen war, genauso wenige Schülerinnen zählte ${ }^{218}$. Außerdem, so die Leitung weiter, wiesen zumindest die unteren Klassen der Mädchenschule auch immer einen geringen Anteil an Jungen auf, und in der Oberstufe gingen die Mädchen auf die Jungenschule. Dabei ignorierte sie die Tatsache, dass Jungen bis 10 Jahren in einer Mädchenschule die Eltern nicht besorgten und dass die Oberstufe nur einen kurzen Zeitraum beanspruchte und wenige Schülerinnen betraf ${ }^{219}$, bezog sich aber auf die älteren Schüler und Schülerinnen.

212 Vgl. AN/Paris, 60 AJ 128, »État d'émargement des élèves«, 30.10.1925.

213 Vgl. Dakhli 2010, S. 130; vgl. auch Interview der Verfasserin mit Nada Soubra, Beirut, 28.11.2008.

214 Vgl. Kassir 2003, S. 378.

215 Vgl. die Tabelle im Anhang.

216 Vgl. AN/Paris, 60 AJ 127, »Comité de patronage«, Sitzung vom 30.11.1924; 60 AJ 130, »Comité de patronage«, Sitzung vom 22.02.1929; ebd., Sitzung vom 16.04.1927.

217 Vgl. Ende 1994, S. 55. Der Reformgelehrte Rašīd Riḍā beispielsweise lehnte die Koedukation $\mathrm{ab}$.

218 Vgl. AN/Paris, 60 AJ 130, »Comité de patronage«, Sitzung vom 16.04.1927.

219 Auch die Notizen eines Vertrauten des Collège protestant français, Philippe Bianquis, erwähnen 1927 den von verschiedenen Seiten in Beirut monierten Umstand, dass die Oberstufenklassen der Mission laïque von beiden Geschlechtern besucht wurden. Vgl. KREBS/Eyrard 2007, S. 147. 
Als Lösung des Mangels an Schülerinnen schlug Direktor Ruche Schuluniformen und Zeichenunterricht vor und wurde darin von Generalsekretär Besnard unterstützt ${ }^{220}$. Die Begründung der Schuluniform ist vor allem aus Ruches eigener republikanischer Prägung heraus zu erklären, zeugt aber auch von seiner Unfähigkeit, sich dem Problemhorizont der Eltern anzupassen. Außerdem war dem Direktor sehr daran gelegen, dass die wohlhabenderen Schülerinnen ihren Reichtum nicht zu deutlich zur Schau stellten, und bat deshalb seine Kollegen, auf ein diskretes Auftreten der Schülerinnen zu achten: »Il s'agit de lutter contre une vanité un peu débordante, le prestige de la fortune, des ajustements plus ou moins riches, la coquetterie excessive $\ll^{221}$. Der Zeichenunterricht hingegen entsprach dem Curriculum der anderen französischen Schulen im Libanon für die Mädchenbildung und sollte die laizistische Schule als ebenso attraktiv und >standesgemäß positionieren.

Die Schülerinnen sollten sich auch in anderen künstlerischen Fähigkeiten schulen und zu einer umfassend kulturgebildeten und damit attraktiven Ehefrau werden. Allerdings darf auch nicht vergessen werden, dass die speziell für Schülerinnen konzipierten Fächer diesen auch neue Handlungskompetenzen im privaten und beruflichen Feld gaben. Beispielsweise bot das Collège protestant français Kurse in Hauswirtschaft und anderen Fächern $\mathrm{an}^{222}$. Diese Unterrichtseinheiten hatten auch eine politische Dimension, weil sie als Beitrag der Frauen zum Aufbau der libanesischen Nation propagiert wurden ${ }^{223}$.

Den libanesischen Eltern war eine gute und solide Ausbildung ihrer Töchter sehr wichtig. Während für manche Eltern das Ziel eine möglichst hoch dotierte Ehe war, konnten wenige Schülerinnen sogar noch studieren. Es scheint aber, als ob die Absolventinnen der französischen Schulen nicht in gleichem Maße in einen Beruf einstiegen, wie dies Ellen Fleischmann für die Schülerinnen der amerikanischen Sidon Girls' School im Süden des Libanons gezeigt hat. Fleischmann zufolge ergriffen fast alle der Abgängerinnen einen Beruf außerhalb des Hauses ${ }^{224}$. In den Schulen der Alliance israélite setzte sich erst allmählich die Einsicht durch, aus emanzipatorischen und ökonomischen Gründen die Frauen in handwerklichen Berufen auszubilden, die sie in Ateliers der Organisation ausüben konnten ${ }^{225}$.

220 Vgl. AN/Paris, 60 AJ 129, Brief von Ruche an Besnard, Beirut, 15.11.1925; Antwort von Besnard am 27.11.1925.

221 Vgl. AN/Paris, 60 AJ 131, »Réunion des professeurs«, Sitzung vom 23.02.1929.

222 Vgl. Eyrard/Khoury/Krebs 2006, S. 63. Wie Fleischmann 2010, S. 32, bezüglich der Sidon Girls' School betont, wurden die Hauswirtschaftskurse von den Schülerinnen auch subversiv genutzt, indem sie sie über die ihnen zugedachten Tätigkeitsfelder hinaus nutzten.

$223 \mathrm{Vgl}$. Sвaiti 2008, S. 255.

224 Vgl. Fleischmann 2010, S. 61-62.

225 Vgl. Frances Malino, L'émancipation des femmes, in: André Kaspi (Hg.), Histoire de l'Alliance israélite universelle. De 1860 à nos jours, Paris 2010, S. 263-293, S. 275. Allerdings betont 
Die soziale Distinktion, die die Schulen den Mädchen und ihren Eltern ermöglichen sollten, war von großer Bedeutung. Gleichzeitig war den Eltern sehr an einer strengen und exklusiven Erziehung ihrer Töchter gelegen. Aus diesem Grund galten die Internatsschulen der französischen katholischen Orden als besonders schick. Auch einige Muslime wählten die Schulen der katholischen Schwestern für ihre Töchter, um ihren Wohlstand zu zeigen, und fürchteten sich wenig vor deren Proselytismus ${ }^{226}$. Aus demselben Grund war die Frage des Schulbusses von großer Bedeutung, wie die Protokolle der Elternratssitzungen der Mission laïque, aber auch die Notizen der Euvres protestantes françaises zeigen. Der Transport durch die Schule diente zum einen der Sicherheit der Mädchen, und zum anderen war der Schulbus ein Aushängeschild der Schulen, ein Symbol ihrer Wirtschaftskraft und Außenwirkung ${ }^{227}$. Wegen seiner offensichtlichen Finanzkraft wurde das Collège protestant français für viele Eltern, die ihre Töchter nicht auf eine katholische Schule schicken wollten, sehr attraktiv, zumal es nur für Mädchen konzipiert war. Bald überzeugte die Eltern aber auch das inhaltliche Niveau, das attraktive außerschulische Programm und die Persönlichkeit der langjährigen Direktorin Louise Wegmann ${ }^{228}$.

Für die Direktoren und Lehrer der französischen Schulen zeigte sich ihre mission civilisatrice besonders im Bereich der Mädchenbildung. Alle französischen Institutionen waren davon überzeugt, in einer Gesellschaft, in der die Frauen bisher wenig Rechte und Freiheiten hatten, für diese zu kämpfen. Die Alliance israélite universelle betonte ihren missionarischen Anspruch, »'Alliance n'est pas une œuvre d'instruction; elle est une œuvre d'éducation, et d'éducation israélite «229, besonders für die Mädchen. Auch die Mission laïque sah sich als Wegbereiterin der Emanzipation der Frau. So betonte Direktorin Digrado 1913, dass ihre Schule die »éducation plus moderne et [...] instruction plus sérieuse« biete, die sich die jungen Mädchen wünschten $^{230}$. Als Direktor Ruche 1925 nach einer idealen Direktorin für die Mädchenschule der Mission laïque suchte, diente ihm als Vorbild die Schulleiterin einer École normale im französischen Blois, die er in Frankreich mit

Malino auch, dass die Lehrerinnen der Alliance sehr früh soviel verdienten wie ihre männlichen Kollegen.

226 Vgl. Interview der Verfasserin mit Olfat Sharif ('Ulfat Šarīf), Beirut, 13.12.2008.

227 Dieses Phänomen zeigte sich bei allen Mädchenschulen. Für die Mission laïque vgl. z.B. AN/ Paris, 60 AJ 134, Sitzung vom 15.04.1930; 60 AJ 138, »Comité de patronage«, Sitzung vom 29.11.1935: »Toutes les écoles de filles de Beyrouth ont les leurs«.

228 Vgl. Interview der Verfasserin mit May Saikaly, Beirut, 13.11.2008; vgl. Eyrard/KreBs 2007, S. 154-155.

229 AIU/Paris, Paix et Droit, 6/1932, S. 8.

230 Vgl. AN/Paris, 60 AJ 118, Brief von Digrado an den Präsidenten der Mission laïque, Beirut, 02.06.1913. 
seiner Mutter regelmäßig besucht hatte und die er als »[...] une personne d'une haute culture et surtout d'un caractère ferme et souriant« beschrieb ${ }^{231}$.

Indem er den Libanon als "pays où les mœurs ne permettent pas encore la coéducation « bezeichnete, machte Ruche deutlich, dass er das französische republikanische Bildungssystem als weiterentwickelt ansah, weil dort Mädchen und Jungen gemeinsam unterrichtet wurden ${ }^{232}$. Allerdings sah er über die Tatsache hinweg, dass auch in Europa in der Zwischenkriegszeit die Frage der Koedukation noch nicht einheitlich beantwortet wurde ${ }^{233}$. Während die Lehrer der Mission lä̈que ihr republikanisches Modell der Mädchenbildung verfolgten, betonten auch die Jesuiten, dass die muslimischen Mädchen zu wenig Freiheit und Rechte hätten. Während eines Vortrages entwarf Jalabert deshalb folgende Zukunftsvision: »Le jour où ces fillettes, encore strictement voilées, fonderont des foyers, il y pénétrera un peu d'air, un peu de liberté et une morale plus humaine « ${ }^{234}$.

Dieses Überlegenheitsgefühl widersprach der Tatsache, dass es vor allem in Beirut, aber auch im gesamten Libanon viele Mädchenschulen gab, die von anderen ausländischen oder lokalen Institutionen oder Persönlichkeiten unterhalten und in denen die Mädchen ausgebildet wurden. Die Madrasat al-ahlìya, eine von der Libanesin Marie Kassab gegründete Schule im Zentrum von Beirut sowie die Madrasat zahrat-al-ihsān der griechisch-orthodoxen Gemeinschaft bildeten Beispiele aktiver lokaler Mädchenschulen ${ }^{235}$. Die große Anzahl von Mädchenschulen bedeutete auch, dass die Eltern sehr wohl Interesse an der Ausbildung ihrer Töchter hatten. So wünschten sich die Eltern der Mission lä̈que, dass deren Mädchenschule ihre Töchter bis zum Abitur führe. Ruche unterstützte dieses Anliegen, weil nur das Abitur den Schülerinnen ein Studium an der Université Saint-Joseph ermögliche und weil viele andere französische Schulen, insbesondere die der katholischen Frauenorden, zu dem Zeitpunkt ebenfalls Abiturklassen eingerichtet hätten ${ }^{236}$.

Nachdem die Zentrale der Mission lä̈que diesen Plänen aus finanziellen Gründen zunächst sehr reserviert gegenüber stand, führte die laizistische Mädchenschule 1932 die Abiturklassen ein ${ }^{237}$. Diese Änderung und die Ankunft Lucie Lévys als Direktorin der Mädchenschule 1931, so ist zu ver-

231 Vgl. AN/Paris, 60 AJ 128, Brief von Ruche an Besnard, Beirut, 15.11.1925.

232 AN/Paris, 60AJ 130, „Comité de patronage«, Sitzung vom 16.04.1927.

233 Vgl. Joyce Goodman, Social Change and Secondary Schooling for Girls in the `Long 1920s : European Engagements, in: History of Education 36 (2007), H. 4-5, S. 497-513, S. 510.

$234 \mathrm{SJ} /$ Vanves, »Fonds Jalabert«, 1-1C, »Deux conférences de L. Jalabert à l'Université catholique du Louvain les 10 et 11 décembre 1935 «, »Caractères de la mission des Jésuites en Syrie et au Liban«.

235 Vgl. Lattouf 2004, S. 73.

236 AN/Paris, 60AJ 130, „Comité de patronage«, Sitzung vom 16.04.1927.

237 Vgl. AN/Paris, 60 AJ 135, Brief von Ruche an Besnard, Beirut, 23.03.1933. 
muten, waren ein weiterer Grund dafür, dass die Schülerinnenzahlen der Mission lä̈que in der Folge stark anstiegen und dass die Mädchenschule von der Gesellschaft positiver wahrgenommen wurde. So lobte ein ins Französische übersetzter Artikel der Zeitung an-Nahār das Schulfest der Mädchenschule 1934, insbesondere die Darbietungen der Schülerinnen in französischer und arabischer Sprache: »On souligne l'admiration qu'ont suscité parmi les spectateurs [...] la justesse de la prononciation tant en français qu'en arabe. Ce dernier point prouve le soin qu'apporte le Lycée dans l'enseignement des deux langues $\aleph^{238}$.

Die französischen Schulen haben einerseits das patriarchalische System teilweise perpetuiert, andererseits aber auch in gewisser Weise zur Emanzipation der libanesischen Frauen beigetragen. Sie haben das System gestützt, indem sie manche traditionelle Erwartung der libanesischen Eltern erfüllt haben, aber auch indem sie ihre eigenen Vorstellungen der Rolle der Frau in den Libanon transferierten. Die Betonung ihrer Aufgabe als Mutter und Hausfrau formulierte der Jesuit und Professor an der Université Saint-Joseph Raphael in seinem Buch Le rôle de la femme dans la guerre:

La relation des actes héroïques accomplis par des femmes et spécialement par des femmes françaises au cours de la guerre est pour les élèves de nos écoles un vivant enseignement, capable de faire naître en elles les sentiments élevés et les vertus que la femme doit avoir pour être à la hauteur de sa mission familiale et sociale ${ }^{239}$.

Innerhalb der Alliance israélite wurde die Konzentration der Aufgaben der Frau auf den häuslichen Bereich ebenfalls betont, auch wenn manche Stimmen in der Organisation diese Engführung kritisierten und es viele Diskussionen über das Verhältnis und die jeweiligen Rechte und Aufgaben der Geschlechter gab ${ }^{240}$. Auch die Vertreter der Mission lä̈que unterstrichen diese Rolle der Frau, wenn sie schrieben: »Il ne suffit pas de lui donner des notions de lettres et de sciences, il faut s'efforcer d'en faire encore une ménagère, une femme d'intérieur ${ }^{241}$.

238 AN/Paris, 60 AJ 136.

239 MAE/Nantes, IP, 130, »Publications«, Brief ohne Absender und Adressat, Beirut, 06.04.1936. Dieses Buch wurde auch in den staatlichen Schulen im Libanon verwendet.

240 Vgl. Malino 2012, S. 271-273.

241 MLF/Paris, »Fonds de Russie«, 03/942, 125-2-7, »Instructions aux directeurs des établissements de la Mission Laïque Française«, 12.05.1914. 

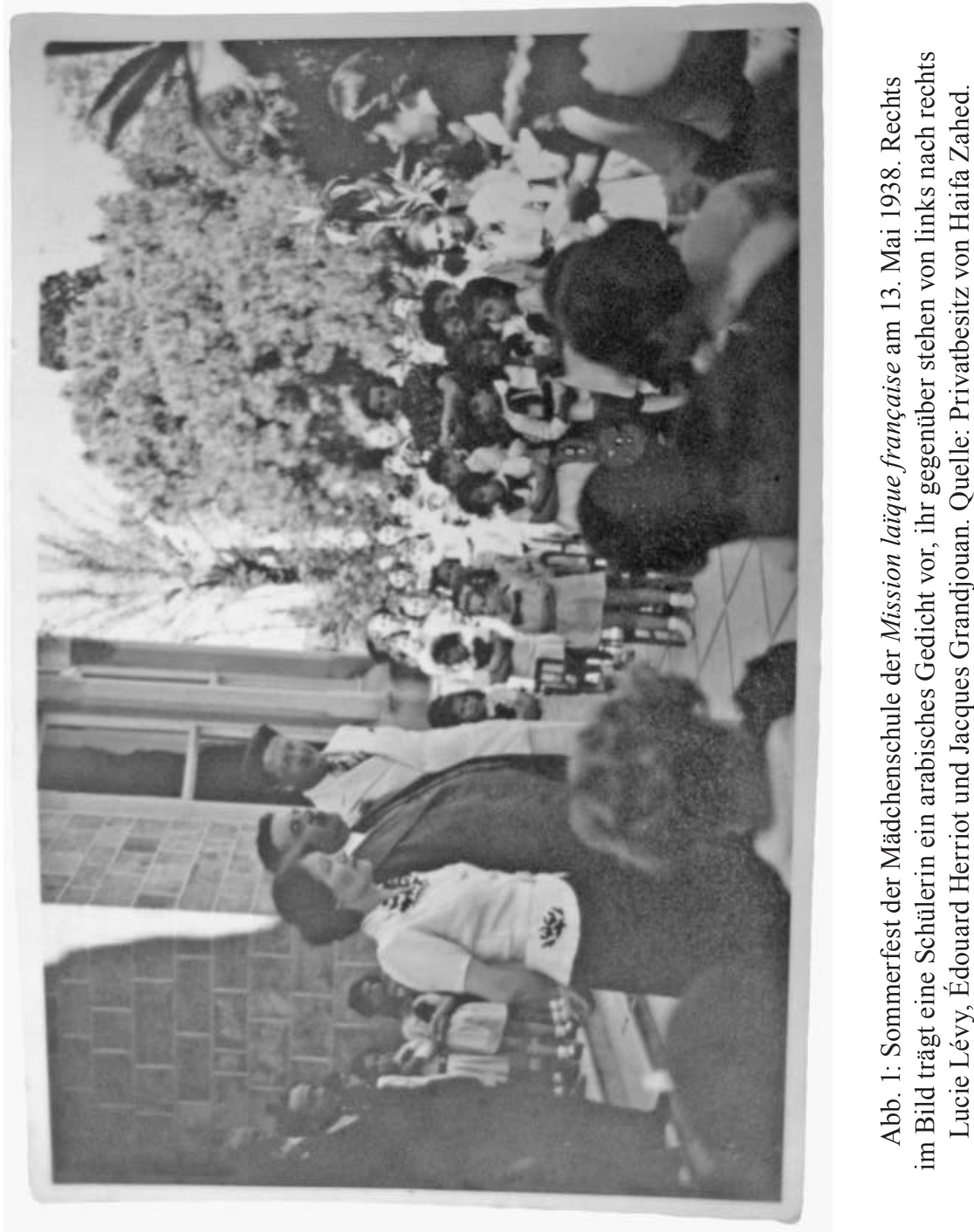
Darüber hinaus zeigten sich die eingeschränkten Rechte der Frauen auch an der Position der Lehrerinnen in der Mission laïque. Einerseits hatten diese von den neuen Ausbildungsmöglichkeiten der Dritten Republik für Frauen profitiert, andererseits traten die Lehrerinnen im Schulalltag viel weniger in Erscheinung als ihre männlichen Kollegen. Ihre Funktion blieb weiterhin auch, ihre Männer zu unterstützen. So führte Ruche 1925 bezüglich seiner Ehefrau, einer ausgebildeten Grundschullehrerin, aus: »Peut-être quand ma femme aura pénétré dans les milieux musulmans réussiront-nous à gagner la confiance des familles chez lesquelles nous devrions recruter le plus d'élèves pour notre lycée de filles « ${ }^{242}$. Ruche erkannte die Tatsache an, dass seine Frau wegen ihres Geschlechts Aktionsmöglichkeiten hatte, die ihm verwehrt blieben, betonte aber auch ihre Rolle als Helferin. Seine Aussage spiegelt die ambivalente Rolle wider, die den französischen Frauen in den 1920er Jahren im kolonialen Kontext neu zukam ${ }^{243}$. Auch in Tunesien, so zeigt eine Studie von Julia Clancy-Smith, konnten die französischen Ordensschwestern in familiäre Bereiche vordringen, die ihren Landsmännern verschlossen blieben ${ }^{244}$.

Darin zeigten sich aber auch gleichzeitig die neuen Wirkungsfelder für die Frauen, schließlich haben sich die französischen Schulen auch an der Stärkung der Rolle der Frau im Libanon beteiligt. Welche Bedeutung dabei speziell die Mission laïque hatte, kann nur vermutet werden. Interessant in diesem Zusammenhang ist die Tatsache, dass die islamische Feministin Nazira Zayn ad-Din (arabisch Naẓ̄ra Zayn ad-Dīn) einige Jahre Schülerin der laizistischen Schule war $^{245}$. Die Schriftstellerin, die als Tochter eines religiösen Gelehrten durch ihre mit dem Koran argumentierenden Forderungen für die Rechte der Frauen in der gesamten arabischen Welt Berühmtheit und Kritik erlangte, besuchte in den 1920er Jahren die Mädchenschule der Mission laïque $^{246}$. Als Drusin war sie dahin möglicherweise ähnlich wie Khalil Taqi ad-Din wegen ihrer Religionszugehörigkeit geworben worden.

Nazira Zayn ad-Din hatte 1928, also während ihrer Schulzeit bei der Mission laïque, ihr Buch Schleier und Entschleiern (as-sufür wa-l-hiğāa) verfasst. Darin kritisierte sie nicht nur die Rolle der konservativen Religionsgelehrten aller Konfessionen für ihre Beschränkung der Frauenrechte ${ }^{247}$, sondern sie bezog sich in ihrer Argumentation auch auf Aussagen des refor-

\footnotetext{
242 AN/Paris, 60 AJ 128, Brief von Ruche an Besnard, Paris, 15.11.1925.

243 Vgl. COOPer 2009, S. 130.

244 Vgl. Clancy-Smith 2009, S. 131.

245 Vgl. AN/Paris, 60 AJ 130, »État d'émargement des élèves« (Schuljahr 1927-1928).

246 Vgl. Miriam Cooke, Nazira Zeineddine al-Halabi. A Pioneer of Islamic Feminism, Oxford 2010; Kassab 2010, S. 195.

247 Vgl. Dakhli 2010; vgl, Margot Badran/Miriam Cooke (Hg.), Opening the Gates. A Century of Arab Feminist Writing, London 1992, S. 270-278.
} 
morientieren Religionsgelehrten al-Ġalāyīn̄̄, welcher sich davon scharf distanzierte. Zayn ad-Din verfasste sogar einen Brief an den Hochkommissar, in welchem sie ihn um die Befreiung der Musliminnen bat, wenn die Muslime es schon nicht selber täten ${ }^{248}$ Auf den Vorwurf der konservativen Gelehrten, sie habe ihre Überzeugungen nur von den ausländischen Missionsschulen kopiert ${ }^{249}$, reagierte sie in ihrem zweiten Buch Die junge Frau und die Scheikhs (al-fatāt wa-š-šuyūhh).

In den Archiven der Mission laïque tauchen die Polemiken dieses Buches nicht auf, aber es ist zu vermuten, dass die häufige Thematisierung der Mädchenschule im Elternrat auch eine Reaktion auf die Debatten um Nazira Zayn ad-Din und über die Rolle der Frau in der Gesellschaft war. Das scheint umso wahrscheinlicher als Zayn ad-Din auch außerhalb des Unterrichts im Umkreis der Mission laïque aktiv war: beispielsweise hielt sie dort 1927 einen Vortrag zum Thema weiblicher Erziehung ${ }^{250}$. Ein Jahr später trug sie auf Anregung des ehemaligen Schülers der laizistischen Schule, Taqi ad-Din as-Sulh, in dessen literarischem Club zu dem Thema »Warum ich die Entschleierung der Verschleierung vorziehe« vor $^{251}$.

Interessanterweise war zu derselben Zeit, als Nazira Zayn ad-Din Schülerin der laizistischen Schule war, Salma Sayegh dort als Arabischlehrerin tätig $^{252}$. Salma Sayegh, die gleichzeitig als Schriftstellerin und Journalistin, unter anderem für die Zeitschrift al-Minerva ${ }^{253}$, arbeitete, machte sich für die Rolle und Bedeutung der Frau in der Gesellschaft stark ${ }^{254}$. Aus ihrer Literatur sprach aber auch eine große Verbundenheit mit dem Libanon sowie eine teils kritische Auseinandersetzung mit dessen Kultur und eine Sorge um dessen Gegenwart und Zukunft. Schon 1912 hatte sie, damals noch unter dem

248 Vgl. Manfred Sing, Lässt sich der Harem Muḥammads feministisch deuten? Die Kontroverse zwischen Widād Sakākīn̄ī und Bint aš-Šāțī, in: Rainer Brunner u.a. (Hg.): XXX. Deutscher Orientalistentag. Freiburg, 24.-28. September 2007, Ausgewählte Vorträge, 2009, S. 6. URL: http://www.dmg-web.de/dot2007/publikation.php (15.05.2013).

249 Vgl. Badran/Cooke 1992, S. 278. Hier wurde die Mission laïque anscheinend wieder mit den religiösen ausländischen Schulen verwechselt.

250 Vgl. Cооке 2010, S. 44. Cooke gibt das Vortragsthema mit »Why girls should be educated« wieder.

251 Vgl. ebd., S. 45.

252 Vgl. AN/Paris, 60 AJ 136, »État du personnel enseignant recruté sur place«; vgl. auch den Artikel der Schülerinnen Lina Ezzedine und Hala Jaroudi in der Schülerzeitschrift L'Éclipse des Lycée Abdel Kader der Mission laïque in Beirut, 1985-1986, S. 60-66: »Historique«, S. 64: »C'est maintenant Monsieur Khatib, Directeur des études arabes, qui a succédé à Salma El Sayeh, auteure du livre An-Nasmāt [Titel mit arabischen Schriftzeichen im Text, E.M.]«.

253 Vgl. Slim/Dupont 2002, S. 387. Die Zeitschrift, die von griechisch-orthodoxen Christinnen in arabischer Sprache herausgegeben wurde, bietet ein Beispiel für das Engagement von Frauen für den arabischen Nationalismus und eine eher traditionelle Rolle der Frauen als Mütter und Ehefrauen.

254 Vgl. L'Orient Le Jour, 21.10.2008, S. 5: »Les femmes dans l'émigration: des pionnières qui ont marqué leur temps«. 
Pseudnym Salwa, in der Zeitung al-Bark die Bewohner Beiruts kritisiert, die blind jeder ausländischen Schule den Vorrang vor den eigenen Einrichtungen gaben ${ }^{255} .1923$ wiederholte sie diese Kritik in ihrem Buch Die Seelen (an-nasamāt):

[...] Beirut, die Stadt des Goldes und des Silbers, die Stadt der Schönheit und der Liebe, die Stadt der Wissenschaft und der Religion, die Stadt der Literatur und der Literaten, die Stadt der Statuen und der Schulen; [aber auch] die Stadt der Freizügigkeit und der Schlechtigkeit und des Erscheinens und des Zeigens ${ }^{256}$.

Ferner betonte sie die tragende Rolle der libanesischen Frauen für die Gesellschaft:

Sogar der Schleier auf den Köpfen der Jungfrauen ist ein Beweis für die ewige und verborgene Tugendhaftigkeit in deinen Frauen; und die Tugendhaftigkeit deiner Frauen ist der Träger (di āma) für den Bau deines Lebens oh Libanon ${ }^{257}$.

Den großen Einfluss, den Sayegh zu der Zeit hatte, zeigt sich auch darin, dass sie in die oben erwähnte Anthologie des Jesuiten Nahla Eingang gefunden hatte, und zwar mit einem Beitrag über die Liebe zur Heimat Libanon, der ihr nationalistisches Engagement noch einmal herausstellt ${ }^{258}$.

Aufgrund ihres hohen politischen, gesellschaftlichen und feministischen Engagements ist sehr wahrscheinlich, dass sie die Gedanken und Überzeugungen mancher Schülerinnen in dieser Richtung beeinflusste. In den 1930er Jahren besuchten auch die Schwester und die Nichte von 'Anbara Salām, Tochter des bekannten sunnitischen Politikers Salīm 'Alī Salām, die Schule der Mission laïque ${ }^{259}$. 'Anbara Salām hatte 1926 während eines Vortrages in Beirut über die Lage der Frau in Europa ihr Kopftuch abgenommen. Mit diesem symbolischen Akt für die Emanzipation der Frau war sie dem Beispiel Hudā Ša rāwīs gefolgt, die 1923 in Kairo ihr Kopftuch abgelegt hatte ${ }^{260}$. Die Präsenz dieser verschiedenen Akteurinnen legt die Vermutung nahe, dass es Ende der 1920er und Anfang der 1930er Jahre in der Mission laïque eine gewisse Gruppe von politisch aktiven Frauen gab, die sich gegenseitig beeinflussten.

255 Zitiert in K.T. Khaїrallah, La Syrie, in: Revue du monde musulman 19 (1912), S. 1-143, S. 112-113.

256 Salma SAYEgh, an-Nasamāt, Beirut 1930, S. 11.

257 SAYegh 1923, S. 13.

258 Vgl. al-Muhtarāt 1930, S. 170-175: iā Lubnān [Oh Libanon].

259 Vgl. Kassir 2003, S. 378; vgl. Interview der Verfasserin mit Haifa Zahed, Beirut, 03.12.2008.

260 Vgl. Margot Badran, Feminists, Islam and Nation: Gender and the Making of Modern Egypt, Princeton 1995, S. 23. 
Allerdings erzeugten nicht alle französischen Schulen in ihren libanesischen Schülerinnen ein feministisches Interesse, und manche Libanesinnen verweigerten sich diesem Engagement auch von sich aus. Beispielsweise berichtet Maud Fargeallah in ihren Memoiren, dass ihre Tante mit Taqi adDin as-Sulh und einer gemeinsamen Freundin der beiden ihre arabisch-nationalistische Ansichten teilte. Die junge Maud empfand es als Zwang, auf den Willen ihrer Tante hin, die in der Organisation an-nahda an-nisà '̌ya (die Erweckung der Frauen) tätig war, Teil dieses »Comité féministe« werden zu müssen ${ }^{261}$. Es bleibt daher festzuhalten, dass die französischen Schulen den Prozess der stärkeren Einbindung der Frauen in das gesellschaftliche Leben weniger provoziert als begleitet haben.

\section{Die Konstruktion der libanesischen Geschichte: Debatten an und über Schulen}

Eine weitere Aufgabe, die die französischen Schulen ähnlich wie die Lehrerausbildung nicht erfüllen konnten oder wollten, betrifft den Geschichtsunterricht und die Schaffung eines einheitlichen libanesischen Geschichtsbildes. Das von den Regierungsinstanzen belassene Vakuum füllten auch die französischen Bildungseinrichtungen nicht: Die unterschiedlichen Schulbücher, die in den Schulen verwendet und zum Teil in deren Umfeld hergestellt wurden, trugen dazu bei, dass kein einheitliches Geschichtsbild die junge libanesische Nation stützen konnte.

Die Forschung hat sich dem Thema der disparaten »Geschichte und Geschichtsschreibung im Libanon $\aleph^{262}$ bereits mehrfach gewidmet. Dabei hat sie besonders die Historiker und ihre Ideen ${ }^{263}$ sowie die Antinomie des pro-syrischen und arabisch-nationalistischen Werkes von 'Umar Farrūhn und Zakī an-Naqqāš (1935) ${ }^{264}$ und der pro-französischen, maronitisch-zentrierten Arbeit von Fu'ād Bustānī und Asad Rustum (1937) ${ }^{265}$ sowie die Werke

261 Vgl. Chamoun 1989, S. 63-64.

262 So der Titel von Havemann 2002.

263 Siehe die klassische Studie von Beydoun 1984. Wie Havemann 2002, S. 2-3 treffend urteilt, ist diese Studie wegen verschiedener Aspekte, unter anderem der prominenten Betonung der konfessionellen Grenzen, mehrfach kritisiert worden, enthält aber auch viele wichtige Detailinformationen.

264 Es handelt sich um das Werk Tarīh Sūrīya wa Lubnān al-Musawar [Bebilderte Geschichte Syriens und des Libanons]. Beide Autoren waren Lehrer der sunnitischen Maqasid-Schulen; vgl. Betty Gilbert-Sleiman, Unifier l'enseignement de l'histoire dans le Liban d'après-guerre. Conditions et limites de l'élaboration de la nouvelle politique publique du manuel scolaire d'histoire 1989-2001, Diss. Aix-Marseille 2010, S. 89.

265 Mūğaz Tarīḥ Lubnān [Überblick über die Geschichte des Libanons]. Das Buch war auf Initiative einiger christlicher Notabeln entstanden, die dem Werk von Farrūhn und an-Naqqāš, wel- 
der Jesuiten herausgehoben ${ }^{266}$. Diese Studien zeichnen ein, zu großen Teilen gerechtfertigtes, sehr monolithisches Bild mit dem pro-französischen und pro-maronitischen Geschichtsbild der katholischen Schulen einerseits und dem der arabischen nationalistischen Kreise andererseits, deren zwei Pole Sbaiti sehr treffend als »Phoenicism or Arabism« beschrieben hat ${ }^{267}$. Dieses Bild soll im Folgenden durch die Hinzuziehung zusätzlicher Bücher, die im direkten Umfeld der französischen Schulen produziert wurden, weiter ausdifferenziert werden. Besonders interessant ist dabei die Haltung der nichtkatholischen französischen Schulen, insbesondere der Mission lä̈que, die zum einen Teil des französischen Mandats war, aber zum anderen im arabischen nationalistischen Milieu agierte.

In der Tat wurden Schulbücher zu >Arenen` der Deutungskämpfe der libanesischen Geschichte, sowohl zwischen Frankreich und dem Libanon als auch innerhalb der libanesischen Gesellschaft. Während die katholischen Schulen vor allem die christliche Vision eines von der restlichen arabischen Welt distinkten Libanons unterstützten, sah die Position der Mission laïque sehr viel ambivalenter aus. Die Quellen machen deutlich, dass die laizistische Schule gefangen war in dem Dilemma, sowohl als französische Institution einem eher christlich geprägten libanesischen Geschichtsbild anzuhängen als auch den Visionen ihrer größtenteils nicht-katholischen Klientel Rechnung tragen zu müssen.

Die Geschichte eines Landes ist zentral für seine Identität als Staat und die Identifikation der Bürger mit diesem Staat ${ }^{268}$. Das gilt umso mehr, ist aber auch umso schwieriger, für gerade entstehende Staaten, die zudem unter fremder Herrschaft stehen ${ }^{269}$. Zahlreiche arabische Intellektuelle beschäftigten sich nach dem Ersten Weltkrieg mit der Geschichte ihres Landes, die zugleich eine Auseinandersetzung mit dessen Identität betraf. Dabei variierten ihre historischen Perspektiven und Urteile nicht nur bezüglich der Vergangenheit ihres Landes als Teil des Osmanischen Reiches, sondern auch im Hinblick auf die britische beziehungsweise französische Mandatsherrschaft ${ }^{270}$. Auch im Libanon waren diese Debatten sehr aktiv. Beispiels-

ches den Libanon in den größeren arabischen Kontext einordnet, ein Geschichtsbild entgegensetzen wollten, das die Singularität des Libanons betont, wie schon der Titel deutlich macht.

266 Vgl. Havemann 2002, S. 163-166. Allerdings betont dieser auch, dass Rustum die Geschichtsauffassung seines Kollegen von Anfang an ablehnte und sich nur aus äußeren Zwängen heraus an dem Projekt beteiligt habe; vgl. KaufMan 2004a, S. 113-119.

267 Vgl. Sвaiti 2008, S. 153.

268 Vgl. Pierre Nora, Between Memory and History. Les Lieux de Mémoire, in: Représentations 26 (1989), S. 7-24, S. 11. In seinem Opus »Lieux de Mémoire« hat Nora die Bedeutung des historischen Gedächtnisses für Frankreich untersucht.

269 Vgl. Benedict Anderson, Imagined Communities. Reflections on the Origin and Spread of Nationalism, London/New York 2006, S. 116-135.

270 Wie Freitag 1991, S. 178-183, gezeigt hat, beurteilten arabisch-nationalistisch orientierte Historiker die osmanische Vergangenheit sehr negativ als eine weitere Phase der Unterdrückung, 
weise wandte sich der sunnitische und nationalistisch geprägte Historiker Muhammad Ğamīl Bayhum, der im Elternrat der Mission lä̈que saß, sehr eindeutig gegen das französische Mandat und den neuen libanesischen Staat und betonte die untrennbare Zusammengehörigkeit Syriens und des Libanons $^{271}$. Dem gegenüber betonten viele christliche und insbesondere maronitische Gelehrte wie beispielsweise Paul Jouplain die besondere Rolle, die der Libanon schon während des Osmanischen Reiches gespielt und zu der ihm Frankreich verholfen hatte ${ }^{272}$. Unter dem Einfluss der antiklerikalen Gesetzgebung in Frankreich, wo er lebte, forderte Jouplain aber auch eine Begrenzung der klerikalen Rechte und Besitztümer ${ }^{273}$. Die griechisch-orthodoxen Historiker zeigten hingegen immer eine viel stärkere Nähe zu den Auffassungen der arabischen Nationalisten ${ }^{274}$.

Über die intellektuellen Debatten hinaus entstanden im Libanon um 1926 herum verschiedene kulturelle Instanzen, um dem Staat seine historischen Bezugspunkte und seine »lieux de mémoire spécifiques« zu geben ${ }^{275}$. Kunst wurde in dieser frühen Phase der libanesischen wie auch der syrischen Nation zu einer »central component in this practice of differentiation and exclusion $\aleph^{276}$. Das gilt insbesondere für den Bau des nationalen Museums, welches mit der Währung, der Flagge und dem Parlamentsgebäude zu den Insignien der »modern nation « gehört ${ }^{277}$. In Beirut beschlossen einige Intellektuelle der lokalen christlichen Elite um Henri Pharaon und Alfred Sursuq 1922 den Bau eines nationalen Museums, das schließlich 1937 fertig gestellt wurde. An diesem Unternehmen beteiligte sich auch die französische Mandatsregierung: Ihr Ziel war unter anderem, Beirut im Gegensatz zu Damaskus zu einer europäisch und nicht arabisch geprägten Stadt zu stilisieren.

während stärker religiös geprägte muslimische Gelehrte den islamischen Charakter des Reiches betonten. Eine heterogene Haltung gegenüber dem Osmanischen Reich, aber eindeutig negative Beurteilung der französischen und britischen Herrschaft nach dem ersten Weltkrieg nahm beispielsweise der sehr bekannte libanesisch-ägyptischen Reformdenker Raš̄ì Riḍā ein. Vgl. auch Mahmoud HADDAD, Arab Religious Nationalism in the Colonial Era: Rereading Rashīd Riḍā’s Ideas on the Caliphate, in: Journal of the American Oriental Society 117 (1997), H. 2, S. 253-277, S. 257, S. 262.

271 Vgl. Havemann 2002, S. 172-175.

272 Vgl. Kapitel 2.1.

273 Vgl. Buheiry 1981, S. 78.

274 Vgl. Beydoun 1984, S. 581. Nur wenige maronitische Autoren teilten diese Auffassungen, dazu zählte Negib Azoury, der 1905 in Paris das Buch »Le réveil de la nation arabe« verfasst hatte und der die französische Unterstützung auch nicht ganz ausschloss. Vgl. Stefan WiLD, Negib Azoury and his book Le réveil de la notion arabe, in: Marwan BuheIRY (Hg.), Intellectual Life in the Arab East, 1890-1939, American University of Beirut 1981, S. 92-104, hier 98.

275 DAKHLI 2009a, S. 236.

276 Heghnar Zeitlian Watenpaugh, Museums and the Construction of National History in Syria and Lebanon, in: Nadine Méouchy / Peter Sluglett (Hg.),The British and French Mandates in Comparative Perspective, Leiden 2004, S. 185-202, S. 188.

277 Ebd, S. 188. 
Deshalb sollten in Beirut vor allem phönizische archäologische Funde präsentiert werden, während in dem zukünftigen Museum in Damaskus arabische und islamische Kunst ausgestellt werden würde ${ }^{278}$. Die Errichtung der Nationalbibliothek in Beirut 1922 galt demselben Ziel ${ }^{279}$. Wie Kaufman deutlich gemacht hat, überschnitten sich in diesen Institutionen vor allem die Überzeugungen und Interessen der Mandatsregierung, der Maroniten und der Jesuiten, die letztere ausgebildet hatten ${ }^{280}$. Besonders der belgische Jesuit Henri Lammens, der in Beirut lebte und lehrte, war für die Herausbildung eines stark christlich-libanistischen Geschichtsbildes und die Betonung der phönizischen Vergangenheit prägend ${ }^{281}$.

Schließlich kam es in dieser Zeit zu einer erhöhten Produktion von Geschichts- und Geographiebüchern für den Unterricht. Das betraf zum einen die staatlichen Schulen, die theoretisch seit der Verfassung der libanesischen Republik 1926 der, faktisch nur theoretischen, Souveränität eines libanesischen Erziehungsministeriums unterstellt waren ${ }^{282}$, aber ebenso die privaten Schulen, zu denen die französischen Einrichtungen gehörten. Von dem 1924 erlassenen Gesetz verpflichtender Schulbücher und Curricula wurden die nicht-staatlichen Bildungseinrichtungen aber bewusst ausgelassen. Auf diese Weise entstanden sehr disparate Präsentationen der libanesischen Geschichte.

Die staatlichen Schulen waren ähnlich wie die libanesischen katholischen Institutionen stark von einem christlichen Geschichtsbild des Libanons geprägt, wie sich zum Beispiel in dem 1928 von Jacques Eddé für die offiziellen Schulen konzipierten Werk »Géographie de la Syrie « ${ }^{283}$ zeigt, das auf Französisch und Arabisch verfasst worden war $^{284}$. So erkannte das Werk zwar an, dass die Muslime in den französischen und britischen Mandatsgebieten die Mehrheit der Bevölkerung stellten ${ }^{285}$, behandelte aber sehr viel

278 Vgl. Dakhli 2009a, S. 235-236; Kaufman 2004a, S. 122-123; Watenpaugh 2004, S. 199-200.

279 Vgl. AN/Paris, aj 16, 6993, »Bibliothèque nationale de Beyrouth«. Ihr Gründer war Philippe de Tarrazi (1865-1956), ein römisch-katholischer Syrer, der selber viele Werke verfasst hatte, unter anderem 1913 das erste Buch über die Geschichte der Presse in der arabischen Welt, Tārīh aș-șihāfa al-'arabīya (Beirut: Al-Matba'a al-adabīya, 1913-33).

280 Vgl. KaUfman 2004a, S. 111.

281 Hassan Quobeissy spricht sogar von einer »Dominanz der Jesuiten« in allen Aspekten des Erziehungswesens während der Mandatszeit. Gilbert-Sleiman 2010, S. 58-59, zitiert aus der Studie von Quobeissy, Ad-dawla wa al-ta alīm ar-rasmī fĩ Lubnān [Der Staat und das staatliche Bildungswesen im Libanon] von 1999.

282 Vgl. Hanf 1969, S. 76.

283 Jacques EdDÉ, Géographie de la Syrie. Adoptée pour l'usage des écoles gouvernementales de la République Libanaise suivant decision de la commission d'examens des livres datée du 4 février 1927, Beirut 1928.

284 Der französischen Tradition folgend, wurden in den Schulen Geschichts- und Geographieunterricht als eine Einheit gesehen.

285 Vgl. EdDÉ 1928, S. 16. 
ausführlicher die verschiedenen christlichen als die islamischen Konfessionen und betonte insbesondere die sehr alte Genealogie der Maroniten ${ }^{286}$. Ähnlich lauteten die Aussagen in anderen für die katholischen Privatschulen konzipierten Büchern ${ }^{287}$.

Hingegen wurde in den Schulen der sunnitischen Maqasid-Organisation das eingangs erwähnte Werk von Farrūh̆ und an-Naqqāšs verwendet, welches dem Libanon keine distinkte Identiät zuerkannte, sondern ihn als Teil dieser arabischen Welt beschrieb ${ }^{288}$. Zudem wurden der Westen und insbesondere die Kreuzzüge sehr viel negativer als in den christlichen Schulbüchern beschrieben $^{289}$. Wie das Geographieheft des ehemaligen Maqasid-Schülers Afif Soubra (arabisch Afîf Sūbra) von 1944 aber zeigt, stellten die Lehrer Frankreich auch als sehr mächtige und einflussreiche westliche Macht dar und brachten dem Land ihre Bewunderung entgegen: »Das französische Volk wurde bekannt für seinen Patriotismus und hängt an seiner Erde, und sie lieben die Demokratie, das Leben und die Ordnung [...] $\ll^{290}$.

Das Hochkommissariat und die französischen Schulen zeigten sich gleichermaßen unfähig, für alle Libanesen kompatible Schulbücher in Umlauf zu bringen. Seit Beginn des Mandats hatte es von verschiedenen Seiten Kritik an den in den Schulen benutzten französischen Geschichtsbüchern gegeben. Auch wenn diese Frage während der gesamten Mandatszeit ein Dauerthema blieb, verdichteten sich die negativen Äußerungen um 1925.

286 Vgl. ebd., S. 14-16.

287 Vgl. beispielsweise G. LevenQ, La Syrie. Géographie élémentaire à l'usage des écoles, Beirut 1920, S. 16: »Le Liban tel qu'il a existé jusqu'en 1920, a été définitivement créé par le statut de $1864 \ll$.

288 Vgl. Havemann 2002, 163-165.

289 Vgl. Sвaiti 2008, S. 186.

290 Vgl. das Schulheft von Afif Soubra (Abb. 2). 


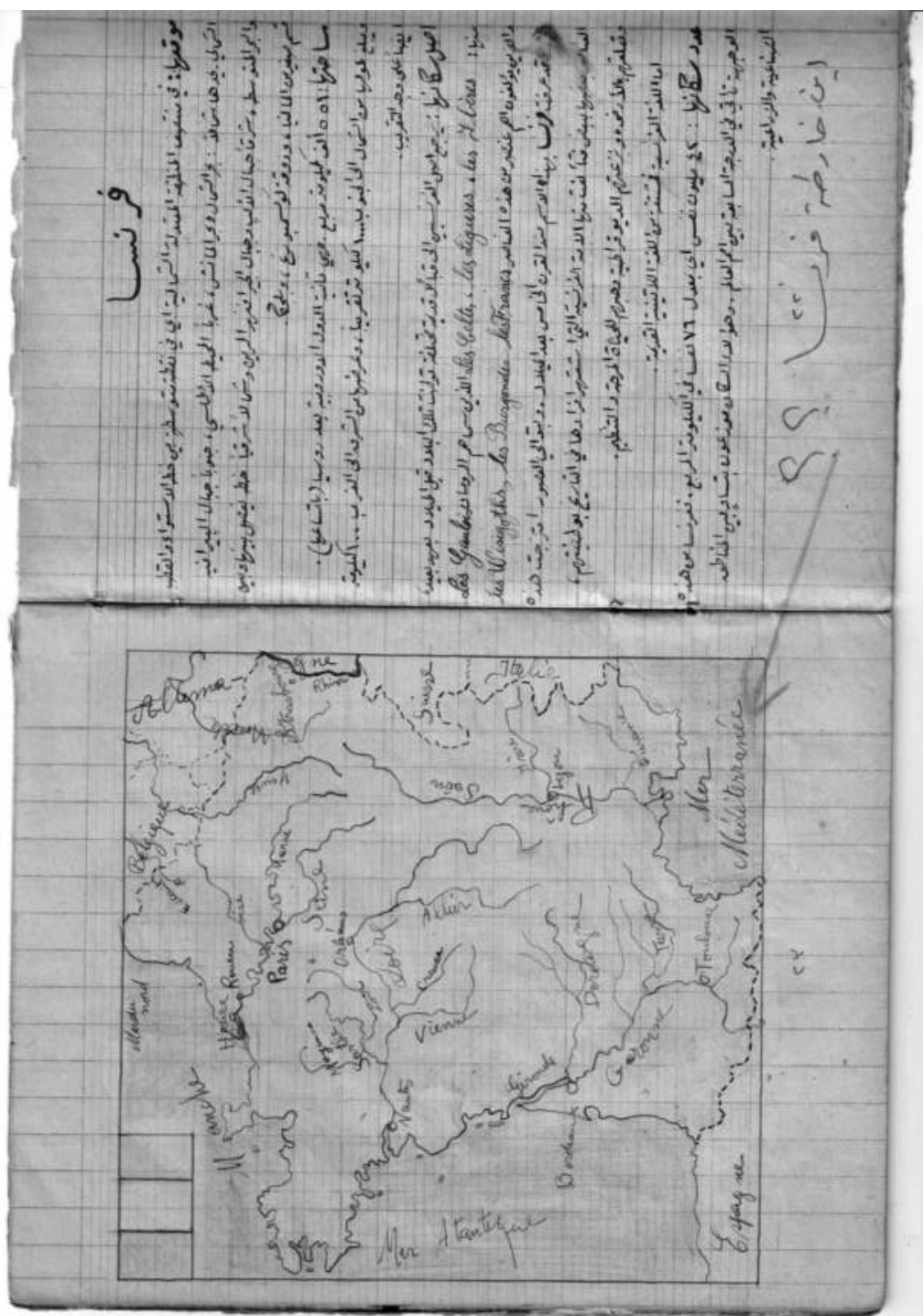

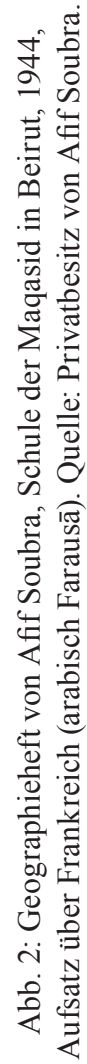


Die ersten Beschwerden über ein Schulbuch in einer katholischen Schule, wahrscheinlich der Filles de la Charité, das Mohammad als »Faux prophète« bezeichnete, tauchten schon 1920 auf ${ }^{291}$. Im Dezember 1923 wurde die Frage erneut akut und Hochkommissar Weygand ließ das Buch, das eine "phrase désobligeante pour la religion musulmane « enthielt, entfernen ${ }^{292}$. Augenscheinlich wurde dieser Erlass nicht konsequent umgesetzt, denn Anfang der 1930er Jahre beschwerten sich einige muslimische Bewohner von Aleppo erneut. Auch wenn alle katholischen Orden daraufhin beteuerten, sie würden dieses Buch nicht mehr benutzen, verfasste Hochkommissar de Martel ein Rundschreiben an alle Schuldirektoren: seit 1924 sei es erlaubt, Schulbücher mit negativen Stellen über den Islam nur dann zu benutzen, wenn vorher die entsprechenden Seiten herausgerissen würden. Am besten wäre es aber, diese Bücher, »qui ne conviennent pas aux écoles du Levant«, gar nicht mehr in Frankreich zu bestellen ${ }^{293}$.

Aber noch 1940 musste der Bildungsbeauftragte Bounoure ein französisches Schulbuch verbieten, weil darin der Satz »J'ai un chien qui s'appelle Moustapha«, auftauchte ${ }^{294}$. An dieser langen Zeitspanne lässt sich sehr gut verdeutlichen, dass viele Kräfte gegen ein einheitliches Geschichtsbild arbeiteten: einige katholische Schulen manifestierten ihre Resistenz gegenüber einem besonderen Respekt vor dem Islam. Das Hochkommissariat zeigte sich unfähig oder sogar unwillig, das Verbot mit Strenge durchzusetzen.

In der Tat praktizierte das Hochkommissariat eine ambivalente Politik in Bezug auf die katholischen Schulen: einerseits sahen seine Vertreter es als problematisch an, dass manche katholischen Geschichtsbücher, die antimuslimische Tendenzen enthielten, von der Mandatsregierung unterstützt würden ${ }^{295}$. Andererseits gratulierten sie dem Verfasser eines profranzösischen und christlich dominierten Schulbuches, weil er geschrieben habe »que la France n'a jamais poursuivi dans ce beau pays une politique de domination $\ll^{296}$.

291 Vgl. MAE/Nantes, IP, 02: 1919-1920, »Instruction Publique«, unterschrieben von »Khoury«.

292 MAE/Paris, CPC, 378: »Instruction Publique/Dossier général«, Bericht von Weygand, Beirut, 22.12.1923.

293 MAE/Nantes, IP, 102: 1933-1934, „Manuels d'histoire utilisés dans les écoles privées«, Rundschreiben an die Schuldirektoren vom 13.01.1933.

294 Es handelte sich um das Werk »La composition française facilitée aux enfants, Cours Élémentaire« von L. Vidal (Éditions Librairie Sacré-Cœur de Rodez, Aveyront). Der Mufti von Beirut hatte Bounoure auf diesen Satz aufmerksam gemacht, der für die Muslime eine Beleidigung bedeutete, da er einen Namen des Propheten enthielt. Vgl. MAE/Nantes, IP, 162: 1940, »Manuels scolaires interdits «.

295 MAE/Nantes, IP, 29: 1924, »Publications«, Brief vom Bildungsbeauftragten Duthoit an Hochkommissar Weygand, Beirut, 15.03.1924, über das Buch des Abbé Ghaleb.

296 Ebd., Brief von de Reffye an Abbé Ghaleb, Beirut, 19.03.1924. 
Diese ambivalente Haltung zeigt sich auch an der Reaktion des Hochkommissariats auf den Vorschlag Jacques Tabets ${ }^{297}$, der bei den jährlichen Abschlussprüfungen einen Preis für libanesische und syrische Geschichte im Wert von 1000 Francs vergeben wollte ${ }^{298}$. Zunächst reagierte das Hochkommissariat zwar positiv:

Je ne puis que vous féliciter de votre généreuse initiative qui doit nous aider dans l'œuvre de renaissance morale et intellectuelle que nous nous efforçons de provoquer et qui ne pourra être efficace que si elle est appuyée par la volonté agissante des populations syriennes et libanaises ${ }^{299}$.

Robert de Caix, der Sekretär des Hochkommissariats, verwehrte sich aber gegen die Konditionen Tabets, dass dieser Preis an die Integration der syrischen Geschichte und Geographie in die Abiturprüfungen gebunden sei, und dass dafür nur ein bestimmtes Buch, La Syrie. Précis historique des Jesuitenpaters Henri Lammens, verwendet werden dürfe ${ }^{300}$. Dieses Buch hatte Lammens 1920 im Auftrag des ersten Hochkommissars in Syrien und im Libanon, General Gouraud, verfasst: Es spiegelt die Auffassung Lammens' von der Geschichte Syriens und des Libanon wider, die laut dem Jesuiten vor allem von der Zeit der Phönizier und der Zeit des französischen Protektorats im Orient im Anschluss an die Kreuzzüge geprägt war und innerhalb derer der Islam und die arabische Expansion nur ein Einflussfaktor unter vielen waren $^{301}$.

297 Tabet hatte 1920 das Buch »La Syrie« verfasst. Im Juli 1924 initiierte er das Komitee der Amis du Musée, um Geld für den Bau des libanesischen Nationalmuseums zu sammeln. Vgl. KaUfMAN 2004a, S. 124.

298 Interessanterweise hatte Tabet in seiner Ausarbeitung des Wettbewerbs schon den Direktor der Mission laïque française als Jurymitglied mit aufgenommen, das heißt er sah die Schule als festen Bestandteil der Beiruter Schullandschaft an.

299 MAE/Nantes, IP, 14, »Écoles privées«, Brief von de Caix an Tabet, 19.05.1922.

300 Ebd., Brief von de Caix an Tabet, 30.05.1922. Ferner, so de Caix, sei es nicht möglich, die Geschichte Syriens isoliert zu betrachten, sondern diese müsse immer in dem Zusammenwirken mit anderen Ländern untersucht und gelehrt werden. Diese Aussage de Caix' überrascht insofern, als Tabets Vorstellung eines großsyrischen Staatswesens ohne arabischen Charakter eigentlich de Caix' Sichtweise entsprach, welche auf der Betonung der Minoritäten in Syrien und im Libanon lag. Vgl. Gérard Khoury, Robert de Caix et Louis Massignon. Deux visions de la politique française au Levant en 1920, in: MÉouchy/SLugLEtT 2004, S. 165-184. Es ist zu vermuten, dass es de Caix in dieser Angelegenheit vor allem darum ging, die Entscheidungshoheit über die kulturellen Aktivitäten zu behalten. Dem gegenüber ließ Hochkommissar Gouraud im September 1922 mitteilen, dass er die Initiative Tabets für sehr gut halte und ihm >grünes Licht` gebe. MAE/Nantes, IP, 14, »Écoles privées«, »Note pour M. le Conseiller pour l'Instruction Publique«, 16.09.1922.

301 Henri SJ Lammens, La Syrie. Précis Historique, Premier et Deuxième Volume, Beirut 1921. 
Vergleicht man diese Publikation und die Vorgaben des Hochkommissariats für den Geschichtsunterricht, kann man sehr viele Parallelen feststellen und so den enormen Einfluss Lammens' auf das von der Mandatsmacht propagierte libanesische Geschichtsbild nachweisen ${ }^{302}$. Das zeigt sich beispielsweise in Eddés Werk an der starken Betonung der christlichen Gemeinschaften im Nahen Osten ${ }^{303} .1924$ entstand eine arabische Version des Werkes, das von da an auch im Geschichtsunterricht arabischsprachiger Schulen verwendet werden konnte ${ }^{304}$.

Der Eindruck einer ambivalenten Haltung des Hochkommissariats verfestigt sich, wenn man die von den Archiven überlieferten Diskussionen über ein neues libanesisches Geschichtsbuch untersucht. Schon 1922 hatte Kultusbeauftragter Duthoit das Projekt angeregt, ein neues Geschichtsbuch für Syrien und den Libanon zu entwerfen ${ }^{305}$. Diese Idee wurde aber weder von Duthoit noch von seinen Nachfolgern weiter konkretisiert. Viele Vorschläge libanesischer Autoren erreichten in dieser Zeit die Mandatsverwaltung. Diese lehnte sie alle ab, entweder weil das Buch zu schwer für die Schüler sei, weil es historische Unwahrheiten enthalte, oder aus anderen Gründen.

Bei ihrem Urteil verließen sich die Mandatsfunktionäre nicht auf ihr eigenes Empfinden, sondern fragten Vertreter verschiedener politischer Strömungen um Rat. Beispielsweise baten sie für den Vorschlag eines Geschichtsbuches von Sélim Nassi, Lehrer an der Schule der Alliance israélite in Aleppo, Muḥammad Kurd 'Alī um seine Meinung. Der Intellektuelle Kurd 'Alī, ein ehemaliger Schüler der Lazaristen in Damaskus, war im Erziehungsministerium in Damaskus tätig, vertrat die Ideen des arabischen Nationalismus, war aber eher kritisch gegenüber der jüngeren Generation von Nationalisten ${ }^{306}$ und kooperierte auch mit der Mandatsmacht ${ }^{307}$. Kurd 'Alī befand, das Buch sei zwar nicht originell, aber immerhin »écrit dans un esprit historique beaucoup plus que l'ouvrage de H. Lammens S.J. [...] >précis historique de la Syrie<[...]« $\ll^{308}$.

302 Vgl. Edmond Chidiac, Scolarisation et Enseignement de l'Histoire au Liban: Formation du citoyen ou facteur de division?, o. O., o.J., S. 1-7, S. 5.

303 Vgl. Lammens 1921, S. IX: als Referenzwerke für die »période moderne« nennt er nur christliche Autoren.

304 Muhtașar tārīh Sūrīya wa-Lubnān. Tárīb al-kitāb al-mu anwan Petite Histoire de la Syrie et du Liban, bi-qalam aḥad al-abā’ al-yasū 'ìyīn, Beirut 1924 [Kurze Geschichte Syriens und des Libanon. Arabische Version des Buches mit dem Titel Petite Histoire de la Syrie et du Liban, von einem Jesuitenpater].

305 AN/Paris, 60 AJ 123 Brief von Mathieu an Besnard, Beirut, 01.03.1922.

306 Rainer Hermann bezeichnet ihn deswegen als »konservativen Erneurer«. Vgl. Rainer HeRMANN, Kulturkrise und konservative Erneuerung: Muhammad Kurd 'Alī (1876-1953) und das geistige Leben in Damaskus zu Beginn des 20. Jahrhunderts, Frankfurt am Main 1990.

307 Vgl. Bocquet 2008, S. 41.

308 MAE/Nantes, IP, 29, 1924, »Publications«, Brief von Muḥammad Kurd 'Alī an Duthoit, Beirut, 21.11.1924. 
In der Tat hatte Kurd 'Ali Lammens' Aussage, die historische Fragmentierung sei eines der zentralen Charakteristika Syriens, als christlichen Fanatismus verurteilt ${ }^{309}$.

In den verschiedenen französischen Schulen sah der Umgang mit Geschichtsbüchern jeweils sehr unterschiedlich aus. Zwar verwendeten alle Einrichtungen auch Geschichtsbücher aus Frankreich, die ein relativ homogenes Bild auf die Levante warfen, aber aufgrund ihrer unterschiedlichen Klientel wurden die einzelnen französischen Schulen bezüglich eigener Lehrwerke vor sehr unterschiedliche Herausforderungen gestellt. Die Trennlinien verliefen also weniger zwischen Franzosen und Libanesen als vielmehr innerhalb der französischen und insbesondere innerhalb der libanesischen Milieus. Auf libanesischer Seite standen sich eine arabisch- oder syrisch-nationalistische, oft muslimisch oder griechisch-orthodox geprägte Sichtweise, die den Libanon als Teil Großsyriens beziehungsweise eines arabischen Reiches verstand, und eine libanistische, größtenteils christlich beziehungsweise maronitisch geprägte Vision gegenüber, die den Libanon als einzelnen, von seinen arabischen Nachbarn verschiedenen Staat ansah.

Zwar gab es in allen französischen Geschichtsbüchern, welche die unterschiedlichen französischen Schulen im Libanon benutzten, eine relativ einheitliche Perspektive auf die arabische Geschichte und den Islam: beide wurden als negativ und dekadent dargestellt ${ }^{310}$. Aber schon in Bezug auf die spezifisch libanesische oder syrische Geschichte sind erste Nuancen zwischen verschiedenen Büchern festzustellen: während ein eher katholisch inspiriertes Schulbuch den Konflikt zwischen Drusen und Maroniten 1860 ausschließlich als Schuld der Drusen darstellte ${ }^{311}$, nannte ein anderes, republikanisch geprägtes Schulbuch des Verlags Hachette die Maroniten als Auslöser des Konflikts, auch wenn es den Drusen eine größere Grausamkeit

309 Vgl. Ulrike Freitag, Writing Arab History: The Search for a Nation, in: British Journal of Middle Eastern Studies 21 (1994), H. 1, S. 19-37, S. 26.

310 Vgl. das republikanisch geprägte Werk von J. IsAAC, Histoire 1789-1851. Résumé AideMémoire, Classe de Première, Paris 1929, S. 81, über die Eroberung Algeriens: »Les tribus d'Arabes nomades et les confédérations de payans bèrbères étaient pratiquement indépendantes. Il n’y avait entre elles qu'un lien, la haine et le mépris du chrétien.«; vgl. das Werk des Rektors des Institut catholique in Paris, Alfred BAudrillart, Histoire générale. Orient - Grèce - Rome - Moyen Âge - Temps modernes - Histoire contemporaine, Paris 1924, S: 47: »La civilisation arabe. Les Arabes déployèrent, dans les contrées où ils s'étaient établiés, une activité prodigieuse. [...] Cependant, [...] cette civilisation, qui était dûe surtout à l'imitation des peuples voisins, fut assez peu originale«. Dieses Buch wurde von den Jesuiten in Beirut verwendet. Vgl. SJ/Vanves, »Fonds Jalabert«, 3-1 F.

311 Vgl. Précis historique de France par un Comité de professeurs, Lyon/Paris 1923, S. 335: »L'expédition de Syrie (1860) fut entreprise pour protéger les chrétiens du Liban contre les Druses«. 
attestierte $^{312}$. Damit unterschied sich die Situation im Libanon von den Konflikten um die Deutungshoheit der indigenen Geschichte anderer kolonialer Regionen. Zwar verwendeten die französischen Schulen im Libanon auch französische Schulbücher, die wie in den Kolonien Frankreich als »notre patrie« beschrieben und damit die Schüler von ihrer eigenen Geschichte entfremdeten ${ }^{313}$. Allerdings wurde die indigene Geschichte in den Kolonien erst ab der europäischen Präsenz dort behandelt ${ }^{314}$. Außerdem wurde sie in der Regel viel stärker als eine Epoche der Stagnation oder der Dekadenz oder gar der Geschichtslosigkeit dargestellt, gegenüber der die Kolonialmacht ihre Geschichte als die des Fortschritts und der Aufklärung konstruierte ${ }^{315}$.

Die katholischen Schulen kannten zu diesem Zeitpunkt keine Diskussionen über die Frage angemessener Geschichtsbücher. Sie mussten zwar auf die oben genannte Kritik reagieren und manche Passagen oder Bücher aus ihrem Unterricht nehmen, was nicht alle Schulen befolgten. Darüber hinaus wurde die Diskussion aber nicht von den Schulen selber initiiert. Vielmehr befanden sie sich in der komfortablen Situation, dass ihre Vision der libanesischen Geschichte als einer besonderen, christlich geprägten Entität mit der Sichtweise ihrer Klientel übereinstimmte. Besonders unter den Maroniten herrschte eine Perspektive auf die eigene Geschichte vor, die den Westen und speziell Frankreich nicht als Bedrohung, sondern als Beschützer, als einen "giron protecteur « ${ }^{316}$ empfand.

Die katholischen Schulen unterstützten eindeutig die libanistische Vision. In ihren französischen und arabischsprachigen Geschichtsbüchern, welche größtenteils von den Jesuiten verfasst worden waren ${ }^{317}$, betonten sie den Ursprung des Libanons bei den Phöniziern und die Eigenständigkeit des Landes $^{318}$. Beispielsweise begann das »Programme d'histoire« der Schule

312 Vgl. J. Isaac/A Malet, Histoire contemporaine depuis le milieu du XIXe siècle, Paris 1930, S. 168: »Chacune [des communautés] pratiquait le brigandage aux dépens de l'autre«.

313 Siehe beispielsweise das Schulbuch »L'année enfantine de Géographie«, Paris ca. 1930, S. 9: "Quel est notre pays? - Notre pays est la France. - Qu'est-ce que la Patrie? - La Patrie est le pays où on est né. - Quel est le devoir de chacun envers sa patrie? - Chacun doit aimer et défendre sa patrie«.

314 Vgl. Altbach/Kelly 1978, S. 14.

315 Vgl. für Indochina COOPER 2004, S. 141-142; für Algerien Pierre Boutan, L'Algérie dans les manuels scolaires des Frères des Ecoles chrétiennes avant 1962, unveröffentlichter Artikel. Allerdings betont Boutan auch, dass die Algerier in den Schulbüchern dieses christlichen Ordens zwar als weniger zivilisiert, aber trotzdem als militärisch sehr stark dargestellt werden.

316 Vgl. Beydoun 1984, S. 569.

$317 \mathrm{Zu}$ diesen Büchern gehörten neben dem schon erwähnten Précis historique de Syrie des Jesuitenpaters Lammens, welches in französischer und arabischer Sprache vorlag, die Histoire du Liban von P. Martin S.J. sowie die Werke Histoire de Beyrouth und Histoire d'Alep von Salih Ibn Yahla. So die Aufzählung des Jesuitenpaters Levenq, in seinem Buch La Syrie, Beirut 1920.

318 Vgl. Havemann 2002, S. 67-68. 
der Jesuiten in Beirut mit dem Themenfeld »La Phénicie: Notions générales géographiques« und behandelte dann die Aspekte »Le Liban: origine, signification, existence « sowie »Le Liban: Importance stratégique $\ll^{319}$. In der Schülerzeitschrift »Essor« der Frères des Écoles chrétiennes, die stark von den Lehrern zensiert wurde, trug ein Artikel den Autorennamen »Un phénicien « ${ }^{320}$. Diese Konstruktion ermöglichte es ihnen, die Rolle des Islams und der Araber zu minimieren und sogar zu umgehen. In diesem Sinne wird die Zeitrechnung in den von den katholischen Schulen benutzten Büchern in die Zeit der Kreuzzüge, der Frankenherrschaft, des französischen Einflusses und der Mandatszeit eingeteilt ${ }^{321}$.

Die Mission laïque erwies sich hingegen als sehr viel handlungsschwächer. Auch wenn die Schule den Archiven nach nie eine Beschwerde bezüglich antimuslimischer Passagen erreichte, da sie die besagten Schulbücher anscheinend nicht benutzte, erwies sie sich selbst als unfähig, ein eigenes Geschichtsbuch zu erstellen. Dabei sahen die Lehrer schon sehr früh Handlungsbedarf, weil sie die Erfahrung machten, dass die französischen Schulbücher nicht adäquat waren. 1923 diskutierten die Lehrer das erste Mal über die »absence de manuels adoptés « $\$$. Auch 1928 betonte Ruche, der Lehrer müsse »les manuels qu'il a entre les mains« der »tonalité qui convient aux élèves« anpassen ${ }^{323}$. Aber noch 1934 berichtete Generalsekretär Besnard, dass die Schulbücher inhaltlich und didaktisch immer noch nicht an die Lebenswelt der Schüler anknüpfen würden ${ }^{324}$.

Erst Mitte der 1950er Jahre, also 10 Jahre nach dem Mandat, ist das erste Schulbuch der Mission laïque über libanesische und syrische Geschichte und Geographie überliefert ${ }^{325}$. Dieses Werk steht in der Kontinuität der Haltung der Mission laïque während der Mandatszeit, die von dem Versuch der Neutralität geprägt war: Zum einen werden zwar die phönizischen Wurzeln des Libanons präsentiert (»Le Liban a été peuplé dans l'antiquité par les Phéniciens ${ }^{326}$ ) und damit der christlichen und französischen Perspektive auf das Land Rechnung gezollt, zum anderen wird aber auch der gleiche Anteil von Christen und Muslimen an der libanesischen Bevölkerung betont (»Il y a

319 SJ/Beirut, 11.D.14: »Beyrouth U.S.J. Collège secondaire III«, »programmes d'études«, »Programme de l'histoire libanaise«.

320 FEC, L'Essor 2, 1922, S. 54-57: »La Foire-Exposition de Beyrouth «.

321 Vgl. Kaufman 2004a, S, 114.

322 AN/Paris, 60 AJ 124, »Rapports mensuels«, 31.01.1923.

323 AN/Paris, 60 AJ 131, »Réunion des professeurs«, Dezember 1928.

324 Revue de l'enseignement français hors de France 31 (1934), H. 106-107, »Le Congrès de la Mission laïque française«.

325 Jacques Gallienne, Géographie de la Syrie et du Liban, Mission laïque française (Erscheinungsdatum zwischen 1954 und 1959).

326 Ebd., S. 45. 
au Liban à peu près le même nombre de chrétiens et de musulmans « ${ }^{327}$ ) und damit die von den Maroniten herausgestellte christliche Mehrheit des Libanons nivelliert.

Während der Mandatszeit befand sich die Mission laïque hingegen in einer Zwickmühle. Einerseits war die laizistische Schule eine französische Institution und als solche der französischen Version der libanesischen Geschichte verhaftet, die sich im Wechselspiel mit den libanesischen Christen entwickelt hatte. So lernten und lehrten die französischen Lehrer der Mission lä̈que, dass die Phönizier ein Element der libanesischen Geschichte waren, weil es so auch in den französischen Geschichtsbüchern stand ${ }^{328}$. Allerdings machten sie daraus nicht, wie zum Beispiel die Jesuiten, eines der Kernelemente der libanesischen Geschichte, sondern waren aufgrund ihrer sehr heterogenen Klientel, die sich vor allem aus Nicht-Katholiken zusammensetzte, verpflichtet, auch deren Geschichtsvisionen zu integrieren.

In den Archiven befinden sich so gut wie keine Spuren von Protesten der Eltern gegenüber dem Geschichtsunterricht der Mission lä̈que. Diese fehlenden Beschwerden überraschen umso mehr, als die Eltern bei anderen Themen wie der arabischen Sprache sehr sensibel waren. Außerdem gab es im Umfeld der Mission laïque einige Autoren historischer Werke: Khalil Taqi ad-Din hatte Anfang der 1930er Jahre zusammen mit zwei Freunden ein arabisches Schulbuch verfasst, welches Bounoure sehr lobte, da es von einem konfessionell gemischten Autorenteam geschrieben worden sei, das zudem von der gesamten Elite gelesen werden könne ${ }^{329}$. Dieses Buch spielt in den überlieferten Lehrersitzungen genauso wenig eine Rolle wie das von Taqi adDin as-Sulh um 1935 niedergeschriebene Werk Al-ğabal al-ḥa 'ir (der perplexe Berg): darin kritisiert er, wie schon in der Anspielung im Titel deutlich wird, die libanistische Vision des Werkes La Montagne Inspirée von Charles Corm, dessen Titel wiederum an La Colline inspirée des nationalistisch und ultra-christlich geprägten französischen Schriftstellers Maurice Barrès anknüpfte ${ }^{330}$. Ebensowenig sind aus den Sitzungsprotokollen des Elternrates Stellungnahmen des stark arabisch-nationalistisch orientierten Intellektuellen Muhammad Ğamīl Bayhum zum Geschichtsunterricht überliefert. Es bleibt also zu vermuten, dass die Eltern, da die Mission laïque größere Skan-

327 Ebd., S. 44.

328 Aus diesem Grund unterrichteten die Geschichtslehrer deren Geschichte auch selbstverständlich. Vgl. AN/Paris. 60 AJ 131, »Réunion des professeurs«, Sitzung vom 27.12.1928. Die von Kaufman 2004, S. 196, angenommene Distanz der Mission laïque zur Lehre von den Phöniziern kann somit nicht bestätigt werden.

329 Vgl. Sвaiti 2008, S. 220.

330 Vgl. ebd., S. 164. 
dale wie muslimfeindliche Passagen in Büchern verhindern konnte, diesem Thema wenig Aufmerksamkeit schenkten und die Schule ihrerseits sich um Neutralität bemühte.

Auf diese Weise haben verschiedene Konfliktebenen die Herausbildung eines einheitlichen libanesischen Geschichtsbildes bis heute verhindert. Bis zum heutigen Tag gibt es kein allgemeingültiges libanesisches Geschichtsbuch und keinen Geschichtsunterricht über den Libanon seit dem Abzug der französischen Truppen 1947331. Während in der Reform des Bildungswesens von 1944 die arabische Sprache neu hervorgehoben wurde, stand die Behandlung der Geschichte auch nach der Mandatszeit in der Kontinuität von vor $1943^{332}$. 



\section{Zwischen Markt und Moderne: Globale und soziale Herausforderungen für französische Schulen und die libanesische Gesellschaft ab 1930}

War es in den 1920er Jahren vor allem um die politische, kulturelle und religiöse Dimension der Unterrichtsfächer selbst gegangen, trat um 1930 die Bedeutung der außerunterrichtlichen Aspekte der Bildungsinstitutionen im Libanon in den Vordergrund. Der erneut starke Bezug der französischen Schulen auf die Zivilisierungsmission lässt sich einordnen in den Wettbewerb der Bildungsstätten um die Frage, welche von ihnen sich angesichts wirtschaftlicher Rezession und sozialen Wandels in der libanesischen Gesellschaft als attraktive Orte behaupten konnte. Da dieser Wandel von vehementen politischen Forderungen nach Unabhängigkeit im Libanon, aber auch im gesamten Nahen Osten begleitet wurde, erscheint demgegenüber die Einbindung der französischen Einrichtungen in das koloniale Regime ihres $\gg$ Mutterlandes`, das sich beispielsweise an ihrer Beteiligung an der Kolonialausstellung in Paris 1930 zeigte, umso paradoxer.

Die libanesische Gesellschaft war in dieser Zeit von wirtschaftlicher Not und politischer Instabilität, aber auch von gesellschaftlichen und kulturellen Ausdifferenzierungen geprägt. Die Weltwirtschaftskrise von 1929 hatte sich massiv auf die finanzielle und berufliche Situation der Libanesen ausgewirkt und führte neben Boykotten gegen die Wirtschaftspolitik der Mandatsmacht auch zu einer verstärkten Anbindung libanesischer Schulen und Individuen an die finanziell noch besser ausgerüsteten französischen Institutionen. Besonders die öffentlichen einheimischen Schulen waren von geringer Anzahl und erfuhren nur eine geringe finanzielle Unterstützung; auch die privaten libanesischen Schulen, von denen es eine weit größere Zahl gab ${ }^{1}$, erhielten weniger Mittel von der Regierung als die französischen Einrichtungen. Allerdings gab es schon seit 1924 für alle Schulen im Libanon weniger Geld aus Paris - bis auf die Mission laïque, die 1929 statt bis dato 1.250 nun 2.550 Millionen Francs für ihre Neugründungen bzw. Umbauten in Damaskus, Aleppo und Beirut erhielt².

11931 gab es laut einer Statistik des französischen Hochkommissariats im Libanon ca. 350 französische Bildungseinrichtungen, hingegen nur 130 staatliche Schulen und ca. 150 private lokale Schulen. Vgl. MAE/Nantes, IP, 83: 1931, „Communautés et œuvres; République Libannaise - année 1931《.

2 Vgl. Barbier-De Bonnay 1983, S. 181-182. Das Außenministerium versuchte in der Folge, die Bedenken der katholischen Kirche wegen geringerer finanzieller Unterstützung dadurch zu 
In der Forschung über Bildungspolitik im Mandatsgebiet Libanon findet die Bedeutung wirtschaftlicher Faktoren oft wenig Berücksichtigung, obwohl diese als ein zentrales Handlungsmotiv für Erziehungsentscheidungen beachtet werden müssen. Darüber hinaus wurde die politische Instabilität der Zeit von der Mandatsregierung keinesfalls behoben, sondern durch die Förderung bestimmter politischer Kandidaten und Gruppen sowie durch das Unterlassen oder Verzögern notwendiger politischer und juristischer Maßnahmen noch verstärkt. Der Kampf um politischen Einfluss zwischen verschiedenen libanesischen Familien und Clans machte sich auch in den Schulen bemerkbar. Insbesondere die Schließung von 100 staatlichen Schulen durch die 1929 an die Macht gekommene Regierung unter dem maronitischen Politiker Emile Eddé sorgte für große Unzufriedenheit, besonders bei den muslimischen Familien, deren Kinder die Mehrheit der staatlichen Schüler ausmachten, und provozierte pro-muslimische Proteste und Sympathiebekundungen in den arabischen Nachbarländern ${ }^{3}$. Der massive Protest und die mangelnde Unterstützung für Eddé durch Hochkommissar Ponsot führten zum Ende der Amtszeits Eddés im Frühjahr 1930 und zu einer anhaltenden politischen Krise, die von der Rivalität zwischen Eddé und seinem maronitischen Konkurrenten Khuri geprägt war und zu einer nur unvollständig funktionierenden Regierung sowie zur Aufhebung der Verfassung 1932 führte ${ }^{4}$.

Neben dem Bemühen der traditionellen Eliten, ihre herausgehobene sozioökonomische Stellung zu wahren ${ }^{5}$, gab es auch neue Gruppen und Individuen, die gesellschaftliches Mitspracherecht forderten: Diese Entwicklung spiegelte sich beispielsweise im Aufbau und Unterhalt von Ehemaligennetzwerken der verschiedenen französischen Schulen im Libanon wider. Man könnte die These aufstellen, dass diese Formen der sozialen Bindung ähnlich wie die des Clans anstelle fehlender starker politischer Strukturen fungierten $^{6}$. Besonders in Beirut, aber auch außerhalb der Hauptstadt wurden die skizzierten wirtschaftlichen und politischen Prozesse noch von einem dritten

zerstreuen, dass es betonte, die Subventionen für die lokalen Schulen seien geringer geworden. Vgl. MAE/Paris, CPC E-Levant 1918-1940, 279: »Établissements religieux français«, Brief des französischen Außenministers an den französischen Botschafter beim Heiligen Stuhl, Paris, 20.03.1929: »Les subventions accordées aux écoles dirigés par des religieux français, loin d'avoir été diminuées ont été légèrement augmentées au cours de ces dernières années. Par contre, les allocations accordées aux écoles indigènes, dirigées par les différents rites, ont été légèrement réduites parce que le Gouvernement français a pu faire inscrire aux budgets locaux des subventions pour ces différentes écoles, qui compensent largement pour elles les diminutions apportées «.

3 Vgl. ZamiR 2000, S. 76-81.

4 Vgl. SAlibi 1965, S. 174-178.

5 Vgl. Dueck 2010, S. 16.

6 So könnte man im Anschluss an Johnson 1986, S. 1-5 argumentieren. Johnson betont außerdem das Fehlen einer Arbeiterschaft als neuer Kategorie aufgrund nicht-existenter Industriali- 
Faktor beeinflusst ${ }^{\top}$ : der Betonung von Moderne und Mondänität innerhalb der sozio-ökonomischen Elite. Die rasante Entwicklung eines städtischen kulturellen Lebens und die Nutzung technologischer Fortschritte führten zu einer Förderung dieser Aspekte auch in den Lehranstalten, in Gestalt von neuen Formen von Soziabilität oder vom Einsatz neuer Medien wie Filmen.

Dieser spannungsgeladene Transformationsprozess soll im Folgenden innovativ aus der Perspektive der französischen Schulen betrachtet werden. Deren Reden und Handeln spiegelte die gesellschaftlichen Spannungen wider, auf welche die Schulen mit dem Versuch reagierten, ein adäquates Bildungsangebot zu gewährleisten, das ihrer Mission, die französische Kultur zu vermitteln, zuträglich war. Ihrem Ringen zwischen dem Anspruch auf kulturelle französische Souveränität und der Notwendigkeit der Anpassung wird in diesem Kapitel anhand der Kolonialausstellung in Paris 1931, den außerunterrichtlichen Aktivitäten, dem Aufbau von Ehemaligennetzwerken und der verstärkten Kooperation mit lokalen Schulen nachgegangen. Auf diese Weise wird das von de Certeau diskutierte Paradigma von sich gegenseitig bedingenden Taktiken und Strategien aktualisiert und durch die multiplen Aneignungs- und Subversionsprozesse problematisiert: So ist nur schwer auszumachen, wer in den Auseinandersetzungen über Bildungsinhalte und -praktiken die Deutungshoheit hatte; vielmehr standen die französischen und libanesischen Akteure trotz der asymmetrischen Strukturen, in denen sie agieren mussten, in einem ständigen Prozess von Forderungen und Zugeständnissen. Allerdings war die Zeit um 1930 weniger von radikalen als von langsamen Veränderungen geprägt.

\section{Koloniale Bildung zum Anfassen:}

\section{Die Beteiligung der Schulen an der Kolonialausstellung $1931^{8}$}

Auf der Kolonialausstellung, die von Mai bis November 1931 in Paris stattfand, präsentierte und feierte Frankreich sich als koloniales Empire. Auch die anderen Kolonialmächte waren dazu eingeladen, beteiligten sich aber nur sehr mäßig an der von der französischen Regierung ausgerichteten Ausstel-

sierung. Er macht aber auch das Argument stark, dass Klientelismus und Patronage neben politischen Strukturen bestanden haben.

7 Vgl. DAKhli 2009a, S. 192-194.

8 Zentrale Ergebnisse dieses Unterkapitels finden sich auch in Esther MöLler, Zwischen Zivilisierungsmission und Selbstdarstellung: Französische Schulen im Libanon und die Pariser Kolonialausstellung 1931, in: Sönke Kunkel/Christoph Meyer Meyer (Hg.), Aufbruch ins postkoloniale Zeitalter. Globalisierung und die außereuropäische Welt in den 1920er und 1930er Jahren, Frankfurt/New York 2012, S. 231-250. 
lung9. Dennoch erfuhr die »exposition coloniale« große Resonanz bei der Bevölkerung: Über acht Millionen Zuschauer wohnten dem Ereignis bei, die Hälfte von ihnen stammte aus Paris, drei Millionen Besucher kamen aus dem restlichen Frankreich und fünfzehn Prozent aus dem Ausland ${ }^{10}$. In der Konzeption betonten die Verantwortlichen zum einen die wirtschaftlichen Aspekte des französischen Kolonialismus. Sie hoben hervor, wie lukrativ das Empire für die französische Gesellschaft war, aber auch, dass die Kolonien von diesem Abhängigkeitsverhältnis profitierten ${ }^{11}$.

Diese Botschaft kam beim Publikum an, nimmt man zum Beispiel den unter dem Pseudonym Marius-Ary Leblond schreibenden kolonialen Schriftsteller aus La Réunion in der Zeitung »La vie« publizierten Bericht zum Maßstab. Darin beschreibt dieser die $»[. .$.$] valeur primordiale de nous œuvres$ économiques qui sont la plus solide et plus indestructible armure de l'action européenne, de la civilisation $\aleph^{12}$. Zum anderen betonten die Organisatoren besonders den zivilisatorischen Aspekt des französischen Kolonialreiches. So lautete die Beschriftung einer Weltkarte, die im Eingang des Ausstellungsgebäudes hing: „C'est avec 769.000 hommes que la France assure la paix et les bienfaits de sa civilisation à ses 60 millions d'indigènes « ${ }^{13}$. Beide Aspekte deuteten darauf hin, dass den Verantwortlichen der Ausstellung bei aller pompösen Inszenierung des französischen Kolonialismus bewusst war, dass das Empire bereits politischen, wirtschaftlichen und ideologischen Erosionsprozessen ausgesetzt war und dass sie deshalb besonders den Nutzen für die französischen Kolonien herausstellten.

Bisherige Studien haben bereits die Bedeutung der Kolonialausstellung für das französische Empire und für die französische Gesellschaft dargestellt ${ }^{14}$, aber der Beteiligung der Kolonien und der Mandatsgebiete nur wenig Beachtung geschenk $\mathrm{t}^{15}$. Umso lohnenswerter erscheint es, im Sinne der »histoire

9 Vgl. Charles-Robert Ageron, L'exposition coloniale de 1931. Mythe républicain ou mythe impérial?, in: Pierre Nora (Hg.), Lieux de mémoire, Paris 1984, Bd. I, S. 493-515, S. 498.

10 Vgl. ebd., S. 505.

11 Vgl. Raoul Girardet, L'idée coloniale en France de 1871 à 1962, Paris 1972, S. 129.

12 Hinter diesem Pseudonym verbergen sich die beiden Schriftsteller und Cousins George Athénas und Aimé Merlo. Vgl. MAE/Nantes, 84, „Valeurs nouvelles du Mandat et intégralité du programme humanitaire français«, in: »La vie« 20 (1931), 14, 01.08. 1931, S. 269. Die beiden hatten die Wochenzeitung La Vie selbst gegründet und von 1921 bis 1952 geleitet. Vgl. Norbert Dodille, Les nouvelles malgaches de Marius-Ary Leblond, in: Revue historique des Mascareignes 5 (2003), H. 5, S. 223-33.

13 Vgl. URL: http://www.histoire-image.org/pleincadre/index.php?i=873 (25.09.2010).

14 Vgl. Martin Evans, Culture and Empire, 1830-1962. An Overview, in: Ders. (Hg.), Empire and Culture. The French Experience, 1830-1940, London 2004, S. 1-23.

15 Vgl. François-Xavier TRÉGAN, Appréhensions et méthodes dans un système mandataire: le cas de la participation des états du Levant à l'exposition internationale de Paris, 1931, in: Nadine MÉouchy (Hg.), France, Syrie et Liban 1918-1946. Les ambiguïtés et les dynamiques de la relation mandataire, Damaskus 2002, S. 91-103. 
croisée« die Perspektive zivilgesellschaftlicher Akteure, sowohl französischer als auch libanesischer Nationalität, auf dieses Ereignis zu untersuchen.

Die Kolonialausstellung in Paris 1931 stellte ein wichtiges Ereignis in der Geschichte der französischen Schulen im Libanon dar. Sie alle nahmen an dieser Ausstellung teil, indem sie entweder Material über ihre Arbeit schickten, um es ausstellen zu lassen, oder Delegationen von Lehrern und Schülern nach Paris entsandten. Die Archive der Schulen geben detailliert über deren Partizipation und Präsentation Auskunft.

Im Folgenden soll gezeigt werden, dass die Schulen mit ihrer Beteiligung an der Kolonialausstellung die französische Zivilisation und damit auch den französischen Kolonialismus zelebrierten, damit aber auch ganz bestimmte Ziele der Selbstdarstellung, Legitimation und Hoffnung auf Unterstützung in Frankreich verfolgten. Die libanesischen Schüler und Lehrer, die diese Veranstaltung besuchten, haben, so die These weiter, in erster Linie nicht die asymmetrischen Machtverhältnisse zwischen Frankreich und seinen kolonialen Gebieten kritisiert, sondern den Besuch der Kolonialausstellung als Gelegenheit einer Reise nach Europa wahrgenommen. Diese Argumente werden erstens anhand der Unterstützung der Zivilisierungsmission durch die Schulen, zweitens durch die direkte Begegnung der Schulmitglieder mit der französischen Öffentlichkeit und drittens mit der Beteiligung der Schulen an den Diskussionen über die libanesische politische Zukunft während der Kolonialausstellung geprüft. Sie zeichnen ein Bild von der Ausstellung als Moment, der trotz der Inszenierung Frankreichs als Kolonialmacht schon das nahende Ende der Mandatsregime implizierte.

Sowohl durch ihre Diskurse als auch durch ihre aktive Teilnahme demonstrierten die meisten französischen Schulen im Libanon ihre Unterstützung der Kolonialausstellung. Um das Datum der Kolonialausstellung herum benutzten alle französischen Schulen, die im Libanon aktiv waren, in ihren verschiedenen Medien wieder verstärkt den Diskurs der Zivilisierungsmission. Besonders auffällig ist diese Entwicklung bei den katholischen Kongregationen. So berichtete der »Bulletin de Mission des Lazaristes« 1931 von der Überreichung der Ehrenlegionsurkunde an die Ordensgründerin der Filles de la Charité, Sœur Gélas, für ihre mission civilisatrice, obwohl dieser Festakt schon 1887 stattgefunden hatte $^{16}$. »Faire rayonner la gloire de la France « wurde ebenfalls 1931 als ein Ziel der Soeurs de Saint-Joseph de l'Apparition formuliert ${ }^{17}$. In dieser Zeit betonten die Kongregationen auch, dass die Ver-

$16 »[\ldots]$ nous espérons que Dieu, qui vous a soutenue jusqu'ici vous conservera longtemps encore à la tête de la mission chrétienne, civilisatrice et patriotique, qu'avec leur aide vous remplissez avec tant de courage et de bonheur«. LAZ/Paris, Bulletin de Mission des Lazaristes 9 (1931), S. 243-280.

17 Luce Camuzet, L'œuvre de Syrie des Sœurs de Saint-Joseph de l'Apparition, Paris 1931, S. 1. 
breitung der »seule vraie culture française $\aleph^{18}$ für sie nicht in Konkurrenz zu ihrer missionarischen Tätigkeit stand ${ }^{19}$.

Neben der Sorge der katholischen Orden, dass die seit 1925 stärker antiklerikal geprägte Mandatspolitik eine erneute Vernachlässigung bedeuten würde, wie sie sie schon in Frankreich selbst erlebt hatten ${ }^{20}$, muss der verstärkte Diskurs der mission civilisatrice aber auch eindeutig in den Kontext der Kolonialausstellung gestellt werden. Mit der Betonung ihrer zivilisatorischen Aufgabe reagierten die Schulen auf die Vorgaben Maréchal Lyauteys, der seit 1927 die Organisation der Kolonialausstellung koordinierte ${ }^{21}$. Louis Hubert Lyautey, der als Militärgouverneur in vielen französischen Kolonien, zuletzt im Protektorat Marokko tätig gewesen war, sah vor, dass die Ausstellung vor allem die zivilisatorischen Errungenschaften Frankreichs in den Vordergrund stellen sollte ${ }^{22}$.

Weiterhin unterstützten die Schulen die Kolonialausstellung, indem sie in ihren Publikationen davon berichteten. Die Mission lä̈que française druckte einen Teil des Prospekts ab, der enthusiastisch und mit einem deutlichen Superioritätsanspruch von der Präsenz Marokkos auf der Kolonialausstellung berichtete: diese zeige Marokkos "possibilités auxquelles nous avons apporté l'occasion de s'épanouir en sécurité « ${ }^{23}$.

Über die diskursive Ebene hinaus zeigten die Institutionen ihre Unterstützung der Selbstinszenierung Frankreichs als zivilisatorische Nation auch darin, dass sie an der Ausstellung selbst als Aussteller teilnahmen. Fast alle Schulen, die in dieser Arbeit untersucht werden, bekundeten ihr Interesse an der Teilnahme. Lediglich bei einigen katholischen Orden finden sich auch Spuren des expliziten Widerstandes gegen die Kolonialausstellung. Neben den hohen Kosten und ihrer ordensgemäßen Zurückgezogenheit führten einige Orden auch den offensichtlich nationalistischen Charakter der Ausstellung als Argument an, um nicht teilnehmen zu müssen. So hieß es in einem Brief des Ordens der Pères Blancs an den Jesuiten Louis Jalabert, der die Repräsentation der katholischen Orden koordinierte:

$18 \mathrm{SJ} /$ Vanves, »Fonds Jalabert«, 1/1 F, Notiz von Chanteur an Weygand, November 1924.

19 Vgl. Kapitel 1.1.

20 Vgl. Elizabeth F. Thompson, Neither Conspiracy nor Hypocrisy: The Jesuits and the French Mandate in Syria and Lebanon, in: E. Tejirian/R. Simons (Hg.), Altruism and Imperialism. Western Cultural and Religious Missions in the Middle East, New York 2002, S. 66-87.

21 Vgl. Ageron 1984, S. 496.

22 Vgl. Evans 2004, S. 16: »[...] the Exhibition projected the civilizing mission within the Empire«.

23 Revue de l'enseignement français hors de France 27 (1930), H. 87, S. 36-37: »Exposition coloniale internationale - Extrait du Bulletin d'information. Le Maroc tout entier«, S. 37. 
Permettez-moi de vous faire une réflexion [...]. Est-ce que l'insistance qu'on met à rappeler les services patriotiques rendus par les missionnaires français, là surtout où leur influence ou leur intervention a contribué à établir le pouvoir ou le protectorat français s'affrontant à des compétitions étrangères (v.g. l'histoire de Mgr Bataillon en Océanie, ou des Pères de l'Esprit en Guinée) ne pourrait pas contribuer à faire naître encore actuellement, dans l'esprit des autorités civiles non françaises, des doutes sur le loyalisme des missionnaires à l'endroit de l'état des choses actuellement établi24?

Jalabert beruhigte ihn, indem er betonte, dass er sehr darauf achten würde, dass es hier keinen berechtigten Vorwurf gebe:

[...] nous ferons le nécessaire pour ne pas encourir de reproche: nous mettrons l'accent sur l'action catholique des missionnaires et signalerons, avec les précautions oratoires voulues, le profit que la Patrie en retire. Il ne s'agit pas de donner des verges pour nous faire fouetter à ceux qui, de bonne foi, mais avec une erreur inconsciente de perspective, reprochent leur ınationalismeく aux Missionnaires français ${ }^{25}$.

Der Vorwurf des Nationalismus der französischen Missionare seitens nichtfranzösischer Autoritäten, den Jalabert hier thematisiert, bezieht sich möglicherweise auf die Haltung arabischer Nationalisten in den kolonialen Gebieten, welche die Nähe der Missionare zu den europäischen Mandatsmächten kritisierten ${ }^{26}$. Gerade zum Zeitpunkt der Kolonialausstellung begannen die sogenannten »Küstenkonferenzen« (arabisch Mu'tamarāt as-sāḥil) ${ }^{27}$, auf denen die Teilnehmer die Unabhängigkeit von Frankreich durch den Abschluss franko-syrischer und franko-libanesischer Verträge forderten. Ebenso gut möglich ist es, dass es hier um die steigende Sympathie des Papstes mit dem italienischen Nationalismus und Faschismus ging ${ }^{28}$. Die französischen Kongregationen hatten große Bedenken, dass sich der Vatikan noch weiter von ihnen entfernen würde, sollten sie auf ihrer Zugehörigkeit

$24 \mathrm{SJ} /$ Vanves, »Fonds Jalabert«, 11/K, Brief eines Père Blanc an Jalabert, Maison Carrée, 10.11.1928.

25 Ebd., Antwort von Jalabert, Paris, 27.1.1928.

26 Diese Kritik findet sich beispielsweise in Artikeln der ägyptischen Zeitungen Le Rayon d'Égypte und al-Manār in den 1930er Jahren. Vgl. Oissila SAAÏDIA, Clercs catholiques et oulémas sunnites dans la première moitié du XX ${ }^{\mathrm{e}}$ siècle. Discours croisés, Paris 2004, S. 283.

27 Vgl. Fahid AL-Khazen, The Communal Pact of National Identities. The Making and Politics of the 1943 National Pact, Oxford 1991, S. 11.

28 Schon seit den 1920er Jahren war es aufgrund der Zentralisierung der religiösen Orden in Rom zu einer stärkeren Orientierung des Vatikans nach Italien gekommen, und diese Entwicklung verstärkte sich in den 1930er Jahren noch. Vgl. Dominique Trimbur, Eugène Tisserant et le Quai d'Orsay, in: Le Cardinal Eugène Tisserant (1884-1972). Une grande figure de l'Église, une grande figure française, Toulouse 2003, S. 215-252, S. 232, 248. 
zu Frankreich beharren ${ }^{29}$. Ferner versuchte Jalabert die Sorgen der Orden zu mindern, indem er nicht von der »exposition coloniale«, sondern von der »exposition missionnaire $\ll \operatorname{sprach}^{30}$.

Die französischen Schulen präsentierten somit sich selbst und ihre Arbeit einer französischen und globalen Öffentlichkeit. Die meisten katholischen und jüdischen Schulen berichteten dabei sehr euphorisch von dem Erfolg ihrer Arbeit. Die Jesuiten verbanden ihre Präsentation zudem mit dem Gedenken an ihre 100-jährige Präsenz in Syrien und Libanon. Dabei verbanden sie französische und missionarische Elemente zu einer Einheit ${ }^{31}$.

Hingegen fiel die Darstellung der laizistischen und protestantischen Schulen nüchterner aus. Das hatte sicher auch damit zu tun, dass, während die katholischen und protestantischen Missionen ${ }^{32}$ jeweils einen eigenen Pavillon zur Verfügung hatten, die Mission lä̈que française und die Alliance israélite universelle gemeinsam in einem anderen Pavillon, wahrscheinlich dem der Alliance française ${ }^{33}$, unterkamen.

Verantwortlich für dieses besondere Augenmerk auf die Missionare, das sich auch räumlich zeigen sollte ${ }^{34}$, war Organisator Lyautey: »Ce que nous voulons montrer et faire ressortir, c'est, dans le cadre des colonies ou anciennes colonies françaises, le rôle de premier ordre joué par les missionnaires au point de vue de l'action civilisatrice auprès des indigènes $\ll^{35}$. Die Unterbringung lag aber auch an den den hohen Kosten, die ein eigener Pavillon erforderte, und die die Mission laïque nicht zu zahlen bereit war. So formulierte ein Verantwortlicher, vermutlich Generalsekretär Besnard, mit einem leichten Seitenhieb auf die Kongregationen, die mehr Geld zur Verfügung hätten:

29 Vgl. Dueck 2010, S. 128f.; René Voillaume, Charles de Foucault et ses premiers disciples. Du désert arabe au monde des cités, Paris 1998, S. 151.

$30 \mathrm{SJ} /$ Vanves, »Fonds Jalabert«, RPO, 105: »Exposition coloniale«.

31 Vgl. Abb. 3.

32 Allerdings betonte die protestantische französische Institution auch, dass sie trotzdem in dem Pavillon ausstellen wolle, den die Mandatsregierung für das Drusengebiet bereitgestellt hatte: »[...] question d'organiser un pavillon spécial pour les Missions Protestantes. Notre Association pourra exposer dans ce pavillon ce qui ne l'empêchera pas de placer des documents sur le dispensaire du Djebel Druze dans la partie de l'exposition réservée spécialement à cet État«. PPFL, »Comptes-rendus du Conseil d'Administration«, Sitzung vom 08.05.1929.

33 In den Archiven fehlen Angaben über den Stellplatz der zwei Institutionen. Da ein Prospekt der Alliance française zur Kolonialausstellung aber beide aufführt, ist zu vermuten, dass sie in dessen Pavillon unterkamen. Vgl. AIU/Paris, »Le Congrès de l'Alliance française à l'exposition coloniale internationale de Paris«, 15.-22.07.1931.

34 Die Orden »occupaient une place de choix au centre de l'avenue des Colonies-françaises et semblaient conduire vers une tour haute de quatre-vingt-deux mètres«. Ageron 1984, S. 503.

$35 \mathrm{SJ} /$ Vanves, »Fonds Jalabert«, Brief von Lesoud an Jalabert, Paris, ohne Datum. 

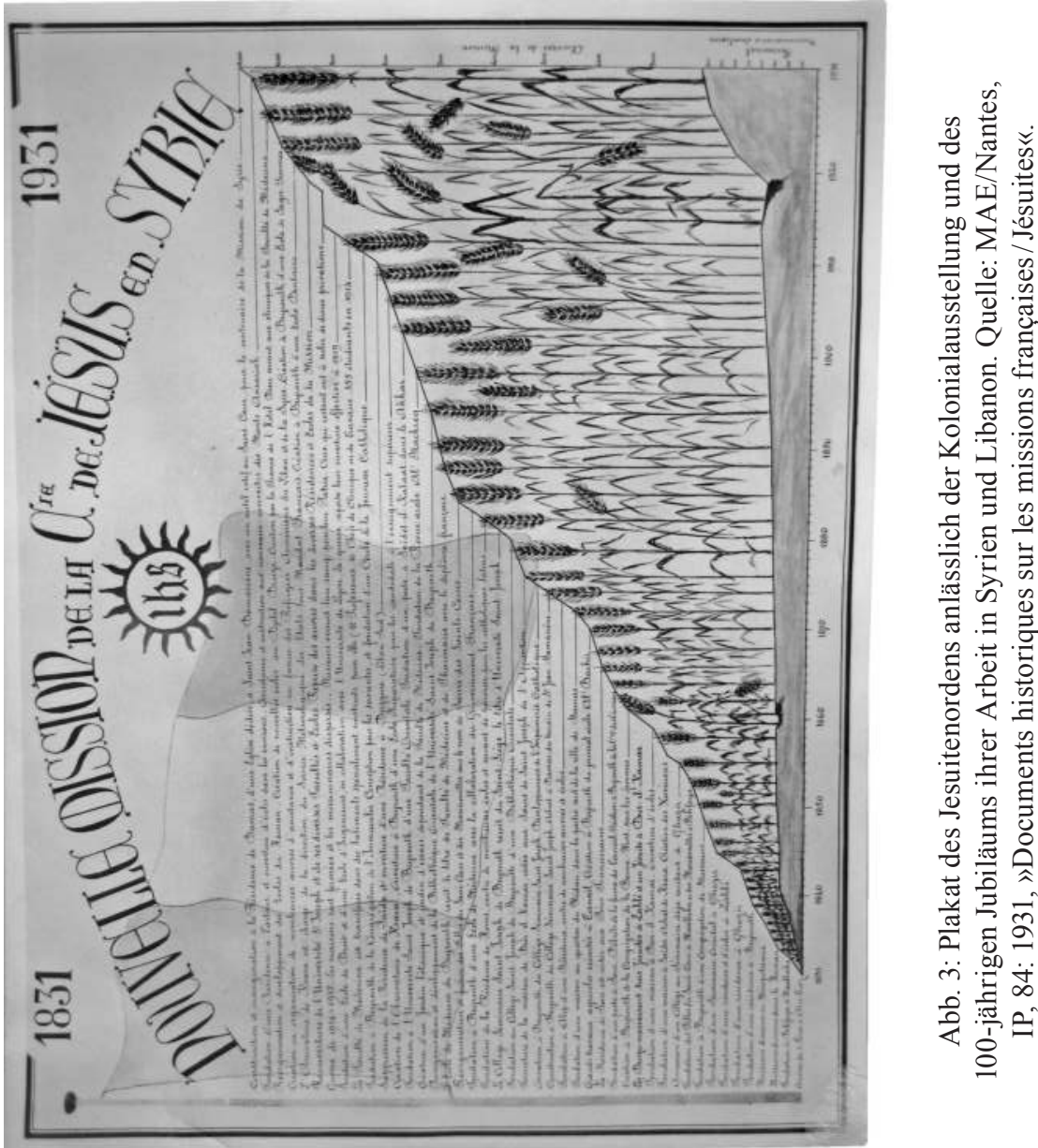
Exposition de 1931. Nous n'avons pas demandé de terrain pour y élever un pavillon [...] Il eût fallu engager de grosses sommes dont nous aurions, le cas échéant, un emploi plus utile. Quoi qu'on en dise, nous n'avons pas, comme certaines congrégations, les moyens de dépenser 1 million et demi pour mettre sous les yeux du public l'œuvre accomplie par nous au dehors. Je le regrette, d'ailleurs, profondément et vous le regretterez avec moi $[\ldots]^{36}$.

Obwohl im französischen Kontext, der von der jahrzehntelangen Fehde zwischen Katholiken und Anti-Klerikalen geprägt war, die Orden schließlich aus der Öffentlichkeit verdrängt worden waren, schien die starke Präsenz der katholischen Missionare keine Brisanz mehr zu haben, denn in den Archiven findet man keinen Protest der Bevölkerung dagegen ${ }^{37}$ : Hier manifestierte sich erneut das laizistische Paradox der Dritten Republik, und der Konsens, der zwischen antiklerikalen und klerikalen, zwischen monarchistischen und republikanischen Kräften in Frankreich bezüglich der Kolonisation bestand, umfasste augenscheinlich auch die Wahrnehmung der Schulen in den französischen Kolonien ${ }^{38}$.

Die Betonung der Rolle der katholischen Institutionen im Libanon zeigte sich auch durch eine kleine Präsentation über »La vie intellectuelle au Levant« anhand von französisch- und arabischsprachigen Büchern aus dem Libanon, die einen christlichen und profranzösischen Blick auf die arabischen Intellektuellen vermittelte ${ }^{39}$. Alle ausgestellten Bücher entstammten der Imprimerie Catholique in Beirut. Diese 1853 gegründete Druckerei der Jesuiten nahm während der Mandatszeit auch die Aufträge für das Hochkommissariat entgegen. Der größte Teil der von ihr gedruckten Autoren entstammte allerdings dem christlichen Milieu, weshalb sie die christliche und frankophile Identität des Libanons betonten ${ }^{40}$.

36 MLF/Paris, »Fonds de Russie«, 03/942, 125-2-6, »Circulaire«, 04.12.1930.

37 Der einzige Protest, den es gegen die Kolonialausstellung insgesamt gab, stammte von den französischen Kommunisten, aber diese verurteilten nicht die Missionare, sondern den Kolonialismus als Ganzen. Vgl. Ageron 1984, S. 499-501.

38 Vgl. ebd., S. 493: »La colonisation [...], sur ce thème la franc-maçonnerie se sentait d'accord avec l'Académie française et les couvents radicaux avec les assemblées des missionnaires«. Vgl. auch GiRARdet 1972, S. 132-135: Zwischen 1919 und 1939 stimmten auch die französischen Sozialisten dieser Ideologie zu. Mehr noch als Girardet, der den Kolonialismus vor allem in einer bestimmten Elite vertreten sah, betonen Blanchard und Lemaire die Präsenz des Kolonialismus in der gesamten französischen Gesellschaft. Vgl. Pascal Blanchard/Sandrine Lemaire, Introduction, in: Dies. (Hg.), Culture impériale. Les colonies au cœur de la République, 1931-1961, Paris 2004, S. 5-32, hier 6-7.

39 Vgl. TrÉGAn 2002, S. 100.

40 Vgl. Libois 2009, S. 117-124. Gerade die von Jesuitenpatern verfassten Schriften zur arabischen Sprache, Literatur und christlichen Theologie machte diese Druckerei zu einem zentralen intellektuellen Motor einer bestimmten ideologischen Auffassung in der Region. Vgl. Bernard Delpal, L'Imprimerie catholique et la Bibliothèque orientale à Beyrouth, in: Étienne 
In ihrem Pavillon dokumentierten die katholischen Orden die Arbeit ihrer Schulen und hoben den Dienst hervor, den sie an Frankreich verrichteten ${ }^{41}$. Ähnlich enthusiastisch äußerte sich nur die Alliance israélite universelle ${ }^{42}$. Die Präsentation der Euvres protestantes françaises sah sehr viel nüchterner aus, auch wenn sie die rezente Gründung des Collège protestant français in Beirut 1927 eindeutig als Erfolgsgeschichte darstellte ${ }^{43}$. Auch die Mission lä̈que française berichtete von dem soliden Erfolg ihrer Jungenschule im Libanon und dem langsamen Durchbruch der Mädchenschule, verschwieg aber auch gewisse Schwierigkeiten nicht: Nach Ansicht von Generalsekretär Besnard bildeten sie zu viele Abiturienten aus, die dann Jura oder Medizin studierten, aber keine Anstellung fänden. Hingegen sei es wichtiger, auf die landwirtschaftliche, technische und wirtschaftliche Ausbildung der jungen Libanesen zu setzen ${ }^{44}$.

Die französischen Schulen präsentierten darüber hinaus konkrete Produkte ihrer Arbeit im Libanon. Dazu gehörten neben Schautafeln auch Arbeiten von Schülern. Die Direktion der Schulen hatte die Lehrer dazu aufgerufen, dementsprechende Arbeiten anfertigen zu lassen, wie das Beispiel der Mission laïque zeigt:

Le Directeur invite ses collègues à songer à la préparation de l'Exposition coloniale, il recommande de constituer des recueils de devoirs [...] qui permettent de faire ressortir l'originalité de nos méthodes d'enseignement du français ${ }^{45}$.

Bemerkenswert erscheint ferner Ruches Betonung der Bemühungen um die arabische Sprache, wodurch er dem Duktus der Mission laïque treu blieb: »il invite MM. les professeurs d'Arabe à préparer des documents du même genre pour l'enseignement de l'arabe $\wedge^{46}$. Neben den Schülerarbeiten wurden Fotos von Schülern aufgehängt, sodass die abstrakte Vorstellung von der Arbeit der Schulen in der Levante für die Zuschauer in Paris personalisiert und vorstellbar wurde.

FoullLouX/Bernard Hours (Hg.), Les jésuites à Lyon XVI ${ }^{e}-X^{\mathrm{e}}$ siècles, Lyon 2005, S. 161172.

41 So betonten die Dames de Nazareth, wie begeistert die französischen Besucher von dem Französischniveau ihrer Schülerinnen in Beirut waren. Vgl. AJV, RPO 105, »Dames de Nazareth«.

42 Vgl. MAE/Nantes, IP, 84, »Alliance israélite«.

43 Vgl. ebd., »Association française protestante«.

44 Siehe den Bericht Besnards über die Arbeit der Mission laïque française: »[...] pour conjurer ce danger [...] orienter les jeunes gens vers les carrières agricoles, industrielles et commerciales [...]«. AIU/Paris, »Le Congrès de l'Alliance française à l'exposition coloniale internationale de Paris«, 15.-22.07.1931, S. 106.

45 AN/Paris, 60 AJ 133, »Réunion des Professeurs«, Januar 1931.

46 Ebd. 
Die französischen Schulen im Libanon schickten aber nicht nur Material nach Paris, sondern sie nahmen auch in Gestalt ihrer Lehrer und Schüler selbst an der Ausstellung teil. Die Teilnahme der Lehrer hatte ganz unterschiedliche Motive. Einige Lehrer reisten nach Paris, da sie im Rahmen der Kolonialausstellung für ihre Dienste ausgezeichnet wurden ${ }^{47}$. Die Ehrung betraf Lehrer aller französischen Schulen, der privaten katholischen, laizistischen, jüdischen und protestantischen Einrichtungen ebenso wie der staatlichen Schulen, beschränkte sich laut Liste des Hochkommissariats aber auf französische Staatsangehörige. Die Kolonialausstellung zelebrierte also nicht nur das französische Empire, sondern auch die Personen, die daran beteiligt waren. Auch wenn konkrete Belege fehlen, ist stark anzunehmen, dass einige Lehrer ferner an der während der Kolonialausstellung stattfindenden Konferenz »sur l'adaptation de l'enseignement aux colonies et dans les pays d'outre-mer« teilnahmen ${ }^{48}$. Dort wurde diskutiert, nicht ob, sondern wie französische Schulen in den Kolonien wirken sollten. Für diese Tagung war in der Zeitschrift der Mission laïque geworben worden ${ }^{49}$, deshalb ist es sehr wahrscheinlich, dass einige Lehrer daran teilnahmen und sich nur wenige, wenn überhaupt - wie bei einigen politisch eher links eingestellten sogenannten instituteurs militants innerhalb der Mission lä̈que hätte vermutet werden können - an der von den Kommunisten initiierten Protestbewegung gegen die Ausstellung beteiligten ${ }^{50}$. Allerdings bildete deren Kritik am Kolonialismus nur eine Minderheitenposition, denn auch die französischen Sozialisten unterstützten bis 1939 die koloniale Expansion Frankreichs ${ }^{51}$.

Neben den französischen Lehrern besuchten auch einige libanesische Lehrer und Schüler der französischen Schulen im Libanon die Kolonialausstellung. Die Schüler waren Teil der vom Beiruter Komitee der »Union des Français à l'Étranger« organisierten Reise. Für einen erheblichen Unkostenbeitrag reisten sie nach Paris und wurden dabei, so die Zusicherung an die libanesischen Eltern, sorgsam beschützt. In der Schule der Mission laïque machte Ruche bei den Familien für diese Reise Werbung, und das Angebot fand großen Anklang; so berichtete Soubret ${ }^{52}$ von einem »dépassement

47 Vgl. MAE/Nantes, IP, 84, »Propositions de récompenses«.

48 Vgl. Denise Bouche, Histoire de la colonisation française, Paris 1991, S. 246-247. Da diese Konferenz vom 22. bis 29. August 1931 stattfand, fiel sie in die Ferienzeit der Lehrer, die viele Lehrer der Mission laïque in Frankreich verbrachten. Auf diese Weise war eine Teilnahme weniger zeit- und kostenaufwendig, als wenn sie aus dem Libanon angereist wären.

49 Revue de l'enseignement français hors de France, 1929-1930, S. 134: »Congrès colonial et international des Membres de l'enseignement «.

50 Vgl. Ageron 1984, S. 499-501.

51 Vgl. Le Pautremat 2003, S. 56.

52 Der Präsident des Elternbeirates der Mission laïque in Beirut war in dieser Zeit auch Vorsitzender der Union des Français à l'Étranger in Beirut. 
prévu du nombre d'étudiants et d'étudiantes $\aleph^{53}$. Neben französischen Kongregationen nahmen auch private lokale Schulen wie die eindeutig nationalistisch ausgerichtete Madrasat al-ahlīya von Marie Kassab ${ }^{54}$ an dieser Reise teil. Sowohl die Mission lä̈que als auch die Madrasat al-ahlīya hatten viele Schüler und Schülerinnen aus dem frankreichkritischen Milieu, deren Eltern aber anscheinend keine Vorbehalte hatten, ihr Kind an dieser pro-kolonialistischen Ausstellung teil haben zu lassen. Da im Programm unter anderem ein Empfang durch den Präsidenten der Republik vorgesehen war ${ }^{55}$, ist zu vermuten, dass die Eltern diese Reise eher als eine prestigeträchtige Fahrt betrachteten. Durch den enormen Kostenaufwand konnten nur begüterte Eltern ihren Kindern diese Möglichkeit bieten und schufen so ein weiteres soziales Distinktionsmerkmal.

Die libanesischen Lehrer fuhren zum einen als Begleiter ihrer Schüler mit nach Paris. Zum anderen wollte der Direktor der Mission lä̈que den langjährigen arabischen Kollegen diese Reise aber auch als Belohnung ihrer treuen Dienste an der Schule darbieten ${ }^{56}$. Interessanterweise sind keine negativen Äußerungen der Schüler oder Lehrer gegenüber der offensichtlichen französischen imperialen Bekenntnisse auf dieser Ausstellung festgehalten. Im Gegenteil: Renée Ferrera, eine arabische Lehrerin der Alliance israélite, die in Frankreich das Lehrerseminar besucht hatte ${ }^{57}$, berichtete begeistert von der Möglichkeit, Paris wieder zu sehen:

[...] un de mes vœux ardents, celui de retourner en France se réalisait enfin. [...] En approchant des côtes de France je me sentais émue. N'est-il pas curieux que nous, institutrices de l'Alliance, éprouvions à revoir la France un sentiment analogue à celui que l'on ressent pour son pays natal ${ }^{58}$.

Bezüglich der Kolonialausstellung selber schrieb sie in ihrem Bericht an den Präsidenten der Alliance israélite: »À l'exposition coloniale, l'oriental s'est retrouvé dans son élément et les si jolis pavillons illuminés pendant la nuit, le théâtre d'eau ont enchanté le voyageur ${ }^{59}$. Auch wenn man diese Aussage

53 MAE/Nantes, IP, 84, »Caravanes Universitaires«, Brief von Soubret an die Priorin der Franziskanerinnen in Damaskus, Beirut, 20.07.1931.

54 Vgl. ebd., Telegramm des Hochkommissariats nach Paris, 01.08.1931.

55 Vgl. ebd., Brief von Soubret an Priorin der Franziskanerinnen in Damaskus, Beirut, 20.11.1931: »[...] vos élèves seront aussi présentées au Président de la République«.

56 Vgl. AN/Paris, 60 AJ 133, Brief von Ruche an Besnard, Beirut, 31.12.1930.

57 Höchstwahrscheinlich handelt es sich um Renée Ferrera, die vor ihrer Zeit in Beirut noch in Marrakech und Meknes in Marokko unterrichtet hatte. Vgl. AIU/Paris, Liban V E 506, »Maroc XXVI E 402«, »Maroc XXXI E 531«.

58 AIU/Paris, »Liban VE 43-65«, »Mlle Ferrara«, Brief von Ferrara an den Präsidenten der Alliance israélite, Beirut, 10.12.1931.

59 Ebd. 
wegen des obrigkeitlichen Rahmens, in dem der Brief geschrieben wurde, und wegen der Dankbarkeit, die die Reisenden sicher zeigen sollten ${ }^{60}$, mit Vorsicht bewerten muss, überrascht doch die Identifikation der Absenderin mit der orientalistischen Präsentation ihrer Heimat, die diese Ausstellung ausmachte. Sie unterscheidet sich deutlich von dem Bericht einer ägyptischen Wissenschaftler-Delegation, welche 1889 auf dem Weg zu einem Kongress bei der Weltausstellung in Paris Halt gemacht hatten und die die Inszenierung des »ägyptischen Chaos« irritiert und verärgert hatte ${ }^{61}$. Mit der positiven Bewertung der Veranstaltung stand die Lehrerin schließlich im Gegensatz zu den algerischen und indochinesischen Kommunisten, die diese auf das Schärfste verurteilten ${ }^{62}$.

Diese positiven Reaktionen können vor allem durch zwei Umstände erklärt werden. Neben dem schon erwähnten sozialen Prestige, das eine solche Reise bedeutete, knüpfte diese an die Tradition der Europareise an, welche gebildete und reiche arabische junge Leute seit der osmanischen Zeit unternahmen $^{63}$. Während der Mandatszeit gab es viele Absolventen französischer Schulen im Libanon, die einen Teil oder ihr ganzes Studium in Frankreich absolvierten ${ }^{64}$. Interessanterweise nahmen vor allem Schülerinnen der französischen Schulen im Libanon an der organisierten Reise nach Paris teil. Es ist daher zu vermuten, dass die Eltern ihren Töchtern in diesem beschützten Rahmen einen Besuch Europas ermöglichen wollten, welcher ihnen während ihres Studiums nicht erlaubt, sondern den Männern vorbehalten war ${ }^{65}$.

Ein anderer möglicher Grund für die positive Rezeption der Ausstellung durch die Libanesen könnte gewesen sein, dass diese ihre Heimat nicht als Teil des Kolonialreiches wahrnahmen, welches die Ausstellung als Besitz Frankreichs darstellte. Schließlich trugen die Schulen auf der Ausstellung zu einem Moment der Gleichzeitigkeit des Ungleichzeitigen bei, da sie sich einerseits als Teil des Kolonialreiches präsentierten, während andererseits bereits über die künftige Unabhängigkeit des Libanon verhandelt wurde. Diese Ambi-

60 Andererseits enthält das Archiv der AIU euch eindeutig kritische Briefe gegenüber der Direktion, was auf eine relative Meinungsfreiheit schließen lässt.

61 Vgl. Timothy Mitchell, Die Welt als Ausstellung, in: Randeria/Conrad 2002, S. 148-176, hier 148-149.

62 Vgl. Ageron 1984, S. 501. Allerdings gibt es auch Berichte nicht-französischer Besucher aus den französischen kolonialen Gebieten, die nicht explizit politisch organisiert waren, die ähnlich positiv von der Ausstellung berichteten.

63 Vgl. YARED 1996; für Ğūrǧī Zaydān siehe Souad SLim, L’image de l'Occident chez Jurjī Zaydān, à travers son voyage en Europe (1912), in: Bernard Heyberger/Carsten Walbiner (Hg.), Les Européens vus par les Libanais à l'époque ottomane, Würzburg 2002, S. 209-223; Abdallah NAaman, Histoire des Orientaux en France. Du I ${ }^{\mathrm{er}}$ au XX ${ }^{\mathrm{e}}$ siècle, Paris 2000, S. 115-121.

64 Vgl. Kapitel 7.3.

65 Eine Ausnahme waren die jungen Frauen aus dem Nahen Osten, die als Novizinnen zum französischen Mutterhaus kamen oder die bei der »École normale orientale« der Alliance israélite ihre Ausbildung bei Paris absolvierten. Vgl. Kapitel 1.4. 
valenz zeigte sich sowohl in der Präsentation des Libanons und Syriens im Rahmen der Ausstellung als auch in den Gesprächen, die dort geführt wurden. Syrien und Libanon befanden sich in einer schwierigen Situation. Zwar waren beide Länder nach ihrer Bereitschaft zur Teilnahme gefragt und ihnen war ein eigener Pavillon zugeteilt worden, allerdings bestimmte Lyautey, und damit die französische Regierung, was und wie sie sich dort präsentierten ${ }^{66}$.

Die Schulen fanden sich im doppelten Sinne mitten in diesen Diskussionen wieder: So berichtete der Jesuit Jalabert, er habe Robert de Caix, den für die Mandatsgebiete zuständigen Sekretär im Außenministerium, bei der Eröffnung des Pavillons getroffen. Während diese Veranstaltung das Mandat als Teil des französischen Empire feierte, unterrichtete ihn de Caix zeitgleich über den »abandon de très brève échéance du Mandat ${ }^{67}$. Jalabert war entsetzt und gleichzeitig beruhigt, dass de Caix ihn einlud, an dem frankolibanesischen Vertrag mitzuarbeiten, der die Privilegien und Rechte der Jesuiten auch über das Mandatsende hinaus garantieren würde:

En tout cas, M. de Caix que j'ai vu hier m'a dit qu'on travaille à ce traité et m'a invité à venir conférer avec lui sur les articles qui devront sauvegarder nos œuvres et leurs possibilités d'action. C'est grave, aussi je vous attends avec impatience, de manière à ce que nous puissions faire cela d'un commun accord ${ }^{68}$.

In einer Monographie, die kurz nach der Ausstellung 1934 veröffentlicht wurde, kam Jalabert, der die Präsentation der katholischen Orden koordiniert hatte, erneut auf dieses Thema zu sprechen. Unter dem Titel »Syrie et Liban: Réussite française? « räumte er zwar ein, Frankreich habe in Syrien und Libanon einige Dinge zu schnell realisieren wollen, insgesamt bezeichnete er das französische Engagement in Syrien und im Libanon aber als Erfolg ${ }^{69}$. Der Kultusbeauftragte des Hochkommissariats Gabriel Bounoure beglückwünschte ihn zu diesem Buch, bedauerte aber, dass Jalabert die Rolle der Christen ein wenig zu stark betont habe:

Vous avez été avant tout le bon avocat des minorités. C'est un rôle qui doit être tenu de temps en temps. Le Haut-Commissaire arbitre un débat où plusieurs parties font entendre tour à tour d'excellentes raisons. Il est très nécessaire que la cause des plus faibles

\footnotetext{
66 Vgl. TRÉGan 2002, S. 97.

$67 \mathrm{SJ} /$ Vanves, »Fonds Jalabert«, 12/2 A: »Mission de Syrie-Liban«, »Correspondance avec le P. de Bonneville (juin 1932)«, Brief von Jalabert an den Rektor der Jesuitenuniversität in Beirut Bonneville, Paris, 19.06.1931.

68 Ebd.

69 Vgl. Louis Jalabert, Syrie et Liban. Réussite française?, Paris 1934, S. 233.
} 
trouve, quand il le faut, une grande voix pour dépeindre cette inquiétude et cette angoisse de l'Orient chrétien qui avaient si vivement frappé Barrès en $1914^{70}$.

Bounoures Verweis auf die Minderheiten ist insofern interessant, als die Kategorie der religiösen Minderheiten in der Levante, insbesondere in Syrien, in den 1930er Jahren von der Mandatsregierung als Argument genutzt wurde, ihre Präsenz dort zu rechtfertigen - das Etikett der Minderheit durfte sich aber nicht länger auf die Christen beschränken, sondern musste auch die nicht-sunnitischen muslimischen Minderheiten beinhalten ${ }^{71}$.

Frankreich könne sich nicht, so Bounoure weiter, auf eine Gemeinschaft konzentrieren, sondern müsse der ganzen Bevölkerung gerecht werden:

Le Mandat de la France est une œuvre difficile et sévère comme toute œuvre de justice. À la France de prouver si elle est vraiment une nation de princes, car allier intimement la force et la justice est le vrai fait des vrais princes $^{72}$.

Der Appell von Bounoure für eine gerechte Kolonialpolitik Frankreichs deckte sich mit der Veränderung in der Haltung des Kolonialministers Albert Sarraut zu Frankreichs Engagement in den Kolonien in dieser Zeit. In dem zum Zeitpunkt der Kolonialausstellung verfassten Werk Grandeur et servitude coloniales äußerte sich der Politiker sehr viel kritischer gegenüber der französischen Kolonialpolitik als in früheren Jahren ${ }^{73}$. Diese veränderte Haltung betraf nicht nur Sarraut, sondern auch die gesamte koloniale Lobby in Frankreich, die die Beziehung zu den Kolonien nun nicht mehr vorrangig in den Kategorien von Herrschaft und Vormacht definierte. Vielmehr sah sie sie stärker als eine Art Vertrag zwischen Kolonisierern und Kolonisierten, der beide betraf und beiden ein Nebeneinander ermöglichen musste ${ }^{74}$.

Einer der ausschlaggebenden Faktoren für diese Veränderung war die britische Politik im Nahen Osten, die von Frankreich, Syrien und Libanon aus genauestens beobachtet wurde: Großbritannien hatte 1930 den Irak in die Unabhängigkeit entlassen, und 1932 wurde der arabische Staat Mitglied des Völkerbundes. Die darauf folgenden verstärkten Forderungen der syrischen und libanesischen Nationalisten nach Unabhängigkeit brachten die Regierung in Paris zu der schmerzhaften Erkenntnis, die Mandate im Nahen Osten seien

$70 \mathrm{SJ} /$ Vanves, RPO, 21, »Mission de Syrie«, Brief von Bounoure an Louis Jalabert, Beirut, 21.12.1934.

71 Vgl. Benjamin Thomas White, The Emergence of Minorities in the Middle East. The Politics of Community in French Mandate Syria, Edinburgh 2011, S. 138-143.

72 SJ/Vanves, RPO, 21, »Mission de Syrie«, Brief von Bounoure an Louis Jalabert, Beirut, 21.12.1934.

73 Vgl. Albert Sarraut, Grandeur et servitude coloniales, Paris 1931, S. 12.

74 Vgl. Girardet 1972, S. 270. 
nicht mehr endlos und undefiniert, sondern verlangten nach einer baldigen Lösung ${ }^{75}$. Schon 1931 war in Paris der Text für einen franko-syrischen Vertrag ausgearbeitet worden, den Hochkommissar Ponsot 1933 wieder zur Sprache brachte, den der Nationale Block im syrischen Parlament aber blockierte ${ }^{76}$. Die Unabhängigkeit der Mandatsgebiete rückte somit in greifbare Nähe.

Während die Vertreter der katholischen Schulen sich erst spät mit der Vorstellung des Mandatsendes auseinandersetzten, hatte Edmond Besnard, der Generalsekretär der Mission lä̈que, schon 1926 das französische Vorgehen in Syrien und Libanon kritisiert ${ }^{77}$. Insbesondere hatte er die enge Verbindung von Mandatsfunktionären und katholischen Missionsorden angeprangert, welche er als Verletzung der Neutralität ansah, die der Völkerbund Frankreich auferlegt hatte ${ }^{78}$.

2. Bildung von Körper und Geist:

Die Rolle der Erziehung außerhalb des Klassenzimmers

Die Herausstellung der schulischen Aktivitäten über den Unterricht hinaus geschah aber nicht nur in Frankreich, sondern auch im Libanon und in den Schulen selbst. In der Tat stieg um 1930 das Angebot außerunterrichtlicher Aktivitäten in den französischen Schulen stark an, auch wenn es diese Tätigkeiten, in geringerer Anzahl, schon seit der osmanischen Zeit in den Lehranstalten gegeben hatte.

Neben den traditionellen Theateraufführungen boten die Schulen vermehrt Vorträge, Sportdarbietungen, Filmvorführungen und Konzerte an. Die Forschung hat dieses Thema bis jetzt fast unberührt gelassen, mit Ausnahme zweier interessanter Studien zum Kino während der Mandatszeit, welche aber keinen Bezug zu Schulen als Orte dieser kulturellen Praxis herstellen ${ }^{79}$. Während die französische Regierung diese Aktivitäten vor allem für Propagandazwecke und im Sinne einer beginnenden auswärtigen Kulturpolitik im Libanon nutzen wollte ${ }^{80}$, frequentierten die Libanesen die Veranstaltungen als Ausdruck eines sich stark entwickelnden modernen und, besonders in

75 Vgl. White 2011, S. 138-139.

76 Vgl. ebd., S. 139.

77 Vgl. Edmond Besnard, Faut-il rester en Syrie?, in: Les Cahiers des Droits de l'Homme 21 (1926), S. 492-496.

78 Vgl. Deguilhem 2004, S. 332.

79 Vgl. Thompson 2000, S. 197-210; Dueck 2010, S. 147-154. Dueck beschränkt sich hier auf staatliche französische Archive und auf die Zeit des Zweiten Weltkriegs, Thompson nimmt noch Beiruter Zeitungen und einige Akten der Jesuiten als Quellen hinzu und betont besonders die Gender-Perspektive.

80 DuEck 2010, S. 10, spricht überzeugend auch von beginnenden diplomatischen Beziehungen zwischen den europäischen Mächten und den Mandaten in dieser Zeit. 
Beirut, städtischen Lebens sowie als Medium einer nationalen oder gemeinschaftlichen Identitätssuche. Die französischen Schulen selbst versuchten beiden Seiten gerecht zu werden und förderten darüber hinaus die außerunterrichtlichen Aktivitäten als Ausdruck einer ganzheitlichen Erziehung, welche in dieser Zeit ein neues Ideal in der Pädagogik darstellte ${ }^{81}$. Inwiefern sie die drei Funktionen der außerunterrichtlichen Aktivitäten - Propagandainstrumente, Echo einer ganzheitlichen Erziehung und Ausdruck einer städtischen modernen und nationalen kulturellen Identität - umsetzten, soll im Folgenden anhand der unterschiedlichen Tätigkeiten beleuchtet werden.

Wie durch andere Bereiche ihrer Arbeit boten die französischen Schulen im Libanon durch die außerunterrichtlichen Aktivitäten der französischen Propaganda im Libanon ein Forum. Zu diesem Zweck bediente sich die französische Regierung auch der Alliance française, einer 1883 mit einem stark kolonialen Impetus gegründete Organisation zugunsten einer französischen auswärtigen Kulturpolitik ${ }^{82}$. Auch wenn, oder gerade weil die Alliance française im Libanon wegen der schon vorhandenen vielen französischen Schulen nicht so große Bedeutung wie in anderen Ländern erlangen konnte, veranstaltete sie Vortragsreihen und andere Aktivitäten und kooperierte eng mit den Schulen ${ }^{83}$. Zusätzlich organisierte und finanzierte die französische Regierung selbst Tourneen von Musikern, die unter anderem im Libanon Halt machten und in den französischen Schulen Konzerte gaben. So musizierte Anfang 1925 der französische Pianist André Laumonier nur für die Schüler der Mission lä̈que française in Beirut ${ }^{84}$, zwei Monate zuvor hatte der Klavierspieler Volodarsky sein Abschlusskonzert in der laizistischen Schule gegeben, welches mit einem Vortrag des französischen Gouverneurs des Libanons, Vandenberg, endete ${ }^{85}$.

Ein wichtiges Motiv der gesteigerten Tätigkeiten der Mandatsmacht $a b$ Anfang der 1930er Jahre stellte die Konkurrenz der amerikanischen Stiftungen dar, die in diesem Bereich sehr aktiv waren ${ }^{86}$. Diese Gefahr brachte auch

81 Vgl. Winfried Böнm, Die Reformpädagogik: Montessori, Waldorf und andere Lehren, München 2012; speziell für Frankreich vgl. Annick OHAyon u.a. (Hg.), L'éducation nouvelle. Histoire, présence et devenir, Bern 2007. Zur ambivalenten Beziehung zwischen dieser neuen Richtung der Pädagogik und dem katholischen Milieu in Frankreich vgl. Winfried BöHm, Éducation nouvelle et christianisme - une liaison difficile, in: Michel SoËTARD (Hg.), Identité et Altérité en Éducation, Angers 1996, S. 21-35.

82 Vgl. François Cнавет, La politique culturelle française et la diplomatie de la langue. L'Alliance française (1883-1940), Paris 2006, S. 21.

83 Im Frühjahr 1925 hielt der Lehrer der Mission laïque Rebours einen Vortag bei der Alliance française zum Thema »Une promenade à Jérusalem et aux environs«. Vgl. AN/Paris, $60 \mathrm{AJ}$ 127, »Rapports mensuels«, März 1925.

84 Vgl. ebd., Januar 1925.

85 Vgl. ebd., »Rapports mensuels«, November 1924.

86 Vgl. Chaвет 2006, S. 247. Für das weltweite Engagement amerikanischer Stiftungen und ihre Rolle als kultureller Arm der US-amerikanischen Regierung vgl. Katharina RIETZLER, Before 
den Kultusbeauftragten des Hochkommissariats Bounoure dazu, die Mission laïque zu bitten, das Niveau ihrer Vorträge noch zu verbessern, einen separaten Raum dafür herzurichten und über weitere Mittel nachzudenken, um den französischen Einfluss zu bewahren. Das Ziel war eindeutig »de garder sous notre influence le public que nous avions réussi à grouper autour des conférences du Lycée. Nous avons à lutter contre la concurrence très bien armée des Américains « ${ }^{87}$.

Die Schulen beteiligten sich durch die Bereitstellung von Räumen und Infrastrukturen außerdem an der Verbreitung der französischen Wissenschaften wie der Ethnologie, die einen Bezug zu den Kolonien hatten, seitens der Regierung in Paris. Durch die Organisation von Vortragsreisen exportierte die Mandatsmacht damit eine Perspektive auf nicht-europäische Gesellschaften, die starke ethnozentrischen Tendenzen in sich trug. Ein eher liberaler Vertreter war in dieser Hinsicht der französische Ethnologe Lucien LévyBruhl (1857-1939), der 1932 in der Mission lä̈que in Beirut zum Thema: ॥Y-a-t-il une mentalité primitive qui requièrt d'être étudiée pour elle-même?" hielt ${ }^{88}$. Die Beschäftigung mit »europäischen « und »primitiven « Denkweisen stellte Lévy-Bruhls zentrales Forschungsinteresse dar, über das er kurz zuvor zwei Werke verfasst hatte ${ }^{89}$. Während er selber betonte, er sehe keinen hierarchischen Unterschied zwischen beiden Arten, wurde ihm die starke Trennung zwischen Zivilisation und Wildheit zum Vorwurf gemacht ${ }^{90}$. Interessant ist, dass er diesen Vortrag in Beirut vor einem nicht ausschließlich europäischen Publikum hielt. Es ist davon auszugehen, dass die libanesischen Zuhörer sich eindeutig auf die Seite der Zivilisation stellten und daher von den Ausführungen Lévy-Bruhls nicht schockiert waren ${ }^{91}$. Das zeigte sich auch am Tag nach dem Vortrag, als sich verschiedene französische und libanesische Repräsentanten, unter anderem Bounoure und seine Frau, zu einem Mittagessen mit Lévy-Bruhl im Haus des Direktors Ruche trafen. Allerdings hatte sich der arabisch-nationalistische Politiker Riad as-Sulh wegen anderer Verpflichtungen entschuldigt: während die Gesellschaft um einen Repräsentanten der Kolonialwissenschaft ${ }^{92}$ versammelt war, führte as-Sulh in Damas-

the Cultural Cold Wars: American Philanthropy and Cultural Diplomacy in the Interwar Years, in: Historical Research 84 (2011), H. 223, S. 148-164, S. 161.

87 AN/Paris, 60 AJ 134, »Rapports mensuels«, Februar 1932.

88 Revue de l'Enseignement français hors de France 30 (1933), H. 191, »Assemblée Générale«, 23.02.1933, S. 38-46.

89 Lucien LÉVy-Bruhl, L'âme primitive, Paris 1927; Ders., Le surnaturel et la nature dans la mentalité primitive, Paris 1931.

90 Vgl. Jean-Louis Fabiani, Rezension zu Frédéric Keck, Lucien Lévy-Bruhl. Entre philosophie et anthropologie, contradiction et participation, Paris 2008, in: Annales 65 (2010), H. 4, S. 10461048.

91 Vgl. Kapitel 6.1.

92 Zur Entwicklung der Anthropologie in den Kolonien vgl. SAID 1994, S. 205. 
kus Verhandlungen mit den Repräsentanten des Mandats ${ }^{93}$. Diese Episode macht einmal mehr das Nebeneinander kolonialer und antikolonialer Praktiken deutlich.

Im Zuge der auswärtigen Kulturpolitik Frankreichs wurden die Schulen auch in die schon seit langem gängige Praxis der Theateraufführungen ${ }^{94}$ und die damit verbundenen ideologischen Debatten eingebunden. Die wichtige Rolle des Theaters versuchte sich die französische Regierung zunutze zu machen, indem sie Tourneen französischer Truppen im Libanon in den 1920 er und 1930er Jahren organisierte und unterstützte ${ }^{95}$. Wie das Beispiel der Aufführung der »drei Musketiere« in Beirut 1921 zeigt, welche von Schülern der Jesuiten wegen ihrer frivolen Anspielung auf Nonnen und Mönche boykottiert wurde ${ }^{96}$, enthielten die Theaterstücke großes Potential für ideologische Streitigkeiten, nicht nur zwischen Franzosen und Libanesen, sondern auch innerhalb dieser Gruppen. Zwischen den französischen Schulen sorgte die Vorführung des stark jesuitenkritischen Stückes »Le juif errant« nach dem Roman von Eugène Sue durch eine französische Theatergruppe in Beirut 1923 für Auseinandersetzungen. Ein Verantwortlicher der Mission laïque kritisierte den Boykott durch die Jesuiten in einem Bericht an den französischen Abgeordneten Daladier auf das Schärfste, allerdings auch um seine Organisation im Gegensatz zu den Jesuiten als Verfechter der Dritten Republik darzustellen ${ }^{97}$.

Diese Positionen entsprachen den Debatten innerhalb der libanesischen Gesellschaft zu dem Stück, zwischen Jesuiten und Maroniten auf der anderen und Freimaurern und Griechisch-Orthodoxen auf der anderen Seite ${ }^{98}$. Im Fall der »drei Musketiere « unterstützte der Hochkommissar den Protest der katholischen Studenten und versprach, alle Stücke in Zukunft zu zensieren ${ }^{99}$. In der Tat griff die Mandatsmacht in der Folge aktiv in das Theaterprogramm

93 Vgl. AN/Paris, 60 AJ 135, Brief von Ruche an Besnard, Beirut, 05.11.1932.

94 Vgl. Kapitel 4.1.

95 Vgl. Kassir 2003, S. 372-373.

96 In ihren Berichten an den Provinzial stellten die Jesuiten in Beirut es so dar, als ob diese Initiative von den Studenten ausging. Vgl. SJ/Vanves, RPO, 92: »Lettres et nouvelles périodiques 1927-1958«: »[...] de M. Chanteur. 27 janvier 1921. Beyrouth. [...] Une troupe française jouait >les Mousquetaires au Couvent<. [...] Les jeunes gens catholique se sont émus. Ils sont venus me trouver et me faire part de leur désir de protester. Je les ai priés d'attendre le résultat d'une démarche que j'allais tenter auprès du Gouverneur pour obtenir un changement de programme [...]. Le soir, pas de réponse à ma lettre. Ces jeunes gens décident d'acheter des sifflets et de se répandre dans la salle du théâtre [...] « Es ist aber mit Elizabeth Thompson zu vermuten, dass die Studenten dazu von den Jesuiten animiert wurden. Vgl. Thompson 2000, S. 202.

97 Vgl. MLF/Paris, »Fonds de Russie«, 03/942, Chemise 125-2-40 »Situation politique«, »De l'influence française en Orient (note remise à Daladier, député de Vaucluse, le 27 février 1923)《.

98 Vgl. SLim 2005, S. 221.

99 Vgl. Thompson 2000, S. 202. 
ein: So erhielt das Stück »Salaheddine el Ayoubi« von Issa Nahas 1923 ein Aufführungsverbot, durfte aber, nachdem er einige Passagen herausgenommen hatte, im »Théâtre Cristal« gespielt werden ${ }^{100}$.

Gerade in den 1930er Jahren kam aber noch ein neues und deshalb sehr attraktives Medium hinzu: das Kino. Die französischen Schulen nutzten diese Technologie sowohl zur Verbreitung der französischen Zivilisation als auch zur Gewinnung libanesischer Interessenten für ihre Einrichtungen. Viele Gruppen versuchten in der Tat in dieser Zeit, sich zunutze machen, dass das Kino als modernes Medium im Libanon sehr beliebt war: so griffen politische Parteien im Libanon darauf als Mittel und Ort ihres antikolonialen Engagements zurück. Wie Elizabeth Thompson gezeigt hat, instrumentalisierte die französische Mandatsmacht das Kino nicht nur, indem sie es als »primary tool of the French civilizing mission« benutzte, sondern auch, indem sie es nach ihren Vorstellungen zensierte ${ }^{101}$. Gegen Ende des Zweiten Weltkrieges wurde das Kino zudem ein Mittel der Kriegspropaganda sowie der Konkurrenz zwischen den französischen und britischen Truppen, aber auch ein Ausdrucksmittel unterschiedlicher syrischer und libanesischer politischer Positionen gegenüber den Alliierten ${ }^{102}$.

Die Nutzung des Kinos durch die französischen Schulen spiegelt all diese Elemente wider. Zum einen entwickelte sich eine starke Konkurrenz unter den Schulen anhand der Frage: wer ist am modernsten? Die Jesuiten rühmten ihr »cinéma parlant « explizit in der Zeitschrift ihrer Schule in Beirut ${ }^{103}$. Dessen Attraktivität wurde dadurch gestärkt, dass es nur sehr wenige Kinos in Beirut gab ${ }^{104}$, die Besorgung von Leinwand, Apparat und Filmen sehr kostspielig und das Beschaffen von Filmen im Libanon sehr schwierig waren ${ }^{105}$. Da zum Medium Kino in den 1930er Jahren vor allem die in westlichen Schulen ausgebildete Elite Zugang hatte ${ }^{106}$, boten die Schulen nun auch anderen Gesellschaftsgruppen und nicht-katholischen Kreisen die Möglichkeit, dieses Medium kennenzulernen. Zum Beispiel konzipierten die Lehrer der Mission lä̈que eine Serie von landeskundlichen Filmen für ihre Schüler ${ }^{107}$. Das große Interesse der Eltern zeigt sich beispielsweise in der Bitte eines Vaters,

100 Vgl. Joseph Khoueiri, Théâtre arabe. Liban, 1847-1960, Louvain-la-Neuve 1984, S. 113.

101 Thompson 2000, S. 200.

102 Vgl. Dueck 2010, S. 150.

103 Vgl. NDJ, L’U, Juni 1934: »Le ciné parlant«. Auf drei Seiten mit Fotos und Zeichnungen erklärte der Autor Antoine Baz, an der Jesuitenuniversität in Beirut und in Paris ausgebildeter Ingenieur, inwiefern das neue Kino in der Lage sei »d'agrandir et de moderniser l'ancienne cabine de projection «.

104 Beispielsweise gab es 1936 nur sieben Kinos in Beirut, und in Damaskus und Aleppo mit fünf bzw. in Tripoli mit drei Kinos noch weniger Einrichtungen. Vgl. Dueck 2010, S. 150.

105 Vgl. den Bericht des Direktors der Mission laïque während der Lehrerkonferenz am 28.03.1925. AN/Paris, 60 AJ 125, »Réunion des Professeurs«.

106 Vgl. Dueck 2010, S. 150.

107 Vgl. AN/Paris, AJ 129, »Rapports mensuels«, Bericht vom Februar 1927. 
Daoud Nahoul, an die Mission lä̈que, Filmvorführungen für den Unterricht $\mathrm{zu}$ verwenden und so die anderen Schulen der Stadt zu übertrumpfen ${ }^{108}$.

Des Weiteren transportierten viele der in den Schulen vorgeführten Filme einen kulturpolitischen Inhalt und ihre Auswahl durch die Schulen verdeutlicht sowohl die politischen Tendenzen und Interessen der Lehrer als auch die relevanten Themen der Zeit. Während von der Mission laïque fast keine Filmtitel überliefert sind ${ }^{109}$, zeigt die Filmliste der Jesuiten-Schulen Filme zumeist profranzösischen und prochristlichen Inhalts. Darüber hinaus besprachen die Jesuiten selbst, unter anderem in einer eigenen Zeitschrift, aktuelle Filme und zensierten die Filme vor, die sie öffentlich zeigten ${ }^{110}$. 1929 beispielsweise zeigten die Jesuiten einen Film über französische Ordensmänner als Soldaten außerhalb Frankreichs ${ }^{111}$, der den Patriotismus der Kongregationen deutlich machen sollte. Anlässlich des franko-libanesischen Vertrages von 1936 wurde nicht nur ein Film über dieses Übereinkommen ausgewählt, sondern auch ein, in den Worten des Präfekten, »Dokumentarfilm« (documentaire) über Skifahrer. Allerdings handelte es sich bei »L'Ivresse blanche« (auf Deutsch »Der Weiße Rausch«) um den 1931 von dem deutschen Regisseur Arnold Franck mit Leni Riefenstahl als Hauptdarstellerin gedrehten Film. Zum Zeitpunkt der Ausstrahlung in Beirut hatte Riefenstahl schon den eindeutig pro-nationalsozialistischen Film »Triumph des Willens« gedreht. Die Schulleitung war sich der Brisanz des Films anscheinend bewusst, und um jeder Fehlinterpretation vorzubeugen, hielt Lehrer Bériel einen Vortrag über den Film. Trotz des »préjugé défavorable du documentaire« waren die Schüler sehr an dem Ski-Film interessiert, berichtet der Präfekt in seinem Tagebuch ${ }^{112}$.

Neben politisch aufgeladenen Filmen zeigten die Jesuiten auch westeuropäische »Kassenschlager«, die der Unterhaltung dienten und durch die die Schule auf das steigende gesellschaftliche Interesse an Unterhaltungsfilmen antwortete. 1939 sahen die Schüler laut einer Archivnotiz »Eddy la sauvageonne«, was wahrscheinlich den Film »Heidi la sauvageonne« meint, eine 1937 unter dem Namen »Heidi« von dem amerikanischen Regisseur Allan Dwan verfilmte Version des Romans von Johanna Spyri.

108 AN/Paris, 60 AJ 127, »Comité de patronage«, Sitzung vom 16.06.1924 : »M. Daoud Nahoul émet le vœu que l'enseignement par le cinématographe puisse être prochainement organisé au collège, qu'il désirerait voir devancer dans cette voie les autres établissements«.

109 Im November 1924 berichtete Direktor Matthieu von dem Vortrag des Vizepräsidenten der »Ligue Aéronautique«, den dieser mit dem Abspielen kleiner Filme der französischen Armee beendete. Vgl. AN/Paris, AJ 127, »Correspondance«, Brief von Mathieu an Besnard, Beirut, 05.11.1924.

110 Vgl. Thompson 2000, S. 197.

111 SJ/Beirut, »Diaire collège Beyrouth«, 3 A 29: »Diaire 1928-1934«, April 1929.

112 SJ/Beirut, 3 A 30: »Collège de Beyrouth. Diaire du P. Préfet 1934-1947«, Eintrag vom 15.01.1937. 
Über die Verbreitung der französischen Zivilisation im Sinne der Mandatsmacht hinaus bildete das Ideal einer ganzheitlichen Erziehung ein weiteres zentrales Motiv für die Förderung außerunterrichtlicher Aktivitäten innerhalb der französischen Schulen im Libanon. Die Einrichtungen setzten dies besonders durch Vorträge für die Allgemeinbildung und Sportangebote um. In Europa hatten Reformpädagogen wie Maria Montessori und Visionäre wie der Gründer der Pfadfinderbewegung Robert Baden-Powell zwar schon zu Beginn des 20. Jahrhunderts ihre Ideen zu einer Förderung des Geistes und des Körpers formuliert, aber deren Breitenwirkung entfaltete sich sowohl inner- als auch außerhalb Europas erst langsam. Im Nahen Osten bildeten die Zionisten in Palästina ein Zentrum der Rezeption dieser Pädagogik $^{113}$, was, wie der oben genannte Bericht eines Lehrers der Mission laïque zeigt, in den umliegenden Ländern sehr deutlich wahrgenommen wurde.

Im Geiste dieses Ideals setzten die Schulen zum einen auf die Organisation von öffentlichen Vorträgen beziehungsweise ganzen Vortragsreihen. Redner waren Persönlichkeiten aus Politik, Militär Wissenschaft und Kultur, zumeist aus Frankreich, aber auch Lehrer der Schulen selber, die in den Räumen der Schule oder in einem anderen öffentlichen Raum referierten. Diese Vorträge sollten zum einen die Lehrer weiterbilden. Der Direktor der Mission laïque hielt seine Kollegen wiederholt an, zu den Vorträgen zu erscheinen - ein Indiz dafür, dass deren Interesse nur mäßig war ${ }^{114}$. Angesprochen werden sollte aber auch die libanesische Öffentlichkeit, zu welcher primär die ehemaligen Schüler zählten. Diese sollten durch die Vorträge ihr Allgemeinwissen vervollständigen ${ }^{115}$. Die Vorträge umfassten zum einen allgemeine Themen über die französische Geschichte, Kultur, und Musik, die in allen Schulen ähnlich lauteten. Zum anderen variierten die Vorträge aber auch je nach Schultyp.

Während die katholischen Schulen Vorträge zu christlichen Themen anboten, wandten sich die Ausführungen bei der laizistischen Schule auch religionskritischen Inhalten $\mathrm{zu}^{116}$. Darüber hinaus kamen bei der Mission laïque stärker arabische Redner und Themen zu Wort. Diese bikulturelle Ausrichtung wurde von Direktor Ruche 1929 auch explizit gewünscht ${ }^{117}$. Unter ande-

113 Vgl. Ludwig LiegLe, Zur Transformation von »Reformpädagogik« und utopischem Sozialismus im jüdischen Gemeinwesen Palästinas, in: Jürgen Schriewer (Hg.), Weltkultur und kulturelle Bedeutungswelten. Zur Globalisierung von Bildungsdiskursen, Frankfurt/New York 2007, S.117-148, S. 145.

114 Ruche verkündete im Januar 1929, die Teilnahme der Lehrer an den Vorträgen solle Pflicht sein. Vgl. AN/Paris, 60 AJ 131, »Réunion des Professeurs«, Januar 1929.

115 So formulierte Ruche: »[...] ils viendraient chercher un complément de culture générale et trouver peut-être la voie d'une spécialisation«. Revue de l'enseignement français hors de France 26 (1929), H. 79, S. 136.

116 Vgl. Kapitel 5.1.

117 Vgl. AN/Paris, 60 AJ 131, »Réunion des Professeurs«, Januar 1929. 
rem sprach »M. Gennardi, inspecteur des Wakfs« über »l'évolution du droit et de la doctrine musulmane $\ll^{118}$. Als sehr viel kontroverser erwies sich der Vortrag von Khalil Taqi ad-Din, einem ehemaligen Schüler, und Georges Kfoury, dem Arabischlehrer der laizistischen Schule, über »le problème de l'adaptation de la langue arabe aux nécessités de la civilisation moderne et des rapports de l'arabe littéraire et de l'arabe parlé« ${ }^{119}$. Laut einem Bericht der Mission laïque hatte dieser Vortrag eine Außenwirkung in der intellektuellen Szene, denn »les solutions proposées ont soulevé dans le monde cultivé des controverses passionnées ${ }^{120}$. Einen Beweis für das Interesse an diesen Themen über die französischen Schulen hinweg lieferte die Anfrage des Direktors des libanesischen Collège universel in Aley, »de voir des professeurs du Lycée de Beyrouth venir faire des conférences à ses élèves « ${ }^{121}$.

In den französischen Schulen im Libanon manifestierte sich das Ideal einer ganzheitlichen Erziehung außerdem im stärkeren Gewicht auf sportliche Aktivitäten, welche darüber hinaus auch mit der Betonung nationaler Identität in Verbindung gebracht werden kann ${ }^{122}$. Besonders auffällig ist die neue Aufmerksamkeit gegenüber dem Sport in den katholischen Schulen. Hatten diese lange Zeit dem Sport gar keine oder nur sehr geringe Aufmerksamkeit geschenkt, mehrten sich ab Ende der 1920er Jahre die Aktivitäten und Erwähnungen rund um das Thema Sport. Verstärkt betonten nun auch die katholischen Schulen den Nutzen eines gesunden Körpers für den Geist, und sogar für die Gemeinschaft:

[...] les plaisirs de l'esprit ne suffisent point. Il faut développer nos muscles et parfaire notre entrainement sportif. [...] On ne vous demande pas d'être un Hercule. Simplement un garçon sain, vigoreux. Ton [sic!] corps n'est qu'un outil au service de ton âme et de ton esprit. Au service des autres aussi. Il faut être fort pour être utile ${ }^{123}$.

In der Folge stellten sie die sportliche Aktivität als ideale Tätigkeit während der Ferien dar (»Les vacances telles que nous les rêvons«) als Gegensatz zum »lange Ausschlafen« und zu »Hause bleiben« (»Les vacances telles que nous les vivons trop souvent « $)^{124}$. Gleiches gilt für die Schulen der Alliance israélite, deren Verantwortliche den großen Nutzen der Bewegung in der freien Natur für die physische und moralische Entwicklung der Schüler

118 Revue de l'enseignement français hors de France 26 (1929), H. 79, S. 137.

119 Ebd.

120 Ebd.

121 Revue de l'enseignement français hors de France 23 (1926), H. 64, S. 362.

122 In der Forschung wird aktuell sehr viel über die Verbindung von Sport, Körper, Nationalismus und Moderne gearbeitet. Vgl. z.B. Erik N. Jensen, Body by Weimar: Athletes, Gender, and German Modernity, Oxford 2010.

123 SJ/Beirut, 11.D.15, »Collège Secondaire IV«, »Journal de Vacances«, 1940.

124 Siehe die Zeichnungen in der Schulzeitschrift Nous du Collège, 1947, S. 1-2. 
betonten $^{125}$. Außerdem organisierten alle französischen Schulen ab Ende der 1920er Jahre sogenannte »fêtes sportives«, die Sportwettkämpfe und Darbietungen beinhalteten ${ }^{126}$. In den Schulzeitschriften wurde ausführlich über die sportlichen Aktivitäten der Schulen berichtet ${ }^{127}$.

Darüber hinaus wurde Sportunterricht Teil der Schulcurricula und zeigte eine deutlich politische Konnotation. 1928 engagierte das Collège protestant français eine Sportlehrerin tschechischer Herkunft, Anna Kovalenko ${ }^{128}$. Sie war, ebenso wie ihr Mann, auch an der Schule der Mission laïque tätig ${ }^{129}$. Herr Kovalenko unterrichtete außerdem an der Schule der Jesuiten in Beirut $^{130}$. An allen diesen Schulen führte das Ehepaar die Sportart der Sokols ein, eine rhythmische Sportgymnastik zu Musik, die sich in Osteuropa im Zuge der entstehenden Nationalismen entwickelt ${ }^{131}$ und auch auf nationalistische Bewegungen im Nahen Osten großen Einfluss hatte ${ }^{132}$.

Interessant ist, dass diese nationalistisch inspirierten Sportbewegungen auch bei Veranstaltungen vorgeführt wurden, welche unter der Schirmherrschaft eines Mandatsfunktionärs standen ${ }^{133}$. So scheint es, dass die innovative und ansprechende Seite dieser Sportart die Gefahr missliebiger Interpretation verdrängte, und hier zeigt sich einmal mehr die Überschneidung kolonialer und nationalistischer Praktiken. Die Schüler reagierten auf das erweiterte Sportprogramm sehr unterschiedlich. Einige zählten den Unterricht bei Frau Kovalenko zu den Gründen, warum sie gerne auf das Collège protestant français gingen ${ }^{134}$. Bei der Mission lä̈que gab es hingegen, laut des Berichts von Direktor Ruche, wenig Interesse der Schüler an der Vorbereitung einer »exhibition de gymnastique sportive« mit Herrn Kovalenko im

125 Vgl. AIU/Paris, Paix et Droit 6, Juni 1932, S. 8-12: A.H. Navon, »L'École Normale Israélite Universelle (1867-1932)«, hier S. 11: »Depuis deux ans, [...] six semaines de grandes vacances en plein air. Sous la direction du commandant Fabre, un des promoteurs en France des Camps de vacances, ils mènent la vie d'éclaireurs, aux Mesnuls, pour le plus grand profit de leur développement physique et moral«.

126 Für die Jesuiten siehe den Bericht in der Schulzeitschrift L’U, Juni 1935, S. 54-77: »Fête des jeux«.

127 Vgl. FEC, Palmarès, 1926-1927, S. 142: Unter der Überschrift »Fête sportive« zeigt ein Foto »M. Coury, profeseur d'éducation physique au barreau« und ein anderes »La pyramide«, aus Schülern errichtet. Für die AIU vgl. AIU/Paris, Paix et Droit 7, Juli 1938, S. 9-10: »La vie dans les écoles de l'Alliance Israélite«.

128 Vgl. Eyrard/Khoury/Krebs 2006, S. 111.

129 Vgl. AN/Paris, 60 AJ 136, »État du personnel enseignant recruté sur place«.

130 Vgl. FEC, L'Essor, Februar 1926, S. 6-7: »Fête sportive «.

131 Vgl. Claire E. Nolte, The Sokol in the Czech Lands to 1914: Training for the Nation, Basingstoke 2002 , S. 2-4.

132 Laurens 2002, S. 279, nennt das Beispiel der Phalanges Libanaises, die 1936 von Pierre Gemayel gegründet wurden. Vgl. Kapitel 7.2.

133 Beispielsweise fanden sie Einsatz bei einem Fest der Jesuiten unter Vorsitz von Admiral Rivet. Vgl. NDJ, »L'U«, Juni 1935, S. 54-57: »Fête des jeux«.

134 Interview der Verfasserin mit May Saikay, Beirut, November 2008. 
Mai 1929. Ruche zufolge lag das mangelnde Engagement an dem ausgeprägten Individualismus der Schüler: »[Ils] détestent le travail en commun dont ils ne sentent pas la valeur éducative ${ }^{135}$.

Gerade um diesen Erziehungswert des Sportes ging es den Lehrern. Die mangelnde Begeisterung der Schüler mag auch damit zusammengehangen haben, dass der Sportunterricht an der Mission lä̈que bis dahin in der Regel von Angehörigen des französischen Militärs abgehalten worden war, die sicher ein sehr disziplinorientiertes Programm anboten ${ }^{136}$. Viele Eltern hingegen unterstützten die Initiativen zur Förderung des Sportunterrichts in den Schulen. So lobte ein Journalist der pro-französischen Beiruter Zeitung L'Orient den Einsatz und Erfolg der Lehrer und Schüler der Schule der Frères des Écoles chrétiennes anlässlich ihres Sportfestes 1927:

Si la gymnastique, à laquelle on consacre en somme bien peu de temps au cours d'un semestre, a donné d'aussi heureux résultats, comment s'étonner des succès éclatants obtenus par le Collège du Sacré-Cœur dans toutes les branches de l'enseignement, auquel maîtres et élèves se donnent tout entiers ${ }^{137}$ !

Die Schule legte großen Wert auf die sportlichen Leistungen ihrer Schüler, und porträtierte und kommentierte die Gewinner unter ihren Schülern bei den verschiedenen Wettbewerben ausführlich ${ }^{138}$. Auch bei der Mission laïque betonte der arabische Nationalist Riad as-Sulh die Bedeutung des Sportes: er werde der Schule viele muslimische Schüler bringen können, wenn sich die Mission laïque unter anderem verpflichte, den Sportunterricht weiterzuentwickeln ${ }^{139}$. Der hier angedeutete Zusammenhang zwischen arabischem Nationalismus und Sport ist insofern interessant, als, wie Christoph Schuhmann herausgearbeitet hat, sich die arabischen Nationalisten mehr von der Form als vom Inhalt faschistischer (Jugend-) Organisationen inspirieren ließen ${ }^{140}$. Für diese Vereinigungen war Sport ein zentrales Element der Organisation und

135 AN/Paris, 60 AJ 131, »Réunion des professeurs«, 02.05.1929.

136 Vgl. AN/Paris, 60 AJ 126, Brief von Mathieu an Besnard, Beirut, 21.11.1923: »M. Rouanet a été mis à ma disposition par l'Armée Française du Levant«, um den Sportunterricht zu leiten.

137 Autor: M.N., Artikel in der Zeitung L'Orient, abgedruckt in FEC, L'Essor, Februar 1928, S. $36-37$.

138 Vgl. FEC, L'Essor, Februar 1929, S. 10: „Sami Daouk. Le champion!«

139 AN/Paris, 60 AJ 133, Brief von Ruche an Besnard, Beirut, 06.06.1931. Die anderen von asSulh gestellten Bedingungen lauteten, dass jeden Morgen die Internatsschüler von einem Arzt untersucht würden und dass die Schule die Preise herunterstufe.

140 Vgl. Christoph Schumann, Symbolische Aneignungen. Antun Sa'adas Radikalnationalismus in der Epoche des Faschismus, in: Gerhard Höpp / Peter Wien/René Wildangel (Hg.), Blind für die Geschichte? Arabische Begegnungen mit dem Nationalsozialismus, Berlin 2004, S. 155189. 
Einheit. Es ist also denkbar, dass die Nationalisten den Sportunterricht der französischen Schulen auch attraktiv fanden, weil er ihrem Ideal einer Organisation der Jugend für einen nationalen Zweck entsprach.

Neben dem Ideal einer ganzheitlichen Erziehung bestimmte ein dritter Grund das vermehrte Aufkommen außerunterrichtlicher Aktivitäten: die Entwicklung eines modernen städtischen, stark an Frankreich ausgerichteten, aber sich auch bewusst davon abgrenzenden Lebens im Libanon und insbesondere in Beirut. Diese Entwicklung fand in den Schulen ihren Widerhall beziehungsweise geschah im Austausch mit den Aktivitäten in den Erziehungseinrichtungen, wie sich an der Bedeutung der Musik zeigen lassen kann.

Ab 1930 erhielt die Musik in den französischen Schulen einen größeren Stellenwert. Die Schüler konnten Musikunterricht nehmen, Vorträge über Musik und Konzerte wurden organisiert. Die dargebotene Musik entstammte vor allem der klassischen europäischen Musik. So unterrichteten die fünf Musiklehrer des Collège du Sacré-Cœur 1929 - bis auf die Mandoline die Instrumente des klassischen europäischen Orchesters: Geige, Harmonie, Cello und Kontrabass sowie Klavier ${ }^{141}$. Im Nahen Osten waren diese Instrumente erst Anfang des 20. Jahrhunderts eingeführt worden ${ }^{142}$.

Trotz der Dominanz europäischer Musik fand aber auch die traditionelle arabische Musik ihren Platz in den Schulen: im Mai 1931 hielt Lehrer Chevrier zwei Vorträge über Mendelssohn und Schubert, sein Kollege Rebours hingegen gab »une leçon sur la musique arabe«. Beide Präsentationen wurden »illustrées par un concert de musique occidentale et orientale donné avec le concours des élèves et l'aide bénévole de la Maison Pathé « ${ }^{143} .1933$ gaben die Schüler der Mission laïque musikalische Darbietungen, die von Lamartines Reise in den Orient inspiriert wurden, darunter auch arabische Stü$\mathrm{cke}^{144}$. Diese Beispiele zeigen erneut deutlich, dass die Mission laïque française auch bezüglich der Musik stärker als die katholischen Schulen ihre Offenheit gegenüber der arabischen Kultur unter Beweis stellen wollte, dass die Ergebnisse aber nicht frei von orientalistischen Konnotationen waren. Darüber hinaus hatte der Musikunterricht gerade in den Mädchenschulen einen hohen Stellenwert für das soziale Ansehen der Schülerinnen. Reiche und einflussreiche Libanesen aller Konfessionen ließen ihre Töchter Musik-

141 Vgl. FEC, L'Essor, Februar 1929, S. 27.

142 Vgl. Ines Weinrich, Fayruz und die Brüder Rahbani. Musik, Moderne und Nation im Libanon, Würzburg 2006, S. 30.

143 AN/Paris, 60 AJ 133, Brief von Ruche an Besnard, Beirut, 28.05.1931.

144 Revue de l'enseignement français hors de France 30 (1933), H. 104, S. 173-174: »Lamartine au Lycée Français de Beyrouth«. 
instrumente lernen, weil dies zu den Fertigkeiten einer umfassend gebildeten Frau zählte ${ }^{145}$.

Den Darbietungen und Vorträgen zu klassischer europäischer Musik entsprach die Entwicklung des musikalischen Lebens in Beirut. Hinsichtlich Musizieren und Musikkonsum muss deutlich zwischen einer städtischen und einer ländlichen Tradition unterschieden werden ${ }^{146}$. In Beirut entwickelte sich um 1930 eine einerseits an Europa angelehnte, andererseits auf der Suche nach einer eigenen Tradition befindliche Musikszene. Dazu gehörte das Beiruter Musikkonservatorium, das schon 1910 ein erstes Mal von Wadīi Șabrā gegründet worden war, sich 1925 in die nationale Musikschule umwandelte und 1929 zum nationalen Konservatorium wurde ${ }^{147}$. Sabrā, der in Paris studiert hatte, richtete sein Programm stark an der klassischen europäischen Musik aus, aber auch die arabische Musik fand ihren, wenn auch marginalen, Platz ${ }^{148}$. Kurze Zeit später wurde außerdem die Akademie der schönen Künste in Beirut gegründet, von Alexis Boutrus, einem ehemaligen Schüler der Mission lä̈que ${ }^{149}$. Neben den Musikschulen florierte in Beirut die Darbietung von Konzerten vor allem europäischer Prägung. Diese wurden zum einen von der »colonie française«, die aus französischen Staatsangehörigen bestand, besucht. Der Einfluss dieser französischen Community auf das Stadtleben darf sicher nicht unter-, sollte aber auch nicht überschätzt werden. Denn gleichzeitig besuchte eine frankophone libanesische Elite aus allen religiösen Gemeinschaften diese gesellschaftlichen Ereignisse. Auch wenn die Beiruter Elite sich also unter die französischen Theater- und Konzertbesucher mischte, begeisterte sie sich ebenso für die arabische Musik; besonderen Erfolg hatte beispielsweise »la nouvelle chanson arabe $\aleph^{150}$. Mit ihren Angeboten konnte sich die Mission laïque dieses Interesse zunutze machen.

Parallel zu der rasanten Entwicklung eines städtischen Lebens im Libanon und insbesondere in Beirut wurde im Umfeld der christlichen französischen Schulen aber auch ein Diskurs über die moralischen Gefahren und die Dekadenz, die diese Mondänität und Modernität in sich barg, laut. Mit der schon erwähnten Zensur von Kinofilmen wollten die Jesuiten dazu beitragen, diese Gefahren einzudämmen. Ähnlich engagierte sich der protestantische fran-

145 Vgl. Interviews der Verfasserin mit Nada Soubra (Nāda Sūbra), Beirut, 28.11.2008 und mit Olfat Sharif, Beirut, 13.12.2008.

146 Vgl. WeINRICH 2008, S. 50.

147 Vgl. Ali Jihad Racy, Lebanon, in: Grove Dictionary for Music and Musicians. URL: http:// www.oxfordmusiconline.com (24.10.2010).

148 Vgl. MAE/Nantes, »Beyrouth Consulat Général B«, »Prospectus du Conservatoire national de musique de la République Libanaise, fondé en 1926«. Die Lehrer waren russischer, französischer und arabischer Herkunft, gleiches galt für die Musikstile, die unterrichtet wurden.

149 Vgl. AN/Paris, 60 AJ 136, »Procès Verbal de la Réunion des Anciens Élèves du Lycée du samedi 3 février 1934«. Bezüglich Boutrus vgl. WeINRICH 2006, S. 54.

150 KASSIR 2003, S. 383. 
zösische Pastor Jean Jousselin für eine Eindämmung der Jugendkriminalität und der Prostitution in Beirut. In seiner Statistik der verschiedenen Arten der Jugendkriminalität verglich er die Situation im Libanon in der Stadt und auf dem Land Anfang der 1930er Jahre mit der Situation in Paris 1921 ${ }^{151}$. Damit machte er unterschwellig klar, dass sich Kriminalität und moralische Dekadenz immer parallel zur Entwicklung einer Stadt als Metropole entwickeln. Auch Bianquis, der als Französischlehrer an der amerikanischen Universität arbeitete, riet einem Freund in Frankreich davon ab, seinen Sohn »à cause du climat et de l'atmosphère également déprimants $^{152}$ in die Levante zu schicken. In einer Abhandlung über die Prostitution im Libanon kritisierte Jousselin außerdem eindeutig die französische Mandatsmacht, die nichts dagegen unternehme, dass »les Territoires sous Mandat Français en question [...] sont dans une mesure limitée, des pays de destination et d'origine pour la traite des femmes.... $\ll^{153}$. Während der Pastor hier auf das gängige orientalistische Motiv der Unterdrückung der Frau im Orient rekurriert, hat er die jungen Frauen und Männer im Blick, wenn seine Schrift mit dem eindringlichen Appell endet: „Voulons-nous aider à ce que nos fillettes aient moins de risques d'être irrémédiablement perdues? Voulons-nous faire quelques chose pour nos fils et nos filles? « ${ }^{154} \mathrm{Um}$ diese Hilfe für die Söhne und Töchter in die Tat umzusetzen, pries Jousselin das von französischen Protestanten gegründete Foyer des Jeunes an, in dem die Jugendlichen in einem »guten und reinen Geist« ihre Freizeit verbringen könnten ${ }^{155}$.

Auch wenn Jousselin also nicht im Sinne einer orientalistischen Sichtweise die »orientalische Gesellschaft« oder deren Mentalität für die von ihm konstatierte Dekadenz verantwortlich machte, sah er die Lösung doch in importierten Modellen aus Europa, um die Jugendlichen wieder auf den srichtigen Weg` zu bringen und bediente sich somit erneut der Idee der Zivilisierungsmission.

\section{Die Ehemaligenarbeit der französischen Schulen}

Die rasante Entwicklung und gewachsene Bedeutung eines städtischen Lebens sowie die Auswirkungen der wirtschaftlichen Krise im Libanon zeigten sich auch in der Ehemaligenarbeit der französischen Schulen, die ab 1930

151 J. JoussELin, Enquête sur la jeunesse délinquante et la prostitution au Liban en 1932, Beyrouth 1933, S. 9.

152 PPFL, »Foyer des Jeunes Beyrouth 1933-1948«, Brief von Bianquis an Henri [Allens?], Beirut, 26.01.1933.

153 Jousselin 1933, S. 43.

154 Ebd., S. 48.

155 Ebd., S. 49. 
einen neuen Elan erhielt. Schon während des Osmanischen Reiches hatte es in vielen französischen und anderen Bildungseinrichtungen Alumnivereinigungen gegeben ${ }^{156}$, aber in den 1930er Jahren wurden diese stärker aufgewertet und institutionalisiert. Für alle Schulen waren diese Zusammenschlüsse von zentraler Bedeutung; gerade deshalb beschäftigte es die Mission laïque besonders, dass ihre Ehemaligenarbeit sehr viel schwerfälliger anlief als die der anderen französischen Schulen. In regelmäßigen Abständen beschwerten sich die Direktoren der laizistischen Schulen in ihren Berichten an die Zentrale in Paris über das fehlende Engagement ihrer Alumni ${ }^{157}$. Der Direktor der Mission laïque in Beirut, Mathieu, führte den mangelnden Einsatz unter anderem auf die Gewohnheit der Ehemaligen aller französischen Schulen zurück, nach der großen Sommerpause erst sehr langsam wieder aktiv zu werden ${ }^{158}$. Da die anderen Schulen aber nicht mit dem geringen Engagement ihrer Ehemaligen kämpften, greift Mathieus Generalisierung zu kurz. In der Tat unterstützten die Alumni der katholischen und jüdischen Schulen deren Arbeit sehr viel stärker, auch wenn die Vereinigungen in allen Schulen primär von der Schulleitung initiiert wurden.

Dieser Umstand erklärt sich zum einen durch die Tatsache, dass die anderen, vornehmlich katholischen französischen Schulen für ihre Ehemaligen attraktiver waren, weil diese sich dadurch Vorteile für ihre Integration in die privilegierten gesellschaftliche Kreise unter dem Mandat, zu welchen die katholischen Schulen bevorzugten Zugang hatten, erhofften. Darüber hinaus schien die ganzheitliche Einbindung in ein Netzwerk, das neben materiellen Vorteilen auch emotionale, soziale und religiöse Integration bot, ausschlaggebend für den Erfolg zu sein.

Da die katholischen und jüdischen Schulen mit ihren Schülern mehr Lebensbereiche teilten als die Mission laïque, verlief ihre Ehemaligenarbeit, so die These, letztlich erfolgreicher als die der laizistischen Schule. Um mit der Kapitaltheorie von Bourdieu zu sprechen, welcher die Mechanismen der Marktwirtschaft nicht nur in der Ökonomie selbst, sondern auch in den kulturellen, sozialen und religiösen Beziehungen festgemacht hat ${ }^{159}$, war also

156 Vgl. die Gründung der Association catholique de la jeunesse de Beyrouth 1910 durch ehemalige Schüler der Lazaristenschule in Ayntoura. LAZ/Paris, »Beyrouth Coprrespondance 1896-1918«, Brief von Bahri und Romon, Beirut, 29.03.1910.

157 So enthielten viele Spalten der »Rapports mensuels«, die der »Amicale des Anciens« gewidmet war, in den Jahren 1922-1923 oder 1928-1929 den Vermerk »Rien à signaler«. Vgl. AN/ Paris, 60 AJ. Einzig 1925 und 1934 verzeichnete die Vereinigung vermehrte Aktivitäten. Vgl. AN/Paris, 60 AJ 128, »Rapports mensuels«, Oktober 1925; 60 AJ 136, »1933-1934«.

158 Vgl. AN/Paris, 60 AJ 126, Brief von Mathieu an Besnard, Beirut, 05.11.1924: »Les anciens élèves, suivant une habitude déplorable, dont souffrent tous les établissements scolaires, se sont attardés et ont opéré leur rentrée au fur et à mesure de leur retour des différents lieux d'estivage, dans le courant du mois d'octobre tout entier«.

159 Pierre Bourdieu hat diese Theorie in seinem Werk La Distinction (Paris 1979) (Deutsch Die feinen Unterschiede, Frankfurt am Main 1982) anhand der Fragen von kulturellen Praktiken 
der Grad der Häufung von materiellem, sozialem und symbolischem Kapital durch Schulen und ihre Alumni auschlaggebend für den Erfolg ihrer Netzwerkarbeit. Diese These soll im Folgenden an den materiellen, sozialen, emotionalen, religiösen und kulturellen Aspekten der Ehemaligenarbeit in den französischen Schulen überprüft werden.

Ein zentrales Motiv der Ehemaligenvereinigungen bildete die gegenseitige Hilfe der Ehemaligen bei der materiellen und damit sozialen Integration in die Gesellschaft. Dazu gehörten sowohl die Hilfe bei der Suche nach einer lukrativen Arbeit als auch die Weitergabe von hilfreichen Informationen und die Vermittlung von Kontaktpersonen. Die materielle Dimension der Ehemaligenvereinigung wird anhand der Definition deutlich, die der Direktor der katholischen Lazaristenschule in Ayntoura, Sarloutte, der Vereinigung mitgab, die 1938 auf seine Initiative gegründet worden war: diese sei »un échange de relations pratiques, utilitaires, où seraient signalés les offres et demandes d'emplois, les renseignements de tous genres qui peuvent rendre service dans l'ordre matériel ${ }^{160}$.

Auch die Ehemaligenarbeit der Mission laïque prägte dieses Motiv, denn Direktor Ruche berichtete mehrfach stolz von den lukrativen Anstellungen, die er ehemaligen Schülern verschafft hatte, so im Januar 1925 mit dem Eintrag: »Amicale des Anciens élèves. J'ai fait placer deux anciens élèves dont l'un à la compagnie SHELL « ${ }^{161}$. Die gegenseitige materielle Hilfe entsprach auch einem wichtigen Motiv der Ehemaligen für ihr Engagement. So versuchten die Alumni der Mission lä̈que, den Vorteil des "Secours mutuel « zu nutzen, als sie sich 1934 verstärkt in die Vereinigung einbrachten ${ }^{162}$. Laut Direktor Ruche lag der Grund für diese plötzliche Aktivität seiner ehemaligen Schüler in der drastischen Arbeitslosigkeit, was die materielle Bedeutung der Alumnivereinigung noch einmal belegt ${ }^{163}$.

Allerdings kamen die Erfolge der Mission lä̈que in der Vermittlung lukrativer Arbeitsstellen in Anzahl und Ansehen nicht an die Ergebnisse der katholischen Schulen heran. 1920 beispielsweise war der Politiker und spätere Präsident Bishara al-Khuri, ein ehemaliger Jesuitenschüler, durch Empfehlung des Jesuitenpaters Cattin von Hochkommissar Gouraud zum Generalsekretär der Regierung des Ğabal Lubnān ernannt worden ${ }^{164}$. Auch die Schule der Frères des Écoles chrétiennes konnte mit ihren Erfolgen werben

(Kunst, Essen u.a.) in den unterschiedlichen Milieus in Frankreich entwickelt. Zur kritischen Diskussion dieser Theorie siehe Martin Herz, Disposition und Kapital. Ein Beitrag zur Bourdieu-Debatte, Wien 1996, S. 192-196.

160 LAZ/Paris, Association amicale des anciens élèves d'Antoura. Bulletin annuel, 1938, S. 1.

161 AN/Paris, 60 AJ 132, »Rapports mensuels«, Januar 1925.

162 Revue de l'enseignement français hors de France 31 (1934), H. 110, S. 232-248.

163 Vgl. AN/Paris, 60 AJ 136, Brief von Ruche an Besnard, Beirut, 08.02.1934.

164 Vgl. Salibi 1965, S. 171. 
und präsentierte in der Schulzeitschrift regelmäßig eine Page des Anciens, auf der sie die Studienplätze und -fächer sowie die Anstellungen ehemaliger Schüler in Wirtschaft, Politik und Administration präsentierte ${ }^{165}$.

Die in sie gesetzten Hoffnungen konnten die katholischen Schulen damit in vielen Fällen erfüllen ${ }^{166}$. Die Erwartung einer Vermittlung hochdotierter Stellen formulierten auch die Eltern der Mission laïque. So äußerte ein muslimischer Vater 1935 gegenüber der Mission laïque den Wunsch, dass die Schule zum privilegierten Rekrutierungspool für Regierungsposten würde: »Obtenir du gouvernement libanais une subvention, et du H.C.F. [Haut-Commissariat français] qu'il considère le Lycée comme le seul établissement officiel et réserve des fonctions gouvernementales à ses anciens élèves « ${ }^{167}$.

Im Sinne dieser Lesart ist auch zu vermuten, dass die geringeren Erfolgschancen der laizistischen gegenüber den katholischen Schulen 'Umar Da'uq, bis dato enger Partner der Mission lä̈que, dazu brachten, 1938 Präsident der Ehemaligenvereinigung der Lazaristenschule in Ayntoura zu werden ${ }^{168}$. Gleichzeitig steht das Vorgehen Da'uqs stellvertretend für eine häufige Praxis vieler Libanesen der Mittel- und Oberschicht, in verschiedenen Schulen Engagement zu zeigen. Die Leiterin des Collège protestant français, Louise Wegmann, sprach von einem regelrechten »nomadisme« vieler Schüler zwischen verschiedenen Einrichtungen ${ }^{169}$.

Es ging also in allen Schulen eindeutig um die Schaffung und Wahrung einer exklusiven und damit elitären Gruppe, in der materielle und soziale Distinktion eng miteinander verknüpft waren. Die Zeitschrift der ehemaligen Schüler der Lazaristen in Ayntoura drückte dieses Ziel folgendermaßen aus:

Créer une association amicale, c'est continuer la vie du Collège, unir dans un lien moral les membres d'un même établissement, permettre aux plus jeunes de connaître les Anciens, fournir à ceux qui sont avantagés le moyen de venir en aide à ceux qui attendent, qui désirent un emploi, une place au soleil ${ }^{170}$.

165 Vgl. FEC, L'Essor, Februar 1927, S. 20-21: »Le succès des anciens élèves«. Vgl. auch Abb. 4.

$166 \mathrm{Zu}$ den konkreten Karrieren ehemaliger Schüler vgl. Kapitel 7.4.

167 AN/Paris, Brief von Ruche an Besnard, Beirut, 22.021935.

168 LAZ/Paris, Association amicale des anciens élèves d'Antoura. Bulletin annuel 3 (Mai 1940), S. 50.

169 Vgl. Louise Wegmann, Les écoles au Liban, in: Le Monde non-chrétien 3 (1947), S. 287-299, S. 295.

170 LAZ/Paris, Association amicale des anciens élèves d'Antoura. Bulletin annuel 3 (Mai 1938), S. 1. 


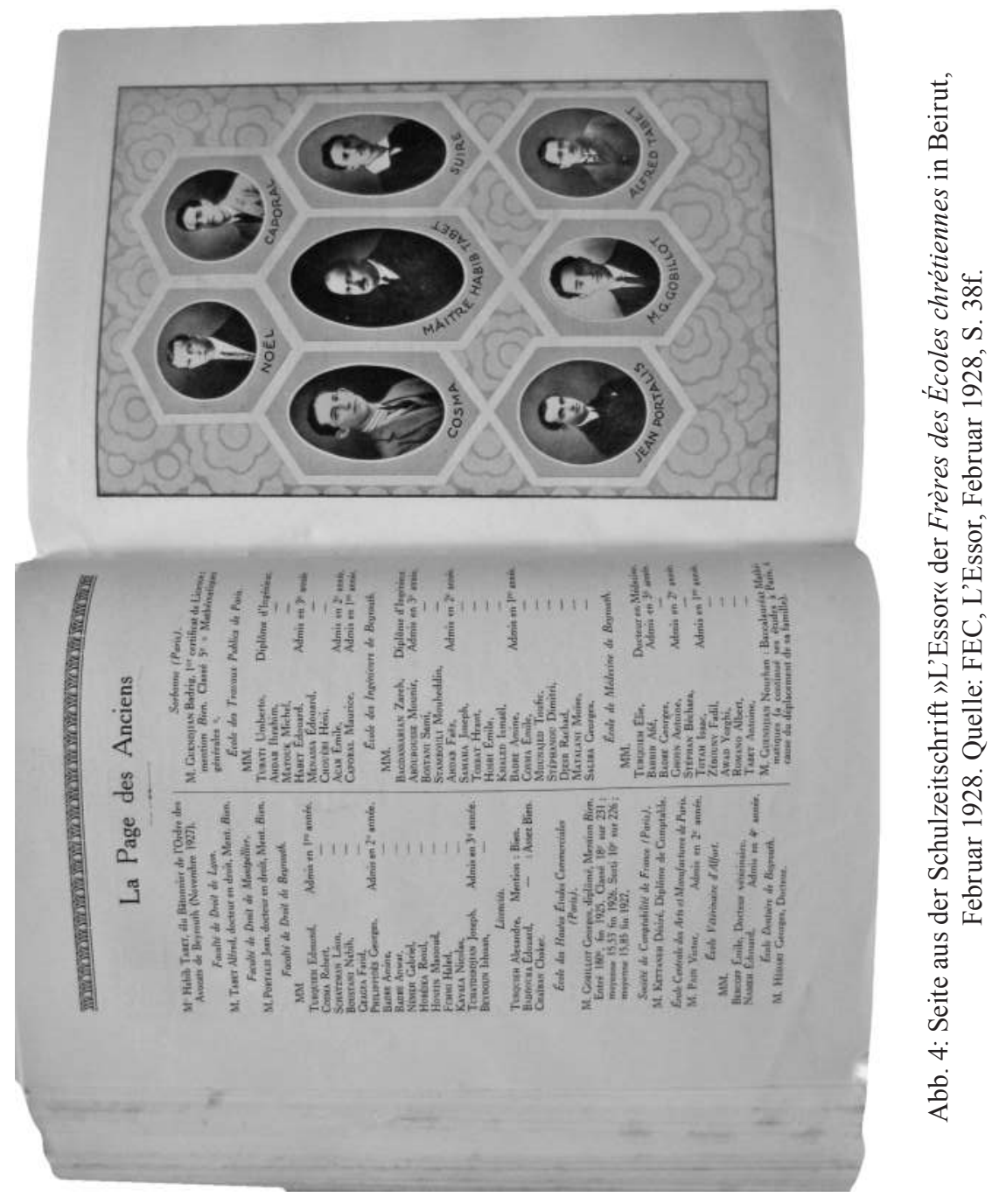


Das Bild vom »Platz an der Sonne«, den die »Anciens«, die arrivierten Ehemaligen, den Wartenden, »ceux qui attendent«, schaffen sollten, bedeutete eindeutig eine Hilfe innerhalb derselben sozialen, kulturellen oder religiösen Gruppe und bezog sich nicht auf die Unterstützung sozial benachteiligter Schüler durch wohlhabende Ehemalige.

Um den exklusiven Charakter seiner Alumnivereinigung beizubehalten, lehnte der Direktor der Mission lä̈que in Beirut, hierin einig mit dem Präsidenten der Ehemaligen, auch den Vorschlag eines Mitgliedes ab, die Vereinigung auch für Mitglieder zu öffnen, die nicht Schüler der Schule waren: »M. le Proviseur et M. le Président [...] démontrent«, so heißt es in dem Protokoll, »la contradiction qu'il y aurait à accepter dans le cercle [...] des jeunes gens ayant fait leurs études dans d'autres établissements $\aleph^{171}$.

Auch die Schulen profitierten selbst stark von den Ehemaligenvereinigungen, denn ein solches Forum ermöglichte ihnen den direkten und informellen Zugang zu den einflussreichen Kreisen in Politik, Verwaltung und Wirtschaft. Gerade in politischen Umbruchzeiten waren diese Verbindungen von großer Bedeutung. Aus diesem Grund hob der Direktor der Jesuitenschule in Beirut, Cattin, zu Beginn des Mandats in einem Brief an den Hochkommissar die zentrale Bedeutung der ehemaligen Schüler hervor, die er noch stärken wolle:

Les Anciens sont très nombreux à Beyrouth, $\mathrm{y}$ composent la société dirigeante et influente, et, par conséquent, y constituent une force morale importante. [...] pour la presque totalité, animés des meilleurs sentiments de sympathie pour la France et pour le général Gouraud. [...] mon projet [...] de rapprocher de plus en plus ces deux éléments français et indigènes ${ }^{172}$.

In diesem Sinne freute sich sein Nachfolger Chanteur 1926, dass die neue libanesische Regierung vier ehemalige Schüler enthalte: »Le premier ministère de la République Libanaise a été assez heureusement constitué: quatre anciens élèves ${ }^{173}$. Außerdem profitierten die Lehranstalten von den Spenden, die zahlungskräftige Ehemalige ihrer Schule zukommen ließen. Die Archive der Schulen bezeugen immer wieder Spendeneingänge allgemeiner Art oder für bestimmte Zwecke ${ }^{174}$. Schließlich bedeutete die Aktivität einflussreicher

171 AN/Paris, 60 AJ 136, »Procès-Verbal de la Réunion des Anciens élèves du Lycée du samedi 3 février 1934 «.

172 SJ/Beirut, 11. D. 15, »Distribution des Prix 1920«, Brief von Cattin an Gouraud, 23.06.1920.

$173 \mathrm{SJ} /$ Vanves, »Fonds Jalabert«, 25 B, Brief von Chanteur an Jalabert, Beirut, 03.06.1926.

174 Beispielsweise betonte die Zeitschrift der Ehemaligenvereinigung der Lazaristen in Ayntoura, dass sie nur mit Hilfe der großzügigen Spende von »un entre vous« hatte gedruckt werden können. Vgl. LAZ/Paris, Association amicale des anciens élèves d'Antoura. Bulletin annuel 3 (Mai 1938), S. 1. Die einmaligen Spenden ergänzten die regelmäßigen Mitgiederbeiträge, die z.B. an der Schule der Lazaristen 40 Francs im Jahr betrugen. 
Persönlichkeiten in der Alumnivereinigung ein gewichtiges Renommee für die Schulen, mit welchem sie weitere Schüler werben konnten.

Auch wenn alle französischen Schulen die Ausbildung einer Elite anstrebten und propagierten, fiel ihr Verständnis dieses Begriffes durchaus unterschiedlich aus. So ging es den Schulen der Alliance israélite weniger um eine materielle als geistige Elite, die die Gesellschaft von innen heraus modernisieren sollte. Diese Vorstellung entsprach auch der tatsächlichen sozialen Situation der meisten ihrer Schüler, die nicht aus wohlhabenden Familien kamen. Die zentrale Bedeutung der Ehemaligen formulierte der Allianceinterne Inspektor Sémach 1931 folgendermaßen:

Il y a ainsi [...] des membres de notre personnel qui, ayant quitté l'enseignement, restent fidèles à leur ancien idéal, soutien de l'œuvre de l'Alliance, propagateur de ses idées. Autour d'eux viennent se ranger les anciens élèves des écoles qu'ils conseillent, qu'ils inspirent, qu'ils guident dans leur effort d'évolution. À Beyrouth, une jeunesse consciente de sa mission, vit et agit ${ }^{175}$.

Bei der Mission laïque wurde noch ein weiterer Aspekt der Elite betont, denn viele Lehrer brachten aus Frankreich und aus ihrer eigenen Erfahrung die republikanische Vorstellung einer Elite mit, die sich durch Leistung und nicht durch Besitz auszeichnete. Allerdings widersprach diese Idee der Ansicht der meisten Eltern ihrer Schüler, denen an einer sozio-ökonomisch gut gestellten Klientel gelegen war und die dieses auch zeigen wollten ${ }^{176}$. So kann der von der Mission lä̈que gefundene Kompromiss als konkretes Beispiel der von Elizabeth Thompson konstatierten kolonialen zivilen Ordnung im MandatsLibanon der 1930er Jahre gelten, welche sie als Mittelweg zwischen den französischen Ideen von der Souveränität des Volkes und der Brüderlichkeit und libanesischen paternalistischen Privilegien beschreibt ${ }^{177}$.

Über den materiellen Nutzen hinaus sollten die Ehemaligen aber auch durch emotionale, kulturelle und soziale Beziehungen miteinander verbunden werden. Diese Dimension machte aus den Ehemaligenvereinigungen

175 AIU/Paris, Paix et Droit 4 (April 1931), S. 7-11: »A travers les Communautés Israélites d'Orient. Visite des Écoles de l'Alliance Israélite«, S. 8.

176 Zudem zwangen finanzielle Überlegungen zu einer Aufnahme wohlhabender Schüler. Vgl. AN/Paris, 60 AJ 129, »Budget récapitulatif 1926-1927«:»Faute d'instructions écrites précises sur la politique scolaire à suivre le Directeur s'est efforcé de se conformer à l'esprit de propagande de la M.L.F., de chercher à étendre notre action sur un plus grand nombre d'élèves, d'assurer sur de plus larges bases ce recrutement de l'élite auquel veut se consacrer en France l'École Unique. N'est-ce pas dans cet esprit que sont données les instructions de la M.L.F. Devons-nous au contraire restreindre notre action aux élèves riches et écarter de nos établissements des enfants souvent travailleurs et intelligents parce qu'ils sont pauvres ??? [sic] Le Directeur a cherché en vain dans les archives du Lycée des Directives écrites sur ce sujet«.

177 Vgl. Thompson 2000, S. 16. 
nicht nur ein Kontaktnetzwerk, sondern einen Ort der Zugehörigkeit und der Geselligkeit. Das französische Wort »sociabilité« kennzeichnet am besten diese Form der sozialen und emotionalen Verbundenheit, die verschiedene Ausprägungen der Institutionalisierung erfahren kann und im Unterschied zum Netzwerk an einen bestimmten Ort gebunden ist ${ }^{178}$. Die Ehemaligenvereinigungen der Schulen verfügten über spezifische Räume, in denen sie sich versammeln konnten ${ }^{179}$. Für den Direktor der Mission laïque war die Tatsache, dass seine Ehemaligen 1933 im Gegensatz zu den katholischen und protestantischen Einrichtungen immer noch keinen eigenen Raum zur Verfügung hatten, ein Grund, warum seine Schule weit weniger attraktiv war:

Il faut faire un effort pour retenir nos anciens élèves et les empêcher d'aller grossir les rangs de la jeunesse catholique ou protestante. Mais l'un ou l'autre de ces deux groupements peut mettre à la disposition des jeunes un cercle très bien installé (même avec cinéma parlant) et dirigé par un professeur spécialement affecté à cette tâche. Pouvonsnous faire les frais de l'installation d'un cercle au Lycée ${ }^{180}$ ?

In der Tat formulierten auch die Ehemaligen der Mission lä̈que selbst, als sie 1934 aktiv wurden, den Wunsch nach einem Ort der Geselligkeit innerhalb ihrer Schule. Sie hofften »d'avoir au lycée un lieu de réunion, une sorte de cercle où ils puissent venir les instants de la journée qui ne sont pas consacrés au travail ${ }^{181}$. Als sich die Alumnivereinigung der Mission lä̈que dann im März 1934 neu formierte, betonte ihr erster Präsident Khalil Taqi ad-Din noch einmal, sie sei »avant tout une Amicale « ${ }^{182}$. Interessanterweise gehörten der Ehemaligenvereinigung der Mission laïque auch Frauen an ${ }^{183}$, während die Gruppen in den katholischen Schulen nach Geschlechtern getrennt waren. Es ist zu vermuten, dass dieser Umstand in einer Gesellschaft, in

178 Als erster französischer Historiker hat Maurice Agulhon das Phänomen der »sociabilité« an der Bedeutung von Vereinigungen in Südfrankreich im 18. Jahrhundert untersucht, vgl. Maurice Agulhon, La sociabilité méridionale: confréries et associations dans la vie collective en Provence Orientale à la fin du $18^{\text {ème }}$ siècle, Aix-en-Provence 1966. Im Anschluss hat Jean-François Sirinell, die französischen Kreise der »sociabilité« in der Moderne analysiert und diese definiert als »un groupement permanent ou temporaire, quel que soit son degré d'institutionalisation, auquel on choisit de participer«. Jean-François SIRINELLI, Effets d'âges et phénomènes de génération dans le milieu intellectuel français, in: Cahiers de l'Institut d'Histoire du Temps Présent 6 (1987), S. 5-48, S. 7.

179 So wünschte die Ehemaligenvereinigung der Mission laïque, die bis dahin im Lehrerzimmer getagt hatte, 1922 einen eigenen Raum. Vgl. AN/Paris, 60 AJ 125, »Rapports mensuels«, Oktober 1922.

180 Vgl. AN/Paris, 60 AJ 136, »Rapport mensuel du 20 mai au 20 juin 1933«, »Amicale des Anciens élèves «.

181 AN/Paris, 60 AJ 136, Brief von Ruche an Besnard, Beirut, 08.02.1934.

182 Ebd., »Compte rendu de la séance des anciens élèves du Lycée du 24 mars 1934«.

183 Vgl. ebd., »1933-1934«. Das Protokoll der eingegangenen Mitgliedsbeiträge enthielt einige Frauennamen. 
der die Geschlechter in vielerlei Hinsicht noch getrennte Bereiche hatten, der Mission laïque zusätzliche Schwierigkeiten bereitete, gleichzeitig aber auch in bestimmten Kreisen zusätzliches kulturelles respektive symbolisches Kapital einbrachte.

Diese Form der Geselligkeit sollte eine starke soziale und emotionale Bindung der Ehemaligen untereinander und mit der Schule garantieren. In diesem Sinne sah der erste Direktor der Mission lä̈que, Deschamps, in der Ehemaligenarbeit das Ziel, »à faire de certains nos amis ${ }^{184}$. Um eine enge Verbundenheit herzustellen, sollten beispielsweise innerhalb der Ehemaligenvereinigung der Lazaristen in Ayntoura Hochzeiten und andere wichtige Ereignisse bekannt gegeben werden ${ }^{185}$. Auch Direktor Ruche von der Mission läque berichtete 1928 von »des naissances, des mariages« und bat die Ehemaligen, alle interessanten Neuigkeiten mitzuteilen ${ }^{186}$.

Die Schaffung dieses Informationsnetzwerkes durch die Schulen beschränkte sich aber nicht nur auf das Gebiet des Libanons, sondern sollte weltweit alle Ehemaligen umfassen ${ }^{187}$. Dabei erwies sich allerdings ein breites Netzwerk mit Ehemaligen, welche emigriert waren, durchaus als zwiespältig. Das betraf am stärksten die Alliance israélite: Einerseits konnten sich die Ehemaligen in der Emigration gegenseitig helfen:

Dans les républiques sud-américaines, on rencontre par centaines les anciens élèves des écoles du Maroc, et plus récemment des élèves des écoles de Syrie; [...] l'Egypte offre des débouchés nombreux et c'est également par centaines qu'y émigrent les élèves de Syrie, de Palestine et même de la Turquie d'Europe ${ }^{188}$.

Wie das Beispiel ausgewanderter libanesischer Schiiten in Westafrika zeigt, konnten die Ehemaligen aber auch eine starke finanzielle Stütze für die Schulen $\operatorname{sein}^{189}$. Andererseits erschwerte der Weggang vieler ehemaliger Schüler

184 AN/Paris, 60 AJ 122, Brief von Deschamps an den Präsidenten der Mission laïque, Beirut, 10.03.1920.

185 Vgl. LAZ/Paris, Association amicale des anciens élèves d'Antoura. Bulletin annuel 3 (Mai 1938), S. 1.

186 AN/Paris, 60 AJ 130, »Amicale des anciens élèves«, Mai 1928. In den Ehemaligenverzeichnissen der von den Jesuiten gegründeten Schule Notre Dame de Jamhour stehen bis heute die Daten der Eheschließungen der ehemaligen Schüler mit dem Datum ihres Abschlusses.

187 Die Jesuiten gründeten sogar eine Vereinigung, die alle Ehemaligen ihrer Schulen im Libanon und in Ägypten umfasste. Vgl. SJ/Vanves, RPO 99, »Anciens élèves Beyrouth Le Caire Alexandrie«; Mouawad 2005, S. 200. In ähnlicher Manier trafen sich die Ehemaligen der Schulen der Frères des Écoles chrétiennes in Beirut, Alexandria und Kairo im Schuljahr 1926-1927 in Paris. Vgl. FEC, Palmarès, 1926-1927, S. 3.

188 AIU/Paris, Bulletin de l'Alliance israélite universelle, 67/1905, S. 105-120, »Écoles primaires $«$, S. 6.

189 Vgl. Tamara Chalabi, The Shi' is of Jabal 'Amil and the New Lebanon. Community and Nation State 1918-1943, New York 2006, S. 150. 
auch die Organisation der konkreten Aktivitäten, wie Direktor Penso von der Alliance israélite in Beirut schmerzlich feststellen musste ${ }^{190}$.

Verbunden mit der emotionalen Anbindung spielte die religiöse Identität der Schulen und ihrer Absolventen eine Rolle in der Ehemaligenarbeit. Wenn beide Seiten in diesem Bereich übereinstimmten, so die These, verstärkte dies das Gefühl der Zusammengehörigkeit. Ein guter Teil der außerunterrichtlichen Aktivitäten, in die die Ehemaligen eingebunden wurden, betraf auch religiöse Aspekte. Hier waren die katholischen und auch die jüdischen Schulen, zum Teil auch das Collège protestant français, klar im Vorteil gegenüber der Mission lä̈que. Wie in den vorherigen Kapiteln deutlich wurde, verband die konfessionell geprägten Schulen mit ihrer Klientel oft die gemeinsame Religionszugehörigkeit. Davon ausgehend kam es auch zur Gründung spezifisch religiöser Vereinigungen, wie des in den 1920er von den Jesuiten gegründeten Cercle de la jeunesse catholique. Das Ziel dieser nach dem Vorbild der Association Catholique de la Jeunesse Française konzipierten Vereinigung war ein »œuvre de rayonnement moral intense « ${ }^{191}$.

Auch innerhalb der Mädchenschulen gab es diese Vereinigungen. Beispielsweise waren die ehemaligen Schülerinnen der Søurs de Saint-Joseph de l'Apparition in Beirut in einer »Congrégation Mariale « zusammengefasst. Ihrem Tagebuch ist zu entnehmen, dass sie sich regelmäßig trafen, um die Messe und andere religiöse Feste gemeinsam zu feiern, aber auch, um karitativ tätig zu werden ${ }^{192}$. Die im Archiv der Schule erhaltenen Protokolle der Treffen ermöglichen einen seltenen Einblick in die konkreten Aktivitäten der Frauen, verraten durch ihren formalen Charakter aber wenig über die persönliche Wahrnehmung der Gruppe durch die einzelnen Teilnehmerinnen, die sich größtenteils aus den ehemaligen Schülerinnen der wohlhabenden Familien rekrutierten ${ }^{193}$.

Ebenso entwickelten die Schulen der Filles de la Charité Modelle und waren in der Lage, ihre ehemalige Schülerschaft an sich zu binden, indem sie für ihre »Waisen und ehemaligen Waisen und ehemaligen Schüler und Schülerinnen « (»orphelins et orphelines, anciens orphelins et anciennes orphelines, anciens élèves et anciennes élèves des classes « $)^{194}$ Katechismusstunden abhielten. Die Tatsache, dass einige ehemalige Schüler und Schülerinnen der katholischen Schulen selber Nonnen, Mönche oder Priester wurden, verstärkte das Band der religiösen Zugehörigkeit und Verbundenheit.

190 Vgl. AIU/Paris, »Liban VIIE 81-81«, Brief von Penso an den Präsidenten der Alliance israélite, Beirut, 20.12.1939.

191 SJ/Vanves, RPO, 82, Bulletin du Cercle de la jeunesse catholique, 1928-1929, S. 11.

192 Vgl. SJA, »Congrégation Mariale 1942-1947«.

193 Die politische Ebene tritt einmal in Erscheinung, als im Eintrag von November 1943 zu lesen ist, »à cause des évènements « habe das Treffen verschoben werden müssen.

194 Vgl. LAZ//Paris, »Beyrouth Correspondance 1896-1918«, Brief von Dinet, Beirut, 13.06.1908. 
Die Mission laïque hingegen konnte zum einen kein religiös starkes Modell bieten, da sie sich explizit aus diesem Bereich heraushielt. Zum anderen waren ihre ehemaligen Schüler sehr viel stärker religiös durchmischt und feierten deshalb auch nicht gemeinsam religiöse Feste, sondern begingen sie getrennt voneinander. Beispielsweise waren in der Ehemaligenvereinigung der Mission lä̈que neben den sunnitischen auch die schiitischen Schüler, die insgesamt nur eine Minderheit bildeten, vertreten. So war unter ihnen Hassan Osseiran (arabisch Hasan 'Usayrān), der wahrscheinlich zu der frankophilen schiitischen Familie Munīr 'Usayrāns gehörte' ${ }^{195}$. Der Laizismus als gemeinsame Idee über die verschiedenen Religionen hinweg konnte die Mehrheit der Ehemaligen nicht motivieren.

Eine Ausnahme bildete Khalil Taqi ad-Din, der ihre Erfahrung "sur les bancs du Lycée entre jeunes gens de confession et de nationalité diverses « ${ }^{196}$ nicht als Nachteil, sondern gerade als Reichtum sah. Um diese Ideen noch über die Ehemaligen hinaus innerhalb der libanesischen und syrischen Bevölkerung zu verbreiten, regte er die Gründung einer laizistischen Zeitschrift $\mathrm{an}^{197}$. Weil die Archive auf seinen Brief, der auch einen Kostenvoranschlag enthielt, keine Antwort enthalten, ist zu vermuten, dass der Druse weder bei der Mission lä̈que noch bei den anderen Ehemaligen genug Unterstützung für seine Idee fand, und sie nie in die Tat umgesetzt wurde. Da Khalil Taqi ad-Din und Taqi ad-Din as-Sulh sich, wie Asher Kaufman gezeigt hat, bei einem Zirkel libanesischer Schriftsteller trafen ${ }^{198}$, wird aber auch deutlich, dass es viele Beziehungen zwischen den Ehemaligen außerhalb ihrer Schule gab und dass man den Bezugspunkt der Alumnivereine nicht als exklusive soziale Anbindung überbewerten darf.

Während die Mission laïque bezüglich der religiösen Aspekte keine so starke Verbindung mit ihren Schülern aufbauen konnte wie die anderen Schulen, glichen sich aber alle Schulen in der Motivation, ihre Erziehungsarbeit auch über die Schulzeit hinaus weiterzuführen und damit in der kulturellen Dimension der Ehemaligenarbeit. Die Lehranstalten waren überzeugt, ihre »Erziehungsmission« sei noch nicht abgeschlossen und bedürfe einer weiteren Begleitung der Ehemaligen. Hier trägt auch wieder die Idee der ganz-

195 Vgl. AN/Paris, 60 AJ 136, »Procès-Verbal de la Réunion des Anciens Élèves du Lycée du samedi 3 février 1934«. Bezüglich der Osseirans vgl. Chalabi 2006, S. 142. Bezüglich der Situation der Schiiten im Libanon in der Mandatszeit allgemein vgl. FirRo 2003, S. 159-175. Die Schiiten sind in dieser Arbeit bis jetzt nicht untersucht worden, weil sie nur wenige Schüler stellten, aber eine Analyse dieser Schüler und ihrer Eltern könnte interessante Einblicke geben in die aktuelle Forschung über die Integration dieser Gemeinschaft in den Libanon.

196 AN/Paris, 60 AJ 136, 1933-1934, »Compte-rendu de la séance des anciens élèves du Lycée du 21 mars $1934 \ll$.

197 Vgl. Kapitel 5.1.

198 Vgl. Kaufman 2004a, S. 186. Dieser Zirkel ging interessanterweise auf die Initiative Charles Corms zurück, dessen Meinung die zwei Muslime nicht teilten, den sie aber schätzten. 
heitlichen Erziehung ihre Früchte. Besonders auffällig ist dabei der paternalistische Blick, den die französischen Schulen weiterhin auf ihre ehemaligen Schüler hatten: Ziel der Vereinigungen selber, aber auch der Vorträge und anderer sozio-kultureller Veranstaltungen war »parfaire l'éducation de nos anciens élèves«, wie Deschamps 1920 betonte. Er wollte ihnen sogar das Verständnis von Gemeinschaftssinn vermitteln, das ihnen fehle: »On est très individualiste dans ce pays; tout article qui aura pour effet de développer ou de faire naître chez les Syriens le sens social sera le bienvenu parce que d'une grande utilité « ${ }^{199}$. Auch die katholischen Schulen hatten, wie hinsichtlich des Katechismus schon anklang, dieses Verständnis von der Erziehung über die Schulzeit hinaus. Gerade was ihre emotionale Zugehörigkeit anbelangte, war es notwendig, dass die Schulen das Vertrauen ihrer Ehemaligen hatten. Die katholischen Schulen waren hier erfolgreicher, weil sie oft schon seit Generationen Kinder derselben Familien unterrichteten ${ }^{200}$.

In gradueller Abstufung wurde eine starke französische Prägung der Alumni als positiv wahrgenommen. Sowohl viele der Schulen selbst als auch französische Besucher rühmten sich und ihre Schüler, wenn sie diese Prägung realisiert sahen. So betonte der Direktor der Alliance israélite, seine ehemaligen Schüler rezipierten die französische Presse ${ }^{201}$. Etwas zögerlicher reagierte die Mission laïque. Vielmehr betonte die Direktion der laizistischen Schule in Beirut, ihr Ziel sei keineswegs aus den Schülern »des Français de seconde zone« zu machen ${ }^{202}$. Ähnlich hieß es in einem Dokument der Jesuiten Ende der 1930er Jahre bezüglich der Erziehung junger Drusen: »Maintenir intact le lien de tradition et la fidélite au sol [...] donner à son attachement au pays un caractère plus conscient $[\ldots] \ll^{203}$ Trotzdem hofften natürlich alle Schulen, dass ihre Schüler mit der französischen Kultur vertraut gemacht würden und blieben, um als verlässliche kulturelle und auch wirtschaftliche Partner Frankreichs aufzutreten ${ }^{204}$.

199 AN/Paris, 60 AJ 122, Brief von Deschamps an den Präsidenten der Mission laïque, Beirut, 10.03.1920.

200 Vgl. Interview der Verfasserin mit Camille Hechaïmé, Beirut, 24.10.2008.

201 Vgl. AIU/Paris, »Liban IXE 96b«, Abschrift der Rede Sidis beim Schulfest 1925: »Nos anciens élèves non seulement parlent et écrivent couramment le français ou s'en servent dans leurs relations d'affaires mais la plupart l'ont adopté comme langue de famille [...], enfin tous lisent avidement les publications de la libraire française. Il est rare qu'il s'en trouve qui ne soit pas abonné à un journal français«.

202 Vgl. AN/Paris, 60 AJ 136, »Compte-rendu du Comité de Patronage«, Sitzung vom 29.03.1934.

203 SJ/Beirut, 8.C.21, »Le mandat français en Syrie et au Liban dans le domaine de l'éducation. Le Djebel Druse« (ca. 1939).

204 Vgl. AN/Paris, 60 AJ 136, »Compte-rendu du Comité de Patronage«, Sitzung vom 29.03.1934. 


\section{Die Verlagerung der Zivilisierungsmission: \\ Verstärkte Kooperationen mit lokalen arabischsprachigen Schulen}

Die angespannte wirtschaftliche Lage im Libanon, die Mittelkürzungen für die lokalen Schulen, aber auch das Bewusssein der französischen Bildungseinrichtungen für die Notwendigkeit der Zusammenarbeit mit den einheimischen Institutionen führten zu einer engeren Kooperation der französischen mit den lokalen Schulen. Somit kam es zu verstärkten Aktivitäten außerhalb der Mauern der französischen Schulen. Dieses Phänomen ist vor allem für die Mission laïque dokumentiert und lässt sich unter anderem auf die verstärkte Förderung der laizistischen Schule durch die Kulturabteilung des Quai d'Orsay ab 1929 zurückführen ${ }^{205}$. Die Zusammenarbeit zeigte sich vor allem in der Entsendung von französischen Lehrern an die libanesischen Lehranstalten und in der gemeinsamen Handhabung von Stipendien des Hochkommissariats. Diese zwei Aspekte der Erweiterung des Radius' der französischen Schulen und ihre Bedeutung für die Regierung in Paris sowie für die lokalen Schulen sollen im Folgenden untersucht werden.

Die Forschungsliteratur hat das Phänomen der entsandten französischen Lehrer, der sogenannten professeurs détachés ${ }^{206}$, in den lokalen Schulen bis jetzt zu Unrecht gar nicht oder nur sehr marginal beachtet ${ }^{207}$. Dabei bietet diese Praxis wertvolle Einblicke in die komplexen Erwartungen der französischen Regierung, der libanesischen Schulen und der französischen Schulen selbst und macht zudem deutlich, dass die französischen staatlichen und edukativen Instanzen die Interaktion mit libanesischen Schulen viel stärker als zu Beginn des Mandats in den libanesischen Institutionen verankerten. Auch wenn nicht abschließend geklärt werden kann, von welcher Partei diese Initiative ausging, profitierten sowohl die französische Regierung als auch die libanesischen Schulen massiv davon. Indes betonten die Verantwortlichen der Mission lä̈que auch ihre Schwierigkeiten mit einem zu großen Druck ihrer libanesischen Partner.

205 Vgl. Barbier-DE Bonnay 1983, S. 181-182. Im Gegensatz zu den anderen französischen Schulen, deren Budget gleich blieb, erhielt die Mission laïque Mittel für ihre Neugründungen in Beirut, Damaskus und Aleppo.

206 Dies ist der Begriff in der französischen Administration für die entsandten Lehrer.

207 Dueck 2010, S. 103, referiert lediglich die Meinung eines libanesischen Interviewpartners, dass die sunnitische Maqasid vom Hochkommissariat mit französischen Lehrern und Büchern ausgestattet wurde, findet aber dafür in den Archiven kein Indiz. Auch ich erhielt im Interview mit dem ehemaligen Schüler der Maqasid Afif Soubra diese Information. Er berichtete von dem Physiklehrer René Pernault, der ein paar Schüler einige Male zu sich nach Hause eingeladen hatte. Vgl. Interview mit Afif Soubra, Beirut, 28.11.2008. 
Da die entsandten Lehrer vom französischen Erziehungsministerium für eine bestimmte Zeit freigestellt werden mussten (in der Regel ein bis zwei Jahre) ${ }^{208}$, oblag die Abwicklung der französischen Regierung. Wenngleich von dieser Praxis auch einige staatliche Schulen im Libanon profitierten ${ }^{209}$, gingen die meisten Lehrer an eine der zahlreichen privaten Schulen im Land. Neben der direkten Entsendung von Paris gab es auch bei der Mission laïque in Beirut schon angestellte Lehrer, welche dann an eine lokale Schule abgeordnet wurden. Dieses Phänomen ist von den anderen französischen Schulen im Libanon nicht bekannt, was entweder an der mangelhaften Überlieferung durch die Quellen oder an der Tatsache lag, dass die anderen Einrichtungen diese Form der Kooperation nicht praktiziert haben ${ }^{210}$.

Die französischen Autoritäten waren sehr an der Entsendung der Lehrer in die libanesischen Schulen interessiert. Vom Erziehungsministerium freigestellt, wurden die Lehrkräfte vom Außenministerium in die unterschiedlichen konfessionellen und überkonfessionellen Einrichtungen im Libanon geschickt. Einige Lehrer gingen an die griechisch-orthodoxe Schule Madrasat zahrat-al-ihssān in Beirut ${ }^{211}$, andere an die sunnitischen Einrichtungen für die Ausbildung der religiösen Gelehrten, die Madrasat al-'ulamā' (französisch École des oulémas) aber auch an die maronitische Schule Madrasat al-hikma (französisch Collège de la Sagesse) und die jüdische Schule Talmud Torah $^{212}$.

Auch überkonfessionelle Schulen wie die Madrasat al-ahlīya $a^{213}$ und das Collège universel (arabisch al-Ǧämi'at al-watanīya) in Aley ${ }^{214}$ erhielten eine französische Lehrkraft. Damit betonte die französische Regierung wieder einmal ihren Anspruch, ihren Einfluss in allen Milieus zu verankern, auch gerade in den Gemeinschaften, in welchen das Mandat sehr kritisch gesehen oder sogar abgelehnt wurde. Daneben war auch die Konkurrenz zu den ande-

208 Davon unterscheiden sind, trotz einiger Überschneidungen, die schon erwähnten »détachés militaires«, die statt ihres Militärdienstes zwei Jahre an einer Schule im Ausland unterrichteten.

209 Vgl. MAE/Nantes, SOFE, 222, „Syrie - Professeurs détachés 1927-1932«. Beispielsweise war Alice Farges an der École normale für Mädchen in Beirut tätig.

210 In einem Interview mit Prof. Slim in Beirut im Dezember 2008 erfuhr ich, dass die Schule der Frères des Écoles chrétiennes in Beirut mit dem Collège de la Sainte Famille in Fanar kooperierte, um diese auf die Situation der Koedukation vorzubereiten.

211 Vgl. MAE Nantes/SOFE, 222, „Syrie - Professeurs détachés 1927-1932«: Emilienne Goulet war seit 1926 in Beirut, zunächst drei Monate bei der Alliance israélite dann zwei Jahre in der griechisch-orthodoxen Schule Madrasat zahrat-al-iḥsān.

212 Das betraf vor allem die Talmud Torah der jüdischen Gemeinschaft. Vgl. MAE Nantes, IP, 102: 1933-1934, »Rapports d'inspection«.

213 Vgl. MAE/Nantes, SOFE, 222, »Syrie - Professeurs détachés 1927-1932«. Allerdings wurde diese Kooperation aus nicht näher erläuterten Gründen später von der französischen Regierung beendet.

214 Vgl. ebd. 
ren westlichen Mächten, welche einen kulturellen Einfluss im Land hatten, ein zentrales Motiv. So war Hochkommissar Ponsot 1932 besonders erfreut, als Elias Khoury (arabisch Ilyās Hūūī), der Direktor des Collège universel in Aley, der bis dahin immer nur die amerikanische Universität in Beirut um die Entsendung von zwei Lehrern gebeten hatte, seine Bitte um zwei détachés militaires nun an ihn richtete ${ }^{215}$.

Allerdings war trotz des Interesses der Regierung die Abwicklung der Entsendungen von Lehrern an lokale Schulen auch sehr umständlich und repräsentierte die oft zeitraubenden Prozeduren innerhalb der verschiedenen französischen Regierungsinstanzen. Beispielsweise wandte sich Mašnūq, der Direktor der Schule Madrasat al-hurğ (»École des pins«), welche von der Maqasid unterhalten wurde, 1931 direkt an das französische Erziehungsministerium, um die Entsendung zweier Grundschullehrer zu bitten. Der Außenminister, an den das Erziehungsministerium diese Anfrage weiterleitete, fragte wiederum den Hochkommissar in Beirut um Rat. Da Mašnūq auf dessen Vorladung nicht zu einem Gespräch erschien, beschloss der Hochkommissar, die Angelegenheit nicht weiterzuverfolgen ${ }^{216}$.

Die Auswahl der Lehrer, welche an eine lokale Schule abgeordnet wurden, belegt noch einmal das Interesse der Regierung an einem guten und für die Libanesen zufriedenstellenden Ablauf dieser Praxis, da es sich in der Regel um gut ausgebildete und erfahrene Lehrer handelte. Gerade die muslimisch-sunnitischen Schulen, um die die Regierung sich seit Mitte der 1920er Jahre verstärkt bemühte, erhielten besonders gut ausgebildete Lehrer: André Barguet, Lehrer an der École des oulémas, beherrschte das Sanskrit ${ }^{217}$, Pierre Robin, den 'Umar Da'uq für die École des pins einwarb, hatte in Frankreich die Agrégé-Prüfung abgelegt ${ }^{218}$. Er blieb sehr lange in Beirut und wurde sogar nach Bounoure und Picon der dritte Direktor des frankophonen Verlages École des Lettres ${ }^{219}$.

Die lokalen Schulen selbst erwiesen sich als ein aktiver und fordernder Partner hinsichtlich der Entsendung von französischen Lehrern. Ihre Zielstrebigkeit manifestierte sich darin, dass sie ihre Anfragen sowohl an die Mission

215 Vgl. ebd., Brief von Ponsot an das Außenministerium, Beirut, 25.03.1932. Zur Konkurrenz der ausländischen Schulen untereinander vgl. Kapitel 7.1.

216 Vgl. MAE/Nantes, SOFE, 222, Brief des Erziehungsministeriums an das Außenministerium, Paris, 08.08.1931; Brief des Außenministeriums an das Hochkommissariat, Paris, 17.08.1931; Brief des Hochkommissariats an das Außenministerium, Beirut, 12.10.1931; Brief des Außenministeriums an das Erziehungsministerium, Paris, 28.10.1931. Im Februar desselben Jahres hatte die Mission laïque allerdings schon einen Lehrer, M. Cornet, an diese Schule abgesandt. Vgl. AN/Paris, 60 AJ 133, »Budget«, Brief von Ruche an Besnard, Beirut, 17.02.1931.

217 Vgl. MAE/Nantes, IP, 145, Brief von Pezé an Bounoure, Broumana, 06.08.1938. Bildungsbeauftragter Bounoure bat für seine Bereitstellung sogar noch um eine zusätzliche Subvention, welche ihm gewährt wurde.

218 Vgl. MAE/Nantes, SOFE, 376, Brief von Puaux an das Außenministerium, Beirut, 25.08.1939.

219 Vgl. Aвоu 1962, S. 367. 
laïque als auch an den Hochkommissar und an die französische Regierung in Paris direkt richteten. Insgesamt war ihr Engagement von einem starken Pragmatismus gepräg $\mathrm{t}^{220}$. So finden sich in den Quellen keine Beschwerden über Probleme mit den entsandten Lehrern. Eine Ausnahme bildete Lehrer Roche, der Ende der 1930er Jahre an der École des oulémas tätig war. Über den Vorfall liegen keine Details vor, aber zu seiner Verteidigung formulierte sein französischer Kollege Pezé, Roche sei Opfer eines Schülers gewesen und habe sich von einem jungen Ägypter beeinflussen lassen ${ }^{221}$.

In ihren Begründungen für die Bitte um einen französischen Lehrer nannten die libanesischen Schulen entweder inhaltliche oder materielle Motive. So erklärte der Direktor einer muslimischen Schule in Beirut seine Bitte mit der Wichtigkeit der französischen Sprache: »afin que je puisse être tranquille sur l'enseignement de cette langue qui est à mes yeux de très grande importance $\ll^{222}$. Auch der Präsident der Maqasid, Da uq, nannte als Ziel der Kooperation »la propagande de la langue française parmi les jeunes Musulmans de Beyrouth $\ll^{223}$.

Da das Beherrschen der französischen Sprache für eine erfolgreiche berufliche und soziale Integration im Mandats-Libanon notwendig war, müssen die Aussagen gar nicht als mehr oder weniger ernstgemeinte Unterstützung der Zivilisierungsmission gedeutet werden. An anderer Stelle nannte Da'uq auch offen den Geldmangel der Schule als Grund für seine Anfrage ${ }^{224}$. Die libanesischen Schulen profitierten finanziell sehr stark von diesen französischen Lehrern, für die sie ja kein Gehalt zu zahlen hatten. Aus diesem Grund versuchten die Schulen, so viele »détachés« wie möglich zu bekommen. Am erfolgreichsten zeigte sich dabei 'Umar Da' uq ${ }^{225}$. Interessanterweise ist in den Archiven der Maqasid diese Kooperation mit den französischen Institutionen nicht verzeichnet ${ }^{226}$. So kann festgestellt werden, dass Pragmatismus das stärkste Motiv der lokalen Schulen für eine Kooperation mit den französischen Autoritäten war ${ }^{227}$.

220 Für die stark säkular-nationalistisch geprägte Schule Madrasat al-ahlīya siehe Nadya SBAITI, »If the Devil taught French«. Strategies of language and learning in French mandate Beirut, in: Osama Abi-Mershed (Hg.), Trajectories of Education in the Arab World. Legacies and Challenges, London/New York 2009, S. 59-83, hier 66-71.

221 Vgl. MAE/Nantes, IP, 145, Brief von Pezé an den »Conseiller«, Broumana, 06.08.1938.

222 Vgl. MAE/Nantes, IP, 83, Brief des Direktors der »École al-Azharieh al-Islamieh« an das Erziehungsministerium, Beirut, 19.09.1931.

223 Vgl. AN Paris/ 60 AJ 133, Brief von Da'uq an Besnard, Beirut, 13.10.1929.

224 Vgl. MAE/Nantes, SOFE, 376, Brief von Puaux an das Außenministerium, Beirut, 25.08.1939.

225 Er forderte viele Stipendien und abgesandte Lehrer von der Mission laïque. Ruche wollte ihm diese nicht geben, wusste aber auch, dass viele seiner Schüler von der Maqasid kamen und dass er Da'uq deshalb nachgeben musste. Vgl. AN/Paris, 60 AJ 132, Brief von Ruche an Besnard, Beirut, 29.12.1930.

226 Gespräch mit Nadya Sbaiti, Barcelona, 25.07.2010.

$227 »$ They used its ressources for social or economic advantage«. DuECK 2010, S. 102. 
Während die lokalen Schulen den maximalen Nutzen aus der Bereitstellung der Lehrer ziehen wollten und die Zentrale der Mission laïque in Paris diese Kooperation voll unterstützte, stieß die Bereitschaft zur Zusammenarbeit bei den Lehrern der laizistischen Schule in Beirut auch auf Grenzen. Die Konflikte entzündeten sich dabei vor allem an den Forderungen 'Umar Da'uqs, welche der Schulleiter als anmaßend empfand. Die Zentrale der Mission lä̈que hingegen war bereit, für die Entsendung französischer Lehrer an lokale Schulen auch finanzielle Verpflichtungen einzugehen ${ }^{228}$. Generalsekretär Besnard begründete diese Initiativen damit, dass »une telle mesure ne peut être que profitable à la culture française ${ }^{229}$. Darüber hinaus stand Besnard seit 1930 in engem Kontakt mit Marx, dem neuen Direktor der Euvres françaises, also der Kulturabteilung im Außenministerium, und es scheint, dass viele seiner Entscheidungen in der Angelegenheit mit dieser Instanz abgesprochen und von ihr bestimmt wurden.

Eine andere Form der Kooperation zeigte sich bezüglich der Stipendien des Hochkommissariats. Hier kam es zu einem regelrechten Tauschgeschäft zwischen französischen und libanesischen Schulen. Letztere übergaben den französischen Einrichtungen ihre Schüler zusammen mit deren Stipendien und konnten so deren Weiterbildung garantieren. Um 1930 wurde damit das schon bezüglich der Stipendien zu Beginn des Mandats behandelte Phänomen der Nutzung französischer Strategien durch die Libanesen wieder virulent, aber mit dem Unterschied, dass sich die Kooperation nun vom Ort der französischen Schulen löste und in die libanesischen Einrichtungen hineingetragen wurde. Auch wenn es sich hier aufgrund der politischen Machtasymmetrien weiterhin um koloniale Bildung handelte, zeugte die deutliche Interessensbekundung der lokalen Schulen von deren gestärktem Mitspracherecht.

Wie eng die Aspekte von entsandten Lehrern und Stipendien miteinander verbunden waren, zeigt die Zusammenarbeit der Mission laïque mit den jüdischen Schulen im Libanon. Ohne größere Schwierigkeiten erfolgte die Kooperation der Mission lä̈que bezüglich der Bereitstellung französischer Lehrer mit den Talmud Torah, den Schulen der jüdischen Gemeinschaft im Libanon. Direktor Ruche wollte diese Zusammenarbeit im Jahr 1934 schon einmal, wahrscheinlich aufgrund ökonomischer Zwänge, beenden, aber die Zentrale der Mission laïque erteilte diesem Vorschlag eine deutliche

228 Vgl. AN/Paris, 60 AJ 133, »Beyrouth«, handschriftliche Notiz vom 30.03.1931: »Budget spécial. Écoles de Syrie. Des fondateurs d'écoles privées nous demandent des maîtres compétents. Nous avons intérêt à leur donner satisfaction. Aussi avons-nous prévu pour l'année scolaire en cours une subvention de 51.560 Frs pour le traitement de deux instituteurs détachés à l'École de la bienfaisance musulmane et à l'École israélite [...] .

229 Ebd., Brief von Da'uq an Besnard, Beirut, 13.10.1929. 
Absage $^{230}$. Parallel dazu kooperierte die Mission lä̈que auch mit den Schulen der Alliance israélite, welche ihrerseits gegenüber den Talmud Torah wegen deren Nähe zum Zionismus ablehnend eingestellt waren. Am Beispiel der Talmud Torah zeigt sich auch sehr deutlich das 〉lokale Tauschgeschäft $<$, das den Alltag aller Schulen im Libanon prägte: während die Mission laïque den Talmud Torah und der Alliance israélite Französischlehrer zur Verfügung stellte, übergaben diese der laizistischen Schule ihre Schüler und die damit verbundenen Stipendien des Hochkommissariats ${ }^{231}$. Aus diesem Grund lagen die Motive der Mission laïque dafür, sich an der Kooperation mit den lokalen Schulen zu beteiligen, zum einen in den Vorgaben aus Paris, zum anderen in der Sicherung von Schülern und finanziellen Mitteln.

Etwas schwieriger erwies sich die Zusammenarbeit mit der Maqasid. Hier sah Direktor Ruche in Beirut zwar auch den Nutzen einer solchen Kooperation, denn diese ermögliche es der Mission laïque, einen gewissen Einfluss auf die Maqasid zu bewahren: »Peut-être serait-il encore temps de nous assurer un droit de regard sur cet établissement en y déléguant un professeur de Français « ${ }^{232}$. Die Formulierung »droit de regard« verrät sehr deutlich den paternalistischen Blick, den Ruche auf die Schulen der Maqasid hatte. Er schrieb Besnard aber auch, dass er diese Idee für schädlich für die Mission laïque halte ${ }^{233}$. Ein Jahr später wiederholte er seine Bedenken wegen einer zu großen Einflussnahme Da uqs, räumte aber ein, dass sich die Mission laïque um eine gute Zusammenarbeit bemühen müsse, da die meisten ihrer muslimischen Schüler von der Maqasid kämen: »Elle tarit la source musulmane de notre recrutement tant pour les garçons que pour les filles $\aleph^{234}$. Allerdings wollte er der Abordnung eines weiteren Lehrers nur zustimmen, wenn die Maqasid die 26 Stipendiaten, die sie der Mission lä̈que auferlege, wieder selber finanzieren würde ${ }^{235}$. 1933, als die Maqasid-Schulen zur Konkurrenz geworden waren, schlugen sich die Bedenken Ruches noch deutlicher in Kritik nieder. Die Maqasid, merkte er indigniert an, habe erst vor einiger Zeit Lehrer der Mission lä̈que weggeschickt und bitte nun erneut um einen Philosophielehrer:

230 Vgl. AN/Paris, 60 AJ 136, Brief von Ruche an Besnard, Beirut, 21.04.1934.

231 Für die komplexe Frage der Beziehungen zwischen der Mission laïque und den verschiedenen jüdischen Schulen im Libanon vgl. Esther MöLLER, Clientélisme, concurrence ou coopération? Les écoles de la Mission laïque française face aux écoles israélites au Liban entre 1909 et 1943, in: Jérôme BocQuET (Hg.), L'enseignement français en Méditerranée. Les missions et l'Alliance israélite universelle, Rennes 2010, S. 147-163.

232 AN Paris, 60 AJ 132, Brief von Ruche an Besnard, 04.08.1930.

233 Vgl. ebd., Brief von Ruche an Besnard, Beirut, 06.11.1929.

234 Vgl. AN/Paris, 60 AJ 133, Brief von Ruche an Besnard, Beirut, 29.12.1930.

235 Vgl. ebd. 
L'École des Pins veut nous faire concurrence pour la préparation au baccalauréat $2^{\text {ème }}$ partie. Voilà donc une école qui s'est fondée en 1925 par suite de l'opposition des musulmans à la politique française, qui a été encouragée par le Haut-Commissaire, dont toute la propagande a eu pour but et pour effet de détourner les élèves musulmans du Lycée de Beyrouth, à laquelle nous avons eu la faiblesse de prêter des professeurs dont elle s'est débarrassée sans égard ni pour eux ni pour nous, et qui a l'audace de venir chercher les instruments de la concurrence qu'elle veut nous faire ${ }^{236}$.

Während die Beziehung zwischen Da uq und der Mission laïque in dieser Zeit erkaltete, nutzte der sunnitische Geschäftsmann, wie oben dargelegt, seine Kontakte zum Hochkommissariat, um dieses um zusätzliche Französischlehrer zu bitten, was sowohl der Hochkommissar als auch das französische Außenministerium unterstützten.

Diese Episode zeigt sehr deutlich die »taktische « Politik Da uqs angesichts der »strategischen « französischen Erziehungspolitik. Gleichzeitig offenbart sie die quasi "paternalistische Enttäuschung« der Mission laïque, dass das »libanesische Kind«, um das man sich gekümmert hat, nicht dankbarer sei, sondern einem nun sogar den »Thron« streitig mache. Homi Bhabha hat im Rahmen der Postcolonial Studies die Angst der westlichen Kolonialherren und -damen vor einer zu großen Ähnlichkeit mit den Einheimischen stark gemacht, um auf diese Weise das Bild der ständigen Übermacht des Westens gegenüber den Kolonien zu untergraben ${ }^{237}$. Ohne dieses Bild eins zu eins auf die vorliegende Situation übertragen zu wollen und zu können, spiegelt diese doch eine ähnlich paternalistische Perspektive wider. In die Enttäuschung mischte sich nun auch Angst um die Konkurrenz mit muslimischen Schulen.

236 Vgl. AN/Paris, 60 AJ 135, Brief von Ruche an Besnard, Beirut, 13.12.1933.

237 Vgl. Homi Bнавна, The Location of Culture, London/New York 2008, S. 58, 86, 124. 



\section{Angst, Anpassung, Aufbruch: Reaktionen auf das nahende Mandatsende}

Bedeutende außen- und innenpolitische Ereignisse ab 1935 wiesen darauf hin, dass die Tage des Mandatsregimes im Libanon gezählt waren und bewirkten auch im Umfeld der französischen Schulen für Franzosen und Libanesen gleichermaßen einen Einschnitt. Ihre Reaktionen darauf reichten - auf beiden Seiten - von einer stärkeren Betonung des französischen Kolonialismus und der historischen Beziehungen zwischen Frankreich und der Levante bis zur Hervorhebung des libanesischen und arabischen Nationalismus und ihres Beitrages zum Aufbau des libanesischen Staates.

Der politische Einschnitt dieser Jahre zeigte sich sowohl auf transnationaler als auch auf nationaler und lokaler Ebene. Auf binationaler Stufe handelten Frankreich und Libanon nach dem franko-syrischen Vorbild einen Vertrag aus. Die Wahl eines linken Regierungsbündnisses in Frankreich, des Front populaire, sowie die anhaltenden Forderungen der syrischen und libanesischen arabischen Nationalisten hatten diese Verhandlungen nötig und möglich gemacht ${ }^{1}$. Emanzipatorische Schritte in der Region, wie die Unabhängigkeit des Irak 1932, der anglo-ägyptische Vertrag 1936 und die Unruhen in Palästina ab 1936 übten zusätzlichen Druck auf Frankreich aus, den Mandatsgebieten mehr Autonomie zu gewähren ${ }^{2}$. Ziel der Verträge war, in beiden Ländern das Mandatsregime durch dreijährige Verträge zu ersetzen, an deren Ende die Unabhängigkeit Syriens und des Libanons stehen sollte.

Allerdings würde Frankreich auch darüber hinaus eine privilegierte Position behalten und unter anderem den Aufbau der Armee in beiden Ländern überwachen, in technischen Fragen der Ansprechpartner bleiben und eine privilegierte diplomatische Vertretung behalten ${ }^{3}$. Im Libanon sollte die französische Armee sogar, im Gegensatz zu Syrien, während der Vertragsdauer volle Bewegungsfreiheit haben ${ }^{4}$. Aus Angst vor zu scharfer Kritik legte Hochkommissar Damien de Martel (1933-1939) diesen Vertragsentwurf den libanesischen Partnern erst zwei Tage vor Ende der Verhandlungen vor ${ }^{5}$.

1 Vor allem die syrischen Nationalisten hatten immer wieder einen Vertrag wie den zwischen Großbritannien und dem Irak 1930 gefordert, und in der Tat baute der franko-syrische Vertrag stark auf diesem Modell auf. Vgl. Bocquet 2008, S. 89; Laurens 2000, S. 270-287.

2 Vgl. Chaigne-Oudin 2006, S. 223.

3 Vgl. Salibi 1965, S. 181-182.

4 Vgl. Zamir 2000, S. 212-213.

5 Vgl. ebd., S. 211. 
Auch wenn es unter den Libanesen viele Meinungsverschiedenheiten bezüglich des Vertrages gab, stimmte das libanesische Parlament dem Vertrag schließlich am 13. November 1936 einstimmig zu${ }^{6}$.

Im Gegensatz dazu herrschte unter den französischen Verhandlungspartnern keinerlei Einigkeit: gegen die linken, progressiven Politiker standen die konservativen Kräfte, vornehmlich innerhalb der kolonialen Partei, des Klerus und der Armee, die den Schutz der religiösen Minderheiten weiter gewahrt wissen und die Levante, insbesondere den Libanon, nicht als strategisches Hinterland aufgeben wollten ${ }^{7}$. Die fragile innenpolitische Situation und die wirtschaftliche Rezession in Frankreich ${ }^{8}$ versuchten beide Seiten für ihre Argumente zu nutzen. Aufgrund dieser Schwierigkeiten und wegen der aufziehenden Gefahr eines neuen Krieges durch die militärische Wiedererstarkung Deutschlands und Italiens wurde der Vertrag nie vom französischen Parlament ratifiziert ${ }^{9}$.

Der Zweite Weltkrieg legte alle Verhandlungen auf Eis, und der ungeklärte Status wurde durch die ständig wechselnden Hochkommissare noch perpetuiert. So kam es während des Vichyregimes zum Austausch mehrerer Funktionäre durch vichytreue Beamte, unter anderem wurde Hochkommissar Gabriel Puaux (1939-1940) durch General Henri Dentz (1940-1941) ersetzt, während dieser nach der deutschen Niederlage wieder von Vertretern des freien Frankreichs, General Georges Catroux (1941-1943) und Jean Helleu (1943-1944), abgelöst wurde. Um sich die Unterstützung der lokalen Bevölkerung zu sichern, erklärte Catroux am 8. Juni 1941 die Unabhängigkeit Syriens und des Libanons, die aber faktisch nicht erfolgte ${ }^{10}$.

Als bei den libanesischen Wahlen im Herbst 1943 Bishara al-Khuri siegte, setzte er die Mandatsartikel außer Kraft. Daraufhin löste Helleu die Verfassung auf, und in der Folge kam es zu Demonstrationen vieler Libanesen und zu Festnahmen, unter anderem Riad as-Sulhs, durch die Armee. Die Freilassung der Politiker am 22. November 1943 machte aus diesem Tag den libanesischen Nationalfeiertag. Erst durch den erhöhten Druck Großbritanniens und der libanesischen Politiker sah sich Frankreich nun gezwungen, die Unabhängigkeit des Libanons tatsächlich anzuerkennen ${ }^{11}$. Dieser Prozess war für die französischen und libanesischen Befürworter des Mandats sehr schmerzhaft, und sie weigerten sich lange, der neuen Realität ins Auge

6 Vgl. Salibi 1965, S. 182.

7 Vgl. Chaigne-Oudin 2006, S. 225.

8 Vgl. Jean-Claude Brunet, Crise française des années 1930, in: Jean-François Sirinelli (Hg.), Dictionnaire historique de la vie politique française au XXe siècle, Paris 2003, S. 305-307.

9 Jacques Couland, Le Front populaire et la négociation des traités avec les États du Levant, in: Walid Arbid u.a. (Hg.), Méditerranée, Moyen-Orient : Deux siècles de relations internationales. Recherches en hommage à Jacques Thobie, Paris 2003, S. 501-520, S. 519.

10 Vgl. Laurens 2002, S. 302.

11 Vgl. Ghassan TuÉni, Le livre de l'indépendance, Beirut 2002, S. 234-266. 
zu sehen. Erst 1946 war die Unabhängigkeit mit dem Rückzug der französischen und britischen Truppen aus dem Libanon und Syrien auch faktisch erfolgt.

All diese außenpolitischen Faktoren beeinflussten das politische und gesellschaftliche Leben im Libanon stark. Die Wahl Emile Eddés, des bevorzugten Kandidaten Frankreichs, zum Präsidenten des Zedernstaates im Januar 1936 beendete zwar eine jahrelange Fehde zwischen Eddé und seinem ebenfalls maronitischen Konkurrenten Bishara al-Khuri um diesen Posten, die die libanesische Politik dominiert und gelähmt hatte, konnte die politischen Lagerkämpfe aber nicht beenden ${ }^{12}$. Al-Khuri und sein aus Christen und Muslimen bestehender, 1934 gegründeter, Konstitutioneller Block (arabisch al-Kutla al-Dustürīya) forderten die Wiederherstellung der Verfassung und vertraten die Unabhängigkeit des Libanons sowie eine christlich-muslimische Verständigung und die klare Einbindung des Libanons in sein arabisches Umfeld ${ }^{13}$. Eddé hingegen, an der Spitze des Nationalen Blocks (arabisch al-Kutla al-Wațanīya al-Lubnānīya) $)^{14}$, war Anhänger des Libanismus, einer besonderen Form des libanesischen Nationalismus, die sich für einen explizit christlichen Libanon, mit, je nach Ausrichtung der einzelnen Vertreter, mehr oder weniger losen Verbindungen nach Frankreich, einsetzte ${ }^{15}$. Auch wenn die 1932 von Hochkommissar Ponsot aufgelöste Verfassung 1937 wieder eingesetzt wurde, blieb die politische Situation äußerst prekär, die Mandatsmacht intervenierte oft und viele Regierungen wechselten einander $a b^{16}$.

Die unsichere und angespannte Lage zeigte sich auch in der Mobilisierung vieler politischer Gruppen in der Gesellschaft sowie in einer stärkeren Fraktionierung der religiösen Gemeinschaften. Die Aushandlung des frankolibanesischen Vertrages hatte vor allem die Muslime aktiviert, die sich in den 1930er Jahren erneut für eine Vereinigung der muslimischen Teile des Libanons mit Syrien starkmachten ${ }^{17}$. Die syrischen Panarabisten vereinigten sich 1933 in der Konferenz von Qarnāyil im Libanon zur Liga der Nationalen Aktion (arabisch 'Usbat al-'amal al-qawmī) und forderten explizit die absolute Unabhängigkeit und Souveränität der Araber ${ }^{18}$. Im Gegensatz dazu

12 Über diese Fehde ist sehr viel geschrieben und geurteilt worden. Während Eddé in der Regel sehr negativ, nämlich als arrogant, egoistisch, frankreichabhängig und antimuslimisch dargestellt wird, wird al-Khuri als ein kooperativer, mit den Muslimen eine nationale Einheit suchender Politiker dargestellt. Vgl. zum Beispiel SALIBi 1965, S. 172-173. Neuere Studien bemühen sich aber um eine differenzierte Darstellung. Vgl. Michel VAN LeEuw, Emile Eddé. Biographie politique, Aux sources de la république 1884-1949, Beirut o.J. (Manuskript).

13 Vgl. Firro 2000, S. 133; Traboulsi 2007, S. 93.

14 Dieser darf nicht mit dem nationalen Block in Syrien verglichen werden. Vgl. Kassir 203, S. 400.

15 Vgl. Zamir 2000, S. 72-73; SAlibi 1965, S. 186.

16 Vgl. Zamir 2000, S. 214.

17 Vgl. Salibi 1965, S. 180.

18 Vgl. Schumann 2001, S. 257. 
trat die 1932 von Anțūn Sa'āda gegründete Syrisch Nationalistische Partei (arabisch al-hizb as-sūrī al-qawmī) für eine syrische Nation ein ${ }^{19}$. Der griechisch-orthodoxe Libanese Sa āda verstand unter der Wiederherstellung des »historischen Syriens" sowohl Syrien als auch Libanon und vertrat einen dezidierten Säkularismus, der viele Angehörige konfessioneller Minderheiten anzog. Nachdem Sa āda 1935 von der Mandatsmacht zu einer Gefängnisstrafe verurteilt worden war, erlebte seine Partei einen Aufschwung in den 1940er Jahren, verlor aber an Einfluss mit dem Tod ihres Gründers 1949: Im Gegensatz zum libanesischen und arabischen Nationalismus fehlten dieser Bewegung »die mobilisierenden Mythen und Symbole $\ll^{20}$. Spätestens nach Abschluss des Vertrages gab es aber auch eine Gruppe sunnitischer Muslime, die sich mit der neuen Realität eines libanesischen, getrennt von Syrien existierenden Staates arrangiert hatte ${ }^{21}$. Unter anderem als Reaktion auf die Aktivitäten der Unionisten mit Syrien organisierten sich die libanesischen Christen in Form einer Jugendorganisation, der Kata'ib (arabisch hizb al-Katā'ib al-Katā'ib al-lubnānīya) oder Phalanges libanaises, um für die Autonomie des Libanons gegenüber seinen arabischen Nachbarn einzutreten ${ }^{22}$.

Gleichzeitig erwachte zum ersten Mal in den maronitischen Kreisen, die bis dahin nahezu geschlossen das Mandat verteidigt hatten, Kritik an der französischen Herrschaft. Ausgelöst wurde die Protestbewegung durch den Patriarchen 'Arīda, welcher 1932 gegen den Willen der Jesuiten zum neuen Oberhaupt der maronitischen Kirche gewählt worden war. Seine Ablehnung der Wirtschaftspolitik in den Mandatsgebieten, die von einer Monopolisierung in den Händen Frankreichs geprägt war, nährte auch in der maronitischen Gemeinschaft den Wunsch nach mehr Unabhängigkeit von Frankreich. 'Arị̄a hatte sich unter anderem gegen das von den Franzosen auferlegte Tabak-Monopol ${ }^{23}$ ausgesprochen, und in der Folge kam es nicht nur zu einer Reihe von Streiks gegen dieses Monopol, sondern auch zu einer Annäherung des Patriarchen mit den syrischen Nationalisten ${ }^{24}$.

19 Vgl. Traboulsi 2007, S. 102.

20 Vgl. Schumann 2001, S. 261.

21 Vgl. Khoury 1987, S. 613.

22 Vgl. Traboulsi 2007, S. 102.

23 Das Monopol lag bei einer privaten franko-libanesischen Gesellschaft, der Campagnie libanosyrienne de Tabac, die im Libanon $25 \%$ und in Syrien $40 \%$ Steuern auf Tabak verlangte. Vgl. KHOURY 1987, S. 451.

24 Vgl. Zamir 2000, S. 134; Firro 2003, S. 135-144. Wie Firro 2003, S. 144, aber deutlich macht, änderte sich 'Arị̣̄as Politik nach Abschluss des Vertrages 1936 wieder in Richtung einer Annäherung mit Frankreich, da, so Firro, sein eigentliches Interesse der Schutz seiner Gemeinschaft, der Maroniten, war. 
Auf die Gründung der Kata'ib wurde auf muslimischer Seite wiederum mit der Schaffung einer paramilitärischen Jugendorganisation muslimischer Pfadfinder, der Najjada (arabisch Nağāda), geantwortet ${ }^{25}$. Angesichts einer massiv blockierten und eingeschränkten Landespolitik entwickelten diese Gruppen ein starkes politisches Gewicht und leisteten einen zentralen Beitrag zur Debatte um die nationale Identität des Libanons ${ }^{26}$. Die vielen internationalen, nationalen und lokalen Veränderungen machten aus dem Jahr 1936 deshalb »one of the most turbulent years in the interwar-period « ${ }^{27}$.

Diese politischen Ereignisse wirkten sich auf verschiedene Art und Weise auf die französischen Schulen im Libanon aus. Bei der Mission lä̈que erfolgte durch das Ende des Direktorats von Ruche im Oktober 1935 eine einschneidende Veränderung, aber inwieweit die Ablösung durch seinen Nachfolger Jacques Olivier Grandjouan auch politisch motiviert war, kann nur vermutet werden. Auch wenn die Mission laïque selbst die Verlängerung seines Vertrages um weitere fünf Jahre beantragt hatte, lehnte das Ministerium in Paris die Petition wegen einer »Warnung« des Ministeriums $a b^{28}$. Ruche hatte sich in seinem letzten Amtsjahr mit 'Umar Da'uq überworfen, vielleicht war dies der ausschlaggebende Grund ${ }^{29}$. Wegen großer Spannungen mit der Zentrale der Mission lä̈que in Paris blieb Grandjouan aber nur drei Jahre im $\mathrm{Amt}^{30}$ und wurde von René Latrouite abgelöst, welcher von 1927 bis 1935 als Kultusbeauftragter bei der Regierung des syrischen Staates von Lattakia

25 Vgl. Traboulsi 2007, S. 102; Zamir 2000, S. 233-234. Schumann 2001, S. 264, nennt auch die Gründung der syrischen sozialistischen Nationalpartei als einen Auslöser für die Entstehung von Kata' ib und Najjada.

26 Vgl. Dueck 2010, S. 184. Eine kleine kommunistische Partei, die in den frühen 1930er Jahren gegründet wurde, wurde umgehend von der Mandatsregierung verboten. Vgl. FIRro 2003, S. $129-130$.

27 Zamir 2000, S. 189.

28 Was genau dieses »avertissement du ministère« bedeutete, konnte nicht rekonstruiert werden. Vgl. AN/Paris. F 17, 25346/Lucien Ruche, Brief von Ruche an das Erziehungsministerium, Beirut, 26.04.1935.

29 Einmal hieß es auch, Ruche habe Schulden angehäuft, weil er die Schulgelder nicht konsequent genug eingeforder hätte. Vgl. AN/Paris, 60 AJ 138, Brief von Lehericy an Grandjouan, Beirut, 25.11.1935.

30 Vgl. z.B. MLF/Paris, 60 AJ 139, »Finances«, Brief von Grandjouan an Besnard, Beirut, 03.11.1936; Antwortschreiben von Besnard, Paris, 10.11.1936: Grandjouan berichtete von Protesten arabischer und französischer Lehrer, als er den mit diesen verwandten Schülern Vergünstigungen entzogen hatte, darunter Madame Tuéni (Tuwaynī). Besnard entgegnete, er hätte sich vorher mit ihm absprechen sollen und so unter anderem erfahren, dass Tuwaynī ihm für eine Reduzierung des Schulgeldes oft seine Zeitung an-Nahār zur Verfügung gestellt hatte. Interessanterweise fielen das Urteil des französischen Inspektors 1937 und ein Schreiben von Lehrern der Schule 1938 über Grandjouan sehr viel positiver aus. Beide Instanzen lobten sein Engagement, seine Ehrlichkeit und das Wachstum der Schule unter seiner Führung. Die Lehrer stellten besonders sein Anliegen heraus, die Schule von alten Mauscheleien und »Erpressungen« zu befreien. Vgl. MLF/Paris, »Dossiers de personnel«, Dossier Nr. G 4200 A/ 022.7, Brief von Laminy, Inspektor der Académie de Paris, 09.12.1937; Brief der Lehrer der Mission laïque an Besnard, Beirut, 03.06.1938. 
und von 1935 bis 1938 als Direktor des Lycée der Mission laïque in Damaskus tätig gewesen war ${ }^{31}$. Latrouites Tätigkeit als Direktor bis 1946 zeugt von den vielen Kontinuitäten innerhalb der Bildungspolitik über das Mandatsregime hinaus. In den anderen französischen Schulen im Libanon gab es keinen augenscheinlichen Wechsel um 1935, sondern die Reaktionen auf die politischen Ereignisse geschahen eher schleichend.

Während alle französischen Bildungseinrichtungen zwar weiterhin ihrer genuinen Aufgabe, der Ausbildung junger Libanesen, nachkamen, wurden sie auch zu Orten der Verhandlung der Dekolonisierung. In dieser Funktion unterstützten sie, in unterschiedlichem Maß, die französische Präsenz im Libanon durch eine wieder verstärkte Betonung der französischen Zivilisierungsmission, boten andererseits aber auch nationalistischen Stimmen ein Forum. Das erste Unterkapitel thematisiert die erstmalige gegenseitige Annäherung der französischen Schulen angesichts der als bedrohlich empfundenen Konkurrenz anderer westlicher Bildungseinrichtungen und der dahinterstehenden Mächte. Ein weiteres Unterkapitel untersucht den Einfluss nationalistischer Debatten und Positionen innerhalb der französischen Schulen. Ferner werden die Auswirkungen der Anerkennung des Libanons als Staat in einem arabischen Umfeld auf die Curricula der einzelnen Schulen analysiert. Schließlich rückt das letzte Unterkapitel die Karriereziele und Berufswege der Absolventen der französischen Schulen als Seismographen sowohl der sich wandelnden libanesischen Gesellschaft als auch der Anpassungsfähigkeit der Schulen am Ende der Mandatszeit in den Mittelpunkt.

\section{Zusammen gegen den Feind: \\ Der Schulterschluss der französischen gegenüber anderen ausländischen Schulen}

Das steigende Interesse anderer westlicher Bildungseinrichtungen und der sie unterstützenden Regierungen am Libanon ab den 1930er Jahren führten, so die These dieses Unterkapitels, zu einer Zunahme von als bedrohlich empfundenen äußeren Faktoren, welche die französischen Schulen erstmals näher zusammenrücken ließen. Ein weiterer Aspekt, der diese Entwicklung beeinflusste, war der steigende Druck der unterschiedlichen nationalistischen Bewegungen im Land auf das Mandatsregime, welcher im nächsten Unterkapitel thematisiert wird.

Die stärkere Annäherung und Zusammenarbeit zwischen den verschiedenen französischen Schulen ist vor allem auffällig für die Beziehung zwischen der Mission lä̈que française und den Jesuiten, die bis dahin ihre gegensei-

31 Vgl. MLF/Paris, »Dossiers de personnel«, Dossier Nr. G 4200 A/ 027.12. 
tige Ablehnung besonders deutlich zum Ausdruck gebracht hatten. Alle französischen Schulen hatten sich seit den Zeiten des Osmanischen Reiches viel eher als Konkurrenten denn als Teilhaber an einem gemeinsamen französischen Unternehmens gesehen ${ }^{32}$. Die Sorge um Subventionen durch den französischen Staat, um eine höchstmögliche Anzahl von als Lehrer freigestellten Soldaten ${ }^{33}$ sowie gegenseitiger Argwohn prägten ihre Beziehungen. Das galt insbesondere für das Verhältnis zwischen der Mission lä̈que und den katholischen Schulen.

Diese starke Konkurrenz wich ab Mitte der 1930er Jahre zunehmend Momenten der Kooperation, eine Entwicklung die nach Ende des Mandats fortgesetzt werden sollte ${ }^{34}$. Als stärkste Konkurrenten nahmen die französischen Schulen die amerikanischen und italienischen Bildungseinrichtungen wahr - wenn auch zu unterschiedlichen Graden: Während die Mission lä̈que vor allem die Konkurrenz der Amerikaner fürchtete, beschäftigte die katholischen Schulen der steigende Einfluss der italienischen Einrichtungen. Die französische Regierung teilte diese Sorgen, auch wenn sie die italienischen Schulen, aufgrund der dahinterstehenden Expansionspolitik Mussolinis als unmittelbar bedrohlicher empfand als die amerikanischen Initiativen, die zu dem Zeitpunkt noch vor allem aus privater Hand stammten. Die außenpolitischen Spannungen Frankreichs mit Deutschland und Großbritannien, die sich ab Ende der 1930er Jahre intensivierten, wirkten sich hingegen weniger stark auf die Bildungspolitik in der Levante aus.

Für die Mission lä̈que war insbesondere die Konkurrenz der französischen Schule an der American University of Beirut (AUB) von großer Tragweite. Schon 1933 berichtete Direktor Ruche dem Generalsekretär der Organisation von einem Gespräch mit dem sunnitischen und frankophilen Geschäfts-

32 Vgl. Kapitel 1, 2, 3, 4, 5 und 6.

33 Zum Kampf um diese détachés militaires vgl. z. B. SJ/Vanves, »Fonds Jalabert«, 7 1/B, Brief vom Direktor der Jesuitenschule Sautier an Jalabert, 14.09.1937: »À propos de M. Bounoure, parlez-lui de M. Michel Villey. Villey, détaché à la Mission Laïque, est le fils du professeur Villey; il prépare une thèse sur les Croisades. Je l'avais démandé à M. Bounoure, comme détaché en surnombre à la nouvelle Bibliothèque; il me l'a accordé, mais en le comptant, dans le nombre des 23 détachés qui nous sont régulièrement donnés par l'Instr. Publ. [Instruction Publique]. Du Ht. Commissariat [das Kultusministerium des Hochkommissariat, E.M.]; le P. de Bonneville a déjà affecté ces 23 sans y comprendre Villey; [...] Je crois que si M. Bounoure veut vraiment, il peut...«.

34 Vgl. Henri Jalabert, Les Institutions Scolaires Françaises au Liban, in: Georges und Edith Corban-Mertens (Hg.), France-Liban. Revue, o.J. [ungefähr 1960, E.M.], S. 26.29, S. 28 : „Après une première période assez pénible, les rapports ne tardèrent pas à se normaliser entre les maisons installées depuis longtemps et les nouveaux venus, pour aboutir enfin à la grande cordialité qui est de règle aujourd'hui.«; Wegmann 1947, S. 296: »Ce n'est donc pas le terme de concurrence, c'est plutôt ceux d'émulation, de poussée à des recherches perpétuelles que j'emploierai $[\ldots] \ll$. 
mann und Politiker 'Abdallāh Bayhum ${ }^{35}$, einem Mitglied des Elternkomitees, der die steigende Attraktivität der französischen Schule an der amerikanischen Universität thematisiert hatte. Diese biete nicht nur weniger strenge Prüfungen und kleinere Klassen, sondern gelte darüber hinaus als weniger vom französischen Mandat kompromittiert: „L'université américaine paraît moins compromettre aux nationalistes qu'une école française même aussi libérale que le sont les écoles de la M.L.F. [Mission laïque française] «36. Ruches Nachfolger Grandjouan ärgerte sich besonders, dass die Amerikaner, die er als »notre concurrent« bezeichnete, ihnen zuvorgekommen waren und vor der Mission laïque eine Landwirtschaftssektion eröffnet hatten ${ }^{37}$.

Die Sorgen der Mission lä̈que waren durchaus berechtigt. Mitte der 1930er Jahre vergrößerte die amerikanische Universität ihre 1926 eröffnete französische Schule, die »Section Française«. Diese orientierte sich am französischen System und bot den Schülern einen Unterricht in französischer Sprache mit französischen Abschlüssen ${ }^{38}$. Ab Mitte der 1930er Jahre wuchs die Zahl ihrer Schüler sehr schnell, jedes Jahr kamen 50 neue Kandidaten hinzu $^{39}$, darunter einige Schüler der Mission laïque. Auch auf einen guten Arabischunterricht legte die französische Schule der amerikanischen Universität viel Wert ${ }^{40}$. War die Studentenschaft der amerikanischen Universität in ihren ersten Dekaden vor allem christlich gewesen, stieg insbesondere ab 1940 der Anteil muslimischer Studenten deutlich an ${ }^{41}$. Besonders schockiert war Ruche, als er im Herbst 1934 vom Wechsel Khalil Taqi ad-Dins als Französisch- und Arabischlehrer zu den Amerikanern erfuhr. Ruche empfand seinen Weggang als einen Verrat und fragte lakonisch nach den »fallacieux prétextes«, mit welchen Taqi ad-Din diesen Gesinnungswandel erklären würde ${ }^{42}$. Interessanterweise taucht seine Zeit bei der Mission laïque, im Gegensatz zu seiner Präsenz an der amerikanischen Universität, in der Bio-

35 Bayhum aus einer der sieben bekanntesten sunnitischen Familien in Beirut saß zwischen 1921 und 1934 der Vereinigung der Beiruter Geschäftsmänner vor; nach seiner Ernennung als Senator und Abgeordneter zwischen 1926 und 1932 war er 1934-1935, 1939-1941 und 1943 Staatssekretär. Vgl. EdDÉ 2008, S. 514; Zamir 2000, S. 155; Firro 2003, S. 132.

36 AN/Paris, 60 AJ 135, Brief von Ruche an Besnard, Beirut, 17.01.1933.

37 AN/Paris, 60 AJ 139, Brief von Grandjouan an Besnard, Beirut, 15.05.1937.

38 IC/Beirut, »A Short History of International College, by Shafik Jeha«, 1972, S. 7.

39 IC/Beirut, »Petite Histoire de la Section Française du Collège International de BeyrouthLiban«, Anhang Nr. 2.

40 Diese Wertschätzung wurde auch von außen wahrgenommen. So berichtete die Zeitung L'Orient im Februar 1934, dass die Schule anhand einer arabischen Tragödie »vient encore une fois, de montrer aux parents de ses élèves, son attachement à la langue arabe et l'intérêt qu'elle porte à l'enseignement de cette langue«, L'Orient, 23.02.1934, S. 3: »A l'École française de l'Université Américaine«.

41 Vgl. Stephen B.L. Penrose, That They May Have Life: The Story of the American University of Beirut. 1866-1914, Princeton, New Jersey 1941, S. 333: 1940 betrug der Anteil muslimischer Studenten $37 \%$ und jüdischer Studenten $10 \%$.

42 AN/Paris, 60 AJ 137, Brief von Ruche an Besnard, Beirut, 30.09.1934. 
graphie Khalil Taqi ad-Dins nicht auf ${ }^{43}$. Ebenso zogen sich auch im syrischen Aleppo während der Unruhen im Zusammenhang mit den Verhandlungen um den franko-syrischen Vertrag viele Muslime wegen ihrer Kritik an Frankreich von der Mission laïque zurück und wandten sich den amerikanischen Einrichtungen $\mathrm{zu}^{44}$.

In der Tat bildeten sich Mitte der 1930er Jahre an der AUB einige Studentengruppen, welche in verschiedenen geheimen Gesellschaften den arabischen Nationalismus unterstützten ${ }^{45}$. Diese Tendenz wurde durch den hohen Anteil von Studenten aus anderen arabischen Ländern, in denen der Nationalismus noch stärker verankert war, unterstüzt ${ }^{46}$. Die Initiativen gingen aber nicht auf die Direktion der Universität, sondern auf die Studenten selbst zurück $^{47}$. Die Intention der Leitung war nicht in erster Linie, den französischen Schulen Konkurrenz zu machen, sondern sich diesen anzupassen, da ihre eigene Schule bis dahin immer mehr Schüler verloren hatte: Durch das Mandat war es nun wichtiger, französisch- als englischsprachige Kompetenzen zu besitzen ${ }^{48}$. Außerdem wurde an der American University of Beirut bis in die 1940er Jahre hinein keine offene Kritik am französischen Mandat laut ${ }^{49}$. Schließlich hatte die Hochschule neben liberalen auch repressive Tendenzen $^{50}$. Sicher ist aber, dass die amerikanische Universität faktisch weniger abhängig vom Mandat war und den Ruf hatte, einen freieren Geist zu vertreten $^{51}$ sowie die erste Generation arabischer Nationalisten beherbergt zu

43 Vgl. Amyuni 1998, S. 758.

44 MAE/Nantes, SOFE, 378, »Établissements de la Mission Laïque en Syrie«, Brief von Besnard an Marx, 04.04.1936: »Il est évident que l'hostilité qui règne actuellement en Syrie à l'égard de tout ce qui est français ne favorise pas le développement de nos institutions. [...] pour des raisons d'atmosphère locale, un certain nombre de Musulmans témoignent d'une certaine réserve envers la Mission laïque et cèdent aux sollicitations américaines qui se piquent de dispenser la culture française en pratiquant la plus stricte neutralité politique«.

45 Vgl. Anderson 2011, S. 19; Dueck 2010, S. 170.

46 Gerade im Gegensatz zur französischen Université Saint-Joseph war diese Tendenz zu beobachten. Im akademischen Jahr 1932-1933 war die Zusammensetzung der Studenten an der AUB wie folgt: Libanon 111, Syrien 47, Palästina 100, Ägypten 28, Irak 28, Iran 19, Jordanien 5, Indien 2, Äthiopien 1, Europa und USA 70. Demgegenüber lautete die Verteilung an der USJ: Libanon 371, Syrien 98, Ägypten 43, Palästina 9, Irak 6, Iran 6, Jordanien 1, Europa 61. Vgl. MAE/Nantes, IP, 102.

47 Vgl. Anderson 2011, S. 19, 114: Der Nationalismus der Studenten wurde unter anderem in der Zeitschrift der »Student Arab Society«, al-'Urwa al-Wuthqa, vertreten.

48 Vgl. IC/Beirut, »A Short History of International College, by Shafik Jeha«, 1972, S. 7.

49 Vgl. Betty Anderson, Modernity to Arab Nationalism. An Intellectual Shift at the American University of Beirut in the 1930s, Vortrag auf dem World Congress of Middle Eastern Studies/ Barcelona, 22.07.2010.

50 Vgl. Schumann 2001, S. 221.

51 Havemann 2002, S. 98-100. In den 1930er Jahren ließen sich die ersten amerikanischen Ölgesellschaften im Nahen Osten nieder, aber ein explizites Interesse der Vereinigten Staaten von Amerika, sich im Nahen Osten als wichtige Macht zu etablieren, entstand erst nach dem Zweiten Weltkrieg. Vgl. Laurens 1996. 
haben $^{52}$. In der Tat gab es unter den Lehrern der amerikanischen Bildungseinrichtungen, neben sehr missionarisch orientierten Kräften, auch »other more secular-oriented professors [who] resisted any missionary identification $\ll^{53}$.

Neben der Mission laïque empfanden auch die katholischen Schulen verstärkt die Konkurrenz der amerikanischen Institutionen. Auch sie verloren Schüler an die sogenannte »French Section« der amerikanischen Universität ${ }^{54}$. So >verhörte< der Direktor der Universität der Jesuiten in Beirut 1933 einen arabischen Lehrer seiner Schule zu der Frage, ob dieser ein »homme de principe« gewesen sei. Zum Glück konnte Ghalbouni glaubhaft versichern, dass er kein Angebot einer anderen Schule angenommen habe, auch der amerikanischen Universität nicht. Seine Erklärung, dass diese keine Zweitbeschäftigung an einer anderen Institution akzeptierten, war vom Verfasser oder Adressaten des Berichtes im Nachhinein unterstrichen worden ${ }^{55}$. Allerdings reihte sich der Argwohn der Jesuiten auch in die traditionelle, religiös bedingte, Konkurrenz der katholischen Orden gegenüber den amerikanischen und englischen Schulen ein, die als protestantische Einrichtungen unmittelbare Konkurrenten ihrer religiösen Mission darstellten. Schon 1923 hatte ein Bericht der Filles de la Charité mit dieser Konkurrenz die Gründung von Schulen in Gegenden legitimiert, in denen »les Américains protestants ont établi toutes leurs œuvres de propagande $\ll^{56}$. Ebenso betonten die Jesuiten in Tanail einige Jahre später, dass ihre Schule »prendra le dessus à celle des Protestants $\ll^{57}$.

Die protestantischen und jüdischen Schulen empfanden die Attraktivität der amerikanischen Einrichtungen als weniger problematisch. Der Direktor der Alliance israélite berichtete 1939 ganz objektiv von der Qualität des Arabischunterrichts an der amerikanischen Universität ${ }^{58}$. Die französischen Protestanten verband mit den Amerikanern die gemeinsame Konfession, weswegen es zu weniger harten Urteilen kam. Außerdem arbeiteten sie bei verschiedenen Projekten zusammen, zum Beispiel bei der Entwicklung

52 Vgl. Kamal Salibi, A House of Many Mansions. The History of Lebanon Reconsidered, London/New York 1988, S. 44.

53 David M. Ment, The American Role in Education in the Middle East: Ideology and Experiment, 1920-1940, in: Paedagogica Historica 47 (2011), H. 1-2, S. 173-189, S. 178.

54 Vgl. IC/Beirut, »Alumni Office«: In der Beschreibung der Schulkarrieren neu aufgenommener Schüler heißt es häufig »Enseignements suivis antérieurement: Pères Jésuites«. So beispielsweise bei Ishac Klat, der 1938 an die Schule kam.

55 SJ/ Vanves, RPO 62, Brief von Ghalbouni an Bonneville, Beirut, 07.11.1933.

56 Vgl. LAZ/Paris, »Moyen Orient - Filles de la Charité - Divers», 1923, »Rapport général sur les Maisons des Filles de la Charité de la Province Syrie, Palestine, Egypte«.

57 SJ/Beirut, 12.C.12, »Tanail École normale«, 13.09.1929.

58 AIU/Paris, »Liban VIIE, 81-86«, Brief von Penso an den Präsidenten der Alliance israélite, Beirut, 15.06.1939: »[...] l'arabe occupe depuis longtemps une place d'honneur dans l'emploi du temps $[\ldots]$ au Collège américain $[\ldots] \ll$. 
einer protestantischen Jugendorganisation, der Union Chrétienne des Jeunes Gens nach dem Vorbild der amerikanischen Young Men's Christian Association (YMCA) ${ }^{59}$. Allerdings differenzierte Philippe Bianquis, ein französischer Protestant, der an der amerikanischen Universität von Beirut arbeitete, stark zwischen seinem Arbeitgeber und den anderen amerikanischen Schulen im Libanon, an welchen Frankreich seiner Einschätzung nach oft einen sehr schlechten Ruf genieße ${ }^{60}$.

Ein weiterer Konkurrent der französischen Schulen waren die italienischen Orden, die vor allem die französischen katholischen Schulen beschäftigten. 1938 berichtete Jalabert an den französischen Außenminister über den »effort italien qui se dépense sans compter« in Aleppo und bat um Propagandamaterial, um diesem entgegenzuwirken ${ }^{61}$. Aus diesem Grund betonte ein Prospekt der Lazaristen in Ayntoura 1931 auch, welch wichtigen Platz der Italienisch- wie auch der Englischunterricht in ihrer Schule einnehmen würden ${ }^{62}$.

Die Sorge der katholischen Orden vor der italienischen Konkurrenz resultierte aus der verstärkten Anstrengung Italiens Mitte der 1930er Jahre, ihren kulturellen Einfluss in der Levante wieder zu beleben, sowie aus der größeren Nähe des Vatikans zum italienischen Staat. Nach seiner Verdrängung als dominante Kultur durch das Französische hatte Italien schon seit 1900 wieder eine verstärkte Aktivität im Mittelmeerraum entwickelt und blieb damit für Frankreich ein potentieller Konkurrent seiner Interessen ${ }^{63}$. Nach dem Ersten Weltkrieg sah sich Italien als ungerechtfertigten Verlierer des Vertrags von Versailles und monierte, dass es nicht auch Mandate im Nahen Osten zugewiesen bekommen hatte. Unter Mussolini formulierte es dann seine Ambitionen im Osten neu. Politische Aktivitäten unterstützten die Gründung faschistischer Gruppen in der Levante, kulturelle Angebote wie Sprachkurse, Radiosendungen, die durch Radio Bari verbreitet wurden ${ }^{64}$,

59 Vgl. KreBs/Eyrard 2007, S. 168.

60 Vgl. PPFL, Brief von Pierre Bianquis an seinen Vater, Beirut, 02.01.1926: »[...] je serai aussi très content de ta venue, car à part l'université, trop d'autres organisations protestantes considèrent les Français (comme les Syriens) comme d'une race inférieure et taillable à merci«.

$61 \mathrm{SJ} /$ Vanves, »Fonds Jalabert«, 26 Q, »Correspondance du P. Louis Jalabert avec M. J. Poirier au Ministère des Affaires Étrangères, novembre 1934-février 1938«, Brief von Jalabert an Poirier, Paris, 17.02.1938.

62 Vgl. LAZ/Paris, Bulletin des Missions des Lazaristes 9 (Juli 1931), S. 202-226: »Les Lazaristes en Syrie«: »Antoura [...] La vie du Collège: L'étude de la langue française est soignée d'une manière très spéciale: elle est la base de tout l'enseignement donné, c'est la langue de la conversation. [...] Les langues étrangères sont loin d'être ignorées, a fortiori méconnues, entre autres, l'Anglais, si important pour ces [...] villes d'Orient, et l'Italien ont leur place de choix«.

63 Daniel Grange, L'Italie et la Méditerranée 1896-1911, Bd. II, Rom 1994, S. 1513-1514.

64 Größter Feind Italiens im Nahen Ostens war laut Radio Bari Großbritannien. Vgl. Massimiliano Fiore, Anglo-Italian Relations in the Middle East, 1922-1940, Surrey 2010, S. 45. 
und Fahrten nach Italien sollten die Syrer und Libanesen für das Mittelmeerland einnehmen. In der Tat war deren Akzeptanz durchaus beachtlich ${ }^{65}$.

Für die Förderung der italienischen Schulen suchte die Regierung vor allem die Zusammenarbeit mit den katholischen Orden italienischer Provenienz ${ }^{66}$. Der schon 1931 von den Jesuiten befürchtete Schulterschluss des Vatikans mit dem italienischen Staat ${ }^{67}$ schien nun Realität zu werden. Ihr Verhältnis zu dem Delegierten der römischen Kurie in Syrien, Giannini, erkaltete sichtlich, da die französisch-patriotisch orientierten Jesuiten Gianninis italienischen Nationalismus verurteilten ${ }^{68}$. In diesem Sinne berichteten Ordensmitglieder aus der Levante voller Genugtuung von der Kritik der muslimischen Zeitung an-Nidā' (Der Ruf) gegen Giannini, der unter anderem in einigen Frauenklöstern die französische durch die italienische Flagge hatte ersetzen lassen ${ }^{69}$. Hier vermischten sich auf beiden Seiten religiöse und nationale Gefühle und Argumente.

Für die Alliance israélite stellten die italienischen Schulen zwar schon seit Ende der 1920er Jahre eine ernst zu nehmende Konkurrenz dar, aber die Organisation profitierte teilweise auch davon, weil nicht alle jüdischen Schüler die teureren italienische Einrichtungen besuchen konnten und deshalb zur Alliance kamen $^{70}$. Die Mission lä̈que hingegen empfand die italienische Konkurrenz schon eher als bedrohlich ${ }^{71}$.

Auch wenn deutsche und britische Schulen für die französischen Einrichtungen ebenfalls als Konkurrenten wahrgenommen wurden, erscheinen sie in den Quellen nicht in demselben Maße als Gefahr wie die amerikanischen und italienischen Schulen ${ }^{72}$. Der deutsche Einfluss wurde vielmehr

65 Vgl. Dueck 2010, S. 121-126.

66 Vgl. Chaigne-Oudin 2006, S. 175-185.

67 Vgl. Kapitel 6.1.

68 Vgl. Thompson 2000, S. 5.

$69 \mathrm{Vgl}$. SJ/ Vanves, »Fonds Jalabert«, 26 Q, »Correspondance du P. Louis Jalabert avec M. J. Poirier au Ministère des Affaires Étrangères, novembre 1934-février 1938«, Brief von Jalabert an Poirier, Paris, 17.02.1938.

70 AIU/Paris, »Liban XE 96c«, Brief von Sidi an den Präsidenten der Alliance israélite, Beirut, 26.10.1927: »À noter que ce qui s'était produit l'année dernière pour l'École des Sœurs s'est produit cette année pour l'école italienne. Presque toutes les élèves juives gratuites de cet établissement, une trentaine, ont été renvoyés, la direction exigeant d'elles un payement pour l'écolage. Nous en avons admis une vingtaine, quelques-unes gratuitement $\ll$.

71 Vgl. MAE/Nantes, SOFE, 258, »Rapport Besnard«, 1934. Unter anderem berichtet Besnard von einem Projekt in Alexandria welches »échoue grâce au Grand-Rabbin qui met toute son influence au service de l'italien«.

72 Zwar zählte Direktor Ruche von der Mission lä̈que 1932 im Libanon unter den 67 Sekundarschulen 28 französische, 11 amerikanische, fünf englische, zwei italienische und 22 lokale (private und staatliche) Einrichtungen, aber die britischen Schulen schienen ihn nicht weiter zu beunruhigen. Vgl. AN/Paris, 60 AJ 135, »1932-1933«, Brief von Ruche an Besnard, Beirut, 14.10.1932. Die deutschen Schulen erwähnte Ruche zum Beispiel 1932 einmal in Verbindung mit den italienischen Einrichtungen: »Une concurrence allemande et italienne qui peut nous faire assez de tort [...]«. Ebd., Brief von Ruche an Besnard, Beirut, 05.10.1932. 
auf politischer Ebene gefürchtet, da sich einige arabische Nationalisten dem Nationalsozialismus nahe fühlten und Vertreter des Dritten Reiches sich die anti-französischen und anti-britischen Tendenzen im Nahen Osten zunutze machten $^{73}$. Die einzige Episode, die die hier untersuchten Archive bezüglich des Nationalsozialismus wiedergeben, bezieht sich auf ein Hakenkreuz, das der 12-jährige Sohn des Amīr Amīn Arslān, ein Schüler der Mission lä̈que, 1940 an die Schulwand gemalt hatte, das Mitschüler aber schnell wegwischten und das Bounoure als ungefährlich einstufte, da Arslān noch ein Kind sei und vorher die deutsche Schule besucht habe ${ }^{74}$.

Die franko-britische Konkurrenz entwickelte sich vor allem im Zweiten Weltkrieg neben der militärischen und politischen auch auf der kulturellen Ebene $^{75}$. Insbesondere seit der Besetzung des Libanon durch die britische Armee im Juli 1941 wurde der Druck des Verantwortlichen der britischen Delegation, General Spears, auf die Franzosen, Syrien und Libanon die wirkliche Unabhängigkeit zu garantieren, immer größer ${ }^{76}$. Von den hier untersuchten französischen Schulen selbst wurde der Wettbewerb mit britischen Schulen aber laut der Quellen, abgesehen von der schon immer bestehenden Konkurrenz zwischen französischen katholischen und britischen protestantischen Bildungsstätten ${ }^{77}$, weniger unmittelbar wahrgenommen ${ }^{78}$.

In ihren Schreiben an französische Regierungsvertreter betonten die Direktoren der französischen Schulen die ausländische Konkurrenz, die sie als Bedrohung für ihre eigene Existenz empfanden, sehr deutlich. Da diese Situation zumindest auch von Teilen der französischen Regierung als Gefahr wahrgenommen wurde, fielen die Hilferufe der Schulen auf fruchtbaren Boden. So berichtete Besnard 1939 einem ehemaligen Minister von den materiellen Engpässen der Mission laïque, von welchen besonders »nos

73 Vgl. Dueck 2010, S. 132-140; Götz Nordbruch, Nazism in Syria and Lebanon. The Ambivalence of the German Option, 1933-1945, London/New York 2009, S. 136-141. Bezüglich der Frage, ob die Annäherung an den Nationalsozialismus Ausdruck einer tiefen Überzeugung der arabischen Intellektuellen oder reine Strategie war, plädiert Nordbruch für eine deutliche Differenzierung hinsichtlich der unterschiedlichen Aspekte.

74 Vgl. MAE/Paris, IP, 192, »Propagande étrangère«, Brief von Besnard an Bounoure, 29.05.1940: »Un seul élève a manifesté quelquefois des sympathies allemandes: c'est le fils de l'Emir Amin Arslan [Amīr Amīn Arslān], qui a fait toutes ses premières études à l'École allemande de Beyrouth. Mais c'est un enfant (12-13 ans) sans autorité sur ses condisciples et qui a, une fois ou deux, dessiné sur les murs une croix gammée aussitôt effacée par les camerades ou les surveillants $\ll$.

75 Vgl. Dueck 2010, S. 142-163; Laurens 2002, S. 313-321.

76 Vgl. ZAMIR 2005. Zamir macht aber sehr eindrücklich die Ambivalenz auch der britischen Politik deutlich, welche ihre eigene Position im Nahen Osten durch Zugeständnisse der Franzosen verbessern wollte.

77 Vgl. Kapitel 2.4.

78 Dueck 2010, S. 142-163, betont zwar den Einfluss der franko-britischen Konkurrenz auf den Bildungsbereich in der Levante, aber vor allem zum Ende des Zweiten Weltkrieges und von Seiten der Regierungen aus. 
concurrents étrangers« profitieren würden ${ }^{79}$. Auch die katholischen Schulen betonten die Konkurrenz bei Kontakten mit französischen Regierungsvertretern. Ein Jesuit formulierte in einer Rede anlässlich des Besuchs des französischen Konsuls:

Grâce à la protection que la France accorde à ses vaillants enfants, les missionnaires poursuivent leurs œuvres de zèle, les écoles se fondent, les sciences prospèrent, la foi est maintenue, l'influence étrangère, protestante surtout, est combattue avec énergie et succès ${ }^{80}$.

Als eine Antwort auf die ausländische Konkurrenz erhöhte die französische Regierung ab Mitte der 1930er Jahre die Subventionen für die Schulen, was sich besonders bei den katholischen Orden bemerkbar machte, die in den Jahren zuvor merklich weniger Geld bekommen hatten ${ }^{81}$. Um den gemeinsamen »patriotischen Geist« zu stärken, lud der französische Generalkonsul in Beirut zudem alle Direktoren französischer Bildungseinrichtungen als »Compatriote[s] « zu einem Gespräch »dans un intérêt français« ein, bei welchem die »propagande française au Levant« thematisiert werden sollte $^{82}$. Ebenso rief Bounoure 1940 alle französischen Schulen auf, trotz der Umstände mit einer »énergie toute nouvelle plus puissante« weiterzuarbeiten und sicherte ihnen die Unterstützung der französischen Regierung $\mathbf{z u}^{83}$.

Die italienische Konkurrenz wie auch diejenige Deutschlands wurde von Frankreich aus mit viel Sorge betrachtet. Die Militarisierung beider Länder ließ Angst vor einem neuen Krieg entstehen. Allerdings bezog man in Paris die Levante nicht prioritär in dieses Szenario mit ein und reagierte sehr spärlich auf die besorgten Berichte der Vertreter des Hochkommissariats ${ }^{84}$. Auch bezüglich der amerikanischen Konkurrenz zeigten sich die französischen Politiker nicht einig. Zwar wurde die amerikanische Universität, wie AnnieLucie Chaigne-Oudin gezeigt hat, von vielen Vertretern des Hochkommis-

79 Vgl. MLF/Paris, »Fonds de Russie«, Brief von Besnard an Roustan, 06.06.1939: »[...] le matériel scientifique de nos lycées était devenu notoirement insuffisant [...]. Cette nécessité est d'autant plus présente en Orient que de gros efforts sont faits dans ce sens par nos concurrents étrangers (Italiens, Anglais, Américains)«.

80 SJ/Beirut, 12.C.12, »Monsieur le Consul« (Manuskript für eine Rede beim Besuch des Konsusls).

81 Beispielsweise erhielten die Jesuiten 1937 50\% mehr Subventionen als das Jahr zuvor und 1938 noch einmal mehr Geld. Vgl. SJ/Beirut, 11.A.26, Brief von Bounoure an Mejasson, Beirut, 30.07.1938.

82 MAE/Nantes, »Beyrouth Consulat Général B«, 50, »Propagande française au Levant«, Briefvorlage des französischen Konsuls Delanda an »Monsieur et Cher Compatriote«, Beirut, 19.05.1933.

$83 \mathrm{SJ} /$ Beirut, 11.A.26, Brief von Bounoure an die Schuldirektoren, 12.08.1940.

84 Vgl. Chaigne-Oudin 2006, S. 194. 
sariats als »le haut-lieu de l'activité anti-française « angesehen ${ }^{85}$, aber es gab auch Gegenstimmen. So betonte Hochkommissar de Martel 1937, dass er die französische Schule der AUB als nicht so gefährlich empfinde; vielmehr solle man sich freuen, dass sie auch etwas für den Einfluss der französischen Kultur tue ${ }^{86}$.

In der Tat schienen einige Verantwortlichen in Paris und Beirut mit der amerikanischen Universität lieber in Kooperation zu treten, um einen Einfluss auf sie zu erlangen. So gestatte Anfang 1937 der Direktor der Kulturabteilung des Außenministeriums, Jean Marx, die Entsendung der ersten détachés militaires an die Schule der amerikanischen Universität und betonte gegenüber dem Hochkommissariat in Beirut die Notwendigkeit, Taktgefühl zu zeigen und die Kontrollen auf das Personal und nicht auf die Schulen zu beziehen $^{87}$. Als kosmopolitischer und eher kirchenkritischer Intellektueller zählte Marx aber nicht zu der Gruppe innerhalb des Außenministeriums, die im Einklang mit der parti colonial Frankreichs Kolonien und Mandate um jeden Preis behalten wollte ${ }^{88}$.

Auf die als starke Konkurrenzsituation empfundene neue Bildungslandschaft im Libanon reagierten die französischen Schulen selbst mit einer gegenseitigen Annäherung in Worten und Taten; gleichzeitig unterstrichen sie erneut ihre Beteiligung an der französischen Zivilisierungsmission und, in unterschiedlichem Ausmaß, ihre Zugehörigkeit zum Mandat, das sie als Schutz wahrnahmen. Die Annäherung der Schulen durch ein verändertes Reden übereinander zeigte sich sehr auffällig beim Jesuitenorden. Ab 1935 sprachen die Jesuiten in Beirut das erste Mal positiv über einen Direktor der Mission laïque. Nachdem er Anfang 1936 einem Vortrag Grandjouans beigewohnt hatte, beschrieb Sautier diesen als »homme de très haute culture, causeur extraordinaire (sujet: Pédagogie moderne), et voulant être un homme d'action ${ }^{89}$. Sein Korrespondent in Paris, Jalabert, zeigte sich im Herbst 1934 auch das erste Mal versöhnlich gegenüber der Mission laïque. In einem Artikel mit dem Titel »En Syrie et Liban« in der Zeitung Le Figaro bedauerte er zwar, dass die Missionare nicht mehr die einzigen Ansprechpartner Frankreichs seien und nicht mehr so stark unterstützt würden, da »la France laïque a instauré ou développé des œuvres neutres dans la ligne de sa politique scolaire métropolitaine $\aleph^{90}$. Zum Glück, so Jalabert weiter, werde die Arbeit der

85 Ebd., S. 170.

86 MAE/Nantes, SOFE, 376, Brief von de Martel an das Außenministerium in Paris, Beirut, 04.05.1937.

87 Ebd., Brief von Marx an Abraham im Erziehungsministerium in Paris, Paris, 21.01.1937.

88 Vgl. Maurice Degros, Jean Marx (1994-1972), in: Bibliothèque des Écoles des chartes 131 (1972), S. 684-687; Khoury 1987, S. 33.

$89 \mathrm{SJ} /$ Vanves, »Fonds Jalabert«, 7 1/B, Brief von Sautier an Jalabert, Beirut, 18.01.1936.

90 Vgl. SJ/Vanves, RPO 15/6, »Coupures de presse«. 
katholischen Missionare aber immer noch gebraucht und schließlich könnten doch alle Schulen gut nebeneinander existieren.

Ebenso zeigten sich die Vertreter der Mission lä̈que versöhnlicher, behielten aber ihre Vorbehalte über die privilegierte Position der katholischen Schulen, insbesondere der Jesuiten, bei. In einem Schreiben Anfang der 1930er Jahre rekurrierte ein Verantwortlicher der laizistischen Organisation ohne Spitze gegen die katholischen Orden auf die Tradition französischer Präsenz im Libanon:

Si [...] c'est par l'enseignement, par la diffusion de sa culture, que la France conservera là-bas son autorité et son prestige, n'est-il pas regrettable de penser que, faute des quelques millions nécessaires, nous risquons de perdre en Syrie et au Liban tous les sacrifices qui on déjà éte consentis et qui se chiffrent par milliards ${ }^{91}$ ?

Auch der neue Direktor der Mission laïque in Beirut seit 1935, Grandjouan, zollte den Methoden der Jesuiten Anerkennung und bescheinigte ihren Schülern eine viel bessere moralische Erziehung als seinen eigenen Zöglingen ${ }^{92}$. Allerdings brachten seine Erfahrungen in Beirut Grandjouan bald dazu, die Jesuiten auch kritisch zu sehen. Besonders warf er ihnen ihren Monopolanspruch auf das Hochschulwesen im Libanon vor, und beanstandete, dass sie darin von namhaften Institutionen wie der Universität von Lyon und dem Service des Euvres françaises à l'Étranger im Quai d'Orsay unterstützt würden. Er bat den Generalsekretär deshalb um Fürsprache für seine Schule bei Édouard Herriot, der zu dem Zeitpunkt Präsident der französischen Nationalversammlung und gleichzeitig Präsident der Mission laïque war, auch wenn dieser, so Grandjouan, die Jesuiten sehr schätze ${ }^{93}$.

Die Herausstellung der gemeinsamen Aufgabe der Schulen in den Mandatsgebieten wurde auch von der prokolonialen Presse in Frankreich selbst praktiziert, auch wenn diese die Konkurrenz zwischen den Schulen nicht gänzlich vergaßen. So berichtete die Zeitung Le Petit Parisien im Oktober enthusiastisch: »Missions françaises catholiques, protestantes, laïques, autorités françaises militaires et civiles rivalisaient de zèle et de bonté à l'égard des populations de ces territoires actuellement confiées à notre tutelle $\ll^{94}$.

91 AN/Paris, 60 AJ 135, »Notes pour une lettre pour M. le Président«, ca. 1932.

92 AN/Paris, 60 AJ 138, Brief von Grandjouan an Besnard, Beirut, 18.05.1936.

93 AN/Paris, 60 AJ 139, Brief von Grandjouan an Besnard, Beirut, 21.12.1937.

94 SJ/Vanves, »Fonds Jalabert«, 12-2, Le Petit Parisien, 18.10.1945, S. 1: »L'œuvre magistrale de la France en Syrie et au Liban«. Bezüglich dieser proimperialistischen französischen Zeitschrift siehe William H. SchneIder, An Empire for the Masses. The French Popular Image of Africa, 1870-1900, Westport, Connecticut/London 1982, S. 202. 
Neben der diskursiven Annäherung zeigte sich die stärkere Zusammenarbeit der Schulen auch in der gemeinsamen Mitarbeit in verschiedenen Gremien. Beispielsweise nahmen Laizisten und Katholiken an verschiedenen Gremien teil, unter anderem an den Sitzungen eines Komitees zum Schutz der Kindheit, das 1936 gegründet worden war ${ }^{95}$. Die Vertreter der französischen Schulen engagierten sich außerdem in der 1934 vom Hochkommissariat gegründeten »Ratgeberversammlung« (Réunion des Conseillers), in welcher sie über pädagogische Fragen diskutierten und die von ihnen genutzten Modelle und Bücher zur Debatte stellten ${ }^{96}$. Die Mandatsmacht unterstützte diese Kooperationen ausdrücklich, beispielsweise schlug der Hochkommissar 1936 vor, die Direktoren der katholischen, laizistischen und jüdischen Schulen zur Mitarbeit in einer Société nationale d'Encouragement au Bien einzuladen ${ }^{97}$.

Auf das Gefühl der Bedrohung von außen reagierten die französischen Schulen ferner mit einer Verteidigung des französischen Einflusses im Libanon. Das zeigte sich in einem erneut auffällig häufigen Bezug auf die Idee der mission civilisatrice. So formulierte der Jesuitenpater Jalabert während einer Konferenz in Leuven 1935: »[...] dans les écoles de ses [er spricht von Frankreich, E. M.] religieux [...] on enseignât le français, et [...] avec notre langue, notre civilisation se répandît $[\ldots] \ll^{98} .1938$ bekräftigte er die zentrale Rolle der Schule für diese Zivilisierungsmission: „C'est par elle [die französische Sprache, E. M.] que nous avons le meilleur moyen d'action et de civilisation dans le pays $«{ }^{99}$. Der Diskurs der mission civilisatrice in den französischen Schulen, insbesondere den katholischen, zeigte auch nach Mandatsende eine große Kontinuität. Diese Beständigkeit von Diskursen und Praktiken, die sich während der Mandatszeit formalisiert hatten, wurde von den Schulen und den französischen Autoritäten gleichermaßen gepflegt. Beispielsweise wurde 1948 einem Lazaristen die Ehrenlegionswürde zuerkannt mit

95 »Un groupe de Français s'est réuni pour étudier des projets de protection de l'enfance [...] toutes croyances [...] le P. le Génissel fait partie du comité ainsi que le Proviseur«. SJ/ Vanves, »Fonds Jalabert«, 26/L, Brief von Sautier an Jalabert, Beirut, 18.01.1936. Die Mission laïque hatte schon in den 1920er Jahren mit der amerikanischen Universität und anderen lokalen Schulen zusammengearbeitet, so zum Beispiel für den Aufbau einer »section interscolaire d'éclaireurs à Beyrouth«. Die Vertreter der lokalen Schulen kamen unter anderem von der griechisch-katholischen Schule »collège patriarcal« und dem maronitischen »Collège de la Sagesse«. Vgl. AN/Paris, 60 AJ 125, »Rapports mensuels«, Dezember 1922. In dieser Zeit war das Verhältnis der MLF zur AUB noch nicht von einem Gefühl der Konkurrenz dominiert, weil die Amerikaner ihre »French Section« noch nicht aufgebaut hatten.

$96 \mathrm{SJ} /$ Beirut, 8.C.21, Bericht über die »Réunion des Conseillers«.

97 MAE/Nantes, IP, 230, »Société nationale d'Encouragement au Bien«, Brief von de Martel an den französischen Außenminister, Beirut, 28.01.1936.

$98 \mathrm{SJ} /$ Vanves, »Fonds Jalabert«, 1 1/C: »Deux conférences de L. Jalabert à l'Université catholique du Louvain les 10 et 11 décembre $1935 \ll$.

$99 \mathrm{SJ} /$ Vanves, »Fonds Jalabert«, 7-1/K, Brief von Jalabert an Sautier, Paris, 19.05.1938. 
der Begründung, er höre nicht auf, der »cause française au Levant« selbstlos und mit Eifer zu dienen ${ }^{100}$. Auch Bounoure, nach der libanesischen Unabhängigkeit in der Kulturabteilung der französischen Botschaft tätig, schloss sich den Glückwünschen an, denn niemand habe »mieux servi l'idée religieuse et l'idée française $\ll^{101}$.

Ebenso rekurrierte die Alliance israélite universelle in den Jahren um 1935 sehr oft auf den Begriff der »civilisation française $« ~^{102}$. Im November 1936, wenige Tage vor Unterzeichnung des franko-libanesischen Vertrages, stellte die Direktorin der Mädchenschule Esther Penso voller Euphorie noch einmal das »œuvre éducative et civilisatrice« der Alliance israélite, das diese dank der großzügigen Hilfe Frankreichs, »notre protectrice séculaire«, leisten könne, heraus ${ }^{103}$. Bei der Mission laïque betonte Direktor Ruche ebenfalls 1934 als Ziel seiner Schule »garder nos élèves à la culture française « ${ }^{104}$, und 1938 hob Grandjouan den Beitrag der Schulen zur Verbreitung der »culture française $\ll$ hervor ${ }^{105}$.

Es fällt auf, dass die Vertreter der laizistischen Organisation den Begriff der Kultur in dieser Zeit sehr viel häufiger benutzten als den der Zivilisation, welcher hingegen zum vertrauten Vokabular der katholischen Orden geworden war. Auch wenn diesbezüglich keine belegten Äußerungen vorliegen, ist es möglich, dass die Mission laïque sich mit dieser Wortwahl von den katholischen Schulen abgrenzen wollte. Da sie darüber hinaus auch bezüglich des Libanons von dessen $»$ culture nationale $\ll^{106}$ sprach, kann aber auch vermutet werden, dass die Laizisten, bewusst oder unbewusst, auf die arabischen Nationalisten reagierten. Diese orientierten, wie für den pan-arabischen Nationalisten Sātii al-Huṣrī gezeigt wurde, ihren Nationenbegriff eher an dem deutschen als an dem französischen oder englischen Verständnis von Nation ${ }^{107}$

100 LAZ/Paris, »Beyrouth - Notes pour l'Histoire«, Brief an A. Gendre (Visiteur Provincial des Lazaristes, Beyrouth), Beirut, 19.02.1948.

101 Ebd., Brief von Bounoure an Gendre, Beirut, 25.03.1948.

102 AIU/Paris, Paix et Droit, Janaur 1936; siehe auch Paix et Droit, Oktober-Dezember 1939, S. 8: Dort wird sie mit »civilisation de Racine et de Pascal« umschrieben.

103 AIU/Paris, »Liban VIIE 81-86«, Brief von Esther Penso an den Präsidenten der Alliance israélite, Beirut, 05.11.1936.

104 AN/Paris, 60 AJ 136, »Comité de patronage«, Sitzungsprotokoll vom 29.03.1934.

105 AN/Paris, 60 AJ 140, Brief von Grandjouan an Besnard, Beirut, 08.01.1938. In diesem Brief spricht er sich gegen die französische Schule der AUB aus, denn im Gegensatz zu ihrer Schule sei »l'œuvre de cette école [...] loin d'être utile à la culture française et à la cause française«.

106 Revue de l'enseignement français hors de France 30 (1933), S. 104.

107 Vgl. Dueck 2010, S. 82; William L. Cleveland, The Making of an Arab Nationalist. Ottomanism and Arabism in the Life and Thought of Sati' al Husri, Princeton 1971, S. 85: »[...] he himself was largely a man of French culture and outlook. His ideas on nationalism, however, stemmed more from the German romantic nationalists«. Suleiman 2003, S. 131, betont aber auch die Unterschiede zwischen der deutschen Romantik und dem Denken al-Ḥuṣris, da letzterer unter anderem die Idee einer »ursprünglichen« Sprache und eines »ursprünglichen« Volkes ablehne. 
und rekurrierten deshalb stärker auf Kultur als auf Zivilisation. 1933 druckte die Zeitschrift der Mission laïque Auszüge eines Buches ab, dessen französische Autorin zwar die Mandatspolitik kritisierte, aber doch den Wunsch äußerte, Frankreich bliebe in Syrien »pour y accomplir >la mission sacrée de civilisation qui lui fut confiée $\ll «^{108}$. Mit der unkommentierten Veröffentlichung dieses Werkes zeigte die Mission lä̈que ihr Einverständnis mit der dargelegten Position.

Ferner reagierten die Schulen auf die empfundene Bedrohung mit der Verteidigung des Mandatsregimes, das sie als Schutz ihrer Institutionen und ihres Status' wahrnahmen. So betonten die Jesuiten in Beirut ihre Unterstützung für eine Fortdauer des Mandats. In seinen Ansprachen zu Beginn der akademischen Jahre 1933, 1934 und 1935 wies Rektor Beauregard auf die zentrale Rolle der Treue gegenüber der Tradition des französischen Protektorats hin, die den Libanon bis dahin gekennzeichnet hätten ${ }^{109}$. In diesem Sinne kritisierte er 1936 den franko-libanesischen Vertrag als voreilig und ließ verlauten, dieser sei der Idee der Kooperation beider Länder nicht angemessen: »Puisque collaborer c'est agir, on croirait volontier que pour le faire, il ne faut que s'attéler résolument à la besogne commune et tirer le char à plein collier « ${ }^{110}$.

Ebenso machten die französischen Schulen auch auf emotionaler Ebene deutlich, wie sehr sie sich mit der Mandatsmacht identifizierten. So wurde der Direktor der Schule der Lazaristen in Ayntoura, Ernest Sarloutte, in einem Artikel der Ehemaligenzeitschrift regelrecht als Personifizierung des uneigennützigen Werkes der Mandatsmacht konstruiert: »[...] la vie d'abnégation et de sacrifice du R.P. Sarloutte [...] est le signe même de l'œuvre désintéressée accomplie dans nos pays par la Puissance Mandataire $\ll^{111}$. Die Betonung der emotionalen Verbundenheit ging natürlich oft einher mit existentiellen Belangen, wie der Fortführung der finanziellen Unterstützung durch die französische Regierung. Um diese Verbindung zu unterstreichen, schickte der Jesuitenpater Delore, der in den libanesischen Bergen viele Dorfschulen unterhielt, mit seinen Bitten um Subventionen auch Fotos mit, die von der Verbundenheit der Schulen und Schüler mit Frankreich zeugten: „Vive la France! L. Khoury« stand auf einer Tafel, vor der ein kleiner Junge, wahrscheinlich besagter L. Khoury, posierte ${ }^{112}$.

108 Revue de l'enseignement français hors de France 30 (1933), H. 103, Bibliographie: V. de Saint Point, »La vérité sur la Syrie«, S. 155.

109 Siehe den Abdruck seiner Reden in der Schulzeitschrift L'U der Jahre 1933, 1934, 1935.

110 Vgl. NDJ, L'U, 5/Januar 1936, »Discours de Rentrée des Facultés. Allocution du R.P. Costa de Beauregard, Recteur de l'Université Saint-Joseph, à la Messe du Saint Esprit le 10 novembre $1935 \ll$, S. 7-13, S. 8.

111 LAZ/Paris, Association amicale des anciens élèves d'Antoura. Bulletin annuel, Mai 1938, S. 26-27: »Le R.P. Sarloutte Commandeur de la Légion d'Honneur (Libanaise)«.

112 MAE/Nantes, SOFE, 376, »Affaire Père Delore«. Vgl. Abb. 5. 


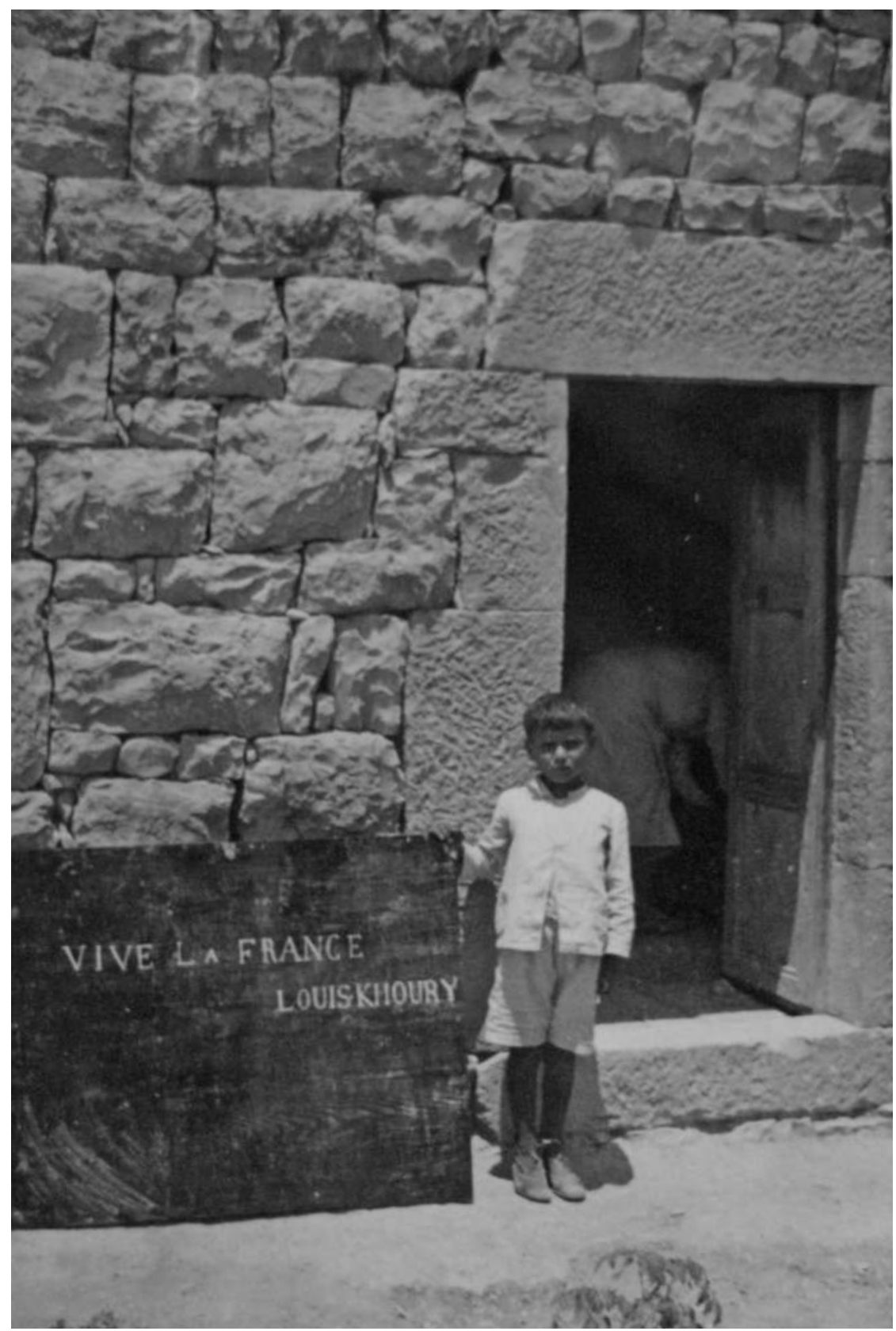

Abb. 5: Foto, das einem Schreiben des Jesuitenpaters Joseph Delore an das französische Außenministerium im Jahr 1936 beilag. Quelle: MAE/Nantes, SOFE, 376, Brief von Delore, Ghazir, 30.08.1936. 
Als 1943 die libanesische Unabhängigkeit ausgerufen wurde und die libanesische neben der französischen Flagge über der Universität der Jesuiten wehte, strich der Direktor in der Schulzeitschrift noch einmal die Treue als oberstes Prinzip über dem Nationalismus heraus und brachte damit seine Hoffnung zum Ausdruck, dass die enge Beziehung der libanesischen Katholiken zu den Jesuiten und darüber hinaus zu Frankreich auch nach der Unabhängigkeit bestehen bliebe ${ }^{113}$. Die Alliance israélite wiederum betonte insbesondere die militärische Sicherheit, die das Mandat für sie bedeutete. Während die Muslime sich, so Direktor Penso nach Abschluss des Vertrages 1936, am »Höhepunkt des Deliriums« vor Freude befanden, hob er die Bedeutung der äußeren Symbole der französischen Herrschaft hervor, die nun bald der Vergangenheit angehören würden:

Le régime du Mandat prendra bientôt fin. La Syrie et le Liban, la Syrie surtout, manifeste bruyamment sa joie. Les musulmans, de ces deux pays, sont au paroxysme du délire. >Plus de mandat, plus de Français. Indépendance complète, entière, absolue. Nous serons nos maîtres; ni tuteur, ni gêneur<. L'Islam triomphe. [...]

Tant que le drapeau français flottait sur nos têtes, nous nous sentions en pleine sécurité. L’armée française nous protégeait. Le Haut-Commissaire réprimait vite les abus et faisait redresser tous les inquiets ${ }^{114}$.

Da ihr Vertrauen in Frankreich zwar bestehen bleibe, aber in diesen »moments anxieux« erschüttert sei, so der Direktor weiter, könnten sich die syrischen Juden nur an die Alliance israélite, »leur généreuse protectrice, leur mère toujours aimante et pleine de sollicitude « wenden ${ }^{115}$. Damit wendeten sie eine Bezeichnung, die sie oft für Frankreich gebraucht hatten, nun auf ihre eigene Institution an. Als fürsorgende und beschützende Mutter hatte sich auch die Mandatsmacht selbst immer wieder inszeniert ${ }^{116}$.

Manche libanesische Schulen rekurrierten gleichermaßen auf diese starke emotionale Aufladung des Mandatsregimes. In einem Brief an den Präsidenten der französischen Nationalversammlung Édouard Herriot beschrieb der libanesische Pater Michel Ehmeji, welcher sich als »simple moine libanais, directeur d'une école purement française« vorstellte, Frankreich als »Mère protectrice« und bat gleichzeitig um finanzielle Zuwendung ${ }^{117}$. Ehemejis Anfrage wurde durch verschiedene Instanzen gegeben und schließlich mit einer Empfehlung an den Hochkommissar im Libanon weitergeleitet.

113 NDJ, Nous du Collège, 72, 12.08.1943, S. 4: »Fidélité«.

114 AIU/Paris, »Liban 1 C 1«, Brief des Direktors in Beirut an den Präsidenten der Alliance israélite in Paris, Beirut, 19.06.1936.

115 Ebd.

116 Vgl. Thompson 2000, S. 58.

117 MAE/Nantes, SOFE, 376, Brief von Michel Ehmeji an Herriot, Meyfouc, ohne Datum. 
Schließlich drückten auch die Verantwortlichen der Mission laïque, obgleich weniger enthusiastisch als Sarloutte, ihr Zugehörigkeitsgefühl zum Mandat und damit zu Frankreich aus. Beispielsweise schilderte Direktor Ruche das nahende Ende des Mandats als eine Situation, die seiner Schule viele neue Zwänge aufbürde ${ }^{118}$, und Generalsekretär Besnard, der in der Regel sehr darauf bedacht war, die Interessen der Libanesen und Syrer zu berücksichtigen, schrieb an seinen Freund Jean Marx im französischen Außenministerium: »Certes, j'aime bien la Syrie, mais j'aime mieux la France et souffre réellement de voir comment on en parle « ${ }^{119}$.

Einige Positionen innerhalb der Mission laïque spitzten sich gegen Ende der 1930er Jahre noch stärker zu und spiegelten die allgemeine Entwicklung in den nationalistischen Milieus der französischen Community in der Levante: Deren pro-französischen Gefühle wurden nach der militärischen Niederlage Frankreichs gegen Deutschland im Juni 1940 noch verstärkt. Sie spiegelten die Entwicklung in Frankreich selbst wider, wo das Vichy-Regime und seine Anhänger die Bedeutung der Kolonien und des Empire für das Mutterland hervorhoben und zu einer Wiedergeburt ihres Landes durch die Kolonien aufriefen ${ }^{120}$. Der Einfluss dieser Ideen auf die französischen Schulen im Libanon zeigt sich beispielsweise in einem Brief, den zwei französische Väter von Schülern an der Mission lä̈que an Hochkommissar Dentz schrieben, in dem sie sich über einige namentlich genannte Lehrer empörten, die ihrer Meinung nach als ehemalige Kommunisten und jetzige Opportunisten die Erziehung der Kinder und das Ansehen Frankreichs stark schädigten. Als Konsequenz baten sie um die »Reinigung« der Schule von diesen »Elementen«:

Un peu de nettoyage par là, Monsieur le Général, et le prestige de la France y gagnera ce que le parti communiste y perdra, le Lycée Français retrouvera alors la place de choix qui aurait toujours dû être la sienne, parmi les établissement [sic!] scolaires des Etat [sic!] sous Mandat ${ }^{121}$.

118 AN/Paris, 60 AJ 130, Brief von Ruche an Besnard, Beirut, 04.02.1928: »Il est certain qu’à mesure que nous nous rapprochons de l'émancipation définitive des peuples sous mandat les exigences de leurs jeunes nationalismes seront plus impérieuses et plus taquines qu'elles ne le sont actuellement«.

119 MAE/Nantes, SOFE, 223, Brief von Besnard an Marx, 06.05.1930.

120 Vgl. Pascal Blanchard/Ruth Ginio, Révolution impériale: le mythe colonial de Vichy, in: Pascal Blanchard/Sandrine Lemaire (Hg.), Culture impériale. Les colonies au cœur de la République, 1931-1961, Paris 2004, S. 125-143. Die Autoren machen aber auch deutlich, dass sich die Anhänger de Gaulles ebenfalls dieser Logik bedienten.

$121 \mathrm{MAE} /$ Nantes, IP, 169, »Lycées de Beyrouth «, Brief an Dentz von zwei Eltern (Namen unleserlich), Beirut, 15.01.1941. 
Auch wenn die beiden Eltern sicher nicht die Haltung aller Lehrer und Eltern der Mission laïque vertraten, führte ihre Initiative doch zu der Bitte des Direktors Latrouite an den Bildungsbeauftragten des Hochkommissariats, die zwei libanesischen Lehrer Georges Attieh und Nassib Mokarem entlassen zu können, ersteren wegen unbefriedigender professioneller Arbeit (»activité professionnelle insuffisante«) und letzteren, da seine Stelle nicht mehr notwendig sei (»dont le poste peut être supprimé «) $)^{122}$. Da aber beide in dem Elternbrief als Kommunisten bezeichnet worden waren, scheinen politische Motive für ihre Entlassung ausschlaggebend gewesen zu sein ${ }^{123}$.

Mit der dargelegten gegenseitigen Annäherung der verschiedenen französischen Einrichtungen im Libanon zeigte sich zum ersten Mal das einigende Potential der Idee der Zivilisierungsmission, welches Politiker und Gelehrte schon so lange propagierten ${ }^{124}$. Ohne das Gefühl der äußeren Bedrängung hätte diese Entwicklung wahrscheinlich so nicht stattgefunden. Auch wenn die Schulen also einerseits das Mandat verteidigten, öffneten sie sich, teilweise notgedrungen, andererseits auch dem neuen Status des Libanon. Diese ambivalente Position, die Individuen und Gruppen insbesondere in der Übergangsphase zwischen kolonialen und postkolonialen Regimen kennzeichnet, zeigt sich hiermit auch bezüglich des Mandatsregimes.

\section{Die Schulen als Forum für nationalistische Bewegungen}

Eng verbunden mit dem Gefühl der Bedrohung durch äußere Faktoren, die die Bedrohung der Position Frankreichs in der Levante durch die außenpolitischen Interessen anderer westlicher Mächte wiederspiegelte, waren für die französischen Schulen die Entwicklungen innerhalb der libanesischen Gesellschaft. Die Ausweitung der Kritik am Mandatsregime auf weitere Kreise führte zu neuen politischen und religiösen Konstellationen und Bewegungen, die sich auch auf die Klientel der französischen Bildungseinrichtungen auswirkte. Auch wenn die Schulen, wie dargelegt, das Mandat und den französischen Einfluss im Libanon verteidigten, bemühten sie sich innerhalb der Schulmauern um ein Klima politischer Neutralität. Gleichzeitig boten sie den diversen nationalistischen Bewegungen, die sich um die verschiedenen französischen Einrichtungen gruppierten, ein Forum, welches sie mehr oder weniger aktiv unterstützten. Schließlich haben sie alle in dieser Zeit verstärkt oder ganz neu ihren Beitrag zum Aufbau und zur Entwicklung der libanesi-

122 Vgl. ebd., Brief von Latrouite an Bounoure, Beirut, 20.05.1941.

123 Ein anderes Motiv war, wie in Frankreich, die Zugehörigkeit zum Judentum. So bat Latrouite auch um die Entlassung von Michel Lévy. Vgl. ebd., Notiz vom 01.05.1941: »Personnel dont il y a lieu de prévoir le départ«.

124 Vgl. Kapitel 1. 
schen Nation betont. Diese drei Aspekte sollen im Folgenden nach der Darstellung der punktuellen Auflösung traditioneller Partnerschaften zwischen den Institutionen und ihren Klienten erläutert werden.

Das Gefühl der Verunsicherung vieler französischer Schulen angesichts des nahenden Mandatsendes wurde noch dadurch verstärkt, dass es teilweise zur Veränderung in der Zusammensetzung ihrer traditionellen Klientel kam, die nur zum Teil durch die höhere Attraktivität anderer westlicher Einrichtungen begründet und darüber hinaus sowohl finanziell als auch politisch motiviert war. Die Mission laïque verlor Mitte der 1930er Jahre Teile ihrer angestammten Klientel, welche sich aus den griechisch-orthodoxen und muslimisch-sunnitischen Gemeinschaften zusammensetzte ${ }^{125}$, während die katholischen Schulen auf eine kritischere Haltung der katholischen Libanesen gegenüber dem Mandat reagieren mussten.

Direktor Grandjouan von der Mission lä̈que bedauerte vor allem den Weggang der wohlhabenden sunnitischen Familien und bemerkte, die Schule sei von einer aristokratischen zu einer demokratischen geworden ${ }^{126}$. Für viele Familien waren aber auch die hohen Schulgelder der laizistischen Schulen weder zu bezahlen noch nachzuvollziehen. Gerade für die aufstiegsorientierte Mittel- und Unterschicht waren Nähe zum Wohnhaus und Bezahlbarkeit die zentralen Auswahlkriterien für die eine oder andere Schule ${ }^{127}$. So schrieb der Journalist einer arabischsprachigen Beiruter Zeitung im Herbst 1934:

Das säkulare College [al-kullīya al-'almānīya] erhält viel Schulgeld für die Verbreitung der säkularen Kultur, nicht für die finanzielle Bereicherung.

Wir danken dem säkularen College für seine Mühen in der Verbesserung der Jugend des Landes und für seine Demonstration der wahren säkularen Kultur; deshalb gibt es dort keine Spur von religiösem oder rassischem Fanatismus. Aber mit unseren Gefühlen können wir nicht über seine Schulgelder hinweggehen; wer an ihm vorbei geht, klagt nicht über die Gier [der Schule]; obwohl sie viele Schüler hat, und obwohl die Freidenker gute Werbung für sie machen, nimmt die Schule noch viele Gebühren, genau wie die Universität der Jesuiten und wie die Schule der Frères. [...] Die Verwaltung des säkularen College scheint nicht die Krise und die finanzielle Notlage zu fühlen, oder wenn es sie fühlt, kümmert es sie nicht. [...]

Das säkulare College trägt eine Verpflichtung, nicht nur für den Unterricht, sondern auch für die Verbreitung der säkularen Kultur im Libanon und in Syrien, wie es Monsieur Besnard am Ende seines Besuches in Beirut erklärt hat. Und deshalb muss

125 Vgl. die Tabelle im Anhang.

126 Vgl. AN/Paris, 60 AJ 138, »Correspondance 1935-1936«, Brief von Grandjouan an Besnard, Beirut, 18.02.1936.

127 Vgl. Schumann 2001, S. 213. 
diese Kultur möglichst viele Studenten erreichen. Das säkulare College möchte, dass die Väter es lieben, damit sie ihre Kinder auf die Schule schicken und deren Schulgeld bezahlen. Und in diesem Geist gibt es in einigen Instituten weit weg von Beirut viel mehr Studenten, weil die Gebühren dort niedriger sind. Und wenn das säkulare College Einspruch erhebt, weil es für seine Lehrer hohe Gehälter bezahlen muss, im Gegensatz zu den Jesuiten, welche nichts oder wenig bezahlen, antworten wir, dass dieses nicht begründet, warum es seine Gebühren denen der Jesuiten-Universität anpasst. Denn in diesem Land gibt es viele Schulen und Fakultäten außer den Jesuiten, welche ihre Lehrer genauso bezahlen wie das säkulare College, und ihre Gebühren sind hundert Prozent billiger ${ }^{128}$ !

Manche muslimische Familien schickten ihre Kinder nun auch auf die neu entstandenen oder modernisierten islamischen Schulen. Da die französische Regierung einige von diesen Einrichtungen in den 1930er und 1940er Jahren besonders förderte, wurde für die Eltern der Besuch einer französischen Schule noch weniger attraktiv ${ }^{129}$. In einem Bericht an die Kulturabteilung des Quai d'Orsay beschwor Generalsekretär Besnard deshalb die Notwendigkeit, den Eltern der Mission laïque finanziell entgegenzukommen, sei es durch längere Zahlungsfristen, Stipendien oder die Freistellung vom Schulgeld - Hauptsache, so Besnard, man könne der Krise und der Konkurrenz standhalten $^{130}$. Die laizistische Organisation setzte diese Notwendigkeit in die Tat um, reagierte auf die in Beirut lautgewordene Kritik und kürzte ihr Schulgeld im Herbst 1936 massiv $^{131}$.

Nichtsdestotrotz wandten sich einige muslimische Eltern auch katholischen Schulen zu. So zog sich 'Umar Da'uq, bis dahin ein verlässlicher Partner der Mission lä̈que française, wegen Streitpunkten mit Direktor Ruche vor allem um materielle Fragen, merklich von dieser zurück ${ }^{132}$. Erst ein Jahr nach seinem Amtsantritt begegnete der neue Direktor Grandjouan ihm zum ersten Mal, da Da'uq wieder Mitglied des Elternkomitees war ${ }^{133}$. In dieser

128 Artikel »al-Kullīya al-'almānīya«, ohne Autor, Datum und Name der Zeitung. Direktor Ruche schickte diesen Artikel am 30.09.1934 nach Paris. Vgl. AN/Paris, 60 AJ 137.

129 Vgl. Jennifer DuEck, A Muslim Jamboree: Scouting and Youth Culture in Lebanon under the French Mandate, in: French Historical Studies 30 (2007), S. 485-516, S. 504.

130 MAE/Nantes, SOFE, 378, »Budgets des écoles MLF Syrie 1935-1936«, 04.04.1936: »Il faut faire des concessions pour attirer ou garder des élèves, consentir des délais de paiement, accorder bourses et exonérations partielles...bref faire face, avce le plus de souplesse possible, aux difficultés nées de la crise et de la concurrence«.

131 Laut Bericht des Collège protestant français betrug die Kürzung sogar 50\%, was der protestantischen Schulen aber nicht wie befürchtet viele Schüler abstreitig machte. Vgl. PPFL, »Comptes-rendus du Conseil d'Administration 1925-1950«, Sitzung vom 09.10.1936.

132 Vgl. AN/Paris, 60 AJ 137. In einem Brief vom 21.09.1935 bat die Zentrale in Paris Ruche dringend um die Beilegung seines Streites mit Da uq, einem »vieil ami du Lycée«.

133 AN/Paris, 60 AJ 138, Brief von Grandjouan an Besnard, Beirut, 20.01.1936. 
Zeit engagierte sich Da uq unter anderem als Präsident der 1938 entstandenen Ehemaligenvereinigung der Schule der Lazaristen in Ayntoura ${ }^{134}$. Da diese Gruppierung viele einflussreiche Männer umfasste, zu denen Da'uq zählte und weiter zählen wollte, ist seine Entscheidung sowohl aus persönlichen als auch aus machtpolitischen Motiven heraus zu erklären: nach 1933 zählte Da uq zu den Vertreten der führenden sunnitischen Familien, die akzeptiert hatten, offizielle Posten in den legislativen und exekutiven Institutionen des libanesischen Staates anzunehmen ${ }^{135}$, und diese Tendenz wurde nach Abschluss des franko-libanesischen Vertrages, der die Grenzen des Staates festlegte, noch einmal verstärkt.

Zusätzlich führte die neue Kritik der Maroniten am Mandatsregime und die stärkere Konfessionalisierung und Faktionalisierung unter Maroniten und Sunniten gleichermaßen ${ }^{136} \mathrm{zu}$ einem engeren Zusammenschluss von Vertretern der Eliten unterschiedlicher Konfessionen ${ }^{137}$, der dadurch noch gefestigt wurde, dass man sich gemeinsam gegen neu entstehende Parteien und Eliten aus der Mittelklasse zur Wehr setzen wollte ${ }^{138}$.

Während sich einige Muslime von Mission laïque zurückzogen ${ }^{139}$, stieg der Proporz christlicher Schüler stark an. Hatten die mit Rom unierten Gemeinschaften bis Ende der 1920er Jahre weniger als die drittstärkste Gruppe gestellt, wuchs ihr Anteil ab 1930 merklich und stellte im November 1935 sogar die Mehrheit in der Jungenschule der Mission laïque ${ }^{140} .1938$ bildeten aber wieder die sunnitischen Schüler die größte Gruppe ${ }^{141}$. Interessanterweise blieb der Anteil der sunnitischen Schülerinnen in der Mädchenschule

134 Vgl. Kapitel 6.4.

135 Vgl. Firro 2003, S. 134.

136 Für die Maroniten siehe Ebd., S. 128; für die Sunniten siehe Ebd., S. 149-150. Die These der stärkeren Konfessionalisierung der Sunniten bestätigt unter anderem der in Kapitel 5.2 zitierte Zeitungsartikel, der voller Überraschung von der Teilnahme muslimischer Schüler der Mission laïque am Freitagsgebet in der Moschee berichtet.

137 Zamir 2000, S. 166, berichtet von einem gemeinsamen Protest führender Händler und Financiers christlicher und muslimischer Herkunft, darunter Michel Chiha und 'Umar Da'uq, gegen das Tabakmonopol im Mai 1936.

138 Vgl. FirRo 200, S. 130-131.

139 Auch wenn sich einige Muslime von der Mission laïque zurückzogen und damit unter anderem die Kritik der arabischen Nationalisten an der Mandatspolitik zum Ausdruck widerspiegelten, war die Situation aber nicht so angespannt wie in Syrien, wo sowohl die Schulen der Mission laïque als auch die Franzosen sehr viel härtere Kritik der Bevölkerung erfuhren. So schilderte Generalsekretär Besnard im März 1936 die Schwierigkeiten der Organisation in Aleppo, wo die Muslime sehr aufgebracht seien. Vgl. MAE/Nantes, SOFE, 378, »Etablissements de la Mission Laïque en Syrie«, Brief von Besnard an das SOFE, Paris, 14.03.1936.

140 Vgl. AN/Paris, 60 AJ 138, »Religion et nationalité des élèves«, November 1935: Die drei meistrepräsentierten Gemeinschaften waren zu diesem Zeitpunkt die lateinischen Christen (104 Schüler), Sunniten (101 Schüler) und Griechisch-Orthodoxen (38 Schüler). Vgl. auch die Zahlen der Tabellen im Anhang.

141 Vgl. MLF/Paris, 60 AJ 140, »Statistique des élèves«, 1937-1938. 
gleichbleibend sehr hoch ${ }^{142}$. Auch die Zusammensetzung im Elternkomitee bezeugte Ende 1937 noch eine sunnitische Mehrheit ${ }^{143}$, was den Rückzug muslimischer Familien etwas relativiert. Der höhere Anteil katholischer Schüler in der Jungenschule lässt sich zum einen mit der gestiegenen Anzahl französischer Staatsangehöriger erklären ${ }^{144}$. Dasselbe Phänomen existierte auch in den katholischen französischen und protestantischen Schulen im Libanon $^{145}$. Hinzu kam zum anderen, dass nun auch libanesische katholische Kinder verstärkt die laizistische Schule besuchten.

Die Folge war eine stärkere christliche Prägung der Schulen der Mission laïque française in Beirut. Dies war neben der oben dargelegten Annäherung der Schulen ein weiterer Grund für die plötzlich positive Berichterstattung christlicher libanesischer Zeitungen über die laizistische Schule ${ }^{146}$. Nach dem Zweiten Weltkrieg verstärkte sich die Nähe der Mission lä̈que zum christlichen Milieu noch. So heißt es in den Memoiren eines französischen Lehrers, der 1946 an die Schule kam, alle seine Kollegen würden im (christlich dominierten) Stadtteil Achrafieh leben - ein sicheres Indiz für das Milieu, in dem sie sich zuhause fühlten ${ }^{147}$.

Als ein weiterer Grund für diese Entwicklung muss die plötzliche Distanz des neuen maronitischen Patriarchen 'Arịḍa zu Frankreich ${ }^{148}$ und in der Folge auch zu den katholischen Schulen ins Feld geführt werden, die insbesondere die Jesuiten stark beschäftigte. In einem Brief an Jalabert nach Paris 1936 bedauerte der Direktor der Jesuitenschule in Beirut die Auflösung ihrer traditionellen Nähe zum maronitischen Oberhaupt sehr:

142 Vgl. MLF/Paris, 60 AJ 138, »Statistique des élèves«, 1935-1936: Die drei am stärksten repräsentierten Gemeinschaften waren die Sunniten (105 Schülerinnen), lateinischen Christen (86 Schülerinnen) und Griechisch-Orthodoxen (40 Schülerinnen).

143 Vgl. AN/Paris, 60 AJ 140, Liste der Mitglieder des »Comité de Patronage«: Die Liste vermerkt 9 Sunniten, 2 Drusen, 2 Freimaurer, 1 Maroniten, zwei Griechisch-Orthodoxe und einen »m.ch.« [evtl. musulman chiite, also ein Schiit, E.M.] unter den Mitgliedern.

144 Von 1930 bis 1935 stieg die Zahl französischer Schüler und Schülerinnen von 67 auf 202 an, aber die Zahl libanesischer Zöglinge blieb mit 455 Im Jahr 1930 und 371 im Jahr 1935 immer noch die höchste. Vgl. ebd.

145 Für die Schule der Lazaristen in Ayntoura vgl. Hachem 2003, S. 231. Für das Collège protestant français vgl. Eyrard/KREBS 2007, S. 157: Zwischen 1933 und 1938 nahm der Anteil libanesischer Schülerinnen von $69 \%$ auf 54\% ab, der französischer Zöglinge von 16\% auf 19\% zu; allerdings stieg auch der Anteil arabischer Schülerinnen aus dem Nahen Osten insgesamt von $4,9 \%$ auf $16,7 \%$.

146 Vgl. L'Orient, 10.09.1931: »Lycée Français de la Mission laïque«. Auch die Jesuiten berichteten nun positiv über die Tätigkeiten Grandjouans, zum Beispiel über seinen Vortrag im Januar 1936. Vgl. AN/Paris, 60 AJ 139.

147 Vgl. LeFĖVRe 2004, S. 115.

148 Nach Abschluss des franko-libanesischen Vertrages näherte sich 'Arīụa Frankreich wieder an. Auch wenn er für seinen Wendekurs von der zeitgenössischen Presse stark kritisiert wurde, sieht FIRro 2003, S. 144, in seiner Haltung weniger Widersprüche als vielmehr die Bestätigung der Prioritäten 'Arīụas: das Wohl seiner, der maronitischen Gemeinschaft. 
Espérons que tout se calmera et se tassera peu à peu. Il est certain que Bekerké [Sitz des maronitischen Patriarchen, E.M.] n'a pas le beau rôle depuis bien des mois et cela aussi, la perte d'influence aux dépens des Syriens et des traditions met beaucoup d'amertume humiliée au cœur de nos amis maronites...sans leur donner raison, je le regrette pour eux et avec eux, car malgré tout, ce sont eux qui ont dans ce pays le cœur le plus français et le plus catholique ${ }^{149}$.

'Arị̣̂a sympathisierte mit den syrischen Nationalisten ${ }^{150}$, was den Jesuiten gar nicht behagte. In einem weiteren Brief nach Paris berichtete Sautier voller Entsetzen, dass sich der Patriarch sogar mit den Muslimen verbündet hätte: »Il m'a dit textuellement: >[...] les musulmans sont avec nous, et nous entendrons aussi leur voix. [...] Nous voulons défendre notre peuple de la corruption de l'Occident, et nous sommes prêts à tout pour cela< $[. . ..] \ll^{151}$. Die Jesuiten waren sich zwar noch der Verbundenheit einiger maronitischer Bischöfe wie 'Abdallāh Hūrēi sicher, welcher die Ansichten 'Arīụas nicht teilte' ${ }^{152}$. Aber ihr Bemühen bei Hochkommissar de Martel, den Patriarchen abzusetzen, scheiterte $^{153}$. Außerdem spürten die Jesuiten deutlich die Ablehnung, die Frankreich auch von einigen maronitischen Schulen wie der Madrasat al-hikma (Collège de la Sagesse) entgegenkam.

Diese Schule, die 1874 von dem maronitischen Erzbischof von Beirut, Joseph Debs gegründet worden war, hatte in den 1930er Jahren in der Tat unter ihren Schülern viele Anhänger des libanesischen Nationalismus ${ }^{154}$. Allerdings muss betont werden, dass diese feindliche Stimmung auch von der französischen Regierung und den französischen Schulen im Libanon besonders hervorgehoben wurde. Letztere nahmen die maronitische Einrichtung als Konkurrenz wahr, weil diese nun verstärkt auch das französische Curriculum anbot und so die Eltern erreichte, die ihre Kinder sonst auf eine französische Schule geschickt hätten ${ }^{155}$. So berichtete der Direktor der Jesuitenschule in Beirut im Januar 1936 von der Aufführung eines Theaterstücks in dieser Schule und von der anschließenden Rede des Bischofs Bustānī, die vom libanesischen Patriotismus und der Kritik an Frankreich von Seiten des Publikums zeugte:

\footnotetext{
$149 \mathrm{SJ} /$ Vanves, »Fonds Jalabert«, 26/L, Brief von Sautier an Jalabert, 21.01.1936.

150 Vgl. Firro 2003, S. 138.

$151 \mathrm{SJ} /$ Vanves, »Fonds Jalabert«, 26/L, Brief von Sautier an Jalabert, 16.02.1935.

152 Vgl. ebd., Brief von Sautier an Jalabert, 04.03.1935. Vgl. auch ZAMIR 2000, S. 171-173.

153 Vgl. Zamir 2000, S. 171-173.

154 Vgl. Dueck 2010, S. 208.

155 Vgl. ebd., S. 96.
} 
[...] il termine: ^Vive le Collège de la Sagesse < [...] tonnerre d'applaudissement; ১vive la France < [...] silence glacial; il ajoute alors rapidement: >Vive le Liban < [...] les applaudissements reprennent très vifs; c'est tout à fait typique ${ }^{156}$.

Sautier stellte deshalb voller Bedauern fest, dass ihre Schulen nun als »étrangères« wahrgenommen würden ${ }^{157}$. Ebenso hatte die Mission laïque française mit der Kritik der Madrasat al-hikma zu kämpfen: Im Herbst 1934 wurde sie, zusammen mit den Schulen der Jesuiten und der Frères des Écoles chrétiennes zum Zielobjekt einer Kampagne, welche laut Direktor Ruche die maronitische Schule initiiert hatte, und welche sich unter anderem in dem oben zitierten Zeitungsartikel über die Schulgelder der Mission laïque niederschlug ${ }^{158}$.

Um in diesem Dilemma zwischen Verteidigung des französischen Mandats und Anerkennung seines nahenden Endes nicht tatenlos zu verharren, bemühten sich alle französischen Schulen um Neutralität in politischen Fragen. Sie waren darauf aus, ihre Institution als einen möglichst neutralen Raum zu bewahren, in dem ihre Schüler sich weiterhin aufhalten und miteinander lernen konnten, auch wenn deren jeweiliges Umfeld verschiedene oder sogar konträre politische Ansichten vertrat. Diese Haltung entsprach auch den Verlautbarungen des Hochkommissariats, nach welchen die Mandatsmacht im libanesischen Erziehungswesen eine Abgeklärtheit bewahren müsse, die alle trennenden Tendenzen auflöse: »[...] cette sérénité supérieure qui confond et désarme les passions fanatiques et assure le mieux l'ascendant et l'autorité morale de nos éducateurs $\ll^{159}$. Dass die Aktivitäten der Mandatsregierung wie auch der Schulen in der Praxis oft eine andere Sprache sprachen, ist im Rahmen dieser Arbeit schon mehrmals gezeigt worden.

Aus dem Bemühen um Neutralität heraus verboten die Jesuiten jegliche politische Aktivität ihrer Schüler auf dem Schulgelände: »Principe: Pas de politique pour les élèves. Ce n'est pas de leur âge. [...] nuit au travail [...] à la bonne entente ${ }^{160}$. Auf dem Schulgelände, so die Vorgabe weiter, sei den Schülern auch das Tragen von erkennbaren Zugehörigkeitszeichen verboten, aber außerhalb der Schule sei dies Sache der Eltern. Die Gruppe, mit der anscheinend die meisten Schüler sympathisierten, waren die Phalanges libanaises: Der Autor des Dokuments befürchtete, dass, wenn die Schüler ihre Zugehörigkeit zu dieser Gruppe zeigen würden, andere Gruppen wie die Najjada ebenfalls aktiv werden würden ${ }^{161}$.

$156 \mathrm{SJ} /$ Vanves, »Fonds Jalabert«, 26/L, Brief von Sautier an Jalabert, Beirut, 24.01.1936.

157 Ebd.

158 Vgl. AN/Paris, 60 AJ 137, Brief von Ruche an Besnard, Beirut, 21.09.1934.

159 MAE/Nantes, IP, 102: 1933-1934, »Manuels d'histoire utilisés dans les écoles privées«.

160 SJ/Beirut, 11.D.14, »Participation aux Phalanges Libanaises«, ohne Datum, aber vor 1939.

161 Vgl. ebd. 
Die Mission laïque hatte schon in den 1920er Jahren neben der religiösen auch die politische Neutralität betont ${ }^{162}$. 1931 wiederholte die Organisation diesen Anspruch als Vertrauensgrund der Eltern gegenüber ihrem Unterricht: »La neutralité de l'enseignement, dans ces pays d'Orient si divisés par les croyances, inspire confiance aux familles $\left\langle^{163}\right.$. Aus diesem Grund war Generalsekretär Besnard im Frühjahr 1933 sehr bemüht, beim französischen Außenministerium Beschwerde darüber einzureichen, dass der libanesische Journalist und Besitzer der Zeitung La Syrie, Georges Vayssié, die Mission laïque als Hort und Unterstützer der syrischen Einheit beschrieben habe ${ }^{164}$. Der Quai d'Orsay beeilte sich, Besnard zu versichern, Vayssié werde diesbezüglich instruiert werden ${ }^{165}$.

Der Anspruch der französischen Schulen, ihre Institutionen frei von politischen Debatten und Demonstrationen zu halten, erwies sich als geradezu unmöglich, und sie konnten nicht verhindern, dass sie zum Forum unterschiedlicher nationalistischer Bewegungen wurden. Während in dieser Zeit in allen Schulen im Libanon nationalistische Tendenzen existierten ${ }^{166}$, stellte sich die Situation für die französischen Einrichtungen als besonders schwierig dar. In manchen Fällen unterstützten die Schulen diese Bewegungen aber sogar mehr oder weniger aktiv. Dabei fanden sich Kinder von Vertretern diverser politischer Richtungen oft in bestimmten französischen Schulen wieder: Während die Mission laïque française, wenn auch mit Abstrichen, weiterhin privilegierter Ansprechpartner der arabischen und syrischen Nationalisten war, stellten die katholischen Schulen die Anlaufstelle der libanesischen Nationalisten, der Vertreter des sogenannten Libanismus, dar. Die an den protestantischen und jüdischen Schulen vertretenen politischen Positionen sind nicht offensichtlich bestimmten Bewegungen und Parteien zuzuordnen.

Unter den Eltern und Partnern der Mission laïque fanden sich neben einigen frankophilen Libanesen viele Verfechter des syrischen und arabischen Nationalismus, also der Idee einer Vereinigung des Libanons mit Syrien beziehungsweise mit der arabischen Welt. Muslime wie Riad as-Sulh und Muhammad Ğamīl Bayhum repräsentierten den Höhepunkt der anti-französischen und pro-syrischen Tendenzen der libanesischen Muslime um 1935 ${ }^{167}$. Riad as-Sulhs von Frankreich erzwungenes Exil in den 1920er Jahren und

162 Vgl. Kapitel 5.2.

163 MAE/Nantes, SOFE, 197, »Mission laïque«, Brief von Besnard an den Präfekten von Paris, Paris, 08.06.1931.

164 Vgl. AN/Paris, 60 AJ 135, Brief von Ruche an Besnard, Beirut, 14.03.1933: Die Zeitung La Syrie hatte unter anderem berichtet, die Schüler der Mission laïque hätten einen Aufruf für die Einheit Syriens mit dem Libanon unterschrieben.

165 Vgl. ebd., Brief des SOFE an Besnard, Paris, 05.04.1933.

166 Vgl. Schumann 2001, S. 219.

167 Vgl. Johnson 1986, S. 25. 
noch einmal kurze Zeit 1935 hatten seine Ablehnung Frankreichs noch verschärft ${ }^{168}$. Der spätere erstere libanesische Ministerpräsident as-Sulh ${ }^{169}$, der mit Bishara al-Khuri als erstem Präsidenten verantwortlich für die Ausarbeitung des Nationalpakts von 1943 zeichnete, war 1936 in die Verhandlungen sowohl des franko-syrischen als auch franko-libanesischen Vertrages involviert. Zunächst ein absoluter Gegner eines eigenen, von Syrien getrennten Staates, machte er später seine Bereitschaft deutlich, den libanesischen Staat anzuerkennen, wenn dieser das mehrheitlich muslimische Tripoli behalte ${ }^{170}$ und wenn die Christen die Unabhängigkeit des Libanons forderten ${ }^{171}$. Für seine politischen Ziele sah Riad as-Sulh eine Zusammenarbeit mit Christen als wichtig und notwendig an. Hier überschnitten sich seine Netzwerke mit denen der Mission lä̈que, denn letztere kooperierte auch mit christlichen Politikern wie Aziz el-Hachem (arabisch 'Azīz al-Hāšim), die ebenfalls das Mandat kritisierten. Der Vorsitzende des Elternrats zeigte sich im Juni 1934 sehr geehrt, al-Hachem als neues Mitglied begrüßen zu dürfen:

Le Président souhaite la bienvenue à notre nouveau collègue M. Aziz el-Hachem. Son dévouement aux institutions du Liban, sa culture française, la modération, la largeur de ses vues sont les promesses d'une collaboration agréable et efficace que le Président est heureux d'annoncer au comité de Beyrouth ${ }^{172}$.

Der Maronit al-Hachem leitete die republikanische Unabhängigkeitspartei (arabisch al-ḥizb al-istiqlāl al-ğumhūrō), die 1931 von Taqi ad-Din, Kāẓim und 'Imād as-Sulh gegründet worden war und deren ursprünglicher Kern aus führenden sunnitischen und drusischen Familien bald um einige christliche Intellektuelle erweitert worden war $^{173}$. Sie kritisierten die Aufhebung der Verfassung und setzten sich für eine Einheit zwischen Christen und Muslimen ein, die durch den arabischen Charakter des libanesischen Staates getra-

168 Vgl. Meir Zamir, An Intimate Alliance: The Joint Struggle of General Edward Spears and Riad al-Sulh to Oust France from Lebanon, 1942-1944, in: Middle Eastern Studies 41 (2005), H. 6, S. 811-832, S. 814-815.

169 Vgl. Seale 2010, S. 159-199, S. 276; Zamir 2005, S. 814. Was in Verbindung mit der Frage von Bildung im Mandatsregime hier besonders von Interesse ist, sind aber weniger seine einzelnen politischen Phasen und Schachzüge als vielmehr die Tatsache, dass er trotz einer absoluten Kritik am Mandat gewisse Zusammenarbeit mit der französischen Schule der Mission laïque pflegte und dieser auch seine Kontakte zur Verfügung stellte.

170 Vgl. Firro 2003, S. 135.

171 Vgl. Zamir 2005, S. 815.

172 AN/Paris, 60 AJ 136, »Rapports mensuels«, »Compte-rendu du Comité de Patronage«, 11.06.1934. Schon im März-April hatte Direktor Ruche von sehr guten Beziehungen mit dem »parti de l'indépendance républicaine présidé par M. Aziz Hachem« berichtet, und erwähnte extra, dieser sei ein ehemaliger Schüler der Jesuiten und selbst Maronit. Vgl. AN/Paris, 60 AJ 136, »Rapports mensuels«, März-April 1934.

173 Vgl. Firro 2003, S. 129, 134-5. 
gen sein sollte ${ }^{174}$. In der Tat gehörte al-Hachem zu den wenigen, die Riad as-Sulh im Herbst 1936 von seiner Generalabrechnung mit den libanesischen Christen ausnahm: Letzteren warf er mangelnde Kooperation und Abhängigkeit von Frankreich vor und erklärte, fortan eine ausschließlich muslimische Politik zu verfolgen ${ }^{175}$. Die Mitglieder dieser Partei fanden sich also im Umfeld der Mission laïque wieder und repräsentierten jene neu entstehenden Eliten, die sowohl von den alten Eliten als auch von der Mandatsregierung unter de Martel kritisiert wurden - und die ihrerseits letzteren vehement kritisierten ${ }^{176}$. Diese Kritik berührte auch die Mission lä̈que, denn im Mai 1938 berichtete al-Hachem Generalsekretär Besnard vom Besuch von Édouard Herriot, Präsident des Abgeordnetenhauses (1936-1940) und Präsident der Mission laïque (1930-1957) in den Mandatsgebieten: Von Herriots Besuch war er begeistert, bedauerte aber, dass niemand mit diesem sprechen konnte, weil de Martel ihn völlig abschottete, statt dessen einen Film über Syrien und Libanon zeigte und ihn nur mit einigen »offiziellen« Nationalisten in Damaskus sprechen ließ. Daraus leitete al-Hachem die Forderung nach dem notwendigen Abzug de Martels und nach fähigen Männern an der Spitze des Landes ab:

C'était pénible à voir: Le représentant de la France M. de Martel se prêter à de tels manœuvres enfantines pour tromper nos chefs et leur faire voir des choses sous un aspect différent. Dire que des hommes pareils arrivent à durer ! Il est temps que la France pense un peu à notre pays, qu'elle nous sauve de ce cauchemar. [...] Nous voulons une saine organisation, une pratique économique sage et prudente et surtout des hommes propres à la tête du pays ${ }^{177}$. [...] La Syrie et le Liban ne peuvent plus le [d.h. de Martel, E. M.] supporter davantage ${ }^{178}$.

Wie nah elementare politische Debatten und praktische und pragmatische Anliegen beieinander lagen, zeigt der weitere Inhalt des Briefes: Darin bittet al-Hachem Besnard um Hilfe für einen gewissen Herrn Dupin, damit dieser als Magistrat bleibe und leitet ihm außerdem eine Bitte um Anstellung

174 Vgl. Traboulsi 2007, S. 99. Zisser 2000, S. 16-17, macht deutlich, dass Taqi ad-Din und Kazim as-Sulh, insbesondere letzterer, den ideologischen Hintergrund für Riad as-Sulhs politische Positionen lieferten, und ab den frühen 1930er Jahren betonten, eine Anerkennung des und Integration in den libanesischen Staat schließe eine Verfechtung panarabischer Ideen nicht aus.

175 »The other Christians, except for you, Aiziz al-Hashen, and a handful of your friends, are all in the pay of France«. Zitiert in ZamiR 2000, S. 209.

176 Vgl. ebd., S. 167.

177 Möglicherweise spielt al-Hachem hier auf die Affäre de Martels mit Raiska de Kerckove, der Ehefrau des belgischen Konsuls, an. Vgl. Chamoun 1989, S. 73.

178 MLF/Paris, »Fonds de Russie«, 03-942, Brief von Aziz al-Hachem an Besnard, Beirut, 31.05.1938. 
eines ehemaligen Schülers der Mission lä̈que weiter ${ }^{179}$. Angesichts prekärer politischer und ökonomischer Verhältnisse waren solche Verbindungen existenziell und wurden so weit wie möglich genutzt.

Wie nah die laizistische Schule dem geschilderten politischen Zirkel blieb, zeigte sich auch in der Aufnahme Taqi ad-Din as-Sulhs ${ }^{180}$, eines ehemaligen Schülers und Cousins Riad as-Sulhs ${ }^{181}$, als Arabischlehrer im Dezember $1935^{182}$. Als Schüler hatte Taqi ad-Din as-Sulh 1930, wie schon erwähnt, anlässlich der Gedenkfeier der Märtyrer während des Ersten Weltkrieges ${ }^{183}$ eine Rede gegen das französische Mandat gehalten - und dieses mit der sehr autoritären Herrschaft Cemal Paschas ${ }^{184}$ gleichgesetzt ${ }^{185}$. Diese Episode liefert damit eines der raren und wertvollen Beispiele für die agency der Schüler als politisch handelnden Subjekten. Kultusbeauftragter Bounoure wehrte sich vehement gegen diese Gleichsetzung mit dem autoritären Herrscher und verlangte von Direktor Ruche harte Maßnahmen gegen den Schüler. Auch wenn Ruche den Standpunkt as-Sulhs durchaus nachvollziehen konnte, bemühte er sich, Bounoure gegenüber nicht als anti-französisch aufzutreten:

Je suis très embarrassé de répondre à $\mathrm{M}$. Bounoure. $\mathrm{M}$. Solh reconnaît et maintient les propos qu'il a tenus. D'autre part, les arguments de M. Bounoure paraissent assez solides bien qu'il ait quelque naïveté [...] à s'étonner que nos élèves profitent de la leçon que leur donne notre littérature, notre morale et notre histoire. Cependant cet incident peut être exploité contre nous, il peut paraître difficile d'admettre que l'Etat français paye des professeurs qui se permettent à son égard les propos que M. Solh s'est permis. $[\ldots]$ j'ai l'honneur de vous demander des instructions $[\ldots]^{186}$.

Später wurde Taqi ad-Din as-Sulh noch dezidierter politisch aktiv. Neben der erwähnten Partei gründete er mit seinen Brüdern Kāẓim und 'Imād die Zeitung an-Nidā', die sich sehr kritisch gegenüber dem Mandat äußerte und

179 Vgl. ebd.

180 Taqi ad-Din as-Sulh (1909-1988) arbeitete in den 1930er Jahren als Journalist, Literaturlehrer und im Informationsministerium, bevor er 1964-1968 als Parlamentsmitglied, 1964-1965 als Innenminister und 1973-1974 als Premierminister tätig war. Er galt als moderater Politiker. Vgl. Johnson 1986, S. 58-60; Traboulsi 2007, S. 181-182.

181 Vgl. SAlibi 1965, S. 187.

182 Vgl. AN/Paris, 60 AJ 136, »État du personnel enseignant recruté sur place«, ca. 1934-1935; Ebd., »Rapports mensuels«, Dezember 1935.

$183 \mathrm{Zu}$ den Männern, die wegen des Aufstandes gegen die Osmanen zum Tode verurteilt wurden, gehörte auch Riad as-Sulh, der wegen seines jungen Alters aber verschont wurde. Vgl. EDDÉ 2008, S. 549.

184 Diese war in der Tat von einer sehr harten Politik gegenüber dem Libanon geprägt gewesen, da er verantwortlich für die Hinrichtungen gewesen war. Vgl. Thompson 2000, S. 23.

185 AN/Paris, 60 AJ 132, Brief von Ruche an Besnard, Beirut, 29.05.1930.

186 Ebd. 
für den arabischen Nationalismus einsetzte ${ }^{187}$. Er stand auch in engem Kontakt zu anderen Mandatskritikern im Umfeld der Mission laïque, wie dem Schriftsteller Muhammad Ğamīl Bayhum ${ }^{188}$. Diesem schrieb er 1935 auf dem Briefpapier der Mission lä̈que, er habe seinen Auftrag erhalten und werde ihn ausführen ${ }^{189}$. Worauf sich dieser Auftrag bezog, ist nicht nachzuvollziehen, zu vermuten ist eine Aktivität im politischen oder literarischen Bereich.

Generalsekretär Besnard unterstützte die enge Verbindung der Schule mit den nationalistischen Netzwerken und betonte 1936 sogar, die Organisation müsse sich bemühen, angesichts der Nationalisten als »établissements nationaux « zu erscheinen ${ }^{190}$. Ruches Nachfolger Grandjouan hatte es sehr viel schwerer, die muslimischen Nationalisten in der Schule zu halten. Er bedauerte dies und erwähnte in den Berichten nach Paris voller Stolz die Artikel, die von ihm und seiner Frau in nationalistischen Blättern und von seiner Frau in Bayrūt, einer dezidiert muslimischen Zeitung, erschienen waren ${ }^{191}$.

Außerdem bemühte Grandjouan sich, die nationalistischen Pfadfinderbewegungen anzusprechen, welche in dieser Zeit einen Aufschwung erlebten ${ }^{192}$. In einer Rede vor Eltern und einer breiten Öffentlichkeit sprach der Direktor, selbst Pfadfinder ${ }^{193}$, über die wichtigen Erkenntnisse Robert Baden-Powells, des Gründers der Pfadfinderbewegung. Gerade für die muslimischen Pfadfinder waren die Ideen Baden-Powells zentral ${ }^{194}$. Aus diesem Grund berich-

187 Vgl. Ayalon 1995, S. 89.

188 Zu seinen historischen Schriften vgl. Kap. 5.2. Der bekennende Freimaurer, der 1927 den Posten des Bildungsministers ablehnte, präsidierte außerdem von 1922 bis 1941 die Vereinigung der islamischen Jugend (arabisch ittiḥad aš-šabība al-islāmīya) und gründete 1943 den Islamischen Block (arabisch al-kutla al-islāmīya). Schließlich gehörte er verschiedenen literarischen Zirkeln an, so war er 1934 Vizepräsident der von Charles Corm geleiteten literarischen Akademie. Vgl. Havemann 2002, S. 173; Eddé 2008, S. 516. Wie lange er im Elternrat der Mission laïque tätig war, kann nicht genau rekonstruiert werden, seine Teilnahme ist auf jeden Fall für die Jahre 1925 bis 1928 belegt. Vgl. AN/Paris, 60 AJ 127, »Comité de patronage«, Sitzung vom 24.02.1925; 60 AJ 131, »Comité de patronage«, Sitzung vom 30.12.1928.

189 Vgl. Hassān Halaz̄ẹ, al-Mu'arrih al-'Alāma Muḥammad Ğamīl Bayhūm [Der Historiker und Gelehrte Muhammad Jamil Bayhum], Beirut 1980, S. 163.

190 MAE/Nantes, SOFE, 378, Brief von Besnard an Marx, 04.04.1936: »Il est évident que l'hostilité qui règne actuellement en Syrie à l'égard de tout ce qui est français ne favorise pas le développement de nos institutions. Les Musulmans devraient être, avec les Israélites, nos meilleurs clients. Nous nous efforçons de maintenir l'esprit qui fait que les extrémistes euxmêmes considèrent nos lycées comme des établissements nationaux«.

191 Grandjouans Artikel erschienen, von Arabischlehrer Kfoury übersetzt, Ende November 1935 in den Zeitungen al-Aḥrār, an-Nahār und al-Ittiḥād. Vgl. AN/Paris, 60 AJ 139, »Rapports mensuels«, November 1935. Der Artikel seiner Frau, »La pensée en germe«, erschien, von einem ehemaligen Schüler übersetzt, in der Zeitung Bayrūt. Vgl. AN/Paris, 60 AJ 139, Brief von Grandjouan an Besnard, Beirut, 13.05.1937.

192 Vgl. Dueck 2010, Kapitel 3.

193 Vgl. AN/Paris, 16 aj/6993, Brief von Grandjouan an den Rektor der Akademie von Paris, Beirut, 17.02.1935.

194 Vgl. Dueck 2010, S. 209. 
tete eine arabischsprachige Beiruter Zeitung sehr begeistert von der Rede Grandjouans:

Grandjouan, Direktor des säkularen College in Beirut, hielt am Freitagnachmittag einen Vortrag über die Methode der Erziehung und des Studiums. Es gab eine große Menge öffentlicher und prominenter Männer und die großen französischen und libanesischen Beamten. [...] Außerdem hat er über die Bewegung von Sir Baden-Powell in England gesprochen, die mehr als 3 Millionen Jugendliche zählt. [...]

Er beendet seine gute Rede mit der Aussage, dass die Familien der Schule bei der Erziehung der Kinder helfen sollen. Die Familie ist ein großer Helfer für die Schule und mit ihr beginnt die wahre Erziehung. Und am Ende der Rede erzählte er die folgende Geschichte: Eine Frau ist zu Baden-Powell gegangen und hat ihn um Rat für ihr Kind gefragt. Sie sagte: Ich habe Angst dass ich zu früh bin mit meiner Frage, weil mein Kind klein ist. Er fragte: wie alt? Sie sagte: 18 Monate. Er sagte: Sie sind 18 Monate zu spät für einen Rat gekommen, Madame. Die Leute haben applaudiert ${ }^{195}$.

Wie alle anderen Schulen im Libanon verfügte auch die Mission lä̈que über eine Pfadfindergruppe, welcher nur muslimische Mitglieder angehörten ${ }^{196}$. Inwiefern diese Gruppe aber mit den Najjada verbunden war, lässt sich nicht rekonstruieren. Da viele Mitglieder der Najjada in der Maqasid rekrutiert wurden ${ }^{197}$ und die Mission lä̈que eng mit der Maqasid zusammenarbeitete, waren hier Überschneidungen sehr wahrscheinlich.

Gegenüber der Mission laïque boten die katholischen Schulen vor allem den nationalistischen Bewegungen, die sich für einen eigenständigen und christlich geprägten Libanon einsetzten, ein Forum. Bei den Jesuiten waren das zum einen die Vertreter und Sympathisanten der Kata'ib, die sich für einen christlichen Libanon einsetzten. Auch wenn die Jesuiten keine Aktivitäten der Phalanges libanaises auf ihrem Gelände duldeten, machten sie in ihrer internen Korrespondenz keinen Hehl aus ihrer »sympathie pour beaucoup de buts« dieser Bewegung ${ }^{198}$. Schließlich war der Gründer der Bewegung, Pierre Gemayel, ihr Schüler gewesen und hatte immer den Einfluss seiner Lehrer auf sein Denken betont ${ }^{199}$. Eine offene Unterstützung zeigte

195 AN/Paris, 60 AJ 139, Artikel zum Thema »Die Jugend am Scheideweg (Aš-Šabība 'ala muftariq al-țuruq) «.

196 Vgl. AN/Paris, 60 AJ 137. Im April 1935 machte die Gruppe der »Éclaireurs du Lycée« einen Ausflug nach Baalbek. In den Archiven sind einige Gruppenfotos, die die Jungen in der typischen Pfadfinderuniform zeigen. Außerdem fertigten sie einen Bericht ihres Ausfluges in französischer Sprache an, der von Ruche mit seinen Korrekturen versehen aufbewahrt wurde.

197 Vgl. Dueck 2010, S. 187.

198 SJ/Beirut, 11.D.14, »Participation aux Phalanges libanaises«.

199 Vgl. Jacques Nantet, Pierre Gemayel, Paris 1986, S. 19: »Ses maîtres jésuites ont une grande influence sur lui. [...] [il] évoque [...] toujours avec respect et reconnaissance notamment le père Cattin, le père de Bonneville et le père Chanteur«. 
der Orden allerdings erst 1948, als er auf der Titelseite seiner Schulzeitschrift Nous du Collège das Portrait und ein Grußwort des Kata'ib-Gründers Gemayel abdruckte ${ }^{200}$.

In der Tat unterhielten die Jesuiten eine ambivalente Position zu den Libanisten, deren christliche Prägung sie schätzten, deren Forderung nach der libanesischen Unabhängigkeit sie aber ablehnten. Das zeigt sich auch daran, dass die Kata'ib unter anderem der Pfadfinderbewegung Scouts du Liban nahestand, welche sich 1937 an der von den Jesuiten mit Argwohn betrachteten Madrasat al-hikma von der französischen Dachorganisation Scouts de France gelöst hatte, um eine stärkere libanistische Linie im Gegensatz zum arabischen Nationalismus zu unterstützen ${ }^{201}$. An den katholischen Schulen hingegen dominierten weiterhin die Scouts de France, deren Symbole und Ideen stark an dem von französischen Katholiken entwickelten Modell orientiert blieben. Bezeichnend ist beispielsweise, dass zur Fédération Nationale Libanaise, die diese und andere Pfadfindergruppen vereinte, kein einziger Muslim gehörte ${ }^{202}$. Das Ziel der Scouts de France war zudem die kulturell-politische Verbreitung des französischen Einflusses, und die Bewegung wurde als Instrument gegen den Einfluss anderer ausländischer Mächte verstanden ${ }^{203}$. In der Tat entsprach die starke Aktivität der Pfadfinder in den katholischen Schulen einer parallelen Entwicklung in Frankreich, wo die katholische Erneuerungsbewegung seit den 1920er Jahren zur Gründung und gesteigerten Aktivität einer Vielzahl von Vereinigungen, darunter der katholischen Pfadfinder, geführt hatte ${ }^{204}$. Interessanterweise geschah in vielen Schulen der Wechsel von den Scouts de France zu den Scouts du Liban schleichend. So wechselte die Pfadfindergruppe der Lazaristenschule in Ayntoura 1938 ihren Namen, ohne dass diese Umorientierung näher erklärt wurde 205 .

Neben den Jugendgruppen verkehrten in den katholischen Schulen viele Vertreter des libanesischen Nationalismus, die ihre Vorstellungen etwas weniger radikal formulierten als die Mitglieder der Kata'ib. Die Idee des Phöniziertums, welche sie als Schüler bei den Jesuiten kennen gelernt hatten, verwandelten sie nun in ein politisches Programm, das die christliche Identität des Libanons als eigenständigen Staat betonte. Dazu zählten Politi-

200 Vgl. NDJ, Nous du Collège, 113-114, 06.06.1948: »Message de Pierre Gemayel, Chef supérieur des Kata'eb«.

201 Vgl. Dueck 2010, S. 208.

202 Vgl. MAE/Nantes, IP 71, »Scoutisme«, »Mission des Scouts de France au Levant«.

203 Vgl. ebd.: »Raisons nationales. Faire pénétrer l'idée française [...] en utilisant la puissance de l'attrait du scoutisme; combattre les influences étrangères très intenses«.

204 Vgl. Gérard Cholvy, Le renouveau catholique en France, in: Jacques Keryell (Hg.), Louis Massignon et ses contemporains, Paris 1997, S. 29-41, S. 36.

205 Vgl. LAZ/Antoura, »Depuis 1923: Antoura à l'avant-garde du scoutisme«, S. 16-20. 
ker wie der spätere Präsident Alfred Naccache (arabisch an-Naqqāš) ${ }^{206}$, der den Jesuiten, auch nach der Mandatszeit, eng verbunden blieb ${ }^{207}$. Allerdings hielten nicht alle maronitischen Politiker, die wie Naccache die Ordensschule besucht hatten, engen Kontakt zu ihrer Alma mater ${ }^{208}$.

Auch die anderen katholischen Schulen bewegten sich in ähnlichen politischen libanesischen Kreisen wie die Jesuiten. Allerdings betonten die Frères des Écoles chrétiennes, die einerseits ihr französisches Nationalgefühl sehr herausstellten, andererseits den Patriotismus der politischen Bewegungen im Libanon. Schon 1931 berichtete die Schulzeitschrift sehr positiv von den Feierlichkeiten zur fête des martyrs. Während dieser wurden die Namen der im Jahr 1916 von der Hohen Pforte erhängten Libanesen verlesen wurden, weshalb das Ereignis einen stark patriotischen Charakter hatte ${ }^{209}$. Im selben Jahr hielt die Schulchronik die Rede des sunnitischen pro-französischen Politikers Muḥammad al-Ğisr fest, der während einer Theateraufführung den drusischen Herrscher im Chouf-Gebirge des 16. und 17. Jahrhunderts, Fahr ad-Dīn ${ }^{210}$ als »modèle de notre patriotisme« bezeichnet hatte ${ }^{211}$. Da der antiosmanische Aufstand 1915 nicht auf Ablehung Frankreichs gestoßen war ${ }^{212}$, muss hier kein Widerspruch zwischen pro-französischen, pro-nationalistischen und anti-osmanischen Tendenzen gesehen werden. Diese Bekundungen hielten Kata'ib-Anhänger aber nicht davon ab, 1937 vor der Schule der Frères des Écoles chrétiennes zu skandieren: „Français, rentrez chez vous $\ll^{213}$ !

Eine so ausgeprägte politische Richtung wurde innerhalb des Collège protestant français weder von der libanesischen Klientel vertreten noch von der Schulleitung unterstützt, was sicher an der relativ heterogenen Zusammen-

206 Vgl. Traboulsi 2007, S. 92, 104: 1941 setzte Dentz Naccache als neuen Staatschef und Nachfolger von Eddé ein.

207 Bezüglich Naccache und seines Engagements für die Ehemaligenarbeit der Jesuitenschule vgl. seinen Artikel in NDJ, L’U, Juni 1934: »Nos anciens. Rapport du 10 juin 1934«.

208 Dueck 2010, S. 93 behauptet, allerdings ohne dies zu belegen, al-Khuri hätte im Gegensatz zu Eddé nach seiner Schulzeit enge Beziehungen mit den Jesuiten unterhalten. Diese These kann nicht erhärtet werden, zumal die Jesuiten 1937 von guten Beziehungen mit Eddé berichteten. Vgl. Vgl. SJ/Vanves, »Fonds Jalabert«, 7/1, B, »Correspondance Sautier-Jalabert 19361939«, Brief von Sautier an Jalabert, 17.05.1937. 1934 waren allerdings beide Politiker Mitglieder im Ehemaligenkomitee ihrer ehemaligen Schule. Vgl. SJ/Jamhour, L'U, 1/1934, »Comité des Anciens Élèves au 1 janvier 1934«. So kann kein eindeutiges Urteil gefällt werden.

209 FDC, L'Essor, 21/1931, S. 7-11.

210 In dem Geschichtsverständnis aller libanesischen Gemeinschaften wird dieser drusische Herrscher aus dem frühen 17. Jahrhundert als positive Vaterfigur bezeichnet. Vgl. TRABOuLsI 2007, S. 5-8.

211 FDC, L'Essor, Februar 1931, S. 10-11.

212 Beispielsweise erfolgte die Umbenennung des zentralen Platzes in Beirut zum »Place des Martyrs«, in Gedenken an die 1915 erhängten Nationalisten durch Cemal Pascha, durch die französische Mandatsmacht. Vgl. Kassir 2003, S. 339.

213 Vgl. Interview der Verfasserin mit Frère Michel, Beirut, 17.12.2007. 
setzung der Schülerschaft lag. Aus diesem Grund gab es unter den Schülerinnen, die in den meisten Fällen die Positionen ihrer Eltern vertraten, eine Spaltung in pro- und anti-französische Lager: Standen viele Eltern der griechisch-orthodoxem Gemeinschaft, die den Hauptanteil der Schülerinnen ausmachte, dem syrischen oder arabischen Nationalismus nahe ${ }^{214}$, vertraten die maronitischen Eltern oft den Libanismus und eine große Nähe zu Frankreich. Aus diesem Grund kam es regelmäßig zu heftigen Diskussionen ${ }^{215}$. Direktorin Wegmann bemühte sich aber immer um eine starke Neutralität, auch wenn ihr sehr gute Beziehungen zu führenden libanesischen Politikern nachgesagt wurden ${ }^{216}$.

In eine noch andere Richtung gingen die politischen Fronten innerhalb der Alliance israélite universelle. Während deren Klientel und Lehrer in der Frage der Zugehörigkeit des Libanon wie schon ausgeführt den weiteren Schutz durch Frankreich wünschten, beschäftigte sie politisch vor allem die Auseinandersetzung zwischen Zionisten und Nicht-Zionisten, in welcher die Alliance israélite klar gegen die Zionisten stand ${ }^{217}$. Nichtsdestotrotz verfolgten sie die Ereignisse in Palästina besonders seit den Aufständen von 1936 sehr aufmerksam und bangten um das Schicksal der dortigen Juden ${ }^{218}$.

Auch wenn die jüdischen und protestantischen Schulen ebenfalls über Pfadfindergruppen verfügten, waren deren Éclaireurs israélites ${ }^{219}$ und Éclaireuses unionistes de France ${ }^{220}$ weniger politisch markiert als die der laizistischen und katholischen Schulen. Vielmehr betonte die Alliance israélite die individuelle, familiäre, religiöse und gesellschaftliche Stärkung der Jugendlichen durch diese Zugehörigkeit ${ }^{221}$. Zwar berichtete die Lehrerin der Alliance israélite Esther Penso 1936, dass ihre Pfadfinder bei dem Besuch eines französischen Admirals französische patriotische Gesänge dargeboten hatten ${ }^{222}$, aber hier schien es sich vor allem um die übliche Ehrerbietung gegenüber einer französischen Persönlichkeit gehandelt zu haben.

214 Vgl. Traboulsi 2007, S. 81; Slim/Dupont 2002, S. 381-383.

215 Vgl. Interview der Verfasserin mit May Saikaly, Beirut, 13.11.2008.

216 Vgl. Interview der Verfasserin mit Claudine Arnac, Paris, 03.2009.

217 So verwehrte sich Direktor Sidi in Beirut 1927 gegen ein Mitglied des Elternrates seiner Schule, den er als »sioniste ardent« bezeichnete. Vgl. AIU/Paris, »Liban XE 96c«, Brief von Sidi an den Präsidenten der Alliance isralélite, Beirut, 01.06.1927.

218 Vgl. AIU/Paris, »Liban 1 C 1«, Brief der Schule der AIU in Beirut an ihren Präsidenten in Paris, Beirut, 19.06.1936.

219 Vgl. DueCK 2010, S. 189.

220 Vgl. Krebs /Eyrard 2007, S. 156.

221 Vgl. AIU/Paris, Paix et Droit 3, März 1937, S. 8-10: »La vie dans les écoles de l'Alliance Israélite«, hier besonders Seite 8: »Les écoles de l'Alliance et le scoutisme«.

222 AIU/Paris, »Liban VIIE 81-86«, Brief von Esther Penso an den Präsidenten der Alliance israélite, Beirut, 05.11.1936: »Dans la cour de l’École des filles, nos >Scouts< [sic!], filles et garçons, organisèrent une petite cérémonie qui plut beaucoup à l'Amiral. Le chef pria notre hôte de hisser le ১Drapeau des Scouts〈, tandis que les Jeunes éclaireurs entonnaient: ১La Mar- 
Abschließend sollen noch einmal zwei Beispiele genannt werden, die den Einfluss der Ereignisse dieser Zeit auf das politische Bewusstsein der Schülerschaft deutlich machen und seltene Zeugnisse der agency dieser von der Forschung oft nicht wahrgenommenen gesellschaftlichen Gruppe bieten.

Im Dezember 1936 beschwerten sich die Bewohner des Internats der Mission lä̈que in Beirut in einem Brief an den Generalsekretär Besnard in Paris über die zu strenge, militärische Disziplin der neuen Schulleitung. Vor allem monierten die Schüler, dass der neue »Hauptaufseher« (Surveillant général) herablassend auf sie herabblicke:

\section{Monsieur,}

Nous soussignés élèves internes du Lycée français de Beyrouth avons l'honneur d'exposer à votre Excellence que la prétendue discipline et les mesures de militarisation prises par la direction du lycée nous déplaisent totalement et nous rendent réfractaires. La diminution croissante des élèves est une des conséquences du nouveau régime. Le mépris et le dédain qu'a particulièrement le surveillant général pour les orientaux aggravent la situation. L'esprit libéral, devise de nos lycées, fait défaut.

Désespérés, nous venons par cette demande solliciter de votre bienveillance de bien vouloir écouter nos plaintes et améliorer l'organisation de l'internat. Nous osons espérer que notre demande sera prise en considération.

Veuillez agréer, Monsieur le Secrétaire général, nos respects les plus sincères.

N.B.: 22 Internes dont 4 Français ${ }^{223}$.

Dieses Dokument ist deshalb so wertvoll, weil es nachweislich von den Schülern selbst verfasst wurde, wie der vehemente Ton und die Unterschriften unter dem Brief bezeugen ${ }^{224}$. Die Tatsache, dass die Schüler sich direkt an Besnard wandten, macht zum einen ihre wenig vertrauensvolle Beziehung zum Direktor ihrer Schule, Grandjouan, zum anderen auch ihr Selbstbewusstsein deutlich. In diesem Sinne erhoben sie auch den Anspruch, den Rückgang der Schülerzahlen erkennen zu können. Mit der Art ihrer Argumentation erinnert dieser Schülerbrief sehr an die Vorgehensweisen der libanesischen Eltern und Notabeln gegenüber der Schule. Es ist also zu vermuten, dass die Schüler ihre Väter zum Vorbild nahmen.

Bei den Jesuiten bezeugen die Archive eine solch kritische Haltung der Schüler gegenüber ihrer Schule erst 1946. Die genaueren Umstände sind nicht bekannt, aber anscheinend hatte es eine Diskussion zwischen Ober-

che sous l'Étendard . Le salut au drapeau terminé, les petits garçons chantèrent un chant sur la marine: >L'hymne du Matelot.«

223 AN/Paris, 60 AJ 139, Stempel der Ankunft des Briefes in Paris: 14.12.1936.

224 Der Brief wurde interessanterweise nur von den 18 libanesischen der insgesamt 22 Internatsschüler unterschrieben, ihre vier französischen Klassenkameraden waren also daran nicht beteiligt. 
stufenschülern und ihrem Lehrer zum Thema Freiheit gegeben, denn in der Folge ließen sich die Schüler in einer Mischform zwischen Brief und Aufsatz über ihre Wahrnehmung der Schule und deren Umgang mit Disziplin und Freiheit aus. Die Mehrheit der Schüler forderte mehr Freiheit und monierte die zu große Strenge, welche sie zu Kleinkindern mache. Daneben gab es auch einige Schüler, die eine harte Disziplin einforderten, weil sie notwendig sei. Interessanterweise verglich einer dieser Schüler auch sich und seine Kameraden mit denen der Mission laïque und kam zu dem Ergebnis, dass er und seine Mitschüler nicht intellektuell, aber moralisch und spirituell den Schülern der laizistischen Schule überlegen seien ${ }^{225}$.

Die Schulen boten den unterschiedlichen nationalistischen Bewegungen nicht nur ein Forum, sie betonten am Ende des Mandats auch sehr stark ihren Beitrag zum Aufbau des libanesischen Staates und stellten sich damit, so die hier vertretene These, auf die neuen politischen Umstände ein.

Die Verantwortlichen der Mission laïque hatten ihre Unterstützung des libanesischen Staates schon zu Beginn der Mandatszeit herausgestellt. 1934 bekräftigte Ruche diese Ansicht, und betonte darüber hinaus in paternalistischer Manier, die Mission lä̈que habe ihren Schülern im Sinne einer mission civilisatrice gezeigt, was ।wahrer und aufgeklärter Patriotismus sei: »Nous avons éclairé leur patriotisme [...] et fait d'eux des hommes et des Syriens « ${ }^{226}$. Wie die Stellungnahmen ihrer libanesischen Partner aber seit Beginn der Tätigkeit der Mission laïque deutlich machen, haben diese einige Ideen der laizistischen Schule geteilt, aber ihr Verständnis von Nation und Patriotismus ganz klar aus anderen Quellen bezogen.

Die katholischen Schulen betonten erst ab Beginn der 1930er Jahre verstärkt ihren Beitrag zur libanesischen Nation. Auf diese Art und Weise zeigten die Schulen nicht nur ihre Akzeptanz des neuen Regimes, sondern sie reagierten auch auf den stärkeren Nationalismus, der sich in Form des Libanismus auch in den christlichen Milieus ausbreitete. Anhand der Schule der Lazaristen in Ayntoura ist diese Entwicklung besonders eindrücklich festzustellen. So sprach die Zeitschrift der Ehemaligen ab 1938 regelmäßig von dem Dienst dieser Ehemaligen an ihrem Land (»Les anciens au service du pays « $)^{227}$. In diesem Sinne hatte auch der Direktor der Schule, Sarloutte, 1931 seine Beschwerde begründet, dass keiner seiner Lehrer in der Prüfungskom-

225 Siehe die Schüleraufsätze in SJ/Beirut, 11.D.14: Brief von André Chikani, 30.03.1946; Brief von Emile Chehab, 03.04.1946; Brief von Victor Jalne [Name unleserlich], 06.04.1946; Brief von Olriade [Name unleserlich] Cosmidis, 03.04.1946; Brief von Abbas Hamyé; Brief von Gabriel Korkmaz, 09.04.1946; Brief von Joseph Basile Khoury, 05.04.1946; Brief von Michel Cattan, 07.04.1946.

226 AN/Paris, 60 AJ 136, »Comité de patronage«, Sitzung vom 29.03.1934.

227 LAZ/Paris, Association amicale des anciens élèves d'Antoura. Bulletin annuel, Mai 1938, S. 42 . 
mission für das libanesische Abitur sitze: »[...] à vrai dire, il est libanais plus que tout autre, puisque avant la guerre, Tripoli et Beyrouth n'appartenaient pas au Liban $[\ldots] \ll^{228}$.

Interessanterweise betonte Sarloutte diese Zugehörigkeit zum Libanon gegenüber einem Mandatsfunktionär, das heißt, dass er auch den französischen Autoritäten deutlich machen wollte, wie eng seine Schule mit dem Libanon verbunden sei, um ihr im sich entwickelnden Bildungssystem einen Platz zu sichern. Darüber hinaus entsprach diese Einschätzung aber auch seinem eigenen Gefühl der Verbundenheit mit dem Libanon ${ }^{229}$.

Nach dem Mandatsende verdeutlichten die Jesuiten ihre Akzeptanz des neuen Staates durch die libanesischen Politiker, die sie als Ehrenvorsitzende ihrer jährlichen Sommerfeste und Preisverleihungen designierten ${ }^{230}$. In diesem Sinne fand das Schuljahresendfest der Schule der Jesuiten in Beirut 1946 unter Vorsitz des libanesischen General Ghazi statt und sein Erscheinen begleitete sowohl die Musik der libanesischen Armee als auch die gehisste libanesische Flagge ${ }^{231}$. Damit behielten die Jesuiten die Praktiken der Mandatszeit bei und ersetzten die französischen durch libanesische Repräsentanten. Ein deutliches Zeichen für ihre Anerkennung des neuen Staates setzten auch die Lazaristen, die 1944 auf die Titelseite ihrer Ehemaligenzeitschrift ein Foto von Bishara al-Khuri, dem libanesischen Präsidenten, und erst auf der zweiten Seite ein Foto von Paul Beynet, dem französischen Delegierten für Syrien und Libanon, platzierten ${ }^{232}$.

Vom Collège protestant français und von der Alliance israélite sind solche Betonungen ihres Beitrages zum Aufbau der libanesischen Nation seltener überliefert. Die jüdische Schule hisste ab 1936 zwar zu großen Ereignissen nun auch die libanesische Flagge ${ }^{233}$, hielt sich aber aus den geschilderten Gründen in ihrer Beziehung zu dem Zedernstaat sehr bedeckt. Die Mutterorganisation der protestantischen Schule, die in ihrem Bulletin vom November 1937 über die neuen Verträge zwischen Frankreich und Syrien und Libanon informierte, hielt sich mit einem Urteil zurück und gab ihrer Erleichterung Ausdruck, dass im Libanon ihr weiteres Arbeiten nicht gefährdet sei ${ }^{234}$. Inte-

228 MAE/Nantes, IP, 84, »Examens officiels des Etats. République Libanaise« (1931), Brief von Sarloutte an den Generalinspektor, Antoura, 25.05.1931.

229 Vgl. Kapitel 1.3.

230 Vgl. NDJ, »Distribution solennelle des prix«. Folgende Ehrenvorsitzende wurden eingeladen: 1926 Charles Debbas; 1927 Bishara al-Khuri; 1934 Habib Pacha al-Saad; 1936 Emile Eddé.

231 NDC, Nous du Collège, 99/28.06.1946, S. 2: »De fête en fête«.

232 LAZ/Paris, Association amicale des anciens élèves d'Antoura. Bulletin annuel, 1944.

233 Vgl. AIU/Paris, Paix et Droit 4, April 1939, S. 10-11: »Dans les écoles de l'Alliance Israélite«. Während des Besuchs von Hochkommissar Puaux wurden die libanesische und französische Flagge gehisst.

234 Vgl. Défap/Paris, Euvres protestantes françaises de Syrie et du Liban, Bulletin semestriel 8, November 1947, S. 4-5: »La situation en Syrie et au Liban - les récents traités«. 
ressanterweise betonten die Verantwortlichen der Euvres protestantes françaises als ihre dringlichste Aufgabe unter anderem die Unterstützung indigener evangelischer Gemeinden und ihrer Pastoren sowie ein gutes Verhältnis zur griechisch-orthodoxen Gemeinschaft, der sie besonders nahe standen ${ }^{235}$. Die französischen Protestanten sahen demnach ihren Beitrag in der Unterstützung der kirchlichen libanesischen Emanzipation.

\section{Der arabische Libanon in den Curricula}

Die Akzeptanz des Libanon als eines unabhängigen Staates in einem arabischen Umfeld, die bei den französischen Schulen allmählich einsetzte bzw. einsetzen musste, fand ihren konkreten Widerhall in den Diskussionen um die Curricula der Bildungsstätten. Insbesondere die stärkere Betonung der arabischen Sprache in allen Einrichtungen spielte dabei eine Rolle. Von Seiten der Verfechter einer französischen Präsenz im Libanon wurde dieser Prozess als sehr schmerzhaft empfunden und von vielen Einsprüchen und viel Bedauern begleitet. Beispielsweise beurteilte der Jesuit Jalabert 1938 die neue »Convention Universitaire « in den Mandatsgebieten in Teilen sehr kritisch und sah darin einen herben Verlust für die französische Zivilisierungsmission, weil der Anteil der französischen Sprache reduziert und die französischen und syrischen Abiturprüfungen gleichgestellt wurden:

Le sacrifice qu'on fait de la langue française est vraiment inadmissible. C'est par elle que nous avons le meilleur moyen d'action et de civilisation dans le pays et par conséquent y renoncer est vraiment quelque chose d'incompréhensible ${ }^{236}$.

Im Gegensatz zur Mission laïque betonten die katholischen und jüdischen französischen Schulen erst ab Mitte der 1930er Jahre die Bedeutung der arabischen Sprache und Kultur und integrierten sie stärker in den Unterricht. Das Collège protestant français glich in seiner Ausrichtung eher der laizistischen Schule, weil es die wichtige Rolle des Arabischen im Lehrplan schon seit seiner Gründung herausgestellt hatte ${ }^{237}$. Die Schulen der Alliance israélite bemerkten ab 1936, dass sie der arabischen Sprache nicht den Platz gegeben hatten, den diese in den anderen Schulen erhalte, und beschlossen

235 Vgl. ebd.: »[...] les plus importantes sont le soutien moral à apporter aux églises protestantes indigènes et et à la préparation de leur pasteurs, les relations avec l'Eglise orthodoxe-grecque $[\ldots] \ll$.

236 Vgl. SJ/Vanves, Fonds Jalabert, 7/1, B, »Correspondance Sautier-Jalabert 1936-1939«, Brief von Jalabert an Sautier, Paris, 19.05.1938. Sautier äußerte sich ähnlich pessimistisch.

237 Vgl. den Schulprospekt der Schule in Défap/Paris, »Le Collège Protestant Français de Jeunes Filles de Beyrouth«, S. 3: »[...] les cours d'arabe obligatoires pour les élèves du pays«. 
daher, diesen Fehlstand zu ändern und der Bitte ihrer Schüler um eine stärkere Betonung des Arabischen nachzugeben. So berichtete Direktor Penso 1939 nach Paris:

Nous nous sommes efforcés, ces dernières années [...], d'intéresser nos élèves - filles et garçons - à l'étude de l'arabe, la langue du pays. Alors que l'arabe occupe depuis longtemps une place d'honneur dans l'emploi du temps et notamment au Lycée Français de la Mission Laïque Française et au Collège américain, très peu d'heures lui étaient réservées dans nos classes. Toute la jeunesse israélite formée dans nos écoles se ressentait de cette infériorité, et il nous a fallu combler d'urgence cette lacune ${ }^{238}$.

Hatten die Schüler der Alliance israélite die Notwendigkeit des Arabischen bis zu dem Zeitpunkt nicht gesehen, erfuhren sie im Alltag, so der Schulleiter weiter, dass Arabischkenntnisse ihnen halfen, schneller eine Anstellung zu finden ${ }^{239}$. Bezeichnenderweise waren Pensos Bezugsgrößen für den Vergleich mit anderen Lehreinrichtungen die laizistische Schule und die amerikanische Universität, was deren stärkeren Bezug zu den arabischen Nationalisten und Muslimen, die dieser Sprache größere Bedeutung beimaßen als die Christen, noch einmal untermauert. Aus diesem Grund entstand eine Kooperation der Alliance israélite in Beirut mit der Mission lä̈que, welche den jüdischen Schulen zusätzlich zu deren eigenen Lehrern ihre Arabischlehrer für einige Stunden pro Woche zur Verfügung stellte. Penso war mit dem Ergebnis sehr zufrieden: Er verkündete stolz, seine Schule könne nun mit den lokalen arabischsprachigen Schulen rivalisieren und hob hervor, dass bei der Prüfung des Certificat libanais die erste Schülerin der Alliance israélite in Syrien und Libanon erfolgreich teilgenommen habe. Zudem gab er der der Hoffnung Ausdruck, dass die derzeitigen christlichen und muslimischen Arabischlehrer bald von jüdischen Kollegen ersetzt werden könnten ${ }^{240}$.

238 AIU/Paris, »Liban VIIE 81-86«, Brief von Penso an den Präsidenten der Alliance israélite, Beirut, 15.06.1939.

239 Vgl. AIU/Paris, Brief von Penso an den Präsidenten der Alliance israélite, Beirut, 15.06.1939: »[...] depuis, cette amélioration n'a fait qu'augmenter et les élèves qui terminent maintenant nos classes possèdent en arabe des connaissances très satisfaisantes qui les aident à trouver facilement un gagne-pain lucratif«.

240 »Outre Mlle Henriette Kettab et M. Georges Chicani, nous nous sommes assurés la collaboration de trois autres professeurs d'arabe attachés au lycée de la Mission laïque et qui ont été autorisé à donner chacun quelques heures par semaine dans nos établissements scolaires. Ces professeurs ont fait réaliser à nos élèves des progrès très sensibles. L'un deux, Monsieur Abed-el-Nour, qui est un pédagogue de marque, surveille le travail de Mlle Kettab et de M. Chicani. Nous élèves peuvent aujourd'hui rivaliser avec ceux des écoles libanaises où la langue officielle est l'arabe, et réussissant, comme eux, dans les Examens du Certifical libanais. C'est la première fille des Écoles de l'Alliance en Syrie et au Liban qui a pu affronter de tels examens, et sa réussite a produit une excellente impression sur nos élèves, sur leurs parents et sur les autorités locales. [...] Nous pourrions ainsi dans un avenir prochain, compter pour 
Mit dieser Erweiterung ihres Arabischprogramms reagierte die Alliance israélite aber nicht nur auf die Bitten ihrer Schüler. Darüber hinaus, so scheint es, war diese Anpassung das Ergebnis eines Prozesses, innerhalb dessen die Mitglieder der jüdischen Schulen in Beirut wie ihre libanesischen Glaubensgenossen realisiert hatten, dass das Ende des Mandats unausweichlich war und sie deswegen den Platz des Libanons in einem arabischen Umfeld akzeptierten und sich darauf einstellten. Exemplarisch für die veränderte Haltung der jüdischen Gemeinschaft im Libanon kann ein Brief an die libanesischen Vertreter in den Verhandlung zum franko-libanesischen Vertrag im Juni 1936 gelten, in welchem die Autoren ihre Zugehörigkeit zum Libanon deutlich machten ${ }^{241}$. Außerdem war die arabische Sprache, gemeinsam mit dem Französischen, ein deutliches Signal gegenüber den Zionisten, die die hebräische Sprache hervorhoben ${ }^{242}$. In der Tat, so betont Schulze, wanderten die libanesischen Juden lange nicht nach Palästina aus, sondern blieben noch nach der Entstehung des Staates Israel und dem Beginn der israelischarabischen Kriege, auch wenn sie im Nationalpakt von 1943 nicht repräsentiert wurden ${ }^{243}$. Erst nach 1967 bzw. nach der israelischen Invasion im Libanon 1982 emigrierte die jüdische Gemeinschaft fast vollständig ${ }^{244}$.

Die ebenso auffällig zentralere Rolle der arabischen Sprache in den katholischen Schulen lässt sich besonders gut bei den Jesuiten beobachten. Ihre Schulzeitschriften enthielten, wie auch die der Lazaristen in Ayntoura, am Ende der Mandatszeit mehr Artikel auf Arabisch ${ }^{245}$. Insbesondere nach der Unabhängigkeit verfassten Lehrer auch Schriften über die positiven Aspekte der arabischen Sprache. So ermutigten die Erzieher im »Carnet de vacances« von 1946, das die Schüler durch die langen Sommerferien begleiten sollte, zum »bien écrire l'arabe ${ }^{246}$. Unter den empfohlenen literarischen Werken

l'enseignement même de l'arabe, sur des anciens élèves israélites qui remplaceraient dans nos écoles de Syrie et du Liban, nos professeurs actuels, tous musulmans ou chrétiens. " AIU/ Paris, Penso, »Rapport trimestriel «, 04.01.1940.

241 Vgl. Norman Stillman, The Jews of Arab Lands in Modern Times, Philadelphia/New York 1991, S. 325-327.

242 Vgl. AIU/Paris, »Liban I B 4«, Brief von Großrabbiner Tagger an die Alliance israélite in Paris, Beirut, 30.06.1922.

243 Vgl. Schulze 2001, S. 63: von den sechs nicht repräsentierten Gemeinschaften waren die Juden mit ca. 6000 Mitgliedern die größte.

244 Vgl. ebd., S. 4.

245 Vgl. z.B. NDJ, Nous du Collège, 5/ 27.11.1941, S. 3: » Aṣ-ṣaff al-sayyār aw-šağara ıal-bābāya«" (Die Klasse auf Wanderschaft oder der >Papaya<-Baum). Darin berichtet ein Schüler von einem Ausflug seiner Klasse auf das Land und den Begegnungen mit den Anwohnern. Bzgl. Ayntoura siehe LAZ/Paris, Association amicale des anciens élèves d'Antoura. Bulletin annuel, 1/ Mai 1938, S. 52: »Našīd madrasat 'Anțūra[sic !] « (Das Lied der Schule von Antoura); 2/Mai 1939, S. 34: » Li-dِikrā l-yūbīl al-mi’awī t-țālit li-š-šă ir al-afransī Ǧān Rāsīn« (Zur Erinnerung an das dreihundertjähre Jubiläum des französischen Dichters Jean Racine); Ebd., S. 35: » Al-lug̉a al-'arabīya fī madrasat 'Anțūra « (Die arabische Sprache in der Schule von Antoura). 246 Vgl. NDJ, »Carnet de vacances«, 1946, »Pour bien écrire l'arabe«. 
fanden sich interessanterweise nicht nur christliche Autoren wie die Mitglieder der Emigranten-Gruppe Mīhāầ l Nu'ayma und Ğibrān Halīl Ğibrān, sondern mit Țaha Husayn auch nicht-christliche Autoren, die damit nicht dem bis dato üblichen arabischen Literatur-Kanon der Jesuiten entsprachen ${ }^{247}$. Bemerkenswert ist auch, dass 1939 das erste Mal in den Aufzeichnungen der Jesuiten in Beirut das arabische Theaterstück, das ihre Schüler seit der Zeit des Osmanischen Reiches zu Ehren des maronitischen Klerus und ihrer Eltern vor Beginn der Fastenzeit aufführten, mit seinem Namen verzeichnet ist ${ }^{248}$.

Auch innerhalb der Lehrerschaft der Jesuiten kam Anfang der 1940er Jahre eine Diskussion über den Stellenwert der arabischen Sprache in ihren Schulen auf. Sie erlebten diese Debatte zwanzig Jahre nach der Mission laïque ${ }^{249}$. Zwar betonten die Jesuiten im Januar 1942 weiterhin, dass alle Fächer auf Französisch unterrichtet werden sollten, fragten sich aber auch, ob es nicht möglich sei, in den Klassen eine Stunde pro Woche, aufgrund der »importance pratique du vocabulaire de ces deux matières«, Geschichte und Geographie auf Arabisch zu unterrichten ${ }^{250}$. Zwei Wochen später diskutierten die Lehrer über mögliche Methoden, die es den Schülern, die oft in Arabisch dachten, erleichtere, anhand von »transpositions d'arabe parlé en arabe écrit« ihre Gedanken in arabischem Dialekt in korrektem Arabisch niederzuschreiben $^{251}$. Außerdem sprachen sie über die Möglichkeit, den meisten ihrer Schüler das libanesische Abitur nahezulegen ${ }^{252}$. Im März 1942 schließlich hielten sie in ihrem Sitzungsprotokoll fest, dass die libanesische Kultur praktisch ein »mélange des deux cultures orientale et occidentale« sei. Sie fragten sich aber, wie der Anteil der jeweiligen Kultur aussehe ${ }^{253}$. Sie selbst stellten fest, dass es zu vielen dieser Fragen keine Antworten gebe.

Ein wichtiger Grund für die prominentere Behandlung der arabischen Sprache in den katholischen Schulen lag in einer veränderten Haltung der katholischen Kirchen selbst und ihrer Mitglieder zu dieser Sprache. Deshalb trafen die katholischen Schulen, ähnlich wie dies die Mission laïque zwanzig Jahre zuvor erlebt hatte, auf eine positivere Einstellung zum Arabischen.

247 Vgl. Kap. 4.

248 SJ/Beirut, 3 A 30: »Collège de Beyrouth. Diaire du P. Préfet 1934-1947«, 01.02.1939: »Pièce arabe [...] A1 Samaouaal«. Es handelt sich höchstwahrscheinlich um ein Stück über den arabischen Kämpfer und Dichter as-Samaw'āl b. 'Ādiya' aus dem 6. Jahrhundert. Sein Clan konvertierte zum Judentum und lebte auf der arabischen Halbinsel. Der Beiruter Jesuit Louis Cheikho hatte 1909 einen Aufsatz über Gedichte über diesen Mann veröffentlicht. Diwan d'as-Samaou'al d'après la récension de Niftawaihi, Beirut: Imprimerie Catholique, 1909.

249 Vgl. Kapitel 4.2.

250 Vgl. SJ/Beirut, 11.D.14, »Réunion des professeurs 1942/questions de programmes«, Sitzung vom 27.01.1942.

251 Vgl. ebd., Sitzung vom 10.02.1942.

252 Ebd.

253 Vgl. ebd., Sitzung vom 10.03.1942. 
Zum einen hatte sich im Laufe der Entwicklung des libanesischen Nationalismus auch dessen Bezug zur arabischen Sprache intensiviert. Einige Vertreter dieser Richtung schrieben sogar auf Arabisch, wie beispielsweise Said 'Aql, der vor allem für seine Dichtung in libanesischem Dialekt bekannt ist ${ }^{254}$. Zum anderen kristallisierte sich in dieser Zeit die Betonung des arabischfranzösischen Bilingualismus heraus, der den drohenden Verlust des Französischen als zentrale Sprache im Libanon auffangen wollte. Besonders in den christlichen Milieus beheimatet, vertraten die Anhänger des Bilingualismus eine Vorstellung des Libanons, in welcher die arabische und die französische Sprache harmonisch koexistierten und sich ergänzten:

Le Libanais [...] se redouble ici en Chrétien et Musulman, dans la mesure même où partisans et adversaires du bilinguisme fondamental représentent respectivement la majorité de la communauté chrétienne et la majorité de la communauté musulmane, le Musulman exclusivement sensible à l'héritage culturel arabe, le Chrétien y joignant, dans le même sentiment, l'héritage culturel occidental et en particulier français ${ }^{255}$.

Von den Vertretern wurde dieses Nebeneinander beider Sprachen als natürliche Eigenart des Libanons dargestellt, die schon seit langer Zeit die Gegend geprägt habe ${ }^{256}$. Außerdem, so diese Autoren weiter, könne so die arabische Sprache in die libanesische Kultur integriert werden, ohne dass das Französische verdrängt werde.

An der neuen Wertschätzung der arabischen Sprache und der Herausbildung des Bilingualismus waren Mitglieder und Verantwortliche der katholischen Kirchen, innerhalb des Vatikans, aber auch in den lokalen orientalischen lokalen Kirchen, zentral beteiligt. Das 19. und frühe 20. Jahrhundert war von einer starken Zentralisierung und »Romanisierung « der orientalischen Katholiken durch den Vatikan geprägt gewesen ${ }^{257}$. Auch wenn es bis 1950 keine katholische Doktrin über den Islam gab ${ }^{258}$, was von einer begrenzten Beschäftigung mit der arabischen Welt zeugt, befassten sich ab Mitte der 1930er Jahre einige Gruppen und Personen innerhalb der katholischen Kirche mit der Situation der Kirchen im Nahen Osten und entwickelten eine größere Sensibilität für die Einbeziehung lokaler Riten, Anschauungen und Sprachen ${ }^{259}$. Treibende Kräfte eines Dialogs mit dem Islam waren hier

254 Vgl. Kaufman 2004, S. 172-173.

255 Vgl. Авоч 1962, S. 157.

256 Vgl. ebd., S. 177.

257 Vgl. Claude Prudhomme, Stratégie missionnaire du Saint-Siège sous Léon XIII (1878-1903). Centralisation romaine et défis culturels, Rom 1994, S. 528.

258 Erst der Orientalist und bekennende Katholik Louis Massignon setzte ein Umdenken in Bewegung, indem er durch den gemeinsamen Ursprung in Abraham die Ökumene von Islam und Christentum propagierte. Vgl. Avon 2005, S. 25.

259 Vgl. SAaïdia 2004, S. 82-96. 
Kardinal Tisserant sowie die Orden der Pères Blancs, Dominikaner und Jesuiten, insbesondere Christophe de Bonneville, der von 1927 bis 1930 Direktor der Université Saint-Joseph in Beirut und von 1930 bis 1936 Provinzial von Lyon war, bevor er von 1936 bis 1939 die Mission der Jesuiten in Syrien und im Nahen Osten leitete. Diese Annäherung ging einher mit einer stärkeren Einbindung der orientalischen Kirchen, was auch eine größere Zentralisierung zur Folge hatte. So weitete Papst Pius XI. 1937 die Zuständigkeit der 1862 geschaffenen und 1917 umbenannten Kongregation für die Orientalische Kirche aus, so dass in Gebieten mit mehrheitlich orientalischen Christen fortan alle Katholiken, sowohl orientalischer als auch lateinischer Zugehörigkeit, der Kongregation unterstanden ${ }^{260}$. In der Folge kam es auch zu einer neuen Sensibilität für die arabische Sprache ${ }^{261}$.

Auf Seiten der lokalen Kirchen selbst war schon von der neuen Nähe des maronitischen Patriarchen 'Arị̄a zu den arabischen Nationalisten die Rede. Diese Zusammenarbeit stärkte auch die Nähe der maronitischen Gläubigen zur arabischen Sprache, auch wenn das Syriakische die liturgische Sprache der maronitischen Kirche blieb, im Gegensatz zur griechisch-melkitischen Kirche, die im 18. Jahrhundert das Arabische gewählt hatte ${ }^{262}$. Kaufman weist allerdings zu Recht darauf hin, dass im Libanon auch während der Blütezeit der Frankophonie in den 1930er und 1940er Jahren die meisten Bewohner lieber Arabisch sprachen und lasen und dass diese Sprache auch in den von Maroniten dominierten Bergdörfern das führende Idiom blieb ${ }^{263}$. So ist ein Umdenken vor allem unter der urbanen, stark von den französischen Schulen beeinflussten Bevölkerung auszumachen. Beispielsweise nutzten die Mitglieder der Kata'ib das Arabische, um für ihre Sache Werbung zu machen ${ }^{264}$. Allerdings hoben die Maroniten oft den libanesischen Dialekt hervor, um auf diese Weise ihren Unterschied zu den muslimischen und arabischen Nationalisten zu betonen ${ }^{265}$. Katholische Orden wie die Jesuiten beteiligten sich an diesem Prozess, wie ihre Unterstützung des frankoarabischen Bilingualismus deutlich macht ${ }^{266}$. Nach dem Ende des Mandats wurden diese Vorstellungen noch weiter ausgearbeitet und praktiziert. Bei-

260 Vgl. Ulrike Koltermann, Päpste und Palästina. Die Nahostpolitik des Vatikans von 1942 bis 1947, Münster 2001, S. 27. Gleichzeitig wurde Cardinal Tisserant 1937 zum Bischof ernannt, um in liturgischer Hinsicht auf gleicher Ebene mit den orientalischen Patriarchen zu stehen, blieb ihnen aber durch seinen Kardinalstitel überlegen. Vgl. Trimbur 2003, S. 246.

261 Vgl. SaAïdia 2004, S. 96.

262 Vgl. Suleiman 2003, S. 209.

263 Vgl. Kaufman 2004a, S. 170-171.

264 Vgl. ebd., S. 192.

265 Vgl. Womack 2012, S. 16. Diese Bewegung erfuhr ihren Höhepunkt in den 1960er Jahren; Kaufman 2004, S. 173; Suleiman 2003, S. 205.

266 Dieser Prozess begann natürlich schon sehr viel früher, nämlich mit der Ankunft der Missionare im Libanon. Vgl. Henry Laurens, Le Liban et l'Occident. Récit d'un parcours, in: Vingtième Siècle. Revue d'Histoire 32 (1991), S. 25-32, S. 27; Aвоu 1962, S. 102, 111. Der 
spielsweise hielt der Cénacle Libanais, ein 1947 von Michel Asmar gegründeter Kreis, der über gesellschaftliche Themen diskutierte, seine Sitzungen abwechselnd auf Französisch und Arabisch ab ${ }^{267}$.

Die stärkere Wertschätzung der arabischen Sprache auch unter den libanesischen Katholiken, hatte, so ist zu vermuten, starken Einfluss auf die Retrospektive der ehemaligen Schüler katholischer Schulen. So betonte ein Absolvent der Jesuitenschule in Beirut, am Ende des Mandats habe es einen regelrechten Wettbewerb zwischen den verschiedenen Schulen gegeben, wer über die besten Arabischlehrer verfügte, und jede Schule versuchte sich mit illustren Persönlichkeiten zu schmücken ${ }^{268}$. Er selber berichtete stolz von Fu'ād Bustān̄̄ ${ }^{269}$ als seinem Arabischlehrer Anfang der 1940er Jahre. Auch der Politiker Helou schrieb über seine ehemaligen Arabischlehrer: »Plusieurs d'entre eux, parmi les plus importants: Cheikho, Malouf, Salhani et bien d'autres, figuraient au rang des plus illustres représentants des Lettres arabes $\ll^{270}$.

\section{In die Unabhängigkeit entlassen: \\ Berufs- und Karrierewege von Absolventen und \\ Absolventinnen französischer Schulen}

Im Juni 1941 veranstaltete eine Gruppe ehemaliger Schüler der Schule der Frères des Écoles chrétiennes im Einvernehmen mit den Ordensbrüdern eine Vortragsreihe zu verschiedenen Berufszielen. Unter dem Titel »Pour mieux choisir / Pour mieux servir«, stellten sie in folgender Reihe die verschiedenen Tätigkeitsfelder vor: Militär (»La carrière militaire«), Medizin (»La carrière médicale«), Verwaltung (»La carrière administrative«), Justiz (»Le Barreau«), Landwirtschaft (»Agriculteur«), »Menschenfischer« (»Pêcheur H'hommes «), also Priester oder Missionar ${ }^{271}$. Ziel der Vortragsreihe, so die Veranstalter, sollte sein, neben den materiellen und intellektuellen Voraussetzungen auch den »menschlichen und sozialen Wert« sowie die besondere Situation des Berufes im Libanon vorzustellen: war dieser "schon versperrt? Vielversprechend? Geehrt? Herabwürdigend? Wie sah es mit dem >großen Geld aus $\ll^{272}$ ?

Autor, selber Jesuit, erklärt zudem in pauschalisierender Weise die Christen zu Vertreten und die Muslime zu Gegnern des Bilingualismus. Vgl. Авоu 1962, S. 157.

267 Vgl. Kaufman 2004a, S. 233.

268 Vgl. Interview der Verfasserin mit Camille Hechaïmé, Beirut, 24.10.2008.

269 Zu Bustānīs Biographie vgl. Havemann 2002, S. 165; Kaufman 2004, S. 170.

270 Helou 2002, S. 19-20.

271 FEC, L'Essor, Juni 1941, S. 24-29.

272 »Encombrée? Prometteuse? Honorée? Avilie? La question `gros sous«?« Vgl. FEC, L’Essor, Juni 1941, S. 25. 
Diese Episode macht eindrücklich deutlich, dass die Absolventen der französischen Schulen im Libanon am Ende ihrer Schulzeit nicht nur in ihre persönliche und berufliche Unabhängigkeit entlassen wurden. Ab Mitte der 1930er Jahre befand sich auch ihr Land eindeutig im Umbruch und auf dem langsamen Weg in die Unabhängigkeit. Hatte sie ihre Schulzeit auf diese Eigenständigkeit im doppelten Sinne vorbereitet? Welche Positionen vertraten Schulen, Eltern und die französische Regierung in Bezug auf dieses Thema? Können Unterschiede zwischen einzelnen Schulen festgestellt werden? Anhand der Vorstellung der unterschiedlichen, von Absolventen französischer Einrichtungen gewählten Studien- und Berufswege soll nach dem Erfolg der Bildungsstätten in dem Versuch, eine adäquate Vorbereitung auf das professionelle Leben ihrer Alumni zu leisten, gefragt werden.

Die Analyse zeigt, dass die französischen Schulen zu großen Teilen die Anforderung der französischen Regierung erfüllen konnten, eine frankophone Klientel zu prägen, die wirtschaftlich, politisch und kulturell auch nach ihrer Schulzeit in enger Beziehung zu Frankreich stand. Gleichzeitig waren sie in vielen Fällen in der Lage, die Erwartung ihrer Klientel zu befriedigen, welche durch den Schulbesuch ihren sozialen Status wahren oder verbessern wollte. Darüber hinaus deuteten die Karrieren der meisten ehemaligen Schüler aber eher auf eine Kontinuität als auf einen Wandel ihrer sozialen Identität angesichts der politischen Veränderungen hin. Auch wenn man die aktive Rolle der Schulen bei dieser Entwicklung nicht unterschätzen darf, fungierten sie dennoch weniger als Initiatoren denn als Begleiter der Prozesse, die zu einer Etablierung der Alumni in die libanesische Gesellschaft am Ende der Mandatszeit führten.

Ein erster Erfolg für die französischen Schulen zeigt sich darin, dass die meisten ihrer Absolventen für ihr Studium und ihren Beruf im frankophonen Umfeld blieben. Hinsichtlich ihres Studiums entschied sich die Mehrheit der Alumni für die französische Universität der Jesuiten, Saint-Joseph, in Beirut, in der Mandatszeit neben der amerikanischen Universität die einzige Hochschule im Land ${ }^{273}$. Das galt neben den Absolventen der Jesuitenschulen selbst und der anderen katholischen Schulen auch für diejenigen der Mission laïque - neben der offensichtlichen Begründung durch die französische Sprache, die dort gesprochen wurde und die sie in der Regel viel besser beherrschten als das Englische, bedeutet dies auch, dass sich die ideologischen Unterschiede

273 Die erste libanesische Hochschulgründung erfolgte 1953 mit der Eröffnung der libanesischen Universität, der Fu'ād Bustān̄̄ als erster Rektor vorstand. Vgl. Hanf 1969, S. 133-136. Allerdings blieben deren Diplome lange Zeit weniger anerkannt als die von USJ und AUB ausgestellten Abschlüsse, was viel mit den viel bescheideneren Mitteln, die der libanesischen Universität zur Verfügung standen, zu tun hatte. Vgl. Havemann 2002, S. 107-110. 
zwischen den französischen Institutionen nicht auf diese Wahl auswirkten ${ }^{274}$. Nur wenige Absolventen, vor allem aus den Schulen der Mission lä̈que und dem Collège protestant français, entschieden sich für ein Studium an der American University of Beirut ${ }^{275}$. Allerdings bedeutete ein Studium an der amerikanischen Universität nicht unbedingt eine Aufgabe des frankophonen sozialen Umfeldes ${ }^{276}$.

Nur eine Minderheit der Absolventen französischer Schulen ging für die volle Länge oder einen Teil ihres Studiums nach Frankreich. Diese Tatsache zeigt deutlich, dass die französischen Abschlüsse, die sie an ihrer Schule erworben hatten, weniger der realen Möglichkeit, in Frankreich zu studieren, galt als vielmehr einer Aufwertung ihres sozialen Status ${ }^{277}$. Die jungen Männer, welche sich für ein Studium in Frankreich entschieden, sollten die Welt kennen lernen und vor allem ihre Kenntnisse der französischen Sprache und Kultur perfektionieren ${ }^{278}$. Insbesondere viele spätere libanesische Politiker, unterschiedlicher Konfession, absolvierten ihr ganzes Studium oder Teile davon in Frankreich ${ }^{279}$. Dabei galt ihr Aufenthalt dem Erlernen ausgewählter Disziplinen, in den meisten Fällen des Rechts, der Medizin oder des Ingenieurswesens ${ }^{280}$.

Interessanterweise kamen die libanesischen Studenten nicht nur nach Paris, welches aufgrund seiner hohen politischen, intellektuellen und sozialen Bedeutung weltweit ein selbstverständlich begehrtes Reiseziel darstellte,

274 Vgl. Interview mit der ehemaligen Schülerin der Mission laïque française Fatmé Saghir, Beirut, 18.10.2007.

275 Beispielsweise absolvierte May Saikaly ihr Zahnmedizinstudium an der amerikanischen Universität und arbeitete dann in der Praxis ihres Vaters mit. Vgl. Interview der Verfasserin mit May Saikali, Beirut, 08.12.2008. Auch Taqi ad-Din as-Sulh wechselte zum Studium an die amerikanische Universität. Vgl. Guilain P. Denoeux, Eintrag »Sulh, Taki al-Din al- (19091988)«, in: Encyclopedia of the Modern Middle East and North Africa, Bd. 2, Detroit 2004, S. 2119-2120, S. 2119.

276 So besuchte May Saikaly weiterhin die Gottesdienste der französischen protestantischen Gemeinde in Beirut.

277 Vgl. Interview der Verfasserin mit Camille Hechaïmé, Beirut, 24.10.2008.

278 So berichtet der spätere Politiker Nicolas de Bustros in seinen Memoiren über seine Zeit in Paris: »[...] pendant que je me transformais en Parisien [...]«. Nicolas de Bustros, Je me souviens, Beirut: Librairie Antoine, 1983, S. 35.

279 Vgl. Naaman 2004, S. 134: der Autor nennt hier Emile Eddé, Bishara al-Khuri, Sami as-Sulh, Riad as-Sulh, Michel Zakkur, Bahij Taqi ad-Din und Salim Haydar. Wie Naaman und andere Autoren deutlich machen, konnte der Aufenthalt in Paris auch der Flucht vor Konflikten mit der Mandatsmacht dienen, wie der Fall von Riad as-Sulh und Michel Zakkur zeigt. Vgl. auch die Biographie von Kamal Jumblatt: Igor Timofeev, Kamal Jumblatt et le destin tragique du Liban, Paris/Beirut 2000, S. 42.

280 Vgl. FEC, Palmarès 1925-1926, S. 3: »Page des Anciens«. Unter den gewählten Studienfächern in Frankreich firmieren Recht, Wirtschaftswissenschaften, Ingenieurswesen und höheres Handwerk (»Arts et Manufactures«); vgl. auch LAZ/Paris, Association amicale des anciens élèves d'Antoura. Bulletin annuel, 3/Mai 1940, S. 34; ebd., 4/1941, S. 25; ebd., 6/1943, S. 42: auch hier waren Medizin, Zahnmedizin und Recht führend. 
sondern auch in eine der Städte im Süden, Lyon, Montpellier, Grenoble oder Marseille $^{281}$. Die Destinationen im Süden Frankreichs erklären sich unter anderen durch die zahlreichen, Jahrhunderte alten Verbindungen dieser Städte, insbesondere Lyons, mit dem Libanon ${ }^{282}$. Wirtschaftliche Beziehungen, aber auch die kulturelle Vertrautheit durch die Ankunft der Schiffe aus dem Nahen Osten in Marseille waren für die Wahl dieser Städte verantwortlich, weshalb auch nordafrikanische Studenten dort $\mathrm{zu}$ finden waren ${ }^{283}$.

Darüber hinaus profitierten die Studenten von den französischen Netzwerken ihrer Alma mater im Libanon. Hier waren die Absolventen katholischer Schulen klar im Vorteil, da diese über lange gewachsene Strukturen und eine größere Anzahl an Mitgliedern und Gemeinschaften verfügten als die anderen Bildungsstätten. Beispielsweise suchte der spätere Politiker Kamal Joumblatt (arabisch Kamāl Ğunbulāt), als er um 1937 für das Jurastudium nach Paris kam, zunächst das Wohnheim der Lazaristen auf, wo er mit Hilfe eines Empfehlungsschreibens aus Ayntoura empfangen wurde ${ }^{284}$. Wie ein Lehrer der Mission laïque in Beirut, Parisot, während einer Lehrerkonferenz 1929 feststellte, verfügten die Alumni der katholischen Schulen, im Gegensatz zu den Schülern der Mission lä̈que, über eine Anlaufstelle und wurden direkt in das französische Leben involviert, während die Schüler der Mission lä̈que isoliert blieben. Er schlug deshalb ein Wohnheim in Frankreich speziell für ihre Absolventen vor:

Ceux qui sortent des écoles de la Mission Laïque sont moins bien partagés que ceux qui sortent des écoles confessionnelles. Ces derniers, aussitôt arrivés en France, sont happés, dirigés, mêlés à la vie Française. Les nôtres, au contraire, sont un peu isolés. $\mathrm{Ne}$ serait-il possible de créer à Paris un foyer pour les élèves de nos écoles ${ }^{285}$ ?

Laut Direktor Ruche wurde die Frage eines eigenen Wohnheims bereits diskutiert, aber da die Archive keine Informationen über konkrete Schritte enthalten, scheint es bei dem Entwurf geblieben zu sein.

Die französische Regierung unterstützte den Aufenthalt junger Libanesen in Frankreich zu einem gewissen Grad. Auf diese Art und Weise konnte sie

281 Vgl. FEC, Palmarès 1924-1925, S. 29: »Page des Anciens«; 1926-1927, S. 2: »Page des Anciens«. Die angegebenen Studienorte waren neben Paris und Beirut Montpellier, Aix und Lyon; LAZ/Paris, Association amicale des anciens élèves d'Antoura. Bulletin annuel, 2/Mai 1939, S. 37: Absolventen waren in Paris, Lyon und Grenoble.

282 Vgl. Kapitel 2.2. Vgl. auch Seurat 1977, S. 173, 179. Lyon war nicht nur der Ausgangspunkt für die Jesuiten, die in den Nahen Osten gingen, sondern auch die Heimat und das Tätigkeitsfeld von Édouard Herriot, dem französischen Politiker und langjährigen Präsidenten der Mission laïque française.

283 Vgl. Le Pautremat 2003, S. 326.

284 Vgl. Timofeev 2000, S. 42.

285 AN/Paris, 60 AJ 131, »Réunion des Professeurs«, Januar 1929. 
die wirtschaftlichen, aber auch die politischen Beziehungen, die sie zu den Absolventen der französischen Schulen aufbauen wollte, verfestigen. Gleichzeitig konnte sie die Kooperationen wirtschaftlicher, politischer und kultureller Natur, welche sie nach der libanesischen Unabhängigkeit fortzuführen und weiterzuentwickeln gedachte, vorbereiten ${ }^{286}$.

Um diese Beziehungen insbesondere mit den Katholiken zu verfestigen, stellte die französische Regierung 1937 für 99 Jahre ein Gebäude in der Rue d'Ulm in Paris, also direkt im intellektuellen Zentrum der Stadt, zur Verfügung, in welchem der maronitische Patriarch anlässlich seiner Besuche in Frankreich beherbergt werden sollte, in welchem aber auch libanesische Priester und Studenten unterkommen konnten ${ }^{287}$. Dieses Foyer franco-libanais wurde vor allem von den Spenden französischer konservativer christlicher Politiker, Ordensmitglieder und Funktionäre finanziert, aber auch einige frankophone und frankophile Libanesen und sogar Papst Pius XI. beteiligten sich an dem Projekt ${ }^{288}$. Den Vorsitz des Verwaltungsrates hatten Bérard, der Präsident des Verwaltungsrates der Banque de la Syrie et du Liban, Fegali, der Delegierte des Patriarchen bei der französischen Regierung und Schoeffler, ein $» g o u v e r n e u r$ honoraire des Colonies $\ll$ inne ${ }^{289}$.

Diese Personalbesetzung macht deutlich, dass die französische Regierung auch im Hinblick auf die libanesische Unabhängigkeit ihre traditionellen Verbindungen zur maronitischen Gemeinschaft pflegen wollte und dadurch auch die katholischen libanesischen Studenten in besonderer Weise förderte. Das bis heute existierende und funktionierende Foyer franco-libanais hat ihrer Politik Recht gegeben. Zudem kann vermutet werden, dass die französische Regierung, ähnlich wie bezüglich der nord-afrikanischen Muslime in Frankreich, bemüht war, diese unter einer gewissen Kontrolle zu behalten und so die Gründung und Aktivität anti-französischer und nationalistischer Kreise zu minimieren ${ }^{290}$.

Darüber hinaus unterstützte die französische Regierung den Aufenthalt junger libanesischer und syrischer Studenten aller Konfessionen in Frankreich, indem sie ihnen Stipendien und Praktika in verschiedenen Einrichtungen gewährleistete. Der Fall des syrischen Studenten Jémil Salibi, der 1925 um einen Aufenthalt in Paris bat und dafür sowohl die Erlaubnis des

286 Vgl. DueCK 2010, S. 10.

287 Vgl. AN/Paris, 16 aj 6986, »Liban/Foyer franco-libanais à Paris 1935-1939«, Rundbrief des Ehrenkomitees »pour la construction du foyer franco-libanais«, Paris, August 1937.

288 So waren unter den Spendern des Jahres 1935-1936 Henri de Jouvenel, Damien de Martel, Ernest Sarloutte, Louis Jalabert, Halim Bey Melhame und M. Derwiche Haddad. Vgl. AN/ Paris, 16 aj 6986, »Liban/Foyer franco-libanais à Paris 1935-1939«, »Liste des souscripteurs du foyer franco-libanais «, 1935-1936.

289 Vgl. ebd., Brief des Präsidenten des Foyer franco-libanais an den Rektor der Universität Charlety, Paris, 14.02.1939.

290 Vgl. Le Pautremat 2003, S. 321-326. 
Erziehungsministers als auch eine positive Stellungnahme des Rektors der Académie de Paris ${ }^{291}$ erhielt, ist interessant, weil Saliba ebenfalls einen Brief schrieb und sich, um sein Anliegen zu unterstützten, auch selbst des Diskurses der Zivilisierungsmission bediente:

Et moi, si attaché à l'idéal français, je serai plus apte à entreprendre en Orient, la propagation des idées modernes de civilisation, de progrès et de démocratie afin de faire, par là, de la Syrie une petite France ${ }^{292}$.

Damit rekurrierte er auf die Logik der französischen Regierung, welche der Überzeugung war, die Studenten konnten, beispielsweise im Erziehungswesen, von den französischen Methoden profitieren und diese dann an ihre Landsleute weitergeben. So beurteilte ein Mandatsfunktionär 1943 an den Rektor der Akademie in Paris den Auslandsaufenthalt des syrischen Studenten Sabbagh: »Il serait, en effet, souhaitable que M. Sabbagh pût profiter en France de nos méthodes d'enseignement et en faire bénéficier ses compatriotes syriens $\ll^{293}$.

Auch wenn die französische Regierung diese Auslandsaufenthalte also unterstützte, blieb angesichts der großen Anzahl an Schülern, die in den Mandatsgebieten an französischen Schulen das baccalauréat und damit den Zutritt zu französischen Hochschulen erlangt hatten, die Zahl der Austauschstudenten aber überschaubar: beispielsweise befanden sich im Studienjahr 1939/ 1940250 Studierende aus Syrien und Libanon in Paris ${ }^{294}$, und 1941 verzeichnete das Außenministerium 39 Stipendiaten aus Syrien und dem Libanon auf dem Gebiet des besetzten Frankreichs ${ }^{295}$. Im Vergleich zu den ca. 600 Studenten aus ganz Nordafrika, die sich in dieser Zeit in der Metropole aufhielten ${ }^{296}$, war der Anteil der Nahoststudenten zwar nicht unerheblich, aber es muss doch der Eindruck verwehrt werden, es habe sich um >Massenauswanderungen` nach Frankreich gehandelt. Eine solche groß angelegte Bewegung gaben weder das Budget der Eltern noch die Mittel der französischen Regierung, deren Land sich seit Beginn der 1930er Jahre auch in einer wirtschaftlichen Krise befand ${ }^{297}$, her.

291 Als solcher war er für die Schulen und Universitäten zuständig.

292 AN/Paris, aj 16, 6993, »Correspondances diverses 1924-1948«, Brief Salibi an den Rektor, Paris, 26.10.1925.

293 Ebd., Brief des Hochkommissars an den Rektor, Paris, 02.12.1943.

294 Vgl. MAE/Paris, »Guerre 1939-1945 Vichy Levant«, 77, »personnel«, »Note pour la sousdirection d'afrique-Levant« du Ministère des Affaires étrangères, Vichy, 31.10.1940. 1934 befanden sich laut Le Pautremat 2003, S. 302, noch 300 syrische Studenten in Paris.

295 Vgl. MAE/Paris, »Guerre 1939-1945 Vichy Levant«, Nr. 77: »personnel«, »Boursiers et Stagiaires des Gouvernements Syriens et Libanais se trouvant en territoire occupé «.

296 Vgl. Le Pautremat 2003, S. 323, der Zahlen von 1938 vorliegen hat.

297 Vgl. ebd., S. 68. 
Von größerer Relevanz für die Masse der Absolventen französischer Schulen war die Auswahl an Berufsfeldern, die ihnen im Libanon selbst zur Verfügung stand. Die massive Emigration nach Amerika während des Ersten Weltkrieges hatte seit Beginn des Mandats und insbesondere nach der Weltwirtschaftskrise nachgelassen ${ }^{298}$, und die hier untersuchten Archive verzeichnen nur wenige Alumni, die in andere französisch dominierte Regionen, beispielsweise nach Algerien, gingen ${ }^{299}$. Angesichts der politischen und wirtschaftlichen Krise, die auch den Libanon traf, war die Frage der Berufswahl umso entscheidender. Aus diesem Kontext erklären sich auch die eingangs geschilderten Vortragsreihen. Zwei Jahre später organisierte eine Gruppe ehemaliger Schüler der Jesuiten um Charles Helou, den Journalisten und späteren libanesischen Minister und Staatspräsidenten, in Beirut eine ähnliche Vortragsreihe mit fast identischem Profil ${ }^{300}$. Auffälligerweise waren bei beiden Veranstaltungen die meisten Redner Libanesen ${ }^{301}$, das heißt, es ging den Organisatoren eindeutig um eine libanesische Perspektive auf die Berufe. Das große Interesse in der Bevölkerung an diesen Vorträgen zeigt sich laut Helou auch in der Tatsache, dass diese, im Gegensatz zu anderen Veranstaltungen, die er organisierte, mehr Zuschauer hatten als der Raum füllen konnte ${ }^{302}$.

In der Beschreibung, die die Schulzeitschrift der Frères des Écoles chrétiennes von ihrer anfangs zitierten Vortragsreihe gab, fiel das Urteil für jeden der vorgestellten Berufe ähnlich aus: sie bedürften, so der Autor, einer ernsthaften Vorbereitung und Ausübung, brächten aber viel persönliche und nationale Ehre. Wie fiel nun die Wahl der Absolventen aus, und inwiefern bildete ihre Wahl eine Antwort auf die allmähliche Dekolonisierung ihres Landes?

Die Alumni wählten zu großen Teilen die in den Vortragsreihen vorgestellten Berufsfelder, also Medizin, Recht, Administration, Lehramt und Priesteramt, aber in den Bereichen Militär und Landwirtschaft, die von den Schulverantwortlichen angepriesen worden waren, war die Nachfrage sehr viel geringer. Die Berufe des Ingenieurs, des Journalisten und des Händlers, die die Schulen nicht vorstellten, waren außerdem sehr gefragt. Welche sozi-

298 Vgl. Gildas Brégain, Syriens et Libanais d'Amérique du Sud (1918-1945), Paris 2008, S. 13: Der Autor verzeichnet für die Zeit von 1918 bis 1930 eine Zahl von 250000 Emigranten, von denen nur $10 \%$ zurückkehrten.

299 Beispielsweise nennt der Palmarès der Frères des Écoles chrétiennes 1927-1928 zwei Absolventen, die an die Landwirtschaftsschule nach Algier gingen. Ihre Namen, Edmond Goudeau und Léon Latour, lassen aber darauf schließen, dass es sich um Franzosen handelte.

300 Vgl. Helou 2002, S. 34.

301 Bei den Frères des Écoles chrétiennes wurde nur das Berufsfeld des Militärs von einem Franzosen vorgestellt; bei den Jesuiten referierten nach einem Vortrag eines Mandatsfunktionärs über die Diplomatenkarriere libanesische Redner über die Berufe des Anwalts, des homöopathischen Arztes und des Priesters; das Berufsfeld des Lehrers oder Professors wurde von einem französischen Ökonomen vorgestellt.

302 Vgl. Helou 2002, S. 34. 
alen, politischen und ökonomischen Gründe und Konsequenzen diese Entscheidungen hatten, soll im Folgenden untersucht werden. Interessanterweise gab es wenige Unterschiede zwischen den verschiedenen hier untersuchten Schulen, wenn man vom Beruf des Priesters oder Missionars absieht, der nur in den katholischen Schulen eine Rolle spielte.

Die Wirtschaft war ein wichtiges Betätigungsfeld vieler Absolventen französischer Schulen. Einige wurden Geschäftsleute oder Händler und übernahmen in der Regel die Unternehmen ihrer Familie ${ }^{303}$. Damit blieben sie in einem gerade für Beirut traditionellen Beruf, der auf gewachsenen Strukturen und einem intensiven Handel mit Syrien aufbaute, und konnten den sozialen Status der Familie weiterführen. Auch wenn das Mandatsregime den Libanon in wirtschaftlicher Hinsicht nicht auf die Unabhängigkeit vorbereitet hatte, gab es zwischen 1926 und 1939 doch eine Phase des Wachstums, die erst nach dem Rückzug der französischen Armee in einer Rezession endete $^{304}$. Daneben gab es auch ehemalige Schüler, die in den neu gegründeten internationalen Firmen, besonders in der Ölindustrie, tätig wurden und die damit einen Weg einschlugen, der nicht durch ihre Familie vorgezeichnet war $^{305}$. Da das Mandatsregime aber die Industrie nur wenig gefördert hatte, gab es wenige inländische und ausländische Investoren ${ }^{306}$, und dieses Berufsfeld blieb sehr beschränkt.

Viele Schüler, vor allem aus Familien der aufsteigenden Mittelklassen, entschieden sich auch für ein Studium der Rechtswissenschaften und arbeiteten später als Anwälte, Richter oder in der Verwaltung ${ }^{307}$. Gerade der tertiäre Sektor war im Libanon während der Mandatszeit stark ausgebaut worden und versprach neue Aufstiegschancen ${ }^{308}$. Das Hochkommissariat hatte zudem große Teile des Rechtssystems stark verändert und dem französischen Modell angepasst ${ }^{309}$, und die frankophonen Schul- und Universitätsabsolven-

303 Beispielsweise übernahm der Absolvent der Jesuitenschule Michel Chiha eine Position in der Bank, die seiner Familie gehörte. Vgl. Kaufman 2004a, S. 159-160.

304 Vgl. Chidiac 2002, S. 343.

305 Vgl. das in Kapitel 6.1 genannte Beispiel eines Ehemaligen der Mission laïque, der bei SHELL angestellt wurde. Vgl. außerdem Interview der Verfasserin mit Afif Soubra, Beirut, 28.11.2008. Der Sohn eines Schreiners hatte eine Schule der Maqasid besucht, war dann zum Ingenieursstudium an die Universität Saint-Joseph gegangen und arbeitete später mit verschiedenen amerikanischen Firmen an großen Brückenprojekten. Vgl. Chidiac 2002, S. 342.

306 In Syrien war dies sogar noch weniger geschehen als im Libanon. Vgl. ebd., S. 342; Le PaUtreMAT 2003, S. 57.

307 Ein besonders prominentes Beispiel ist der spätere Minister Salīm Taqla. Vgl. Anne-Laure Dupont, Sélim Takla, un destin libanais, in: Gérard Khoury (Hg.), Sélim Takla 1895-1945. Une contribution à l'indépendance du Liban, Paris/Beirut 2004, S. 19-40, S. 21. Die Zeitschriften der französischen Schulen verzeichnen etliche ähnliche Beispiele.

308 Vgl. Chidiac 2002, S. 343.

309 Vgl. Nadine Méouchy, La réforme des juridictions religieuses en Syrie et au Liban (19211939) : raisons de la puissance mandataire et raisons des communautés, in: Jean-Pierre LuI- 
ten konnten die Gesetzestexte sehr gut verstehen und sahen vielleicht auch die Chance, diese nach der Unabhängigkeit des Landes wieder zu verändern. Es fällt auf, dass viele der Juristen gleichzeitig oder später eine politische Karriere einschlugen ${ }^{310}$, ein anderes Berufsfeld, welches stark von den politischen Umständen des Landes abhängig war und in den späten 1930er Jahren auch Aufstiegsmöglichkeiten zu versprechen begann ${ }^{311}$. Allerdings gab es auch in der Justiz ein gewisses Establishment ${ }^{312}$.

$\mathrm{Zu}$ den Berufen, die in einem Staat angesichts der Unabhängigkeit als Weg zur Herausbildung einer technischen Elite ${ }^{313}$ galten, zählte neben Ingenieuren und Juristen auch der des Arztes, welcher von vielen Absolventen gewählt wurde. Nachdem die Einführung der westlichen Medizin in der arabischen Welt Ende des 19. Jahrhunderts für viel Skepsis gesorgt hatte ${ }^{314}$, war der Beruf des Arztes besonders durch die Arbeit der amerikanischen und französischen Universität in der Mandatszeit sehr anerkannt ${ }^{315}$.

Ein weiterer Beruf, welcher stark von der politischen Situation des Landes abhängig war und den einige Absolventen wählten, war der des Journalisten. Dieses Berufsfeld ermöglichte auch Angehörigen der Mittelklassen eine Tätigkeit, zudem konnten Frauen sich hier politisch äußern, wie die Beispiele von Salma Sayegh, die bei der Mission laïque als Lehrerin arbeitete, oder der ehemaligen Schülerin Nazira Zayn-ad-Din zeigen ${ }^{316}$. Angesichts einer sehr strengen Zensur der libanesischen Presse durch die Mandatsmacht war das

ZARD (Hg.), Le choc colonial et l'islam. Les politiques religieuses des puissances coloniales en terre d'islam, Paris 2006, S. 359-382.

310 Siehe das Beispiel von Sami as-Sulh, Riad as-Sulh, Emile Eddé, Bishara al-Khuri und anderen.

311 Beispielsweise stammte der Jurist Charles Helou aus kleinen Verhältnissen, welche er nur durch Protektion überwinden konnte. Vgl. Schumann 2001, S. 239. Die Ehemaligenzeitschrift der Lazaristenschule von Ayntoura widmete den Politikern unter sich immer ein paar Zeilen. Vgl. z.B. LAZ/Paris, Association amicale des anciens élèves d'Antoura. Bulletin annuel, 1/ Mai 1938, S. 42: »Nous sommes heureux de constater que le Ministère actuel Khaled Chéhab compte deux de nos anciens«. In den nächsten Jahren wuchs die Zahl dieser Ehemaligen, die in die Politik gingen.

312 Vgl. Schumann 2001, S. 241.

313 Vgl. Hayma ZeIFA, Les élites techniques locales durant le mandat français en Syrie (19201945), in: Nadine Méouchy / Peter Sluglett (Hg.), The British and French Mandates in Comparative Perspectives, Leiden 2004, S. 497-518.

314 Vgl. Philippe Bourmaud, Cultiver sa réputation. L’image des médecins au Proche-Orient à l'ère des réformes ottomanes $\left(\mathrm{XIX}^{\mathrm{e}}\right.$-début $\mathrm{XX}^{\mathrm{e}}$ siècle), in: Tempora. Annales d'Histoire et d'Archéologie 18 (2007), S. 1-17.

315 Dieser Beruf wurde auch oft von einer Generation auf die andere übertragen. So wurde Anwar Soubra, der in den 1920er Jahren Schüler der Mission läque in Beirut war, ein von der Stadt Beirut angestellter Arzt wie sein Vater. Diese Informationen stammen von Afif Soubra, einem Verwandten Anwars.

316 Vgl. Kapitel 5.4. Vgl. auch Slim/Dupont 2002; DaKhli 2009a, S. 184-192. 
Zeitungswesen politisch besonders brisant ${ }^{317}$. Manche ehemaligen Schüler gründeten sogar eigene Zeitungen. Dabei stand jede Zeitung für ein politisches Programm. Die Absolventen der katholischen Schulen waren zumeist in frankophonen und in der Regel frankophilen Zeitungen aktiv, das prominenteste Beispiel ist hier die Zeitung L'Orient des ehemaligen Jesuitenschülers Georges Naccache ${ }^{318}$. Etwas kritischer gegenüber dem französischen Mandat eingestellt war die Zeitung Le Jour, 1934 von Michel Chiha gegründet, um seinem Schwager Bishara al-Khuri und dessen Partei, dem Konstitutionellen Block eine Plattform zu bieten ${ }^{319}$. Die ehemaligen Schüler der Mission laïque hingegen engagierten sich bei Zeitungen, die in der Regel arabischsprachig waren und der Mandatsmacht entweder distanziert oder sogar offen kritisch gegenüber standen, wie das Beispiel von Taqi ad-Din as-Sulh und das der Zeitschrift an-Nidā' zeigen.

Den Beruf des Landwirts hingegen wählten nur sehr wenige Absolventen, was damit zusammen hängen kann, dass viele Schüler der hier untersuchten Institutionen selbst aus der Stadt kamen und keinen Bezug zur Landwirtschaft hatten. In der Tat herrschte angesichts dieses Berufsfeldes ein eklatanter Unterschied zwischen den Erwartungen und Hoffnungen der Schulen sowie der französischen Regierung und den Aspirationen der Absolventen. In allen französischen Schulen gab es Ende der 1930er Jahre Überlegungen zu einer Belebung der Landwirtschaftsschulen und anderer technischer Berufe. »Le Liban manque de techniciens, et surtout de paysans compétents«, formulierte Grandjouan 1936 $6^{320}$. Im Jahr 1938 fertigte das Hochkommissariat eine Studie über die technischen Berufe im Libanon $\mathrm{an}^{321}$. Auch manche Libanesen sahen diese Notwendigkeit. Grandjouan berichtete von der Bitte 'Umar Da'uqs, an der Mission lä̈que eine Landwirtschaftsklasse aufzubauen ${ }^{322}$.

In der Schulzeitschrift der Jesuiten erschien 1935 ein Artikel eines ehemaligen Schülers über die Vorteile der Landwirtschaft ${ }^{323}$. Der Autor begegnete der möglichen Angst der Schüler, durch die Landwirtschaft zu »verwildern«, indem er betonte, dass auch dieses Berufsfeld mit dem städtischen Leben verbunden blieb: ^D'ailleurs, vous ne pourrez pas devenir un ısauvageく. Car la fréquentation des administrations vous sera indispensable $\ll^{324}$. Den Schülern,

317 Vgl. Nadine MÉouchy, La presse de Syrie et du Liban entre les deux guerres (1918-1939), in: Revue des mondes musulmans et de la Méditerranée 95-98 (2002), S. 55-70.

318 Vgl. Kassir 2003, S. 387.

319 Vgl. Zamir 2000, S. 37. 1971 fusionierten Le Jour und L'Orient zu L'Orient Le Jour.

320 AN/Paris, 60 AJ 138, Brief von Grandjouan an Besnard, Beirut, 20.01.1936.

321 Vgl. MAE/Nantes, SOFE, 145: 1938, »Publications«, »Etude sur l'enseignement technique au Liban«.

322 Vgl. AN/Paris, 60 AJ 138, Brief von Grandjouan an Besnard, Beirut, 20.01.1936.

323 Vgl. NDJ, L'U, Juni 1935, S. 21-29: »Ferez-vous de l'agriculture. Les carrières agricoles au Liban et en Syrie« (Autor Jean Debbané).

324 Ebd., S. 25. 
die nicht überzeugt waren oder deren Familien nicht über Ländereien verfügten, riet er, mit dem Ingenieursberuf eine für die Landwirtschaft komplementäre Tätigkeit zu erlernen. Angesichts der mangelnden Förderung, welche die Landwirtschaft in der Mandatszeit erhalten hatte ${ }^{325}$, ist zu vermuten, dass dieses Tätigkeitsfeld trotz der Bemühungen der Schulen als wenig attraktiv galt. Da aber in Syrien und im Libanon während der Mandatszeit 40-60\% der Bevölkerung in der Landwirtschaft arbeiteten, führten sowohl die mangelhafte Förderung als auch das geringe Interesse der Sekundarschulabsolventen zu einer Krise dieses Sektors ${ }^{326}$.

Eine ebenso geringe Rolle scheint für die Absolventen das Berufsfeld des Militärs gespielt zu haben. 1942 waren 42.462 Libanesen bei der britischen Armee und 10.500 bei der französischen Armee angestellt ${ }^{327}$, aber in den Archiven der Schulen tauchen libanesische Militärangehörige nicht auf oder werden nicht besonders gewürdigt $t^{328}$. Das hat sicherlich damit zu tun, dass die politische Situation im Libanon gegen Ende der Mandatszeit sehr instabil war und verschiedene europäische Machthaber einander ablösten. Zudem war die französische Armee 1941 von Deutschland besiegt worden, ihre Führung wechselte, auch im Libanon, zwischen Vichy-Regierung und Regime der Freien Franzosen unter de Gaulle, und während des Zweiten Weltkrieges erfüllte sie im Nahen Osten neben der britischen Armee eher eine auxiliäre Rolle ${ }^{329}$. Somit verfügte der Militärberuf über ein geschmälertes Prestige und bot langfristig kaum Aufstiegsmöglichkeiten, zumal laut franko-libanesischem Vertag die französische Armee im Libanon weiterhin verbleiben und der libanesischen Armee nur begrenzte Kompetenzen überlassen würde. Schließlich hat die Tatsache, dass das Militär als Stütze des Mandatsregimes arbeitete und auch als solche von vielen Libanesen negativ wahrgenommen wurde ${ }^{330}$, sicher nicht zur Attraktivität dieses Berufes beigetragen.

Den Beruf des »Menschenfischers«, also des Priesters oder des Missionars, wählten einige Absolventen der katholischen Schulen ${ }^{331}$. Sie erfüllten damit eines der Ziele, das diese Schulen seit ihrer Gründung immer verfolgt hatten. Da der Beruf des Priesters in den christlichen Milieus im Libanon sehr angesehen war, ergriffen ihn auch Söhne aus gut situierten Fami-

325 Vgl. Chidiac 2002, S. 342; Le Pautremat 2003, S. 56-57.

326 Vgl. Schumann 2001, S. 191.

327 Vgl. Chidiac 2002, S. 344.

328 Die Schulzeitschrift der Lazaristen druckte nur den Erfahrungsbericht eines französischen Alumni ab, der zur Armee gegangen war, ab. Vgl. LAZ/Paris, Association amicale des anciens élèves d'Antoura. Bulletin annuel 3 (Mai 1940), S. 22-24.

329 Vgl. Zamir 2005, S. 816; Laurens 2002, S. 313-314.

330 Vgl. Thompson 2000, S. 42, 52.

331 Vgl. beispielsweise LAZ/Paris, Association amicale des anciens élèves d'Antoura. Bulletin annuel 8 (Mai 1945), S. 17-20: »Un ancien élève missionnaire en Chine. Nicolas Baroudi $(1868-1930) \ll$. 
$\operatorname{lien}^{332}$. Eng mit dieser Profession verbunden war das Berufsfeld des Lehrers, dem viele Absolventen der französischen Schulen nachgingen, der aber ein ambivalentes Prestige innehatte. Ein Teil der Alumni wurde in der eigenen ehemaligen Schule tätig. Alle Institutionen bemühten sich, ihre sehr guten Schüler zu diesem Schritt zu überzeugen. Allerdings schwankte der Anteil ehemaliger Zöglinge, die dann Lehrer wurden, zwischen den Institutionen: während bei der Alliance israélite nahezu alle Lehrkräfte unter den »meilleurs élèves « ihrer eigenen Schulen rekrutiert wurden ${ }^{333}$, war der Anteil bei den katholischen Schulen etwas geringer, da diese Wahl in der Regel die Entscheidung zum Ordensleben oder Priesterdasein mit einschloss ${ }^{334}$. Die Mission laïque und das Collège protestant français rekrutierten vornehmlich ihre Arabischlehrer unter den ehemaligen Schülern ${ }^{335}$.

Der hohe Anteil ehemaliger Schüler innerhalb der Lehrkörper ist bezeichnend für das Bemühen der Schulen um einheimische Lehrer, die den Geist der Institution kannten und weitertrugen. Wie Bourdieu und Passeron in ihrer Studie über das Schulsystem in Frankreich herausgearbeitet haben, wirkten gute Schüler, die selber Lehrer wurden, systemstabilisierend: »Anciens bons élèves qui voudraient n'avoir pour élèves que de futurs professeurs, les enseignants sont prédisposés par toute leur formation et par toute leur expérience scolaire à entrer dans le jeu de l'institution « ${ }^{336}$.

Darüber hinaus unterrichteten die ehemaligen Schüler, die Lehrer wurden, auch in lokalen Schulen im Libanon oder gründeten sogar ihre eigene Institution: Die Jesuiten waren sehr froh über den indirekten Einfluss, den sie auf diese Art und Weise ausüben konnten:

Les autres écoles libres, épiscopales ou paroissiales, sont souvent tenues par nos anciens élèves: Prêtres, Moines, Laïcs; de la sorte la Mission influe encore indirectement sur tout le reste de l'instruction libre qui se donne en dehors d'elle ${ }^{337}$.

332 Beispielsweise wurde Camille Hechaïmé, dessen Vater wohlhabend gewesen war, Mitglied und Lehrer des Jesuitenordens. Vgl. Interview der Verfasserin mit Camille Hechaïmé, Beirut, 24.10.2008.

333 AIU/Paris, Paix et Droit, 6/Juni 1932, S. 8-12, S. 9: »Il est décidé qu'on choisira les meilleurs élèves des écoles israélites pour les préparer par des études spéciales à l'enseignement dans les écoles de l'Orient et qu'on leur accordera, jusqu'à la fin de leurs études, une allocation qui leur donnera des moyens d'existence«.

334 Frère Michel von den Frères des Écoles chrétiennes und Camille Hechaïmé bei den Jesuiten wählten diesen Weg. Vgl. Interviews der Verfasserin mit Frère Michel, Beirut, 08.12.2007, und mit Camille Hechaïmé, Beirut, 24.10.2008.

335 Ein schon erwähntes Beispiel bei der Mission laïque war Taqi ad-Din as-Sulh. Vgl. außerdem AN/Paris, 60 AJ 137, Brief von Ruche an Besnard, Beirut, 04.06.1935. Darin bat Ruche den Generalsekretär um die Anstellung einiger ehemaliger Schüler bei der Mission laïque.

336 Bourdieu/Passeron 1970, S. 139, Fn. 6.

337 SJ/Vanves, RPO 21/3, »La Mission de Syrie, environ 1927«. 
Im Gegensatz dazu zeigte sich der Direktor der Mission laïque unglücklich über die Tatsache, dass einige seiner ehemaligen Schüler später Lehrer in lokalen Schulen wurden. Während er einen gewissen Nutzen für den französischen Einfluss nicht verleugnen konnte, empfand er diese lokalen Schulen doch vor allem als Konkurrenz:

Il en résulte une extension certaine de l'enseignement du français- ce dont nous ne saurions nous plaindre- mais les recettes de nos lycées n'en pâtissent pas moins. Il faut faire des concessions pour attirer ou garder des élèves, consentir des délais de paiement, accorder bourses et exonérations partielles [...] bref faire face, avce le plus de souplesse possible, aux difficultés nées de la crise et de la concurrence ${ }^{338}$.

Der Unterschied zwischen beiden Institutionen hängt wohl damit zusammen, dass die Jesuiten ihre ehemaligen Schüler in katholischen, das heißt ihnen ähnlich gesinnten Einrichtungen wussten, während die Mission lä̈que mit der Ausrichtung der islamischen Privatschulen, in denen ihre ehemaligen Schüler vor allem tätig waren, wenig gemein hatte. In demselben Sinn muss der Ärger des Direktors der Alliance israélite interpretiert werden, dass einige seiner ehemaligen Partner zu den Zionisten »übergewechselt« $\operatorname{seien}^{339}$.

Von den Lehrern selber wurde das Berufsfeld des Lehrers sehr unterschiedlich aufgenommen.

Für die ehemaligen Schüler der katholischen Schulen, welche Priester wurden und in der Regel gleichzeitig auch unterrichteten, war dieser Beruf durchaus ehrenhaft, und auch in dem eher ärmlichen Milieu, in dem die Alliance israélite tätig war, war die Lehrtätigkeit ein angesehener Beruf. Im Umfeld der Mission laïque hingegen scheint dieser Berufszweig keinen hohen Stellenwert gehabt zu haben. So schreibt Mīšāl Gurayib in seinen Memoiren, er sei trotz seiner exzellenten Noten nur Lehrer geworden, während seine Klassenkameraden, weil sie aus reichen Familien stammten, auch mit schlechten Noten Minister wurden ${ }^{340}$. Im Gegensatz zu anderen Regionen unter kolonialer französischer Kontrolle, wo die Lehrer über einen hohen Status und im Prozess der Dekolonisierung über große politische Bedeutung verfügten ${ }^{341}$,

338 MAE/Nantes, SOFE, 378, Brief von Besnard an Marx, 04.04.1936.

339 Vgl. AIU/Paris, »Liban I B 4«, Brief des Großrabbiners Tagger an den Großrabbiner von Paris Lévy, Beirut, 09.10.1922: »Vous ne pouvez pas vous imaginer, cher Collègue, ce que je souffre moralement pour défendre les écoles de l'Alliance et leurs personnels ici et à Damas, calomniés par les journaux de Palestine [...] et en même temps une bande de Sionistes extrémistes à Beyrouth et quelques anciens professeurs de l'Alliance ayant à leurs têtes le directeur du Talmud-Torah M. Ventoura lequel j'ai fait expulser«.

340 Vgl. Mīšāl ĠurayiB, Mudakkirat mārūnī, Beirut 1983, S. 45. Zu seiner Person siehe SchumanN 2001, S. 211-213.

341 Vgl. für Tunesien Pierre Vermeeren, La formation des élites marconaines et tunisiennes. Des nationalistes aux islamistes, 1920-2000, Paris 2002, S. 26: Ali Belhaoune, ein junger Arabi- 
schien dieser Beruf im Libanon eher eine nachstehende Alternative darzustellen. Die geringe Attraktivität mag zum einen mit der Tatsache zu tun haben, dass dieser Beruf im Libanon mit seiner traditionell hohen Schuldichte bekannt und wenig innovativ war. Zudem standen viele lokale Schulen unter dem Ruf, schlecht ausgestattet und wenig modern zu sein. Ein gewichtiger Grund scheint schließlich auch gewesen zu sein, dass die mangelhafte und wenig aufgewertete Ausbildung der Lehrer während der Mandatszeit sowie der daraus resultierende Mangel eines Berufsstandes der Lehrer diese Situation weiter negativ beeinflusst hat ${ }^{342}$.

Zusammenfassend lässt sich sagen, dass sich die französischen Schulen im Libanon in verschiedener Art und Weise mit dem sich ankündigenden Ende des Mandats auseinandergesetzt haben. Durch ihre finanzielle und administrative Abhängigkeit von Frankreich, aber auch durch den eigenen Patriotismus, blieben manche von ihnen Festungen des Mandats, aber versuchten gleichzeitig, sich dem stärkeren arabischen Nationalismus anzupassen. Auf der Ebene der Curricula und der Berufsfelder gab es bei den französischen Schulen verschiedene Bereiche der Anpassung an die neuen politischen Verhältnisse, insgesamt jedoch zeichneten sich die Schulen durch eine große Kontinuität aus, die, im Gegensatz zu Syrien, über die Mandatszeit hinaus fortbestehen sollte.

schlehrer am Collège Sadiki in Tunis, engagierte sich führend im Protest gegen die französische Kolonialpolitik; vgl. für Algerien Fanny ColonnA, Instituteurs algériens 1883-1939, Paris 1975, S. 189: Einige algerische Grundschullehrer forderten ein Mitspracherecht in Erziehungsfragen, was bis dato noch niemand gewagt hatte.

342 Vgl. Kapitel 5.2. In der Tat verfügt der Libanon, im Gegensatz zu anderen arabischen Ländern wie zum Beispiel Ägypten, bis heute über keinen Lehrerberufsstand. 



\section{Fazit und Ausblick}

Im Archiv der Jesuiten in Beirut befinden sich aus der Zeit kurz nach der libanesischen Unabhängigkeit Übersetzungen verschiedener Zeitungsartikel arabischsprachiger nationalistischer Blätter. Darunter ist auch die Meldung, ein Schüler der Jesuitenschule in Beirut sei von seiner Lehrerin geohrfeigt worden, weil er behauptet hatte, die Unabhängigkeit des Libanons habe sich im Jahr 1943 und nicht schon 1920 vollzogen. Der zugehörige Kommentar der syrischen Zeitung ad-Dìyār fragte lakonisch, warum die libanesischen Schüler sich noch in den Händen der Kolonisatoren befänden, zumal diese als Ordensangehörige ja aus ihrem eigenen Land vertrieben worden wären:

Pourquoi ces écoles demeurent-elles un agent d'espionnage du pays, un rappel du passé honteux et un outil du colonisateur qui cherche à rester? Pourquoi ces petits libanais la proie des loups colonisateurs? [...] Est-il permis que l'éducation de nos enfants soit toujours confiée à ces »mis hors leurs pays« à qui nous avons donné gîte, fait du bien et même donné la vie'?

Auch wenn sich nicht rekonstruieren lässt, wie sich die Begebenheit in der Schule wirklich ereignet hat, verdeutlicht diese Episode, dass die libanesische Unabhängigkeit mitnichten das Ende der französischen Schulen im Libanon und ihres Einflusses auf die Gesellschaft bedeutete. Zudem hatte der Deutungskampf über die libanesische Geschichte nun erst begonnen und ist bis heute nicht beendet ${ }^{2}$. Am Schluss dieser Arbeit soll deswegen neben einer Zusammenfassung der Ergebnisse ein Ausblick auf die Situation der französischen Schulen im Libanon nach 1943 und ihre Bedeutung für die postkoloniale Entwicklung des Bildungswesens und der gesellschaftlichen Situation im Libanon gegeben werden. Auf diese Weise werden noch einmal die zentralen Beiträge der Arbeit zur Forschung über das Verhältnis von Kirche, Religion und Staat in Frankreich, die Beziehung zwischen Frankreich und dem Nahen Osten und die Transformation indigener Eliten im Libanon des 20. Jahrhunderts deutlich gemacht.

1 SJ/Beirut, 11.D.14, »Affaire Wadih Tatros«.

2 Vgl. Gilbert-Sleiman 2010. 


\section{Ergebnisse}

Die französischen Schulen im Libanon waren Orte, an welchen die Idee der Zivilisierungsmission in Form von Diskursen und kulturellen wie sozialen Praktiken von Franzosen und Libanesen gleichermaßen verhandelt und in verschiedener Weise angeeignet, zurückgewiesen und transformiert wurde. Auf diese Art und Weise konnte französische Herrschaft über den Libanon mit Hilfe der Idee der Zivilisierungsmission implantiert und praktiziert werden. Gleichzeitig wurde diese Idee aber von den libanesischen Empfängern performativ mitgestaltet, entweder indem diese die französische Vormachstellung begrüßten oder weil sie dadurch ihre eigenen sozialen, religiösen und ökonomischen Interessen verfolgen konnten.

Allerdings wurde die französische Zivilisierungsmission aber auch immer stärker und breiter kritisiert, je länger die französische Mandatsherrschaft andauerte. So wurde die Idee der Zivilisierungsmission in Form vielfältiger Diskurse und Praktiken gleichzeitig stabilisiert und in Frage gestellt. Diese Diskurse und Praktiken variierten je nach der ideologischen Ausrichtung der verschiedenen Schulen und ihrer jeweiligen Klientel, insbesondere was die Fragen von Religion und Nation betraf, zeigten aber auch erstaunliche Ähnlichkeiten in Bezug auf Geschlecht oder Klasse. Die skizzierten Formen der Verhandlung und Rezeption vollzogen sich auf der Ebene der französischen Regierung, auf der Ebene der libanesischen Bevölkerung und auf der Ebene der Schulen selbst.

Die französische Regierung hat die französischen Schulen als Teil ihrer kulturellen Machtpolitik im Libanon wahrgenommen und sie so in einen direkten Zusammenhang mit der Idee der Zivilisierungsmission gestellt. Allerdings haben die Regierungsvertreter den Begriff in ihren Reden wenig verwendet, sondern vielmehr Frankreich und die Dritte Republik selbstverständlich als Verkörperung der mission civilisatrice verstanden und die Schulen als eines ihrer ausführenden Instrumente angesehen. Hatte die Aufmerksamkeit der französischen Regierung während des Osmanischen Reiches und zu Beginn der Mandatszeit vor allem den katholischen Schulen im Libanon gegolten, betonten die Repräsentanten Frankreichs seit Mitte der 1920er Jahre, dass die mission civilisatrice alle französischen Schulen einbeziehe. Grund dafür waren sowohl eine stärker laizistische Politik in Frankreich als auch die deutliche Kritik der nicht-katholischen Bevölkerung am Mandatsregime, welche im syrischen Aufstand von 1925 ihren Höhepunkt fand.

Die erweiternde Umdeutung der französischen Version der Zivilisierungsmission wurde seitens der Mandatsregierung dadurch praktisch deutlich, dass sie die katholischen Schulen weniger und die laizistischen Schulen stärker finanziell unterstützte und dass ihre Vertreter vergleichsweise häufiger an den Aktivitäten der Mission laïque teilnahmen. Gleichwohl blieb 
ihre Nähe auch zu den katholischen Schulen als traditionellen Partnern im Libanon bestehen. Das zeigte sich beispielsweise während der Kolonialausstellung im Jahr 1931, als alle Schulen der französischen Öffentlichkeit präsentiert wurden, aber die katholischen Schulen einen besonders exponierten Platz erhielten. Die Arbeit bestätigt somit einerseits die von der Forschung bereits betonte Ambivalenz der französischen Kulturpolitik der Dritten Republik, welche in Frankreich die Bildungsarbeit der Kongregationen verbat, diese aber in den außereuropäischen Regionen weiter unterstützte. Sie macht aber auch deutlich, dass es sehr unterschiedliche Wellen der Unterstützung gab, welche die Bildungseinrichtungen aufgrund der pro- oder antiklerikalen Haltung der Regierungsverantwortlichen durchlebten. Zudem zeigt die erstmals geleistete Untersuchung der Förderung der laizistischen und jüdischen Schulen im Libanon en détail, dass diese nur nach politischem Kalkül der französischen Regierung als Alternative zu den katholischen Institutionen wahrgenommen wurden, um die libanesische Klientel Frankreichs so weit wie möglich zu fassen.

Angesichts des nahenden Mandatsendes seit Mitte der 1930er Jahre und der steigenden Konkurrenz anderer westlicher Mächte in der Region erhielten durchweg alle französischen Schulen wieder stärkere finanzielle Unterstützung seitens der Mandatsregierung. Sie wurden jetzt sowohl als Verteidiger des französischen Einflusses im Libanon als auch als vermittelnde Instanzen gegenüber den Libanesen wahrgenommen. Über unmittelbare Subventionen hinaus nutzten Vertreter der französischen Regierung im gesamten Untersuchungszeitraum weitere Praktiken wie Stipendien oder die Organisation außerunterrichtlicher Aktivitäten, um die libanesische Bevölkerung an sich zu binden. Hier wurden Gemeinsamkeiten, aber auch Unterschiede zwischen der Bildungspolitik in den französischen Kolonien und in den Mandatsgebieten deutlich. Auch wenn Regierungs- und Schulvertreter den unterschiedlichen Status beider Regime betonten, kam es in der Praxis doch zur Übernahme vieler Praktiken aus den Kolonien in die Mandatsgebiete mit dem Ziel, loyale Untertanen zu schaffen. Allerdings schuf die Mandatsmacht im Libanon anders als in den Kolonien ein flächendeckenderes Schulsystem, welches aber weniger Rücksicht auf lokale Traditionen nahm. Zudem zeichnete sich die Mandatsbildungspolitik durch eine große Unentschlossenheit mit komplizierten administrativen Vorgängen aus, wie die nie geklärte Angelegenheit der Lehrerausbildung zeigte.

Die libanesische Klientel der französischen Schulen im Libanon hat sich den Diskurs der Zivilisierungsmission ebenfalls zunutze gemacht. Dabei haben die unterschiedlichen Bevölkerungsgruppen, welche sich um die verschiedenen französischen Schulen gruppierten, diesen Diskurs unterschiedlich besetzt. Die katholischen und insbesondere die maronitischen Libanesen, welche vor allem die katholischen französischen Schulen besucht haben, 
bezogen sich häufig auf die mission civilisatrice. Dadurch sprachen sie sich für die französische Herrschaft im Libanon aus, welche sie als essentiell für ihre Position als Christen in einer muslimisch dominierten Region ansahen. Das belegen Briefe sowie literarische Werke ehemaliger Schüler der katholischen Schulen. Auf diese Weise wurde der Bezug zur mission civilisatrice und damit zur französischen Kultur auch als Identitätsmarker eines nicht-muslimischen, zu Beginn des Mandats stark vom arabischen Umfeld abgegrenzten Selbstverständnisses eingesetzt. Ähnliches gilt für die extrakurrikularen Aktivitäten in den katholischen Schulen. Durch diese kulturelle Praxis haben die Libanesen ihre Identität und soziale Position in der Gesellschaft geformt und verteidigt. Da die katholischen Schulen, insbesondere die der Jesuiten, privilegierten Zugang zu den Entscheidungsstrukturen der Mandatsmacht und darüber hinaus aufgrund ihrer Tradition einen guten Ruf als Ausbildungsstätten der Elite hatten, wurden sie, wie das Beispiel 'Umar Da'uqs zeigte, auch von muslimischen Libanesen frequentiert. Somit betont die vorliegende Arbeit nicht nur die Kontinuität der Eliten im Libanon vor, während und nach der Mandatszeit betont, sondern zeigt auch, dass die französischen Schulen und Bildung allgemein als Kaderschmiede von bestehenden Eliten und Aufstiegsmöglichkeit für Unter- und insbesondere Mittelschichten galten. Auch wenn die Stimmen der Libanesen, welche die jüdischen und protestantischen französischen Schulen besucht haben, nicht im selben Umfang eruiert werden konnten, weisen die wenigen Zeugnisse auf vergleichbare Aneignungsstrategien hin.

Eine leicht veränderte Haltung innerhalb der katholischen Libanesen machte sich Mitte der 1930er Jahre bemerkbar, als auch Teile dieser Gemeinschaften Kritik am Mandat äußerten. Einige Katholiken entfernten sich stärker von Frankreich als Schutzherrschaft, indem sie sich in politischen Gruppierungen gegen das Mandat engagierten, behielten ihre Verbundenheit zur französischen Sprache und Kultur aber bei. Die Analyse der Schularchive bestätigt diese vorsichtige Entfremdung bei gleichzeitiger Nähe und belegt auch den Einfluss der katholischen Schulen auf das politische Denken ihrer Zöglinge, auch wenn die Schulen selbst sich in politischen Dingen neutral zu verhalten suchten.

Die Klientel der Mission lä̈que, welche durch ihre nicht-katholische Identität und deutliche Kritik am Mandat eine von der Forschung bisher unterbelichtete Dimension der französisch-libanesischen Beziehungen darstellt, hat sich in ihrer Interaktion mit der laizistischen Schule und mit den französischen Regierungsvertretern ebenfalls der Begriffe und Argumente der mission civilisatrice bedient. Allerdings muss bezüglich der laizistischen Schule stärker zwischen den verschiedenen Gruppen innerhalb der Klientel unterschieden werden. Die sunnitischen Notabeln haben die Mission lä̈que vor allem genutzt, um ihre Position in der libanesischen Gesellschaft unter fran- 
zösischer Herrschaft zu behaupten und zu verbessern, wie sich deutlich an ihren Forderungen zu besserem Zugang zur Université Saint-Joseph zeigt. Das heißt, sie nutzten die ideellen Überzeugungen der Mission lä̈que-Vertreter für ihre sozio-ökonomischen Interessen: Sie teilten in keiner Weise die in Form der laizistischen Zivilisierungsmission transferierte Religionskritik der Lehrer der Mission laïque, sondern interpretierten den dort propagierten Laizismus zu ihren Gunsten, das heißt für eine größere Freiheit in der Religionsausübung der Schüler durch Einhalten des Ramadans und anderer muslimischer Festtage. Manche griechisch-orthodoxen und drusischen Partner der laizistischen Schule hingegen, die größtenteils der Mittelschicht angehörten, haben stärker die Idee einer laizistischen Zivilisierungsmission im Sinne einer Veränderung ihrer Gesellschaft in Richtung eines stärker säkular geprägten Staates geteilt. Die Auseinandersetzungen, die zwischen beiden Gruppen zeitweilig auftraten, belegen also neben der Existenz von Meinungsverschiedenheiten auch die von der Forschung in anderen Themenbereichen erforschten Konflikte zwischen alten und neuen aufstrebenden Eliten, wobei letztere in der Regel Schwierigkeiten hatten, sich zu behaupten. Der relative Aufstieg mithilfe von Bildung zeigt sich auch in der Analyse der jüdischen französischen Schulen, deren Schüler aufgrund ihrer wirtschaftlich schlechteren Verhältnisse nur bedingten sozialen Aufstieg erfuhren.

Vereint waren beide Gruppen innerhalb der Mission laïque aber in der Nutzung der von der Mandatsregierung und den Schulen angebotenen Aktivitäten. Sie verstanden diese als Möglichkeiten der stärkeren kulturellen und sozialen Integration in die Gesellschaft. Die Ehemaligenarbeit, der Elternrat und andere kulturelle Praktiken der Mission lä̈que machen diese Aneignung deutlich, zeigen aber auch deren Grenzen auf - etwa, wenn eine Institution wie die Alumnivereinigung der Mission laïque wenig Zuspruch fand.

Weiterhin bestätigt die Untersuchung einerseits den von Nahosthistorikern betonten Pragmatismus der Libanesen, insbesondere der muslimischen Ober- und Mittelschichten in Bildungsfragen, welche stärker auf Nähe, Erreichbarkeit und Prestige der Schulen setzten als auf deren ideologische Orientierung. So erklärt sich sicher auch zum Teil die Attraktivität der laizistischen Bildungsstätte für sunnitische und drusische Schüler, welche die französische Regierung besonders förderte. Andererseits zeigen die unterschiedlichen Klientelen der französischen Bildungseinrichtungen meiner Einschätzung nach doch auch eine Sensibilität und Präferenz für religiöse und politische Linien, die die französischen Schulen vertraten.

Die Einbeziehung der gesamten Bandbreite französischer Bildungseinrichtungen hat somit die zuweilen von der Forschung vorgenommene Engführung der Beziehungen zwischen Frankreich und dem Libanon auf die Christen bzw. Katholiken notwendig erweitert und zudem die These gestärkt, 
dass Libanesen zwischen französischer Regierung einerseits und französischer Sprache und Kultur andererseits unterschieden. Während die unterschiedlichen Schulen der libanesischen Bevölkerung also durchaus Aufstiegsmöglichkeiten boten, muss das Urteil über den Beitrag Frankreichs und der französischen Schulen zum Aufbau einer nationalen Identität im Libanon kritischer ausfallen. Zwar haben die Schulen stark zur Bildung und Entwicklung der Identität des Libanon beigetragen, aber dieser Einfluss hatte auch spaltenden Charakter. Zum einen blieben die französischen Schulen nach der Unabhängigkeit weiterhin besser ausgestattet als die staatlichen Schulen und vertieften somit den Graben zwischen ausländischen, fremdsprachigen Eliteschulen und einheimischen Einrichtungen, die stärker das Arabische und die eigene Geschichte in den Vordergrund stellten. Zum anderen kannte das in beinahe allen französischen Schulen vermittelte Geschichtsbild, wie schon angedeutet, nur eine Version der libanesischen Vergangenheit. Es bleibt zu eruieren, wie hoch der Beitrag der Schulen zu dieser Spaltung war. Sicher ist, dass sie nichts oder nur sehr wenig zur Schließung dieser Kluft beigetragen haben.

Die Analyse hat schließlich erwiesen, dass die Direktoren und Lehrer der Schulen den Interessen nicht nur der französischen Regierungsvertreter, sondern auch der libanesischen Bevölkerung stärker verpflichtet waren als es die Forschung bisher herausgestellt hat. Gleichzeitig wurden eigene Handlungsspielräume, die durchaus genutzt wurden, aufgezeigt. Der Bezug auf den Diskurs der mission civilisatrice findet sich in den Unterlagen aller Schulen. Immer wieder wird deutlich, dass die Schulvertreter die Zivilisierungsmission, die sie sowohl auf Frankreich als auch auf ihre eigene Arbeit bezogen, als ein wichtiges Motiv ihres Engagements ansahen. Sie waren überzeugt, mit Hilfe der mission civilisatrice ihre eigenen Werte vermitteln zu können; dabei ging es ihnen nur sekundär um die Ausbildung Frankreich-treuer Verbündeter: Während beispielsweise die katholischen Schulen zivilisiert sein mit dem katholischen Glauben gleichsetzten, waren die Vertreter der laizistischen Schulen davon überzeugt, ihre laizistische Vorstellung der Zivilisierungsmission sei die passende Gesellschaftsform für den Libanon.

Trotz eines unterschiedlichen Verständnisses von Zivilisation und Zivilisierungsmission vereinte sie deshalb mehr als sie trennte. Die vorliegende Arbeit kann somit zum einen die insbesondere von Talal Asad betonte Verwobenheit religiöser, vor allem christlicher, und laizistischer Vorstellungen und Praktiken anhand der Bildungseinrichtungen bestätigen: Beispielsweise teilten die Lehrer vieler Schulen einen orientalistischen Blick auf den Libanon oder vertraten eine Version der libanesischen Geschichte, die aufgrund der Betonung des Phöniziertums von der jesuitischen Forschung stark beeinflusst war. Gleichzeitig unterstreichen die feinen Unterschiede in der Interpretation der Zivilisierungsmission, beispielsweise die Betonung der Zivi- 
lisation, die bei den katholischen Schulen erst später einsetzte, auch die Notwendigkeit der Differenzierung eines allzu homogenen Verständnisses der mission civilisatrice und bestätigen die eingangs behauptete Interpretation der Zivilisierungsmission als leeren Signifikanten: In der Tat ermöglichte der Bezug darauf die Koexistenz ganz unterschiedlicher Interpretationen.

An den historischen Wendepunkten 1909, 1920, 1925, 1930 und 1935 wurde jeweils deutlich, dass Direktoren und Lehrer sich besonders häufig des Diskurses der mission civilisatrice auch deshalb bedient haben, um in Krisenmomenten ihre Loyalität zur französischen Regierung zu betonen und deren finanzielle und ideelle Unterstützung $\mathrm{zu}$ erhalten. In vorliegenden Korrespondenzen mit französischen Regierungsvertretern präsentierten sich dabei die verschiedenen französischen Schulen als die swahren< Vertreter der französischen mission civilisatrice und setzten sich explizit von den anderen französischen Schulen ab. Das betraf vor allem die katholischen Schulen und die Mission lä̈que française. Aus diesem Grund waren sie von einem starken Konkurrenzdenken geprägt, welches sich erst gegen Ende des Mandats und angesichts der Zunahme äußerer Faktoren, welche die Schulen als bedrohlich empfanden, in Richtung einer stärkeren Zusammenarbeit veränderte.

Um auf die Forderungen und Sensibilitäten ihrer libanesischen Klientel einzugehen, passten die Schulen Diskurs und soziale Praxis, insoweit sie sich auf die mission civilisatrice bezogen, an. Dabei wurde in der Analyse deutlich, dass die katholischen Schulen in dieser Hinsicht weniger vorsichtig waren und sein mussten als die Mission lä̈que. Das zeigte sich unter anderem an der Frage der französischen und arabischen Sprache. Während die Eltern der Mission laïque française die zentrale Rolle der arabischen Sprache im Curriculum herausstellten und die laizistische Schule zu deren Umsetzung drängten, konnten die katholischen Schulen stärker ihre eigene Bewertung der Sprachen im Schulalltag durchsetzen. Auch wenn sich die Jesuiten in ihren wissenschaftlichen Arbeiten dem Arabischen widmeten, stimmten sie mit den anderen katholischen Schulen darin überein, dieser Sprache im Curriculum eine weniger zentrale Bedeutung als dem Französischen zukommen zu lassen.

Der Unterschied zwischen den Schulen lag zum einen an der längeren Erfahrung der katholischen Schulen im Libanon und zum anderen daran, dass sie über ihre religiöse Zugehörigkeit mehr kulturelle Gemeinsamkeiten mit ihrer libanesischen Klientel teilten als die laizistischen Schulen. Außerdem war die Klientel der Mission lä̈que weniger homogen als die der katholischen und jüdischen Schulen. Auch wenn die katholischen Einrichtungen in vielen Bereichen mehr Erfolg hatten, erwies sich die Mission laïque doch in einigen Aspekten insofern als Vorreiter, als ihre Vertreter schon zu Beginn des Mandats jene stärkere Anpassung der Unterrichtsinhalte an den Libanon vertraten, welche die katholischen Schulen erst gegen Ende des Man- 
dats diskutierten. Darüber hinaus erwies sich die stärkere Professionalisierung der Lehrer der Mission laïque und des Collège protestant français als das zukunftsträchtige Modell.

Damit ist insgesamt deutlich geworden, dass die Aneignung und Aushandlung der mission civilisatrice in Form von Diskursen und sozialen Praktiken nur in der Interaktion zwischen den drei Akteursebenen geschehen konnte. Diese Interaktion ließe sich schematisch als ein Wechselverhältnis der drei Akteursgruppen im Hinblick auf Strategie und Taktik darstellen. Somit bekräftigt die Arbeit die von der postkolonial inspirierten Forschung der letzten Jahre betonten mannigfaltigen Reaktionen indigener Gesellschaften auf koloniale Machtansprüche, die zwischen Übernahme, Verweigerung und Aneignung mit dem Ziel der subversiven Transformation liegen: Die Aneignungsgrenzen der Zivilisierungmission verliefen längst nicht nur zwischen den >mächtigen Franzosen unterschiedlichen Gruppen wurden zu unterschiedlichen Zeitpunkten und auf unterschiedliche Weise zu Strategen und Taktikern.

\section{Historischer Ausblick}

Trotz des Mandatsendes 1943 und des Abzugs der französischen und britischen Truppen aus dem Libanon 1946 blieben viele der politischen, wirtschaftlichen und sozialen Strukturen auch nach der Unabhängigkeit bestehen, was sich insbesondere im Erziehungssektor zeigte.

Das musste mit leichtem Bedauern eine amerikanische Kommission feststellen, die 1946 eine Prüfung der Bildungssituation im Libanon und der Chancen für ein amerikanisches Engagement vornahm:

The French, having lost Lebanon, are still exerting great efforts through the Euvres Françaises and through their schools to maintain their cultural influence. There is no doubt that in this they have the support of a section of the Christian population which has been brought up along French lines and is loath to see this influence weaken. Already, however, a perceptible shift towards English and a demand for it are noticeable. Nevertheless, if what has happened in Egypt in the last century is any measure, French cultural influence will probably remain strong for a long time to come ${ }^{3}$.

Alle in dieser Arbeit untersuchten französischen Schulen existierten auch nach Ende des französischen Mandats weiter. Bis auf die jüdischen Schulen der Alliance israélite universelle, welche aufgrund der politischen Ereignisse

3 Roderic D. Matthews/Matta Akrawi, Education in Arab Countries of the Near East, Wanshington/D.C. 1949, S. 465. 
im Libanon in den 1970er Jahren schlossen, sind die in Beirut angesiedelten Schulen bis heute tätig. Ein Unterschied zu der Mandatszeit zeigte sich neben den Änderungen im Lehrplan vor allem bei der Klientel der Schulen. In den Schulen der Mission lä̈que française stieg der Anteil christlicher Schüler entsprechend dem in den letzten Jahren der Mandatszeit beobachteten Trend noch stärker. In den katholischen Schulen kam es zu einer Spaltung zwischen den Einrichtungen der Jesuiten und der Lazaristen auf der einen Seite, welche sich an einer mehrheitlich katholischen und wohlhabenden Klientel orientierten, und den Schulen der Filles de la Charité, der Sours de Saint-Joseph de l'Apparition und der Frères des Écoles chrétiennes auf der anderen Seite, die immer mehr muslimische Schüler aus ärmeren sozialen Schichten unterrichteten. Mit dieser Entwicklung ging einher, dass vor allem die Schulen der Jesuiten, aber auch die der Lazaristen, sowie die Mission lä̈que française gemeinsam mit den amerikanischen Schulen im Libanon bis heute als Ausbildungsstätten der Elite gelten. Von der französischen Regierung wurden diese Schulen nach der Unabhängigkeit nur noch unterstützt, wenn sie explizit als französische Schulen galten, aber alle Einrichtungen wurden in Form von abgesandten Lehrern (den sogenannten détachés culturels) und durch die Abnahme des französischen Abiturs in den Sekundarschulen weiterhin unterstützt ${ }^{4}$. Die schon am Ende der Mandatszeit begonnene Kooperation zwischen den französischen Schulen intensivierte sich nach der Unabhängigkeit noch stärker und verlor ihren ideologischen Kampfcharakter.

Die französische Regierung sah die Schulen auch nach der Unabhängigkeit des Libanon als einen Ort an, um ihren Einfluss im Land geltend $\mathrm{zu}$ machen. Die Mission culturelle française, die als kulturelle Abteilung der französischen Botschaft im Libanon für den kulturellen Einfluss Frankreichs im Land verantwortlich war, verfolgte damit, nicht nur mit Blick auf das Personal ${ }^{5}$, kontinuierlich politische Linien, die ihren Ursprung in der Mandatszeit hatten. Die Frankophonie, welche die französische Regierung gemeinsam mit anderen frankophonen Ländern ihrer näheren oder weiteren kolonialen Vergangenheit ${ }^{6}$ als Idee, aber auch als Institution entwickelte, um den französischen kulturellen Einfluss in der Welt zu bewahren und zu vergrößern und deren Parallelen zur französischen kolonialen Vergangenheit

4 Vgl. z.B. NDJ, A 4, »Ambassade de France. Mission culturelle«, 1963-1973.

5 Ihr erster Leiter bis 1952 war Gabriel Bounoure, von 1923 bis 1943 Kultusbeauftragter des Hochkommissariats. Zu seiner Person vgl. Khoury (Hg.) 2004.

6 In der Tat waren in den 1960er Jahren Vertreter der frankophonen afrikanischen Länder in dieser Bewegung aktiver als die französische Regierung, die allerdings spätestens seit den 1980er Jahren stark in die Institutionalisierung der Frankophonie eingriff. Vgl. Ingo Kolвоom, Francophonie: Von der kulturellen zu politischen Frankophonie, in: Ingo Kolвoom/Thomas Koтschi/ Edward Reichel (Hg.), Handbuch Französisch, Berlin 2002, S. 462-468. 
von einigen Autoren benannt werden ${ }^{7}$, fasste auch im Libanon Fuß. In der Tat bleibt die französische Sprache und Kultur im Libanon bis heute sehr präsent, wie französischsprachige Zeitungen, Fernsehsender und Romane sowie vehemente Verfechter der libanesischen Frankophonie bezeugen ${ }^{8}$.

Auch wenn die Beziehung Frankreichs zu den Maroniten in den letzten Jahren des Mandats gelitten hatte, überdauerte ihre enge Verbindung, und bis heute besucht der maronitische Patriarch direkt nach seinem Amtsantritt den französischen Präsidenten. Erfolgte durch den libanesischen Bürgerkrieg von 1975 bis 1990 einerseits eine Ernüchterung auf Seiten der frankophonen und frankophilen Bevölkerung im Libanon, verstärkten die vielen Libanesen, die in dieser Zeit nach Frankreich und danach wieder zurück in ihr Land gingen, die wirtschaftlichen und politischen Beziehungen beider Länder.

Wie während der Mandatszeit erfuhr das libanesische staatliche Bildungssystem auch nach der Unabhängigkeit sehr lange wenig Förderung. Die gesetzlichen Bestimmungen der libanesischen Regierung privilegierten weiterhin die privaten Bildungseinrichtungen und räumten ihnen viele Freiheiten bezüglich ihrer Curricula ein ${ }^{9}$. Den langsam entstehenden staatlichen Schulen und Universitäten fehlte zudem das Geld, welches die französischen und amerikanischen Schulen zum Teil aus dem Ausland, zum Teil aber auch von ihren ehemaligen Schülern erhielten. Die amerikanischen Schulen expandierten entsprechend nach Ende des französischen Mandats, aber vor allem seit dem Ende des Bürgerkrieges und gewannen großen Einfluss im Libanon ${ }^{10}$. Ausgelöst durch die amerikanische Exilerfahrung vieler Libanesen, aber auch durch eine gewisse Enttäuschung über Frankreichs passive Rolle während des Bürgerkrieges verlor das Französische in den letzten Jahren an Popularität. Dieser Rückgang setzte nicht zuletzt deshalb ein, weil sich Englisch auch im Libanon als Sprache der Globalisierung durchsetzte. Die englische Sprache wurde zum Inbegriff von Moderne und Fortschritt, wel-

7 Vgl. Gabrielle Parker, Gabrielle, The Fifth Republic and the Francophone Project, in: Kamal Salhai (Hg.), French in and out of France. Language Policies, Intercultural Antagonisms and Dialogue, Frankfurt am Main 2002, S. 11-33.

8 Vgl. die Beiträge in dem Tagungsband von Walid Arbid/Simone Dreyfus/Edmond Jouve (Hg.), La Francophonie au Liban, Paris 1997; vgl. auch Alexandre NAJJAR, Pour la francophonie, Beirut 2008.

9 Vgl. Ghazi M. Ghait/Kassim A. Shabann, Language-in-Education Policy and Planning: The Case of Lebanon, in: Mediterranean Journal of Educational Studies, 1/1996, H. 2, S. 95-105, S. 100: Laut Gesetzeserlass 7000 von 1950 durften die privaten ausländischen Schulen ihr Curriculum und ihre Abschlüsse selbst bestimmen.

10 Der Charakter der AUB als Versammlungsort arabisch-nationalistischer Strömungen, welcher sich während des Mandats schon angekündigt hatte, entwickelte sich in den 1960er Jahren sehr stark. Vgl. die Erinnerungen von Raja SHeнаdeн, Fremd in Ramallah. Mein Leben als Sohn im besetzten Palästina, Hamburg: Europa Verlag, 2002. Shehadeh absolvierte kurz vor dem Bürgerkrieg sein Jurastudium an der AUB und war von den unterschiedlichen nationalistischen Gruppierungen umgeben. 
che die Elite des Landes für sich beanspruchte ${ }^{11}$. Diejenigen christlichen und muslimischen Libanesen, die sich als Elite des Landes verstehen, frequentieren nun verstärkt die amerikanischen Schulen, während interessanterweise die weniger privilegierten Gemeinschaften - in erster Linie die Schiiten - in ihren Schulen vor allem Französisch lernen ${ }^{12}$.

Trotz dieser Einbußen unterscheidet sich die Situation des Libanons damit radikal von anderen ehemaligen Gebieten unter französischer Kontrolle, vor allem von Syrien, wo die sozialistisch-arabische Politik der Bat-Regierung seit 1963 fast jeglichen französischen Einfluss im gesellschaftlichen Leben, aber auch in den Schulen, beendet hat ${ }^{13}$. Außerdem gibt es beachtliche Differenzen zwischen dem Libanon und den ehemaligen französischen Kolonien in Nordafrika, insbesondere Algerien als integralem Bestandteil des Hexagons, wo der Kampf um Unabhängigkeit wegen seiner Gewalttätigkeit als sehr viel einschneidender erlebt wurde und wo trotz der Frankophonie seit den 1960er Jahren eine deutliche Arabisierungspolitik herrscht. Im Gegensatz hierzu schreiben viele Autoren und Journalisten im Libanon auch heute auf Französisch und sehen diese Tatsache nicht als problematisch an, auch wenn es im Zedernstaat ebenfalls von Frankreich enttäuschte Politiker und Intellektuelle gibt. Mit den ehemaligen französischen Kolonien, aber auch mit den Kolonien anderer ehemaliger europäischer Kolonialmächte teilt der Libanon aber unter anderem den schwierigen Umgang mit der eigenen Geschichte $^{14}$. Damit reiht er sich ein in eine Vielzahl von Staaten, für welche die Auseinandersetzung mit ihrer kolonialen Vergangenheit - eine conditio sine qua non für die kulturelle Identitätsfindung - bis heute eine wesentliche Ursache angespannter politischer Verhältnisse ist.

11 Vgl. Roland Löffler, Anglophonie versus Frankophonie in Beirut - ein Clash of Languages?, in: Beiruter Blätter des Orient Instituts 5/1997, S. 141-142.

12 Das gilt zum Beispiel für die Schulen der schiitischen Wohlfahrtsorganisation 'Amiliya. Vgl. Chalabi 2006, S. 149.

13 Vgl. Bocquet 2008, S. 252-263.

14 Vgl. für Indien Fischer-Tiné 2003. 

AnHANG 



\section{Abkürzungen}

MAE/Paris Archiv des französischen Außenministeriums/Paris

MAE/Nantes Archiv des französischen Außenministeriums/Nantes

AIU/Paris

AN/Paris

Archiv der Alliance israélite universelle/Paris

MLF/Paris Archives nationales/Paris

PPFL

$\mathrm{CPF}$

Archiv der Mission laïque française/Paris

SHPF

Archiv der Présence protestante française au Liban/Plaisir

Collège protestant français, Beirut

Archiv der Société pour l'Histoire du protestantisme

française/Paris

LAZ/Paris

$\mathrm{SJ} /$ Vanves

Archiv der Lazaristen/Paris

$\mathrm{SJ} /$ Beirut

Archiv der Jesuiten/Vanves

LAZ/Antoura

Archiv der Jesuiten/Beirut

AN/Beirut

Archiv des Collège Saint-Joseph der Lazaristen/Antoura

FDC

Archives nationales/Beirut

Archiv der Filles de la Charité/Beirut

SJA

Archiv der Schule der Sours de Saint-Joseph de

l'Apparition/Beirut

FEC Archiv des Collège français du Sacré-Cour der Frères des écoles chrétiennes/Beirut

NDJ

Archiv des Collège Notre Dame de Jamhour

OIB

Bibliothek des Orient-Instituts/Beirut

SOFE

Service des Euvres françaises à l'Étranger (innerhalb des Außenministeriums)

IP Syrie/Liban Instruction publique (Kultusministerium des französischen Hochkommissariats in Syrien und Libanon)

RPO Province du Proche-Orient (Archivbestand der Jesuiten) 



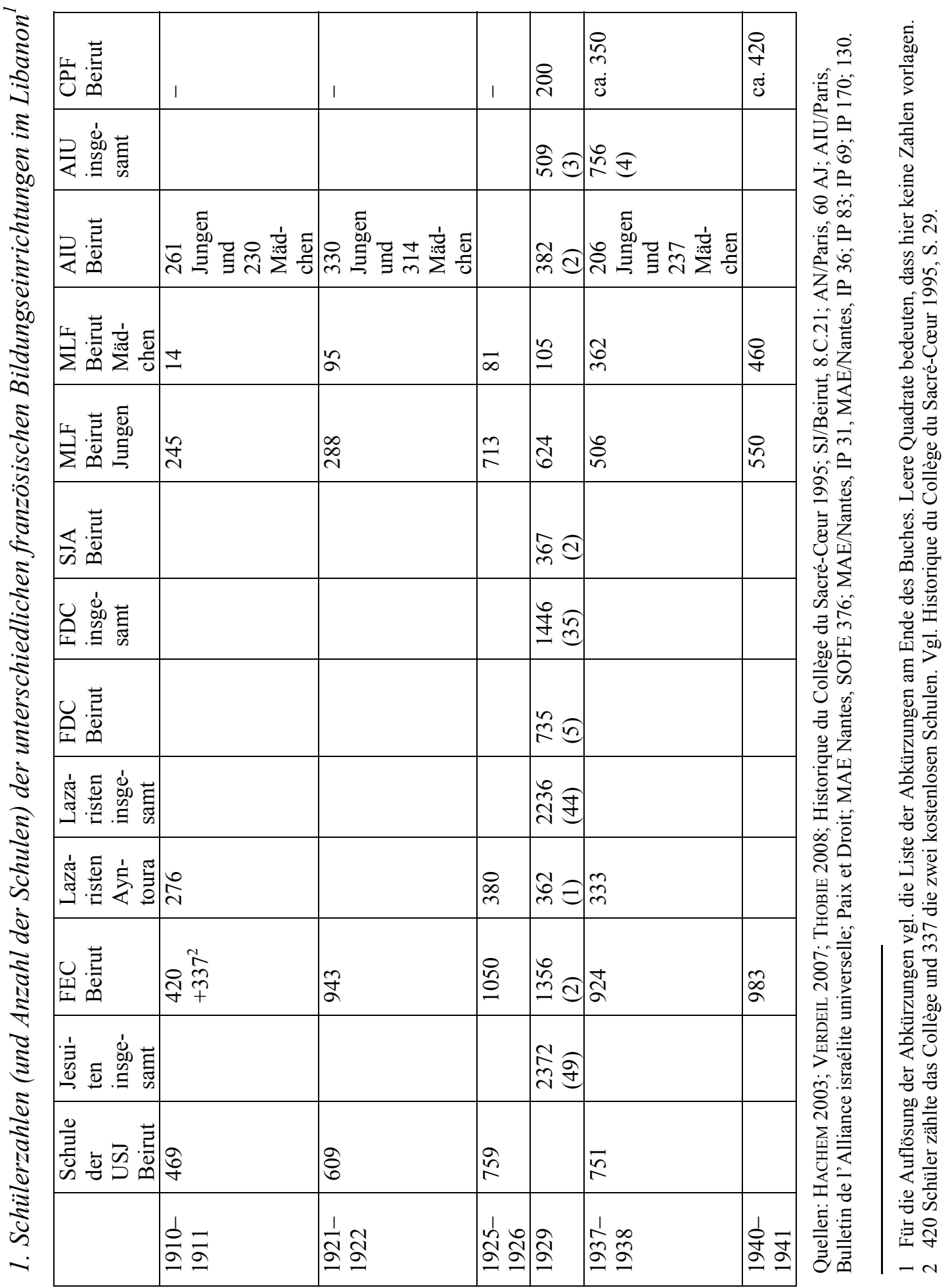



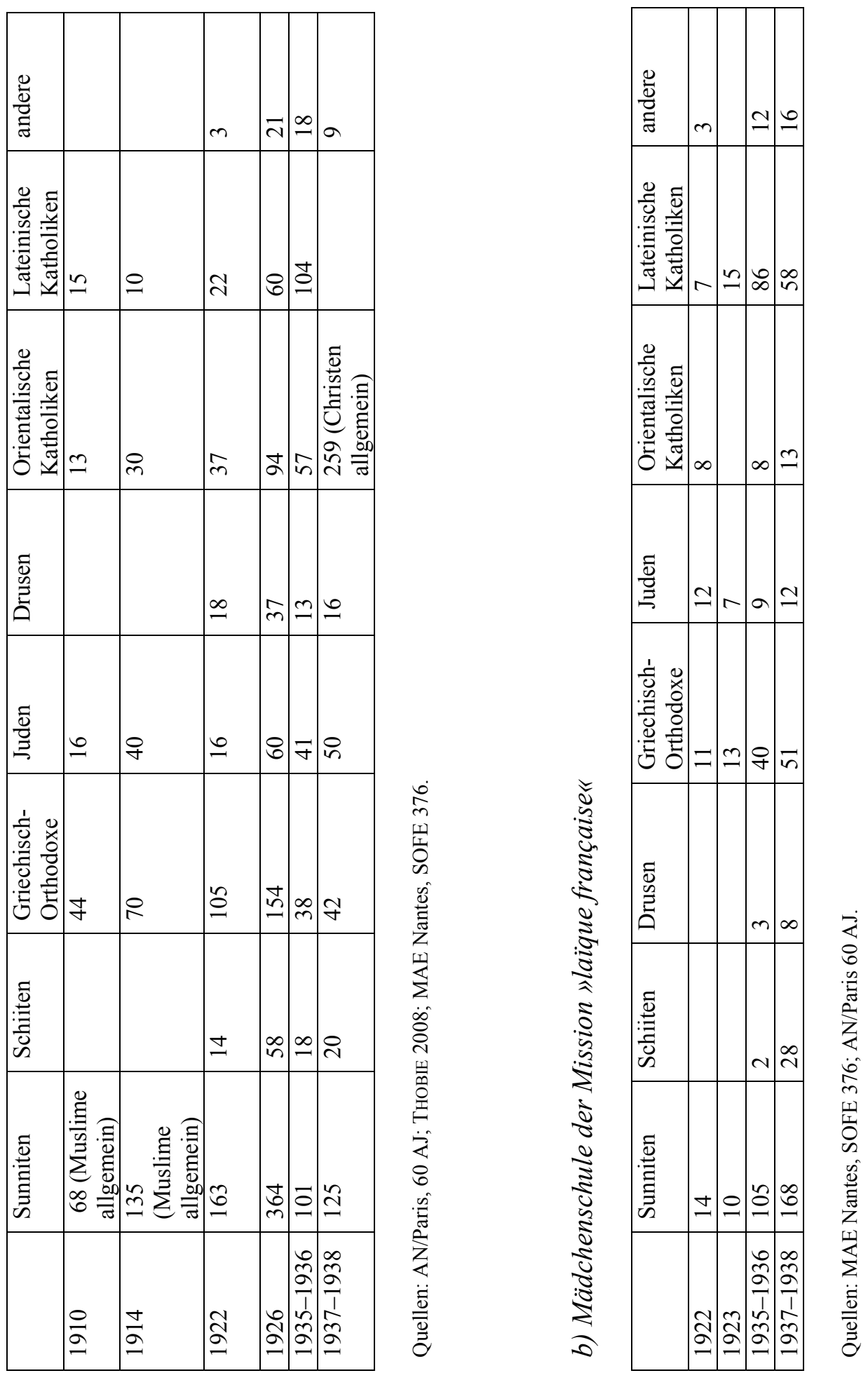

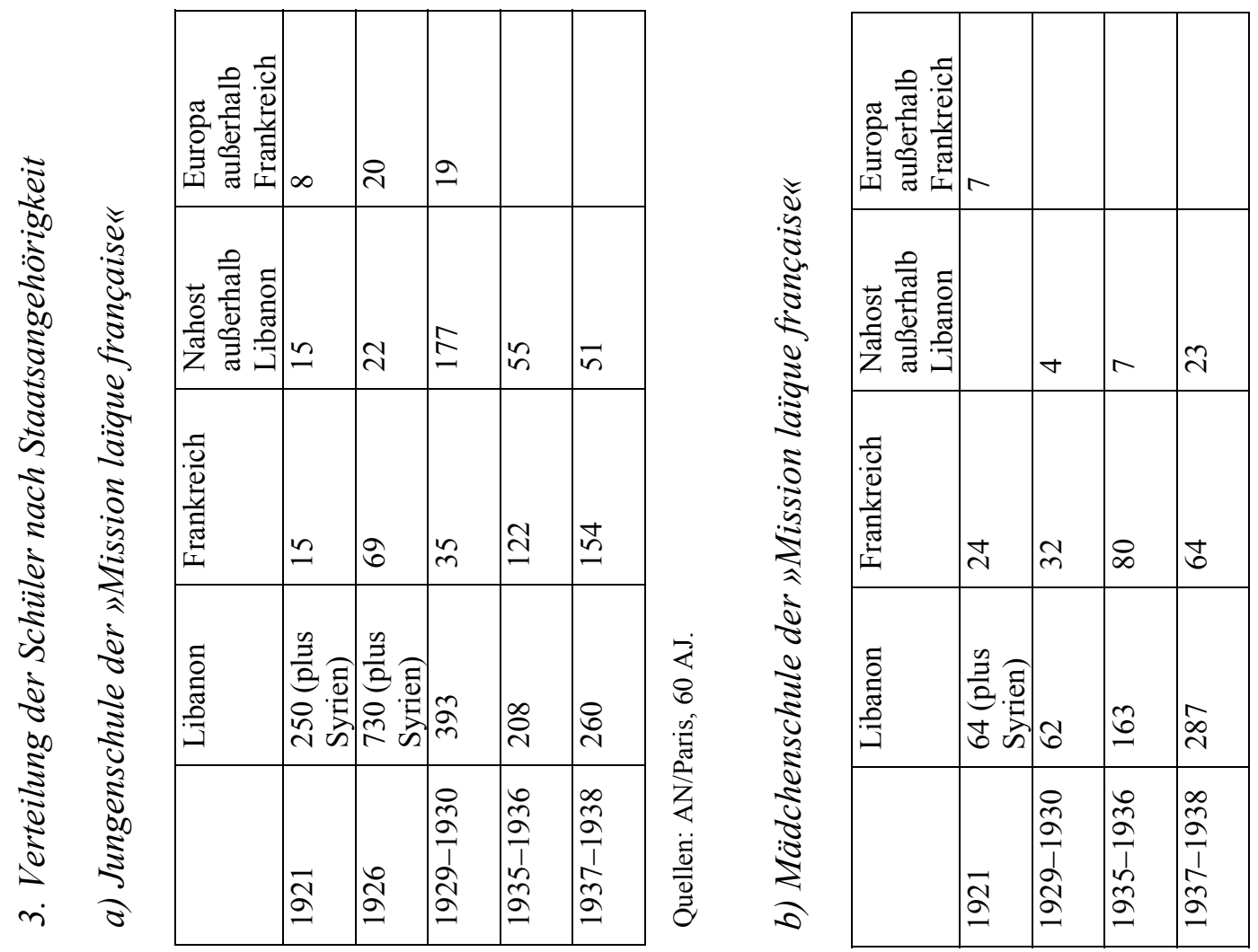

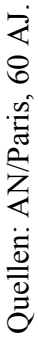




\begin{tabular}{|c|c|c|c|c|c|c|c|}
\hline 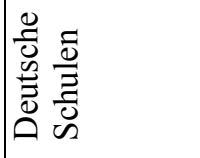 & & & & $\sim$ 离 & ${ }_{N} \stackrel{\varrho}{\varrho}$ & & $\ddot{\infty}$ \\
\hline 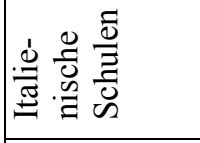 & & & & 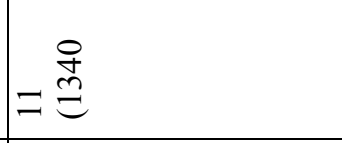 & $0 \stackrel{\widetilde{d}}{\approx}$ & & 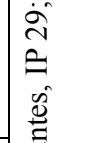 \\
\hline 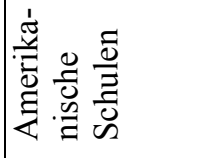 & & & & 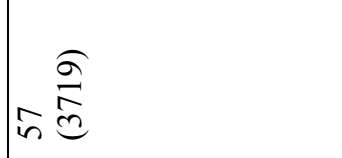 & $=\underbrace{\infty}$ & & 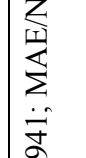 \\
\hline 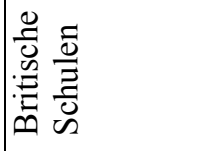 & & & 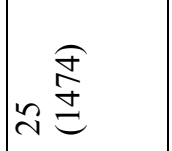 & 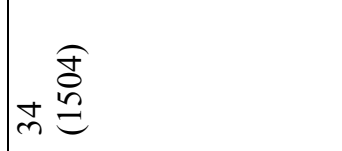 & $\approx \stackrel{\frac{\pi}{2}}{\frac{0}{d}}$ & & $\mid \begin{array}{l}z \\
z \\
z= \\
: 0 \\
0 \\
0\end{array}$ \\
\hline 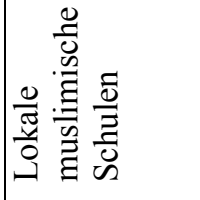 & & & & 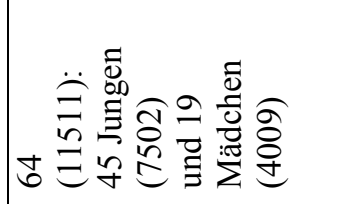 & & & $\begin{array}{l}0 \\
0 \\
0 \\
01 \\
01 \\
0 \\
0 \\
0 \\
0 \\
0 \\
\end{array}$ \\
\hline 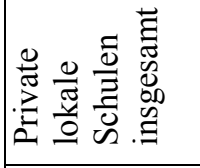 & & & & 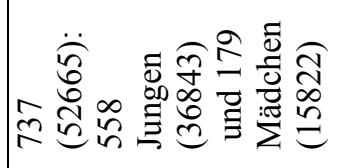 & & & 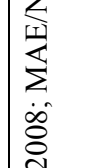 \\
\hline 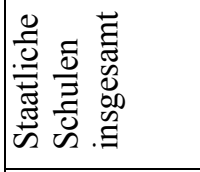 & & 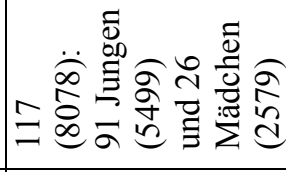 & 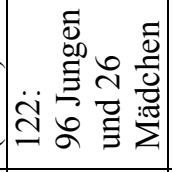 & 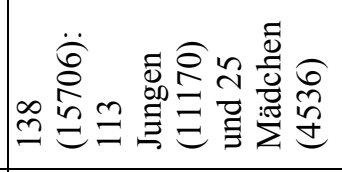 & & & 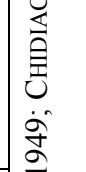 \\
\hline 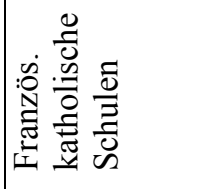 & & & & & & & 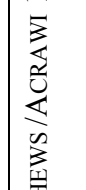 \\
\hline 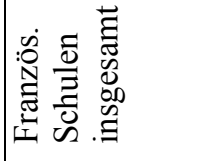 & 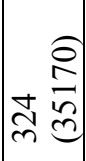 & & & 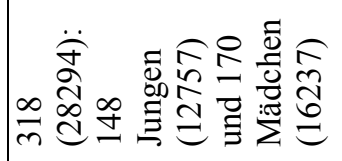 & & 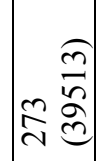 & 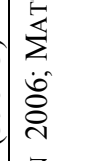 \\
\hline 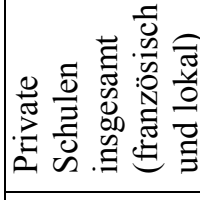 & & 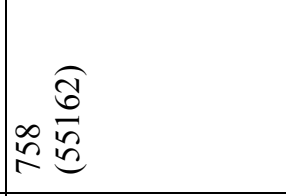 & & & & & 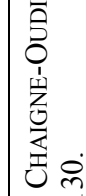 \\
\hline & $\stackrel{\Xi}{\sigma}$ & $\stackrel{\widehat{\Omega}}{\Omega}$ & 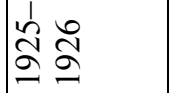 & $\tilde{\Omega}$ & $\stackrel{\infty}{\varrho}$ & $\underset{\mathcal{I}}{\mathcal{I}} \stackrel{\mathcal{Z}}{\mathcal{g}}$ & $\begin{array}{l}\frac{\bar{\Xi}}{\bar{\sigma}} \\
\bar{\sigma}\end{array}$ \\
\hline
\end{tabular}




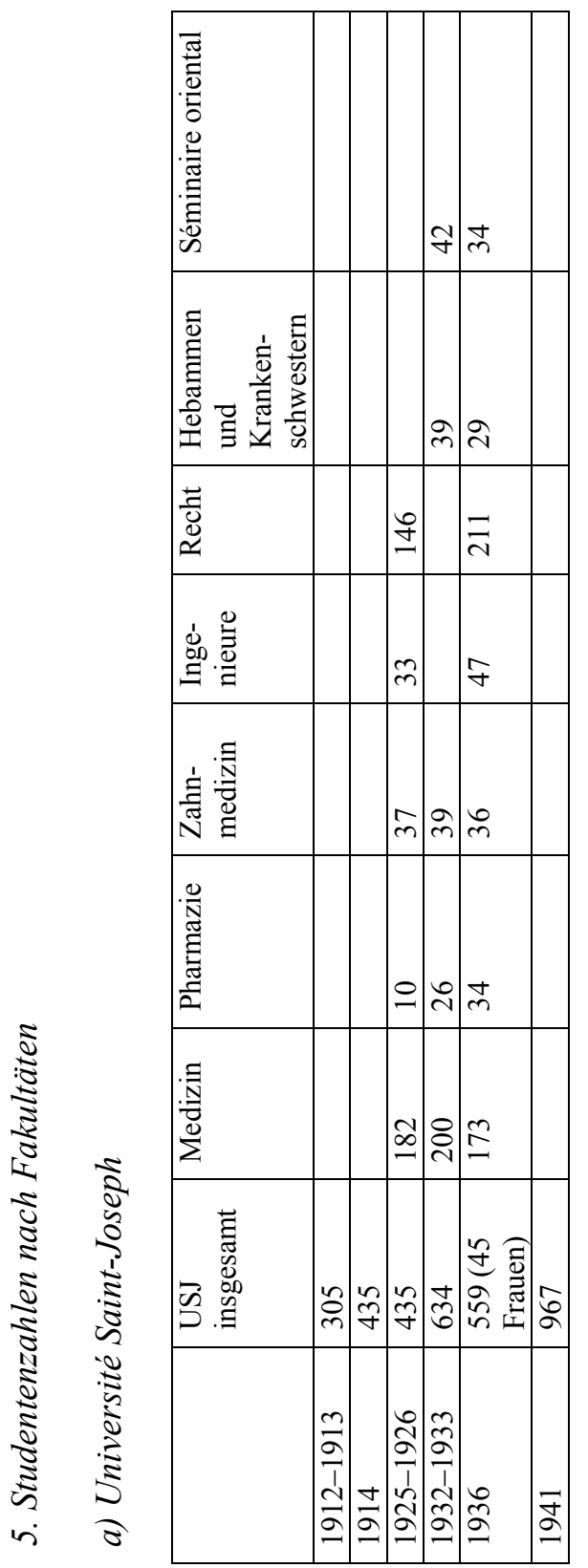

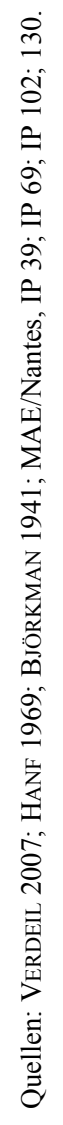

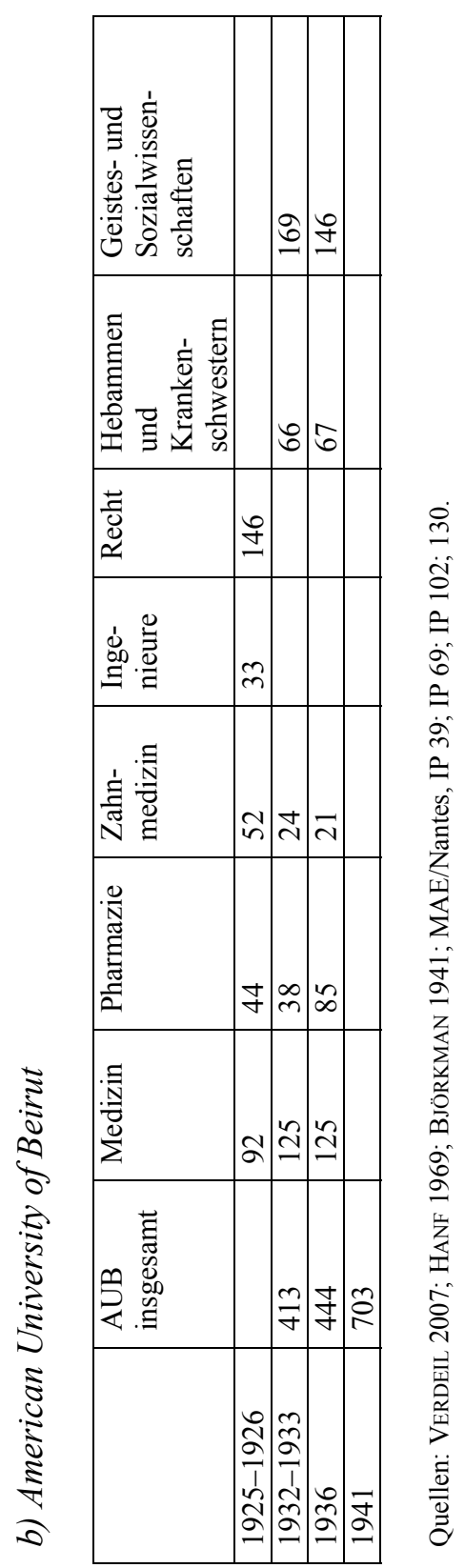





\title{
Archive und Interviewpartner
}

\author{
1. Frankreich
}

Archives nationales, Paris

Aktenbestand der Académie de Paris:

- 16 aj 6497/6986/6993/4734

Aktenbestand der Mission laïque française in Beirut:

- 60 AJ 118-140

Aktenbestand des Erziehungsministeriums / Personalakten von Lehrern:

- F 17/25346 (Lucien Ruche)

- F 17/24052 (Émile Chaufour)

Archiv des Ministère des Affaires étrangères (MAE), Paris

»Correspondance politique et commerciale - Levant 1918-1940« (CPC):

- 103-106: »1918-1929: Syrie - Instruction Publique«

- 279: »Etablissements religieux français«

- 378: »Instruction Publique/Dossier général 1922-1929«

- 660: »Professeurs français en Syrie«

»Guerre 1939-1945 Vichy Levant«:

- vol. 76: »Généralités«

Archiv des Ministère des Affaires étrangères, Nantes

»Beyrouth Consulat Général/Série A«:

- 177: »Établissements religieux et laiques (1901)《

- 191: »Demandes de bourses«

- 207: »1907: Allucations établissements religieux et laïques«

- 255: »Franc-maçonnerie musulmane«

- 352: »Écoles laïques«

- 359: „Société de Bienfaisance, Mission laïque française, Mouzzafer Pacha, gouverneur du Liban«

»Beyrouth Consulat Général / Série B«:

- 27: »Divers 1921-1942«

- 35: »Sœurs de Saint-Joseph de l'Apparition Saida«

- 52: »Lazaristes Beyrouth/Tripoli, Filles de la Charité (1923-1935)« 
- 50: »Établissements religieux d'enseignement, CEuvres 1922-41«

»Service des Euvres françaises à l'Étranger(SOFE) / 1912-1940«/»D-Levant«

- 197: »1930-1932/Mission Laïque Française/Alliance israélite universelle/Allucations«

- 201: »Autorisations scolaires en France«

- 222: »Professeurs détachés«

- 223: »Lycées de la Mission Laïque Française«

- 224: »Candidatures«

- 258: »Mission Laïque/Allucations et Subventions / 1932/1940«

- 375: »Syrie Beyrouth Promotions de Professeurs«

- 376 (ohne spezifischen Titel)

- 377: »Etablissements d'enseignement« (1932-1940)

- 378: »Établissements de la Mission Laïque en Syrie«

»Syrie Liban/Deuxième versement/Instruction Publique« (IP):

- 02: 1919-1920/03: 1920/05: 1921-1922/07: 1921/14: 1922/29: 1924/31: 1924/36: 1925/39: 1925/52: 1926-1927/63: 1927-1928/69: 1929/71: 1929/83: 1931/84: Exposition coloniale de Vincenne 1931/102: 19331934/130: 1936/138: 1937/145: 1938/170: 1941/179: 1942/192: 1940

Archiv der Mission lä̈que française, Paris

- »Fonds de Russie«: 03-941 / 03-942 / 03-943/03-944

- »Personnel de 1896 à 1950 « (»Liste du personnel«)

- »Comptes-rendus du Conseil d’Administration«, 1907-1911

- Zeitschrift Bulletin de la Mission laïque française, 1902

- Zeitschrift Revue de l'enseignement colonial, 1906-1907

- »Liste du personnel« (Buch mit Kurzangaben zu allen Lehrern)

»Dossiers de personnel«:

- Assaf Bey Kfoury (numéro de dossier : G 4200 A/026.13)

- Augustine Corny (numéro de dossier: G 4200 A / 012.9)

- Delhomme (numéro de dossier: G 4200 A/014.6)

- François Le Floch (numéro de dossier: G 4200 A/019.9)

- Jeanne Le Floch (numéro de dossier: G 4200 A/028.5)

- Eugénie Grall (numéro de dossier: G 4200 A / 022.5)

- André Ragon (numéro de dossier G 4200 A / 038.3)

- Elias Muard (numéro de dossier: G 4200 A/ 033.7) 
Archiv der Jesuiten/Vanves

»Fonds Jalabert«:

- 1-1/C: »Deux conférences de L. Jalabert à l'Université catholique du Louvain les 10 et 11 décembre 1935 «

- 1-1/F: »Syrie Liban Enseignement supérieur«

- 1-2/O: »Emploi de la langue française«

- 7-1/B: »Correspondance Sautier-Jalabert 1936-1939«

- 7-1/K: »Statut nouveau des pays sous Mandat (1931)《

- 11: „Centenaire 1931/Exposition coloniale 1931«

- 12/2, A: »Mission de Syrie-Liban. Correspondance avec le P. de Bonneville (juin 1932)《

- 12/2, B: »Mission de Syrie-Liban. Correspondance P. Costa de Beauregard (1931-1937)《

- 12/3, B: »Ecoles de Ghazir (P. Delore)«

- 25/B: »Correspondance Jalabert-Chanteur 1920-1927«

- 26/S: »Correspondance du P. Jalabert avec M. G. Bounoure janvier 1936$1939 \ll$

- 26/L: »Correspondance Jalabert Sautier (Supérieur de la mission) mars 1933-juillet 1936《

- 26/Q: „Correspondance du P. Louis Jalabert avec M. J. Poirier au Ministère des Affaires Étrangères, novembre 1934-février 1938«

- 31: »Détachés militaires«

»Province du Proche-Orient« (RPO):

- 15:»Questions politiques«

- 21: »Mission de Syrie«

- 62: »U.S.J. Collège Secondaire 1877-1957«

- 76: »Correspondance du P. Louis Jalabert au sujet du personnel de la mission 1930-1935«

- 90: »Détachés militaires«

- 99: »Anciens élèves«

- 105: »Exposition coloniale, Pavillon des missions«

M. Ley 138: Proche Orient-Visites 1925-1956

Archiv der Lazaristen/Paris

- »Beyrouth Correspondance 1896-1918«

- »Tripoli Correspondance 1892-1913«

- »Moyen Orient - Filles de la Charité - Divers«

- »Beyrouth - Notes pour l'Histoire«

- Zeitschrift Bulletin des Missions des Lazaristes, 1923-1950 
- Zeitschrift Association Amicale des Anciens Élèves d'Antoura (Bulletins aпnuels), 1938-1947

Archiv der Alliance israélite universelle, Paris

- Zeitschrift Paix et Droit, 1921-1940

- Zeitschrift Bulletin de l'Alliance israélite universelle, 1900-1913

- Archive auf Mikrofilm: »Liban 1 C 1-4«

»Liban V E 43-76«

»Liban VIE 80-81«

»Liban VIIE 81-86«

$»$ Liban IXE 94-96«

$»$ Liban XE 96«

Archiv der Présence Protestante Française au Liban, Plaisir/bei Paris

- »Comptes-rendus du Comité d'Administration«, 1925-1950

- »Dossiers de Professeurs «

- »Beyrouth - Relations culturelles - Subventions 1941-1960«

- »Correspondance de Jean Bianquis«, 1926

- »Foyer des Jeunes Beyrouth 1933-1948«

Archiv des Service protestant de mission, Paris

- »Foyer des Jeunes«

- Ordner mit Prospekten des Collège protestant français 1929-1939

Archiv der Société pour l'histoire du protestantisme français, Paris

- Jousselin, Jean, Enquête sur la jeunesse, Beirut: Imprimerie Catholique, 1933.

\section{Libanon}

Archives nationales, Beirut

- »Actes administratifs du Haut-Commissariat français«, 1919-1923

Archiv der Jesuiten, Beirut

- 8.C.21: »Haut-Commissariat français, Questions scolaires«

- 9.B.34: »Frères Écoles chrétiennes« 
- 11.A.26: »Écoles de la Mission Ensemble«

- 11.B.2: »Ain Ebel«

- 11.D.13 »Collège Secondaire II «

- 11.D.14: »Collège secondaire III«

- 11.D.15: »Collège secondaire IV «

- 12.C.10: »Tanail II Ministère Écoles«

- 12.C.12: »Tanail École normale«

- »Diaire de Remeileh $«$

- »Diaire collège de Beyrouth $«$

Archiv des Collège Saint-Joseph der Lazaristen in Ayntoura

- »Mandat français 1920«

- »Lettres diverses«

- »Depuis 1923, Antoura à l'avant-garde du scoutisme«

- »Cahier de Sujets de Devoirs Français. Dissertations littéraires, morales, Explication de textes etc.« von Émile Joppin (Direktor der Schule)

Archiv der Schule der Sours de Saint-Joseph de l'Apparition, Beirut

- "Historique«

- »Congrégation Mariale«, 1942-1947

Archiv des Collège Notre Dame de Jamhour

- Zeitschrift L'U, 1934-1937

- Zeitschrift Nous du Collège, 1940-1948

- »Distribution solennelle des prix«, 1863-1950

Archiv der Filles de la Charité, Beirut

- »G B 2 Liban«: Beyrouth, Zghorta, Zouk, Beurge, Tripoli

Archiv des Collège du Sacré-Cour der Frères des Écoles chrétiennes, Beirut

- »Historique du Collège français du Sacré-Cœur«

- Zeitschrift L'Essor. Bulletin de l'Académie Jeanne d'Arc, 1921-1949

- Palmarès, 1921-1939

- »Registre des Frères"

- verschiedene Schüleraufsätze 
- »Distribution solennelle des Prix«, 1907-1911

Bibliothek des Orient-Instituts

- Zeitschrift Bulletins mensuels du Haut-Commissariatfrançais, 1920-1930.

Bibliothek der Université Saint-Joseph

- Zeitschrift Revue de l'enseignement français hors de France, 1920-1934

Archiv der Zeitung L'Orient Le Jour, Beirut

- Zeitschrift L'Orient, 1925-1927; 1934

\section{Interviewpartner}

- Haifa Zahed, Beirut/03.12.2008.

- May Saikaly, Beirut/13.11.2008.

- Camille Héchaïmé, Beirut/24.10.2008.

- Olfat Sharif, Beirut/13.12.2008.

- Afif Soubra, Beirut/28.11.2008.

- Nada Soubra, Beirut/28.11.2008.

- Victor Hachem, Beirut/25.11.2008.

- Frère Michel, Beirut/08.12.2007.

- Claudine Arnac, Paris/27.03.2009.

- Sœur Marie-Jacques, Beirut/03.12.2007.

- Sœur Madeleine, Beirut/13.12.2007.

- Rose Ferali, Beirut/05.12.2007.

- Charles Libois, Beirut/05.11.2007. 


\section{Bibliographie}

\section{Geschichtsbücher der Schulen}

BAUDrillart, Alfred, Histoire générale. Orient - Grèce - Rome - Moyen Âge. Temps modernes Histoire contemporaine, Paris 1924.

Calmette, Joseph, Cours complet de langue française. Cours supérieur. Orthographe. Vocabulaire. Analyse. Exercices. Grammaire théorique. Principes de composition et de style, Paris 1912.

Calvet, Jean, Manuel illustré d'histoire de la littérature française, Paris 1934.

Ders., Morceaux choisis des auteurs français du $\mathrm{X}^{\mathrm{e}}$ au XX $\mathrm{XX}^{\mathrm{e}}$ siècle. Classes de $3^{\mathrm{e}}, 2^{\mathrm{e}}$, et $1^{\text {ère }}$, Nouvelle édition, Paris 1920/1935.

De Parvillez, Alphonse/Moncarey, Michel, La littérature française. Manuel pour la préparation au baccalauréat et aux divers examens, Sixième édition, Paris 1922.

Des Granges, Charles-Marc, Morceaux choisis des auteurs français, Deuxième cycle, Paris 1918.

Deuxième année de Méthode Schweitzer, méthode directe pour l'enseignement de la langue françaises aux étrangères, Paris o.J.

Gallienne, Jacques, Géographie de la Syrie et du Liban, Mission laïque française, o.J..

IsAaC, Jules, Histoire 1789-1851. Résumé Aide-Mémoire, Classe de Première, Paris 1929.

Ders. / Malet, Albert, Histoire contemporaine depuis le milieu du XIX ${ }^{\mathrm{e}}$ siècle, Paris 1930.

LeVenQ, G., La Syrie. Géographie élémentaire à l'usage des écoles, Beirut 1920.

Muhtașar tārīh Sūrīya wa-Lubnān. Ta rīb al-kitāb al-mu'anwan Petite Histoire de la Syrie et du Liban, bi-qalam ahad al-abā' al-yasū '̇ȳinn, Beirut 1924 [Kurze Geschichte Syriens und des Libanons. Arabische Version des Buches mit dem Titel Petite Histoire de la Syrie et du Liban, von einem Jesuitenpater].

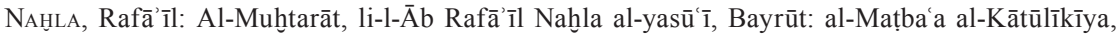
1930 [Eine Anthologie des Jesuiten Rafael Nakhlé, Beirut: Katholische Druckerei, 1930].

Précis historique de France par un Comité de professeurs, Lyon 1923.

SFeIR, Joseph, Petite Grammaire française. Règles, Exercices, Analyses, Vocabulaires, Conjugaisons etc. Destinée spécialement aux enfants du Grand-Liban et de la Syrie, Beirut 1937.

\section{Literatur}

ABÉCAssis, Frédéric, L'enseignement étranger en Égypte et les élites locales 1920-1960. Francophonie et identités nationales, Diss. Aix-Marseille 2000.

Abi-Mershed, Osama (Hg.), Trajectories of Education in the Arab World. Legacies and Challenges, London 2010.

AgERON, Charles-Robert, L'exposition coloniale de 1931. Mythe républicain ou mythe impérial?, in: Nora, Pierre (Hg.), Lieux de mémoire, Bd. I, Paris 1984, S. 493-515.

Agulhon, Maurice, La République. L'élan fondateur et la grande blessure (1880-1923), Paris 1990.

Ders., La sociabilité méridionale: confréries et associations dans la vie collective en Provence Orientale à la fin du $18^{\text {ème }}$ siècle, Aix-en-Provence 1966. 
Al-'Azm, Sadiq Jalal, Ces interdits qui nous hantent. Islam, censure, orientalisme, Marseille 2008.

Al-Khazen, Fahid, The Communal Pact of National Identities. The Making and Politics of the 1943 National Pact, Oxford 1991.

Altbach, Philip G./Kelly, Gail P., Introduction, in: Dies. (Hg.), Education and Colonialism, New York 1978, S. 1-49.

Amyuni, M. T., Eintrag »Taqi al-Din Khalil (1906-87)«, in: Starkey, Paul/Meisami, Julie Scott (Hg.), Encyclopedia of Arabic Literature, Bd. 2, London 2010, S. 758.

Anderson, Benedict, Imagined Communities. Reflections on the Origin and Spread of Nationalism, London/New York 2006.

ANDERson, Betty, The American University of Beirut. Arab Nationalism and Liberal Education, Austin 2011.

Andrew, Christopher Maurice/Kanya-Forstner, Alexander Sydney, The Climax of French Imperial Expansion 1914-1924, Stanford, California 1981.

Anduze, Éric, La franc-maçonnerie au Moyen-Orient et au Maghreb fin XIX ${ }^{\mathrm{e}}$ - début XX $\mathrm{X}^{\mathrm{e}}$ siècle, Paris 2005.

AntéBI, Elizabeth, Les Missionnaires juifs de la France 1860-1939, Paris 1999.

Antonius, George, The Arab Awakening. The Story of the Arab National Movement, London 1938.

Asad, Talal, Religion, Nation-State, Secularism, in: Lehmann, Hartmut/van Der Veer, Peter (Hg.), Nation and Religion. Perspectives on Europe and Asia, Princeton, New Jersey 1999, S. 178-196.

АтіYен, Naim, The Development of Education in Lebanon, in: Beirut College for Women (Hg.), Cultural Resources in Lebanon, Beirut 1969, S. 198-215.

Ders., Schools of Beirut, in: Beirut College for Women (Hg), Beirut - Crossroads of Cultures, Beirut 1970, S. 133-166.

Avez, Renaud, L'Institut français de Damas au palais Azem (1922-1946) à travers les archives, Damaskus 1993.

Avon, Dominique, La cause du Liban selon le jésuite Louis Jalabert (1914-1934), in: FARCY-MAGDENEL, Evelyne (Hg.), Le rôle de la France dans les opérations extérieures: influence, ingérence et/ou mandat. L'exemple du Liban, Montpellier 2007, S. 69-80.

Ders., Les Frères prêcheurs en Orient. Les dominicains du Caire (Années 1910-Années 1960), Paris 2005.

Ders. / Rocher, Philippe, Les jésuites et la société française. XIX ${ }^{e}-X^{e}$ siècles, Toulouse 2001.

Ayalon, Ami, The Press in the Middle East. A History, New York/Oxford 1995.

Bachmann-Medick, Doris, Dritter Raum. Annäherungen an ein Medium kultureller Übersetzung und Kartierung, in: Breger, Claudia/Döring, Tobias (Hg.), Figuren der/des Dritten. Erkundungen kultureller Zwischenräume, Amsterdam 1998, S. 19-36.

BADRAN, Margot, Feminists, Islam and Nation: Gender and the Making of Modern Egypt, Princeton 1995.

Dies./Cooke, Miriam (Hg.), Opening the Gates. A Century of Arab Feminist Writing, London 1992.

Baktiaya, Adil, Syrian Protestant College's Struggle Legitimacy as Reflected in Archival Sources, in: International Review of Turcology 1 (2008), H. 2, S. 25-41 (=Baktiaya 2008a).

Ders., The Ottoman-French Domination Struggle Over the Syrian-Lebanon Territory: The Case of St. Joseph Medical School, in: International Journal of Turcologia 3 (2008), H. 6, S. 68-93 (=Baktiaya 2008).

Bancel, Nicolas/Blanchard, Pascal/Vergès, Françoise, La République coloniale, Paris 2003.

Barbier-De Bonnay, Colette, Le Service des Euvres françaises à l'étranger du Ministre des Affaires étrangères entre les deux guerres mondiales, Paris 1983 (unveröffentlichte Magisterarbeit).

BARres, Maurice, Une enquête aux pays du Levant, Paris 1923.

Becker, Winfried, Christliche Parteien im Frankreich des 19. und 20. Jahrhunderts, in: Kranemann, Benedikt/Wislens, Miriam (Hg.), Religion und laïcité in Frankreich: Entwicklungen, Herausforderungen und Perspektiven, Würzburg 2009, S. 17-33.

Beneton, Philippe, Histoire de mots. Culture et civilisation, Paris 1975. 
Besnard, Edmond, Faut-il rester en Syrie?, in: Les Cahiers des Droits de l'Homme 21 (1926), S. 492-496.

Betts, Raymond F., Assimilation and Association in French Colonial Theory 1890-1914, New York/London 1961.

Beydoun, Ahmad, Identité confessionnelle et temps social chez les historiens libanais contemporains, Beirut 1984.

Внавна Homi, The Location of Culture, London/New York 2008.

BJörkman, Walter, Das syrische Bildungswesen und seine Probleme, in: Die Welt des Islams 23 (1941), H. 3-4, S. 133-155.

Blanchard, Pascal/Ginio, Ruth, Révolution impériale: le mythe colonial de Vichy, in: Blanchard, Pascal/Lemaire, Sandrine (Hg.), Culture impériale. Les colonies au cœur de la République 1931-1961, Paris 2004, S. 125-143.

Ders. / Lemaire, Sandrine, Introduction, in: Dies. (Hg.), Culture impériale. Les colonies au cœur de la République, 1931-1961, Paris 2004, S. 5-32.

Bochmann, Klaus, Frankophonie als inneres Ordnungsprinzip der französischen Nation, in: Frankreich-Zentrum der Universität Leipzig/Institut français de Leipzig (Hg.), Francophonie et Globalisation. Materialien zur V. Französischen Sommeruniversität, Leipzig 1997, S. 60-69.

Bocquet, Jérôme, Gabriel Bounoure et les congrégations enseignantes, in: Khoury, Gérard D. (Hg.), Vergers d'exil. Gabriel Bounoure, Paris 2004, S. 205-221.

Ders., La France, L'Église et le Baas. Un siècle de présence française en Syrie (de 1918 à nos jours), Paris 2008.

Ders., Missionnaires français en terre d'Islam: Damas 1860-1914, Paris 2005.

Ders., Missionnaires français et allemands au Levant: les Lazaristes français de Damas et l'Allemagne, du voyage de Guillaume II à l'instauration du mandat, in: TrimBur, Dominique (Hg.), Europäer in der Levante. Zwischen Politik, Wissenschaft und Religion (19. und 20. Jahrhundert), München 2004, S. 57-75.

Ders., Les Lois anticongréganistses et leurs effets au Levant, in: CABAnEL, Patrick/Durand, JeanDominique (Hg.), Le grand exil des congrégations religieuses françaises 1901-1914, Paris 2005, S. 386-414.

Böнм, Winfried, Die Reformpädagogik: Montessori, Waldorf und andere Lehren, München 2012.

Ders., Éducation nouvelle et christianisme - une liaison difficile, in: Michel Soëtard (Hg.), Identité et Altérité en Éducation, Angers 1996, S. 21-35.

BокоvA, Lenka, La révolution française dans le discours de l'insurrection syrienne contre le mandat français (1925-1927), in: Revue du monde musulman et de la Méditerranée, 52 (1989), H. 2-3, S. 207-217.

Bouche, Denise, Autrefois notre pays s'appelait la Gaule...Remarques sur l'adaptation de l'enseignement au Sénégal, in: Cahiers d'études africaines 8 (1969), H. 29, S. 110-122.

Dies., Histoire de la colonisation française, Paris 1991.

Bouron, Capitaine N., Les Druzes. Histoire du Liban et de la Montagne Haouranaise, Préface du Général Weygand, Paris 1930.

Bourdieu, Pierre, La Distinction, Paris 1979.

Ders., Sozialer Raum und symbolische Macht, in: Ders., Rede und Antwort, Frankfurt am Main 1992, S. 135-154.

Ders., Von der königlichen Macht zur Staatsraison. Ein Modell der Genese des bürokratischen Feldes, in: Ohnacker, Elke/Schultheis, Franz (Hg.), Pierre Bourdieu. Schwierige Interdisziplinarität. Zum Verhältnis von Soziologie und Geschichtswissenschaft, Münster 2004, S. 24-47.

Ders./Passeron, Jean-Claude, La reproduction. Éléments pour une théorie du système de l'enseignement, Paris 1970.

Bourmaud, Philippe, Cultiver sa réputation. L'image des médecins au Proche-Orient à l'ère des réformes ottomanes $\left(\mathrm{XIX}^{\mathrm{e}}\right.$-début $\mathrm{XX}^{\mathrm{e}}$ siècle), in: Tempora. Annales d'Histoire et d'Archéologie 18 (2007), S. 1-17.

Boutan, Pierre, L'Algérie dans les manuels scolaires des Frères des Ecoles chrétiennes avant 1962 (unveröffentlichter Artikel).

Ders., La langue des Messieurs...Histoire de l'enseignement français à l'école primaire, Paris 1996. 
Brahimi, Denise, Volney et Lamartine. Les jeux de l'Orient et de la différence, in: Zinguer, Ilana (Hg.), Miroirs de l'Altérité et Voyages au Proche-Orient, Genf 1991, S. 289-293.

BrÉGain, Gildas, Syriens et Libanais d’Amérique du Sud (1918-1945), Paris 2008.

Broers, Michael, Le Fardeau du Franc. Aufklärung zu Pferde - eine Zivilisierungsmission in Napoleons Europa? in: Barth, Boris / Osterhammel, Jürgen (Hg.), Zivilisierungsmissionen, Konstanz 2005, S. 73-99.

Bruneau, André, Traditions et politiques de la France au Levant, Paris 1932.

Brunet, Jean-Paul, Cartel des gauches, in: Sirinelli, Jean-François (Hg.), Dictionnaire de la vie politique française au XX $\mathrm{XX}^{\mathrm{e}}$ siècle, Paris 2003, S. 179-184.

Ders., Crise française des années 1930, in: SiRInelli, Jean-François (Hg.), Dictionnaire historique de la vie politique française au $\mathrm{XX}^{\mathrm{e}}$ siècle, Paris 2003, S. 305-307.

Buheiry, Marwan, Bulus Nujaym and the Grand Liban Ideal 1908-1919, in: Ders. (Hg.), Intellectual Life in the Arab East, 1890-1939, Beirut 1981, S. 62-83.

Burke, Edmund III, A Comparative View of French Native Policy in Morocco and Syria, 1912 1925, in: Middle Eastern Studies 9 (1973), S. 175-186.

Burrows, Matthew, Mission civilisatrice: French Cultural Policy in the Middle East, 1860-1914, in: The Historical Journal 29 (1986), S. 109-135.

Cabanel, Patrick (Hg.), Une France en Méditerranée. Écoles, langue et culture françaises, XIX $\mathrm{XX}^{\mathrm{e}}$ siècles, Paris 2006.

Ders./Durand, Jean-Dominique (Hg.), Le grand exil des congrégations religieuses françaises 1901-1914, Paris 2005.

Camuzet, Luce, L'œuvre de Syrie des Sœurs de Saint-Joseph de l'Apparition, Paris 1931.

Casanova, José, Europas Angst vor der Religion, Berlin 2009.

CÉSAIRe, Aimé, Discours sur le colonialisme, Paris 1955.

Chabet, François, La politique culturelle française et la diplomatie de la langue. L'Alliance française (1883-1940), Paris 2006.

Chaigne-Oudin, Anne-Laure, La France et les rivalités occidentales au Levant. Syrie-Liban 1918 1939, Paris 2006.

Chalabi, Tamara, The Shi'is of Jabal 'Amil and the New Lebanon. Community and Nation-State, 1918-1943, New York 2006.

Chamoun, Ingrid (Hg.), Visages d'une époque. Maud Fargeallah raconte, Paris 1989.

Chapman-Adisho, Annette Renée, Mission Civilisatrice to Mandate. The French and Education in Syria and Lebanon, M. A. Thesis Louisville, Kentucky 1998.

Charle, Christophe, Introduction to Part I, in: Charle, Christophe/Schriewer, Jürgen/Wagner, Peter (Hg.), Transnational Intellectual Networks. Forms of Academic Knowledge and the Search for Cultural Identities, Frankfurt am Main 2004, S. 197-204.

Charles-Roux, François, France et chrétiens d'Orient, Paris 1939.

Charmes, Gabriel, Voyage en Syrie. Impressions et Souvenirs, Paris 1891.

Chevallier, Dominique, La société du Mont Liban à l'époque de la révolution industrielle en Europe, Paris 1971.

ChidiAC, Edmond, La France au Levant. Le bilan économique du Mandat français en Syrie et au Liban 1920-1946, Diss. Paris 2002.

Ders. (Hg.), Rapports annuels du Ministère des Affaires étrangères à la Société des Nations sur la situation de la Syrie et du Liban, Beirut 2008.

Ders., Scolarisation et Enseignement de l'Histoire au Liban: Formation du citoyen ou facteur de division?, in: o.O. o.J., S. 1-7.

Cholvy, Gérard, Le renouveau catholique en France, in: Keryell, Jacques (Hg.), Louis Massignon et ses contemporains, Paris 1997, S. 29-41.

Chouraqi, André, L’Alliance israélite universelle et la renaissance juive contemporaine (18601960), Paris 1965.

Cioeta, Donald J., Islamic Benevolent Societies and Public Education in Ottoman Syria, 18751882, in: The Islamic Quarterly 26 (1982), H. 2, S. 40-62. 
Clancy-Smith, Julia, L'éducation des jeunes filles musulmanes en Tunisie. Missionnaires religieux et laïques, in: Rochefort, Florence (Hg.), Le pouvoir du genre. Laïcités et religions, 1905-2005, Toulouse 2007, S. 127-143.

Cleveland, William L., The Making of an Arab Nationalist. Ottomanism and Arabism in the Life and Thought of Sati' al Husri, Princeton 1971.

Colonna, Fanny, Educating Conformity in French Colonial Algeria, in: Cooper, Frederick/StoLER, Ann Laura (Hg.), Tensions of Empire. Colonial Cultures in a Bourgeois World, Berkeley, California, 1997, S. 346-370.

Dies., Instituteurs algériens 1883-1939, Paris 1975.

Condette, Jean-François, Histoire de la formation des enseignants en France (XIX ${ }^{\mathrm{e}}-\mathrm{XX}^{\mathrm{e}}$ siècles), Paris 2007.

Conklin, Alice L., A Mission to Civilize. The Republican Idea of Empire in France and West Africa 1895-1930, Stanford 1997.

Dies. / Clancy-Smith, Julia, Introduction: Writing Colonial Histories, in: French Historical Studies 27 (2004), H.3, S. 497-505.

Connell Szasz, Margaret (Hg.), Between Indian and White Worlds. The Cultural Broker, Norman 1994.

Cooke, Miriam, Nazira Zeineddine al-Halabi. A Pioneer of Islamic Feminism, Oxford 2010.

Cooper, Frederick, Colonialism in Question. Theory, Knowledge, History, Berkeley, California 2005 .

Ders. / Stoler, Ann Laura, Between Metropole and Colony. Rethinking a Research Agenda, in: Dies. (Hg.), Tensions of Empire. Colonial Cultures in a Bourgeois World, Berkeley, California 1997, S. 1-56.

Cooper, Nicola, France in Indochina. Colonial Encounters, Oxford 2001.

Dies., Gendering the Colonial Enterprise. La Mère-Patrie and Maternalism in France and French Indochina, in: Fischer-Tiné, Harald/Gehrmann, Susanne (Hg.), Empires and Boundaries. Rethinking Race, Class, and Gender in Colonial Settings, New York 2009, S. 129-145.

Dies., Making Indo-China French: Promoting the Empire through Education, in: Evans, Martin (Hg.), Empire and Culture. The French Experience 1830-1940, London 2004, S. 131-147.

Corcket, Pierre, Les Lazaristes et les Filles de la Charité au Proche-Orient, Beirut 1983.

Corrado, Monica, The Essentials of Freemasonry (al-khulâsa al-mâsûniyya), an Annoted Translation of Luwîs Shaykhû's Article on Freemasonry, in: AHL (Archeology \& History in Lebanon), Winter 2007, S. 34-65.

Costantini, Dino, Mission civilisatrice. Le rôle de l'histoire coloniale dans la construction de l'identité politique française, Paris 2004.

Couland, Jacques, Le Front populaire et la négociation des traités avec les États du Levant, in: ARBID, Walid u.a. (Hg.), Méditerranée, Moyen-Orient: Deux siècles de relations internationales. Recherches en hommage à Jacques Thobie, Paris 2003, S. 501-520.

Curtis, Sarah, Civilizing Habits. Women Missionaries and the Revival of French Empire, Oxford 2010 .

DAGHER, Joseph A., L'Orient dans la littérature française d'après-guerre 1919-1933, Beirut 1937.

DAKHLI, Leyla, Arabisme, nationalisme arabe et identifications transnationales arabes au $20^{\mathrm{e}}$ siècle, in: Vingtième Siècle. Revue d'Histoire 103 (2009), S. 13-25 (= Dakhli 2009b).

Dies., Beyrouth-Damas, 1928: voile et dévoilement, in: Le Mouvement Social, April-Juni 2010, S. $123-140$.

Dies., Une génération d'intellectuels arabes. Syrie Liban 1908-1940, Paris 2009 (= Dakhli 2009a).

Daughton, James P., An Empire Divided. Religion, Republicanism, and the Making of French Colonialism, 1880-1914, Oxford 2006.

DAY, Charles R., Schools and Work: Technical and Vocational Education in France since the Third Republic, Montreal 2001.

Dawn, C. Ernest, The Formation of Pan-Arab Ideology in the Interwar Years, in: International Journal of Middle Eastern Studies 20 (1988), S. 67-91.

De Bustros, Nicolas, Je me souviens, Beirut 1983. 
De Certeau, Michel, L'invention du quotidien. 1. Arts de faire, Paris 1990.

Degros, Maurice, Jean Marx (1994-1972), in: Bibliothèque des Écoles des chartes 131 (1972), S. 684-687.

Degullhem, Randi, Exporter la France laïque dans la Méditerranée ottomane, in: CABAnEL, Patrick (Hg.), Une France en Méditerranée. Ecoles, langue et culture françaises, $\mathrm{XIX}^{\mathrm{e}}-\mathrm{XX}^{\mathrm{e}}$ siècles, Paris 2006, S. 179-190.

Dies., Exporter la laïcité républicaine: la Mission laïque française en Syrie mandataire, pays multiconfessionnel, in: Luizard, Pierre-Jean (Hg.), Le choc colonial et l'islam. Les politiques religieuses des puissances coloniales en terre d'islam, Paris 2006, S. 383-398.

Dies., Impérialisme, colonisation intellectuelle et politique culturelle de la Mission laïque française en Syrie sous Mandat, in: Méouchy, Nadine/Sluglett, Peter (Hg.), The British and French Mandates in Comparative Perspectives, Leiden 2004, S. 321-343.

Dies., L'école secondaire Matktab 'Anbar à Damas, in: Revue du monde musulman et de la Méditerranée 52 (1989), H. 2-3, S. 199-205.

Dies., State Civil Education in Late Ottoman Damascus. A Unifying or a Separating Force? in: Philipp, Thomas / SchäBler, Birgit (Hg.), The Syrian Land. Processes of Integration and Fragmentation, Bilad al-Sham from the $18^{\text {th }}$ to the $20^{\text {th }}$ Century, Stuttgart 1998 (Berliner Islamstudien 6), S. 221-250.

Dies., Turning Syrians into Frenchmen: the Cultural Politics of a French Non-Governmental Organization in Mandate Syria (1920-67) - The French Secular Mission Schools, in: Islam and Christian-Muslim Relations 13 (2002), S. 449-460.

Delisle, Philippe (Hg.), L’anticléricalisme dans les colonies françaises sous la Troisième République, Paris 2009.

DelPal, Bernard, L'Imprimerie catholique et la Bibliothèque orientale à Beyrouth, in: FouillouX, Étienne/Hours, Bernard (Hg.), Les jésuites à Lyon XVI ${ }^{\mathrm{e}}-\mathrm{XX} \mathrm{e}^{\mathrm{e}}$ siècles, Lyon 2005, S. 161-172.

Denoeux, Guilain P., Eintrag »Sulh, Taki al-Din al- (1909-1988)«, in: Encyclopedia of the Modern Middle East and North Africa, Bd. 2, Detroit 2004, S. 2119-2120.

Deschamps, Pierre, Promenade archéologique, in: Dialogues 35/36/37, Éléments pour une histoire de la Mission laïque française 1902-1982 (1982), S. 81-99.

Dirlik, Arif, Chinese History and the Question of Orientalism, in: History and Theory 35 (1996), H. 4, S. 96-118.

DodiLle, Norbert, Les nouvelles malgaches de Marius-Ary Leblond, in: Revue historique des Mascareignes 5 (2003), H. 5, S. 223-233.

Ducruet, Jean/Awit, Henri, L’Université Saint-Joseph de Beyrouth et ses institutions (1875-2002), Beirut 2002.

Dueck, Jennifer, A Muslim Jamboree: Scouting and Youth Culture in Lebanon under the French Mandate, in: French Historical Studies 30 (2007), S. 485-516.

Dies., Educational Conquest. Schools as a Sphere of Politics in French Mandate Syria, 1936-1946, in: French History 20 (2006), S. 442-459.

Dies., Stories of Pride and Shame: Left-Wing Writers and the French Mission to Civilize an Empire, in: Chronos. Revue d'Histoire de l'Université de Balamand 15 (2007), S. 107-130.

Dies., The Claims of Culture at Empire's End. Syria and Lebanon under French Rule, Oxford 2010.

Dufour, Pierre, La France au Levant, Paris 2001.

Dunch, Ryan, Beyond Cultural Imperialism. Cultural Theories, Christian Missions, and Global Modernity, in: History and Theory 41 (2002), S. 301-325.

Dupont, Anne-Laure, Gurgi Zaydan 1861-1914. Écrivain réformiste et témoin de la Renaissance arabe, Damaskus 2006.

Dies., Sélim Takla, un destin libanais, in: Khoury, Gérard (Hg.), Sélim Takla 1895-1945. Une contribution à l'indépendance du Liban, Paris 2004, S. 19-40.

Dies., Une école missionnaire et étrangère dans la tourmente de la révolution constitutionnelle ottomane, in: Cahiers de la Méditerranée 75 (2007), S. 39-57.

Dies., Usages et acculturation de la Franc-maçonnerie dans les milieux intellectuels arabes à la fin du XIX ${ }^{\mathrm{e}}$ siècle à travers l'exemple de Jurji Zaydan (1861-1914), in: Cahiers de la Méditerranée 72 (2006). URL: http://cdlm.revues.org/index1175.html (18.08.2010). 
Dies. / Mayeur-Jaouen, Catherine, Monde nouveaux, voix nouvelles: États, sociétés, islam dans l'entre-deux-guerres, in: Dies. (Hg.), Débats intellectuels au Moyen-Orient dans l'entre-deuxguerres. Revue des mondes musulmans et de la Méditerranée 95-98 (2002), S. 9-39.

Duteil, Simon, Parcours parallèles et construction d'une identité. Les enseignants français dans les colonies françaises sous la Troisième République. Les enseignants formés à l'école Jules Ferry de la Mission laïque française (1902-1914), DEA Le Havre, 2003.

Ebert, Johannes, Religion und Reform in der arabischen Provinz. Husayn al-Gisr at-Traboulsi (1845-1909) - Ein islamischer Gelehrter zwischen Tradition und Reform, Frankfurt am Main 1991.

EdDÉ, Carla, Au temps du mandat français sur la Syrie et le Liban, in: Denise, Fabrice/ Nordiguian, Lévon (Hg.), Une aventure archéologique. Antoine Poidelbard, photographe et aviateur, Marseille 2004, S. 75-89.

Dies., Étude de la composition du conseil municipal beyrouthin (1918-1953). Renouvellement des élites urbaines ou consolidation des notables?, in: FAvier, Agnès (Hg.), Municipalités et pouvoirs locaux au Liban, Beirut 2001, S. 79-102.

Dies., L'émergence de la capitale libanaise à l'ombre du mandat français. Les premiers pas (19181924), Diss. Aix-Marseille/Beirut 2008.

Dies., La mobilisation »populaire« à Beyrouth à l'époque du Mandat. Le cas des boykotts des trams et de l'électricité, in: Méouchy, Nadine (Hg.), France, Syrie et Liban 1918-1946. Les ambiguïtés et les dynamiques de la relation mandataire, Damaskus 2002, S. 349-375.

Eisenberg, Christiane, Kulturtransfer als historischer Prozeß. Ein Beitrag zur Komparatistik, in: Kaelble, Hartmut/Schriewer, Jürgen (Hg.), Vergleich und Transfer. Komparatistik in den Sozial-, Geschichts- und Kulturwissenschaften, Frankfurt 2003, S. 399-417.

El-Solh, Raghid K., Lebanese Arab Nationalists and Consociational Democracy during the French Period, in: Schumann, Christoph (Hg.), Liberal Thought in the Eastern Mediterranean. Late $19^{\text {th }}$ Century until the 1960 s, Leiden 2008 , S. 217-238.

Elboudrari, Hassan, Massignon Louis, in: Pouillon, François (Hg.), Dictionnaire des orientalistes de langue française, Paris 2008, S. 660-661.

Elias, Norbert, Über den Prozess der Zivilisation. Soziogenetische und psychogenetische Untersuchungen, Bd. I: Wandlungen des Verhaltens in den weltlichen Oberschichten des Abendlandes, Frankfurt am Main 1976.

EndE, Werner, Sollen Frauen schreiben lernen? Eine innerislamische Debatte und ihre Widerspiegelung in al-Manār, in: Bellmann, Dieter (Hg.), Gedenkschrift Wolfgang Reuschel. Akten des III. Arabistischen Kolloquiums, Leipzig, 21.-22. November 1991, Stuttgart 1994, S. 49-57.

Espagne, Michel, Die Rolle der Mittler im Kulturtransfer, in: LüSEBRinK, Hans-Jürgen/REICHARDT, Rolf (Hg.), Kulturtransfer im Epochenumbruch. Frankreich - Deutschland 1770-1815, Leipzig 1997, S. 309-329.

Eyrard, Jean-Paul/Khoury, Afaf/Krebs, Georges, Le Collège protestant français de Beyoruth. 80 ans d'excellence, Beirut 2006.

Ders./Krebs, Georges, Le Protestantisme français et le Levant de 1856 à nos jours, Straßburg 2007.

Evans, Martin, Culture and Empire, 1830-1962. An Overview, in: Ders. (Hg.), Empire and Culture. The French Experience, 1830-1940, London 2004, S. 1-23.

Fabiani, Jean-Louis, Rezension zu Frédéric Keck, Lucien Lévy-Bruhl. Entre philosophie et anthropologie, contradiction et participation, Paris 2008, in: Annales 65 (2010), H. 4, S. 1046-1048.

FÄHNDRICH, Hartmut, Orientalismus und Orientalismus. Überlegungen zu Edward Said, Michel Foucault und westlichen »Islamstudien«, in: Die Welt des Islams 28 (1988), S. 178-186.

FAwAZ, Leila, La campagne de Bonaparte en Syrie et ses conséquences locales, in: Revue du monde musulman et de la Méditerranée 52 (1989), H.2-3, S. 77-83.

FAYE, Ousseynou, Une enquête d'histoire de la marge: production de la ville et populations africaines à Dakar, 1857-1960, Diss. Dakar 1999-2000.

Ferry, Jules, La République des Citoyens, Bd. II, hg. von Odile Rudelle, Paris 1996. 
Feuchter, Jörg, Cultural Transfers in Dispute. An Introduction, in: Ders./Hoffmann, Friedhelm/Yun, Bee (Hg.), Cultural Transfers in Dispute. Representations in Asia, Europa and the Arab World since the Middle Ages, Frankfurt am Main 2011, S. 15-37.

FIORE, Massimiliano, Anglo-Italian Relations in the Middle East, 1922-1940, Surrey 2010.

FIrRo, Kais, Inventing Lebanon. Nationalism and the State under the Mandate, London 2003.

FISCHER-Tiné, Harald, Englands interne Zivilisierungsmission. Arbeitshäuser für Europäer im kolonialen Indien (ca. 1860-1914), in: Barth, Boris/Osterhammel, Jürgen (Hg.), Zivilisierungsmissionen, Konstanz 2005, S. 169-198.

Ders., Low and Licentious Europeans. Race, Class and »White Subalternity« in Colonial India, New Delhi 2009.

Ders., Postkoloniale Studien, in: Europäische Geschichte Online (EGO), hg. vom Institut für Europäische Geschichte (IEG), Mainz 2010. URL: http://www.ieg-ego.eu/fischertineh-2010-de (15.06.2011).

Ders., Vom Wissen zur Macht. Koloniale und »nationale« Bildungsmodelle in Britisch Indien, ca. 1781-1920, in: Preisendanz, Karin/Rothermund, Dietmar (Hg.), Südasien in der »Neuzeit«. Geschichte und Gesellschaft, 1500-2000, Wien 2003, S. 90-109.

Flaubert, Gustave, Reise in den Orient. Ägypten, Nubien, Palästina, Libanon. Aus dem Französischen von Reinhold Werner und André Stoll, Frankfurt am Main 1985.

Fleischmann, Ellen, Lost in Translation. Home Economics and the Sidon Girls' School of Lebanon, c. 1924-1932, in: Social Sciences and Missions 23 (2010), S. 32-62.

FortnA, Benjamin, Education and Autobiography at the End of the Ottoman Empire, in: Die Welt des Islams 41 (2001), H. 1, S. 1-31.

Ders., Imperial Classroom. Islam, the State, and Education in the Late Ottoman Empire, Oxford 2002.

Ders., Islamic Morality in Late Ottoman »Secular Schools«, in: International Journal of Middle East Studies 32 (2000), H. 3, S. 369-393.

Foucault, Michel, Die Geburt der Klinik. Eine Archäologie des ärztlichen Blickes, Frankfurt am Main 1988.

Ders., Sexualität und Wahrheit, Bd. 1: Der Wille zum Wissen, Frankfurt am Main 1997.

Ders., Surveiller et punir. Naissance de la prison, Paris 1975.

FourNiÉ, Pierre, Le mandat à l'épreuve des passions françaises: l'affaire Sarrail (1925), in: MÉouCHY, Nadine (Hg.), France, Liban et Syrie 1918-1946. Les ambiguïtés et les dynamiques de la relation mandataire, Damaskus 2002, S. 125-168.

Ders. / Riccioli, Jean-Louis, La France et le Proche-Orient 1916-1946. Une chronique photographique de la présence française en Syrie et au Liban, en Palestine, au Hedjaz et en Cilicie, Paris 1996.

FreitaG, Ulrike, Geschichtsschreibung in Syrien 1920-1990. Zwischen Wissenschaft und Ideologie, Hamburg 1991.

Dies., Writing Arab History: The Search for a Nation, in: British Journal of Middle Eastern Studies 21 (1994), H. 1, S. 19-37.

Frèmaux, Jacques, Les empires coloniaux dans le processus de mondialisation, Paris 2002.

FREY, Marc, Indoktrination, Entwicklungspolitik und $»$ State Building«. Die Vereinigten Staaten in Südostasien 1945-1961, in: Barth, Boris/OSterhammel, Jürgen (Hg.), Zivilisierungsmissionen, Konstanz 2005, S. 335-362.

Fuchs, Eckhardt/LüTH, Christoph, Transnationale Bildungsbemühungen und die Konstruktion des Raumes in historischer Perspektive, in: Bildung und Erziehung 6, 2008, S. 1-10.

Füssel, Marian, Die Kunst der Schwachen. Zum Begriff der »Aneignung« in der Geschichtswissenschaft, in: Sozial.Geschichte 21 (2003), H. 3, S. 7-28.

Gaillard, Jean-Michel, Un siècle d'école républicaine, Paris 2000.

Gelvin, James, The Ironic Legacy of the King-Crane-Commission, in: Lesch, David W. (Hg.), The Middle East and the United States. A Historical and Political Reassessment, Boulder, Colorado 2007, S. 13-29.

Gencer, Mustafa, Bildungspolitik, Modernisierung und kulturelle Interaktion. Deutsch-türkische Beziehungen (1908-1918), Münster 2002. 
Giddens, Anthony, Die Konstitution der Gesellschaft. Grundzüge einer Theorie der Strukturierung, Frankfurt am Main/New York 1995.

Gilbert-Sleiman, Betty, Unifier l'enseignement de l'histoire dans le Liban d'après-guerre. Conditions et limites de l'élaboration de la nouvelle politique publique du manuel scolaire d'histoire 1989-2001, Diss. Aix-Marseille 2010.

Girardet, Raoul, L'idée coloniale en France de 1871 à 1962, Paris 1972.

Ghait, Ghazi M./Shabann, Kassim A., Language-in-Education Policy and Planning: The Case of Lebanon, in: Mediterranean Journal of Educational Studies 1 (1996), H. 2, S. 95-105.

Glass, Dagmar, Der Muqtataf und seine Öffentlichkeit. Aufklärung, Räsonnement und Meinungsstreit in der frühen arabischen Zeitschriftenkommunikation, Bd. II, Würzburg 2004.

Golding, Peter/Harris, Phil (Hg.): Beyond Cultural Imperialism. Globalization, Communication and the New International Order, London 1997.

GoldziHER, Ignaz, Renan als Orientalist. Gedenkrede am 27. November 1893, hg. von Friedrich Niewöhner, Zürich 2000.

Goodman, Joyce, Social Change and Secondary Schooling for Girls in the »Long 1920s«: European Engagements, in: History of Education 36 (2007), H. 4-5, S. 497-513.

Grange, Daniel, L'Italie et la Méditerranée 1896-1911: les fondements d'une politique étrangère, Bd. II, Rom 1994.

Guizot, François, Histoire de la civilisation en Europe depuis la chute de l'empire romain jusqu'à la révolution française, Paris 1871.

HäBerlein, Mark/Keese, Alexander (Hg.): Sprachgrenzen - Sprachkontakte - kulturelle Vermittler. Kommunikation zwischen Europäern und Außereuropäern (16.-20. Jahrhundert), Stuttgart 2010.

HACHEM, Victor, Antoura, de 1657 à nos jours. Une histoire du Liban, Antoura 2003.

Haddad, Adnan, Francophonie. Bilinguisme et Culture, Beirut 2002.

HadDAD, Mahmoud, Arab Religious Nationalism in the Colonial Era: Rereading Rashīd Riḍā's Ideas on the Caliphate, in: Journal of the American Oriental Society 117 (1997), H. 2, S. 253277.

Ḥallāe, Hassān, al-Mu’arrih al-'Alāma Muhammad Ğamīl Bayhūm [Der Historiker und Gelehrte Muhammad Jamil Bayhum], Beirut 1980.

HanioĞLu, M. Şükrü, Notes on the Young Turks and the Freemasons, 1875-1908, in: Middle Eastern Studies 58 (1989), H. 2, S. 186-197.

Ders., Preparation for a Revolution. The Young Turks, 1902-1908, Oxford 2001.

Ders., The Young Turks in Opposition, News York/Oxford 1995.

Hanf, Theodor, Erziehungswesen in Gesellschaft und Politik des Libanon, Bielefeld 1969.

Hanssen Jens, Fin de siècle Beirut. The Making of an Ottoman Provincial Capital, Oxford 2005.

Hardy, Georges, Une conquête morale: l'enseignement en A.O.F., Paris 2005.

Harry, Myriam, Terre d'Adonis. Au pays des Maronites et des Druses, Paris 1930.

Hartmann, Claus Peter, Die Jesuiten, München 2008.

Hausberger, Bernd, Mission: Kontinuität und Grenzen eines universalen Anspruchs, in: Ders. (Hg.), Im Zeichen des Kreuzes. Mission, Macht und Kulturtransfer seit dem Mittelalter, Wien 2004.

Hauser, Julia, Waisen gewinnen. Mission zwischen Programmatik und Praxis in der Erziehungsanstalt der Kaiserswerther Diakonissen in Beirut seit 1860, in: WerkstattGeschichte 57 (2011), S. 9-30.

Havemann, Axel, Geschichte und Geschichtsschreibung im Libanon des 19. und 20. Jahrhunderts. Formen und Funktionen des historischen Selbstverständnisses, Würzburg 2002.

Hayoun, Lina/Tselikas, Effy (Hg.), Les lycées français du soleil: Creusets cosmopolites du Maroc, de l'Algérie et de la Tunisie, Paris 2004.

Helou, Charles, Mémoires, Bd. 1: Prime Jeunesse, Beirut 2002.

Heyberger, Bernard, Barrès Maurice, in: Pouillon, François (Hg.), Dictionnaire des orientalistes de langue française, Paris 2008, S. 50-52. 
Ders., Les Européens vus par les Libanais (XVI - XIX ${ }^{\mathrm{e}}$ siècles), in: HeYBerger, Bernard/WALBINER, Carsten-Michael (Hg.), Les Européens vus par les Libanais à l'époque ottomane, Würzburg 2002, S. 1-22.

Ders., Chrétiens du monde arabe. Un archipel en terre d'islam, Paris 2003.

Ders. / VerdeIL, Chantal, Introduction, in: Dies. (Hg.), Hommes de l'entre-deux. Parcours individuels et portraits de groupe sur la frontière de la Méditerranée, Paris 2009, S. 7-20.

Dies., Sprirituality and Scholarship: The Holy Land in Jesuit Eyes (Seventeenth to Nineteenth Century), in: Heleen Murre-van den Berg (Hg.), New Faith in Ancient Lands. Western Missions in the Middle East in the Nineteenth and Early Twentieth Centuries, Leiden/Boston 2006, S. 19-41.

Hermann, Rainer, Kulturkrise und konservative Erneuerung: Muhammad Kurd 'Alī (1876-1953) und das geistige Leben in Damaskus zu Beginn des 20. Jahrhunderts, Frankfurt am Main 1990.

Herz, Martin, Disposition und Kapital. Ein Beitrag zur Bourdieu-Debatte, Wien 1996.

Hourani, Albert, Arabic Thought in the Liberal Age, 1798-1939, Cambridge 1983.

Ders. / Shehadi, Nahim (Hg.), The Lebanese and the World. A Century of Emigration, London 1992.

Jalabert, Henri, Histoire d'un siècle. Congrégation des Sœurs des Saints-Cœurs de Jésus et de Marie, Beirut 2001.

Ders., Les Institutions Scolaires Françaises au Liban, in: Corban-Mertens, Georges/CorbanMertens, Edith (Hg.), France-Liban. Revue, o.J., S. 26-29.

JALABERT, Louis, Syrie et Liban. Réussite française?, Paris 1934.

Jensen, Erik N., Body by Weimar: Athletes, Gender, and German Modernity, Oxford 2010.

Johnson, Michael, Class and Client in Beirut. The Sunni Muslim Community and the Lebanese State, London 1986.

Ders., Factional Politics in Lebanon: the Case of the Islamic Society of Benevolent Institutions (al-Maqāsid) in Beirut, in: Middle Eastern Studies 14 (1978), H. 1, S. 56-75.

JoNES, Gareth Stedman, Languages of Class. Studies in English Working Class History 1832-1982, Cambridge 1983.

Jouplain, Paul, La Question du Liban. Étude d'Histoire Diplomatique et de Droit International, Paris 1908.

Kara, Cevat, Menschlichkeit, Wohlfahrt und Gesundheit als Ideale spätosmanischer Bildung (1876-1918), in: Heimbach-Steims, Marianne/Wielandt, Rotraud (Hg.), Was ist Humanität? Interdisziplinäre und interreligiöse Perspektiven, Würzburg 2008, S. 283-299.

KasPi, André, Histoire de l'Alliance israélite universelle de 1860 à nos jours, Paris 2010.

Ders. (Hg.), Vichy et les Juifs, in: SiRIneldi, Jean-François (Hg.), Dictionnaire historique de la vie politique française au XX $\mathrm{X}^{\mathrm{e}}$ siècle, Paris 1995, S. 1243-1248.

Kassab, Elizabeth Suzanne, Contemporary Arab Thought. Cultural Critique in Comparative Perspective, New York 2010.

Kassir, Samir, Histoire de Beyrouth, Paris 2003.

Katan Bensamoun, Yvette/Chalak, Rama, Le Maghreb. De l'empire ottoman à la fin de la colonisation française, Paris 2007.

Kaufman, Asher, Henri Lammens and Syrian Nationalism, in: Beshara, Adel (Hg.), The Origins of Syrian Nationhood, London 2011, S. 108-122.

Ders., Phoenicianism: The Formation of an Identity in Lebanon in 1920, in: Middle Eastern Studies 37 (2001), H. 1, S. 173-194.

Ders., Reviving Phoenicia. The Search for Identity in Lebanon, London/New York 2004 (=Kaufman 2004a).

Ders., »Tell Us Our History«: Charles Corm, Mount Lebanon and Lebanese Nationalism, in: Middle Eastern Studies 40 (2004), H. 3, S. 1-28 (=Kaufman 2004b).

Kayali, Hasan, Arabs and Young Turks. Ottomanism, Arabism, and Islamism in the Ottoman Empire, 1908-1918, Berkeley, California 1997.

Kedouri, Elie, Young Turks, Freemasons and Jews, in: Middle Eastern Studies 7 (1971), H. 1, S. 89-104. 
Kelly, Gail Paradise, Teachers and the Transmission of State Knowledge: A Case Study of Colonial Vietnam, in: Altbach, Philip G./Arnove, Robert F./Kelly, Gail P. (Hg.), Comparative Education, New York 1982, S. 176-194.

Keryell, Jacques (Hg.), Louis Massignon. L’Hospitalité sacrée, Paris 1987.

Khalaf, Samir, Cultural Resistance. Global and Local Encounters in the Middle East, London 2001.

KHODR, Georges, Et si je disais les chemins de mon enfance. Introduction de Maxime Eggerer, Paris 1997.

Khoueiri, Joseph, Théâtre arabe. Liban, 1847-1960, Louvain-la-Neuve 1984.

Khoury, Gérard, La France et l'Orient arabe. Naissance du Liban moderne 1914-1920, Paris 1993.

Ders., Robert de Caix et Louis Massignon. Deux visions de la politique française au Levant en 1920, in: Méouchy, Nadine/Sluglett, Peter (Hg.), The British and French Mandates in Comparative Perspectives, Leiden 2004, S. 165-184.

Khoury, Philip S., Syria and the French Mandate. The Politics of Arab Nationalism 1920-1945, London 1987.

Khuri-Makdisi, Ilham, Theater and Radical Politics in Beirut, Cairo, and Alexandria 1860-1914, in: Center for Contemporary Arab Studies (Hg), Occasional Papers, Washington/D.C. 2006.

Dies., The Eastern Mediterranean and the Making of Global Radicalism, 1860-1914, Berkeley, California 2010.

Kiwan, Fadia, La perception du Grand-Liban chez les maronites dans la période du mandat, in: Shehadi, Nadim/Mills, Dana Haffar (Hg.), Lebanon: A History of Conflict and Consensus, London 1988, S. 124-148.

KLinkenberg, Michael F., Das Orientbild in der französischen Literatur und Malerei vom 17. Jahrhundert bis zum fin de siècle, Heidelberg 2009.

KoHL, Karl-Heinz, Abwehr und Verlangen. Zur Geschichte der Ethnologie, Frankfurt am Main 1987.

KoK-Escalle, Marie-Christine, Instaurer une culture par l'enseignement de l'histoire. France 1876-1912, Frankfurt am Main 1988.

Kolboom, Ingo, Francophonie: Von der kulturellen zu politischen Frankophonie, in: Ders. / KoтSCHI, Thomas / ReICHEL, Edward (Hg.), Handbuch Französisch, Berlin 2002, S. 462-468.

Konrad, Felix: Von der >Türkengefahr zu Exotismus und Orientalismus: Der Islam als Antithese Europas (1453-1914)?, in: Europäische Geschichte Online (EGO), hg. vom Institut für Europäische Geschichte (IEG), Mainz 2010. URL: http://www.ieg-ego.eu/konradf-2010-de (14.03.2012).

Koltermann, Ulrike, Päpste und Palästina. Die Nahostpolitik des Vatikans von 1942 bis 1947, Münster 2001.

Korpa, Michel, Gustave Le Bon. Hier et aujourd'hui, Chaintreaux 2011.

Kouyoumdian, Ohannès Pacha, Le Liban à la veille et au début de la grande guerre. Mémoires d'un gouverneur, Paris 2003.

KRÄMER, Gudrun, Geschichte Palästinas. Von der osmanischen Eroberung bis zur Gründung des Staates Israel, München 2003.

LaClaU, Ernesto, Emanzipation und Differenz, Wien 2002.

Lacouture, Jean/Tuéni, Ghassan/Khoury, Gérard, Un siècle pour rien. Le Moyen-Orient arabe de l'Empire ottoman à l'Empire américain, Beirut 2003.

Lammens, Henri SJ, La Syrie. Précis Historique, Premier et Deuxième Volume, Beirut 1921.

Landwehr, Achim, Die Erschaffung Venedigs. Raum, Bevölkerung, Mythos 1570-1750, Paderborn 2007.

Ders., Historische Diskursanalyse, Frankfurt am Main 2008.

Lalande, André, Vocabulaire technique et critique de la Philosophie, Paris 1962.

Lattouf, Mirna, Women, Education and Socialization in Modern Lebanon. $19^{\text {th }}$ and $20^{\text {th }}$ Centuries Social History, Lanham 2004.

Laurens, Henry, L'expédition d'Égypte 1798-1801, Paris 1997.

Ders., L'Orient arabe. Arabisme et islamisme de 1789 à 1945, Paris 2002. 
Ders., La France, l'Angleterre et les Etats-Unis dans la Méditerranée et le monde arabe, in: Relations Internationales 87 (1996), S. 277-292.

Ders., La présence française au Proche-Orient du XVII ${ }^{\mathrm{e}}$ siècle à la Première Guerre mondiale, in: Delpal, Bernard/Hours, Bernard/Prudhomme, Claude (Hg.), France - Levant. De la fin du $\mathrm{XVII}^{\mathrm{e}}$ siècle à la Première Guerre mondiale, Paris 2005, S. 9-20.

Ders., Le Liban et l'Occident. Récit d'un parcours, in: Vingtième Siècle. Revue d'Histoire 32 (1991), S. 25-32.

Ders., Orientales II. La Troisième République et l'Islam, Paris 2004.

Le Bon, Gustave, La civilisation des arabes, Paris 1884.

Le Pautremat, Pascal, La politique musulmane de la France au XX $X^{\mathrm{e}}$ siècle. De l'Hexagone aux terres d'Islam. Espoirs, réussites, échecs, Paris 2003.

LECERF, Jean, L'arabe contemporain comme langue de civilisation, in: Revue africaine 74 (1933), S. 269-295.

Ders., La littérature arabe moderne et l'enseignement de la langue en Syrie, in: Revue africaine 72 (1931), S. 111-138.

LEFÈVRE, Roger, Itinéraire d'un jeune enseignant entre trois guerres et trois continents, Paris 2004.

Lemaire, Jacques, Franc-maçonnerie et laïcité en France et en Belgique, in: Martin, Luis P. (Hg.), Les franc-maçons dans la cité. Les cultures politiques de la Franc-maçonnerie en Europe $\mathrm{XIX}^{\mathrm{e}}-\mathrm{XX}^{\mathrm{e}}$ siècles, Rennes 2000, S. 97-123.

Leroy-Beaulieu, Paul, L'Algérie et la Tunisie, Paris 1897.

LEwIS, Bernard, Islam and the West, New York 1993.

Libois, Charles SJ, La Compagnie de Jésus au »Levant«. La Province du Proche-Orient. Notices historiques, Beirut 2009.

Liegle, Ludwig, Zur Transformation von »Reformpädagogik« und utopischem Sozialismus im jüdischen Gemeinwesen Palästinas, in: Schriewer, Jürgen (Hg.), Weltkultur und kulturelle Bedeutungswelten. Zur Globalisierung von Bildungsdiskursen, Frankfurt am Main 2007, S. 117-148.

LöFfler, Roland, Anglophonie versus Frankophonie in Beirut - ein Clash of Languages?, in: Beiruter Blätter des Orient Instituts 5 (1997), S. 141-142.

Ders., Protestanten in Palästina. Religionspolitik, Sozialer Protestantismus und Mission in den deutschen evangelischen und anglikanischen Institutionen des Heiligen Landes 1917-1939, Stuttgart 2008.

Löw, Martina, Raumsoziologie, Frankfurt am Main 2001.

LoHÉAC, Lyne, Daoud Ammoun et la création de l'état libanais, Paris 1978.

LÜDTKE, Alf, Einleitung: Herrschaft als soziale Praxis, in: Ders. (Hg.), Herrschaft als soziale Praxis, Göttingen 1991, S. 9-63.

LÜSEBRINK, Hans-Jürgen, Interkulturelle Kommunikation. Interaktion, Fremdwahrnehmung, Kulturtransfer, Stuttgart/Weimar 2008.

MacKenzie, John M., Orientalism, History, Theory and the Arts, Manchester 1995.

Majstorac-Kobiljski, Aleksandra, Women Students at the American University of Beirut from the 1920s to the 1940s, in: Oknenhaug, Inger Marie/Flaskerud, Ingvild (Hg.), Gender, Religion and Change in the Middle East, Oxford/New York 2005, S. 67-84.

MaKdisi, Ussama, Artillery of Heaven. American Missionaries and the Failed Conversion of the Middle East, Ithaca/London 2008.

Ders., The Culture of Sectarianism. Community, History, and Violence in Nineteenth-Century Ottoman Lebanon, Berkeley, California 2000.

Ders., Reclaimimg the Land of the Bible: Missionaries, Secularism, and Evangelical Modernity, in: The American Historical Review 102 (1997), H. 3, S. 680-713.

Makhlouf, Georgia, Eclats de mémoire. Beyrouth - Fragments d'enfance, Beirut 2005.

Maksymiak-Fugmann, Malgorzata, Mapping Zionism. Ost und West in zionistischen Konzepten einer jüdischen Nation 1897-1914, Diss. Beer-Sheva 2009.

MaLino, Frances, L'émancipation des femmes, in: KasPi, André (Hg.), Histoire de l'Alliance israélite universelle. De 1860 à nos jours, Paris 2010, S. 263-293. 
Mann, Michael, »Touchbearers upon the path of progress«, in: Fischer-Tiné, Harald/MAnN, Michael (Hg.), Colonialism as Civilizing Mission. Cultural Ideology in British India, London 2004, S. 1-25.

Mantran, Robert (Hg.), Histoire de l'Empire ottoman, Paris 1989.

Marpeau, Benoît, Gustave Le Bon. Parcours d'un intellectuel, Paris 2000.

Martin-Fernandez, Amaya, National, Linguistic, and Religious Identity of Lebanese Maronite Christians through their Arabic Fictional Texts during the Period of the French Mandate in Lebanon, Diss. Washington/D.C. 2009.

Matthews, Roderic D./ Akrawi, Matta, Education in Arab Countries of the Near East, Washington/D.C. 1949.

Mayeur, Françoise, Histoire générale de l'enseignement et de l'éducation en France, Bd. III: De la Révolution à l'École républicaine, Paris 1981.

Dies., L'enseignement secondaire des jeunes filles sous la Troisième République, Paris 1977.

Maset, Michael, Diskurs, Macht und Geschichte: Foucaults Analysetechniken und die historische Forschung, Frankfurt am Main 2002.

Masson, Wilfried, La politique de la France à l'égard des missions catholiques et protestantes allemandes à Beyrouth 1918-1929, Magisterarbeit Lyon 1995.

Mercier, Arnaud, Efficacité du performatif dans les rituels politiques, in: Hermès 43 (2005), S. 31-37.

Meisami, Julie Scott/Starkey, Paul (Hg.), Encyclopedia of Arabic Literature, New York 1998.

Messaoudi, Alain, Lecerf Jean (Orléans, 1894 - Paris, 1980) Arabisant, in: Pouillon, François (Hg.), Dictionnaire des orientalistes de langue française, Paris 2008, S. 573-575.

Ders., The Teaching of Arabic in French Algeria and Contemporary France, in: French History 20 (2006) S. 297-317.

Ment, David M., The American Role in Education in the Middle East: Ideology and Experiment, 1920-1940, in: Paedagogica Historica 47 (2011), H. 1-2, S. 173-189.

Meyer, Michael A., Response to Modernity. A History of the Reform Movement in Judaism, Detroit 1995.

MÉouchy, Nadine, La réforme des juridictions religieuses en Syrie et au Liban (1921-1939): raisons de la puissance mandataire et raisons des communautés, in: LuIZARD, Jean-Pierre (Hg.), Le choc colonial et l'islam. Les politiques religieuses des puissances coloniales en terre d'islam, Paris 2006, S. 359-382.

Dies., La presse de Syrie et du Liban entre les deux guerres (1918-1939), in: Dupont, Anne-Laure/ Mayeur-Jaouen, Catherine (Hg.), Débats intellectuels au Moyen-Orient dans l'entre-deuxguerres, Revue des mondes musulmans et de la Méditerranée 95-98 (2002), S. 55-70.

MidDELl, Matthias, Kulturtransfer und Historische Komparatistik - Thesen zu ihrem Verhältnis, in: Comparativ 10 (2000), S. 7-41.

Miller, Susan G., Gender and the Poetics of Emancipation: The Alliance Israélite Universelle in Northern Morocco, 1890-1912, in: Brown, Carl L./Gordon, Matthew S. (Hg.), Franco-Arab Encounters. Studies in Memory of David C. Gordon, Beirut 1996, S. 229-252.

Millet, Thierry, La Franc-maçonnerie en Syrie sous l'administration française (19201946), in: Cahiers de la Méditerranée 72 (2006), URL : http://cdlm.revues.org/index1178.html (10.09.2010).

Mitchell, Timothy, Colonising Egypt, Berkeley, California 2003.

Ders., Die Welt als Ausstellung, in: Randeria, Shalini/Conrad, Sebastian (Hg.), Jenseits des Eurozentrismus. Postkoloniale Perspektiven in den Geschichts- und Kulturwissenschaften, Frankfurt am Main 2002, S. 148-176.

Möller, Esther, Clientélisme, concurrence ou coopération? Les écoles de la Mission laïque française face aux écoles israélites au Liban entre 1909 et 1943, in: BocQuET, Jérôme (Hg.), L'enseignement français en Méditerranée. Les missions et l'Alliance israélite universelle, Rennes 2010, S. 147-163.

Dies., Lehrer als Träger der Zivilisierungsmission? Die französischen Schulen im Libanon 19091943 als transnationale Bildungsräume aus der Akteursperspektive, in: Dies./WischMEYER, Johannes (Hg.), Transnationale Bildungsräume. Wissenstransfers im Schnittfeld von Kultur, Politik und Religion, Göttingen 2013, S. 171-187. 
Dies., Zwischen Zivilisierungsmission und Selbstdarstellung: Französische Schulen im Libanon und die Pariser Kolonialausstellung 1931, in: Kunkel, Sönke/Meyer, Christoph (Hg.), Aufbruch ins postkoloniale Zeitalter. Globalisierung und die außereuropäische Welt in den 1920er und 1930er Jahren, Frankfurt am Main 2012, S. 231-250.

Dies. / Wischmeyer, Johannes, Transnationale Bildungsräume - Koordinaten eines Forschungskonzepts, in: Dies. (Hg.), Transnationale Bildungsräume. Wissenstransfers im Schnittfeld von Kultur, Politik und Religion, Göttingen 2013, S. 7-20.

Mouawad, Joseph, The Image of France in Maronite Tradition, in: The Beirut Review o.J., S. 85-95.

Moulinet, Daniel, Genèse de la laïcité. À travers les textes fondamentaux de 1801 à 1959, Paris 2005.

Mounier, Pierre, Pierre Bourdieu. Une introduction, Paris 2001.

Muard, Nicolas, Notice historique sur l'origine de la nation maronite et sur ses rapports avec la France, sur la nation druze et sur les diverses populations du Mont Liban, Paris 1844.

Murre-van den Berg, Heleen, Nineteenth-Century Protestant Missions and Middle Eastern Women: an Overview, in: Oknenhaug, Inger Marie/Flaskerud, Ingvild (Hg.), Gender, Religion and Change in the Middle East, Oxford 2005, S. 103-122.

Dies., »Simply by Giving to them Macaroni...«. Anti-Roman Catholic Polemics in Early Protestant Misisons in the Middle East, 1820-1860, in: Marten, Michael/Tamcke, Martin (Hg.), Christian Witness between Continuity and New Beginnings. Modern Historical Missions to the Middle East, Berlin 2006, S. 63-80.

NaAman, Abdallah, Histoire des Orientaux en France. Du I ${ }^{\mathrm{er}}$ au XXe siècle, Paris 2000.

NaJjar, Alexandre, Pour la francophonie, Beirut 2008.

Nammour, Magda, L'image de la femme occidentale dans la presse libanaise entre 1858 et 1914, in: Heyberger, Bernard/Walbiner, Carsten-Michael (Hg.), Les Européens vus par les Libanais à l'époque ottomane, Würzburg 2002, S. 141-173.

Nantet, Jacques, Pierre Gemayel, Paris 1986.

NapolÉon Bonaparte, Campagnes d'Égypte et de Syrie, hg. von Henry Laurens, Paris 1998.

NASEREDDine, Mohamad, La littérature libanaise de langue française : de la recherche d'identité à l'expression d'angoisse, Diss. Paris 1987.

Navon, Albert H., Les 70 ans de l'École Normale Israélite Orientale (1865-1935), Paris 1935.

NipPEL, Wilfried, Griechen, Barbaren und »Wilde«. Alte Geschichte und Sozialanthropologie, Frankfurt am Main 1990.

Nolte, Claire E., The Sokol in the Czech Lands to 1914: Training for the Nation, Basingstoke 2002.

Nora, Pierre, Between Memory and History. Les Lieux de Mémoire, in: Représentations 26 (1989), S. 7-24.

Nordbruch, Götz, Nazism in Syria and Lebanon. The Ambivalence of the German Option, $1933-$ 1945, London/New York 2009.

Nordiguian, Lévon, Les petites écoles du Mont-Liban: Joseph Delore, s.j. (1873-1944), Beirut 2003.

Nouallhat, Yves-Henri, Identité européenne, identité nationale, identité régionale: rivalité ou complémentarité?, in: Wallot, Jean-Pierre (Hg.), Constructions identitaires et pratiques sociales, Ottowa 2002, S. 90-104.

Ohayon, Annick/Ottavi, Dominique/Savoye, Antoine (Hg.), L'éducation nouvelle. Histoire, présence et devenir, Bern 2007.

Osterhammel, Jürgen, Die Verwandlung der Welt, Eine Geschichte des 19. Jahrhunderts, München 2011.

Ders., Europe, the »West« and the Civilizing Mission. The 2005 Annual Lecture, London 2006.

Ders., »The Great Work of Uplifting Mankind«. Zivilisierungsmission und Moderne, in: BarTH, Boris / Osterhammel, Jürgen (Hg.), Zivilisierungsmissionen, Konstanz 2005, S. 363-425.

Ders., Transferanalyse und Vergleich im Fernverhältnis, in: KAELBLE, Hartmut/Schriewer, Jürgen (Hg.), Vergleich und Transfer. Komparatistik in den Sozial-, Geschichts- und Kulturwissenschaften, Frankfurt am Main 2003, S. 439-465. 
Ders., Transkulturell vergleichende Geschichtswissenschaft, in: HAupt, Heinz-Gerhard/KocKA, Jürgen (Hg.), Geschichte und Vergleich. Ansätze und Ergebnisse international vergleichender Geschichtsschreibung, Frankfurt am Main/New York 1996, S. 271-313.

Ders., Vorbemerkung: Westliches Wissen und die Geschichte nichteuropäischer Zivilisationen, in: Küttler, Wolfgang/Rüsen, Jörn/Schulin, Ernst (Hg.), Geschichtsdiskurs, Bd. 4: Krisenbewusstsein, Katastrophenerfahrungen und Innovationen 1880-1945, Frankfurt am Main 1997, S. 307-313.

Ders., Wissen als Macht. Deutungen interkulturellen Nichtverstehens bei Tzvetan Todorov und Edward Said, in: Osterhammel, Jürgen, Geschichtswissenschaft jenseits des Nationalstaats. Studien zu Beziehungsgeschichte und Zivilisationsvergleich, Göttingen 2001, S. 240-265.

Ouzouf, Jacques / Ouzouf, Mona, La République des instituteurs, Paris 1992, S. 134-135.

Ouzouf, Mona, L’École, l'Église et la République (1871-1914), Paris 1982.

Owen, Roger, The Middle East in the World Economy 1800-1914, London/New York 1993.

PAnZaC, Daniel, Révolution française et méditerranée musulmane. Deux siècles d'ambiguïté, in: Revue du monde musulman et de la Méditerranée 52 (1989), H. 2-3, S. 11-17.

Parker, Gabrielle, The Fifth Republic and the Francophone Project, in: Salhai, Kamal (Hg.), French in and out of France. Language Policies, Intercultural Antagonisms and Dialogue, Frankfurt am Main, 2002, S. 11-33.

Paulmann, Johannes, Internationaler Vergleich und interkultureller Transfer. Zwei Forschungsansätze zur europäischen Geschichte des 18. bis 20. Jahrhunderts, in: Historische Zeitschrift 267 (1998), S. 649-685.

Penrose, Stephen B.L., That They May Have Life: The Story of the American University of Beirut.1866-1914, Princeton, New Jersey 1941.

Picaudou, Nadine, La décennie qui ébranla le Moyen-Orient. 1914-1923, Bruxelles 1992.

Pinhas, Luc, Aux origines du discours francophone. Onésime Réclus et l'expansionnisme colonial français, in: Communication et Languages, 140 (2004), S. 69-82.

Pratt, Mary Louise, Imperial Eye. Travel Writing and Transculturation, London 1992.

Preciado, Jacques, L'œuvre de l'Alliance Israélite Universelle au Liban, Congrès de l'AIU, Paris 1960.

Prudhomme, Claude, Stratégie missionnaire du Saint-Siège sous Léon XIII (1878-1903). Centralisation romaine et défis culturels, Rom 1994.

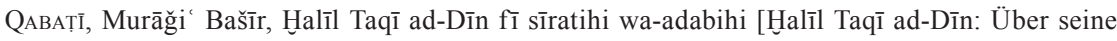
Biographie und seine Literatur], Beirut 2006.

RACY, Ali Jihad, Lebanon, in: Grove Dictionary for Music and Musicians. URL: http://www. oxfordmusiconline.com (24.10.2010).

RANCIÈRE, Jacques, Le philosophe et ses pauvres, Paris 1983.

Randeria, Shalini/Conrad, Sebastian, Geteilte Geschichte - Europa in einer postkolonialen Welt, in: Dies. (Hg.), Jenseits des Eurozentrismus. Postkoloniale Perspektiven in den Geschichts- und Kulturwissenschaften, Frankfurt/New York, 2002, S. 9-49.

RENAN, Ernest: L'Islamisme et la science, conférence donnée à la Sorbonne le 29 mars 1883, avec la réponse d'al-Afghani, Montpellier 2005.

Ders., Mission de Phénicie, Paris 1864.

Ricker, Achille/FAUCHÉr, Jean-André, Histoire de la franc-maçonnerie en France, Paris 1967.

Rietzler, Katharina, Before the Cultural Cold Wars: American Philanthropy and Cultural Diplomacy in the Interwar Years, in: Historical Research 84 (2011), H. 223, S. 148-164.

RifFIER, Jean, Les œuvres françaises en Syrie (1860-1923), Paris 2000.

Rigault, Georges, Histoire générale de l'Institut des Frères des Écoles chrétiennes, Bd. VIII, Paris 1937.

Rioux, Jean-Pierre/Sirinelli, Jean-François, Le temps des masses. Le vingtième siècle, Paris 2005 .

Ristelhueber, R., Les traditions françaises au Liban, Paris 1925. 
Rodrigue, Aron, De l'instruction à l'émancipation. Les enseignants de l'Alliance israélite universelle et les Juifs d'Orient 1860-1939, Paris 1989.

Roederer, Carl/Roederer, Paul, La Syrie et la France, Paris 1917.

Rothermund, Dietmar, Einleitung, in: Ders. (Hg.), Aneignung und Selbstbehauptung. Antworten auf die europäische Expansion, München 1999, S. 1-14.

SAAÏDIA, Oissila, Clercs catholiques et oulémas sunnites dans la première moitié du XX $\mathrm{X}^{\mathrm{e}}$ siècle. Discours croisés, Paris 2004.

ŠABĀRŪ, 'Ișām Muḥammad, Ğam īyat al-maqāṣid al-ḩayrīya al-islāmīya fī Bayrūt [Die islamische wohltätige Gesellschaft in Beirut] (1295-1421/1878-2000), Beirut 2000.

SAID, Edward W., Culture and Imperialism, London 1994.

Ders., Orientalism, New York 1979.

Ders., Out of Place. A Memoir, New York 2000.

Salhab, Nasri, La France et les Maronites, Beirut 1997.

SAlibi, Kamal, A House of Many Mansions. The History of Lebanon Reconsidered, London/New York 1988.

Ders., Beirut under the Young Turks: As Depicted in the Political Memoires of Salīm 'Alī Salām (1868-1938), in: Berque, Jacques / Chevallier, Dominique (Hg.), Les Arabes par leurs archives (XVI ${ }^{\mathrm{e}}-\mathrm{XX}^{\mathrm{e}}$ siècles), Paris 1976, S. 193-215.

Ders., The Modern History of Lebanon, New York 1965.

SAnChEZ-Summerer, Karène, Langue(s) et religion(s) en Palestine mandataire au sein d'institutions éducatives catholiques. Établissements des Frères des Écoles chrétiennes et Sœur de SaintJoseph de l'Apparition 1922-1940, in: Documents pour l'histoire du français langue étrangère ou seconde, 37 (2006), S. 93-132.

Sarasin, Philipp, Geschichtswissenschaft und Diskursanalyse, Frankfurt am Main 2003.

SARraut, Albert, Grandeur et servitude coloniales, Paris 1931.

Ders., La mise en valeur des colonies françaises, Paris 1923.

SAvoie, Philippe, Quelle histoire pour le certificat d'études?, in: Histoire de l'éducation, 85 (2000), S. $49-72$.

SBAiti, Nadya, »If the Devil taught French«. Strategies of language and learning in French mandate Beirut, in: Abi-Mershed, Osama (Hg.), Trajectories of Education in the Arab World. Legacies and Challenges, London/New York 2009, S. 59-83.

Dies., Lessons in History: Education and the Formation of National Society in Beirut, Lebanon, 1920-1960s, Diss. Washington/D.C. 2008.

SchÄBler, Birgit, Civilizing Others. Global Modernity and the Local Boundaries (French/German, Ottoman, and Arab) of Savagery, in: Dies./Stenberg, Leif (Hg.), Globalization and the Muslim World: Culture, Religion, and Modernity, Syracuse 2004, S. 3-29.

Dies., Coming to Terms with Failed Revolutions: Historiography in Syria, France and Germany, in: Middle Eastern Studies 35 (1999), S. 17-44.

Dies., Religion, Rasse und Wissenschaft. Ernest Renan im Disput mit Jamal al-Din al-Afghani, in: Themenportal Europäische Geschichte 2007. URL: http://www.europa.clio-online.de/2007/ Article $=274$ (14.03.2012).

Dies., Von »wilden Barbaren« zur »Blüte der Zivilisation«: Zur Transformation eines Konzeptes und zur Neubewertung des frühen arabischen Nationalismus, in: Rothermund, Dietmar (Hg.), Aneignung und Selbstbehauptung. Antworten auf die europäische Expansion, München 1999, S. $85-109$.

Schneider, William H., An Empire for the Masses. The French Popular Image of Africa, 1870 1900, Westport, Connecticut/London 1982.

Schriewer, Jürgen/CARuso, Marcelo, Globale Diffusionsdynamik und kontextspezifische Aneignung: Konzepte und Ansätze historischer Internationalisierungsforschung, in: Dies. (Hg.), Nationalerziehung und Universalmethode. Frühe Formen schulorganisatorischer Globalisierung, Leipzig 2005 (Comparativ 15 (2005), H. 1), S. 7-30.

Schulze, Kirsten E., The Jews of Lebanon. Between Coexistence and Conflict, Brighton 2009. 
Schumann, Christoph, Symbolische Aneignungen. Antun Sa'adas Radikalnationalismus in der Epoche des Faschismus. In: Höpp, Gerhard/Wien, Peter/Wildangel, René (Hg.), Blind für die Geschichte? Arabische Begegnungen mit dem Nationalsozialismus, Berlin 2004, S. 155-189.

Ders., Radikalnationalismus in Syrien und Libanon. Politische Sozialisation und Elitenbildung 1930-1958, Hamburg 2001.

Ders. (Hg.), Liberal Thought in the Eastern Mediterranean. Late $19^{\text {th }}$ Century until the 1960s, Leiden 2008.

Scotт, James, Weapons of the Weak. Everyday Forms of Peasant Resistance, New Haven 1987.

Sсотт, Joan Wallach, On Gender, Language and Working-Class History, in: International Labour and Working Class History 31 (1987), S. 1-13.

Seale, Patrick, The Struggle for Arab Independence. Riad el-Solh and the Makers of the Middle Modern East, Cambridge 2010.

Sedra, Paul, From Mission to Modernity. Evangelicals, Reformers and Education in NineteenthCentury Egypt, London 2011.

Sehnaoui, Nada, L'occidentalisation de la vie quotidienne à Beyrouth. 1860-1914, Beirut 1981.

Seurat, Michel, Le rôle de Lyon dans l'installation du mandat français en Syrie. Intérêts économiques et culturels, luttes d'opinion (1915-1925), in: Ders., L'État de Barbarie, Paris 1977, S. 173-224.

SiRINELLI, Jean-François, Effets d'âges et phénomènes de génération dans le milieu intellectuel français, in: Cahiers de l'Institut d'Histoire du Temps Présent (6) 1987, S. 5-48.

Sharabi, Hisham, Arab Intellectuals and the West. The Formative Years, 1875-1914, Baltimore/London 1970.

Shehadeh, Raja, Fremd in Ramallah. Mein Leben als Sohn im besetzten Palästina, Hamburg 2002.

Shorrock, William, Anti-Clericalism and French Policy in the Ottoman Empire, 1900-14, in: European Studies Review 4 (1974), H. 1, S. 33-55.

Ders., French Imperialism in the Middle East. The Failure of Policy in Syria and Lebanon 19001914, Madison, Wisconsin 1976.

Singaravélou, Pierre, Aux origines coloniales de la francophonie. Le rôle pionnier des associations et des sociétés savantes, in: Guillaume, Sylvie (Hg.), Les associations dans la francophonie, Pessac 2006, S. 63-74.

Sing, Manfred, Lässt sich der Harem Muḥammads feministisch deuten? Die Kontroverse zwischen Widād Sakākīn̄̄ und Bint aš-Šāṭī, in: Brunner, Rainer/Laut, Jens Peter/REInKowsKi, Maurus (Hg.): XXX. Deutscher Orientalistentag. Freiburg, 24.-28. September 2007, Ausgewählte Vorträge, 2009. URL: http://www.dmg-web.de/dot2007/publikation.php (15.05.2013).

Singer, Amy, Charity in Islamic Societies, Cambridge 2008.

SLIM, Souad, L'image de l'Occident chez Jurjī Zaydān, à travers son voyage en Europe (1912), in: Heyberger, Bernard/Walbiner, Carsten (Hg.), Les Européens vus par les Libanais à l'époque ottomane, Würzburg 2002, S. 209-223.

Dies., Le rôle de la franc-maçonnerie dans le développement des nouvelles idées au Levant, in: Delpal, Bernard/Hours, Bernard/Prudhomme, Claude (Hg.), France - Levant. De la fin du XVII ${ }^{\mathrm{e}}$ siècle à la Première Guerre mondiale, Paris 2005, S. 211-222.

Dies./Dupont, Anne-Laure, La vie intellectuelle des femmes à Beyrouth dans les années 1920 à travers la revue Minerva, in: Dupont, Anne-Laure/Mayeur-Jaouen, Catherine (Hg.), Débats intellectuels au Moyen-Orient dans l'entre-deux-guerres, Revue des mondes musulmans et de la Méditerranée 95-98 (2002), S. 381-406.

Sluglett, Peter, Les Mandats/The Mandates. Some Reflections on the Nature of the British Presence in Iraq (1914-1932) and the French Presence in Syria (1918-1946), in: Méouchy, Nadine/Sluglett, Peter (Hg.), The British and French Mandates in Comparative Perspective, Leiden 2004, S. 103-128.

Sмітн-Kipp, Rita, Emancipating Each Other. Dutch Colonial Missionaries' Encounter with Karo Women in Sumatra, 1900-1942, in: ClanCY-Smith, Julia/ GoudA, Frances (Hg.), Domesticating the Empire. Gender, and Family Life in French and Dutch Colonialism, Charlottesville/London 1998, S. 211-235. 
Somel, Selçuk Akşin, Christian Community Schools during the Ottoman Reform Period, in: ÖzDALGA, Elizabeth (Hg.), Late Ottoman Society. The Intellectual Legacy, London 2005, S. $254-273$.

Ders., The Modernization of Public Education in the Ottoman Empire 1839-1908. Islamization, Autocracy and Discipline, Leiden 2001.

Sommer, Dorothe, Les premières loges écossaises en Grande Syrie, in: Cahiers de la Méditerranée, 72 (2006), S. 321-330.

SONDEREGGER, Ruth, Wie emanzipatorisch ist Habitus-Forschung? Zu Rancières Kritik an Bourdieus Theorie des Habitus, in: Lithes. Zeitschrift für Literatur- und Theatersoziologie 3 (2010), H. 3, S. 18-39.

Spagnolo, John P., The Definition of a Style of Imperialism: The Internal Politics of the French Educational Investment in Ottoman Beirut, in: French Historical Studies 3 (1973), H. 4, S. $563-$ 584.

Sreberny-Mohammadi, Annabelle, The Many Cultural Faces of Imperialism, in: Golding, Peter/Harris, Phil (Hg.): Beyond Cultural Imperialism. Globalization, Communication and the New International Order, London u.a. 1997, S. 49-68.

SteinBaCH, Almut, Sprachpolitik im Britischen Empire: Herrschaftssprache und Integration in Ceylon und den Föderierten Malaiischen Staaten, München 2009.

Steinmetz, Willibald, Das Sagbare und das Machbare. Zum Wandel politischer Handlungsspielräume. England 1780-1867, Stuttgart 1993.

Stillman, Norman, The Jews of Arab Lands in Modern Times, Philadelphia/New York 1991.

SтоLDT, Jürgen, Das Scheitern einer politischen Modernisierung. Säkularisierungsinitiativen im Libanon 1920-1976, Magisterarbeit Universität Freiburg/Breisgau o.J.

Stoler, Ann Laura, Carnal Knowledge and Imperial Power. Race and the Intimate in Colonial Rule, Berkeley, California 2005.

Strohmeier, Martin, Muslim Education in the Vilayet of Beirut, 1880-1918, in: Farah, Caesar E. (Hg.), Decision Making and Change in the Ottoman Empire, Kirksville, Missouri 1993, S. $215-241$.

Suad, Joseph, Women between Nation and State in Lebanon, in: Alarcón, Norma/Kaplan, Ceren/Moallem, Minoo (Hg.), Between Woman and Nation. Nationalism, Transnational Feminisms and the State, Durham/London 1999, S. 162-181.

Suleiman, Yasir, The Arabic Language and National Identity, Edinburgh 2003.

Tamini, Azzam, The Origins of Arab Secularism, in: Tamini, Azzam/Esposito, John (Hg.), Islam and Secularism in the Middle East, New York 2000, S. 13-28.

Terral, Hervé (Hg.), L'école de la République. Une anthologie (1878-1940), Paris 1999.

Testas, Pr., La vie militante de la Bienheureuse Mère Emilie de Vialar. Fondatrice de la Congrégation des Sœurs de Saint-Joseph de l'Apparition 1797-1856, Marseille 1938.

THeIs, Laurent, François Guizot, un protestant très politique, in: Bulletin de la Société de l'Histoire du Protestantisme français 155 (2009), S. 831-840.

THÉvenin, André, La Mission laïque française à travers son histoire. 1902-2002, Paris 2002.

Ders., Pierre Deschamps. Premier missionnaire laïque, Paris o.J..

ThiESSE, Anne-Marie, Ils apprenaient la France. L'exaltation des régions dans le discours patriotique, Paris 1997.

ThoвIE, Jacques, Intérêts et impérialisme français dans l'empire ottoman (1895-1914), Paris 1977.

Ders., La Préhistoire de l'enseignement laïque français à Beryouth (1897-1909), in: ARBID, Walid/Dreyfus, Simone/Jouve, Edmond (Hg.), La Francophonie au Liban. Actes du sixième colloque international francophone du Canton de Payrac et du Pays du Quercy, Paris 1997, S. $159-197$.

Ders., Les intérêts culturels français dans l'empire ottoman finissant. L'enseignement laïque et en partenariat, Paris 2008.

Thompson, Elizabeth, Colonial Citizens. Republican Rights, Paternal Privilege, and Gender in French Syria and Lebanon, New York 2000.

Dies., Neither Conspiracy nor Hypocrisy. The Jesuits and the French Mandate in Syria and Lebanon, in: Tejirian, Eleanor H./Simon, Reeva S. (Hg.), Altruism and Imperialism: Western Cultural and Religious Missions in the Middle East, New York 2002, S. 66-87. 
Tibawi, Abdul Latif, Islamic Education. Its Traditions and Modernization into the Arab National Systems, London 1979.

Timofeev, Igor, Kamal Jumblatt et le destin tragique du Liban, Paris / Beirut 2000.

Traboulsi, Fawwaz, A History of Modern Lebanon, London 2007.

TrÉGAn, François-Xavier, Appréhensions et méthodes dans un système mandataire: le cas de la participation des états du Levant à l'exposition internationale de Paris 1931, in: MÉouchy, Nadine (Hg.), France, Syrie et Liban 1918-1946. Les ambiguïtés et les dynamiques de la relation mandataire, Damaskus 2002, S. 91-103.

Triaud, Jean-Louis, Une laïcité coloniale. L'administration française et l'islam en Afrique de l'ouest (1860-1960), in: Peyrard, Christine (Hg.), Politique, religion et laïcité, Aix-en-Provence 2009 , S. 121-143.

Trimbur, Dominique, Eugène Tisserant et le Quai d'Orsay, in: Le Cardinal Eugène Tisserant (1884-1972). Une grande figure de l'Église, une grande figure française. Actes du Colloque international organisé à Toulouse les 22 et 23 novembre 2002, Toulouse 2003, S. 215-252.

Ders., La revanche des congrégations? Politique anticléricale et présence catholique française en Palestine au début du XX $\mathrm{X}^{\mathrm{e}}$ siècle, in: Luizard, Jean-Pierre ( $\mathrm{Hg}$.), Le choc colonial et l'islam. Les politiques religieuses des puissances coloniales en terre d'islam, Paris 2006, S. 121-135.

Tschurenev, Jana, Imperial Experiments in Education: Monitorial Schooling in India, 1789-1835, Diss. Berlin 2008.

Dies., Incorporation and Differentiation: Popular Education and the Imperial Civilizing Mission in the Early Nineteenth Century India, in: Watt, Carey/Mann, Michael (Hg.), Civilizing Missions in Colonial and Postcolonial South Asia. From Improvement to Development, London 2011, S. 93-124.

TuÉNI, Ghassan, Le livre de l'indépendance, Beirut 2002.

VAn LeEuw, Michel, Emile Eddé. Biographie politique, Aux sources de la république 1884-1949, Beirut o.J. (Manuskript).

VARISCO, Daniel Martin, Reading Orientalism. Said and the Unsaid, Seattle 2007.

Verdeil, Chantal, Les écoles d'Orient. Le réseau scolaire congrégationiste (1880-1914), in: DeLPal, Bernard/Hours, Bernard/Prudhomme, Claude (Hg.), France - Levant. De la fin du XVII siècle à la Première Guerre mondiale, Paris 2005, S. 145-166.

Dies., La Mission jésuite du Mont-Liban et de Syrie (1830-1864), Paris 2011.

Dies., Les jésuites de Syrie (1830-1864): une mission auprès des chrétiens d'Orient au début des réformes ottomanes, Diss. Paris 2003.

Dies., Un établissement catholique dans la société pluriconfessionnelle de la fin de l'Empire ottoman: l'université Saint Joseph de Beyrouth, in: Dupont, Anne-Laure (Hg.), Islam et éducation au temps des réformes modernes. Systèmes scolaires et enjeux de l'enseignement au ProcheOrient et en Afrique du Nord aux XIX ${ }^{\mathrm{e}}$ et XX $\mathrm{XX}^{\mathrm{e}}$ siècles, Paris 2007, S. 28-38 (Cahiers de la Méditerranée 75).

Vermeeren, Pierre, La formation des élites marocaines et tunisiennes. Des nationalistes aux islamistes, 1920-2000, Paris 2002.

Verney, Noel/Dambmann, George, Les Puissances étrangères dans le Levant, en Syrie et en Palestine. Influences politiques et économiques, Finances, Travaux Publics, Industrie et Agriculture, Commerce et Navigation, Paris/Lyon 1900.

Volllaume, René, Charles de Foucault et ses premiers disciples. Du désert arabe au monde des cités, Paris 1998.

Vovelle, Michel, La Marseillaise. La guerre ou la paix, in: Nora, Pierre: Lieux de mémoire, Bd. I, Paris 1997, S. 107-151.

Watenpaugh, Heghnar Zeitlian, Museums and the Construction of National History in Syria and Lebanon, in: Méouchy, Nadine/Sluglett, Peter (Hg.), The British and French Mandates in Comparative Perspectives, Leiden 2004, S. 185-202.

Watenpaugh, Keith David, Being Modern in the Middle East. Revolution, Nationalism, Colonialism and the Arab Middle Class, Princeton 2006. 
Weber, Eugen, Peasants into Frenchmen. The Modernization of Rural France 1870-1914, Stanford, California 2007.

Wegmann, Louise, Les écoles au Liban, in: Le Monde non-chrétien 3 (1947), S. 287-299.

Weil, Patrick, Le statut des musulmans en Algérie coloniale. Une nationalité française dénaturée, in: La Documentation française (Hg.), La Justice en Algérie 1830-1962, Paris 2005, S. 95-109.

Weinrich, Ines, Fayruz und die Brüder Rahbani. Musik, Moderne und Nation im Libanon, Würzburg 2006.

Werner, Michael/Zimmermann, Bénédicte, Vergleich, Transfer, Verflechtung. Der Ansatz der Histoire croisée und die Herausforderung des Transnationalen, in: Geschichte und Gesellschaft 28 (2002), S. 607-636.

White, Benjamin, Rhetorical Hierarchies in France and Syria during the Mandate, in: Chronos. Revue d'Histoire de l'Université de Balamand, 17 (2008), S. 105-121.

Ders., The Emergence of Minorities in the Middle East. The Politics of Community in French Mandate Syria, Edinburgh 2011.

White, Bob W., Talk About School: Education and the Colonial Project in French and British Africa (1860-1960), in: Comparative Education 32 (1996), H. 1, S. 9-25.

WielandT, Rotraud, Das Bild der Europäer in der modernen arabischen Erzähl- und Theaterliteratur, Wiesbaden 1980.

Wien, Peter, Who is »liberal« in 1930s Iraq? Education as a Contested Terrain in a Nascent Public Sphere, in: Schumann, Christoph (Hg.): Nationalism and Liberal Thought in the Arab East. Ideology and Practice, New York 2010, S. 31-46.

Winock, Michel, Jeanne d'Arc, in: Nora, Pierre (Hg.), Les lieux de mémoire, Bd. III: Les France, Paris 1992, S. 675-733.

Winock, Michel, Le siècle des intellectuels, Paris 1999.

Womack, Deanna Ferree, Lubnani, Libanais, Lebanese: Missionary Education, Language Policy and Identity Formation in Modern Lebanon, in: Studies in World Christianity 18 (2012), H. 1, S. 4-20.

YARED, Nazik Saba, Arab Travellers and Western Civilization, London 1996.

Dies., Secularism and the Arab World (1850-1939), London 2002.

Young, Robert C., Postcolonialism. An Historical Introduction, Oxford 2010.

ZACHS, Fruma, The Making of a Syrian identity. Intellectuals and Merchants in Nineteenth Century Beirut, Leiden/Boston 2005.

ZAmir, Meir, An Intimate Alliance: The Joint Struggle of General Edward Spears and Riad alSulh to Oust France from Lebanon, 1942-1944, in: Middle Eastern Studies 41 (2005), H. 6, S. 811-832.

Ders., Lebanon's Quest. The Road to Statehood 1926-1939, London/New York 2000.

Ders., The Formation of Modern Lebanon, London 1985.

ZEIFA, Hayma, Les élites techniques locales durant le mandat français en Syrie (1920-1945), in: Méouchy, Nadine/Sluglett, Peter (Hg.), The British and French Mandates in Comparative Perspectives, Leiden 2004, S. 497-518.

ZISSER, Eyal, Lebanon. The Challenge of Independence, London/New York 2000. 


\section{Register $^{1}$}

\section{Ortsregister}

Ägypten 18, 20, 22, 25f., 35, 37, 52f., $73,76,77,85,86,87,105,120,154$, 154, 161, 170, 172, 226, 259, 288, 318,323

Algerien 31, 34, 44, 53, 60, 62, 76, 170, 178, 198, 288, 376, 395

Ayntoura 18f.

Bilādaš-Šām ～23, 73, 105, 127, 137, 178

Deutschland 24, 53f., 66, 132, 324, $329,336,340,344,380$

Elsass 21, 215

Großbritannien 25f., 31, 37, 52f., 105, 110, 133, 136, 138f., 177, 236, 290, 295, 324f., 329, 335, 340, 380

Indochina $\quad 34,288$

Irak 26, 125, 136, 141, 179, 217, 229, 290,323

Italien $\quad 25,281,324,329,333 f ., 336$

Jordanien 136

Konstantinopel $\quad 87,106,108,122,132$

Libanongebirge (Gabal Lubnan) 14, 18, 105f., 108f., 114, 121, 128f., 250, 305,341

Lyon 105, 338, 369, 373

Madagaskar 76, 87

Marokko 22, 76, 139, 169-172, 280
Marseille $\quad 101,373$

Naher Osten 19f., 34, 89, 99, 102, 108, 297, 299, 301, 333, 368, 373, $375,380,385$

Nordafrika $19,22,87,102,146,169$, $171,207,219,373-375,395$

Osmanisches Reich 14, 22f., 28, 32, 35, 49, 86, 93-134, 140, 151, 161, 235, 261f., 288, 304, 329, 359, 386

Palästina 19-21, 26, 34, 37, 127, 136, 141, 179, 217, 242, 297, 323, 360, 366

Saida $14,129,252$

Syrien 18, 21f., 25, 34f., 76, 78, 81f., $86,87,104,114,120,125,130,136$, $149,150,154,165,170,186,200$, 211, 216-219, 227, 240, 262f., 266, 268, 275, 290, 291, 323-328, 331, 333-335, 353, 374f., 377, 383, 395

Tanail 187, 245

Thessaloniki 22, 70, 76, 86, 96, 110f., 121, 172

Tripoli $14,114,353,363$

Tunesien $\quad 60,76,80,87,172,178,257$

Türkei 172

Vereinigte Staaten von Amerika 30, 136f., 296, 392

Zahlé 71, 116, 204

1 Orte und Personen wurden in der Regel erst ab zweifacher Nennung aufgenommen. Die Begriffe Zivilisierungsmission, Frankreich, Libanon, Paris und Beirut, welche auf fast jeder Seite auftauchen, sind nicht mit aufgenommen worden. 


\section{Personenregister}

Abdülhamid II. $\quad$ 109, $125 f$.

Al-'Azm, Sadiq Jalal 38

Al-Ǧisr, Muhammad 211, 239, 359

Al-Hachem, Aziz (arabisch 'Azīz alHāšim) 353f.

Al-Khuri, Bishara (arabisch Bišāra alHuūrī) 199, 219, 276, 305, 324f., 353, 363, 379

An-Naqqāš, Zakī 260, 264

Aql, Said (arabisch Sa'̄id 'Aql) 199, 210,368

Arslān, Amīr Amīn $\quad$ 238, 240f., 335

As-Sulh, 'Imād 353f.

As-Sulh, Kāẓim 240, 353f.

As-Sulh, Riad (arabischRiyād aṣȘulḥ) 240, 293, 300, 324, 352-354

As-Sulh, Taqi ad-Din (arabisch Taq̄i ad-Dīn aṣ-Sulḥ) 185, 196, 205, 240, 258, 260, 272, 313, 353f., 379

Attieh, Georges 164,345

Baden-Powell, Robert 297, 356f.

Barrès, Maurice 13, 100f., 192, 272

Bayhum, 'Abdallāh 239, 330

Bayhum, Muhammad Ğamīl 238, 262, 272, 352, 356

Besnard, Edmond 70, 142f., 148, 168, 207, 235f., 271, 282, 285, 291, $319,335,344,347,352,356,361$

Bhabha, Homi 38, 321

Bianquis, Philippe $83,303,333$

Bounoure, Gabriel 223, 266, 272, 289f., 292, 317, 335f., 340, 355

Bourdieu, Pierre 15, 44, 156, 179f., 304, 381

Bruneau, André 55

Bustānī, Fu'ād 260, 370, 371

Catroux, Georges 324

Cattin, Père $131,305,308$
Chanteur,Claudius $\quad$ 164-166,202,308

Cheikho, Louis (arabisch Luwīs Šayhū) 111, 207, 370

Chevalley 151-155,160,163f., 167,170

Chiha, Michel (arabisch Mīšāl Šīhāa) 137, 166, 348, 377, 379

Corm, Charles $\quad 185,193,272,356$

Da'uq, Umar (arabisch 'Umar Dā'ūq) 116f., 127, 159, 224, 306, 317-321, 347-379

De Bonneville, Christophe 369

De Caix, Robert 101, 144, 166, 289

De Certeau, Michel 44f.

De Jouvenel, Henri 217, 222

De Lamartine, Alphonse 98f., 101, 193, 301

De Martel, Damien 266, 323, 337, 350,354

Delore, Joseph $\quad 18,341 \mathrm{f}$.

Dentz, Henri 324,344

Deschamps, Pierre 21f., 68, 76, 80, 87, 107f., 111, 113, 115, 117, 121, 128, 131f., 142-144, 154, 157, 168, $170,234,311,314$

Digrado, Marie 77, 120, 253

Drach, Jules 163f., 170

Dupouey 117, 127, 131

Duthoit, Francis 164f., 223, 268

Eddé, Emile (arabisch Imīl Iddah) $137,219,276,325$

Fakhuri, Muhammad (arabisch Muḥammad Fahūīī) 118, 239

Farhi, Joseph 239, 249

Farrūh,'Umar 260, 264

Faysal (arabisch Fayșal) 137, 143

Ferry, Jules 53, 66, 75

Flaubert, Gustave 98, 101 
Foucault, Michel 42, 94

Gemayel, Pierre 357

Ghanem, Choukri (arabisch Šukrī Ġānim) 137

Gouraud, Henri 138, 142-144, 169171, 181, 205

Grandjouan, Jacques 76, 81, 172f., 327, 330, 337f., 340, 347, 356f., 361, 379

Guizot, François $\quad 61,102$

Helleu, Jean 324

Helou, Charles $185,370,376$

Herriot, Édouard 216, 221, 338, 343, 354

Hugo, Victor 74, 190f., 196

Ḥusayn, Ṭāhā 208, 226, 367

Jalabert, Louis $\quad 47,72,173,178,223$, 254, 280-282, 289, 333, 337, 339, 349,364

Jeanne d'Arc 191

Jeantry $164,182,197$

Jouplain, Paul (arabisch Būlus Nuğaīm) 104, 262

Jousselin, Jean 303

Kfoury, Assaf Bey (arabisch 'Assāf Bey Kfūrī) 71, 80

Kfoury, Georges (arabisch Ğūrğ Kfūrī) 71, 204f., 208, 212, 298

Kurd 'Alī, Muhammad 114,208,268f.

La Fontaine, Jean $\quad 190,192$

Lammens, Henri 178, 263, 267-269

Latrouite, René 76, 327f., 345

Le Bon, Gustave 55,178

Lecerf, Jean $\quad 89,200,204,207,212$

Lehéricy, Paul Jean 187, 228

Leroy-Beaulieu, Paul 178f.

Lévy, Lucie 71, 77, 254
Lyautey, Hubert 169-171, 280, 282, 289

Marx, Jean $319,337,344$

Massignon, Louis 179, 242, 243, 368

Mathieu, Émile 70, 76, 143, 148, 173, 187, 201, 204f., 219, 228, 231, 235-237, 304

Molière 190, 192

Montessori, Maria 297

Mundir, Ibrāhīm 210, 212, 231

Musriq, Faris (arabisch Fāris Mušriq) $\quad 115,117,238$

Naccache, Alfred (arabisch anNaqqāš) 359

Naccache, Georges (arabisch anNaqqāš) 379

Nahla, Rafā'îl ２08, 259

Napoleon Bonaparte $52 \mathrm{f}$.

Parisot, Jean 227, 242, 373

Penso,Émile 59,162, 171,312,343,365

Penso, Esther 340,360

Picot, Georges $136,138,144$

Ponsot, Henri $\quad 217,223,291,317,325$

Puaux, Gabriel 324

Racine, Jean 190,366

Renan, Ernest $\quad 66,99-101,178$

Riachy, Habib (arabisch Habīb arRiyāšī) 205, 208

Rousseau, Jean-Jacques 191, 242

Ruche, Lucien 64, 76, 81, 87, 159, $172,210,219,228,230,234,236$, 241f., 252-254, 257, 271, 286, 293, 297, 299f., 305, 311, 320, 327, 329f., $340,347,355$

Rustum, Asad 208, 260

Said, Edward $\quad 36-38,90,98 f ., 172$

Salām, Salīm 'Alī 109, 259 
Sarloutte, Ernest $\quad 305,341,344,362 \mathrm{f}$.

Sarrail, Maurice $\quad$ 216f., 221f., $232 \mathrm{f}$.

Sarraut, Albert 54, 57, 66, 290

Saule, Marie 152-154, 167f.

Sautier, Père $350 f$.

Sayegh, Salma (arabisch Salma Șāyig̀) 208, 258f., 378

Sidi, Maurice $60,145,233$

Soubret, Édouard 238, 286

Spears, Edward 335

Sursuq, Alfred (arabisch Șurșuq)

115, 117f., 262

Taqi ad-Din, Khalil (arabisch Halīl Taqī ad-Dīn) 158, 195, 205, 208, 225-227, 272, 310, 313, 330f.
Tuéni, Gibran (arabisch Ğibrān Tuwaynī) 225, 229, 238f., 245

Vandenberg, Charles 222, 292

Vayssié, Georges 236, 352

Voltaire 191, 193

Wegmann, Louise 253, 306, 329, 360

Weygand, Maxime 55, 103, 143f., $165,216,233,266$

Zaydān, Ğūrğ̄̄ 114, 199

Zayn ad-Din, Nazira (arabisch Naz̄ira Zayn ad-Dīn) 257f., 378

\section{Sachregister}

Agency 246, 355, 361

Akteur 40, 45, 51, 69-91, 95, 278

Alliance française 282,292

Alliance israélite universelle 22, 47, 58-60, 64, 68, 74, 78, 83-87, 89, 94, 97f., 105, 111, 113f., 129f., 132f., 141, 145f., 153, 161, 168, 171, 183, 186, 192f., 201, 213, 233, 252f., 255, 268, 282, 285, 287, 298, 309, 311f., 314, 320 , 332, 340, 343, 352, 360, 363365, 381f., 387, 389, $391 \mathrm{f}$.

Aneignung 28, 40f., 45, 159, 388

Barbaren 191, 293, 379

Collège protestant français $21,47 \mathrm{f}$, 59, 63, 73, 77, 83f., 88, 94, 192, 233, 248f., 252f., 282, 299, 306, 310, 312, $332,349,352,359,363,372,381$, 392

Curriculum 117, 125, 151, 160, 162, 168, 190, 252, 263, 299, 364-370, $391,393 f$.
- französisches Curriculum 168, 350

Dekolonisation/Dekolonisierung 328, 382

Diplomatie 103, 124, 323, 340, 393

Diskurs 16, 29, 32f., 42-45, 49, 51, 94-104, 135, 141-150, 175, 187, 220f., 227, 231, 339, 386f., 391f.

Distinktion 44, 49, 179

- Soziale Distinktion 177, 180f., 185, 197f., 212, 243, 250, 253, $276,287,301,306,371,388$

Disziplin 130, 205, 230, 245, $361 f$.

Ehemaligennetzwerke 44, 47, 158, 225f., 276, 303-315, 348, 362, 373f., 389

Elite 31f., 35, 44, 91, 161, 163, 171, 179, 185f., 205, 231, 237, 243, 276f., 295, 302, 304, 306, 308f., 354, 378, $385,388,393,395$ 
Eltern 47, 109, 129f., 224, 272, 344f., 347, 350-352, 360f., 371, 375

- Elterninteressen 109, 121, 160, 182, 184, 197f., 201, 224, 235, 247, 250, 295, 371

- ökonomische Motive 234f., 304f., 308, 318f., 346f., 386, 389

- politische Motive 234, 304, 346, 386

- religiöse Motive 304,386,389

- soziale Motive 234f., 237, 240, 250, 304, 386, 389

Emigration/Exil 311, 352, 367, 376, 394

Entangled Histories 38f., 41

Entsendung von Lehrern 315-321, 329

- Französischlehrer 126,303,315321

Entwurzelung 242f., 314

Erster Weltkrieg 18, 21, 25, 34, 56, 62, 84, 127, 132f., 136, 145, 147, 153, 156, 162, 168f., 183f., 198, 250, 261, $333,355,376$

Faschismus 281, 300, 333

Filles de la Charité $\quad 20,46 f$., 63, 72, 78, $82,86,184,266,279,312,332,393$

Film 277, 291, 296

Foyer franco-libanais 374

Frankophilie 236, 238f., 284, 313, 329, 352, 359, 374, 379

Franko-libanesischer Vertrag 281, 289, 296, 323-326, 340f., 348, 353, $363,366,380$

Franko-syrischer Vertrag 281, 291, $323,331,353,363$

Frankreich

- Antiklerikale Gesetze 19, 65f., 75, 77, 93, 97, 106, 280, 386

- Antiklerikalismus 17, 21, 54, 93, 96, 223, 262, 284, 337, 387
- Bildungssystem 65f., 68, 75, 88, 188f., 231, 254, 269, 381

- Schulen

- Dominanz der katholischen Schulen 65

- École unique 216

- Enseignement primaire supérieur 162

- Grundschule 66,75-78, $161,166,216$

- Grundschullehrer 162, 286, 317

- Sekundarschule 77, 161, 165f., 216

- Abschlüsse

- Abitur 75f., 162f., 167, 198, 216, 247

- Brevet supérieur 76

- Universitäten

- Agrégation 76,317

- Licence 76

- Bildungspolitik

- Auswärtige Bildungspolitik $17,65,328$

- Kritik an kolonialer Bildungspolitik 21, 28, 94

- Koloniale Bildungspolitik 21, 29, 67f., 76, 94, 146, 169-175, 219, 270

- Dritte Republik 19, 21, 30, 5156, 64f., 75, 90, 95, 102, 146, $151,162,183,187,234,257,294$, 386

- französische Nation 194

- französische Parteien

- Cartel des Gauches 215

- Front Populaire $323 \mathrm{f}$.

- Parti Radical 220

- französische Regierung 26, 42, 47, 52, 54f., 57, 65f., 105f., 133, 179, 197, 215, 220f., 277f., 286, 291-294, 315f., 318, 323, 329, 
335f., 347, 350, 371, 373-375, 379, 390f.

- Französische Revolution 52, 54, 56, 110, 179, 196

- französische Staatsangehörigkeit 71-74, 133, 203, 286, 302, 349

- französischer Staat 30, 35, 54

- Französisches Außenministerium 15, 26, 54, 66, 95, 107, 112, 116f., 128, 142f., 156, 225, 227 , $289,315,321,333,337,344,352$

- Service des Euvres françaises à l'Étranger 23, 46, 107, 315, 319, 337f., 347

- Französisches Bildungsministerium 15, 46, 163, 316f., 375

- Académie de Paris 73, 149, 375

- französischesParlament $\quad 324,338$

- Islampolitik 102, 170f., 179, 374

- Klerikalismus 16, 54, 93, 324, 387

- Kolonialpolitik 16, 24, 183,290, 385

- Kulturpolitik 65

- auswärtige Kulturpolitik 16, 27f., 65, 291f., 294, 387

- Propaganda 291f., 295, 333, 336

- Militär 67, 100, 105, 136, 146, 148, 162, 169, 295, 297, 300, 323325, 335, 343f., 360, 380, 392

- Militärdienst 85, 132, 296, 329

- Monarchismus/Monarchisten 54, 284

- Patriotismus 296, 334, 342-344, 359f., 362

- Republikanismus/Republikaner 17, 54, 65f., 149, 162, 193, 215, 227, 252, 269, 284, 309

- Sprachpolitik $178 f$.
- Verhältnis von Kirche und Staat 23, 61f., 66, 75, 114, 148, 284, 333f., 385

- Wirtschaft 105, 277, 324, 373f.

Französische Schulen im Libanon

- Finanzielle Ausstattung 115, 240, 253, 275, 311

- Französische katholische Schulen allgemein $58,67,72,77,86,94$, 96f., 100f., 105, 113f., 118, 130, 132, 141, 144f., 151, 161, 182, 186-188, 190-192, 198, 201, 206, 213, 222f., 227, 232f., 242, 266, 269f., 282, 291, 297f., 304, 306, 310, 312, 314, 329, 332f., 336, 339, 346f., 349, 352, 359, 362, 364, 366f., 371, 373, 386-388, 390f.

- französische katholische Mädchenschulen 203, 248f., $253 \mathrm{f}$.

- Kritik an katholischen Schulen 222

- Französische Schulen allgemein 140, 152, 189, 215, 222, 269, 350,394

- Konkurrenz der Schulen untereinander 20, 93, 114, 159 (aller Schulen), 233, 292, 317, 320f., 370, 382, 393

Friedenskonferenz von Paris 137

Histoire Croisée 39

Historische Diskursanalyse 42f. Hygiene 130

Identität 40, 54, 69, 89, 177, 180f., 185f., 194, 197f., 201, 206, 212, 231, 242, 261f., 284, 292, 388, 395

- nationale Identität 169,181 , 206, 231, 242, 298, 327, 390

- religiöse Identität 14,312f., 388, 391 
Imperialismus $13,25,66,102,317$, $328-345,358,387$

Industrie 102,122

Intellektuelle 194-196，201，207209, 225, 231, 234, 250, 261f., 284, $337,353,370$

Internat $253,360,373$

Jesuiten 18f., 46f., 58, 63, 66, 72, 81, 101, 105, 111, 122f., 130f., 144f., 156, $158,164,166,174,185-187,190,193$, 198, 201, 207f., 224, 227, 232, 244f., 254f., 261, 263, 270, 272, 282-284, 289, 294, 296, 302, 305, 312, 314, 326, $328,332,334,336-338,341,343,346$, $349,351,357-359,361,363,367,369$, 371, 379, 381f., 385, 388, 390f., 393

- Beziehungen zur Dritten Französischen Republik 19, 62, 294, 337

- Collège Notre Dame de Jamhour 13,47

- Kritik an Jesuiten 209, 294, 338, 351,361

- Schule der Jesuiten in Beirut 185, 202, 205f., 271, 308, 370, 376,385

King-Crane-Kommission 136

Kino 291, 295, 302

Klientel 28, 45, 126, 130, 148, 151, $155,160,163,180,210,212,224$, $228,230,261,269,271,309,312$, 345f., 359f., 371, 386-388, 391

- arme Bevölkerungsschichten $20,180,308,382,388,393,395$

- christliche Klientel 181, 198, 212, 312, 346

- muslimische Klientel 181, 212, 224, 230, 251, 253, 346f., 349

- reiche Bevölkerungsschichten 20, 129, 180, 252f., 287, 301, 308f., 346, 380, 382, 393, 395
Klientelismus 217, 307-309

Kolonialismus 23, 31, 38-41, 247, 277, 292, 321, 338, 344, 393

- Französische Kolonien 26, 34, 49, 53, 55, 66, 71, 76, 101, 108, 170, 181f., 189, 193f., 196, 230, $257,270,275,277-279,284,286$, 288-290, 337, 344, 374, 376, 382, 387,395

- Antikolonialismus 67, 175, 294f., 374, 385

- Kolonialausstellung 275 , 277-291, 387

- Parti colonial 101,177f., 290, 324, 337

- Protektorat 172

- Koloniale Bildung 32, 41, 44, $94,121,147,160,243,319$

- Kolonialkritik 196, 280, 286, 288, 294

Kommunismus $147,286,288$, $344 f$.

Konferenz von San Remo 138

Konfessionelles System im Libanon $23,219,348$

Krankenhäuser $\quad 20,81,139$

Kreuzzüge 144, 264, 267, 271

Kultur 39, 340f.

- französische Kultur 30, 56f., 164f., 178, 194, 297, 314, 337, 340, 372, 388, 390, 394

- westliche Kultur 58, 194, 367

- tafarnūğ 194

- Kulturimperialismus 33

- indigene Kultur 21, 32, 68, 74, 78-84, 182, 194, 367f.

- Transfer/Kulturtransfer 21, 31, 39-41, 45, 65, 69, 93f., 135, 167, 169-175, 187, 230, 303, 312, 377, 387, 389

- Vermittler/Cultural Broker 26, 40f., 97, 159, 234 
Lazaristen 18-20, 46f., 63, 67, 72, 81f., 97, 130, 279, 339, 373, 393

- Collège Saint-Joseph Ayntoura 47f., 82, 86, 99, 233, 305f., 311, 333, 341, 348, 358, 362f., 366, 373

Lehrer 27f., 32, 46, 51, 64, 66, 6991, 130, 161, 173, 237, 257, 286, 296, 332, 344, 376, 381f., 390

- Arabische Lehrer 69-91, 167f., 197, 204, 206, 235, 243-246, 279 , 286f., 332

- Arabischlehrer 188, 197, 204206, 230, 241, 258, 330, 354, 365, 370

- Französische Lehrer 69-91, 132, 171, 257, 286, 349

- Eheschließung 70,86f.

- Französischlehrer 330

- Lehrerausbildung 75-79, 167f., 234, 239, 245f., 257

- École Jules Ferry 75

- Écolenormale israélite orientale 74,78

- Lehrerausbildung der katholischen Orden 77

- Lehrergehälter $80,88 \mathrm{f} ., 153 \mathrm{f}$., 172,244

- Lehrerkollegien 27, 188,207, 245

- Lehrerseminar der Mission laïque française $245 \mathrm{f}$.

- Lehrerseminar/Normalschulen im Libanon 167f., 207, 239, 245,383

- Lehrerseminare der Jesuiten 245

- Lehrerseminare/Normalschulen in Frankreich 70, 75f., 253

- Mobilität 171

Libanon

- Libanesischer Staat 15, 28, 215,
246, 261f., 308, 323, 326, 345, $348,353,362-364$

- Staatsgründung 26, 138

- Verfassung 217, 263, 276, 325

- Wahlen 218,324

- libanesische Nation 292,346, 362

- Libanesische Regierung 47, 139, 218, 276, 306, 308

- Bildungsministerium 139, 167, 198, 241, 245, 263, 351

- Libanesisches Schulsystem 363, 385, 392, 394

- Libanesische Schulabschlüsse 151, 160-169, 372

- Abitur 254, 267, 285

- französisches Abitur 127, 161-164, 166, 203, 216, $241,330,364,375$

- libanesisches Abitur 164 167, 241, 362, 367

- syrisches Abitur 164f., 364

- Brevet 78, 161

- Certificat d'études primaires 161

- Certificat libanais 365

- Libanesische Prüfungen 190, 192f., 198, 209, 267, 330, 362

- Nationalpakt 353, 366

- Parteien im Libanon 325, 379, 325f., 353

- Al-Najjada (arabisch anNağāda) 327, 351, 357

- Kata'ib/Phalanges libanaises 326f., 351, 357-359, 369

- Politik im Libanon 275f., 306, 308, 324f., 327, 355, 379f., 395

- Politiker 166, 173, 210f., 234, 239, 305, 359, 372, 376, 378

- Presse/Zeitung im Libanon 71, 119-121, 149, 155, 166, 174, 
204f., 210f., 217, 225, 228, 239, 247, 258f., 346, 349, 351, 356f., 376, 378f., 394f.

- Al-Ahrār 225, 238, 356

- al-Aḥwāl 155

- An-Nahār 229, 238, 255, 356

- An-Nidā $334,355,379$

- L'Orient 174, 194, 199, 232, 300,379

- La Syrie 236, 352

- Le Jour 379

- Lisān al-Hāl 155

- Private ausländische nicht-französische Schulen $114,123,125$, $128,131,155,162,168,243,245$, 328-346, 394

- Amerikanische Schulen 24, 35, 129f., 252, 293, 329, 331f., 334, 392-395

- Britische Schulen 24, 35, 48, 129f., 329, 334

- Deutsche Schulen 24, 129, 329, 334f.

- Italienische Schulen 24, 129, 329,334

- Russische Schulen 24, 129

- Private lokale Schulen 114, 123, 126, 151, 154f., 162, 168, 241, 243, 245, 286, 315-321, 366, 381, 383, 394, 61

- christliche Schulen 125, 264, 382

- griechisch-orthodoxe Schulen 140,153

- Madrasat zahrat al-iḥsān 254, 316

- jüdische Schulen 129, 316, $319 f$.

- maronitischeSchulen 140,152

- Madrasat al-hikma (Collège de la Sagesse) 316, 350f., 358
- muslimische Schulen 140, 152f., 317, 321, 347, 382

- Kullīya 'utmānīya $126 f$.

- Madrasat al-'ulamā' 316318

- Maqasid (arabisch Maqāṣid) 48, 116, 118, 127, 224, 239, 248, 264f., 317f., 320

- säkulare Schulen

- Collège universel Aley 298, 316f.

- Madrasat al-ahlīya 232, 254, 286, 316

- Staatliche Schulen 123, 125f., 140, 154, 167, 197, 235, 241, 276, 316, 390, 394

- Stadtrat von Beirut 237

- Rolle der Geschlechter 246f., 250-253, 255, 257-259, 288, 302f., 310f., 356, 372, 378, 386

- Feminismus 257-260

- Kopftuch 247, 257, 259

Macht 33, 36f., 42f., 49, 94, 108, 180, 212, 277, 290, 319, 321, 386, 389, 392 Mandat

- Armee/Militär 136, 139, 155,217, 323, 363, 376, 380

- Bankwesen 166, 223, 374

- Bildungsbeauftragter des Hochkommissariats 46, 139, 151, 160f., 164, 223, 292, 345

- Boykott gegen Mandatspolitik 240, 275

- britisches Völkerbundmandat 26, 138, 179, 261, 263, 290

- Bildungspolitik in den britischen Mandaten 141

- Französisches Hochkommissariat 15, 64, 80, 103, 140-142, 145f., 150, 181f., 185, 189f., 197, 207, $225,230,232,236,244,258$, 
262-264, 267f., 284, 308, 315, $318,321,323,333,337,339,343$, 353, 379

- Beziehungen zur katholischen Kirche 154f., 167, 216, 221, 263, 280, 291, 294

- Kritik am Hochkommissariat 232-234, 326

- französisches Völkerbundmandat 23, 25, 30, 34f., 55, 86, 138, $140,167,261,263,278,291,324$, 330

- Kritik am Völkerbundmandat 26, 104, 138, 196, 215-218, 220, 225, 230, 237-240, 262, 286, 291, 295, 303, 316, 331, $335,337,341,345 f ., 348-350$, 352f., 355f., 360, 370, 379, 386,388

- Großlibanon 104, 139, 166

- Industrie 377

- Mandatsbildungspolitik 135, 138f., 142, 144, 150-160, 276

- Kritik an Mandatsbildungspolitik 153

- Mandatswirtschaftspolitik 275, 326

- Verwaltung 26, 77, 139, 156, 203, 218, 221, 237, 299, 306, 308, $348,363,375,377,379,387$

- Wirtschaft/Handel 14f., 116, 121f., 136, 139, 217, 275f., 303, 305f., 308, 314, 321, 329, 355, 371, 373-377

- Weltwirtschaftskrise 275 , $375 \mathrm{f}$.

Mimikry 45, 147

Mission siehe Religion/Kirche

Mission laïque française 21-23, 45, $47,55-58,60,64,66,68-73,75-$ 80, 83-86, 88, 93-97, 99, 105-107, 109-113, 115, 117-119, 121-123,
126-128, 131f., 141-145, 150, 152f., 155, 157f., 162, 166, 168, 171f., 181, 183-189, 191-193, 195f., 198, 200f., 204, 206-211, 215, 219-222, 224-228, 230-248, 255, 258, 271f., 275, 282, 285f., 291-297, 299f., 302, 204-306, 309-312, 314-316, 319f., $327-332,335,337-341,344-351$, 353-357, 361-365, 367, 371-373, 379, 381f., 386-389, 391-393

- Elternrat 116, 186, 224, 233243, 251f., 262, 272, 339, 347, 349, 353, 389

- Jungenschule der Mission laïque française in Beirut 22, 203, 285, 348f.

- Kritik an Mission laïque française 120, 130, 232, 346-347, 351, 361

- Mädchenschule der Mission laïque française in Beirut 48, 77, 113, 120, 161, 203, 227, 248, 250-254, 285, 348

Mittelklasse 186, 209, 306, 346, 348, 377f., $388 f$.

Moderne 58, 60, 109, 117, 125, 207f., 291, 295, 301f., 347, 394

Musik 291f., 301f., 360, 363

- arabische Musik 301f.

- europäische Musik 301f.

\section{Nahḍa $\quad$ 123, 179, 199, 206}

Nationalismus 26, 28, 110, 197f., 217, 227, 242f., 252, 299, 328, 334, $343,345,362,374$

- arabischer Nationalismus 109, 127, 137f., 194, 196, 199f., 210, 217, 220, 231, 234-237, 239-241, 260-262, 268f., 281, 293, 300f., 323 , 325f., 331, 335, 340, 352, $356,358,360,365,369,385$

- französischer Nationalismus 
191, 280f., 344

- libanesischer Nationalismus/Libanismus 137, 200, 218, 269f., 290, 323, 325f., 350, 352, 358, $360,362,368$

- Nation 206, 340, 386

- syrischer Nationalismus 137f., $218,235,237,240,262,269,290$, $323,325 f ., 349,352,360$

Nationalsozialismus 296, 335

Netzwerk 69f., 171, 311

Notabeln 109, 112f., 117, 119, 171, 174, 186f., 218, 226, 234, 238f., 348, $353,361,380,388 f$.

Orientalismus 36-38, 90, 98, 101, $172,301,303,390$

Osmanischer Staat

- Bildungssystem im Osmanischen Reich 112f., 123-134, 161, 246, 248, 250, 291

- Firman 111, 113, 128

- Französischer Einfluss im Osmanischen Reich 94-106, 262, 339

- Französisches Konsulat in Beirut 15, 46, 108, 116f., 123, 128, $156,237,336$

- JungtürkischeRevolution 23,93, $95,102,109-113,124,126 f$

- mutașarrafìya 106, 110

- osmanische Regierung 94f., 105, 107f., 132, 236

- Règlement organique 106, 109

- Tanzimat 124f.

- Vilayet von Beirut 108f., 112, 129

Pädagogik 27f., 188, 207, 209, 227, 237, 292, 337, 339

- Bildungsreisen/Exkursionen 279,288

- Ganzheitliche Erziehung
292, 297f., 201, 313f.

- Koedukation 248, 251, 254

- Lehrmethoden 125, 189, 207, $242,271,367,375$

- méthode directe $189 f$ f.

- Mädchenbildung 152, 216, 246-260

- Pädagogische Reformen 15, 207, 297

Phönizier 185, 261, 263, 267, 270272, 390

Postkolonialismus 36, 328, 339f., 345, 359, 363, 366, 369, 371, 374, 377f., 383, 385, 388, 390, 392f., 395

Praxis 16, 33, 39, 49, 135, 141-151, $187,220,227,339,386$

koloniale Praxis 16, 294, 299

- kulturelle Praxis 29, 32, 42, 44f., 291, 386, 388f.

- soziale Praxis 32, 42, 44f., 157, 159, 175, 311, 386, 391f.

Raum 15

- Ort 15

- Sozialer Raum 43f.

Rechtssystem 216, 377f.

Reiseberichte 98f., 101, 288, 301

Religion $15,54,96,114,119,121,147$, 221, 224, 229-231, 233, 312f., 386

- Armenier 126

- Aufklärung 54, 193

- Christentum 40, 52, 54, 58, 66, 102

- libanesische Christen 193, 204, 230, 232, 271, 284, 289, 325f., 353f., 365, 380, 395

- orientalische Christen 62f., 97, 102, 106, 114, 120, 137f., 145, 217, 222, 268, 368f., 388

- Christlicher Libanon 189, 325, $357 f$.

- Dominikaner 179,369 
- Drusen 106, 153, 157, 161, 195, 208, 216, 226, 230, 269, 314, 353, 389

- Freidenker 228, 230

- Freimaurer 130, 232

- französische Freimaurer 110f., 116, 228, 231, 238

- libanesische Freimaurer 115118, 224f., 231, 238, 294

- Frères des Écoles chrétiennes 18f., 47, 72, 78, 82, 96, 100, 144, 146-148, 163f., 182, 191, 193, 202f., 209f., 270, 300, 305, 346, 350, 359, 393

- Collège français du SacréCœur 47f., 211, 301, 306, 370,376

- Griechisch-Orthodoxe 115f., 118, 120, 126, 149, 195, 199, 218, 250, 254, 262, 269, 294, 326, 346, 360, 364, 389

- Islam 53, 55, 99, 102, 117f., 120, 126f., 166, 171, 178, 199, 219, 226, 257, 263, 266f., 269, 271, 273, 298, 368, 388

- libanesische Muslime 137f., 152, 184f., 199, 204, 218, 220, 223, 230, 232, 239, 247, 269, $271,276,325,343,348,350$, 352f., 356, 365, 369, 395

- Schiiten 311,313,395

- Sunniten 115-118, 120, 215, 218f., 224, 226, 237-239, 250, 313, 321, 326, 329, 346, 348f., $353,359,388 f$.

- Judentum 17, 22, 35, 58, 64f., 111, 229

- orientalische Juden 58-60, 129,239

- französische Juden 59,66,71, 74

- Katholiken 17, 35, 61
- Französische Katholiken 162f., 221, 231, 284, 358, 374

- Libanesische Katholiken 26, 122, 186, 221, 232, 343, 346, 349, 367-370, 374, 387f.

- Maroniten 25f., 103, 106, 109, 114, 118, 137f., 181, 185, 193, 195, 199f., 215, 218f., 224, 232, 260f., 263f., 269, 272, 294, 325f., 348f., 353, 359f., 369, 374

- Beziehung der Maroniten zu Frankreich 115, 118, 137, $215,218,261,270,326$, 360, 374, 387-389, 394

- Maronitische Kirche 140 , 222, 233, 350, 367

- Maronitischer Patriarch 104, 222, 233, 326, 349, 374,394

- Patriach 'Arīạa 326, 349f., 369

- Patriach Hoyek (arabisch Hawayik) 138

- Katholische Kirche 61, 66f., 130, 367f.

- Priester 312, 370, 376f., $380 f$.

- Vatikan 62, 106, 227, 281, 333f., 368f., 374

- Katholische Kongregationen/Orden 17, 24, 62, 95, 128, 132f., 249, 279f., 285, 381

- französische Orden 34, 46, 66, 77, 81, 129, 145, 154, 168, 173, 189, 196, 338

- italienische Orden 333f.

- Konkurrenz der Missionare 24, 129-132, 328-435

- Laizismus 17, 21f., 24, 35, 45, 54, 64, 66, 75, 96f., 105f., 115, 154, 162, 167, 215, 220-234, 313, 
386, $389 f$.

- Melkiten 199, 204, 369

- Mission 24, 62-65, 67, 121, 173, 258, 332

- katholische Missionare 62, 106, 174

- französische katholische Missionare 221, 281, 335

- italienische katholische Missionare 24, 334

- Konversion 132, 184, 253

- Missionar 370,377, 380

- Proselytismus-Vorwurf 113f., 121

- protestantische Missionare 62,67

- amerikanische protestantische Missionare 24, 62, 114, 249

- britische protestantische Missionare 24, 121, 335

- deutsche protestantische Missionare 24

- Moral 130, 241

- Pères Blancs 281, 369

- Pfadfinder 297, 327, 356f.

- christliche Pfadfinder 357 , 360

- jüdische Pfadfinder 360

- muslimische Pfadfinder 356

- Protestantismus/Protestanten 35, 59, 61, 73, 233

- amerikanische Protestanten 23,64

- britische Protestanten 21

- deutsche Protestanten 21

- französische Protestanten 66, $68,233,303,333,364$

- Euvres protestantes françaises $21,47,63,73,84$, $86,88,248,253,275,285$,
364

- libanesische Protestanten 64, 68, 364

- Religionsgelehrte 248,257f.

- Religionskritik 114, 193, 209, 221, 230f., 234, 389

- Religiöse Minderheiten 290,324, 326

- Religiöse Neutralität 227f., 352, 360

- Säkularisierung 216

- Säkularismus 21, 30, 221, 326, 332, 389

Rituale/Symbole 148, 343

- staatliche Rituale/Symbole 262

- libanesisches Museum $262 \mathrm{f}$.

- libanesischeNationalbibliothek 263

- nationale Musikschule Beirut 302

- Akademie der schönen Künste Beirut 302

- libanesische Flagge 343, 363

- französische Nationalhymne $141,146 f$.

- französische Flagge 146f., $334,343,363$

- religiöse Rituale 228, 230

- Ramadan 228, 230,389

Schriftsteller 71, 193f., 204f., 210f., 247, 257f., 313, 388, 395

Schulbibliotheken 99, 103, 188

Schulbücher 56, 101, 189f., 193, 198, 260f., 263, 266, 268-272

Schuldirektoren 27, 76f., 80, 112, 219, 237, 266, 304, 331, 335f., 390

Schulen im Libanon, siehe Libanon

Schüler $\quad 47,140,279,338,361 f$.

- christliche Schüler 140f., 249, 348f., 393

- ehemalige Schüler 166, 193- 
195, 206, 303-315, 355, 357, 362, 370-383, 388, 394

- griechisch-orthodoxe Schüler $249,346,360$

- jüdische Schüler 229, 249

- muslimische Schüler 140f., 228, 249, 251, 320, 346, 348f., 393

- Schülerzahlen 17, 184, 249, 251, 255, 330, 348, 393

Schulfest 145-147, 208, 254

Schulgeld 130, 155f., 159, 165, 346f., 351

Sœurs de Saint-Joseph de l'Apparition 20, 46-48, 61, 153, 279, 312, 393

Soziabilität 310

Sozialer Status 371, 377, 382, 388390

Sozialismus 147, 149, 286

Spenden 222, 308, 311

Sprache 14, 44, 69, 124, 147, 177-213

- Arabische Sprache 19, 49, 7884, 125, 161, 166, 168, 178f., 181f., 188, 195, 197-213, 220, 231, 241, 255, 273, 285, 364-370, $379,385,390 f$.

- Bilingualismus (arabisch-französisch) 368f.

- Arabophonie 44,200,395

- Armenische Sprache 161

- Englische Sprache 84, 161, 182, 331, 333, 371, 394

- Frankophonie 35, 44, 83, 117, 174, 187, 193-195, 199, 236, 302, 317, 369, 371f., 374, $377,379,393,395$

- GriechischeSprache 161,216, 247

- Hebräische Sprache 78, 201, 366

- Italienische Sprache 25, 161 ,
333

- LateinischeSprache 182,216, 247

- Persische Sprache 79

- Syriakische Sprache 369

- Türkische Sprache 79, 182

- Französische Sprache 14, 30, 49, 57, 127, 161, 164, 166, 168, 177-197, 211, 255, 318, 330f., 364, 366, 368, 370-372, 388, 390f., 394

- Muttersprache 187, 203

- Signal 187-189

Stipendien 47, 141, 151, 155-160, 233, 315, 318, 319f., 347, 374, 387

Strategie 44f., 151, 159, 277, 319, 321,392

Subventionen

- des französischen Staates 21f., 24, 52, 105-113, 128, 142f., 151, 153f., 173, 245, 275, 279, 315, 329, 336, 341, 343, 347, 387, 391

- der osmanischen Regierung 105-113

- des Hochkommissariats 142,152154, 222, 232f., 234, 236f., 266

Subversion 196,392

Sykes-Picot-Abkommen $\quad 136,138$

Taktik 44f., 151, 159, 277, 321, 392

Unabhängigkeit $216,218,240,275$, 281, 288, 290f., 323-325, 335, 340, $343,353,358,364,366,371,374$, 377f., 383, 385, 388, 390, 392-395

Universität $\quad 246,306,370-383,394$

- American University of Beirut/ Syrian Protestant College 18, 83, 108, 120, 131f., 208, 210, 248, 317, 329-332, 336f., 365, 371f., 378

- Studenten 331 
- christliche Studenten 330

- katholische Studenten 294

- muslimische Studenten 330

- Studium

- Landwirtschaft 156,285,330, 370, 376, 379f.

- Jura 166, 241, 246, 285, 370, 372f., 376-378

- Medizin 122, 170, 241, 246, 285, 370, 372, 376, 378

- Pharmazie 122, 239, 241

- Wirtschaftsstudium 285

- Ingenieurswesen 372, 377, 378-380

- Studium in Frankreich 156, 186, 288, 372-376

- Université Saint-Joseph 13, 18, 47f., 72, 107, 108, 122f., 132, 158, 161, 164, 166, 173, 186, 195, 201, 223f., 248, 254f., 332, 343, 369, $371,378,389$

Unterricht

- Arabischunterricht 71,197,201203, 224, 241, 330, 332

- Académie de langue arabe 211

- Arabischdiplom 210

- Lehrmittel 208

- Methoden 206-208,241

- Stundenanzahl 198,202f.

- Außerunterrichtliche Aktivitäten 253, 275, 291-303, 387f.

- Französischunterricht

- Lehrmittel 189

- Methoden 188f.

- Sprachniveau 186-188

- Stundenanzahl 188,202

- Geographieunterricht 169, 190, 220, 267, 367

- Geschichtsunterricht 34, 169, 220, 260-273, 367

- arabische Geschichte 125 ,
245,390

- jüdische Geschichte 78

- libanesische Geschichte 260, 385,390

- Hauswirtschaftsunterricht 252

- Katechismus 312,314

- Literatur

- arabische Literatur 169,190, 198, 207f., 367

- französische Literatur 190, 192, 196

- Klassik 190-192, 196

- Moderne 190,277

- Romantik 190-193, 196

- Mathematikunterricht 169

- Moral 197, 242, 302, 333, 362

- Religionsunterricht 197, 224

- Schulbibliotheken 99, 103, 188

- Schulbücher 56, 101,189f., 193, 198, 260f., 263, 266, 268, 272

- Sportunterricht 144, 291, 297300

- Technische Fächer 121f., 285, 379

- Theater 209, 211, 231, 294f., 302, 350, 359, 367

- Zeichenunterricht 252

Vaterland (Wațan) 205f.

Vertrag von Lausanne 138

Vichy-Regime $46,71,324,344$

Völkerbund 25, 137f., 290f.

Vortrag 291f., 297, 301f., 337

Waqf 158,298

Widerstand 28, 40f., 44f., 135, 153, 159, 217, 237

Wissenschaft 61, 178f., 200, 205, 293, 297

- Ethnologie 293

- Fortschrittsglaube 61, 191, 394

- Geographie 101 
- Geschichte 101, 260-273, 297, 390

- Islam 179

- Koloniale Ideologie 54f., 293

- Sozialdarwinismus $54 \mathrm{f}$.

- Technologie 277, 295

- Wirtschaftswissenschaft $101 \mathrm{f}$.

Zensur 378

Zionismus 183, 242, 297,320,360,366

Zivilisation 52, 54f., 56, 59, 61, 293, 340f., 390

- arabische Zivilisation 20, 32, 55,114

- europäische Zivilisation 55, 60,
99, 114

- französische Zivilisation 20, 32, 51f., 54, 56, 59-61, 79, 279, 295, 297, 340, 390

- Universalismus 30,53,56f.

Hierarchie der Zivilisationen 54f., $60,79,84,90,100,150,170,173 \mathrm{f}$., 178, 293

- Zivilisationskritik 114

Zweiter Weltkrieg 84, 85, 295, 324, $335,349,380$ 